\title{
Habitat Selection of Male Eastern Wild Turkey (Meleagris gallopavo silvestris) in West Virginia
}

Jesse L. De La Cruz

West Virginia University

Follow this and additional works at: https://researchrepository.wvu.edu/etd

\section{Recommended Citation}

De La Cruz, Jesse L., "Habitat Selection of Male Eastern Wild Turkey (Meleagris gallopavo silvestris) in West Virginia" (2012). Graduate Theses, Dissertations, and Problem Reports. 3508.

https://researchrepository.wvu.edu/etd/3508

This Thesis is protected by copyright and/or related rights. It has been brought to you by the The Research Repository @ WVU with permission from the rights-holder(s). You are free to use this Thesis in any way that is permitted by the copyright and related rights legislation that applies to your use. For other uses you must obtain permission from the rights-holder(s) directly, unless additional rights are indicated by a Creative Commons license in the record and/ or on the work itself. This Thesis has been accepted for inclusion in WVU Graduate Theses, Dissertations, and Problem Reports collection by an authorized administrator of The Research Repository @ WVU. For more information, please contact researchrepository@mail.wvu.edu. 


\title{
Habitat Selection of Male Eastern Wild Turkey (Meleagris gallopavo silvestris) in West Virginia
}

\author{
Jesse L. De La Cruz \\ Thesis submitted to the \\ Davis College of Agriculture, Natural Resources, and Design \\ at West Virginia University \\ in partial fulfillment of the requirements \\ for the degree of \\ Master of Science
in \\ Wildlife and Fisheries Resources
}

James T. Anderson, Ph.D., Major Advisor John W. Edwards, Ph.D., Committee Member

Michael P. Strager, Ph.D., Committee Member

Division of Forestry and Natural Resources

West Virginia University

Morgantown, West Virginia

2012

Key words: compositional analysis, eastern wild turkey, fixed kernel density, habitat selection, home range, Meleagris gallopavo silvestris, West Virginia 


\section{ABSTRACT \\ Habitat Selection of Male Eastern Wild Turkey (Meleagris gallopavo silvestris) in West Virginia}

\section{Jesse L. De La Cruz}

Eastern wild turkeys (Meleagris gallopavo silvestris) have been the focus of widespread research throughout their range, but research on male wild turkey home range size and habitat resource selection is limited in West Virginia. To address this lack of knowledge, I proposed the quantification of home range within a region (second-order) and core home range within a periphery (third-order) resource selection. Home ranges estimates and regional vector sampling grids were modeled against anthropomorphic land use and landscape cover features, land fragmentation, slope, and aspect raster data within the Geospatial Modeling Environment (GME) to derive proportional resource use and availability data. These data were analyzed by compositional analysis (CA) for 2 study areas in West Virginia. I estimated statewide and District I Study Area (DISA), located in the counties of Harrison, Marion, and Taylor, 50\% and 95\% adult and juvenile UD home range sizes both annually and seasonally. Additionally, I analyzed statewide and DISA second- and third-order resource selection for adults and juveniles both annually and seasonally.

West Virginia Division of Natural Resources personnel monitored 55 radio-equipped male wild turkeys from September 2004 through August 2007 in West Virginia. I found that statewide adult $(\bar{x}=1,409.9 \mathrm{ha}, \mathrm{SE}=180.3)$ and juvenile $(\bar{x}=1,394.3 \mathrm{ha}, \mathrm{SE}=146.6)$ annual statewide $95 \%$ UD home ranges were similar $(P=0.78)$. I also found that statewide adult $(\bar{x}=$ $310.3 \mathrm{ha}, \mathrm{SE}=38.7)$ and juvenile $(\bar{x}=320.6 \mathrm{ha}, \mathrm{SE}=190.3)$ annual $50 \%$ UD home ranges were also similar $(P=0.56)$. My analysis indicated that adult 50\% UD home ranges were similar across seasons $(P=0.68)$ and averaged: fall $-220.2 \mathrm{ha}, \mathrm{SE}=33.8$, fall-winter -241.8 ha, $\mathrm{SE}=$ 43.5, spring -163.0 ha, $\mathrm{SE}=12.7$, spring-summer -199.0 ha, $\mathrm{SE}=26.9$, and winter -211.6 ha, $\mathrm{SE}=56.7$. $\mathrm{I}$ also found that adult $95 \% \mathrm{UD}$ home ranges were similar across all seasons $(P=$ 0.54 ) and averaged: fall $-858.2 \mathrm{ha}, \mathrm{SE}=119.8$, fall-winter $-1,046.6 \mathrm{ha}, \mathrm{SE}=174.8$, spring 685.6 ha, $\mathrm{SE}=66.3$, spring-summer $-821.8 \mathrm{ha}, \mathrm{SE}=106.3$, and winter $-927.6, \mathrm{SE}=238.5$. I found that juvenile 50\% UD home ranges were similar between seasons $(\mathrm{W}=80, P=0.08)$ and averaged: spring -142.1 ha, $\mathrm{SE}=15.5$ and spring-summer $-97.0, \mathrm{SE}=10.7$. Juvenile $95 \%$ UD seasonal home ranges were also similar between seasons $(P=0.17)$ and averaged: spring -800.2 ha, $\mathrm{SE}=123.8$ and spring-summer $-543.8 \mathrm{ha}, \mathrm{SE}=85.0$. Adult $(\bar{x}=1,515.3 \mathrm{ha}, \mathrm{SE}=368.0)$ and juvenile $(\bar{x}=1,323.3$ ha, $\mathrm{SE}=190.1)$ annual DISA 95\% UD home ranges were $\operatorname{similar}(P=$ $0.59)$. I also found that adult $(\bar{x}=327.2 \mathrm{ha}, \mathrm{SE}=79.2)$ and juvenile $(\bar{x}=310.8 \mathrm{ha}, \mathrm{SE}=46.1)$ annual DISA 50\% UD home ranges were similar $(P=0.69)$. My home range results fell within those reported by other male eastern wild turkey studies, but particularly those located in heavily forested areas.

Annual statewide adult second-order land use and land cover resource selection was primarily for forest $(P=0.001)$ while juvenile selection was for forest roads $(P=0.001)$. My analysis also indicated annual statewide adult third-order land use and land cover resource selection was for forest $(P=0.001)$ while juvenile selection was for crop $(P=0.001)$. Seasonal adult statewide third-order land use and land cover resource selection was: spring - forest $(P$ $=0.12)$, fall - forest $(P=0.05)$, winter - forest $(P=0.79)$, spring-summer - forest $(P=0.02)$, and fall-winter - forest $(P=0.04)$. I found that seasonal DISA juvenile third-order land use and land 
cover resource selection was: spring $-\operatorname{crop}(P=0.003)$, and spring-summer $-\operatorname{crop}(P=0.01)$. I also found that both annual statewide adult $(P=0.001)$ and juvenile $(P=0.001)$ second-order land fragmentation resource selection was primarily for edge. The analysis indicated that annual statewide adult third-order land fragmentation resource selection was primarily for perforations $(P=0.006)$ while juvenile selection was still for edge $(P=0.003)$. Seasonal adult statewide third-order land fragmentation resource selection was: spring - edge $(P=0.39)$, fall - edge $(P=$ $0.03)$, winter - perforations $(P=0.64)$, spring-summer - edge $(P=0.51)$, and fall-winter - edge $(P=0.03)$. I found that seasonal DISA juvenile third-order land fragmentation resource selection was: spring - perforations $(P=0.003)$, and spring-summer - perforations $(P=0.006)$. My analysis also indicated that annual statewide adult second-order slope resource selection was primarily for $>24-35 \%$ gradients $(P=0.001)$ and juvenile selection was for $>6-24 \%$ gradients $(P=0.001)$. Annual statewide adult third-order slope resource selection was for $>24-35 \%$ gradients $(P=0.001)$ and juvenile selection was still for $>6-24 \%$ gradients $(P=0.02)$. I found that seasonal adult statewide third-order slope resource selection was: spring $->6-24 \%(P=$ $0.19)$, fall $->6-24 \%(P=0.004)$, winter $-0-6 \%(P=0.84)$, spring-summer $->6-24 \%(P=$ $0.05)$, and fall-winter $->24-35 \%(P=0.21)$. I found that seasonal DISA juvenile third-order slope resource selection was: spring $-0-6 \%(P=0.004)$, spring-summer $->6-24 \%(P=0.006)$. My analysis indicated that annual statewide adult second-order aspect resource selection was not significant $(P=0.20)$ while juvenile was for westerly slopes $(P=0.001)$. Furthermore, my analysis showed that both annual statewide adult $(P=0.53)$ and juvenile $(P=0.12)$ third order slope resource selection was not significant. I found that seasonal adult statewide third-order aspect resource selection was: spring - west $(P=0.28)$, fall - west $(P=0.79)$, winter - east $(P=$ $0.40)$, spring-summer - west $(P=0.53)$, and fall-winter - east $(P=0.60)$. While seasonal DISA juvenile third-order aspect resource selection was: spring - east $(P=0.006)$, and spring-summer - east $(P=0.24)$.

Within the DISA annual adult second-order land use and land cover resource selection was primarily for crop $(P=0.02)$ while juvenile was for pasture-field $(P=0.001)$. However, my analysis indicated that annual DISA adult third-order land use and land cover resource selection was insignificant $(P=0.18)$; juvenile selection was for crop $(P=0.001)$. I found that both annual DISA adult $(P=0.02)$ and juvenile $(P=0.001)$ second-order land fragmentation resource selection was for edge. Similarly, I found that annual DISA adult third-order land fragmentation select was also for edge $(P=0.02)$ while juvenile selection was for perforations $(P=0.001)$. My results indicated that annual DISA adult second-order slope resource selection was not significant $(P=0.26)$ while juvenile selection was for $>6-24 \%$ gradients $(P=0.003)$. Similarly, I found that annual DISA adult third-order slope resource selection to be not significant $(P=$ $0.09)$ while juvenile selection was still for $>6-24 \%$ gradients $(P=0.002)$. I found that annual DISA adult second-order aspect resource selection was for easterly facing slopes $(P=0.04)$ while juveniles aspect selection was not significant $(P=0.09)$. However, I found that annual DISA adult third-order selection of aspect resources was marginally significant for westerly facing slopes $(P=0.05)$; juveniles showed a marginal selection of easterly facing slopes ( $P$ $=0.05)$. Despite the amount of contiguous forest in West Virginia, male wild turkeys are selecting more edge habitats than are proportionally available. Land managers should concentrate on providing such multilayer habitats through planting, cutting, mowing, or even passive management to provide diverse food sources, escape cover, travel corridors, and mating display areas for male wild turkey in West Virginia. 


\section{Acknowledgments}

I first and foremost thank my mother, Carrie, only through her loving strength and support was I able to improve my life through higher education. I also thank my grandfather, Loren V. Kerns, for by his slow spoken guidance and patient hand was I introduced to and grew to love the great outdoors. I thank my sister Sarah and brother Jason for all their support, encouragement, and at times needed consolation. I am also very appreciative to all the great friends that I have made while at WVU for their additional support and shared knowledge.

I am indebted to my major advisor Dr. James T. Anderson for the opportunity he provided to further my collegiate education in the field of Wildlife and Fisheries Resources. The support and guidance he provided is appreciated. I thank Dr. John W. Edwards for his input as a member of my graduate committee. I also thank Dr. Michael P. Strager and Mr. Aaron Maxwell for their vital guidance and support in all matters of spatial modeling and mapping. I thank Mr. Steven Rauch and the West Virginia Division of Natural Resources for the use of data stemming from the Mid-Atlantic Gobbler Study wild turkey project. Finally, I thank the Southern Regional Education Board for without their financial support none of this would be possible.

"... and that he is the maker of his character, the moulder of his life, and the builder of his destiny, he may unerringly prove, if he will watch, control, and alter his thoughts, tracing their effects upon himself, upon others, and upon his life and circumstances, linking cause and effects by patient practice and investigation, and utilizing his every experience, even to the most trivial, everyday occurrence, as a means of obtaining that knowledge of himself which is Understanding, Wisdom, and Power.” - James Allen, As a Man Thinketh 


\section{Table of Contents}

\section{Table of Contents}

Chapter 1 List of Figures $\ldots \ldots \ldots \ldots \ldots \ldots \ldots \ldots \ldots \ldots \ldots \ldots \ldots \ldots \ldots \ldots \ldots \ldots \ldots$

Chapter 2 List of Figures . . . . . . . . . . . . . . . . . . . . . . . .

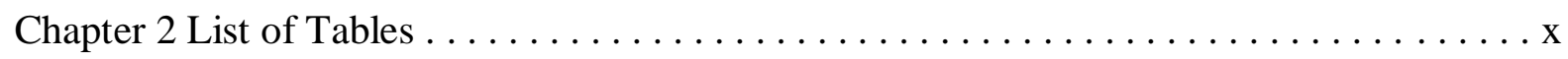

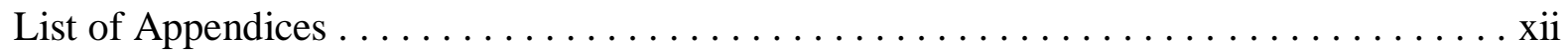

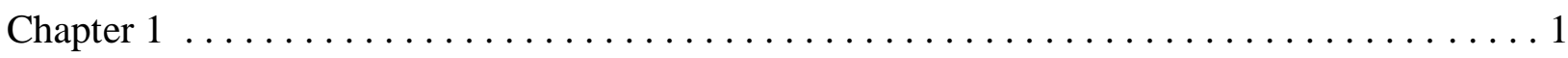

Introduction and Justification for a Male Wild Turkey Home Range Estimate Based Resource Selection Study in West Virginia $\ldots \ldots \ldots \ldots \ldots \ldots \ldots \ldots \ldots \ldots \ldots \ldots \ldots \ldots \ldots \ldots \ldots$

Introduction and Justification. $\ldots \ldots \ldots \ldots \ldots \ldots \ldots \ldots \ldots \ldots \ldots \ldots \ldots \ldots \ldots$

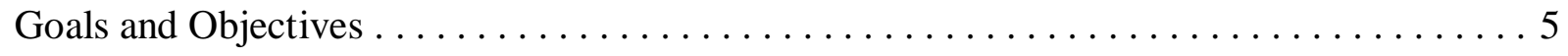

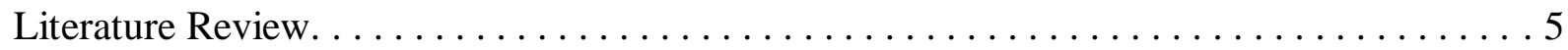

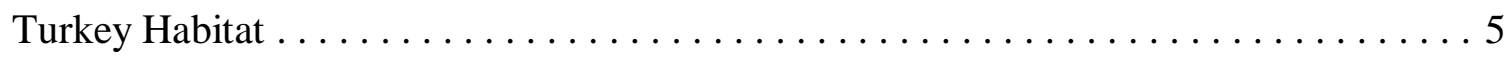

Production, Survival, and Predation $\ldots \ldots \ldots \ldots \ldots \ldots \ldots \ldots \ldots \ldots \ldots \ldots \ldots \ldots \ldots \ldots \ldots$

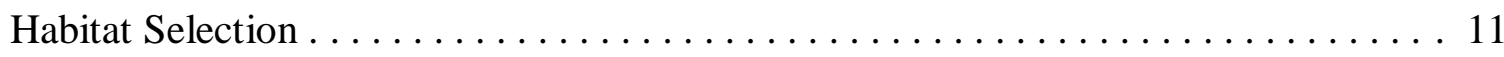

Rio Grande Wild Turkey Habitat Selection $\ldots \ldots \ldots \ldots \ldots \ldots \ldots \ldots \ldots \ldots \ldots \ldots \ldots \ldots \ldots$

Compositional Analysis . . . . . . . . . . . . . . . . . . . 13

Analysis of Home range: Fixed Kernel Method $\ldots \ldots \ldots \ldots \ldots \ldots \ldots \ldots \ldots$

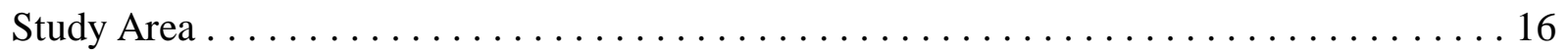

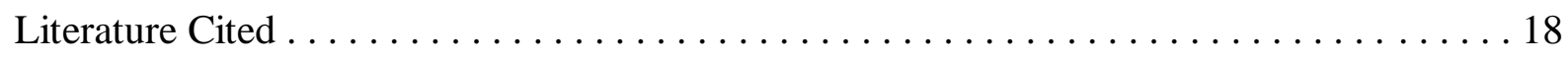

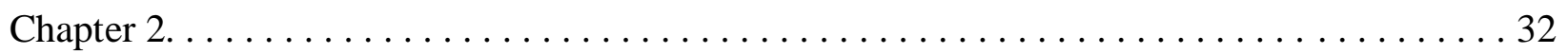

Habitat Selection of the Male Eastern Wild Turkey in West Virginia . . . . . . . . . 32

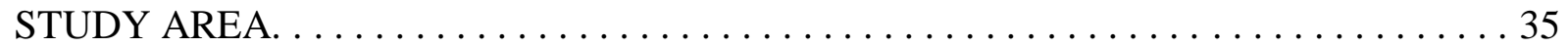

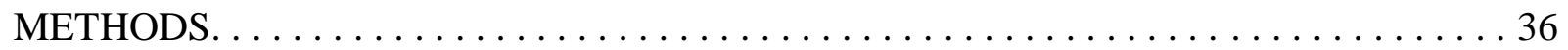

Trapping and Radio Telemetry $\ldots \ldots \ldots \ldots \ldots \ldots \ldots \ldots \ldots \ldots \ldots \ldots \ldots \ldots \ldots \ldots \ldots \ldots \ldots \ldots$

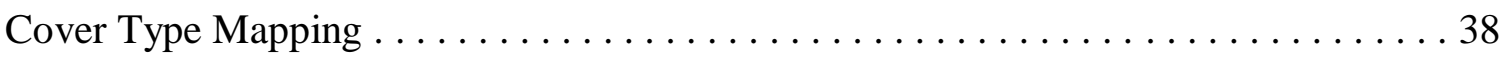

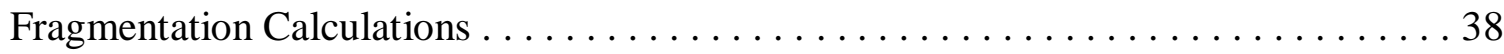

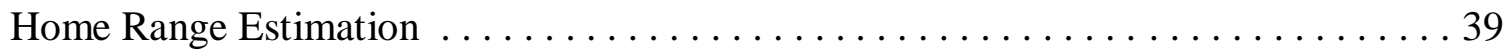

Habitat Selection . . . . . . . . . . . . . . . . . . . . . . . . . .

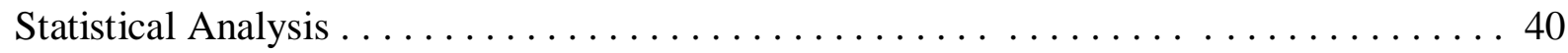

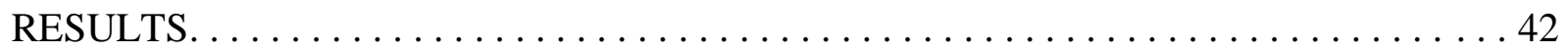




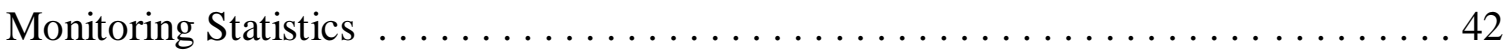

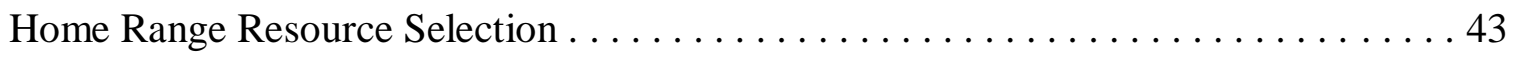

Annual Adult Second-order Selection $\ldots \ldots \ldots \ldots \ldots \ldots \ldots \ldots \ldots \ldots \ldots \ldots \ldots \ldots \ldots$

Annual Juvenile Second-order Selection . . . . . . . . . . . . . . . . . . 43

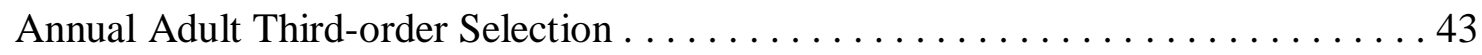

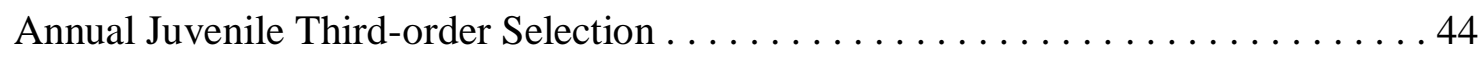

Statewide Adult Seasonal Third-order Selection . . . . . . . . . . . . . . . 44

District I Study Area Seasonal Juvenile Third-order Selection . . . . . . . . . . . 45

District I Study Area Second-order Selection $\ldots \ldots \ldots \ldots \ldots \ldots$

District I Study Area Third-order Selection . . . . . . . . . . . . . . . 47

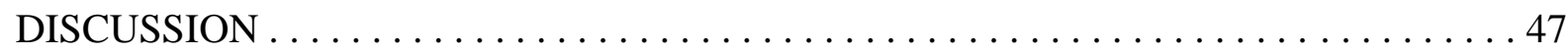

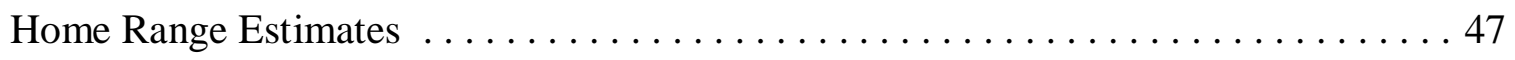

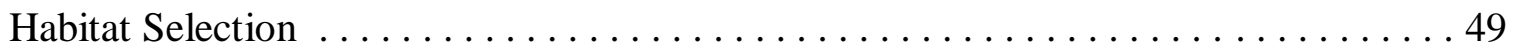

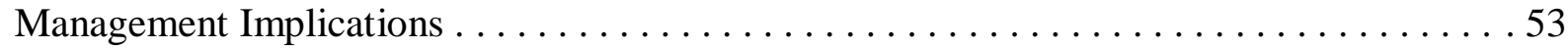

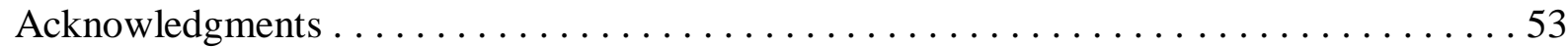

LITERATURE CITED . . . . . . . . . . . . . . . . . . . . . . . . . . 54 


\section{Chapter 1 List of Figures}

Figure 1. West Virginia Statewide Study Area and District I Study Area, 2004-2007. . . . . . 30

Figure 2. Ecological regions of West Virginia, $2004-2007 \ldots \ldots \ldots \ldots \ldots \ldots \ldots \ldots$ 


\section{Chapter 2 List of Figures}

Figure 1. West Virginia Statewide Study Area and the District I Study Area, 2004-2007. . . . 74

Figure 2. Mean annual statewide adult $(n=37)$ and juvenile $(n=29)$ male wild turkey secondorder land use and land cover, land fragmentation, slope, and aspect proportions; use proportions were derived from $95 \%$ UD home ranges $(\bar{x}=1,409.9$ ha, $\mathrm{SE}=180.3 ; \bar{x}=1,394.3 \mathrm{ha}, \mathrm{SE}=$ 146.6) and availability was derived from a proportional summary and weighted average of 2,587 100 ha blocks $(\bar{x}=51,740$ ha, $\mathrm{SE}=12,983.2)$ within 5 ecological regions of West Virginia,

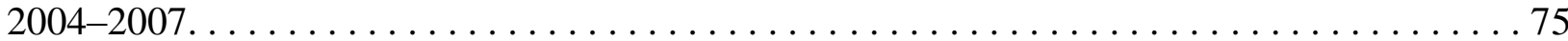

Figure 3. Mean annual statewide adult $(n=37)$ and juvenile $(n=29)$ third-order land use and land cover, land fragmentation, slope, and aspect proportions; use proportions were derived from $50 \%(\bar{x}=310.3 \mathrm{ha}, \mathrm{SE}=38.7 ; \bar{x}=320.6 \mathrm{ha}, \mathrm{SE}=190.3)$ and availability proportions were derived from $95 \%(\bar{x}=1,409.9$ ha, $\mathrm{SE}=180.3 ; \bar{x}=1,394.3$ ha, $\mathrm{SE}=790.8)$ UD home ranges within 5 ecological regions of West Virginia, $2004-2007 \ldots \ldots \ldots \ldots \ldots \ldots \ldots$

Figure 4. Mean fall $(n=9)$, fall-winter $(n=17)$, and winter $(n=8)$ adult wild turkey third-order land use and land cover, land fragmentation, slope, and aspect proportions; use proportions were derived from $50 \%(\bar{x}=220.2$ ha, $\mathrm{SE}=33.8 ; \bar{x}=241.8$ ha, $\mathrm{SE}=43.5 ; \bar{x}=211.6 \mathrm{ha}, \mathrm{SE}=56.7)$ and availability proportions were derived from $95 \%(\bar{x}=858.2$ ha, $\mathrm{SE}=119.8 ; \bar{x}=1,046.6$ ha, $\mathrm{SE}=174.8 ; \bar{x}=927.6, \mathrm{SE}=238.5)$ UD home ranges within 5 ecological regions of West

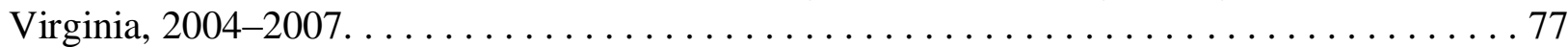

Figure 5. Mean spring $(n=9)$ and spring-summer $(n=17)$ adult wild turkey third-order land use and land cover, land fragmentation, slope, and aspect proportions; use proportions were derived from $50 \%(\bar{x}=163.0 \mathrm{ha}, \mathrm{SE}=12.7 ; \bar{x}=199.0 \mathrm{ha}, \mathrm{SE}=26.9)$ and availability proportions were derived from $95 \%(\bar{x}=685.6$ ha, $\mathrm{SE}=66.3 ; \bar{x}=821.8 \mathrm{ha}, \mathrm{SE}=106.3)$ UD home ranges within 5 ecological regions of West Virginia, $2004-2007 \ldots \ldots \ldots \ldots \ldots \ldots \ldots \ldots \ldots \ldots$

Figure 6. Mean spring $(n=11)$ and spring-summer $(n=11)$ juvenile wild turkey third-order land use and land cover, land fragmentation, slope, and aspect proportions; use proportions were derived from $50 \%(\bar{x}=142.1$ ha, $\mathrm{SE}=15.5 ; \bar{x}=97.0, \mathrm{SE}=10.7)$ and availability proportions were derived from $95 \%(\bar{x}=800.2$ ha, $\mathrm{SE}=123 ; \bar{x}=543.8$ ha, $\mathrm{SE}=85.0)$ UD home ranges within the District I Study Area of West Virginia, 2004-2007. . . . . . . . . . . . . . . . 79 


\section{Chapter 2 List of Figures}

Figure 7. Mean annual adult $(n=9)$ and juvenile $(n=19)$ wild turkey second-order land use and land cover, land fragmentation, slope, and aspect proportions; use proportions were derived from $95 \%(\overline{\mathrm{x}}=1,515.3 \mathrm{ha}, \mathrm{SE}=368.0 ; \overline{\mathrm{x}}=1323.3 \mathrm{ha}, \mathrm{SE}=190.1)$ UD home ranges and availability proportions were derived from 639100 ha sampling blocks within the District I Study Area of

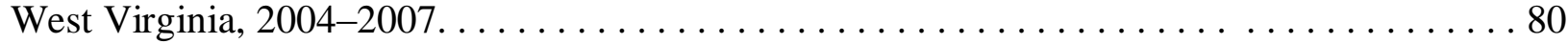

Figure 8. Mean annual adult $(n=9)$ and juvenile $(n=19)$ wild turkey third-order land use and land cover, land fragmentation, slope, and aspect proportions; use proportions were derived from $50 \%(\bar{x}=327.2$ ha, $\mathrm{SE}=79.2 ; \bar{x}=310.8 \mathrm{ha}, \mathrm{SE}=46.1)$ and availability proportions were derived from $95 \%(\bar{x}=1,515.3$ ha, $\mathrm{SE}=368.0 ; \bar{x}=1,323.3 \mathrm{ha}, \mathrm{SE}=190.1)$ UD home ranges within the District I Study Area of West Virginia, $2004-2007 \ldots \ldots \ldots \ldots \ldots \ldots$. . . . . . . . . 81 


\section{Chapter 2 List of Tables}

Table 1. Annual 95\% and 50\% utilization distributions (UD) for Gaussian fixed kernel density estimations $(\mathrm{KDE})$ home ranges, smoothing parameter $(h)$ determined by least squares cross validation, of male eastern wild turkeys from 2 study areas in West Virginia, 2004-2007. . . . 65

Table 2. Second-order land use and land cover resource selection significance and rank of male eastern wild turkeys from 2 study areas in West Virginia, 2004-2007. Use proportions derived from $95 \%$ home range utilization distributions (UD) and availability derived from 100 ha block regional proportional summaries; proportions were analyzed using compositional analysis

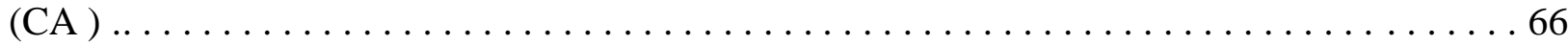

Table 3. Second-order land fragmentation resource selection significance and rank of male eastern wild turkeys from 2 study areas in West Virginia, 2004-2007. Use proportions derived from $95 \%$ home range utilization distributions (UD) and availability derived from 100 ha block regional proportional summaries; proportions were analyzed using compositional analysis

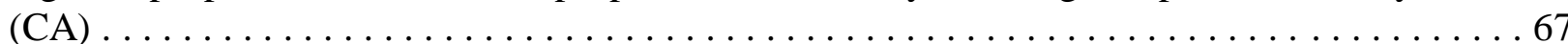

Table 4. Second-order slope resource selection significance and rank of male eastern wild turkeys from 2 study areas in West Virginia, 2004-2007. Use proportions derived from 95\% home range utilization distributions (UD) and availability derived from 100 ha block regional proportional summaries; proportions were analyzed using compositional analysis (CA). . . 68

Table 5. Second-order aspect resource selection significance and rank of male eastern wild turkeys from 2 study areas in West Virginia, 2004-2007. Use proportions derived from 95\% home range utilization distributions (UD) and availability derived from 100 ha block regional proportional summaries; proportions were analyzed using compositional analysis (CA) . . . . 69

Table 6. Third-order land use and land cover resource selection significance and rank of male eastern wild turkeys from 2 study areas in West Virginia, 2004-2007. Use proportions derived from $95 \%$ home range utilization distributions (UD) and availability derived from 100 ha block regional proportional summaries; proportions were analyzed using compositional analysis

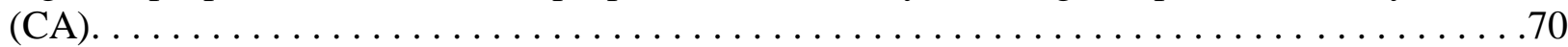

Table 7. Third-order land fragmentation resource selection significance and rank of male eastern wild turkeys from 2 study areas in West Virginia, 2004-2007. Use proportions derived from 95\% home range utilization distributions (UD) and availability derived from 100 ha block regional proportional summaries; proportions were analyzed using compositional analysis (CA) . . . . 71 


\section{Chapter 2 List of Tables}

Table 8. Third-order slope resource selection significance and rank of male eastern wild turkeys from 2 study areas in West Virginia, 2004-2007. Use proportions derived from $95 \%$ home range utilization distributions (UD) and availability derived from 100 ha block regional proportional summaries; proportions were analyzed using compositional analysis (CA) . . . . . . . . . .72

Table 9. Third-order aspect resource selection significance and rank of male eastern wild turkeys from 2 study areas in West Virginia, 2004-2007. Use proportions derived from $95 \%$ home range utilization distributions (UD) and availability derived from 100 ha block regional proportional summaries; proportions were analyzed using compositional analysis (CA) . . . . . . . . 73 


\section{List of Appendices}

Appendix A. I $a-\mathrm{CCXCIV} a$ : Adult and juvenile $50 \%$ and $95 \%$ probability contours of the annual and seasonal Gaussian fixed kernel home range utilization distribution (UD) for 55 male wild turkeys in West Virginia, 2004-2007. Smooth parameter $(h)$ determined by least squares cross validation (land use and land cover, land fragmentation, aspect, and slope raster data used

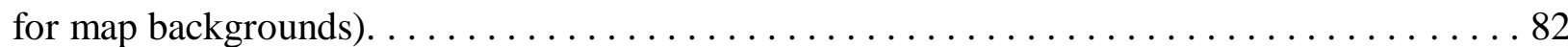

Appendix B. Regional male wild turkey second- and third-order land use and land cover, land fragmentation, slope, and aspect habitat resource selection in regions 2, 3, 4, and 6 in West Virginia, 2004-2007. . . . . . . . . . . . . . . . . . . . . . . . . . 378

Appendix C. Regional 95\% and 50\% utilization distributions (UD) for Gaussian fixed kernel density estimations (KDE) home ranges, smoothing parameter $(h)$ determined by least squares cross validation, of male eastern wild turkeys in West Virginia, 2004-2007. . . . . . . . 381

Appendix D. Id - VIIId: Second- and third-order resource selection significance and rank of male eastern wild turkeys from 4 ecological regions in West Virginia, 2004-2007. Use proportions derived from $95 \%$ home range utilization distributions (UD) and availability derived from 100 ha block regional proportional summaries; proportions were analyzed using

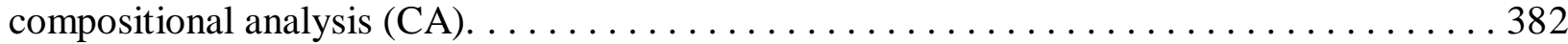




\section{Chapter 1}

Introduction and Justification for a Male Wild Turkey Home Range Estimate Based Resource Selection Study in West Virginia

\section{Introduction and Justification}

Eastern wild turkeys (Meleagris gallopavo silvestris) are an important game species to outdoor enthusiasts and as a prey species for natural predators throughout its range (Kennamer and Kennamer 1995). Between 1902 and 1925 in West Virginia, the peak era of logging activities, wild turkey could only be found in the most remote mountainous regions of the state (West Virginia Department of Natural Resources 1985). Despite being driven nearly to extirpation in the past by extreme logging practices and unregulated hunting, the wild turkey is now found in every county of West Virginia (West Virginia Department of Natural Resources 1985). Due to a successful reintroduction, all 55 counties currently hold a regulated spring bearded turkey (i.e., gobbler) season with certain counties, within the traditional mountainous range, providing fall either sex turkey hunting.

An understanding of habitat selection at multiple temporal and spatial scales for various age classes is vital for the management of wild turkey populations. Despite extensive scientific inquiry on wild turkey in West Virginia research on male turkey is lacking, including habitat selection at specific life stages. In attempts to better understand the dynamics of the wild turkey population, in September 2004, the West Virginia Division of Natural Resources and the Virginia Department of Game and Inland Fisheries initiated the Mid-Atlantic-Gobbler Study (MAGS). The primary goal of MAGS was to determine survival rates of male wild turkey and the impacts of hunting. Despite originally being designed as a study of mortality, MAGS 
provided a unique opportunity to examine home ranges and their associated habitat resource composition. Starting in September 2004 and continuing to August 2007 radio telemetry locations were collected and later used to quantify home range estimates and habitat selection and use of male wild turkey throughout West Virginia.

The area in which an animal lives is its home range (Smith 1974). Habitat use and selection is not mere chance, Aebischer et al. (1993) explains that non-random movement “...determine(s) a trajectory through space and time; its habitat use is the proportion of the trajectory contained within each habitat...an extension of the trajectory is the home range." Knowledge of home range use and selection is vital in establishing habitat requirements and for providing management recommendations. Furthermore, effective management requires sex and age specific understanding of habitat selection at multiple temporal and spatial scales (Tirpak et al. 2010). Past research of such mechanisms that affect the selection and continued use of home ranges has laid the foundation for current investigation. It is known that individuals that display wide-ranging movements within parts of an annual home range risk reduced survival and costly increased time required for relocation (Gauthreaux 1982, Ketterson and Nolan 1983, Badyaev et al. 1996a). However, better familiarity of an area can improve foraging efficiency, predator evasion, and reproductive success (Myers 1981, Ketterson and Nolan 1983, Schieck and Hannon 1989, Beletsky and Orians 1991, Badyaev et al. 1996a) and is often a key influence contributing to social dominance (Dhindsa et al. 1989, Koivula et al. 1993). Specifically, turkey social status is determined largely by age with young individuals being subordinate to older individuals (Healy 1992, Badyaev et al. 1996a) and inquiry into habitat use and selection should reflect this knowledge. 
Anthropomorphic disturbance is at the heart of ever changing natural systems. The development of urban areas, ecological intervention, and an ever evolving system of values are the main reasons for today's dynamic landscape. Following the deforestation period of the early 1900s in the Eastern United States, for the production of timber and farmland, much of the wild turkey restoration movement took place in areas deemed uneconomical as agricultural land (Porter et al. 2011). These abandoned parcels thus reverted to a patchwork of second growth forest, dominated by resource-laden oak-hickory (Quercus spp.-Carya spp.) forest types, old fields, and shrub thickets providing a hospitable environment to the recovery of the wild turkey (Porter et al. 2011). However, due to recent forestry practices including fire suppression and low impact harvesting techniques along with the introduction of exotic diseases such as chestnut blight (Cryphonectria parasitica) and beech bark disease (Nectria Cryptococcus-Neonectria complex), forest canopies are closing and primarily converting to low mast producing forest types dominated by shade-tolerant species such as maples (Acer spp.) (Nowacki and Abrams 2008, Porter et al. 2011).

While management of a wild turkey population incorporates many factors ranging from biological, economic, political, and social impacts, one biological parameter, food (mast), may be the most influential variable in the population dynamics of wild turkey (Kelley et al. 1988). During times of low food availability female turkeys traversed larger tracts of land in search of sustenance in Wetzel County, West Virginia (Swanson et al. 1994). Male turkeys have smaller home ranges in times of surplus mast conditions (Kelley et al. 1988). High turkey populations and small home ranges may be associated with diverse habitats (Kelley et al. 1988) while large home ranges may be linked with low population densities and heavily forested areas (Wigley et al. 1986, Exum et al. 1987, Kelley et al. 1988). Ryan et al. (2004) found a positive correlation 
between mast failure and high fall big game harvest rates; conversely lower harvest totals occurred during high mast production. Data concerning influence of mast conditions on male wild turkey habitat use and selection in West Virginia are limited. It can be concluded that as food availability changes so too will turkey home ranges (e.g., size, composition) (Kelley et al. 1988). The variability of environmental conditions among regions makes it necessary to examine habitats at the local scale (Brown 1980) and previous analysis of habitat resource composition in established home ranges of wild turkey has proven a useful tool for land managers seeking to enhance property concerning the establishment of viable, sustainable population (Speake et al. 1975, Clark 1985 Hurst et al. 1991, Swanson et al. 1994). The ever changing and variable environment of the eastern wild turkey may be approaching its carrying capacity and demands further research to help address current population trends (Porter et al. 2011). From 2004-2009 North America's Eastern wild turkey population has experienced a population decline of 300,751-385,751 with currently 4.8-5.0 million birds in the population (Tapley et al. 2011). West Virginia has experienced its own population decline, reporting the loss of $5 \%$ of its population during the 5 years of 2004-2009, down now to an estimated 100,000 birds (Tapley et al. 2011).

In this study, we examine the effects of various land matrices (e.g., fragmentation, core area) and topographical features (e.g., slope, aspect) on habitat selection and use of male wild turkeys in relation to season, ecological region, and age class in West Virginia. A better understanding of factors that influence the selection of habitat resources composing turkey home ranges will provide information concerning availability, use and selection of resources at the local scale. Information concerning current, local habitat selection will be useful in the management and conservation of turkey populations within West Virginia. 


\section{Goals and Objectives}

My project goal is to quantify habitat selection of male wild turkeys in West Virginia. The project objective is as follows:

1. Examine the selection of various land matrices (e.g., fragmentation, cover type) and topographical features (e.g., slope, aspect) of male wild turkeys in relation to season, spatial scale, and age class for 2 study areas in West Virginia.

\section{Literature Review}

Turkey Habitat

There are numerous recent, telemetry based studies detailing the home range of female (Swanson 1993, Swanson et al. 1994, Taylor 1997, Fearer and Pack 2003) and male (Rauch et al. 2011) wild turkey within West Virginia. Previous, non-telemetry based research addressed several topics including movement studies detailing visual observation of snow trails of flock from one roost to the next (Lewis 1963) and observation of wing-tagged birds (Bailey 1959, Speake et al. 1969, Davis 1973). However, few studies have directly quantified the proportion of land cover-types comprising home ranges in detail or selection of habitat types by individual male wild turkeys.

There have been studies that detail male wild turkey home ranges including those within a specific habitat type, in relation to season and age, and even describing the movements of restocking programs with all variables greatly impacting the area of habitat used. Home ranges have been examined within many different habitat types from the farmland regions of Ohio (Clark 1985) to loblolly pine (Pinus taeda) plantations in Mississippi (Hurst et al. 1991); Hurst et al. (1991) described home range size of male wild turkeys by season. Speake et al. (1975) sampled wild turkeys $(n=20)$ within the states of Alabama and Kentucky and found that 
juvenile birds $(n=4)$ had smaller home ranges than adult birds $(n=16)$ in spring and summer within the pine forest of Alabama, but also found that turkeys had approximately equal home ranges in the hardwood forest of Kentucky showing both difference in age and region. The home ranges of translocated animals have been estimated (Carroll 1982) along with dispersal rates of restocked turkeys in east Texas (Hopkins et al. 1982).

Early dietary analyses helped elucidate the habitats selected by wild turkeys. In Pennsylvania acorns (Quercus spp.), grasses and sedges, wild grapes (Vitis spp.), dogwood (Cornus spp.), wild cherry (Prunus spp.), and snails were consumed throughout the year (Kozicky 1942). In Virginia the analysis of 524 stomach contents showed that acorns, dogwood, wild grape, and corn composed $54 \%$ of the total diet of wild turkeys in the state (Mosby and Handley 1943). Ten 'foods of importance' listed for the eastern mountainous counties of West Virginia: beech nuts (Fagus gradifolia), wild grape, blackberry (Rubus spp.), wild cherry, and dogwood as highly selected foods and beech buds, ferns, hemlock (Tsuga canadensis) leaves, bryophytes, and fungi as emergency foods (Glover and Bailey 1949).

Radio-equipped wild turkey hens selected all nesting habitats in proportion to their availability in northwestern West Virginia (Swanson et al. 1994). Of the 27 nests they located, 16 were in mixed mesophytic hardwoods, 7 in oak-hickory (Quercus-Carya spp.), 2 in unharvested bottomland hardwood stands, 1 in harvested chestnut oak ( $Q$. pinus), and 1 in an unharvest white oak (Q.alba) stand (Swanson et al. 1994). Unharvested chestnut oak, harvested white oak, harvested bottomland hardwood, and nonforested habitats were not selected by hens for nesting (Swanson et al. 1994). Most nests $(n=17)$, were found in thick cover (limbs, tree tops, logging slash) with 6 nests being found under spicebush (Lindera benzoin) and 2 in thickets of blackberry and grape. During late summer hens were located most frequently in chestnut oak 
forest types (characterized by sparsely vegetated understories) coinciding with huckleberry

(Gaylussacia spp.) and blueberries (Vaccinium spp.) (Swanson et al. 1994). Chestnut oak types were not selected by hens with poults in southeastern West Virginia (Pack et al. 1980) but were considered important brood habitat in Pennsylvania (Ross and Wunz 1990).

Bottomland hardwood forests are excellent for the rearing of wild turkey poults because it supports ideal understory vegetation (Healy 1981). This habitat type described as being 60$100 \%$ covered in vegetation with $>50 \%$ being herbaceous having an average canopy height of 20-60 cm (Swanson 1993). In Mississippi and eastern Texas bottomland hardwoods are important brood habitat (Phalen et al. 1986), but such habitats were avoided by hens with broods in southeastern West Virginia (Pack et al. 1980), South Dakota (McCabe and Flake 1985), and Alabama (Exum et al. 1987) due to low insect populations and overly dense vegetation. Production, Survival, and Predation

It has been shown by modeling production (fertility, clutch size, nesting rates, hen success, and poult survival) and survival estimates (Pack et al. 1999) that areas of Virginia and West Virginia have population finite growth rates (Norman et al. 2001). Finite growth rates may be due to the primary forest types of oak, oak-hickory, oak-pine, yellow poplar (Liriodendron tulipifera), and northern hardwoods (beech, cherry, and maple, Acer spp.) in Virginia and West Virginia (Norman et al. 2001). The predominantly forested habitat conditions of these states lack extensive secondary food sources (i.e., agricultural crops) that may be related to the lower production rates of the region (Norman et al. 2001); higher production rates have been linked to secondary food sources in New York and Minnesota where there are mixed forest and agricultural habitats (Porter et al. 1980, Roberts et al. 1995). Production indices in Virginia and West Virginia are limited by nesting rates (Norman et al. 2001). 
Additionally, fall turkey hunting seasons may potentially aid in population decline without higher production or survival (Norman et al. 2001, Alpizar-Jara et al. 2001). Because annual and regional variation in harvest and survival was greater (Pack et al. 1999) than the variation observed in production (Norman et al. 2001) it can be concluded that fall hunting affects population dynamics more than production. Alpizar-Jara et al. (2001) showed, through sensitivity analysis evaluated at various levels of removal, that fall harvest has the strongest negative effect on population growth and future male harvest. Increasing fall harvest survival would create greater increases in the population growth rate and the proportion of males in the population (Alpizar-Jara et al. 2001). However, increasing male survival rates will have no effect on population growth rates unless males are limiting in the population (Alpizar-Jara et al. 2001). Based on the simulations of Alpizar-Jara et al. (2001) a population of turkeys within the states of Virginia and West Virginia could only sustain $15 \%$ fall harvest mortality and remain stationary; a harvest of $10 \%$ would allow for population growth.

In the Ozarks of Arkansas nest predation strongly affected nest habitat selection (Badyaev 1995) and turkeys modified their habitat selection for renesting attempts in relation to those past experiences (Badyaev et al. 1996a); nest predation is the major source of breeding failure in the region (Badyaev 1994). Most annual mortality in the region was associated with prenesting movement; similar mortality was found in Alabama (Speake 1980, Everett et al. 1980), Minnesota (Porter 1978), Massachusetts (Vander Haegen et al. 1988), and Mississippi (Palmer et al. 1993). Extensive spring habitat searching was costly with the probability of nest success decreasing as the season progressed due to the finite amount of high quality nesting habitat (Badyaev 1995, Badyaev et al. 1996a, Badyaev et al. 1996b). Older female turkeys select cover types of greater complexity and variability in habitat structure (Badyaev 1995). These sites 
were characterized by high understory density (shrubs, grasses) and visual obstruction (logs, rocks, slash) at or near the nest (Healy 1981, Ransom et al. 1987, Lutz and Crawford 1987, Schmutz et al. 1989, Day et al. 1991, Rumble and Hodorff 1993). Areas around roads and forest edges were commonly selected for nesting due to a desirable increase in understory density and also by aiding in movement efficiency (Speake et al. 1975, Holbrook et al. 1987, Wertz and Flake 1988). There was a strong age-bias in site fidelity with older female turkeys being more likely to return to previous nesting areas than younger females (Badyaev and Faust 1996). Returning females showed higher reproductive capabilities by producing larger clutches than in previous years and experiencing higher nest survival than non-returning females (Badyaev and Faust 1996); depredation rates did not differ between returning and non-returning females.

Areas selected for first nest attempt and renests have pronounced differences in structural composition; renest areas are more variable and had greater complexity (Williams and Austin 1988, Schmutz et al. 1989, Day et al. 1991). First nest attempts are typically made in patches of large homogenous vegetation but switched to small patches for renests (Badyaev 1995); the switch aids in spatial heterogeneity. This change in cover type may aid in predator avoidance by increasing nest site variability (Storaas and Wegge 1987, Brittas and Willebrand 1991). Areas that contained greater protective nesting cover tended to attract turkeys for multiple years, whereas areas used for nesting that contained little nesting cover were typically abandoned the following spring (Badyaev and Faust 1996). Females selected clear-cuts, overgrown old fields, and pine stands with dense herbaceous understory because of greater nest concealment (Badyaev and Faust 1996); areas most often selected were characterized by dense understory and an open midstory. Cover was not the only important factor, females selected areas at least $80 \mathrm{~m}$ in diameter (Badyaev and Faust 1996). 
Annual survival rates of eastern wild turkey are similar in the states of Missouri (Vangilder and Kurzejeski 1995), Mississippi (Hurst 1988, Palmer et al. 1993), and Iowa (Little et al. 1990). Populations are not always stable as shown in the states of Minnesota (Porter 1978), Massachusetts (Vander Haegen et al. 1988), and Iowa (Little et al. 1990) each having differential survival of adult and subadult hens. In Missouri daily survival rates were higher in the summer and fall and lower in the spring and winter (Vangilder and Kurzejeski 1995). Seasonal turkey survival has been linked to latitude. In Minnesota the highest mortality rates occur during the months of January, February, and March (Porter 1978). However, in Mississippi lower survival rates were reported for the fall and spring (Hurst 1988). Agricultural grains provide nourishment in winter that may lessen winter deaths (Vangilder and Kurzejeski 1995). In Massachusetts (Vander Haegen et al. 1988), Iowa (Little et al. 1990), and Minnesota (Porter et al. 1980) where turkey had access to grain crops populations had significantly higher survival rates during severe winters. Conversely, in New York (Austin and DeGraff 1975) and Pennsylvania (Wunz and Hayden 1975) where turkeys had limited access to agricultural foods death tolls were high during harsh winters.

In the Ozarks of Missouri predation was the greatest cause of hen loss (Vangilder and Kurzejeski 1995), an occurrence not uncommon in other studies of eastern wild turkeys (Everett et al. 1980, Exum et al. 1987, Vander Haegen et al. 1988, Little et al. 1990, Palmer et al. 1993). During one year in Missouri illegal kill of hens was the leading cause of mortality (Vangilder and Kurzejeski 1995); such events were associated with spring gobbler season and small-game hunting seasons. Major hen loss associated with spring gobbler season has been found in Kentucky (Wright and Speake 1975), Alabama (Fleming and Speake 1976), and Iowa (Little et 
al. 1990). Factors that may help drive hen loss during spring gobbler season are gobbling activity, hunter density, and gobbler density (Vangilder and Kurzejeski 1995). Habitat Selection

Male and female wild turkey selected habitats consistently in central Mississippi (Miller et al. 1999). Hardwood sawtimber was the most selected cover-type followed by a combination of early successional and sawtimber pine by nonreproductive females, unsuccessful females during preincubation, and females during fall-winter (Miller et al. 1999); mixed pine-hardwood habitat-types and open habitats were the least selected. Successful females had 7 highly selected habitat types at the within home range scale: 1) hardwood sawtimber, 2) pine sawtimber burned and thinned $>3$ years ago, 3) pine regeneration, 4) hardwood regeneration, 5) pine poletimber, 6) hardwood poletimber, and 7) pine sawtimber burned and not thinned within 3 years were all selected at equal rates (Miller et al. 1999). Males selected 1) pine sawtimber, 2) pine regeneration, and 3) hardwood sawtimber at equal rates during summer and fall-winter (Miller et al. 1999). Hardwood poletimber, hardwood regeneration, and mixed regeneration, and mixed sawtimber not burned within the 3 years were the least selected (Miller et al. 1999). During the spring hardwood sawtimber, pine sawtimber, and pine regeneration were selected most often (Miller et al. 1999).

In Alabama, wild turkeys selected $0.5-12$ year old pine plantations less than their availability, whereas natural pine stands $>21$ years old were selected more than their availability (Kennamer et al. 1980). An avoidance of young pine stands and the selection of older ones may reflect a reluctance of turkey to enter overly dense vegetation; dense understory has been described as unsuitable turkey habitat (Bailey and Rinell 1967, Holbrook and Lewis 1967). In the Piedmont of Virginia, wild turkeys selected pine plantations, leave strips, and large blocks of 
mature hardwood stands in proportion to their availability effectively showing no direct selection of a specific cover-type (Holbrook et al. 1987). The conversion of hardwood stands to loblolly plantations did not eliminate wild turkey habitat (Holbrook et al. 1987). However, it is recommended that 'quality' habitat is maintained in corridors on intensively managed pine forest (Gehrken 1975); interconnecting hardwood leave strips insure interspersion between pine and hardwood cover types (Holbrook et al. 1987). Edges created by corridors between pine and hardwood stands create quality nesting and early brood rearing habitat (Holbrook et al. 1987). In Arkansas, female wild turkeys selected short-leaf pine ( $P$. echinata) and mixed pinehardwood timber over other overstory cover-types (Thogmartin 2001). Selection of pine and mixed pine-hardwood stands was associated with reproduction (Thogmartin 2001). Scarcity of suitable nesting areas in pine stands forced subordinate females to nest in bottomlands, a less suitable nesting habitat type (Thogmartin 1999), increasing both distance moved and home range size (Thogmartin 2001). Home range size as a function of nest site availability differs from prevailing ideas that foraging habitat is the determinant of home range size (Kurzejeski and Lewis 1990). Thogmartin (2001) also found that blackgum (Nyssa sylvatica), red maple (Acer rubrum) and white oak (Quercus alba) were highly selected understory cover-types. Rio Grande Wild Turkey Habitat Selection

In Texas, Rio Grande wild turkeys (Meleagris gallopavo intermedia) select areas of high habitat interspersion (Phillips et al. 2011a). Selected roost sites consisted of live oaks $\geq 9.0 \mathrm{~m}$ tall and canopy coverage of $\geq 56 \%$; roost sites have higher amounts of oaks than random landscapes (Phillips et al. 2011a). Roosting areas also displayed higher oak-edge density with turkeys using this cover to move to and from roost sites (Phillips et al 2011a). Roost sites typically displayed $37 \%$ woody protective cover whereas random sites contained only $22 \%$ total woody cover 
(Phillips et al. 2011a). Both male and female and dispersing and resident turkeys select habitat resources at similar rates (Phillips et al. 2011b). Groups displayed selection of riparian areas, trees, $>4 \mathrm{~m}$ structure, and edge at greater rates than other habitat resources (Philips et al 2011b). However, residents and dispersers both displayed seasonal movements from winter to summer ranges during spring and may be linked to the similarity in selection between the groups (Phillips et al. 2011b). Tree height is the best explanatory variable for winter roost predication in Texas (Swearingin et al. 2011); mean tree height (17 m) was greater than on non-roost sites $(12.5 \mathrm{~m})$. Tree diameter on roost sites $(49.4 \mathrm{~cm})$ is also greater than on non-roost sties $(43.66 \mathrm{~cm})$ and may be an important factor because larger trees often have more limbs of suitable roosting size (Swearingin et al. 2011). Intuitively, mean litter cover (roost $=56 \%$; non-roost $=40 \%$ ) was higher in roost sites while mean shrub cover (roost $=11 \%$; non-roost $=15 \%$ ) was higher on nonroost sites (Swearingin et al. 2011). The eastern cottonwood (Populus deltoids) was often a dominant tree species on roost sites and was utilized for its greater height $(18.6 \mathrm{~m})$ and diameter $(54.4 \mathrm{~cm})$ (Swearingin et al. 2011).

Compositional Analysis

The desire for a better understanding concerning wildlife use of resources is as old as the wildlife profession (Manly et al. 1993). A topic of interest has been the quantification of the "selection" of certain resources (Johnson 1980); do animals use resources more frequently than would be expected by chance given their relative availability? It should be noted that there is no widely accepted definition of habitat selection or a single hypothesis test that completely describes the concept of animal selection of a particular resource (Pendleton et al. 1998). Resource selection analysis methods include estimation of selection indices, hypothesis testing, and regression approaches (Manly et al. 1993, Pendleton et al. 1998). 
Based on the theory developed by Aitchison (1986), compositional analysis was first proposed for the analysis of habitat data by Aebischer et al. (1993). Study designs of types II and III, as described by Manly et al. (1993), can be appropriately described by compositional analysis if individual estimates have been made concerning habitat use and either the combined or separate estimates of habitat availability (Pendleton et al. 1998). Aebischer et al. (1993) discussed 4 problems associated with the analysis of habitat use: (1) determination of sample units (animals rather than individual point locations), (2) nonindependence of habitat proportions, (3) differential use patterns by identifiable groups of animals, and (4) arbitrary definition of availability. Use of animals, rather than individual locations, eliminates biased estimates of average use proportions when the number of sample locations differs among animals (Aebischer et al. 1993, Pendleton et al. 1998).

The proportional use of various habitats is not independent for an individual animal (Pendleton et al. 1998); if the proportional use of a habitat changes invariably the proportional use of one or more separate habitats must decrease ("unit sum" constraint) (Pendleton et al. 1998). Analyses of habitat use should account for this interdependence within the set of habitat use proportions (Pendleton et al. 1998). Animals in habitat use studies are generally placed in identifiable groups (e.g., age, sex, season of observation) with intent to examine habitat use patterns among groups (Pendleton et al. 1998).

Geographical Information Systems (GIS) data can arise from various sources but because compositional analysis requires only estimates of habitat use and availability proportions for each animal it is well suited to handle these types of data. Data may be collected in GIS via data points, lines due to continuous monitoring of movement, portions of mapped use area, or 
volumes obtained from integrating under a utilization surface (Pendleton et al. 1998). All of these data types can be used to produce a proportion of habitats therein.

Determining which habitat classes are and are not selected might be revealed by hypothesis testing approaches like compositional analysis even though animals may not distinguish between some habitat classes we define (Pendleton et al. 1998); degree of selection, with confidence intervals, for each habitat class are computed with this approach. It should be noted that habitats that may be selected at a higher rate than expected due to chance are not necessarily essential for the species' continued presence (Pendleton et al. 1998). Also, it does not directly follow that avoided habitats could not support the species if it were the only habitat available (Pendleton et al. 1998). It is possible that individual fitness may be low in heavily used habitats if use is affected by social structure in the population (Van Horne 1983, Pendleton et al. 1998). Regardless, habitat modification decisions are made based on use and availability data and analysis (Pendleton et al. 1998). However, decisions do not come directly from these test but are extensions of them based on additional assumptions (i.e., selection $=$ necessary; avoidance $=$ unsuitable) (Pendleton et al. 1998); such assumptions may be correct but should still be viewed as assumptions.

Analysis of Home range: Fixed Kernel Method

Wildlife habitat is often determined from radio-telemetry points alone and is often the primary source of information detailing habitat use and selection (Kernohan et al. 1998). Habitat use and selection determined from relocation points only have, however, been generally disregarded as a means of quantifying habitat composition or use because of locational error and inconsistent sample strategies (Kenward 1992, Kernohan et al. 1998). Fixed- and adaptive-kernel density estimators are fairly new home range estimating techniques used in the quantification of 
utilization distribution of an organism's home range (Worton 1989, Seaman and Powell 1996). The adaptive kernel method has been compared to the traditional method of telemetry relocation points as a method of a home range estimator; no difference was found between the 2 methods $(P>0.05)$ (Kernohan et al. 1998). However, Worton (1995) and Seaman and Powell (1996) determined that the fixed kernel provides the least biased results. It is vital to select the proper smoothing parameter or bandwidth $(h)$ when determining home range with a kernel density estimator (Worton 1995); Seaman and Powell (1996) concluded that selecting $h$ by least squares cross-validation performed well. The use of fixed kernel used within GIS may negate inherent error in radio-telemetry data such as locational error and sample strategies of point relocations (Worton 1989). Such a refined home range estimator calculates home range contours and computes and compares probability densities (Worton 1989). Similar patterns in habitat use can be identified from areas of home ranges concerning relocation point data (Kernohan et al. 1998).

\section{Study Area}

Two study areas were used in West Virginia: 1) statewide and 2) Harrison, Marion, and Taylor counties (Figure 1) in north-central West Virginia - District I Study Area (DISA). West Virginia is $78 \%$ forested of which $71 \%$ is comprised of the oak-hickory forest type (Griffith and Widmann 2003). The state is mountainous with elevations ranging from $73-1,524 \mathrm{~m}$. These variations in elevation cause noticeable changes in vegetation from region to region. West Virginia has a state-wide spring gobbler season (bearded turkeys only) and a 4-week either-sex fall wild turkey season in the traditional fall hunting counties (Rauch et al. 2011).

Forest vegetation in the state is broken into 3 physiographic provinces: Eastern Ridge and Valley, Allegheny Mountain and Upland Section, and Western Hill Section (Strausbaugh and Core 1978). The Western Hill Section, adjacent to the Ohio River, is primarily comprised of 
Central Hardwood Forest (xeric), Cove Hardwoods or Mixed Mesophytic Forest (mesic), and Flood Plain communities (hydric). Central Hardwood Forests are a mix of Oak-Pine (Quercus spp. - Pinus spp.) and and Oak-Hickory (Quercus spp. - Carya spp.). In the highest elevations of the state, the Allegheny Mountain and Upland Section, the Northern Hardwoods forest type dominates. This forest type is comprised primarily of sugar maple (Acer saccharum), American beech (Fagus grandifolia), and yellow birch (Betula alleghaniensis), and red spruce (Picea rubens) at the highest elevations. The Eastern Ridge and Valley is made up of an oak-hickorypine forest type. Due to habitat factors that directly or indirectly affect the distribution of vegetation and alter both annual mast conditions and game harvest, West Virginia has been divided into 6 ecological regions (Figure 2) to manage game populations accordingly (Uhlig and Wilson 1952). A better understand of the habitat selections of wild turkeys across the variable landscape of West Virginia is vital for their sound management and conservation.

The District I study area (DISA) is located within the Central Allegheny Plateau an area comprised primarily of Cove Hardwoods; Harrison, Marion, and Taylor counties comprise the DISA and are located in region 4 (Central). Topography of the DISA is primarily mountain ranges with aspects generally in the northeast-southwest orientations. These mountains have steep to very steep hillsides and narrow valleys (Beverage and Yoakum 1980). The area averages $59.5 \%$ forested of which $62.2 \%$ is comprised of oak-hickory (Griffith and Widmann 2003). Turkeys sampled in the DISA were also included in the statewide analysis of habitat selection. 


\section{Literature Cited}

Aebischer, N. J., P. A. Robertson, and R.E. Kenward. 1993. Compositional analysis of habitat use from animal radio-tracking data. Ecology 74:1313-1325.

Aitchison, J. 1986. The statistical analysis of compositional data. Chapman and Hall, London, U.K.

Alpizar-Jara, R., E. N. Brooks, K. H. Pollock, D. E. Steffen, J. C. Pack, and G. W. Norman. 2001. An eastern wild turkey population model for Virginia and West Virginia. Journal of Wildlife Management 65:415-424.

Austin, D. E. and L. W. DeGraff. 1975. Winter survival of wild turkeys in the southern Adirondacks. Proceedings of the National Wild Turkey Symposium 3:55-60.

Badyaev, A. V. 1994. Spring and breeding dispersal in an Arkansas population of wild turkeys: causes of and consequences for reproductive performance. Thesis, University of Arkansas, Fayetteville, Arkansas, USA.

Badyaev, A. V. 1995. Nesting habitat and nesting success of eastern wild turkeys in the Arkansas Ozark highlands. Condor 97:221-232.

Badyaev, A. V., and J. D. Faust. 1996. Nest site fidelity in female wild turkey: potential causes and reproductive consequences. Condor 98:589-594.

Badyaev, A. V., T. E. Martin, and W. J. Etges. 1996a. Habitat sampling and habitat selection by female wild turkey: ecological correlates and reproductive consequences. Auk 113:636646.

Badyaev, A. V., W. J. Etges, and T. E. Martin. 1996b. Ecological and behavioral correlates of variation in seasonal home ranges of wild turkey. Journal of Wildlife Management 60:154164. 
Bailey, R. W. 1959. Preliminary report on wild turkey banding studies as applicable to management in West Virginia. Proceedings of the National Wild Turkey Symposium $1: 146-158$.

Bailey, R. W., and K. T. Rinell. 1967. Management of the eastern wild turkey in the northern hardwoods. Pages 261-302 in O.H. Hewitt, ed. The wild turkey and its management. The Wildlife Society, Washington, D.C., USA.

Beletsky, L. D., and G. H. Orians. 1991. Effects of breeding experience and familiarity on side fidelity in female red-winged blackbirds. Ecology 72:787-796.

Beverage, W. W., and T. D. Yoakum. 1980. Soil survey of Harrison and Taylor counties, West Virginia. U.S. Department of Agriculture, Soil Conservation Service, Washington D.C., USA.

Brittas, R., and T. Willebrand. 1991. Nesting habitat and egg predation in Swedish black grouse. Ornis Scandinavica 22:261-263.

Brown, E. K. 1980. Home range and movement of wild turkeys- a review. Proceedings of the National Wild Turkey Symposium 4:251-261.

Carroll, J. P. 1982. Dispersal, home range and habitat use of translocated eastern wild turkeys (Meleagris gallopavo sylvestris) in Jackson County, Kentuck. Thesis, Eastern Kentucky University, Richmond, Kentucky, USA.

Clark, L. G. 1985. Adjustment by transplanted wild turkey to an Ohio farmland area. Proceedings of the National Wild Turkey Symposium 5:33-47.

Davis, J. R. 1973. Movements of wild turkey in southewestern Alabama. Pages 135-139 in G.C. Sanderson and H.C. Shultz, eds. Wild turkey management: current problems and programs. University of Missouri Press, Columbia, Missouri, USA. 
Day, K. S., L. D. Flake, and W. L. Tucker. 1991. Characteristics of wild turkey nest sites in a mixed grass prairie-oak-woodland mosaic in the northern Great Plains, South Dakota. Canadian Journal of Zoology 69:2840-2845.

Dhindsa M. S., P. E. Komers, and D. A. Boag. 1989. The effects of familiarity with an environment on the dominance relationship between juvenile and adult black-billed magpies. Ornis Scandinavica 20:187-192.

Everett, D. D., D. W. Speake, and W. K. Maddox. 1980. Natality and mortality of a north Alabama wild turkey population. Proceedings of the National Wild Turkey Symposium $4: 117-126$.

Exum, J. H., J. A. McGlincy, D. W. Speake, J. L. Buckner, and F. M. Stanlet. 1987. Ecology of the eastern wild turkey in an intensively managed pine forest in southern Alabama. Tall Timbers Research Station Bulletin 23:70.

Fearer, T. M., and J. C. Pack. 2003. Home range characteristics of female wild turkey in West Virginia. West Virginia Division of Natural Resources PR Report. Charleston, West Virginia, USA.

Fleming, W. J., and D. W. Speake. 1976. Losses of the eastern wild turkey from a stable Alabama population. Proceedings of the Southeastern Association of the Game and Fish Commission 30:377-385.

Gauthreaux, S. A., Jr. 1982. The ecology and evolution of avian migration systems. Pages 93168 in D. S. Farner and J. R. Kind, eds. Avian Biology. Volume 6, Academy Press, New York, New York, USA.

Gehrken, G. A. 1975. Travel corridor techniques of wild turkey management. Proceedings of the National Wild Turkey Symposium 3:113-117. 
Glover, F. A., and R. W. Bailey. 1949. Wild turkey foods in West Virginia. Journal of Wildlife Management 13:255-265.

Griffith, D. M., and R. H. Widmann. 2003. Forest statistics for West Virginia: 1989 and 2000. Resource Bulletin NE-157. Newton Square, Pennsylvania: U.S. Department of Agriculture, Forest Service. Northeastern Research Station, Newton Square, Pennsylvania, USA.

Healy, W. M. 1981. Habitat requirements of wild turkeys in the southeastern mountains. Pages 24-34 in P. T. Bromley and R. L. Carlton, eds. Proceedings of the symposium of habitat requirements and habitat management for the wild turkey in the southeast. Virginia Wild Turkey Foundation, Elliston, Virginia, USA.

Healy, W. M. 1992. Behavior. Pages 46-65 in J. G. Dickson, ed. The wild turkey: biology and management. Stackpole Books, Harrisburg, Pennsylvania, USA.

Holbrook, H. L., and J. Lewis. 1967. Management of the eastern turkey in the southern Appalachian and Cumberland Plateau region. Pages 343-370 in O. H. Hewitt, ed. The wild turkey and its management. The Wildlife Society, Washington, D.C., USA.

Holbrook, H. T., M. R. Vaughan, P.T. Bromley. 1987. Wild turkey habitat preference and recruitment in intensively managed piedmont forests. Journal of Wildlife Management $51: 182-187$.

Hopkins, C. R., J. J. Campo, W. G. Swank, and D. J. Martin. 1982. Dispersal of restocked eastern wild turkeys in east Texas. Annual Conference Southeastern Association of the Fish and Wildlife Agencies 36:578-585.

Hurst, G. A. 1988. Population estimates for the wild turkey on Tallahala Wildlife Management Area. Mississippi Department of Wildlife Conservation. Federal Aid in Wildlife Restoration Annual Report. Project W-48, Study 21:46. 
Hurst, G. A., D.A. Smith, J. D. Burk, and B. D. Leopold. 1991. Wild turkey gobbler habitat use and home range in loblolly pine plantations. Annual Conference Southeastern Association of the Fish and Wildlife Agencies 45:115-123.

Johnson, D. H. 1980. The comparison of usage and availability measurements for evaluating resource preference. Ecology 61:65-71.

Kelley, R. L., G. A. Hurst, and D. E. Steffen. 1988. Home ranges of wild turkey gobblers in central Mississippi. Proceeding of the Annual Conference Southeastern Association of Fish and Wildlife Agencies 42:470-475.

Kennamer, J. E., J. R. Gwaltney, and K. R. Sims. 1980. Habitat preference of eastern wild turkey on an area intensively managed for pine in Alabama. Proceedings of the National Wild Turkey Symposium 4:240-245.

Kennamer, J. E., and M. C. Kennamer. 1995. Status and distribution of the wild turkey in 1994. Proceedings of the National Wild Turkey Symposium 7:203-212.

Kenward, R. E. 1992. Quantity versus quality: programmed collection and analysis of radiotracking data. Pages 231-246 in I. G. Priede and S. M. Swift, eds. Wildlife telemetry: remote monitoring and tracking of animals. Ellis Horwood, New York, New York, USA.

Kernohan, B. J., J. J. Millspaugh, J. A. Jenks, and D. E. Naugle. 1998. Use of an adaptive kernel home range estimator in a GIS environment to calculate habitat use. Journal of Environmental Management 53:83-89.

Ketterson, E. D., and V. Nolan, Jr. 1983. The evolution of differential bird migration. Current Ornithology 1:357-402. 
Koivula, K., K. Lahti, M. Orell, and S. Rytkonen. 1993. Prior residency as a key determinant of social dominance in willow tit (Parus montanus). Behavioral Ecology and Sociobiology $33: 283-287$.

Kozicky, E. L. 1942. Pennsylvania wild turkey food habits. Pennsylvania Game News 13:10-31.

Kurzejeski, E. W., and J. B. Lewis. 1990. Home range, movements, and habitat use of wild turkey hens in northern Missouri. Proceedings of the National Wild Turkey Symposium. 6:67-71.

Lewis, J. C. 1963. Observations on the winter range of wild turkeys in Michigan. Journal of Wildlife Management. 27:98-120.

Little, T. W., J. M. Kienzler, and G. A. Hanson. 1990. Effects of fall either-sex hunting on survival in an Iowa wild turkey population. Proceedings of the National Wild Turkey Symposium 6:119-125.

Lutz, R. S., and J. A. Crawford. 1987. Reproductive success and nesting habitats of Merriams's wild turkey in Oregon. Journal of Wildlife Management 51:783-787.

Manly, B. F., L. L. McDonald, and D. L. Thomas. 1993. Resource selection by animals. Chapman and Hall, London, U.K.

McCabe, K. F. and L. D. Flake. 1985. Brood rearing habitat use by wild turkey hens in south central South Dakota. Proceedings of the National Wild Turkey Symposium 5:121-132.

Miller, D. A., G. A. Hurst, B. D. Leopold. 1999. Habitat use of eastern wild turkeys in central Mississippi. Journal of Wildlife Management 63:210-222.

Mosby, H. S., and C. O. Handley. 1943. The wild turkey in Virginia: its status, life history and management. Division of Game, Commission of Game and Inland Fisheries, Richmond, Virginia, USA. 
Myers, J. P. 1981. A test of three hypotheses for latitudinal segregation of the sexes in wintering birds. Canadian Journal of Zoology 59:1527-1534.

Norman, G. W., J. C. Pack, C. I. Taylor, D. E. Steffen, K. H. Pollock. 2001. Reproduction of Eastern Wild Turkeys in Virginia and West Virginia. Journal of Wildlife Management $65: 1-9$.

Nowacki, G. J., and M. D. Abrams. 2008. The demise of fire and "mesophication" of forest in the eastern United States. BioScience 58:123-128.

Pack, J. C., R. P. Burkert, W. K. Igo, and D. J. Pybus. 1980. Habitat utilized by wild turkey broods within oak-hickory forest of West Virginia. Proceedings of the National Wild Turkey Symposium 4:213-224.

Pack, J. C., G. W. Norman, C. I. Taylor, D. E. Steffen, D. A. Swanson, K. H. Pollock, and R. Alpizar-Jara. 1999. Effects of fall hunting on wild turkey populations in Virginia and West Virginia. Journal of Wildlife Management 63:964-975.

Palmer, W. A., G. A. Hurst, J. E. Stys, D. R. Smith, and J. D. Burk. 1993. Survival rates of wild turkey hens in loblolly pine plantations in Mississippi. Journal of Wildlife Management $57: 783-789$.

Pendleton, G. W., K. Titus, E. DeGayner, C. J. Flatten, and R. E. Lowell. 1998. Compositional analysis and GIS for study of habitat selection by goshawks in southeast Alaska. American Statistical Association and the International Biometric Society Journal of Agricultural, Biological, and Environmental Statistics 3:280-295.

Phalen, P. S., G. A. Hurst, and W. J. Hamrick. 1986. Brood habitat use and preference of wild turkeys in central Mississippi. Proceedings of the Annual Conference Southeast Association of Fish and Wildlife Agencies 40:397-404. 
Phillips, C. E., W. P. Kuvlesky, Jr., S. J. DeMaso, L. A. Brennan, and D. G. Hewitt. 2011 a. Landscape metrics related to Rio Grande wild turkey winter roost in south Texas. Proceeding of the National Wild Turkey Symposium 10:265-273.

Phillips, R. S., W. B. Warren, M. C. Wallace, J. H. Brunjes, IV, E. B. Fish, N. E. McIntyre, S. J. DeMaso. 2011b. Rio Grande wild turkey habitat association during dispersal. Proceeding of the National Wild Turkey Symposium 10:213-225.

Porter, W. F. 1978. The ecology and behavior of the wild turkey (Meleagris gallopavo) in southeastern Minnesota. Dissertation, University of Minnesota, St. Paul, USA.

Porter, W. F., G. C. Nelson, and D. A. Hamilton. 1980. Effects of corn food plots on wild turkeys in the upper Mississippi Valley. Journal of Wildlife Management 44:456-462.

Porter, W. F., W. M. Healy, S. E. Backs, B. F. Wakeling, and D. E. Steffen. 2011. Managing wild turkeys in the face of uncertainty. Proceedings of the National Wild Turkey Symposium 10:1-8.

Ransom, D. Jr., O. J. Rongstad, and D. H. Rusch. 1987. Nesting ecology of Rio Grande turkeys. Journal of Wildlife Management 51:435-439.

Rauch, S. E., J. T. Anderson, and A. A. Billings. 2011. Spring hunting season home range size of male wild turkeys in north central West Virginia. National Wild Turkey Symposium 10:157-164.

Roberts, S. D., J. M. Coffey, and W. F. Porter. 1995. Survival and reproduction of female wild turkeys in New York. Journal of Wildlife Management 59:437-447.

Ross, A. S., and G. A. Wunz. 1990. Habitat use by wild turkey hens during the summer in oak forest in Pennsylvania. Proceedings of the National Wild Turkey Symposium 6:39-43. 
Rumble, M. A., and R. A. Hodorff. 1993. Nesting ecology of Merriam's turkeys in the Black Hills, South Dakota. Journal of Wildlife Managemen 57:789-801.

Ryan, C. W., J. C. Pack, W. K. Igo, J. C. Rieffenberger, A. B. Billings. 2004. Relationships of mast production to big-game harvest in West Virginia. Wildlife Society Bulletin 32:1-9.

Schieck, J. O., and S. J. Hannon. 1989. Breeding site fidelity in willow ptarmigan: the influence of previous reproductive success and familiarity with partner and territory. Oecologia 81:465-472.

Schmutz, J. A., C. E. Braun, and W. F. Andelt. 1989. Nesting habitat use of Rio Grande wild turkeys. Wilson Bulletin 101:591-598.

Seaman, D. E., and R. A. Powell. 1996. An evaluation of the accuracy of kernel density estimators for home range analysis. Ecology 77:2075-2085.

Smith, R. L. 1974. Ecology and field biology. Second Edition. Harper and Row. New York, New York, USA.

Speake, D. W., L. H. Barwick, H. O. Hillestead, and W. Sickney. 1969. Some characteristics of an expanding turkey population. Proceeding of the Annual Conference Southeastern Association of Fish and Wildlife Agencies 23:46-58.

Speake, D. W., T. E. Lynch, W. J. Fleming, G. A. Wright, and W. J. Harnick. 1975. Habitat use and seasonal movements of wild turkeys in the southeast. Proceedings of the National Wild Turkey Symposium 3:122-130.

Speake, D. W. 1980. Predation on wild turkeys in Alabama. Proceedings of the National Wild Turkey Symposium 4:86-101.

Strausbaugh, P. D., and E. L. Core. 1978. Flora of West Virginia, Second Edition. Seneca Books, Morgantown, West Virginia, USA. 
Storaas, T., and P. Wegge. 1987. Nesting habitats and nest predation in sympatric populations of capercaillie and black grouse. Journal of Wildlife Management 51:167-172.

Swanson, D. A. 1993. Population dynamics of wild turkey in West Virginia. Disseration, West Virginia University, Morgantown, West Virginia, USA.

Swanson, D. A., J. C. Pack, C. I. Taylor, P. W. Brown, and D. E. Samuel. 1994. Habitat use of wild turkey hens in northwestern West Virginia. Proceeding of the Annual Conference Southeastern Association of Fish and Wildlife Agencies 48:123-133.

Swearingin, R. M., M. C. Wallace, W. B. Ballard, M. J. Butler, R. S. Phillips, R. N. Walker, S. L. Mckenzie, B. E. Petersen, and D. C. Ruthven, III. 2011. Winter roost characteristics of Rio Grande wild turkeys in the Rolling Plains of Texas. Proceedings of the National Wild Turkey Symposium 10:251-263.

Tapley, J. L., R. K. Abernethy, M. A. Hatfield, J. E. Kennamer. 2011. Status and distribution of the wild turkey in 2009. Proceedings of the National Wild Turkey Symposium 10:19-30.

Taylor, C. I. 1997. Home range and movements of wild turkey hens in the New River valley, Summers County, West Virginia. Pages 67-80 in Proceedings, New River Symposium, April 11-12, 1997, Glade Springs Resort, Daniels, West Virginia. Glen Jean, West Virginia: National Park Service, USA.

Thogmartin, W. E. 1999. Effects of landscape characters on nest-site selection in wild turkeys. Auk 116:912-923.

Thogmartin, W. E. 2001. Home range size and habitat selection of female wild turkeys (Melegris gallopavo) in Arkansas. American Midland Naturalist 145:247-260. 
Tirpak, J. M., W. M. Giuliano, T. J. Allen, S. Bittner, J. W. Edwards, S. Friedhof, C. A. Harper, W. K. Igo, D. F. Stauffer, and G. W. Norman. 2010. Ruffed grouse-habitat preference in the central and southern Appalachians. Forest Ecology and Management 260:1525-1538.

Uhlig, H. G., and H. L. Wilson. 1952. A method of evaluating an annual mast index. Journal of Wildlife Management 16:338-343.

Vander Haegen, W. M., W. E. Dodge, and M. W. Sayre. 1988. Factors affecting productivity in a northern wild turkey population. Journal of Wildlife Management 52:127-133.

Vangilder, L. D., and E. W. Kurzejeski. 1995. Population ecology of the eastern wild turkey in northern Missouri. Wildlife Monographs 130:1-50.

Van Horne, B. 1983. Density as a misleading indicator of habitat quality. Journal of Wildlife Management 47:983-901.

Wertz, T. L. and L. D. Flake. 1988. Wild turkey nesting ecology in south central South Dakota. Prairie Naturalist 20:29-37.

West Virginia Department of Natural Resources. 1985. The wild turkey in West Virginia. Publication \#3. West Virginia Department of Natural Resources, Wildlife Resources Section, Charleston, West Virginia, USA.

Wigley, T. B., J. M. Sweeny, M. E. Garner, and M. A. Melechiors. 1986. Wild turkey home ranges in the Ouachita Mountains. Journal of Wildlife Management 50:540-544.

Williams, L. E., Jr., and D. H. Austin. 1988. The wild turkey in Florida. Technical Bulletin 10. University of Florida Press, Gainsville, Florida, USA.

Worton, B. J. 1989. Kernel methods for estimating the utilization distribution in home range studies. Ecology 70: 164-168. 
Worton, B. J. 1995. Using monte carlo simulation to evaluate kernel-based home range estimators. Journal of Wildlife Management 59:794-800.

Wright, G. A., and D. W. Speake. 1975. Compatibility of the eastern wild turkey with recreational activities at Land Between the Lakes, Kentucky. Proceedings of the Southeastern Association of Game and Fish Commission 29:578-584.

Wunz, G. A., and A. H. Hayden. 1975. Winter mortality and supplemental feeding of turkeys in Pennsylvania. Proceedings of the National Wild Turkey Symposium 3:61-69. 


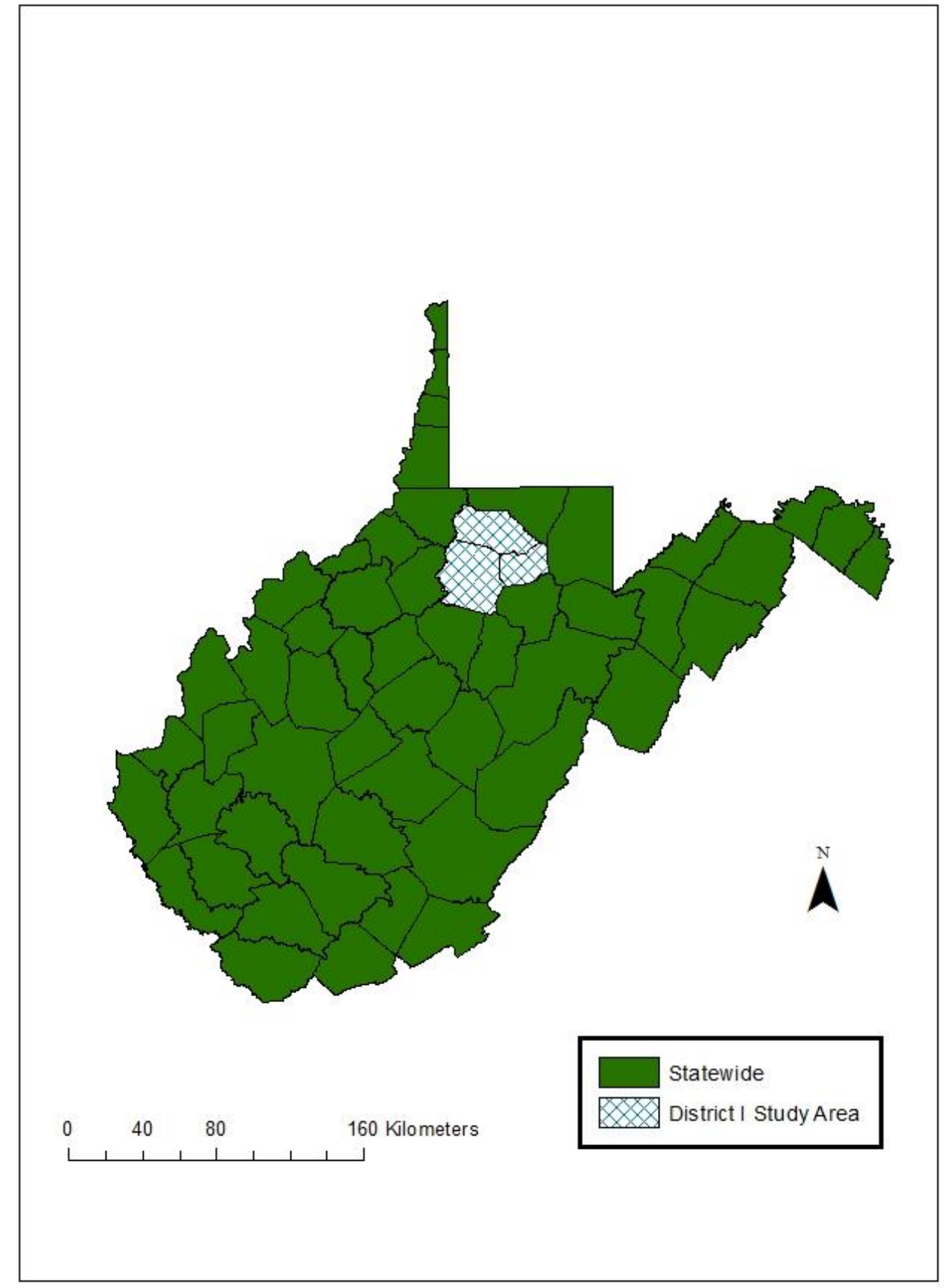

Figure 1. West Virginia Statewide Study Area and District I Study Area, 2004-2007. 


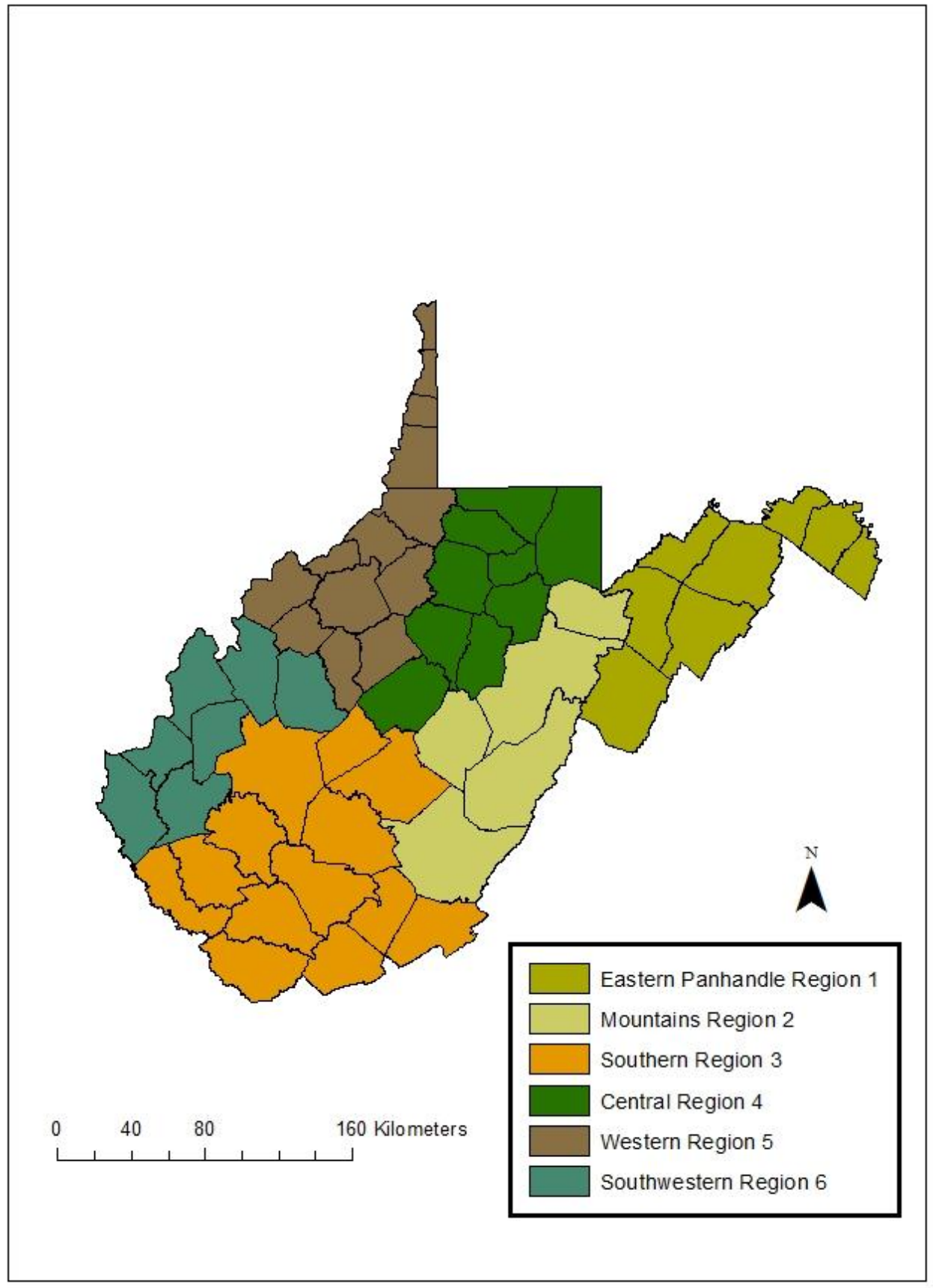

Figure 2. Ecological regions of West Virginia, 2004-2007. 
Chapter $2^{\mathrm{a}}$

Jesse L. De La Cruz

322 Percival Hall

P.O. Box 6125

Morgantown, WV 26506-6125

304/695-3071

jdelacru@mix.wvu.edu

RH: De La Cruz et al. • Male Turkey Habitat Selection

Habitat Selection of the Male Eastern Wild Turkey in West Virginia

JESSE L. DE LA CRUZ ${ }^{1}$, Division of Forestry and Natural Resources, West Virginia

University, P.O. Box 6125, Morgantown, WV 26506, USA

STEVEN E. RAUCH, West Virginia Division of Natural Resources, P.O. Box 99, Farmington, WV 26571, USA

JAMES T. ANDERSON, Division of Forestry and Natural Resources, and Environmental Research Center, West Virginia University, P.O. Box 6125, Morgantown, WV 26506, USA ABSTRACT: Eastern wild turkey (Meleagris gallopavo silvestris; hereafter wild turkey) vary in their selection of home range habitat resources temporally, spatially, and according to specific life-stage needs. We studied the home range size and habitat selection of 55 radio-equipped male wild turkeys from September 2004-August 2007 in West Virginia. Wild turkey displayed variable habitat resource selection particularly between age classes. We found that annual statewide adult regional home range and core home range spatial scale selections of land use and land cover habitat resources were primarily for forested areas. However, juvenile land use and land cover selection was for forest roads at the regional level but for cropland at the core home

\footnotetext{
${ }^{\mathrm{a}}$ This chapter written in the style of The Journal of Wildlife Management

${ }^{1}$ Email: jdelacru@mix.wvu.edu
} 
range spatial scale. In addition, at both spatial scales juvenile land fragmentation resource selection was primarily for edge habitats. However, the annual statewide adult land fragmentation resource selection was for edge at the regional scale but for forest perforations at the core home range scale. Our analysis also indicated that at both spatial scales adults consistently selected for steeper $>24-35 \%$ gradient slopes compared to $>6-24 \%$ gradient slopes selected by juveniles. Our finding suggest that land managers should provide a diverse mosaic of forest, forest perforations, edges, pasture-fields, and if possible, hay cropland to aid in the management of male wild turkey in West Virginia.

KEY WORDS compositional analysis, eastern wild turkey, fixed kernel density, habitat selection, home range, Meleagris gallopavo silvestris, West Virginia.

The Journal of Wildlife Management: 00(0): 000-000, 201X

Historically wildlife biologist thought that the eastern wild turkey (Meleagris gallopavo silvestris; hereafter wild turkey) needed large tracts (i.e., $\geq 6,000$ ha) of continuous forest (Mosby and Handley 1943, Kozicky and Metz 1948, Latham 1956) with the interspersion of forest to open land considered unfavorable (Bailey 1973). Quality habitat was thought to be 60$80 \%$ oak forest, $10-15 \%$ conifer, and openings of $<1$ ha (Kozicky and Metz 1948). However, during the 1970s, 1980s, and early 1990s many radio telemetry studies demonstrated that wild turkey could survive in areas of $<15 \%$ forest cover (Porter 1978, Hecklau et al. 1982, Kurzejeski and Lewis 1985, Kurzejeskei and Lewis 1990). Furthermore, the work of Glennon and Porter (1999) showed that variation in wild turkey abundance could be attributed to edge and patch density and suggested that high interspersion of forest and agriculture increased habitat quality. Specifically, in New York high habitat quality was associated with forest, open, and shrubland habitat-types at a 1:1:1 ratio (Fleming 2003, Porter and Gefell 1996). 
The perception of habitat quality has also changed over time in the Appalachian range of the eastern wild turkey. Like in most of its range, the concept of optimum turkey habitat was described as remote and large areas of contiguous tracts of mast producing hardwood forest (Wunz and Pack 1992). For example, in West Virginia areas containing $>0.6 \mathrm{~km}$ of $\mathrm{road} / \mathrm{km}^{2}$ resulted in reduced turkey abundance (Bailey and Rinell 1968). However, in Pennsylvania, turkeys selected forest with open understories less than smaller tracts of early successional forest presumably for their rich understory (Wunz 1971). Although mature forest may be a key component of turkey habitat, areas of pioneer shrubs and trees associated with herbaceous openings or cropland are also important due to their often more reliable food production (Wunz and Pack 1992).

While early research in eastern hardwood forest observed the importance of herbaceous forest openings (Mosby and Handley 1943) their effects and optimal amounts, as it pertains to turkey populations, is highly variable between, and often inconsistent within, different regions of Appalachia (Wunz and Pack 1992). In Pennsylvania turkeys could inhabit areas of only $26 \%$ forest with selected forested areas being as small as 51 ha (Wunz 1985). Wunz and Pack (1992) estimated that areas with $10 \%$ openings promoted adequate amounts of herbaceous and invertebrate food sources to help sustain turkey populations within eastern hardwood forest types. Porter et al. (2011) concluded that due to the many dimensions of habitat suitability, and with the influence of ever changing land-use over large geographic regions, it will be important to continue building our understanding of turkey habitat selection, use, and needs and to not succumb to complacency due to current turkey abundance.

Due to the high variability in regional wild turkey home range composition, it is important to understand what habitat resources are available to turkeys and which are being most 
commonly selected for to assure the conservation and maintenance of local, quality turkey habitat. Therefore, our objectives were to: 1) estimate annual and seasonal home range size of adult and juvenile male wild turkey and 2) determine resource availability and use as it pertains to anthropomorphic land use and landscape cover, land fragmentation, slope, and aspect at multiple temporal and spatial scales in West Virginia, USA.

\section{STUDY AREA}

We conducted this research over 2 study areas in West Virginia: 1) statewide and 2) the District I Study Area (DISA) which is comprised of Harrison, Marion, and Taylor counties in the Central Region of West Virginia (Figure 1). West Virginia is a mountainous state, with elevations ranging from $73-1,524 \mathrm{~m}$. These variations in elevation cause noticeable changes in vegetation from region to region. West Virginia has a state-wide spring turkey season (bearded turkeys only) and a 4-week either-sex fall wild turkey season in the traditional fall hunting counties which are generally located within the mountainous region of the state (Rauch et al. 2011).

West Virginia is $78 \%$ forested of which $71 \%$ is comprised of the oak-hickory forest type (Griffith and Widmann 2003). The state is classified into 3 physiographic provinces: Eastern Ridge and Valley, Allegheny Mountain and Upland Section, and Western Hill Section (Strausbaugh and Core 1978). The Western Hill Section, adjacent to the Ohio River, is primarily comprised of Central Hardwood Forest (xeric), Cove Hardwoods (mesic), and Flood Plain communities (hydric). Central Hardwood Forests are a mix of Oak-Pine (Quercus spp. - Pinus spp.) and Oak-Hickory (Quercus spp. - Carya spp.). In the highest elevations of the state, the Allegheny Mountain and Upland Section, the Northern Hardwoods forest type dominates. This forest type is comprised primarily of sugar maple (Acer saccharum), American beech (Fagus 
grandifolia), and yellow birch (Betula alleghaniensis). The Eastern Ridge and Valley is comprised of an oak-hickory-pine forest type. The DISA is located within the Central Allegheny Plateau an area comprised primarily of Cove Hardwoods. Topography of the DISA is primarily mountain ranges with aspects generally in the northeast-southwest orientations. The DISA is described as having steep to very steep mountains hillsides and narrow valleys (Beverage and Yoakum 1980); the area averages $59.5 \%$ forested of which $62.2 \%$ being comprised of oakhickory (Griffith and Widmann 2003). Cropland of West Virginia is composed of 89\% hay crop, $9 \%$ grain crops (e.g., corn, soybean), and only $1 \%$ of both wheat and fruit crops (e.g., apples, peaches) (King and Lemmon 2008).

\section{METHODS}

\section{Trapping and Radio Telemetry}

From September-November and January-March of 2004-2007 personnel with the West Virginia Division of Natural Resources trapped wild turkey at 29 sites baited with cracked or whole corn with use of rocket nets or rocket boxes (Kurzejeski and Vangilder 1992). We aged and sexed individuals (juvenile or adult) by the use of feather coloration and pattern (Pelham and Dickson 1992). We followed the methods of Healy and Nenno (1980) to age and sex juvenile turkeys; we aged yearling turkeys (12-16 months) caught in early September by tenth primary feather (Larson and Taber 1980). We weighed all wild turkeys with a spring scale and fitted each with a uniquely numbered aluminum leg band. We assessed and recorded physical condition.

Only male wild turkeys with a mass $>1.6 \mathrm{~kg}$ and having a physical condition of good (minor feather loss, minor scalping) or excellent (no feather loss, no injuries) were used for radio tracking. We released turkeys at the capture site and trapping locations were recorded in Universal Transverse Mercator (UTM) Coordinates. 
We fitted turkeys with backpack transmitters (Advanced Telemetry Systems Inc. (ATS) Isanti, MN) weighing $80 \mathrm{~g}$ attached by $4.8 \mathrm{~mm}$ nylon shock cord (Norman et al. 1997). We set transmitter frequencies between 150 and $152 \mathrm{MHz}$ and each transmitter included a motionmortality sensor (Rauch 2009). We located male wild turkey at least once a week through radio triangulation (Cochran and Lord 1963) with at least 2 directional azimuths to determine location (Andelt and Gipson 1979, Nams and Boutin 1991, Wallingford and Lancia 1991, Zielinski et al. 2004). When only 2 intersecting azimuths were recorded, we only used locations separated by $\geq 60^{\circ}$ and $\leq 120^{\circ}$ (Kurzejeski and Lewis 1990, Sisson and Speake 1994, Miller et al. 2001). We only used locations generated by $\geq 2$ azimuths recorded $\leq 20$ minutes apart in the analysis (Rauch et al. 2011). We also located turkey a minimum of twice per week during peak hunting pressure days, which included the first week of squirrel (Sciurus spp.), white-tailed deer (Odocoileus virginianus) (archery, buck-only firearms, antlerless, and muzzleloader), and spring and fall wild turkey hunting seasons (Rauch et al. 2011). We estimated telemetry error by placing $2.0 \mathrm{~L}$ bottles, filled with a saline solution, with an attached radio transmitter in the forest at the average height of a male wild turkey (46 cm: Townsend et al. 2007). We estimated telemetry error to be $6^{\circ}(\mathrm{SE}=0.84)$ with a mean distance from transmitter location to receiving location of $458.9 \mathrm{~m}$ $(\mathrm{SE}=59.12)(N=18:$ White and Garrott 1990). We computed a $95 \%$ confidence ellipse of 7.7 ha $(\mathrm{SD}=89)$ associated with telemetry error (White and Garrott 1990) in the program LOCATE III (Pacer Computing, Truro, NS, Canada) (Rauch et al. 2011). We only used turkeys with a minimum of 30 locations in home range estimations (Seaman et al. 1999). We pooled telemetry data for each male wild turkey across years and only male wild turkey with a $\geq 9$ month period of locations were used. We used Program LOCATE III to generate UTM coordinates (X and Y coordinates) of the locations associated with telemetry data (Rauch et al. 2011). 


\section{Cover Type Mapping}

We used the plug-in toolset Feature Analyst for geographic information systems (GIS) in the delineation of National Agriculture Imagery Program (NAIP) 2007 aerial photography creating unique land use and land cover raster data. We created land use and land cover raster data that delineated the land features of forest, pasture-field, barren-urban, open water, roads, and crops; because open water (WVDEP), roads (U.S. Census Bureau), and crops (USDA) could not be accurately identified by means of computer delineation and predictive learning, we added them to raster maps by converting polygon features to raster data to generate a new raster mosaic by combining these with the features created using Feature Analyst. To assure the highest level of accuracy possible, we also mitigated for false positives or clutter by labeling the features from the previous classification as either positive or negative, the negative instances are considered incorrect and are masked out (Opitz and Blundell 1999).

\section{Fragmentation Calculations}

We used the Landscape Fragmentation Tool v2.0, which classifies land cover into the 4 categories of patch, edge, perforations and core, to create a land fragmentation raster data set (Vogt et al. 2007). We described core forest pixels to be any forest pixels that are more than 100 $\mathrm{m}$ from the nearest field or non-forest pixel, deriving values from our previously created land use and land cover raster data; the core category was divided into small (<100 ha), medium (100-200 ha), and large (>200 ha) core based on the area of the tract (Vogt et al. 2007). We used an edge width of $100 \mathrm{~m}$ and defined edge pixels as areas along the outside portion of forest tracts; the edge width indicates the distance over which a fragmenting land cover (i.e., field, non-forest) can degrade the land cover of interest (i.e., forest) (Vogt et al. 2007). We defined perforations pixels as areas along the edge of small forest gaps and as being part of a tract containing core pixels; 
perforations pixels are within $100 \mathrm{~m}$ of field or non-forested pixels. We defined patch pixels as small forest fragments that do not contain any core forest pixels (Vogt et al. 2007).

\section{Home Range Estimation}

We constructed home range estimates using the Gaussian, fixed kernel method with least squares cross-validation for the smoothing parameter $(h)$ in the program Geospatial Modeling Environment (GME) 0.6.0.using the function $k d e$; we constructed the associated $50 \%$ and $95 \%$ utilization distributions using the function isopleth and regional 100 ha sampling blocks using the function genvecgrid. The fixed kernel density estimator (KDE) is the most widely accepted method of home range estimation (Kernohan et al. 2001) and generates a continuous intensity surface of an animal's utilization distribution by smoothing the point pattern of animal locations (Silverman 1986, Worton 1989). We used an automated string of code within GME in conjunction with all 50\% and 95\% home range utilization distributions and 100 ha regional sampling blocks to extract environmental raster data via the function isectpolyrst (Beyer 2010); percent composition of each category was extracted at each spatial scale. We use the extracted data from raster images detailing our unique land use and land cover and land fragmentation data along with previously constructed slope and aspect raster data as the basis of our compositional analysis.

\section{Habitat Selection}

We constructed Gaussian kernel density estimations of $95 \%$ and $50 \%$ utilization distributions (UD) and 100 ha regional sampling blocks for male wild turkeys using GME to find annual, seasonal, and regional home range within a region (second-order) and core home range within a periphery (third-order) resource selection. We used the $95 \%$ UD to describe the periphery home range exploited by an individual, while the purpose of computing a 50\% UD was 
to provide an estimate of core utilization of home range (Dickson and Beier 2002). Although the 95\% utilization distribution can be used to describe the total home range, Dickson and Beier (2002) and Seaman et al. (1999) describe it to be of little biological significance and unreliable, regardless of the home range estimator used; because of the nature of the $95 \%$ periphery UD we only viewed it as the cover-types available to and potentially selected by an animal within a given second-order, micro-regional scale.

To determine the presence of second-order habitat selection (i.e., home range within a region) we used an assessment of regional resource availability by summarizing environmental variables that comprised 100 ha sampling blocks, generated using GME, across study areas containing turkey home ranges. We sampled 2,587 statewide and 639 DISA 100 ha vector girds to assess second-order habitat resource selection. We used the results of regional environmental variable assessments as the proportional data defining "available cover-types composition" which were compared in relation to the proportion "used cover-types composition" defined by the $95 \%$ utilization distributions to assess selected habitat of male wild turkeys at the secondorder level, regional scale, via compositional analysis (Johnson 1980, Aebischer et al. 1993, Tirpak et al. 2010). In addition, we used the $95 \%$ utilization distributions as the proportion of "available cover-types composition" which was compared in relation to the proportion "used cover-types composition" defined by the core $50 \%$ utilization distributions to assess third-order, core habitat within a periphery, selected habitat of male wild turkeys (Johnson 1980, Aebischer et al. 1993, Tirpak et al. 2010).

\section{Statistical Analysis}

We followed the framework developed by Johnson (1980) and Aebischer et al. (1993), in which animals select resource use at hierarchical stages, specifically selection of home range 
within a region (second-order selection) and core home range within a periphery (third-order selection). We used the term "habitat composition" in reference to proportions of habitat-types (as defined by vegetation types and other classifying entities) used by or available to an animal (Dickson and Beier 2002); habitat composition sums to $100 \%$. The compositional analysis used the individual animal, not the radio location, as the sampling unit and avoids statistical problems arising from the non-independence of proportions within a habitat composition (Aebischer et al. 1993). Our habitat compositional analysis followed the methodology of Aebischer et al. (1993) which involved the proportional habitat use by individual animals as a basis of analysis. Compositional analysis is comprised of nonstandard multivariate data which encompasses all multivariate analysis of variance (MANOVA) and multivariate analysis of covariance (MANCOVA) linear models (Aebischer et al. 1993).

In most instances we did not have enough telemetry points to look at yearly variation in habitat selection. However, we believe we are justified in polling data across years. We had $n=7$ adult turkeys with enough points to adequately calculate a home range for more than one year (two years $n=5$; three years $n=2$ ) an assessment of yearly home range overlap was conducted. Home range overlap averaged $87.3 \%(\mathrm{SE}=4.08)$ for the $50 \%$ core and $85.7 \%(\mathrm{SE}=4.78)$ for 95\% total home ranges across years. During 2004-2006 total mast indices were relatively stable $(\bar{x}=42, \mathrm{SE}=3.0 ;$ Rauch 2009) and because our overlap analysis suggest consistent home range use between years, we examined home range composition for both age classes (juvenile and adult) across the entire state using total (all point locations) home ranges. We totaled withingroup variation of adult and juvenile dependent $50 \%$ and $95 \%$ UD home range sizes by independent seasonal and regional classes using a Kruskal-Wallis 1-way analysis of variance and between-group age class variation was examined by Wilcoxon signed rank test; juvenile within- 
group seasonal home range variation by Wilcoxon signed rank test because the seasonal analysis contained only 2 categories. We examined differences in the dependent habitat-type variables across the independent variables age (adult, juvenile) and ecological regions using MANOVA and MANCOVA in compositional analysis (Aebischer et al. 1993, Pendleton et al. 1998). We also examined statewide home range composition for both age classes at the following temporal scales: total annual (all point locations), annual spring (March-May), annual spring-summer (points from March-August per bird), annual fall (September-November), and annual fallwinter (points from September-February per bird) (Kelley et al. 1988, Fearer and Pack 2003). We ranked habitat-types according to relative use and significance between-rank differences. Compositional analysis was performed in the statistical program $\mathrm{R}$ in the "adehabitat" package. The "adehabitat" package was developed to study the space use and habitat selection by wildlife (Calenge 2006) including the compositional analysis of habitat cover-types (Johnson 1980, Aebischer et al. 1993).

\section{RESULTS}

\section{Monitoring Statistics}

From September 2004 through August 2007197 male wild turkeys were radioed in West Virginia (representing all 6 ecological regions); 32 were monitored in the DISA. Of the total sample, we used 55 total individuals (22 in the DISA) in the analysis of home range size throughout the state. From these individuals we classified 29 as juveniles (11 were also later included in the adult analysis) and 37 adults from ecological regions 1-4 and 6 (Rauch et al. 2011). 


\section{Home Range Resource Selection}

Annual Adult Second-order Selection. - Annual adult $(n=37)$ 95\% UD home ranges

(Table 1) were similar $\left(\chi_{4,37}^{2}=8.04, P=0.090\right)$ across 5 ecological regions in West Virginia (Figure 1). Adult male wild turkey did not use habitat resources in proportion to their availability at the second-order spatial scale (Figure 2). Turkeys selected for forest, pasture, roads, and crop at higher rates than barren and water (Table 2; Wilks' $\lambda=0.27, P=0.001$ ). Adults also selected for edges, perforations, and $<100$ ha core areas at higher rates than larger patch size categories (Table 3; Wilks' $\lambda=0.11, P=0.001$ ). Turkeys selected for $0-35 \%$ slopes at higher rates than slopes $>35 \%$ (Table 4 ; Wilks' $\lambda=0.59, P=0.001$ ). Adults did not display a disproportionate second-order selection of aspect (Table 5; Wilks' $\lambda=0.87, P=0.200$ ).

Annual Juvenile Second-order Selection. - Annual juvenile $(n=29) 95 \%$ UD home ranges (Table 1) were not different $\left(\chi_{4,29}^{2}=3.34, P=0.500\right)$ across 5 ecological regions in West Virginia (Figure 1). Juvenile male wild turkey did not use habitat resources in proportion to their availability at the second-order spatial scale (Figure 2). Turkeys selected for roads, forest, and pasture at higher rates than other land use and land cover habitat resources (Table 2 ; Wilks' $\lambda=$ $0.100, P=0.001)$. Turkeys also selected for edges at higher rates than other land fragmentation categories (Table 3; Wilks' $\lambda=0.11, P=0.001$ ). Turkeys selected for areas of primarily $>6-24 \%$ gradients at higher rates than other slopes (Table 4; Wilks' $\lambda=0.33, P=0.001$ ). Juveniles also selected for west and east cardinal facing slopes at higher rates than north and south aspects (Table 5; Wilks' $\lambda=0.47, P=0.001$ ).

Annual Adult Third-order Selection. - Unlike adult 95\% UD home ranges $\left(\chi_{4,37}^{2}=8.04\right.$, $P=0.090), 50 \%$ UD home ranges $(n=37)$ varied $\left(\chi_{4,37}^{2}=12.00, P=0.020\right)($ Table 1$)$ across 5 ecological regions in West Virginia (Figure 1). Adult male wild turkey did not use habitats in 
proportion to their availability at the third-order spatial scale (Figure 3). Turkeys selected for forested areas at higher rates than other land use and land cover categories (Table 6; Wilks' $\lambda=$ $0.53, P=0.002)$. Adults also selected for perforations and edges at higher rates than other land fragmentation habitat resources (Table 7; Wilks' $\lambda=0.24, P=0.006$ ). Turkeys selected for areas of $>6-35 \%$ gradients at higher rates than other slope (Table 8 ; Wilks' $\lambda=0.41, P=0.001$ ). Adult did not display a disproportionate third-order selection of aspect (Table 9; Wilks' $\lambda=0.94, P=$ $0.550)$.

Annual Juvenile Third-order Selection. - Along with juvenile 95\% UD home ranges $\left(\chi_{4,29}^{2}=3.34, P=0.500\right), 50 \%$ UD home ranges $(n=29)$ were similar $\left(\chi_{4,29}^{2}=5.71, P=0.220\right)$ (Table 1) across 5 ecological regions in West Virginia (Figure 1). Juvenile male wild turkey did not use habitats in proportion to their availability at the third-order spatial scale (Figure 3), but selected crop, forest, and pasture at higher rates than other land use and land cover habitat resources (Table 6; Wilks' $\lambda=0.34, P=0.001$ ). Juveniles also selected edges, perforations, $\leq 200$ ha core at higher rates than other land fragmentation categories (Table 7; Wilks' $\lambda=0.13, P=$ 0.003). Turkeys selected for $0-35 \%$ slopes at higher rates than slopes $>35 \%$ (Table 8 ; Wilks' $\lambda=$ $0.70, P=0.020)$. Like adults, juvenile did not display a disproportionate third-order selection of aspect (Table 9; Wilks' $\lambda=0.79, P=0.120$ ).

Statewide Adult Seasonal Third-order Selection. - Adult seasonal 50\% $\left(\chi_{4,60}^{2}=3.10, P=\right.$ $0.540)$ and $95 \%\left(\chi_{4,60}^{2}=2.32, P=0.680\right)$ UD home ranges (Table 1) were similar across 5 ecological regions in West Virginia (Figure 1). Adult male wild turkey did not use habitats in proportion to their availability in relation to seasons (Figures $4-5)$. Adult $(n=9)$ turkeys selected forest at marginally higher rates than other land use and land cover habitat resources in the fall (Table 6; Wilks' $\lambda=0.05, P=0.050$ ). Turkey selected for edges at higher rates than other land 
fragmentation categories during fall (Table 7; Wilks' $\lambda=0.23, P=0.030$ ). Adults also selected for areas of $>6-24 \%$ gradient at higher rates than other slopes in the fall (Table 8 ; Wilks' $\lambda=$ $0.05, P=0.004)$. However, turkeys did not display a disproportionate selection of aspect during the fall (Table 9; Wilks' $\lambda=0.84, P=0.790)$. Adult $(n=17)$ selected for forest habitats at higher rates than other land use and land cover habitat resource during fall-winter (Table 6; Wilks' $\lambda=$ $0.42, P=0.040)$. Turkeys also selected for edges and perforations at higher rates than other land fragmentation categories during fall-winter (Table 7; Wilks' $\lambda=0.20, P=0.030$ ). However, adults did not display disproportionate selection of either slope (Table 8; Wilks' $\lambda=0.73, P=$ 0.210 ) or aspect (Table 9; Wilks' $\lambda=0.86, P=0.600$ ) habitat resources during fall-winter. Turkeys $(n=9)$ did not display disproportionate selection for land use and land cover (Table 6; Wilks' $\lambda=0.19, P=0.120$ ), land fragmentation (Table 7; Wilks' $\lambda=0.61, P=0.390$ ), slope (Table 8; Wilks' $\lambda=0.45, P=0.170$ ), or aspect (Table 9; Wilks' $\lambda=0.55, P=0.280$ ) in the spring. Adults $(n=17)$ did, though, select for forest and pasture-field at higher rates than other land use and land cover categories during spring-summer (Table 6; Wilks' $\lambda=0.37, P=0.020$ ). However, adults did not display a disproportionate selection for land fragmentation (Table 7; Wilks' $\lambda=0.05, P=0.510$ ), slope (Table 8; Wilks' $\lambda=0.62, P=0.050$ ), or aspect (Table 9; Wilks' $\lambda=0.85, P=0.530)$ habitat resources during spring-summer. Adult $(n=8)$ also did not display disproportionate selection for land use and land cover (Table 6; Wilks' $\lambda=0.46, P=$ 0.790), land fragmentation (Table 7; Wilks' $\lambda=0.71, P=0.640$ ), slope (Table 8; Wilks' $\lambda=$ $0.77, P=0.840$ ), or aspect (Table 9; Wilks' $\lambda=0.59, P=0.400$ ) in the winter.

DISA Juvenile Seasonal Third-order Selection. - Juvenile seasonal 50\% (W = 80, $P=$ $0.080)$ and $95 \%(\mathrm{~W}=75, P=0.17)$ UD home ranges were similar in the DISA (Figure 1). Juvenile male wild turkey did not use habitats in proportion to their availability in relation to 
seasons (Figures 6). Juveniles $(n=11)$ selected for crop at higher rates than other land use and land cover categories in the spring (Table 6; Wilks' $\lambda=0.002, P=0.003$ ). Turkeys also selected for perforations at higher rates than other land fragmentation habitat resources during the spring (Table 7; Wilks' $\lambda=0.05, P=0.003$ ). Turkeys selected for $0-35 \%$ slopes at higher rates than slopes $>35 \%$ (Table 8 ; Wilks' $\lambda=0.01, P=0.004$ ). Turkeys also selected for eastward facing slopes at higher rates than other aspects (Table 9; Wilks' $\lambda=0.10, P=0.006)$. Juveniles $(n=10)$ selected for crop and forest at higher rates than other land use and land cover categories during spring-summer (Table 6; Wilks' $\lambda=0.06, P=0.010$ ). Turkeys selected for perforations at higher rates than other land fragmentation habitat resources during spring-summer (Table 7; Wilks' $\lambda=$ $0.17, P=0.006)$. Juveniles selected for $0-24 \%$ gradients at higher rates than other slopes during spring summer (Table 8 ; Wilks' $\lambda=0.004, P=0.006$ ). Juveniles did not display a disproportionate selection of aspect during spring-summer (Table 9; Wilks' $\lambda=0.59, P=0.240$ ). DISA Annual Second-order Selection. - Adult and juvenile 95\% (W =74, P=0.590) UD home ranges (Table 1) were similar in the DISA (Figure 1). Both adult and juvenile male wild turkeys did not use habitats in proportion to their availability at the second-order spatial scale (Figures 7). Adults $(n=9)$ selected for crop, pasture-field, and road (Table 2; Wilks' $\lambda=0.02, P$ $=0.020)$ while juveniles $(n=19)$ selected for pasture-field, road, crop, forest, and barren (Table 2; Wilks' $\lambda=0.01, P=0.001$ ) at higher rates than other land use and land cover habitat resource. Adults also selected for edges, forest patches, and $\leq 200$ ha core areas (Table 3; Wilks' $\lambda=0.11$, $P=0.020$ ) while juveniles selected for edges (Table 3 ; Wilks' $\lambda=0.27, P=0.001$ ) at higher rates than other land fragmentation categories. Adults did not display a disproportionate secondorder selection of slope habitat resources (Table 4; Wilks' $\lambda=0.40, P=0.260$ ); however, juveniles selected for $0-24 \%$ gradients (Table 4; Wilks' $\lambda=0.40, P=0.003$ ) at higher rates than 
other slopes. Adult selected for easterly facing slopes at higher rates that other aspects (Table 5; Wilks' $\lambda=0.27, P=0.040$ ); however, juveniles did not display a disproportionate second-order selection of aspect (Table 5; Wilks' $\lambda=0.67, P=0.090$ ).

DISA Annual Third-order Selection. - Adult and juvenile 95\% (W =74, P=0.590) and $50 \%(\mathrm{~W}=77, P=0.690)$ UD home ranges (Table 1) were similar in the DISA (Figure 1). Both adult and juvenile male wild turkeys did not use habitats in proportion to their availability at the third-order spatial scale (Figure 8). Adults $(n=9)$ did not display a disproportionate third-order selection of land use and land cover habitat resources (Table 6 ; Wilks' $\lambda=0.16, P=0.120$ ); however, juveniles $(n=19)$ selected for crop, forest, and pasture-field (Table 6; Wilks' $\lambda=0.21$, $P=0.001)$ at higher rates than other land use and land cover categories. Adults selected for edges perforations, and $\leq 200$ ha core areas (Table 7; Wilks' $\lambda=0.15, P=0.020$ ) and juveniles selected for perforations and edges (Table 7; Wilks' $\lambda=0.29, P=0.001$ ) at higher rates than other land fragmentation habitat resources. Adults did not display a disproportionate third-order selection of slope habitat resources (Table 8; Wilks' $\lambda=0.40, P=0.260$ ); juveniles selected for 0-24\% gradients (Table 8; Wilks' $\lambda=0.40, P=0.003$ ) at higher rates than other slopes. Adult displayed a marginal selection of westerly facing slopes (Table 9; Wilks' $\lambda=0.28, P=0.050$ ) and juveniles displayed a marginal selection of easterly face slopes of aspects (Table 9; Wilks' $\lambda$ $=0.64, P=0.050)$.

\section{DISCUSSION}

\section{Home Range Estimates}

Our home range estimations fell within the range of various male wild turkey home range studies. However, comparing our home range estimates with other studies is difficult and questionable due to the variation in home range estimation methodologies, the pooling of adults 
and juveniles, and ecological variation between regions of the country. Although we did observe variation in male wild turkey home range size in this study, only adult core home ranges varied significantly. However, home range size variations may be influenced by many factors including study length, sample size, monitoring techniques, local habitat composition, and the home range estimation technique used (Kelley et al. 1988, Everett et al. 1979). Our home range estimates are comparable to some of the largest home ranges reported especially those described in areas dominated by forest with few fields (Wigley et al. 1986, Kelley et al 1988, Hurst et al. 1991, Miller et al. 1997), which is the case in our study.

Specifically, Wigley et al. (1986) reported annual home ranges in Arkansas to be 1,423 ha (minimum area method $[\mathrm{MAM}])$, results similar to our own $(1,410 \mathrm{ha})$. Our results were also similar to Smith et al. (1988) who in Louisiana reported annual adult minimum convex polygon (MCP) home ranges to be 1,473 ha. Our home range estimates were equally comparable to Kelley et al. (1988) who in Mississippi reported annual adult home ranges to be 1,418 ha (convex polygon method [CMP]). However, Kelley et al. (1988) reported juvenile home range estimates of 2,204 ha (CPM), a figure 1.6 times larger than our estimate. Additionally, our fallwinter home range estimates were similar to the 1,134 ha assessments made by Godwin et al. (1995) in Mississippi. However, Godwin et al. (1995) reported adult home ranges that were 1,941 ha $(\mathrm{MCP})$ which is 1.4 times the size of our own estimations. Furthermore, the 711 ha and 607 ha spring adult and juvenile home ranges of Miller et al. (1997) are similar to ours; however, they reported a slightly smaller winter home range estimate of 810 .

Although our results show general variation in wild turkey home range sizes among age and season, only adult 50\% core UD home ranges were significantly different among groups; however, sample sizes may have been insufficient in some instances and probably weakened 
testing. Our results could suggest that this variation in adult 50\% core UD home ranges may be due to a function of regional habitat variation. Fearer and Pack (2003) observed differences in female wild turkey home range sizes among ecological regions in West Virginia. Specifically, Fearer and Pack (2003) estimated annual and seasonal home ranges of 315 female wild turkeys in West Virginia using the adaptive kernel home range estimation method. They reported annual adult female mean home range sizes to be 1,823 ha, a figure about 1.3 times larger than our own. Fearer and Pack (2003) also estimated adult female spring and winter mean home ranges to be 994 ha and 947 ha respectively, results similar to our research. However, they estimated juvenile female wild turkey annual home ranges to be 5,296 ha, an estimate 3.8 times larger than our juvenile male wild turkey home ranges.

\section{Habitat Selection}

Neither second- or third-order selection of home range resources by male wild turkey is random in West Virginia. The concordance of overall male second- and third-order selection annually and seasonally between land use and land cover, land fragmentation, slope, and aspect data suggest that our results are not artifacts of features functioning at 1 spatial scale (e.g., anthropomorphic or conspecific avoidance) distorting selection at another scale. Rather, home range size and habitat selection of wild turkey within West Virginia are probably, like in many other studies, affected primarily by life-stage needs and available food resources within specific regions of the state (Mosby and Handley 1943, Porter et al. 1983, Kurzejeski and Lewis 1990). While statewide second-and third-order spatial trends are somewhat stable in terms of resource selection annually for male wild turkey this selection often differs proportionally at seasonal temporal scales concerning age. These results show the adaptive nature of wild turkey to their 
environment and simultaneously demonstrate their use of said environment at specific life-stages (Dickson et al. 1978).

Our results may suggest that juvenile male wild turkey are more selective than are adults whom consistently display selection of forested areas independent of both temporal and spatial scale. Our results agree with Crim (1981) who suggested that adult male wild turkey home ranges are less variable and include less selection of cropland than do juvenile home ranges. Croplands not bordered by mature timber stands were seldom used and never exhibited consistent use in northern Missouri (Kurzejeski and Lewis 1990) and may have contributed to their adult selection status in West Virginia. Additionally, turkeys prefer acorns to crop (Korschgen 1967) which may also help explain the lack of adult male wild turkey selection of cropland in West Virginia. Because cropland of West Virginia is composed of $89 \%$ hay crop (King and Lemmons 2008) selection is probably driven by insect forage instead of grain waste. Crops also do not seem to be selected for during winter in West Virginia as in other states probably due to the small percentage (9\%) of grain crop production (King and Lemmons 2008). It should be noted that the lack of cropland in densely forested areas, as in West Virginia, combined with highly variable mast production has the potential to limit turkey density (Vander Haegen et al. 1988, Little et al. 1990, Porter et al. 1980).

Our results may show, as in Hurst and Stinger (1975) and Pack et al. (1980), the selection of specific habitat type needed during the early life stages of male wild turkey in West Virginia. At both second- and third-order spatial scales juvenile and adult male wild turkeys differed in their annual selection of slope. Adults consistently used at both spatial scales steeper (>24-35\%) gradients than did juvenile birds; juveniles selected for $>6-24 \%$ gradients at both spatial scales. Juvenile seasonal selection of slope in the DISA differs from their annual selection with a higher 
proportional use of 0-6\% slope; this selection is probably in accordance with their temporal selection of cropland. Also, at both second- and third-order spatial scale juvenile and adult male wild turkeys differed in their annual selection of land fragmentation features with adults selecting for forest perforations and juveniles selecting for edges; this is consistent with their respective selection of land use and land cover features. Our data may suggest that juveniles are selecting for more open habitat types of cropland- and pasture-field- forest, road edges than are adults. Furthermore, our results indicate that at the second-order spatial scale juvenile wild turkeys are selecting for roads, primarily forested road edges, at greater rates than are proportionally available. This finding follows numerous studies in which hens with young poults select for such habitat for their diverse herbaceous vegetation, higher insect abundance, and prevalent escape cover (Hurst 1981, Pack et al. 1988, Sisson et al. 1991). Our juvenile selection of similar land features may just be an artifact of these brood patterns or a deliberate selection of highly productive, safe habitats. Selection of aspect for either age group at both various spatial and temporal scales is often insignificant and variable and may be negligible.

The DISA is somewhat unique in its features compared to the rest of the state and resource selection of turkeys there should not be overlooked. Unlike the statewide annual analysis, birds within the DISA selected for more pastures-fields and crops than was available at the second-order spatial scale. Only juveniles in the statewide annual analysis were found to select for crop but in the DISA both adults and juveniles selected for crop on at least one spatial scale. Likewise, statewide third-order selection of land fragmentation favored forest perforations but in the DISA both adults and juvenile wild turkeys were more associated with edges and forest perforations. Our results may suggest that birds within the DISA select for more pasture, field, and cropland habitats than do other male wild turkey in the state. 
It has been well documented that mast abundance and distribution affects home range characteristics like size and habitat composition (Burhans et al. 2000). Kelly et al. (1988) suggested that when mast is abundant turkeys move shorter distances to find food and thus have smaller home ranges. However, when mast is poor wild turkeys expand their range in search of supplemental foods (Kurzejske and Lewis 1990, Healy 1992) which may be found in edge, forest perforations, pastures and fields, and croplands (Healy 1985, Peoples et al. 1996). Kelley et al. (1988) suggested that home ranges size is a mechanism of habitat diversity and large home ranges are often associated with homogeneous, largely forested areas (Wigley et al. 1986, Exum et al. 1987, Kelley et al. 1988), which our analysis supports.

While forest is often the highest ranking resource selection of wild turkey in West Virginia, animals used more edge and forest perforations and $<100$ ha core areas annually than was proportionally available. Due to recent forestry practices like fire suppression and low impact harvesting techniques along with the introduction of exotic diseases like chestnut blight (Cryphonectria parasitica) and beech bark disease (Nectria Cryptococcus-Neonectria complex), forest canopies are closing and are composed primarily of low mast producing forest types dominated by shade-tolerant species such as maples (Acer spp.) (Nowacki and Abrams 2008, Porter et al. 2011). Such forest types with fewer oaks and hickories may leave turkeys without necessary food source levels for long periods of time (McShea et al. 2007). The general loss of young forest in the eastern U.S. means turkeys now exist in more mature forest that provide highly variable foods (Porter et al. 2011). Edge, perforation, and smaller core forest areas may be selected for in West Virginia by adult male wild turkey because of their high productivity and resource diversity (Backs and Bledsoe 2011) and the current successional and forestry trend that have led to potentially less productive forest habitats (Porter et al. 2011). 


\section{MANAGEMENT IMPLICATIONS}

Despite West Virginia being $78 \%$ forested, our results show that selected forest habitats are often areas characterized as fragmented, having high proportions of edges and interior perforations. Such openings and edges within the forest provide much greater invertebrate abundances than do large expanses of mature forest, and active management may be the key to maintaining their proper functionality (Backs and Bledsoe 2011). Furthermore, our data suggest that edges and perforations at the third-order spatial scale, often created by forest roads, are features significantly selected for by juvenile male wild turkey; other forest openings and edges that were not directly quantified by this study include haul-roads, log-landings, and utility rightof-ways. Landowners are encouraged to use these areas only as necessary, being aware that higher amounts of traffic may negatively affect turkey use (McDougal et al. 1990). Forest edges and openings provide multilayer, "complex edge" habitats which offer diverse food sources (e.g., seeds, insects, fruits), escape cover, travel corridors, and mating display areas (Speake et al. 1975, Holbrook et al. 1987, Wertz and Flake 1988) that can be improved or maintained through planting, cutting, mowing, or even passive management for wild turkey (Backs and Bledsoe 2011, McCord and Harper 2011). Like interior forest perforations and edges, pasture-fields are important habitats in West Virginia because of their herbaceous structure and associated high resources abundance; such habitats are maintained by variations of mowing, grazing, and burning techniques (Backs and Bledsoe 2011, McCord and Harper 2011). At the core home range level land managers should attempt to provide $15 \%$ forest perforations and $18 \%$ pasturefield cover types to help provide the habitat needs of both adult and juvenile wild turkey. Management of turkey habitat should be concentrated primarily to slopes of $\leq 24 \%$ gradients with 
little regard to aspect because of the often variable and insignificant selection of the landscape feature.

\section{ACKNOWLEDGMENTS}

Data for this study were collected in conjunction with the Mid-Atlantic Gobbler Study (MAGS), a joint effort between the West Virginia Division of Natural Resources (Wildlife Resources Section) (WVDNR-WRS), the Virginia Department of Game and Inland Fisheries, and the West Virginia State Chapter of the National Wild Turkey Federation. Funding for the MAGS, in part, was provided by the WVDNR-WRS and the Federal Aid in Wildlife Restoration Grant W-48-R. We thank the West Virginia Chapter of the National Wild Turkey Federation for the funding of the transmitters used in the MAGS. We are grateful to J. W. Edwards for reviewing this manuscript and M. P. Strager for instruction pertaining to spatial modeling and mapping and for reviewing this manuscript. This manuscript is scientific article $\mathrm{xxxx}$ of the West Virginia University Agriculture and Forestry Experiment Station.

\section{LITERATURE CITED}

Aebischer, N. J., P. A. Robertson, and R.E. Kenward. 1993. Compositional analysis of habitat use from animal radio-tracking data. Ecology 74:1313-1325.

Andelt, W. F., and P. S. Gipson. 1979. Home range, activity, and daily movements of coyotes. Journal of Wildlife Management 43:944-951.

Backs, S. E. and L. W. Bledsoe. 2011. Invertebrate abundance and vegetative structure in forest openings. Proceedings of the National Wild Turkey Symposium 10:51-63.

Bailey, R. W., and K. T. Rinell. 1968. History and management of the wild turkey in West Virginia. Charleston: West Virginia Department of Natural Resources Division of Game and Fish Bulletin 2:44. 
Bailey, R. W. 1973. Restoring wild-trapped turkeys to nonprimary range in West Virginia.

Proceedings of the National Wild Turkey Symposium 2:181-185.

Beverage, W. W., and T. D. Yoakum. 1980. Soil survey of Harrison and Taylor Counties, West Virginia. U.S. Department of Agriculture, Soil Conservation Service, Washington D. C., USA.

Beyer, H. L. 2010. Geospatial Modeling Environment for ArcGIS. Available at <http://www.spatialecology.com/gme/>.

Burhans, B. J., D. Harmen, and G. W. Norman. 2000. Influence of landscape characteristics on the winter home range dynamics of wild turkeys in western Virginia. Proceedings of the Annual Northeast Fish and Wildlife Conference 56:3.

Calenge, C. 2006. The package "adehabitat" for the R software: A tool for the analysis of space and habitat use by animals. Ecological Modelling 197:516-519.

Cochran, W. W., and R.D. Lord. 1963. A radio-tracking system for wild animals. Journal of Wildlife Management 27: 9-24.

Crim, G. B. 1981. Eastern wild turkey winter habitat in south-central Iowa. Thesis, Iowa State University, Ames City, USA.

Dickson, J.G., C. D. Adams, and S. H. Hanley. 1978. Response of turkey populations to habitat variables in Louisiana. Wildlife Society Bulletin 6:163-166.

Dickson, B. G., and P. Beier. 2002 Home range and habitat selection by adult cougars in southern Californina. Journal of Wildlife Management 66:1235-1245.

Everett, D. D., D. W. Speake, and W. K. Maddox. 1979. Wild turkey ranges in Alabama mountain habitat. Proceeding of the Annual Conference Southeastern Association of Fish and Wildlife Agencies 33:233-238. 
Exum, J. H., J. A. McGlincy, D. W. Speake, J. L. Buckner, and F. M. Stanlet. 1987. Ecology of the eastern wild turkey in an intensively managed pine forest in southern Alabama. Tall Timbers Research Station Bulletin 23:70.

Fearer, T. M., and J. C. Pack. 2003. Home range characteristics of female wild turkey in West Virginia. West Virginia Division of Natural Resources PR Report. Charleston, West Virginia, USA.

Fleming, K. K. 2003. Scale-explicit spatial determinants of population structure in wild turkeys (Meleagris gallopavo silvestris). Dissertation, State University of New York College of Environmental Science and Forestry, Syracuse, New York, USA.

Glennon, M. J., and W. F. Porter. 1999. Using satellite imagery to assess landscape-scale habitat for wild turkeys. Wildlife Society Bulletin 27:646-653.

Godwin, K. D., G. A. Hurst, and B. D. Leopold. 1995. Size and percent overlap of gobbler home range and core-use in central Mississippi. Proceedings of the National Wild Turkey Symposium 7:45-52.

Griffith, D. M., and R. H. Widmann. 2003. Forest statistics for West Virginia: 1989 and 2000. Resource Bulletin NE-157. Newton Square, Pennsylvannia: U.S. Department of Agriculture, Forest Service. Northeastern Research Staion, Newton Square, Pennsylvania, USA.

Healy, W. M., and E. S. Nenno. 1980. Growth parameters and age and sex criteria for juvenile eastern wild turkeys. Proceedings of the National Wild Turkey Symposium 4:168-185.

Healy, W. M. 1985. Turkey poult feeding activity, invertebrate abundance, and vegetation structure. Journal of Wildlife Management 49:466-472. 
Healy, W. M. 1992. Behavior. Pages 46-65 in J. G. Dickson, editor. The wild turkey: biology and management. Stackpole Books, Harrisburg, Pennsylvania, USA.

Hecklau, J., W. F. Porter, and W. M. Shild. 1982. Feasibility of transplanting wild turkeys into areas of restricted forest cover and high human density. Transactions of the Northeast Fish and Wildlife Conference 39:96-104.

Holbrook, H. T., M. R. Vaughan, P.T. Bromley. 1987. Wild turkey habitat preference and recruitment in intensively managed piedmont forests. Journal of Wildlife Management $51: 182-187$.

Hurst, G. A. and B. D. Stinger, Jr. 1975. Food habits of wild turkey poults in Mississippi. Proceedings of the National Wild Turkey Symposium 3:76-85.

Hurst, G. A. 1981. Effects of prescribed burning on the eastern wild turkey. Pages 81-88 in G. W. Woods, editor. Prescribed fire and wildlife in southern forest. Belle W. Baruch Forest Science Institute, Clemson University, Georgetown, South Carolina, USA.

Hurst, G. A., D.A. Smith, J. D. Burk, and B. D. Leopold. 1991. Wild turkey gobbler habitat use and home range in loblolly pine plantations. Annual Conference Southeastern Association of the Fish and Wildlife Agencies 45:115-123.

Johnson, D. H., 1980. The comparison of usage and availability measurements for evaluating resource preference. Ecology 61:65-71.

Kelley, R. L., G. A. Hurst, and D. E. Steffen. 1988. Home ranges of wild turkey gobblers in central Mississippi. Proceeding of the Annual Conference Southeastern Association of Fish and Wildlife Agencies 42: 470-475. 
Kernohan, B. J., R. A. Gitzen, and J. J. Millspaugh. 2001. Analysis of animal space use and movements. Pages 125-167 in J. J. Millspaugh and J. M. Marzluff, editors. Radio tracking and animal populations. Academic Press, San Diego, California. USA.

King, D. R., and J. S. Lemmons. 2008. West Virginia agricultural statistics. USDA/NASS Annual Bulletin 39:15-30.

Korschgen, L. J. 1967. Feeding habits and food. Pages 137-198 in O. H. Hewitt, editor. The wild turkey and its management. The Wildlife Society, Washington, D.C., USA.

Kozicky, E. L., and R. Metz. 1948. The management of the wild turkey in Pennsylvania. Pennsylvania Game News 19:3-31.

Kurzejeski, E. W., and J. B. Lewis. 1985. Application of PATREC modeling to wild turkey management in Missouri. Proceedings of the National Wild Turkey Symposium 5:269284.

Kurzejeski, E. W., and J. B. Lewis. 1990. Home range, movements, and habitat use of wild turkey hens in northern Missouri. Proceedings of the National Wild Turkey Symposium. 6:67-71.

Kurzejeski, E. W., and L. D. Vangilder. 1992. Population management. Pages 165-184 in J. G. Dickson, editor. The wild turkey: biology and management. Stackpole Books, Harrisburg, Pennsylvania, USA.

Larson, J. D., and R. D. Taber. 1980. Criteria of sex and age. Pages 143-202 in S. D. Schemnitz, editor. Wildlife Management Techniques Manual, Forth Edition. The Wildlife Society, Washington, D.C., USA.

Latham, R. M. 1956. The complete book of the wild turkey. The Stackpole Company, Harrisburg, Pennsylvania, USA. 
Little, T. W., J. M. Kienzler, and G. A. Hanson. 1990. Effects of fall either-sex hunting on survival in an Iowa wild turkey population. Proceedings of the National Wild Turkey Symposium 6:119-125.

McCord, J. M. and C. A. Harper. 2011. Brood habitat following canopy reduction, understory herbicide application, and fire in mature upland hardwoods. Proceedings of the National Wild Turkey Symposium 10:65-73.

McDougal, L. A., M. R. Vaughan, and P. T. Broomley. 1990. Wild turkey and road relationships on a Virginia national forest. Proceedings of the National Wild Turkey Symposium 6:96106.

McShea, W. J., W. M. Healy, P. Devers, T. Fearer, F. H. Koch, D. Stauffer, and J. Waldon. 2007. Forestry matters: decline of oaks will impact wildlife in hardwood forests. Journal of Wildlife Management 71:1717-1728.

Miller, D. A., G. A. Hurst, and B. D. Leopold. 1997. Seasonal home ranges of wild turkeys in central Mississippi. Proceedings of the Annual Conference Southeastern Association of Fish and Wildlife Agencies 51:414-425.

Miller, D. A., L. M. Conner, B. D. Leopold, and G. A. Hurst. 2001. Spatial fidelity of wild turkeys between seasons in central Mississippi. Proceedings of the Annual Conference Southeastern Association of the Fish and Wildlife Agencies 55:475-487.

Mosby, H. S., and C. O. Handley. 1943. The wild turkey in Virginia: its status, life history and management. Division of Game, Commission of Game and Inland Fisheries, Richmond, Virginia, USA.

Nams, V. O., and S. Boutin. 1991. What is wrong with error polygons? Journal of Wildlife Management 55:172-176. 
Norman, G. W., J. C. Pack, and G. A. Hurst. 1997. Transmitter selection and attachment technique for wild turkey research. National Wild Turkey Federation Research Bulletin Number 4.

Nowacki, G. J. and M. D. Abrams. 2008. The demise of fire and "mesophication" of forest in the eastern United States. BioScience 58:123-128.

Opitz, D., and S. Blundell. 1999. An intelligent interface for feature extraction from remotely sensed images. Proceedings of the American Society for Photogrammetry and Remote Sensing: $171-177$.

Pack, J. C., R. P. Burkert, W. K. Igo, and D. J. Pybus. 1980. Habitat utilized by wild turkey broods within oak-hickory forest of West Virginia. Proceedings of the National Wild Turkey Symposium 4:213-224.

Pack, J. C., W. K. Igo, and C. I. Taylor. 1988. Use of prescribed burning in conjunction with thinning to increase wild turkey brood range habitat in oak-hickory forest. Transaction of the Northeast Fish and Wildlife Conference 45:37-48

Pelham, P. M., and J. G. Dickson. 1992. Physical characteristics. Pages 32-35 in J. G. Dickson, editor. The wild turkey: biology and management. Stackpole Books, Harrisburg, Pennsylvanian, USA.

Pendleton, G. W., K. Titus, E. DeGayner, C. J. Flatten, and R. E. Lowell. 1998. Compositional analysis and GIS for study of habitat selection by goshawks in southeast Alaska. American Statistical Association and the International Biometric Society Journal of Agricultural, Biological, and Environmental Statistics 3:280-295. 
Peoples, J. C. D. C. Sisson, and D. W. Speake. 1996. Wild turkey brood habitat use and characteristics in coastal plain pine forest. Proceedings of the National Wild Turkey Symposium 7:89-96.

Porter, W. F. 1978. The ecology and behavior of the wild turkey (Meleagris gallopavo) in Southeastern Minnesota. Dissertation, University of Minnesota, Minneapolis, Minnesota, USA.

Porter, W. F., G. C. Nelson, and D. A. Hamilton. 1980. Effects of corn food plots on wild turkeys in the upper Mississippi Valley. Journal of Wildlife Management 44:456-462.

Porter, W. F., G. C. Nelson, and K. Mattson. 1983. Effects of winter conditions on reproduction in a northern wild turkey population. Journal of Wildlife Management 47:281-290.

Porter, W. F., and D. J. Gefell. 1996. Influences of weather and land use on wild turkey population in New York. Proceedings of the National Wild Turkey Symposium 7:75-80.

Porter, W. F., W. M. Healy, S. E. Backs, B. F. Wakeling, and D. E. Steffen. 2011. Managing wild turkeys in the face of uncertainty. Proceedings of the National Wild Turkey Symposium 10:1-8.

Rauch, S. E. 2009. Home range characteristics of the male eastern wild turkey in West Virginia. Thesis. West Virginia University, Morgantown, West Virginia, USA.

Rauch, S. E., J. T. Anderson, and A. A. Billings. 2011. Spring hunting season home range size of male wild turkeys in north central West Virginia. National Wild Turkey Symposium $10: 157-164$.

Seaman, D. E., J. J. Millspaugh, B. J. Kernoham, G. C. Brundge, K. L. Raedeke, and R. A. Gitzen. 1999. Effects of sample size on kernel home range estimates. Journal of Wildlife Management 63:739-747. 
Silverman, B. W. 1986. Density estimation for statistics and data analysis. Chapman and Hall, London, UK.

Sisson, D. C., D. W. Speak, and J. L. Landers. 1991. Wild turkey brood habitat in fire-type pine forest. Proceedings of the Annual Conference Southeast Association of Fish and Wildlife Agencies 45:49-57.

Sisson, D. C., and D. W. Speake. 1994. Spring burning for wild turkey brood habitat: an evaluation. Proceedings of the Annual Conference Southeastern Association of the Fish and Wildlife Agencies 48:134-139.

Smith, W. P., E. P. Lambert, and R. D. Teitelbaum. 1988. Seasonal movement and home range differences among age and sex groups of eastern wild turkeys within southeastern Louisiana. Proceedings of the International Symposium on Biotelemetry 10:151-158.

Speake, D. W., T. E. Lynch, W. J. Fleming, G. A. Wright, and W. J. Harnick. 1975. Habitat use and seasonal movements of wild turkeys in the southeast. Proceedings of the National Wild Turkey Symposium 3:122-120.

Strausbaugh, P. D., and E. L. Core. 1978. Flora of West Virginia, Second Edition. Seneca Books, Morgantown, West Virginia, USA.

Tirpak, J. M., W. M. Giuliano, T. J. Allen, S. Bittner, J. W. Edwards, S. Friedhof, C. A. Harper, W. K. Igo, D. F. Stauffer, G. W. Norman. 2010. Ruffed grouse-habitat preference in the central and southern Appalachians. Forest Ecology and Management 260:1525-1538.

Townsend, D. E. II., S. S. Ditchkoff, and S. D. Fuhlendorf. 2007. Transmitter height influences error of ground-based radio-telemetry. Wildlife Biology 13:98-101.

Vander Haegen, W. M., W. E. Dodge, and M. W. Sayre. 1988. Factors affecting productivity in a northern wild turkey population. Journal of Wildlife Management 52:127-133. 
Vogt, P., K. H. Ritters, C. Estreguil, J. Kozak, T. G. Wade, and J. D. Wickham. 2007. Mapping spatial patters with morphological image processing. Landscape Ecology 22:171-177.

Wallingford, B. D., and R. A. Lancia. 1991. Telemetry accuracy and a model for predicting telemetry error. Proceedings of the Annual Conference Southeastern Association of the Fish and Wildlife Agencies 45:178-188.

Wertz, T. L. and L. D. Flake. 1988. Wild turkey nesting ecology in south central South Dakota. Prairie Naturalist 20:29-37.

White, G. C., and R. A. Garrott. 1990. Analysis of wildlife radio-tracking data. Academic Press, Inc., London, UK.

Wigley, T. B., J. M. Sweeny, M. E. Garner, and M. A. Melechiors. 1986. Wild turkey home ranges in the Ouachita Mountains. Journal of Wildlife Management 50:540-544.

Worton, B. J. 1989. Kernel methods for estimating the utilization distribution in home range studies. Ecology 70:164-168.

Wunz, G. A. 1971. Tolerance of wild turkeys to human disturbances and limited range. Proceedings of the Annual Conference of the Northeastern Association of the Game and Fish Commission 28:45-57.

Wunz, G. A. 1985. Wild turkey establishment and survival in small range units in farmland and suburban environments. Proceedings of the National Wild Turkey Symposium 5:49-53.

Wunz, G. A., and J. C. Pack. 1992. Eastern turkey in eastern oak-hickory and northern hardwood forest. Pages 232-285 in J. G. Dickson, editor. The wild turkey: biology and management Stackpole Books, Harrisburg, Pennsylvania, USA. 
Zielinski, W. J., R. L. Truex, G.A. Schmidt, F. V. Schilexer, K. N. Schmidt, and R. H. Barrett. 2004. Home range characteristics of fishers in California. Journal of Mammalogy 85:649657. 
Table 1. Annual 95\% and 50\% utilization distributions (UD) for Gaussian fixed kernel density estimations (KDE) home ranges, smoothing parameter $(h)$ determined by least squares cross validation, of male eastern wild turkeys from 2 study areas in West Virginia, 2004-2007

\begin{tabular}{|c|c|c|c|c|c|c|c|c|c|c|c|}
\hline \multirow[b]{3}{*}{ Study Area } & \multirow[b]{3}{*}{ Age } & \multirow[b]{3}{*}{ Season } & \multirow[b]{3}{*}{$n$} & \multicolumn{8}{|c|}{ Home range (ha) } \\
\hline & & & & \multicolumn{2}{|r|}{$95 \%$} & \multicolumn{2}{|l|}{ UD } & \multicolumn{2}{|c|}{$50 \%$} & \multicolumn{2}{|l|}{ UD } \\
\hline & & & & $\bar{x}$ & $\mathrm{SE}$ & Min & Max & $\bar{x}$ & SE & Min & Max \\
\hline Statewide & Adult & Annual & 37 & $1,409.9$ & 180.3 & 287.4 & $4,768.4$ & 310.3 & 38.7 & 74.6 & $1,089.8$ \\
\hline Statewide & Juvenile & Annual & 29 & $1,394.3$ & 790.8 & 148.9 & $2,865.7$ & 320.6 & 190.3 & 22.9 & 669.4 \\
\hline District I Study Area & Adult & Annual & 9 & $1,515.3$ & 368.0 & 700.1 & $3,447.3$ & 327.2 & 79.2 & 111.0 & 778.0 \\
\hline District I Study Area & Juvenile & Annual & 19 & $1,323.3$ & 190.1 & 148.9 & $2,422.5$ & 310.8 & 46.1 & 22.9 & 644.4 \\
\hline \multirow[t]{5}{*}{ Statewide } & Adult & Spring & 9 & 685.6 & 66.3 & 426.3 & 838.3 & 163.0 & 12.7 & 98.7 & 214.1 \\
\hline & & Fall & 9 & 858.2 & 119.8 & 380.1 & $1,356.8$ & 220.2 & 33.8 & 77.7 & 347.5 \\
\hline & & Winter & 8 & 927.6 & 238.5 & 392.3 & $2,137.3$ & 211.6 & 56.7 & 63.9 & 457.1 \\
\hline & & Spring-Summer & 17 & 821.8 & 106.3 & 390.8 & $1,953.9$ & 199.0 & 26.9 & 74.6 & 473.1 \\
\hline & & Fall-Winter & 17 & $1,046.6$ & 174.8 & 326.0 & $3,228.4$ & 241.8 & 43.5 & 75.4 & 870.6 \\
\hline \multirow[t]{2}{*}{ District I Study Area } & Juvenile & Spring & 11 & 800.2 & 123.8 & 303.3 & $1,188.6$ & 142.1 & 15.5 & 73.1 & 188.1 \\
\hline & & Spring-Summer & 10 & 543.8 & 85.0 & 148.9 & 855.6 & 97.0 & 10.7 & 22.9 & 125.5 \\
\hline
\end{tabular}


Table 2. Second-order land use and land cover resource selection significance and rank of male eastern wild turkeys from 2 study areas in West Virginia, 2004-2007. Use proportions derived from 95\% home range utilization distributions (UD) and availability derived from 100 ha block regional proportional summaries; proportions were analyzed using compositional analysis (CA).

\begin{tabular}{|c|c|c|c|c|c|c|c|c|c|c|c|}
\hline \multirow[b]{2}{*}{ Study Area } & \multirow[b]{2}{*}{ Age } & \multirow[b]{2}{*}{ Season } & \multirow[b]{2}{*}{$n$} & \multirow[b]{2}{*}{ Wilks' $\lambda$} & \multirow[b]{2}{*}{$P$} & \multicolumn{5}{|c|}{$\operatorname{Rank}^{\mathrm{a}}$} & \multirow[b]{2}{*}{ Water } \\
\hline & & & & & & Forest & Pasture & Crop & Road & Barren & \\
\hline Statewide & Adult & Annual & 37 & 0.27 & 0.001 & $1 \mathrm{~A}$ & $2 \mathrm{~A}$ & $4 \mathrm{~A}$ & $3 \mathrm{~A}$ & $5 \mathrm{~A}$ & $6 \mathrm{~A}$ \\
\hline Statewide & Juvenile & Annual & 29 & 0.10 & 0.001 & $2 \mathrm{~A}$ & $3 \mathrm{~A}$ & $5 \mathrm{~A}$ & $1 \mathrm{~A}$ & $4 \mathrm{~A}$ & $6 \mathrm{~A}$ \\
\hline District I Study Area & Adult & Annual & 9 & 0.02 & 0.020 & $4 B$ & $2 \mathrm{~A}$ & $1 \mathrm{~A}$ & $3 \mathrm{AB}$ & $5 \mathrm{C}$ & $6 \mathrm{D}$ \\
\hline District I Study Area & Juvenile & Annual & 19 & 0.01 & 0.001 & $4 \mathrm{AC}$ & $1 \mathrm{~A}$ & $3 \mathrm{ABC}$ & $2 \mathrm{AB}$ & $5 \mathrm{ABC}$ & $6 \mathrm{D}$ \\
\hline
\end{tabular}

${ }^{\mathrm{a}}$ The same letters following each rank within a row indicates no difference $(P>0.05)$ by compositional analysis (Aebischer et al. 1993). 
Table 3. Second-order land fragmentation resource selection significance and rank of male eastern wild turkeys from 2 study areas in West Virginia, 2004-2007. Use proportions derived from 95\% home range utilization distributions (UD) and availability derived from 100 ha block regional proportional summaries; proportions were analyzed using compositional analysis (CA).

\begin{tabular}{|c|c|c|c|c|c|c|c|c|c|c|c|}
\hline \multirow[b]{2}{*}{ Study Area } & \multirow[b]{2}{*}{ Age } & \multirow[b]{2}{*}{ Season } & \multirow[b]{2}{*}{$n$} & \multirow[b]{2}{*}{ Wilks' $\lambda$} & \multirow[b]{2}{*}{$P$} & \multicolumn{5}{|c|}{$\operatorname{Rank}^{\mathrm{a}}$} & \multirow[b]{2}{*}{$>200 \mathrm{ha}$} \\
\hline & & & & & & Edge & Perforations & Patch & $<100$ ha & 100-200ha & \\
\hline Statewide & Adult & Annual & 37 & 0.11 & 0.001 & $1 \mathrm{~A}$ & $2 \mathrm{~A}$ & $4 \mathrm{BC}$ & $3 \mathrm{AB}$ & $6 \mathrm{D}$ & $5 \mathrm{BC}$ \\
\hline Statewide & Juvenile & Annual & 29 & 0.12 & 0.001 & $1 \mathrm{~A}$ & $2 \mathrm{~B}$ & $3 B$ & 4B & $5 \mathrm{C}$ & $6 \mathrm{C}$ \\
\hline District I Study Area & Adult & Annual & 9 & 0.11 & 0.020 & $1 \mathrm{~A}$ & $4 \mathrm{BC}$ & $2 \mathrm{ABC}$ & $3 \mathrm{ABC}$ & & \\
\hline District I Study Area & Juvenile & Annual & 19 & 0.27 & 0.001 & $1 \mathrm{~A}$ & $3 \mathrm{~B}$ & 4B & $2 \mathrm{~B}$ & & \\
\hline
\end{tabular}

${ }^{a}$ The same letters following each rank within a row indicates no difference $(P>0.05)$ by compositional analysis (Aebischer et al. 1993). Blank spaces in a row indicate that resources were not available for analysis. 
Table 4. Second-order slope resource selection significance and rank of male eastern wild turkeys from 2 study areas in West Virginia, 2004-2007. Use proportions derived from 95\% home range utilization distributions (UD) and availability derived from 100 ha block regional proportional summaries; proportions were analyzed using compositional analysis (CA).

\begin{tabular}{|c|c|c|c|c|c|c|c|c|c|}
\hline \multirow[b]{2}{*}{ Study Area } & \multirow[b]{2}{*}{ Age } & \multirow[b]{2}{*}{ Season } & \multirow[b]{2}{*}{$n$} & \multirow[b]{2}{*}{ Wilks' $\lambda$} & \multirow[b]{2}{*}{$P$} & \multicolumn{3}{|c|}{$\operatorname{Rank}^{\mathrm{a}}$} & \multirow[b]{2}{*}{$>35 \%$} \\
\hline & & & & & & $0-6 \%$ & $>6-24 \%$ & $>24-35 \%$ & \\
\hline Statewide & Adult & Annual & 37 & 0.59 & 0.001 & $3 \mathrm{AC}$ & $2 \mathrm{AB}$ & $1 \mathrm{~A}$ & $4 \mathrm{C}$ \\
\hline Statewide & Juvenile & Annual & 29 & 0.33 & 0.001 & $2 \mathrm{~B}$ & $1 \mathrm{~A}$ & $3 \mathrm{~B}$ & $4 \mathrm{C}$ \\
\hline District I Study Area & Adult & Annual & 9 & 0.55 & 0.260 & $3 \mathrm{~A}$ & $2 \mathrm{~A}$ & $1 \mathrm{~A}$ & $4 \mathrm{~A}$ \\
\hline District I Study Area & Juvenile & Annual & 19 & 0.40 & 0.003 & $2 \mathrm{AB}$ & $1 \mathrm{~A}$ & $3 B$ & $4 \mathrm{C}$ \\
\hline
\end{tabular}

${ }^{a}$ The same letters following each rank within a row indicates no difference $(P>0.05)$ by compositional analysis (Aebischer et al. 1993). 
Table 5. Second-order aspect resource selection significance and rank of male eastern wild turkeys from 2 study areas in West Virginia, 2004-2007. Use proportions derived from 95\% home range utilization distributions (UD) and availability derived from 100 ha block regional proportional summaries; proportions were analyzed using compositional analysis (CA).

\begin{tabular}{|c|c|c|c|c|c|c|c|c|c|}
\hline \multirow[b]{2}{*}{ Study Area } & \multirow[b]{2}{*}{ Age } & \multirow[b]{2}{*}{ Season } & \multirow[b]{2}{*}{$n$} & \multirow[b]{2}{*}{ Wilks' $\lambda$} & \multirow[b]{2}{*}{$P$} & \multicolumn{3}{|c|}{$\operatorname{Rank}^{\mathrm{a}}$} & \multirow[b]{2}{*}{ West } \\
\hline & & & & & & North & East & South & \\
\hline Statewide & Adult & Annual & 37 & 0.97 & 0.200 & $2 \mathrm{~A}$ & $4 \mathrm{~A}$ & $1 \mathrm{~A}$ & $3 \mathrm{~A}$ \\
\hline Statewide & Juvenile & Annual & 29 & 0.74 & 0.001 & $4 \mathrm{C}$ & $2 \mathrm{AB}$ & $3 B C$ & $1 \mathrm{~A}$ \\
\hline District I Study Area & Adult & Annual & 9 & 0.27 & 0.040 & $4 B$ & $1 \mathrm{~A}$ & $2 \mathrm{~B}$ & $3 B$ \\
\hline District I Study Area & Juvenile & Annual & 19 & 0.66 & 0.090 & $3 \mathrm{~A}$ & $1 \mathrm{~A}$ & $4 \mathrm{~A}$ & $2 \mathrm{~A}$ \\
\hline
\end{tabular}

${ }^{\mathrm{a}}$ The same letters following each rank within a row indicates no difference $(P>0.05)$ by compositional analysis (Aebischer et al. 1993). 
Table 6. Third-order land use and land cover resource selection significance and rank of male eastern wild turkeys from 2 study areas in West Virginia, 2004-2007. Use proportions derived from 95\% home range utilization distributions (UD) and availability derived from 100 ha block regional proportional summaries; proportions were analyzed using compositional analysis (CA).

\begin{tabular}{|c|c|c|c|c|c|c|c|c|c|c|c|}
\hline \multirow[b]{2}{*}{ Study Area } & \multirow[b]{2}{*}{ Age } & \multirow[b]{2}{*}{ Season } & \multirow[b]{2}{*}{$n$} & \multirow[b]{2}{*}{ Wilks' $\lambda$} & \multirow[b]{2}{*}{$P$} & \multicolumn{5}{|c|}{$\operatorname{Rank}^{\mathrm{a}}$} & \multirow[b]{2}{*}{ Water } \\
\hline & & & & & & Forest & Pasture & Crop & Road & Barren & \\
\hline Statewide & Adult & Annual & 37 & 0.55 & 0.001 & $1 \mathrm{~A}$ & $2 \mathrm{~B}$ & $6 \mathrm{D}$ & $4 \mathrm{CD}$ & $3 \mathrm{C}$ & $5 \mathrm{DC}$ \\
\hline Statewide & Juvenile & Annual & 29 & 0.35 & 0.001 & $2 \mathrm{~A}$ & $3 \mathrm{~A}$ & $1 \mathrm{~A}$ & $4 \mathrm{~B}$ & $5 \mathrm{C}$ & $6 \mathrm{C}$ \\
\hline District I Study Area & Adult & Annual & 9 & 0.16 & 0.120 & $1 \mathrm{~A}$ & $2 \mathrm{~A}$ & $4 \mathrm{~A}$ & $3 \mathrm{~A}$ & $5 \mathrm{~A}$ & $6 \mathrm{~A}$ \\
\hline District I Study Area & Juvenile & Annual & 19 & 0.21 & 0.001 & $2 \mathrm{~A}$ & $3 \mathrm{~A}$ & $1 \mathrm{~A}$ & $4 \mathrm{~B}$ & $5 \mathrm{BC}$ & $6 \mathrm{C}$ \\
\hline \multirow[t]{5}{*}{ Statewide } & Adult & Spring & 9 & 0.19 & 0.120 & $1 \mathrm{~A}$ & $2 \mathrm{~A}$ & $5 \mathrm{~A}$ & $3 \mathrm{~A}$ & $4 \mathrm{~A}$ & $6 \mathrm{~A}$ \\
\hline & & Fall & 9 & 0.05 & 0.050 & $1 \mathrm{~A}$ & $3 \mathrm{~A}$ & $5 \mathrm{AB}$ & $2 \mathrm{~A}$ & $4 \mathrm{~A}$ & $6 \mathrm{~B}$ \\
\hline & & Winter & 8 & 0.46 & 0.790 & $1 \mathrm{~A}$ & $3 \mathrm{~A}$ & $6 \mathrm{~A}$ & $5 \mathrm{~A}$ & $4 \mathrm{~A}$ & $2 \mathrm{~A}$ \\
\hline & & Spring-Summer & 17 & 0.37 & 0.020 & $1 \mathrm{~A}$ & $2 \mathrm{AB}$ & $5 \mathrm{BCD}$ & $3 \mathrm{C}$ & $4 \mathrm{C}$ & $6 \mathrm{D}$ \\
\hline & & Fall-Winter & 17 & 0.43 & 0.040 & $1 \mathrm{~A}$ & $2 \mathrm{~B}$ & $5 B$ & $6 \mathrm{~B}$ & $4 B$ & $3 \mathrm{AB}$ \\
\hline \multirow[t]{2}{*}{ District I Study Area } & Juvenile & Spring & 11 & 0.002 & 0.003 & $2 \mathrm{~B}$ & $3 \mathrm{C}$ & $1 \mathrm{~A}$ & 4D & $6 \mathrm{D}$ & $5 \mathrm{CD}$ \\
\hline & & Spring-Summer & 10 & 0.06 & 0.010 & $2 \mathrm{~A}$ & $3 \mathrm{~B}$ & $1 \mathrm{~A}$ & $4 \mathrm{C}$ & $6 \mathrm{D}$ & $5 \mathrm{D}$ \\
\hline
\end{tabular}

\footnotetext{
${ }^{\mathrm{a}}$ The same letters following each rank within a row indicates no difference $(P>0.05)$ by compositional analysis (Aebischer et al. 1993).
} 
Table 7. Third-order land fragmentation resource selection significance and rank of male eastern wild turkeys from 2 study areas in West Virginia, 2004-2007. Use proportions derived from 95\% home range utilization distributions (UD) and availability derived from 100 ha block regional proportional summaries; proportions were analyzed using compositional analysis (CA).

\begin{tabular}{|c|c|c|c|c|c|c|c|c|c|c|c|}
\hline \multirow[b]{2}{*}{ Study Area } & \multirow[b]{2}{*}{ Age } & \multirow[b]{2}{*}{ Season } & \multirow[b]{2}{*}{$n$} & \multirow[b]{2}{*}{ Wilks' $\lambda$} & \multirow[b]{2}{*}{$P$} & \multicolumn{5}{|c|}{$\operatorname{Rank}^{\mathrm{a}}$} & \multirow[b]{2}{*}{$>200 \mathrm{ha}$} \\
\hline & & & & & & Edge & Perforations & Patch & $<100 \mathrm{ha}$ & 100-200ha & \\
\hline Statewide & Adult & Annual & 37 & 0.24 & 0.006 & $2 \mathrm{AB}$ & $1 \mathrm{~A}$ & $3 \mathrm{C}$ & $5 \mathrm{C}$ & $6 \mathrm{C}$ & 4BC \\
\hline Statewide & Juvenile & Annual & 29 & 0.13 & 0.003 & $1 \mathrm{~A}$ & $2 \mathrm{AB}$ & $5 \mathrm{C}$ & $3 \mathrm{AC}$ & $4 \mathrm{ABC}$ & $6 \mathrm{BC}$ \\
\hline District I Study Area & Adult & Annual & 9 & 0.15 & 0.020 & $1 \mathrm{~A}$ & $2 \mathrm{AB}$ & $4 \mathrm{~B}$ & $3 \mathrm{AB}$ & & \\
\hline District I Study Area & Juvenile & Annual & 19 & 0.29 & 0.001 & $2 \mathrm{~A}$ & $1 \mathrm{~A}$ & 3B & 4B & & \\
\hline \multirow[t]{5}{*}{ Statewide } & Adult & Spring & 9 & 0.61 & 0.390 & $1 \mathrm{~A}$ & $2 \mathrm{~A}$ & $4 \mathrm{~A}$ & $3 \mathrm{~A}$ & & \\
\hline & & Fall & 9 & 0.23 & 0.030 & $1 \mathrm{~A}$ & $4 \mathrm{~B}$ & $2 \mathrm{AB}$ & $3 \mathrm{AB}$ & & \\
\hline & & Winter & 8 & 0.71 & 0.640 & $3 \mathrm{~A}$ & $1 \mathrm{~A}$ & $4 \mathrm{~A}$ & $2 \mathrm{~A}$ & & \\
\hline & & Spring-Summer & 17 & 0.05 & 0.510 & $1 \mathrm{~A}$ & $2 \mathrm{~A}$ & $4 \mathrm{~A}$ & $3 \mathrm{~A}$ & $6 \mathrm{~A}$ & $5 \mathrm{~A}$ \\
\hline & & Fall-Winter & 17 & 0.20 & 0.030 & $1 \mathrm{~A}$ & $2 \mathrm{~A}$ & 3B & $4 \mathrm{AB}$ & & $5 \mathrm{AB}$ \\
\hline \multirow[t]{2}{*}{ District I Study Area } & Juvenile & Spring & 11 & 0.05 & 0.003 & $2 \mathrm{~B}$ & $1 \mathrm{~A}$ & $3 \mathrm{C}$ & $4 \mathrm{BC}$ & & \\
\hline & & Spring-Summer & 10 & 0.17 & 0.006 & $2 \mathrm{AB}$ & $1 \mathrm{~A}$ & $3 \mathrm{AC}$ & $4 \mathrm{BC}$ & & \\
\hline
\end{tabular}

\footnotetext{
${ }^{\mathrm{a}}$ The same letters following each rank within a row indicates no difference $(P>0.05)$ by compositional analysis (Aebischer et al. 1993).

Blank spaces in a row indicate that resources were not available for analysis.
} 
Table 8. Third-order slope resource selection significance and rank of male eastern wild turkeys from 2 study areas in West Virginia, 2004-2007. Use proportions derived from 95\% home range utilization distributions (UD) and availability derived from 100 ha block regional proportional summaries; proportions were analyzed using compositional analysis (CA).

\begin{tabular}{|c|c|c|c|c|c|c|c|c|c|}
\hline \multirow[b]{2}{*}{ Study Area } & \multirow[b]{2}{*}{ Age } & \multirow[b]{2}{*}{ Season } & \multirow[b]{2}{*}{$n$} & \multirow[b]{2}{*}{ Wilks' $\lambda$} & \multirow[b]{2}{*}{$P$} & \multicolumn{3}{|c|}{$\operatorname{Rank}^{\mathrm{a}}$} & \multirow[b]{2}{*}{$>35 \%$} \\
\hline & & & & & & $0-6 \%$ & $>6-24 \%$ & $>24-35 \%$ & \\
\hline Statewide & Adult & Annual & 37 & 0.41 & 0.001 & $3 B$ & $2 \mathrm{~A}$ & $1 \mathrm{~A}$ & $4 \mathrm{~B}$ \\
\hline Statewide & Juvenile & Annual & 29 & 0.70 & 0.020 & $3 \mathrm{~A}$ & $1 \mathrm{~A}$ & $2 \mathrm{~A}$ & $4 \mathrm{~B}$ \\
\hline District I Study Area & Adult & Annual & 9 & 0.35 & 0.090 & $3 \mathrm{~A}$ & $1 \mathrm{~A}$ & $2 \mathrm{~A}$ & $4 \mathrm{~A}$ \\
\hline District I Study Area & Juvenile & Annual & 19 & 0.34 & 0.002 & $3 \mathrm{C}$ & $1 \mathrm{~A}$ & $2 \mathrm{~B}$ & $4 \mathrm{D}$ \\
\hline \multirow[t]{5}{*}{ Statewide } & Adult & Spring & 9 & 0.45 & 0.190 & $3 \mathrm{~A}$ & $1 \mathrm{~A}$ & $2 \mathrm{~A}$ & $4 \mathrm{~A}$ \\
\hline & & Fall & 9 & 0.05 & 0.004 & $3 B$ & $1 \mathrm{~A}$ & $2 \mathrm{~B}$ & $4 \mathrm{C}$ \\
\hline & & Winter & 8 & 0.77 & 0.840 & $1 \mathrm{~A}$ & $2 \mathrm{~A}$ & $4 \mathrm{~A}$ & $3 \mathrm{~A}$ \\
\hline & & Spring-Summer & 17 & 0.62 & 0.050 & $3 \mathrm{AB}$ & $1 \mathrm{~A}$ & $2 \mathrm{~A}$ & $4 B$ \\
\hline & & Fall-Winter & 17 & 0.73 & 0.210 & $1 \mathrm{~A}$ & $2 \mathrm{~A}$ & $3 \mathrm{~A}$ & $4 \mathrm{~A}$ \\
\hline \multirow[t]{2}{*}{ District I Study Area } & Juvenile & Spring & 11 & 0.01 & 0.004 & $1 \mathrm{~A}$ & $2 \mathrm{AB}$ & $3 \mathrm{AC}$ & $4 \mathrm{D}$ \\
\hline & & Spring-Summer & 10 & 0.004 & 0.006 & $2 \mathrm{AB}$ & $1 \mathrm{~A}$ & $3 B$ & $4 \mathrm{C}$ \\
\hline
\end{tabular}

${ }^{a}$ The same letters following each rank within a row indicates no difference $(P>0.05)$ by compositional analysis (Aebischer et al. 1993). 
Table 9. Third-order aspect resource selection significance and rank of male eastern wild turkeys from 2 study areas in West Virginia, 2004-2007. Use proportions derived from 95\% home range utilization distributions (UD) and availability derived from 100 ha block regional proportional summaries; proportions were analyzed using compositional analysis (CA).

\begin{tabular}{|c|c|c|c|c|c|c|c|c|c|}
\hline \multirow[b]{2}{*}{ Study Area } & \multirow[b]{2}{*}{ Age } & \multirow[b]{2}{*}{ Season } & \multirow[b]{2}{*}{$\mathrm{n}$} & \multirow[b]{2}{*}{ Wilks' $\lambda$} & \multirow[b]{2}{*}{$P$} & \multicolumn{3}{|c|}{$\operatorname{Rank}^{\mathrm{a}}$} & \multirow[b]{2}{*}{ West } \\
\hline & & & & & & North & East & South & \\
\hline Statewide & Adult & Annual & 37 & 0.94 & 0.530 & $2 \mathrm{~A}$ & $1 \mathrm{~A}$ & $3 \mathrm{~A}$ & $4 \mathrm{~A}$ \\
\hline Statewide & Juvenile & Annual & 29 & 0.79 & 0.120 & $2 \mathrm{~A}$ & $1 \mathrm{~A}$ & $3 \mathrm{~A}$ & $4 \mathrm{~A}$ \\
\hline District I Study Area & Adult & Annual & 9 & 0.28 & 0.050 & $3 B$ & $4 \mathrm{~B}$ & $2 \mathrm{~B}$ & $1 \mathrm{~A}$ \\
\hline District I Study Area & Juvenile & Annual & 19 & 0.64 & 0.050 & $3 \mathrm{~A}$ & $1 \mathrm{~A}$ & $4 \mathrm{AC}$ & $2 \mathrm{AB}$ \\
\hline \multirow[t]{5}{*}{ Statewide } & Adult & Spring & 9 & 0.55 & 0.280 & $4 \mathrm{~A}$ & $3 \mathrm{~A}$ & $2 \mathrm{~A}$ & $1 \mathrm{~A}$ \\
\hline & & Fall & 9 & 0.84 & 0.790 & $3 \mathrm{~A}$ & $4 \mathrm{~A}$ & $2 \mathrm{~A}$ & $1 \mathrm{~A}$ \\
\hline & & Winter & 8 & 0.59 & 0.400 & $3 \mathrm{~A}$ & $1 \mathrm{~A}$ & $2 \mathrm{~A}$ & $4 \mathrm{~A}$ \\
\hline & & Spring-Summer & 17 & 0.85 & 0.530 & $4 \mathrm{~A}$ & $3 \mathrm{~A}$ & $2 \mathrm{~A}$ & $1 \mathrm{~A}$ \\
\hline & & Fall-Winter & 17 & 0.86 & 0.600 & $2 \mathrm{~A}$ & $1 \mathrm{~A}$ & $4 \mathrm{~A}$ & $3 \mathrm{~A}$ \\
\hline \multirow[t]{2}{*}{ District I Study Area } & Juvenile & Spring & 11 & 0.1 & 0.006 & $4 \mathrm{~B}$ & $1 \mathrm{~A}$ & $2 \mathrm{AB}$ & $3 \mathrm{AB}$ \\
\hline & & Spring-Summer & 10 & 0.59 & 0.240 & $2 \mathrm{~A}$ & $1 \mathrm{~A}$ & $4 \mathrm{~A}$ & $3 \mathrm{~A}$ \\
\hline
\end{tabular}

${ }^{a}$ The same letters following each rank within a row indicates no difference $(P>0.05)$ by compositional analysis (Aebischer et al. 1993). 


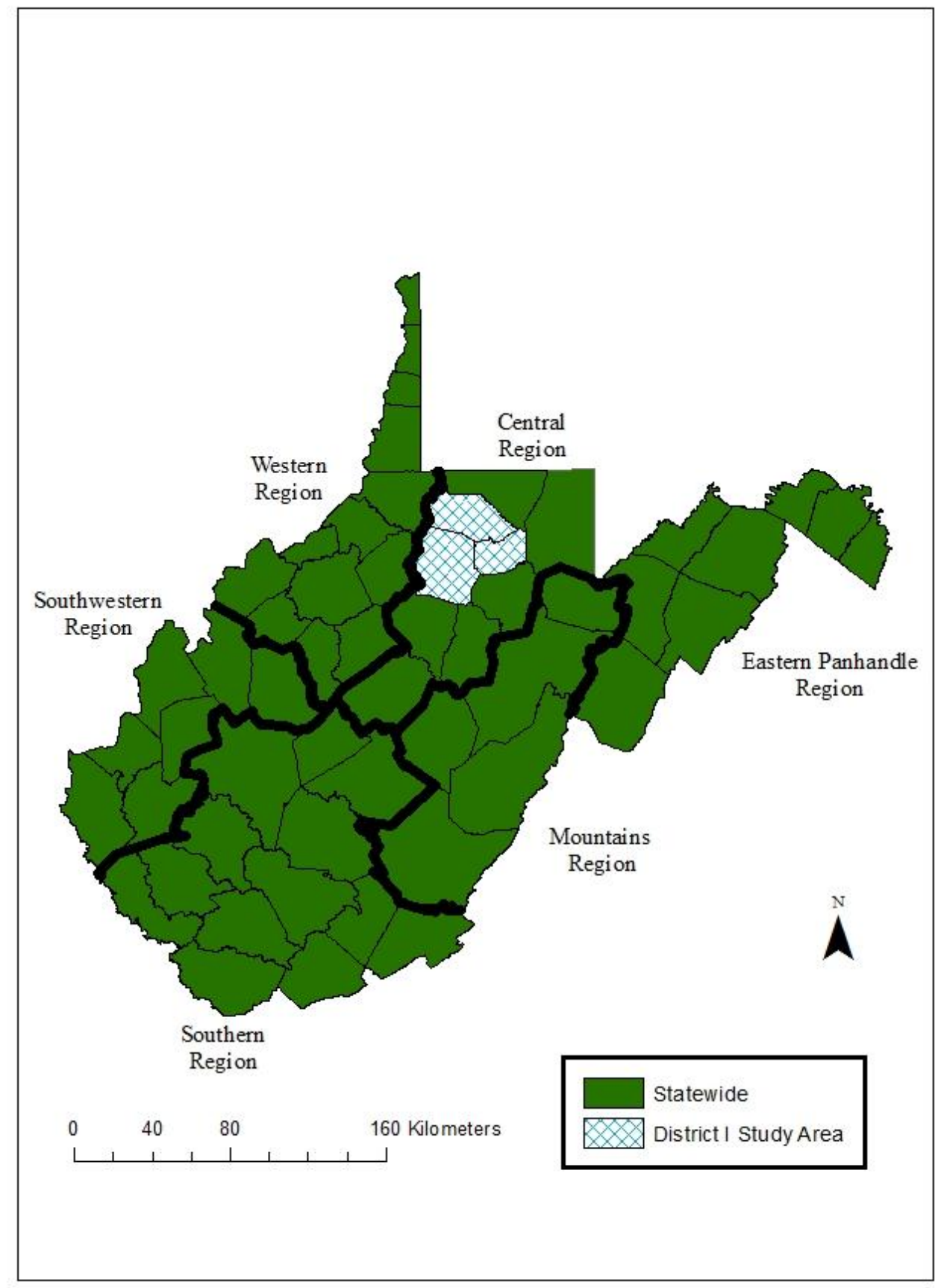

Figure 1. West Virginia Statewide Male Eastern Wild Turkey Study Area and the District I Study Area, 2004-2007. 


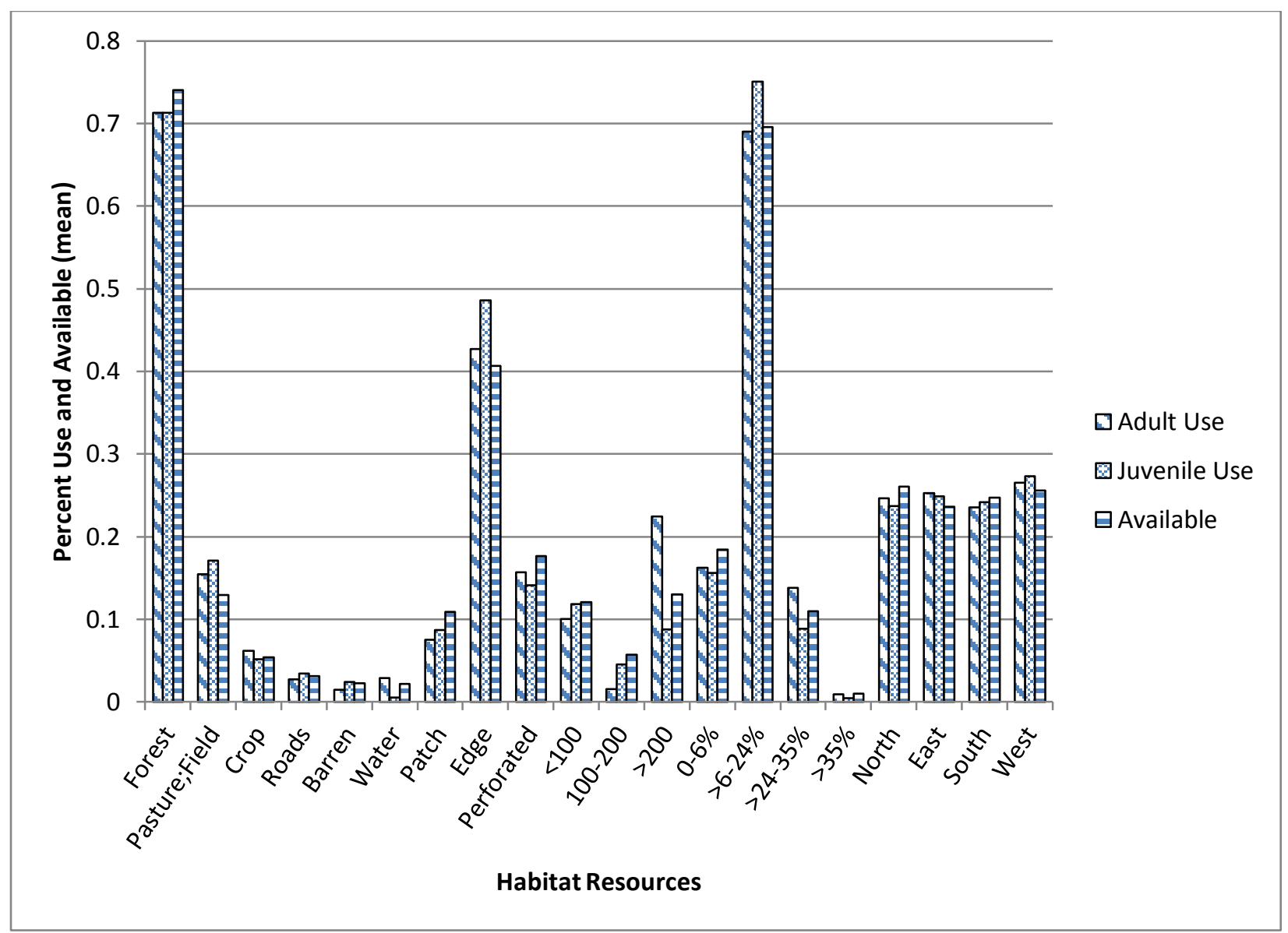

Figure 2. Mean annual statewide adult $(n=37)$ and juvenile $(n=29)$ male wild turkey secondorder land use and land cover, land fragmentation, slope, and aspect proportions; use proportions were derived from $95 \%$ UD home ranges $(\bar{x}=1,409.9$ ha, $\mathrm{SE}=180.3 ; \bar{x}=1,394.3$ ha, $\mathrm{SE}=$ 146.6) and availability was derived from a proportional summary and weighted average of 2,587 100 ha blocks $(\bar{x}=51,740$ ha, $\mathrm{SE}=12,983.2)$ within 5 ecological regions of West Virginia, 2004-2007. 


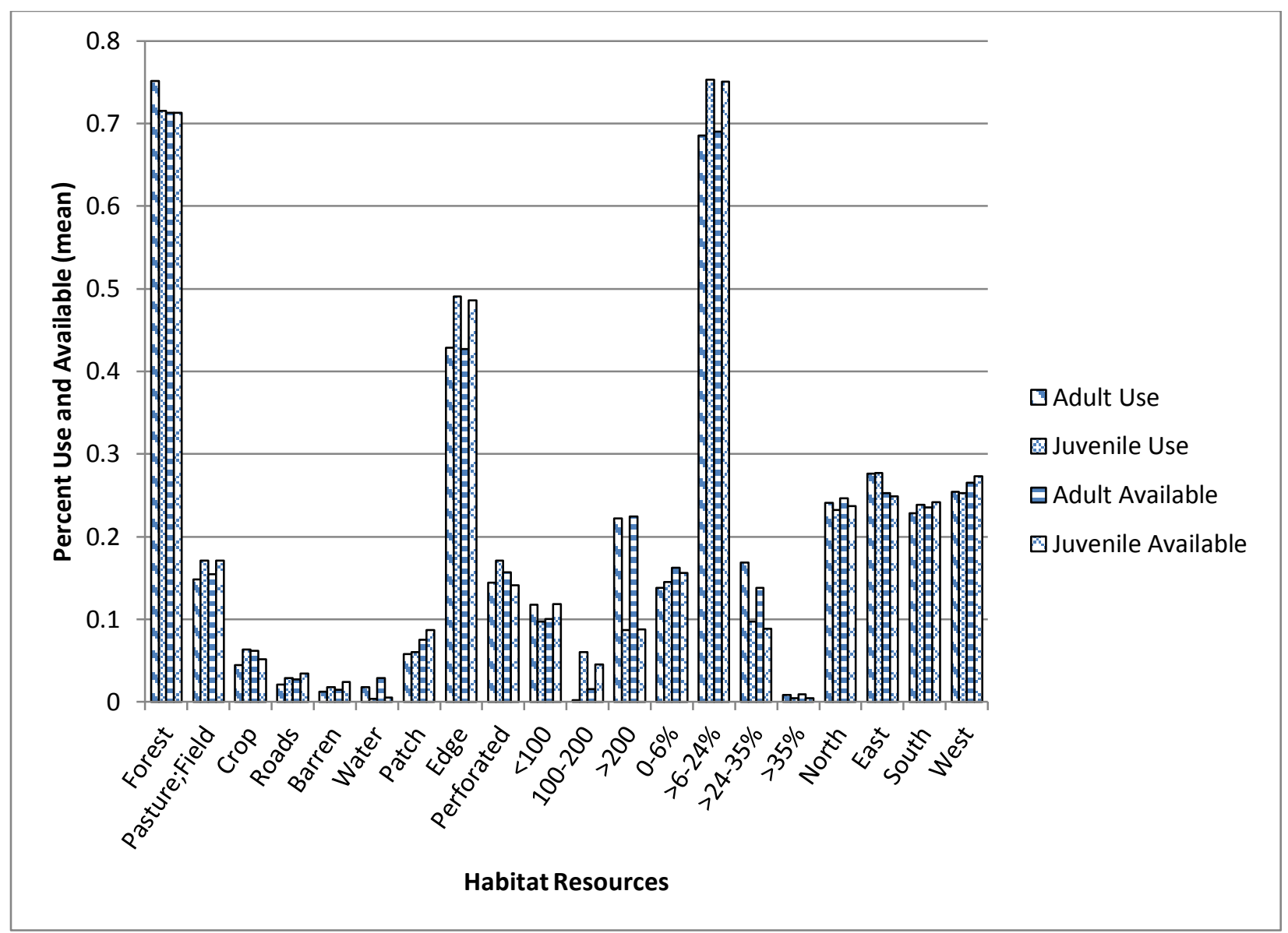

Figure 3. Mean annual statewide adult $(n=37)$ and juvenile $(n=29)$ third-order land use and land cover, land fragmentation, slope, and aspect proportions; use proportions were derived from $50 \%(\bar{x}=310.3$ ha, $\mathrm{SE}=38.7 ; \bar{x}=320.6 \mathrm{ha}, \mathrm{SE}=190.3)$ and availability proportions were derived from $95 \%(\bar{x}=1,409.9$ ha, $\mathrm{SE}=180.3 ; \bar{x}=1,394.3$ ha, $\mathrm{SE}=790.8)$ UD home ranges within 5 ecological regions of West Virginia, 2004-2007. 


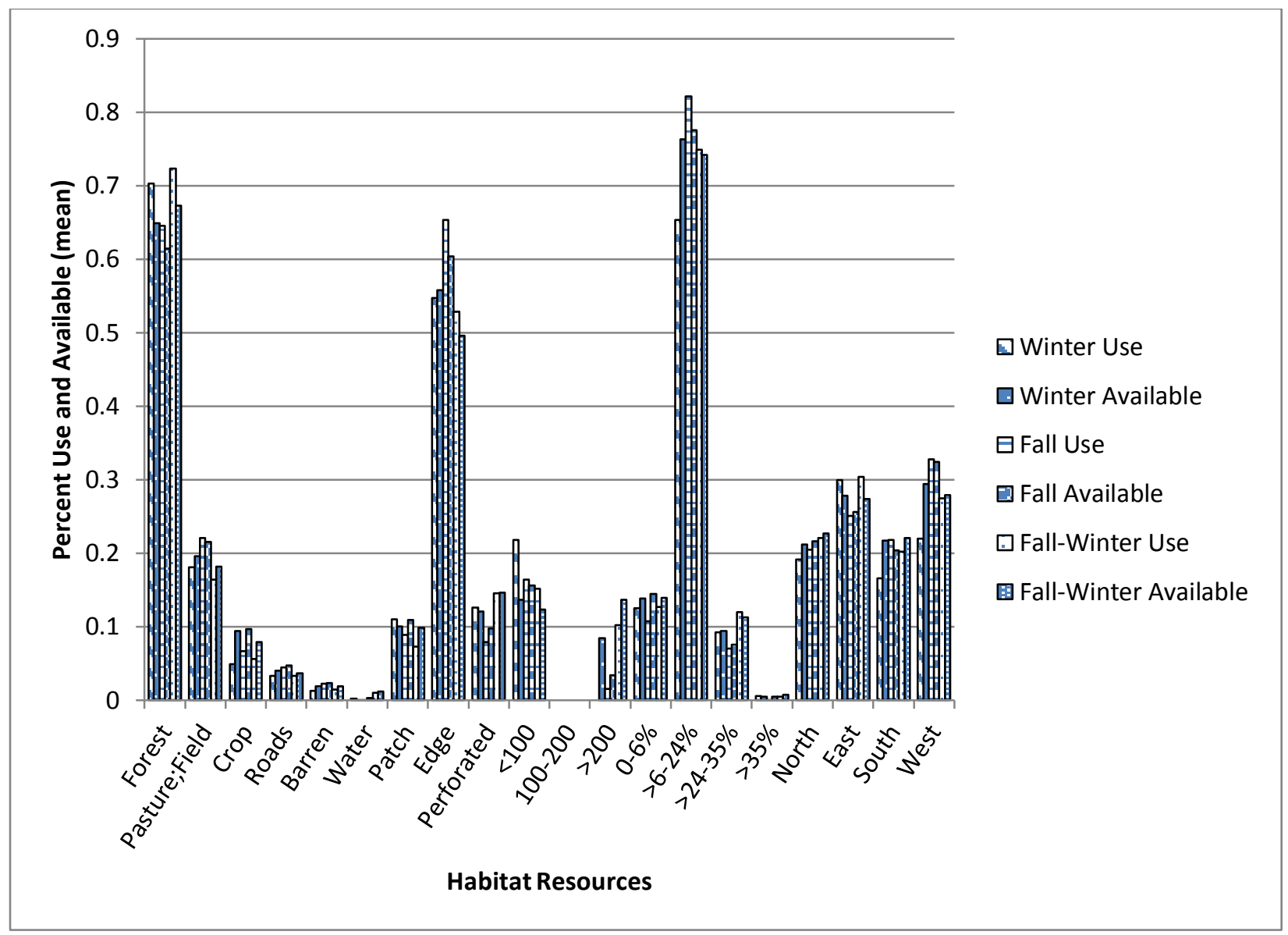

Figure 4. Mean fall $(n=9)$, fall-winter $(n=17)$, and winter $(n=8)$ adult wild turkey third-order land use and land cover, land fragmentation, slope, and aspect proportions; use proportions were derived from $50 \%(\bar{x}=220.2$ ha, $\mathrm{SE}=33.8 ; \bar{x}=241.8$ ha, $\mathrm{SE}=43.5 ; \bar{x}=211.6$ ha, $\mathrm{SE}=56.7)$ and availability proportions were derived from $95 \%(\bar{x}=858.2$ ha, $\mathrm{SE}=119.8 ; \bar{x}=1,046.6$ ha, $\mathrm{SE}=174.8 ; \bar{x}=927.6, \mathrm{SE}=238.5) \mathrm{UD}$ home ranges within 5 ecological regions of West Virginia, 2004-2007. 


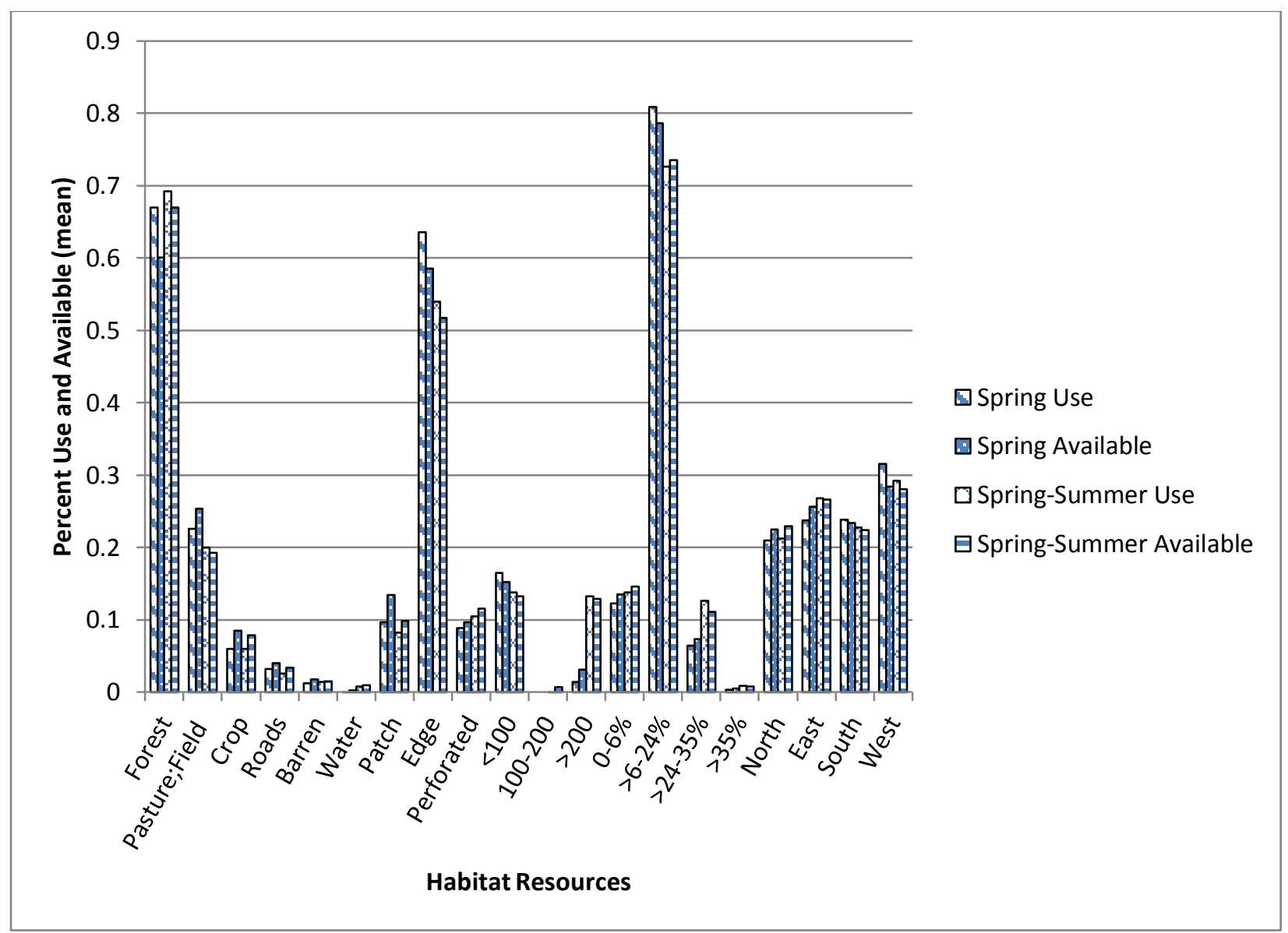

Figure 5. Mean spring $(n=9)$ and spring-summer $(n=17)$ adult wild turkey third-order land use and land cover, land fragmentation, slope, and aspect proportions; use proportions were derived from $50 \%(\bar{x}=163.0$ ha, $\mathrm{SE}=12.7 ; \bar{x}=199.0$ ha, $\mathrm{SE}=26.9)$ and availability proportions were derived from $95 \%(\bar{x}=685.6 \mathrm{ha}, \mathrm{SE}=66.3 ; \bar{x}=821.8 \mathrm{ha}, \mathrm{SE}=106.3)$ UD home ranges within 5 ecological regions of West Virginia, 2004-2007. 


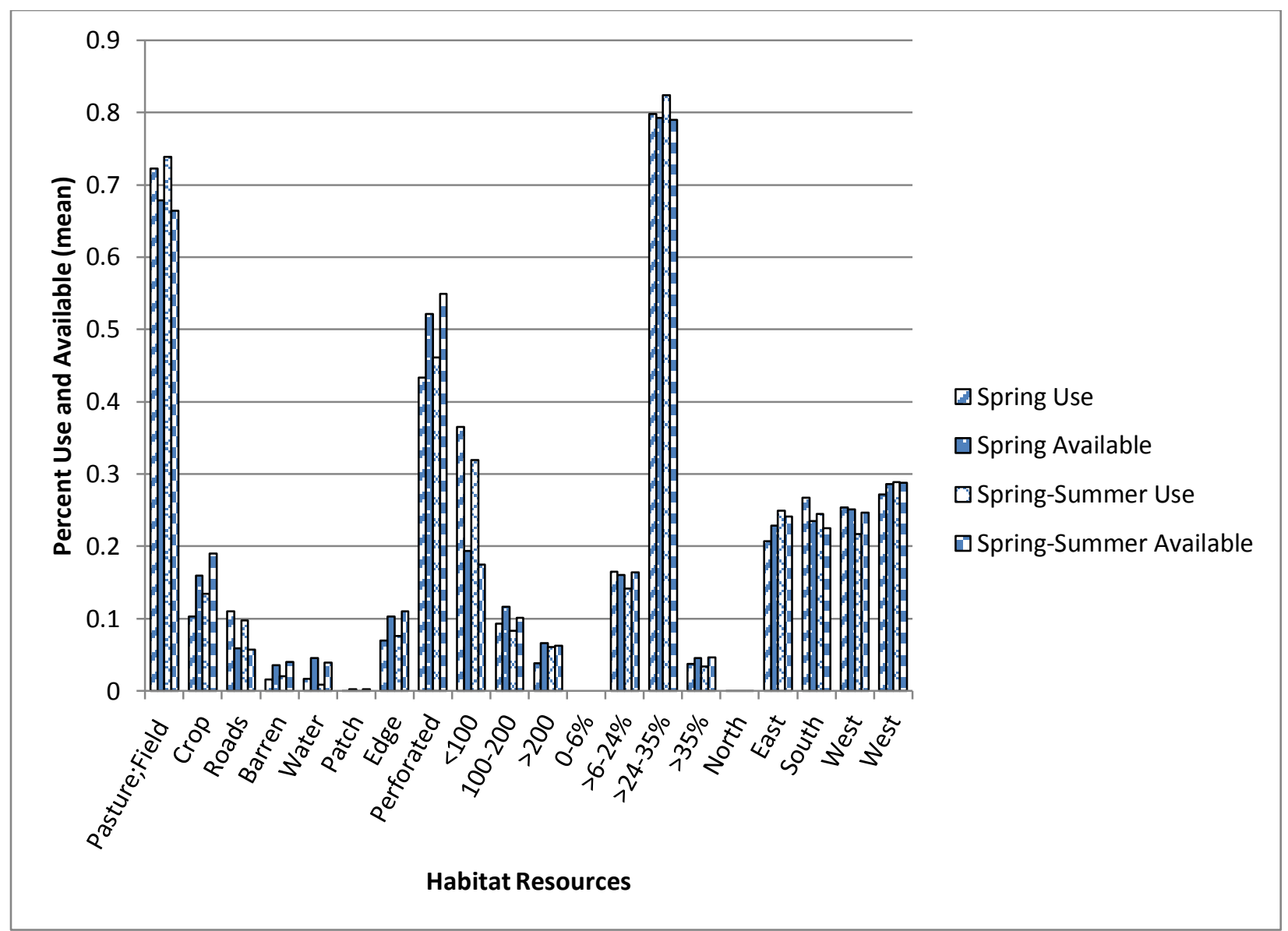

Figure 6. Mean spring $(n=11)$ and spring-summer $(n=11)$ juvenile wild turkey third-order land use and land cover, land fragmentation, slope, and aspect proportions; use proportions were derived from $50 \%(\bar{x}=142.1$ ha, $\mathrm{SE}=15.5 ; \bar{x}=97.0, \mathrm{SE}=10.7)$ and availability proportions were derived from $95 \%(\bar{x}=800.2$ ha, $\mathrm{SE}=123 ; \bar{x}=543.8$ ha, $\mathrm{SE}=85.0)$ UD home ranges within the District I Study Area of West Virginia, 2004-2007. 


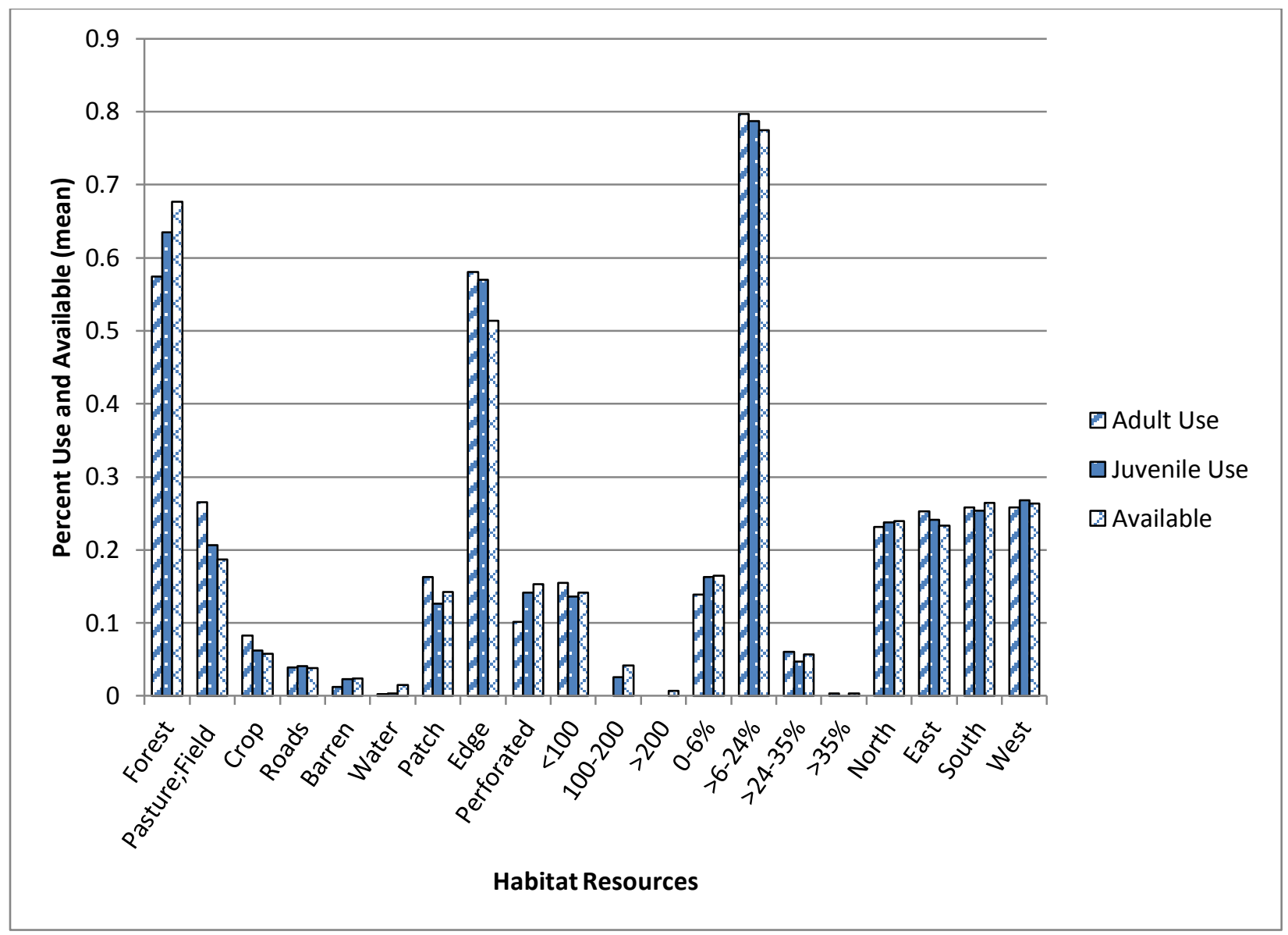

Figure 7. Mean annual adult $(n=9)$ and juvenile $(n=19)$ wild turkey second-order land use and land cover, land fragmentation, slope, and aspect proportions; use proportions were derived from $95 \%(\bar{x}=1,515.3$ ha, $\mathrm{SE}=368.0 ; \bar{x}=1323.3$ ha, $\mathrm{SE}=190.1)$ UD home ranges and availability proportions were derived from 639100 ha sampling blocks within the District I Study Area of West Virginia, 2004-2007. 


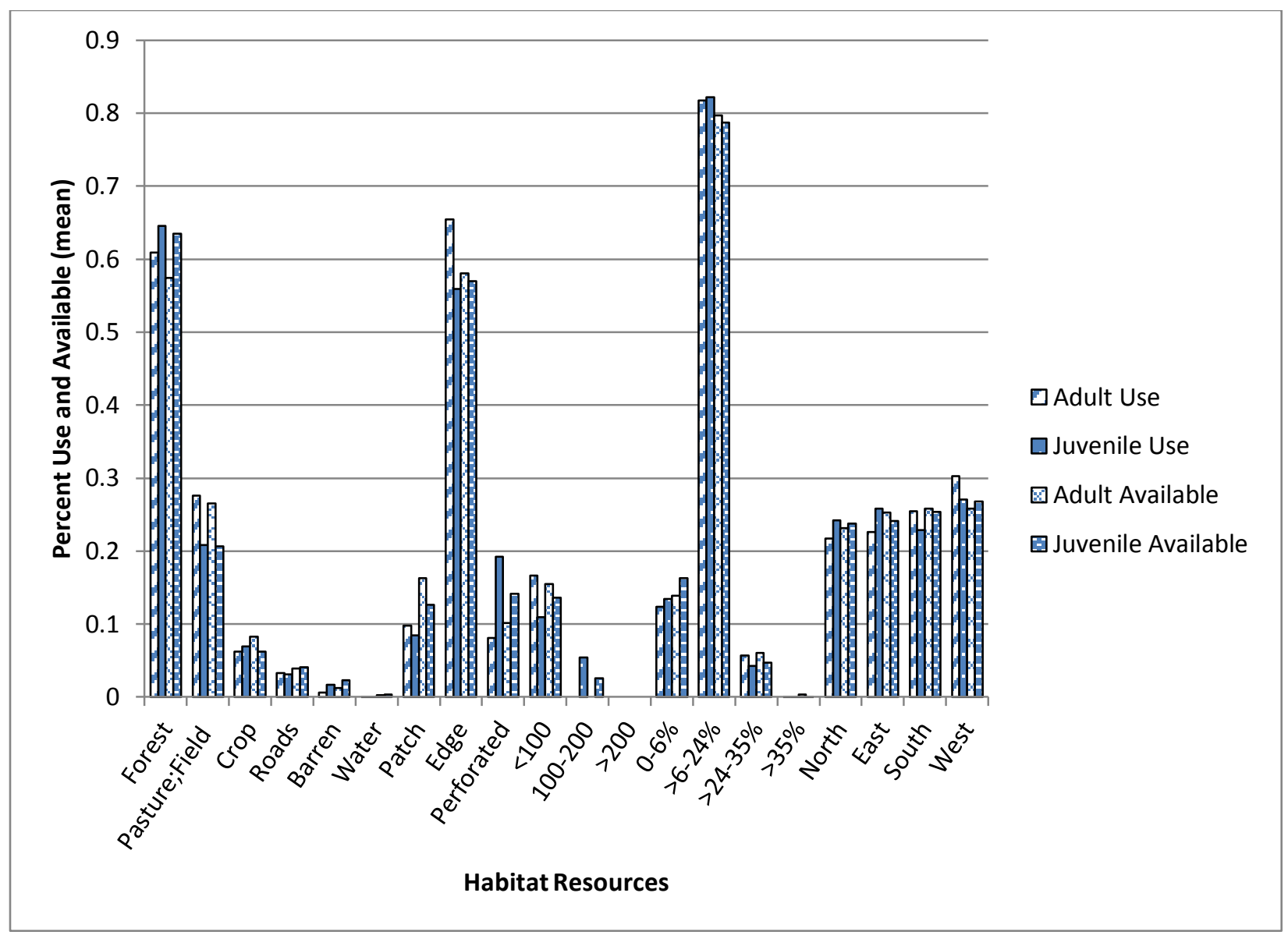

Figure 8. Mean annual adult $(n=9)$ and juvenile $(n=19)$ wild turkey third-order land use and land cover, land fragmentation, slope, and aspect proportions; use proportions were derived from $50 \%(\bar{x}=327.2$ ha, $\mathrm{SE}=79.2 ; \bar{x}=310.8$ ha, $\mathrm{SE}=46.1)$ and availability proportions were derived from $95 \%(\bar{x}=1,515.3$ ha, $\mathrm{SE}=368.0 ; \bar{x}=1,323.3 \mathrm{ha}, \mathrm{SE}=190.1)$ UD home ranges within the District I Study Area of West Virginia, 2004-2007. 


\section{APPENDICES}


Appendix A. I $a$-CCXCIVa: Adult and juvenile 50\% and 95\% probability contours of the annual and seasonal Gaussian fixed kernel home range utilization distribution (UD) for 55 male wild turkeys in West Virginia, 2004-2007. Smooth parameter $(h)$ determined by least squares cross validation (land use and land cover, land fragmentation, aspect, and slope raster data used for map backgrounds). 
Appendix I $a .10001$ (adult, annual) - 50\% core and 95\% periphery probability contours of the annual Gaussian fixed kernel home range utilization distributions. Smoothing parameter $(h)$ determined by least squares cross validation, Taylor County, West Virginia, 2004-2007 (land use and land cover, land fragmentation maps).
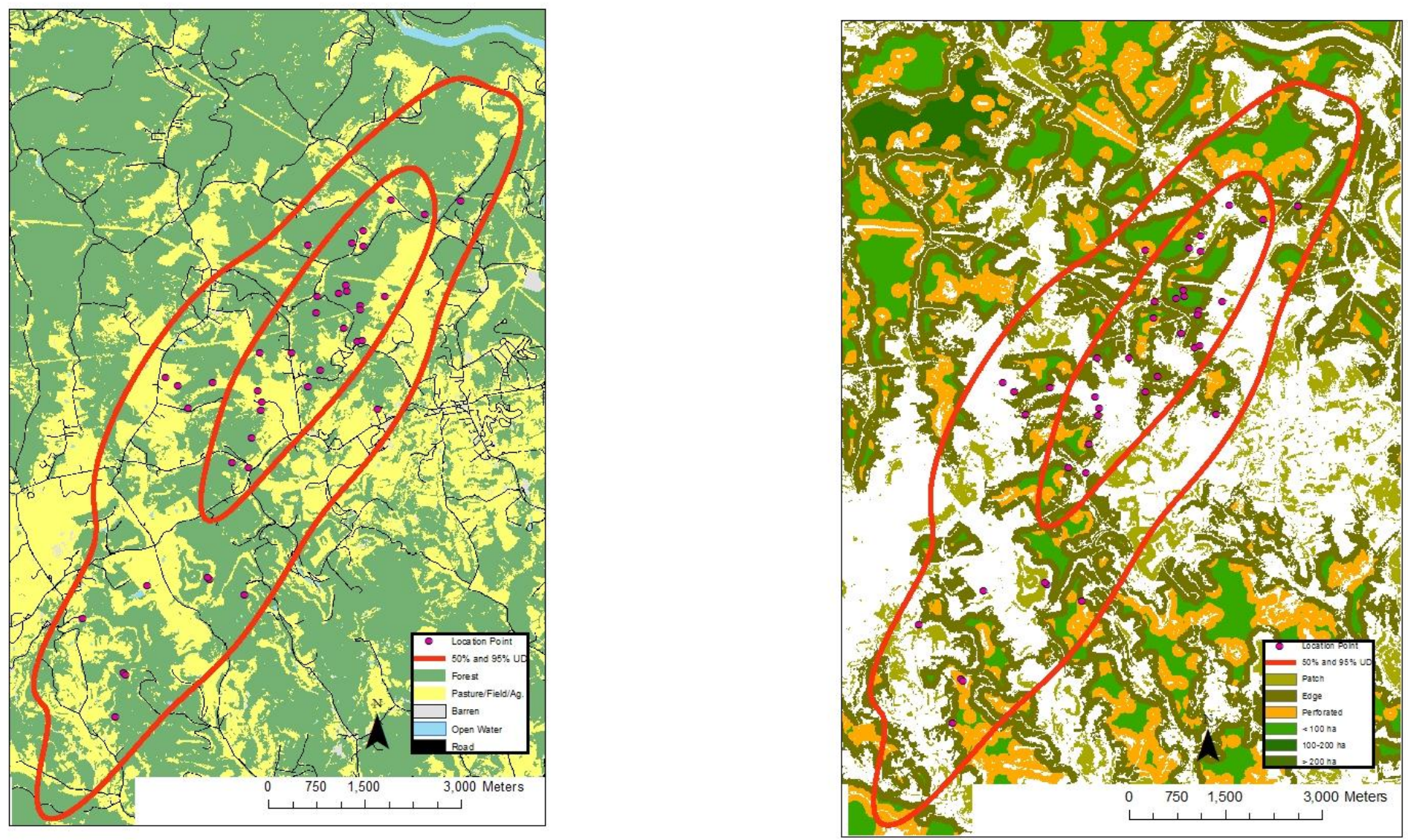
Appendix II $a .10001$ (adult, annual) - 50\% core and 95\% periphery probability contours of the annual Gaussian fixed kernel home range utilization distributions. Smoothing parameter $(h)$ determined by least squares cross validation, Taylor County, West Virginia, 2004-2007 (aspect and slope maps).
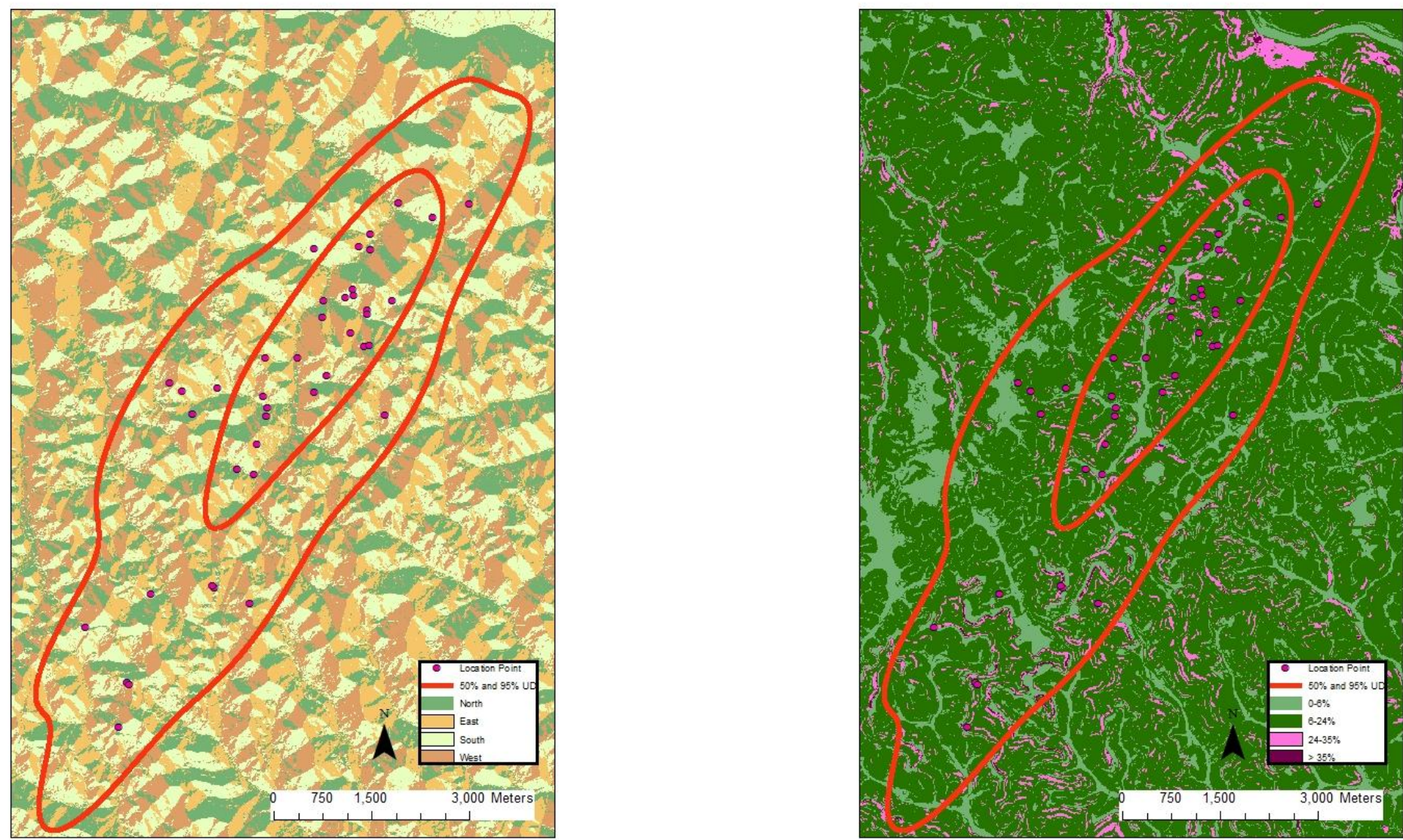
Appendix III $a .10002$ (adult, annual) - 50\% core and 95\% periphery probability contours of the annual Gaussian fixed kernel home range utilization distributions. Smoothing parameter $(h)$ determined by least squares cross validation, Taylor County, West Virginia, 2004-2007 (land use and land cover, land fragmentation maps).
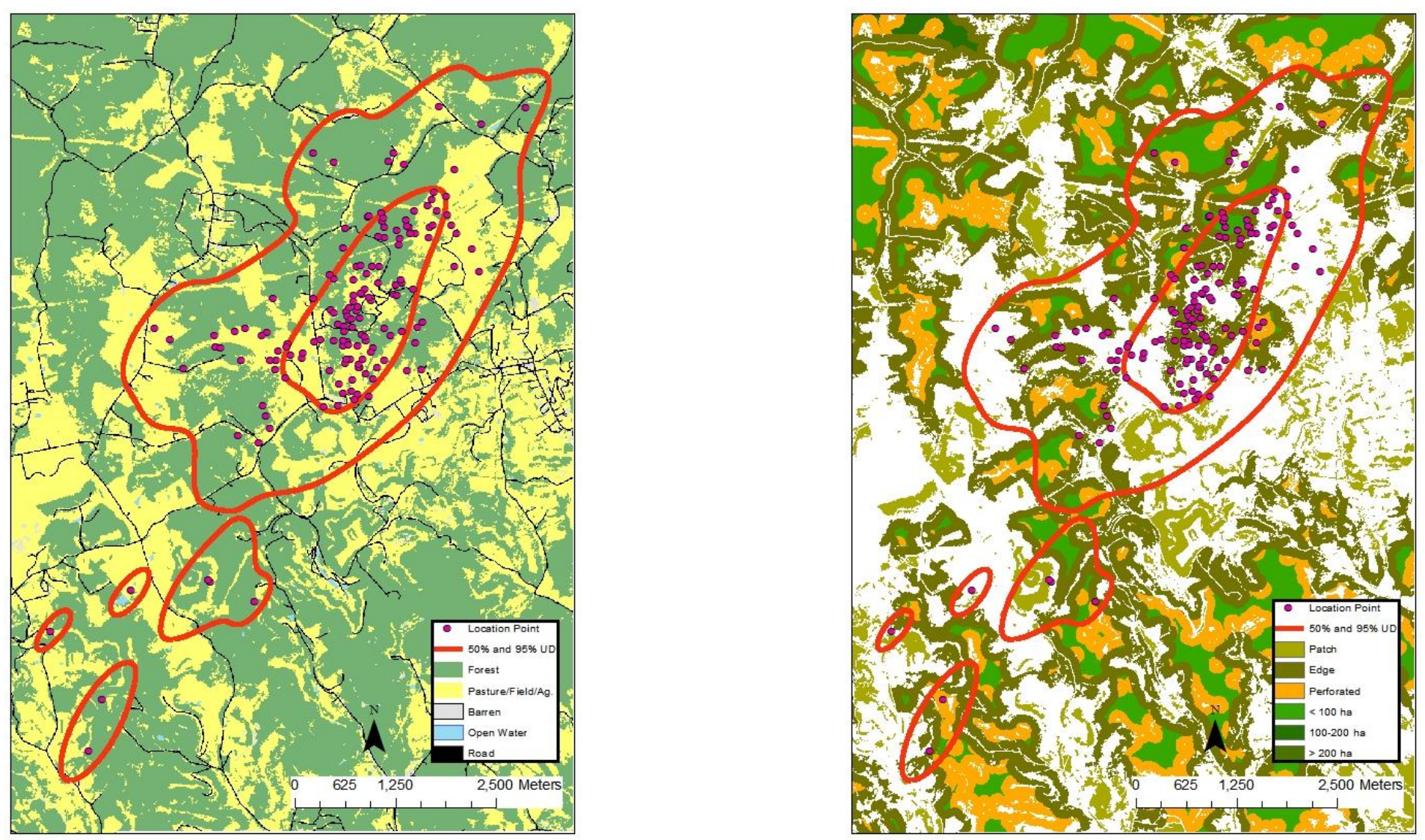
Appendix IVa. 10002 (adult, annual) - 50\% core and 95\% periphery probability contours of the annual Gaussian fixed kernel home range utilization distributions. Smoothing parameter $(h)$ determined by least squares cross validation, Taylor County, West Virginia, 2004-2007 (aspect and slope maps).
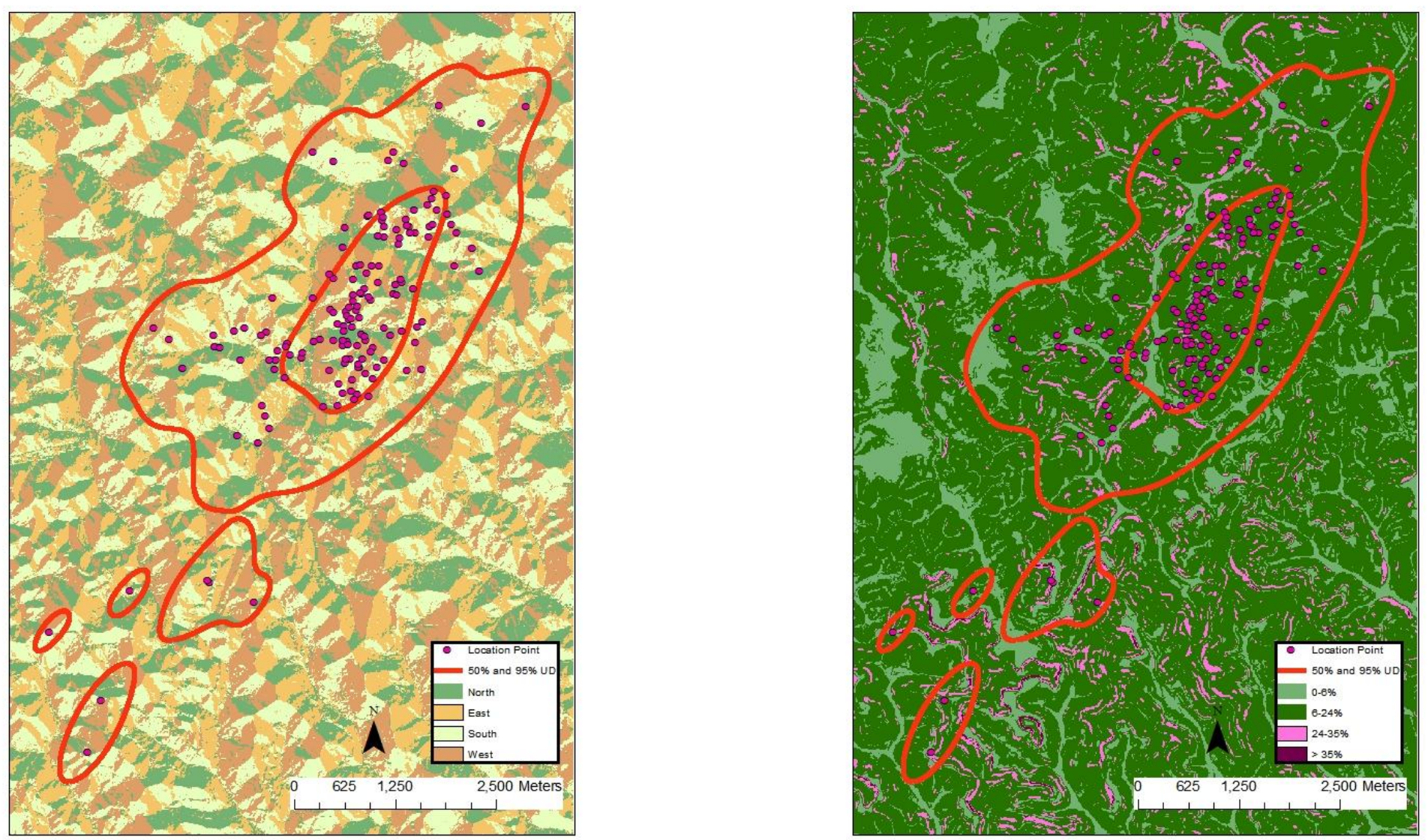
Appendix Va. 10003 (juvenile, annual) - 50\% core and 95\% periphery probability contours of the annual Gaussian fixed kernel home range utilization distributions. Smoothing parameter $(h)$ determined by least squares cross validation, Taylor County, West Virginia, 2004-2007 (land use and land cover, land fragmentation maps).
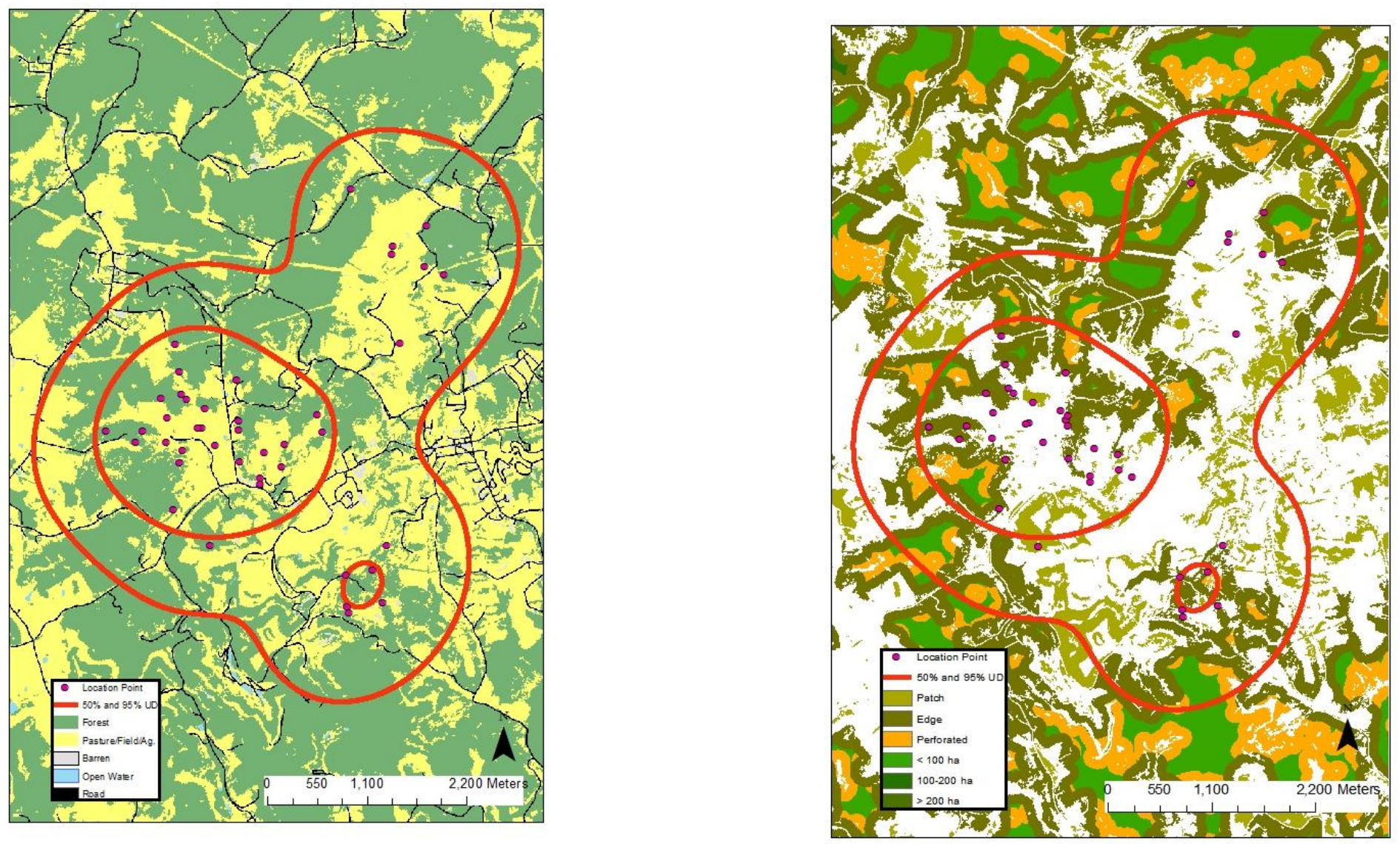
Appendix VIa. 10003 (juvenile, annual) - 50\% core and 95\% periphery probability contours of the annual Gaussian fixed kernel home range utilization distributions. Smoothing parameter $(h)$ determined by least squares cross validation, Taylor County, West Virginia, 2004-2007 (aspect and slope maps).
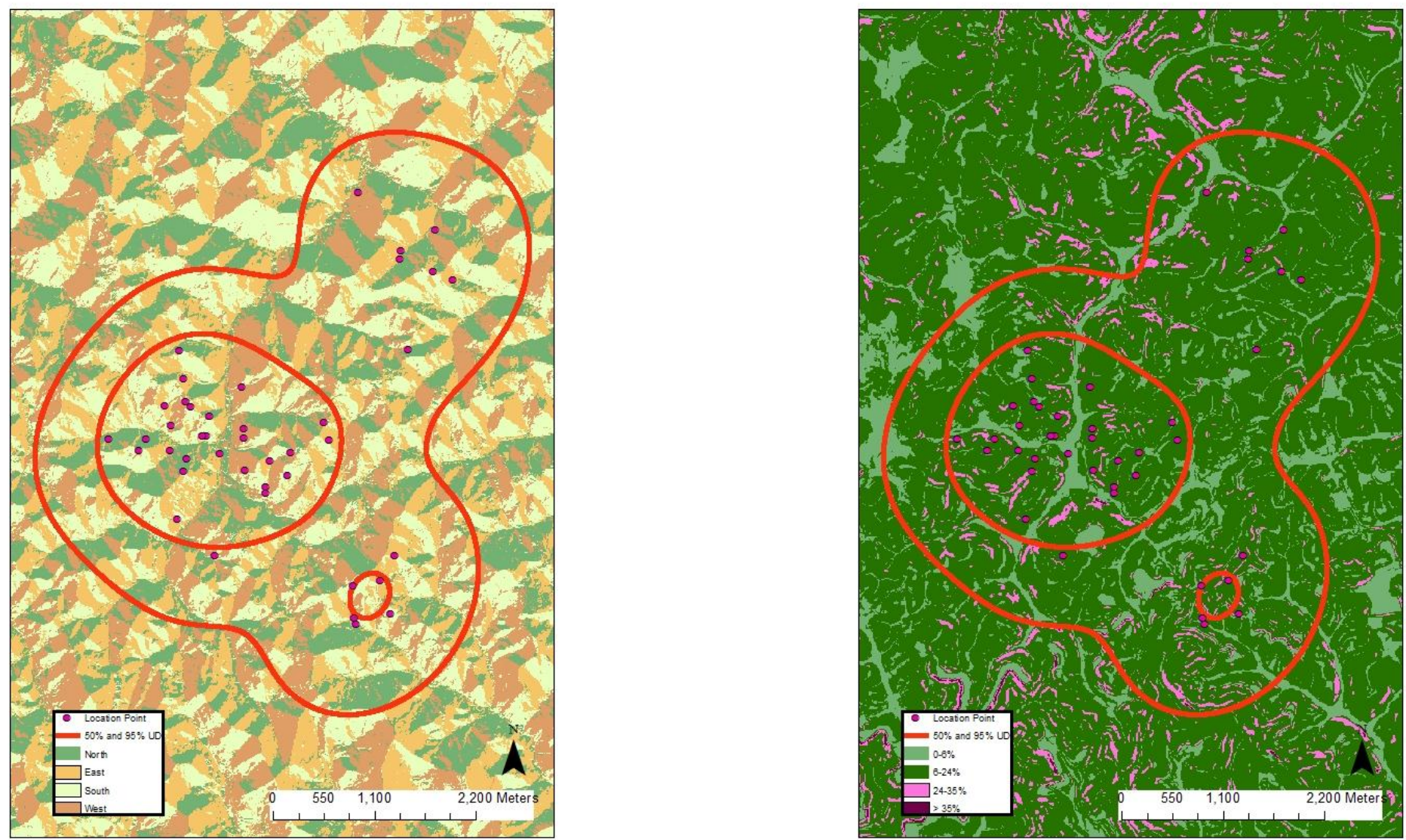
Appendix VII $a$. 10005 (adult, fall-winter) - 50\% core and 95\% periphery probability contours of the fall-winter Gaussian fixed kernel home range utilization distributions. Smoothing parameter $(h)$ determined by least squares cross validation, Taylor County, West Virginia, 2004-2007 (land use and land cover, land fragmentation maps).
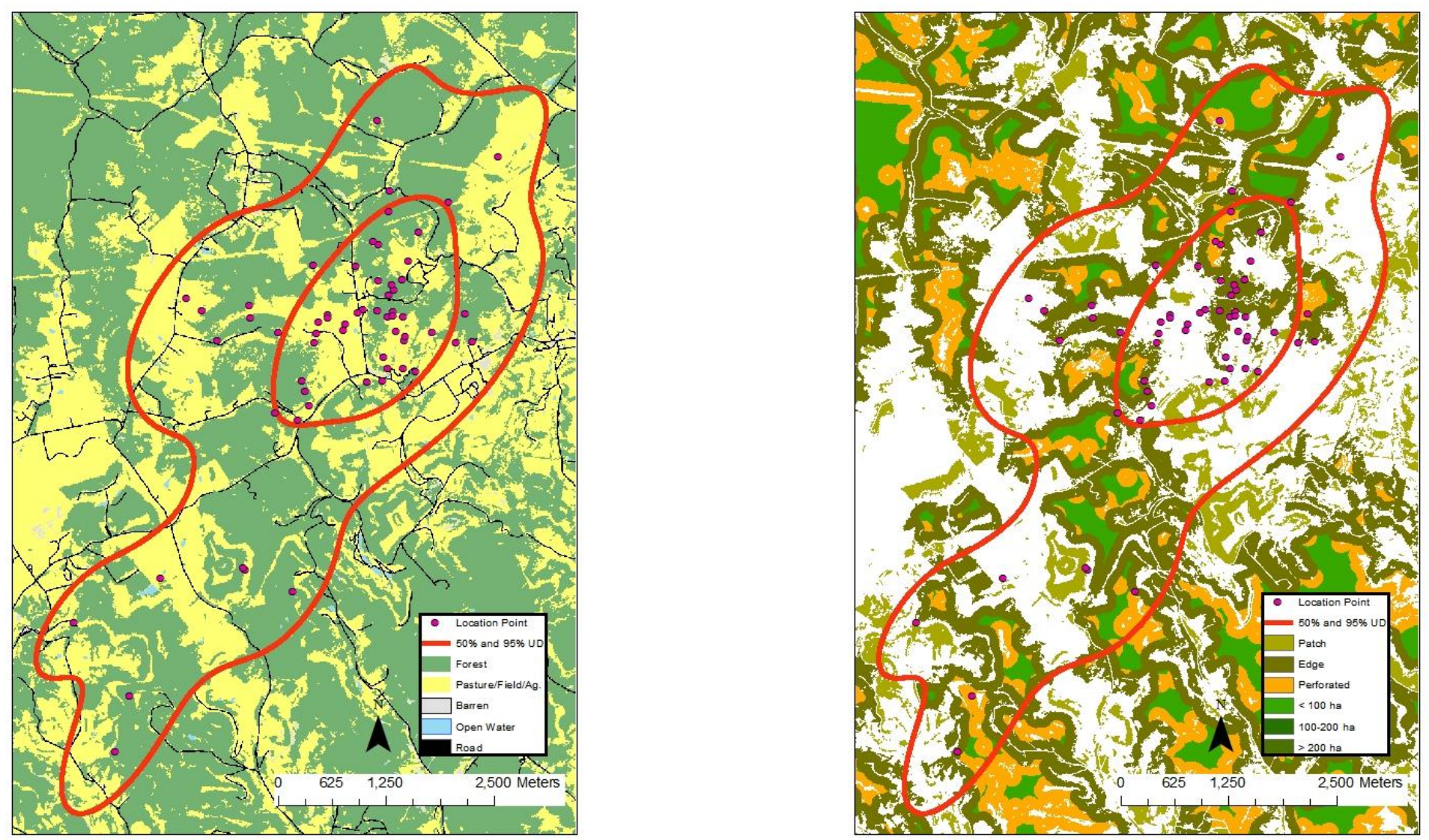
Appendix VIII $a .10005$ (adult, fall-winter) - 50\% core and 95\% periphery probability contours of the fall-winter Gaussian fixed kernel home range utilization distributions. Smoothing parameter $(h)$ determined by least squares cross validation, Taylor County, West Virginia, 2004-2007 (aspect and slope maps).
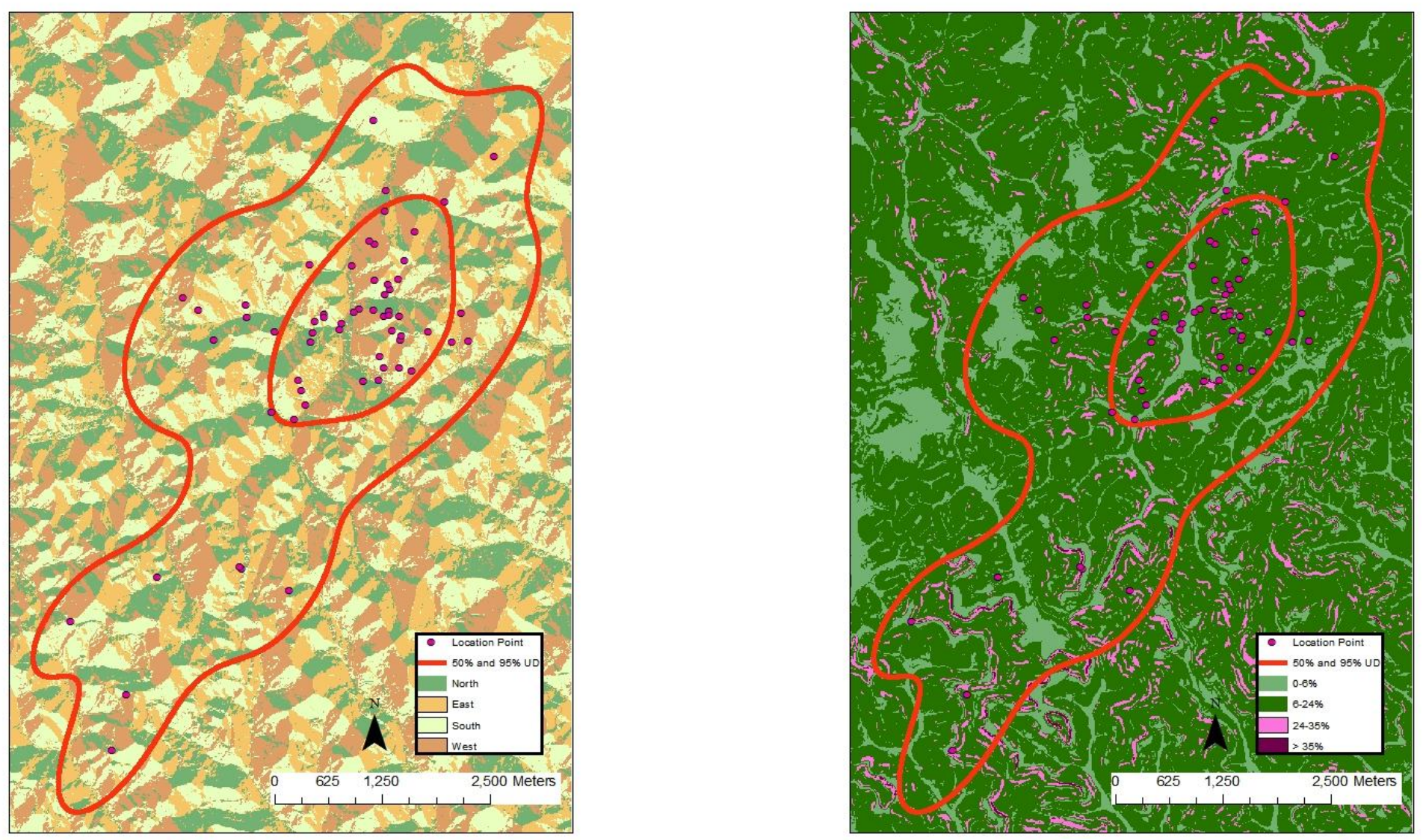
Appendix IX $a .10006$ (juvenile, annual) - 50\% core and 95\% periphery probability contours of the annual Gaussian fixed kernel home range utilization distributions. Smoothing parameter $(h)$ determined by least squares cross validation, Taylor County, West Virginia, 2004-2007 (land use and land cover, land fragmentation maps).
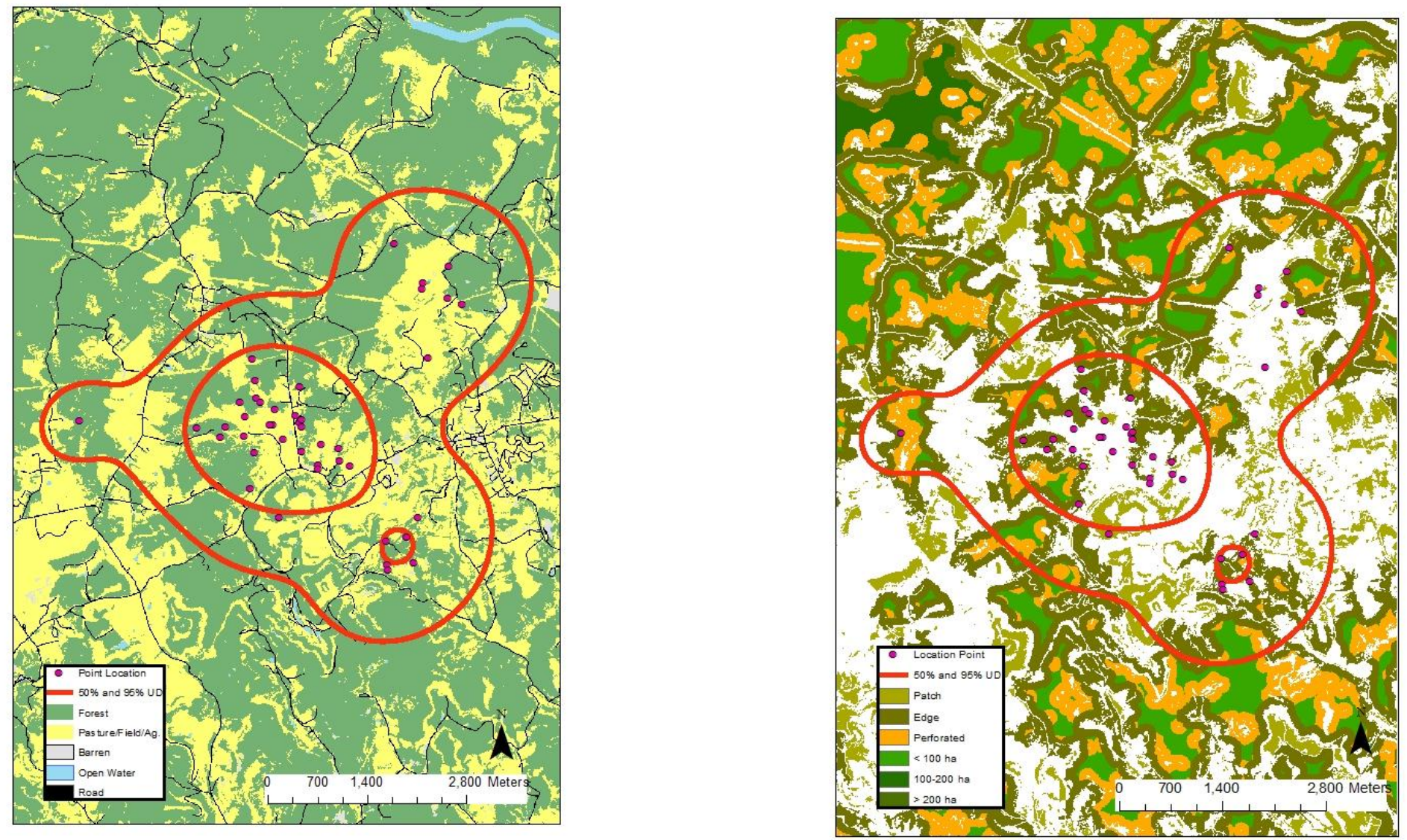
Appendix Xa. 10006 (juvenile, annual) - 50\% core and 95\% periphery probability contours of the annual Gaussian fixed kernel home range utilization distributions. Smoothing parameter $(h)$ determined by least squares cross validation, Taylor County, West Virginia, 2004-2007 (aspect and slope maps).
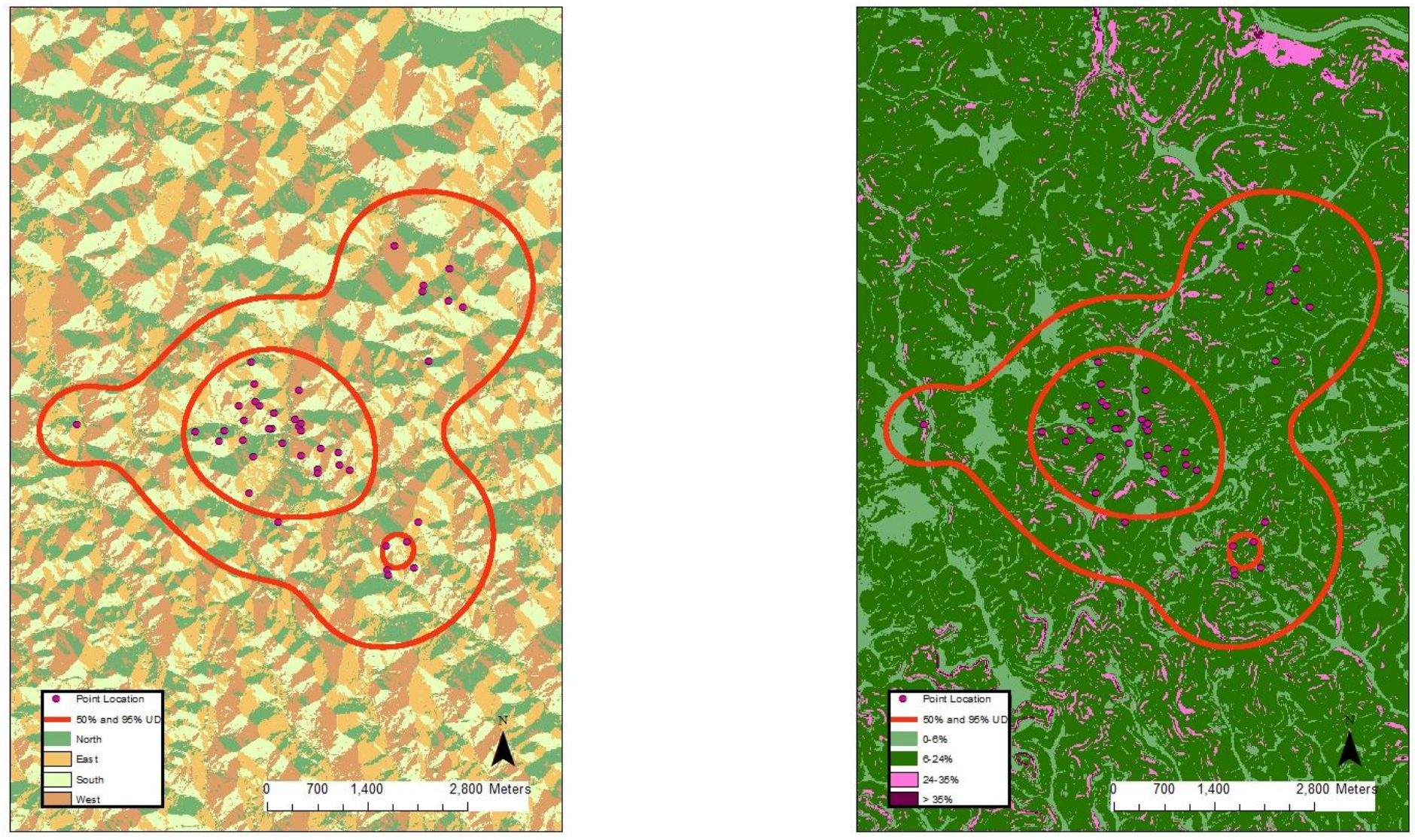
Appendix XIa. 10007 (adult, spring) - 50\% core and 95\% periphery probability contours of the spring Gaussian fixed kernel home range utilization distributions. Smoothing parameter $(h)$ determined by least squares cross validation, Taylor County, West Virginia, 2004-2007 (land use and land cover, land fragmentation maps).
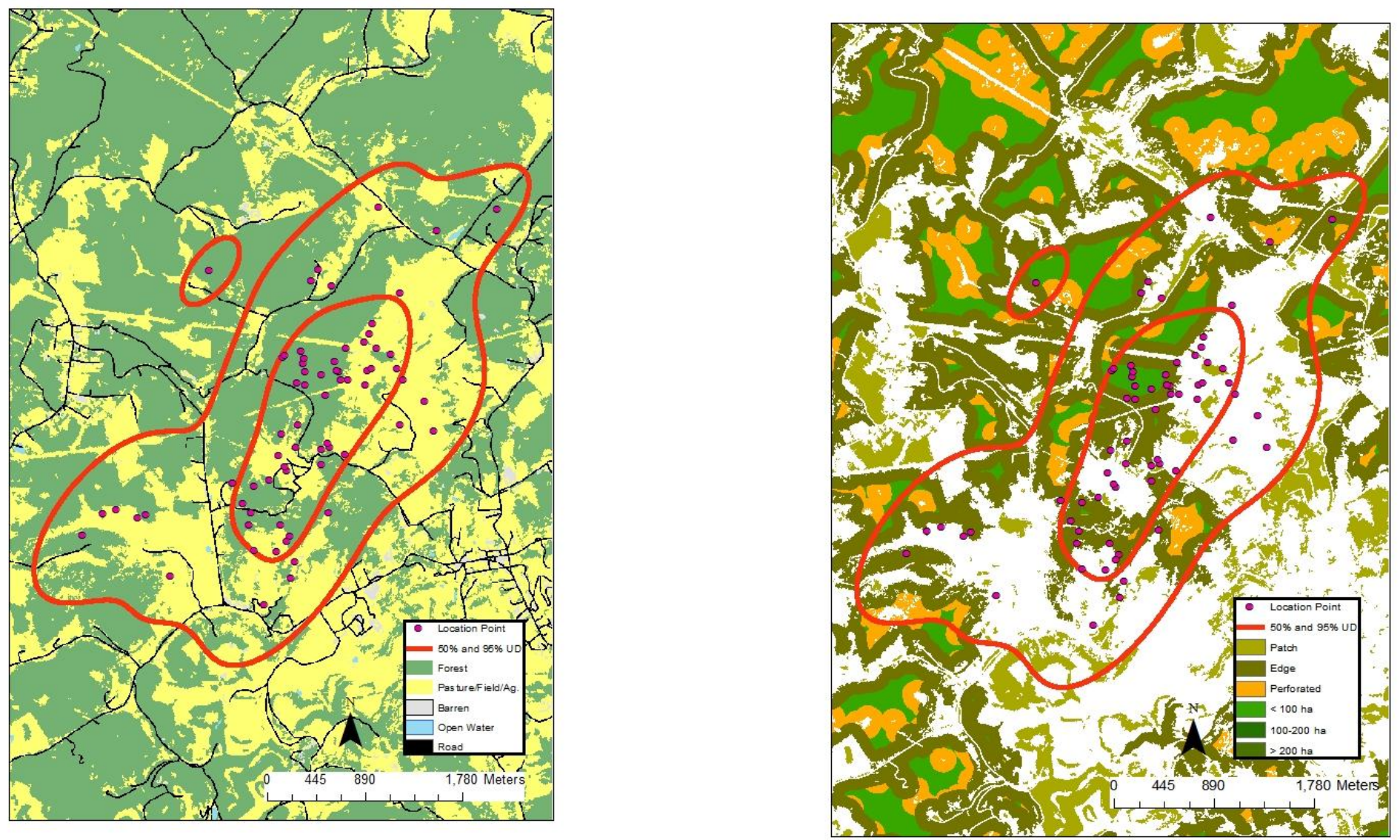
Appendix XIIa. 10007 (adult, spring) - 50\% core and 95\% periphery probability contours of the spring Gaussian fixed kernel home range utilization distributions. Smoothing parameter $(h)$ determined by least squares cross validation, Taylor County, West Virginia, 2004-2007 (aspect and slope maps).
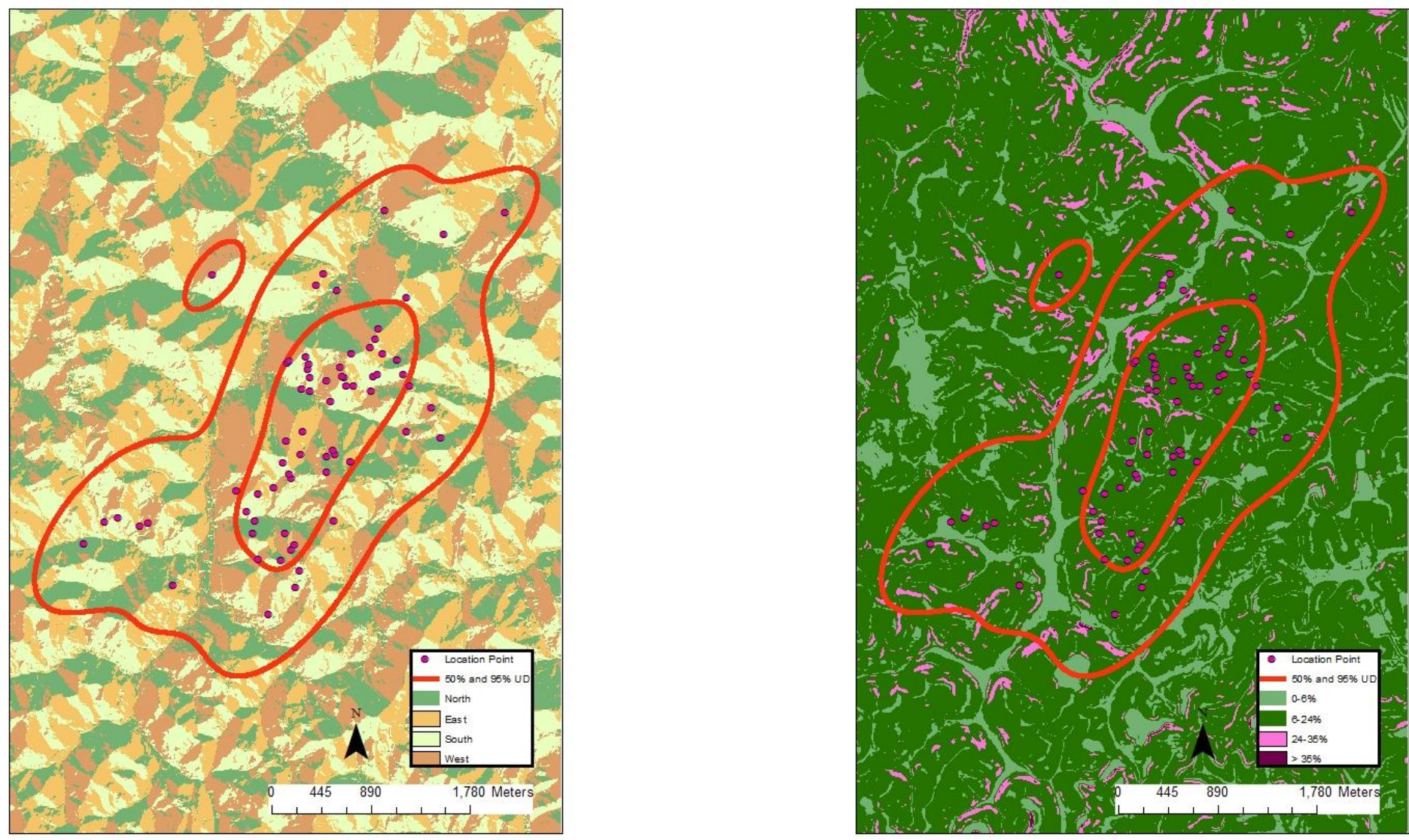
Appendix XIII a. 10008 (adult, spring-summer) - 50\% core and 95\% periphery probability contours of the spring-summer Gaussian fixed kernel home range utilization distributions. Smoothing parameter $(h)$ determined by least squares cross validation, Taylor County, West Virginia, 2004-2007 (land use and land cover, land fragmentation maps).
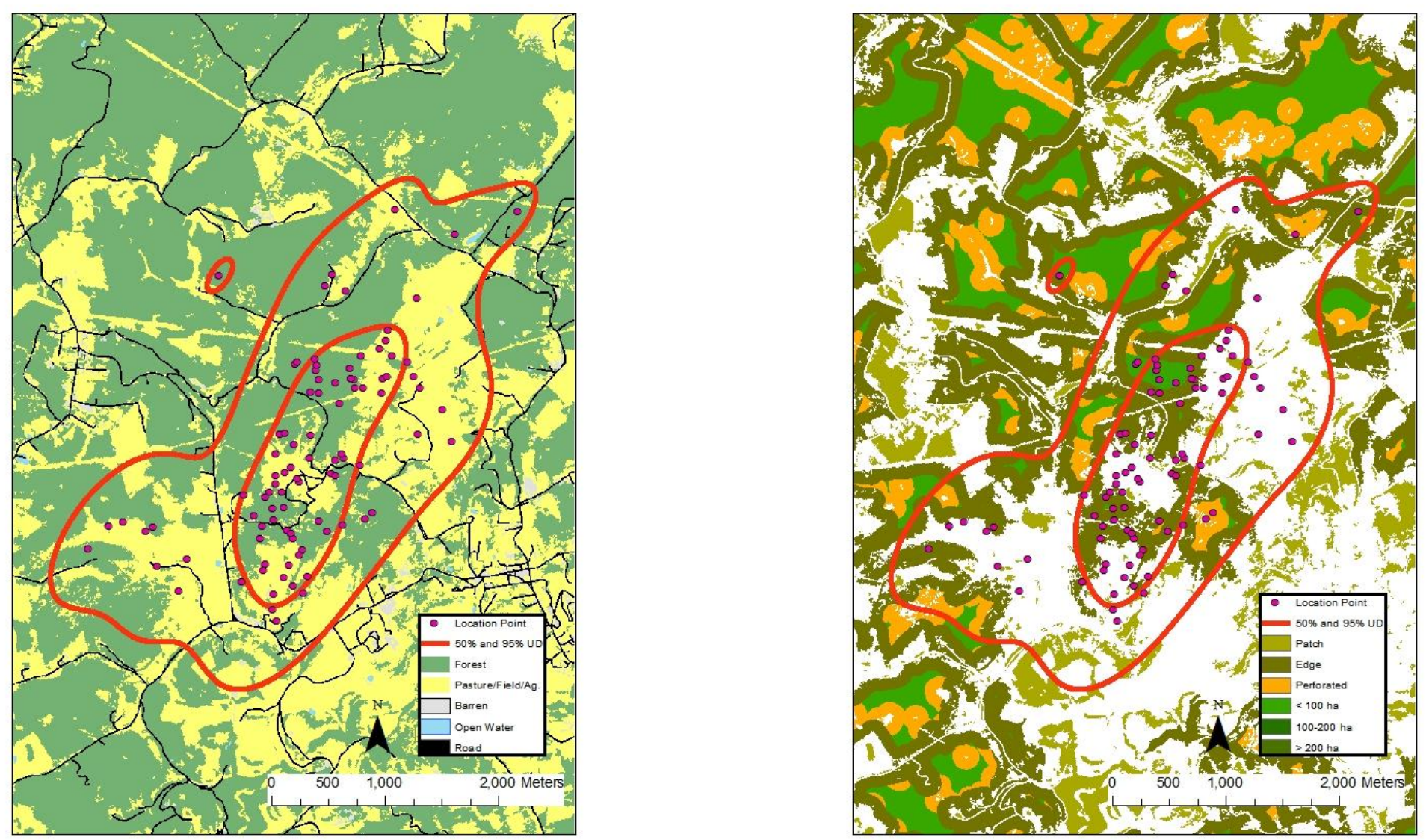
Appendix XIVa. 10008 (adult, spring-summer) - 50\% core and 95\% periphery probability contours of the spring-summer Gaussian fixed kernel home range utilization distributions. Smoothing parameter $(h)$ determined by least squares cross validation, Taylor County, West Virginia, 2004-2007 (aspect and slope maps).
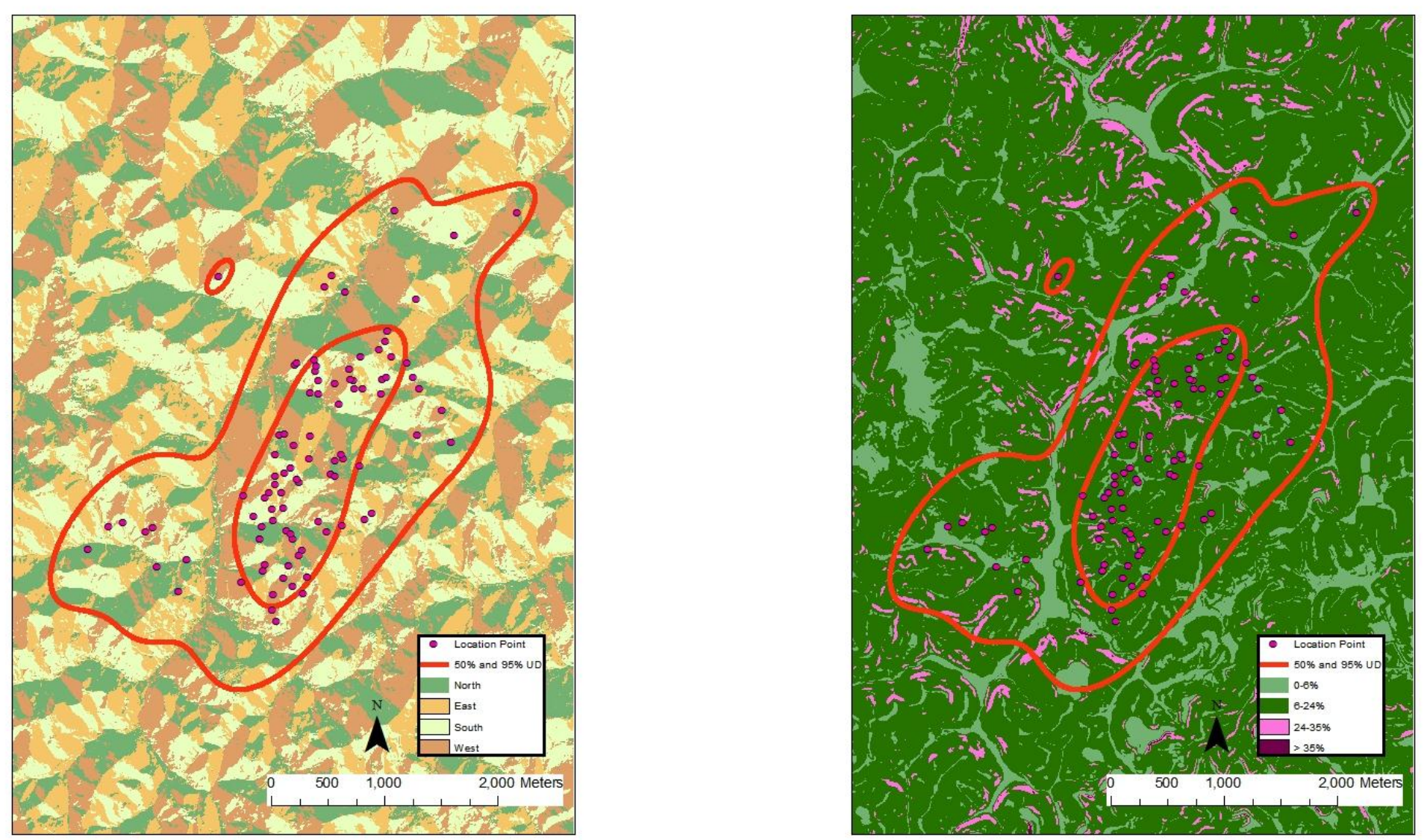
Appendix XVa. 10009 (adult, annual) - 50\% core and 95\% periphery probability contours of the annual Gaussian fixed kernel home range utilization distributions. Smoothing parameter $(h)$ determined by least squares cross validation, Taylor County, West Virginia, 2004-2007 (land use and land cover, land fragmentation maps).
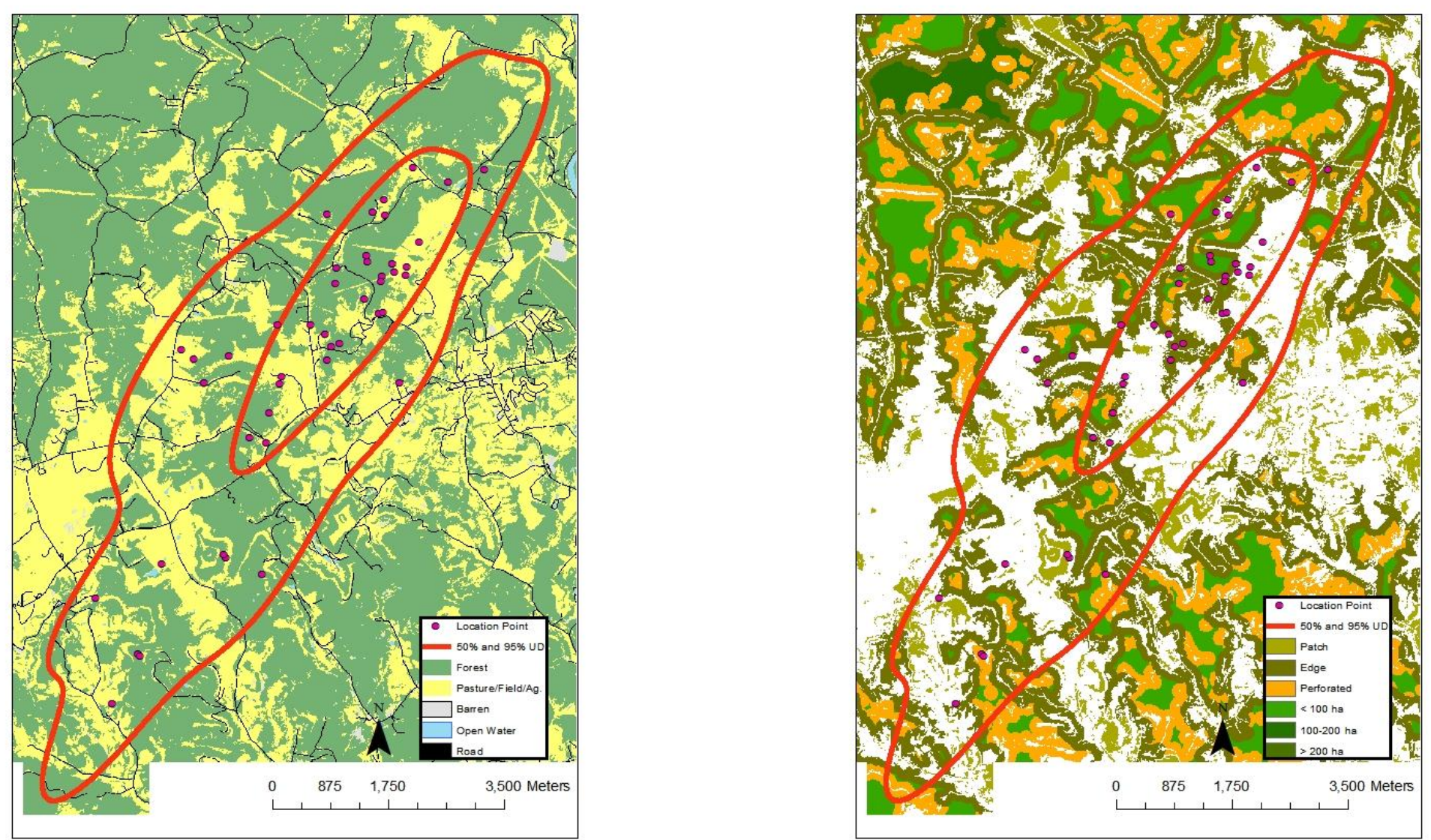
Appendix XVIa. 10009 (adult, annual) - 50\% core and 95\% periphery probability contours of the annual fixed Gaussian kernel home range utilization distributions. Smoothing parameter $(h)$ determined by least squares cross validation, Taylor County, West Virginia, 2004-2007 (aspect and slope maps).
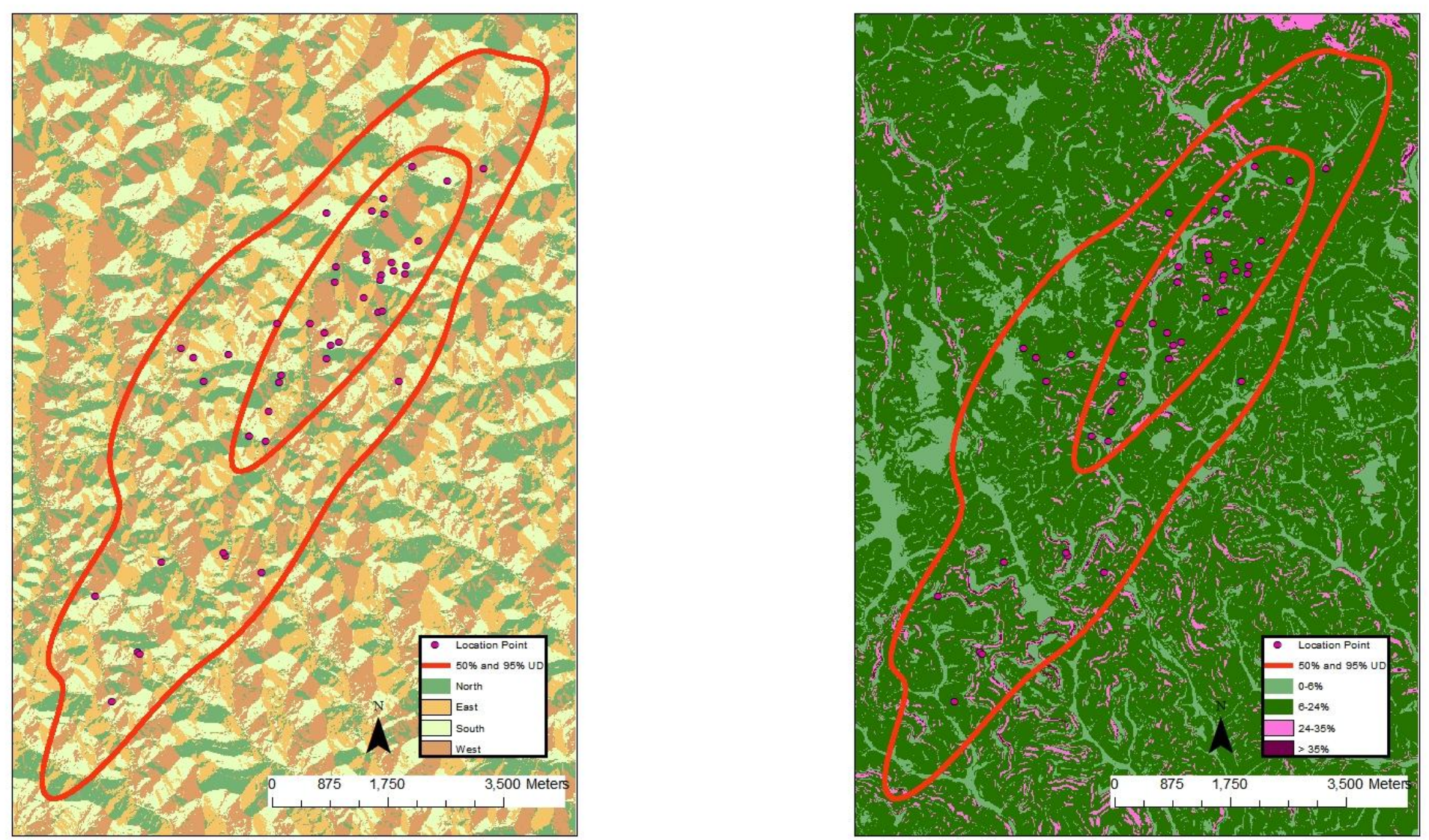
Appendix XVII a. 10010 (juvenile, annual) - 50\% core and 95\% periphery probability contours of the annual Gaussian fixed kernel home range utilization distributions. Smoothing parameter $(h)$ determined by least squares cross validation, Taylor County, West Virginia, 2004-2007 (land use and land cover, land fragmentation maps).
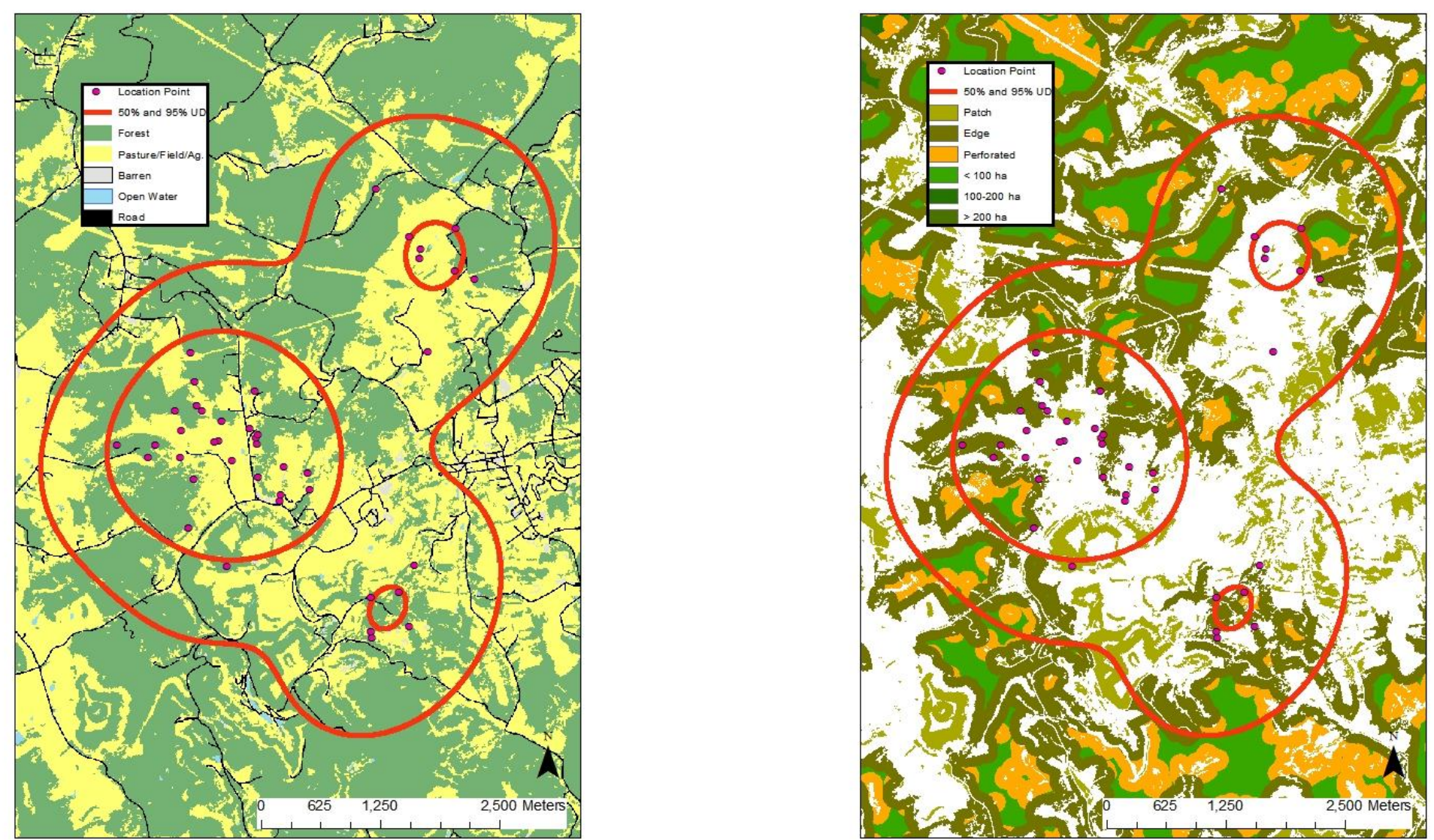
Appendix XVIII a. 10010 (juvenile, annual) - 50\% core and 95\% periphery probability contours of the annual Gaussian fixed kernel home range utilization distributions. Smoothing parameter $(h)$ determined by least squares cross validation, Taylor County, West Virginia, 2004-2007 (aspect and slope maps).
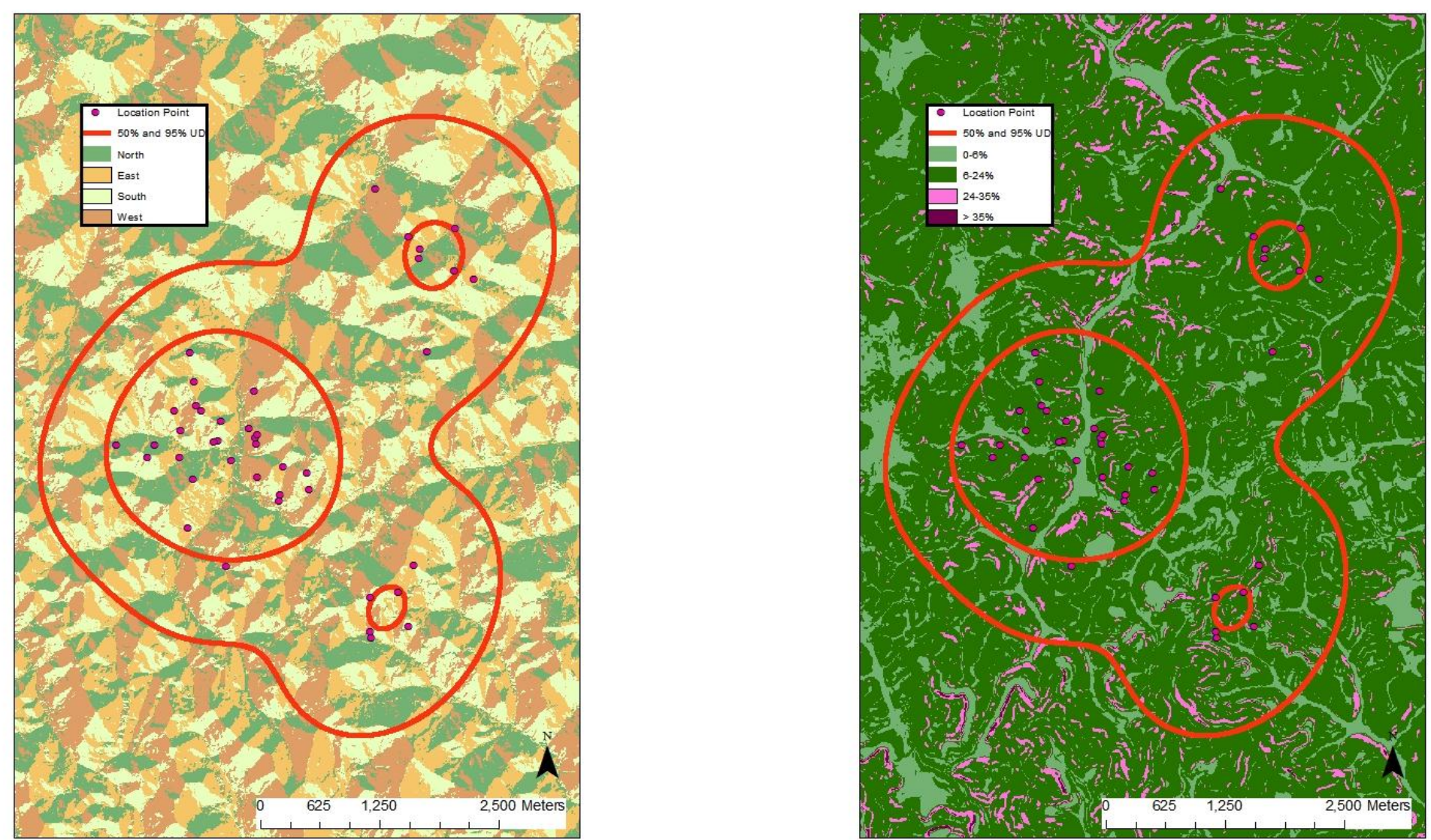
Appendix XIXa. 10011 (juvenile, annual) - 50\% core and 95\% periphery probability contours of the annual Gaussian fixed kernel home range utilization distributions. Smoothing parameter $(h)$ determined by least squares cross validation, Taylor County, West Virginia, 2004-2007 (land use and land cover, land fragmentation maps).
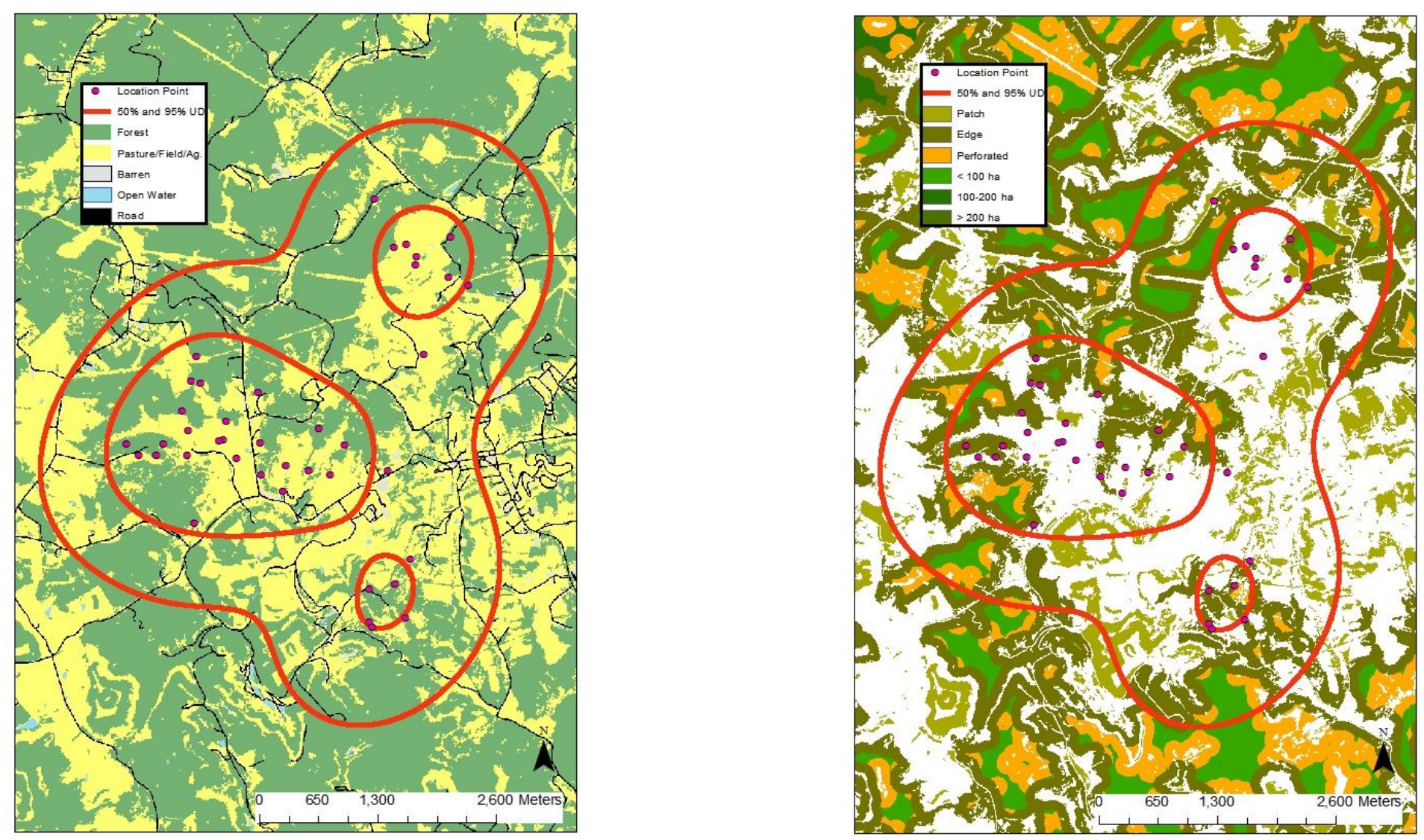
Appendix XXa. 10011 (juvenile, annual) - 50\% core and 95\% periphery probability contours of the annual Gaussian fixed kernel home range utilization distributions. Smoothing parameter $(h)$ determined by least squares cross validation, Taylor County, West Virginia, 2004-2007 (aspect and slope maps).
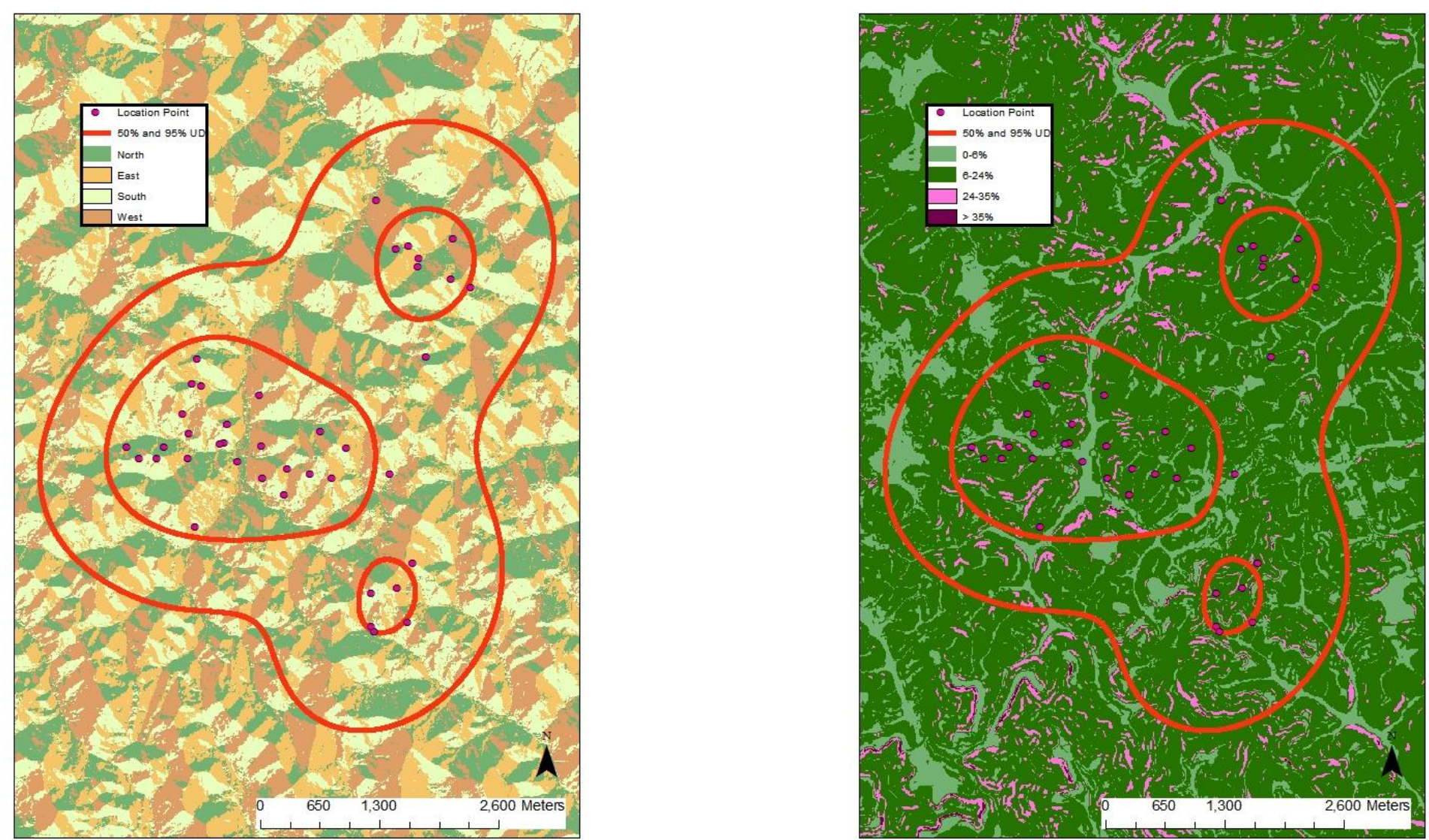
Appendix XXI a. 10012 (adult, annual) - 50\% core and 95\% periphery probability contours of the annual Gaussian fixed kernel home range utilization distributions. Smoothing parameter $(h)$ determined by least squares cross validation, Marion County, West Virginia, 2004-2007 (land use and land cover, land fragmentation maps).
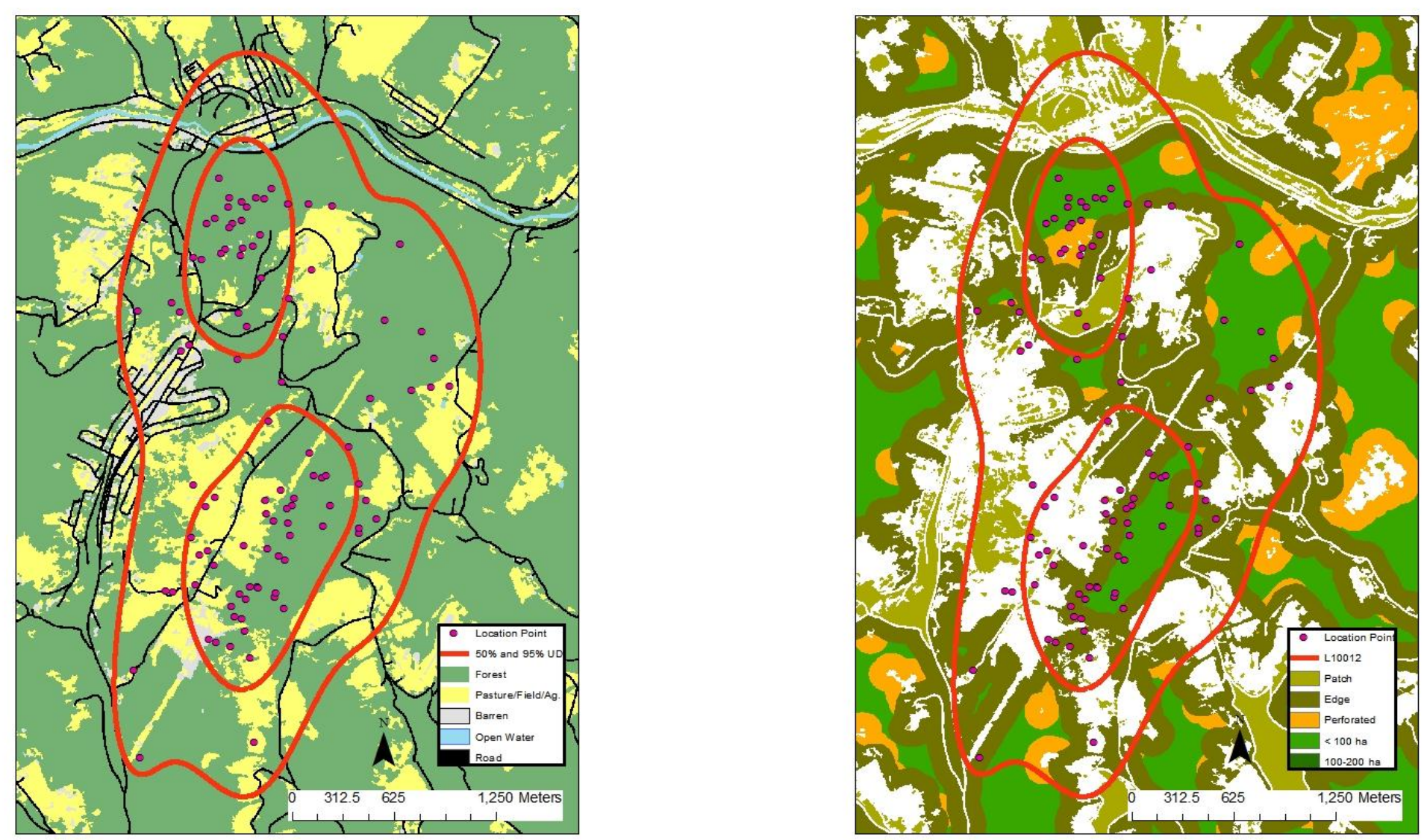
Appendix XXII $a .10012$ (adult, annual) - 50\% core and 95\% periphery probability contours of the annual Gaussian fixed kernel home range utilization distributions. Smoothing parameter $(h)$ determined by least squares cross validation, Marion County, West Virginia, 2004-2007 (aspect and slope maps).
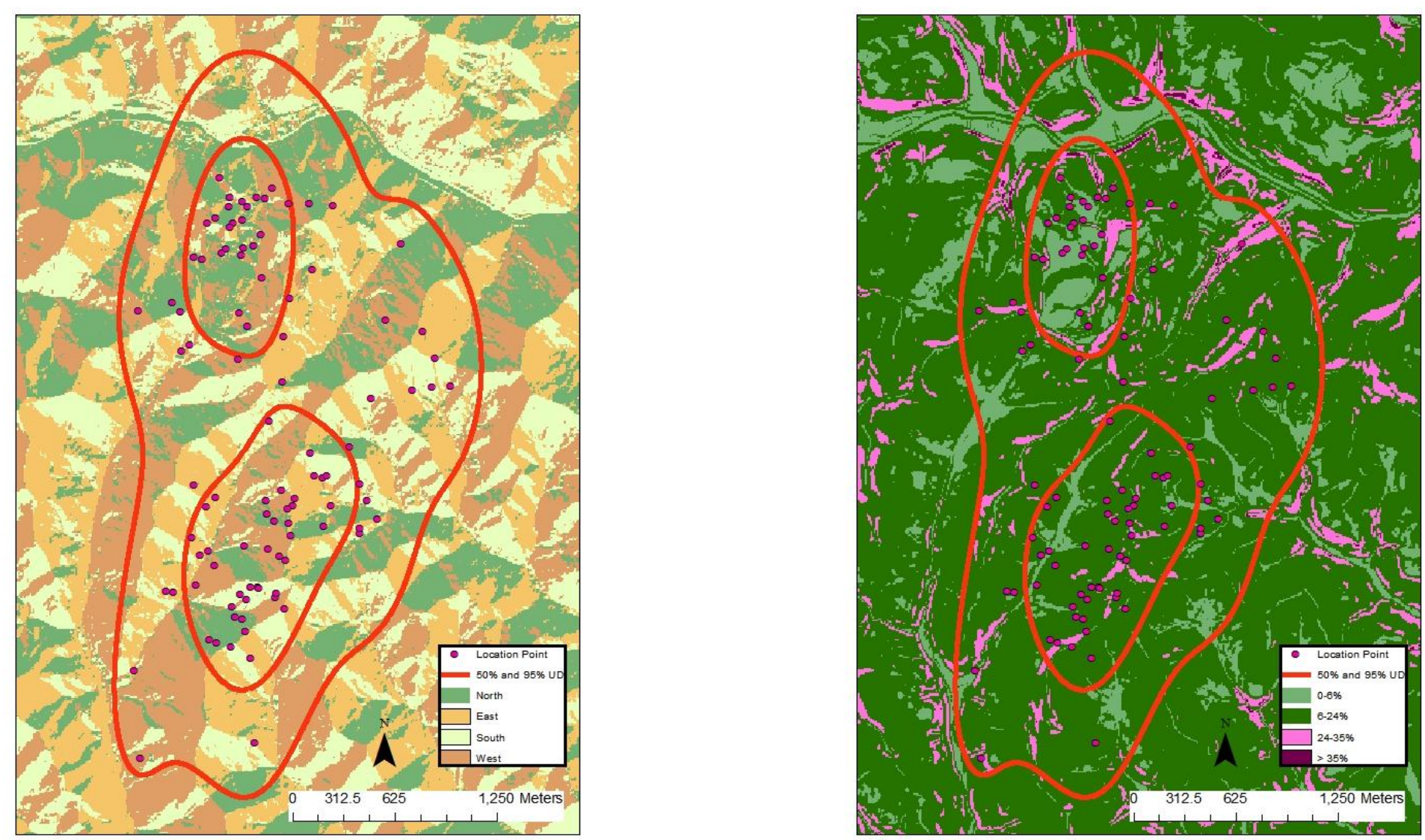
Appendix XXIII a. 10014 (juvenile, annual) - 50\% core and 95\% periphery probability contours of the annual Gaussian fixed kernel home range utilization distributions. Smoothing parameter $(h)$ determined by least squares cross validation, Marion County, West Virginia, 2004-2007 (land use and land cover, land fragmentation maps).
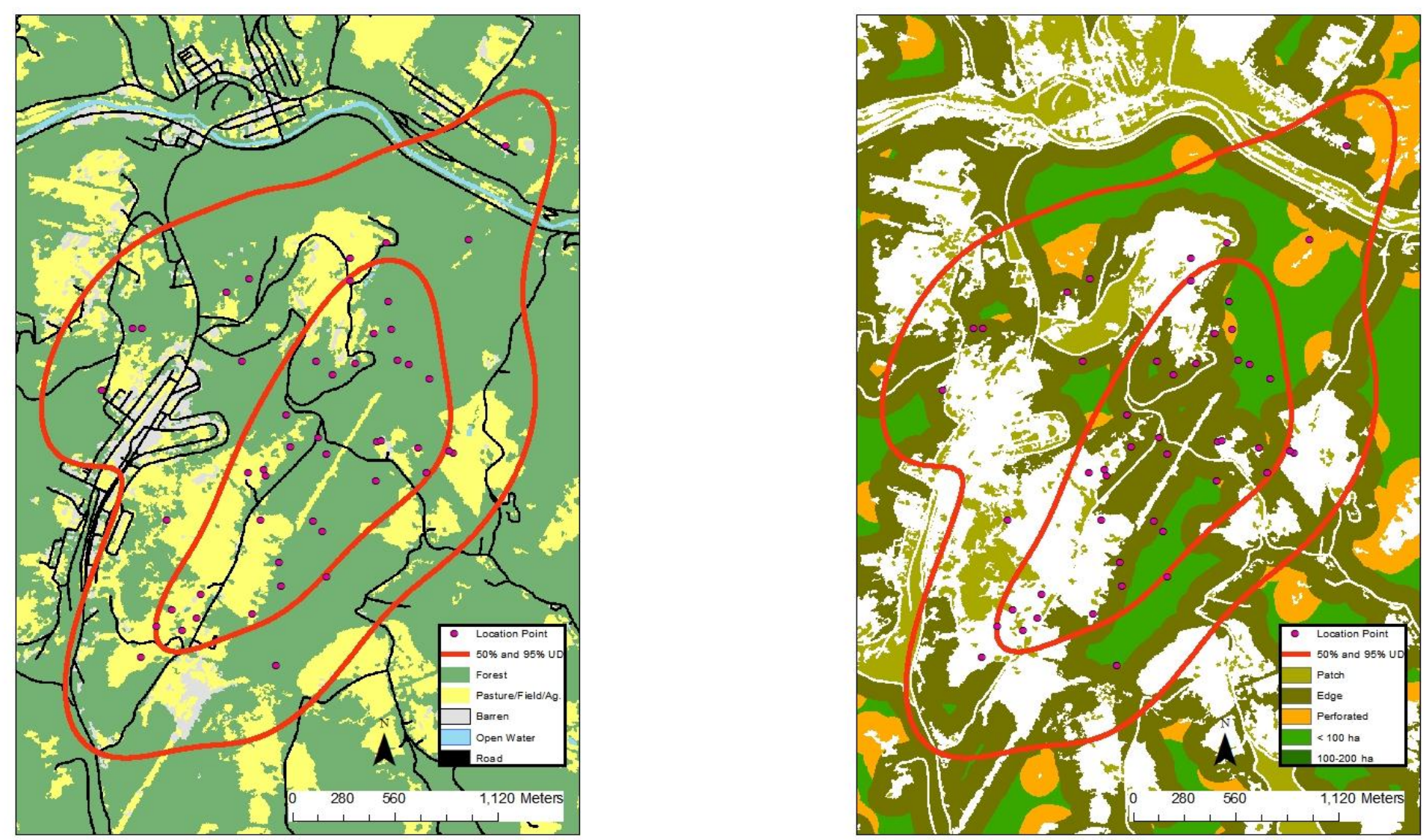
Appendix XXIVa. 10014 (juvenile, annual) - 50\% core and 95\% periphery probability contours of the annual Gaussian fixed kernel home range utilization distributions. Smoothing parameter $(h)$ determined by least squares cross validation, Marion County, West Virginia, 2004-2007 (aspect and slope maps).
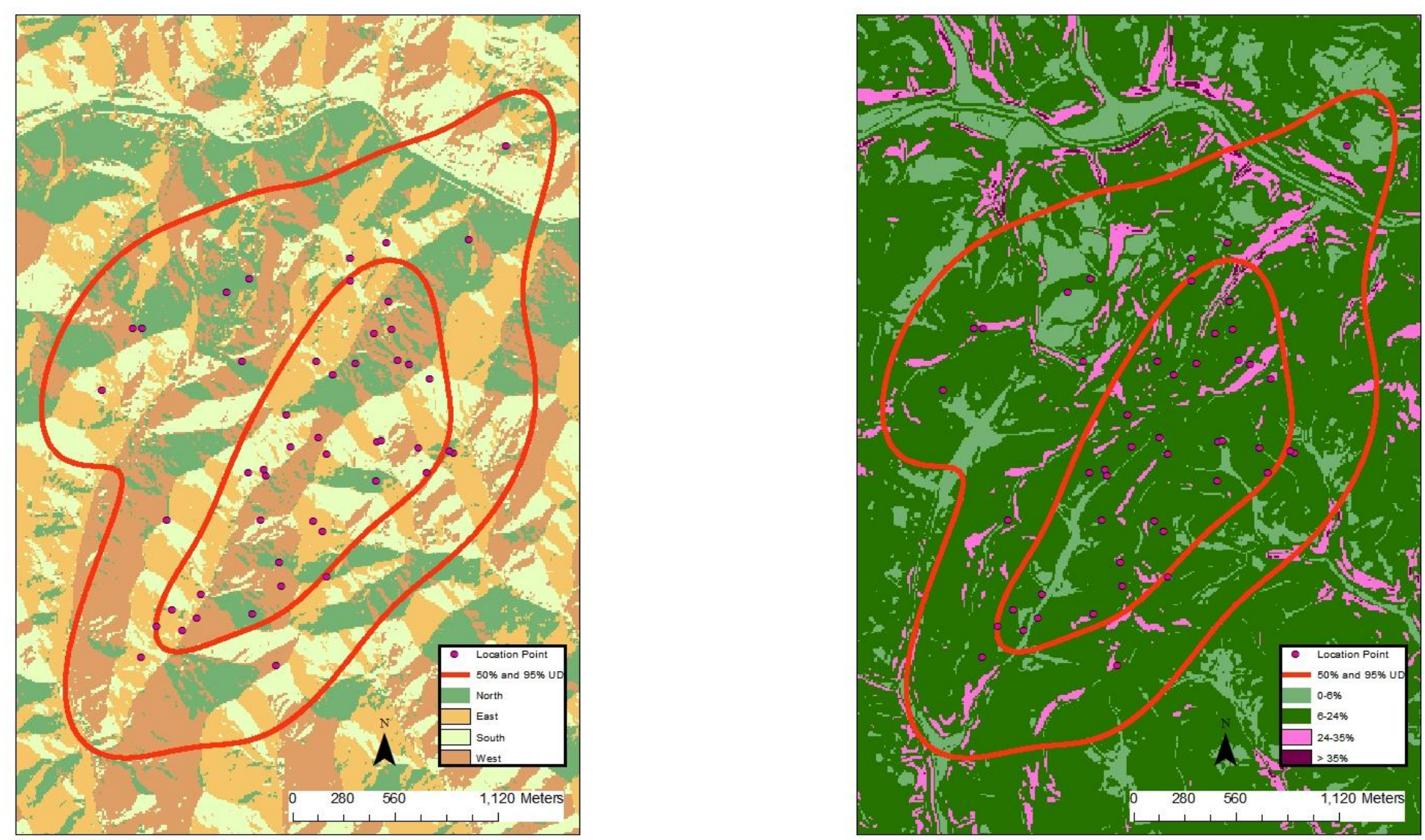
Appendix XXVa. 10015 (adult, fall) - 50\% core and 95\% periphery probability contours of the fall Gaussian fixed kernel home range utilization distributions. Smoothing parameter $(h)$ determined by least squares cross validation, Marion County, West Virginia, 2004 2007 (land use and land cover, land fragmentation maps).
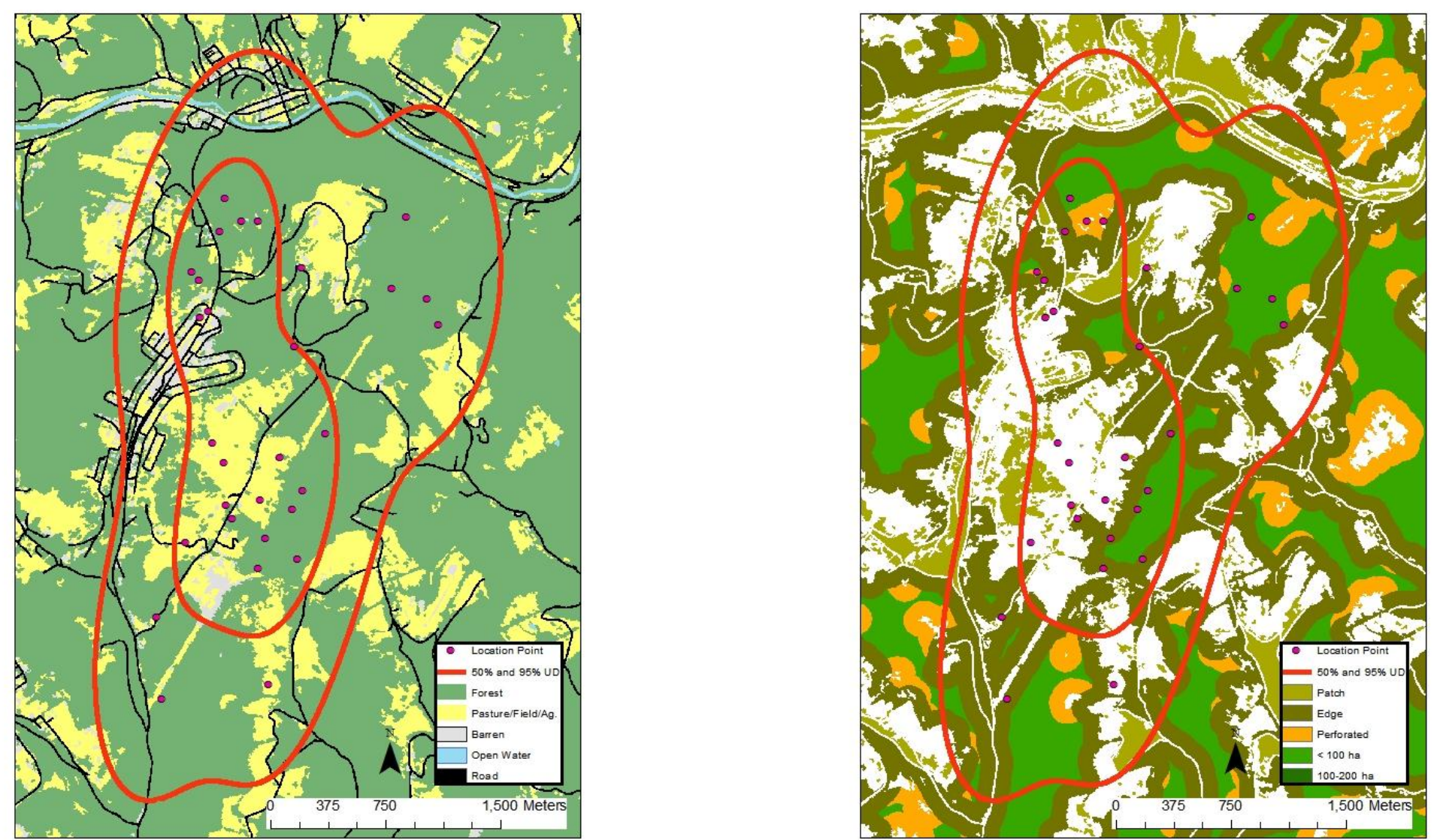
Appendix XXVIa. 10015 (adult, fall) - 50\% core and 95\% periphery probability contours of the fall Gaussian fixed kernel home range utilization distributions. Smoothing parameter $(h)$ determined by least squares cross validation, Marion County, West Virginia, 20042007 (aspect and slope maps).
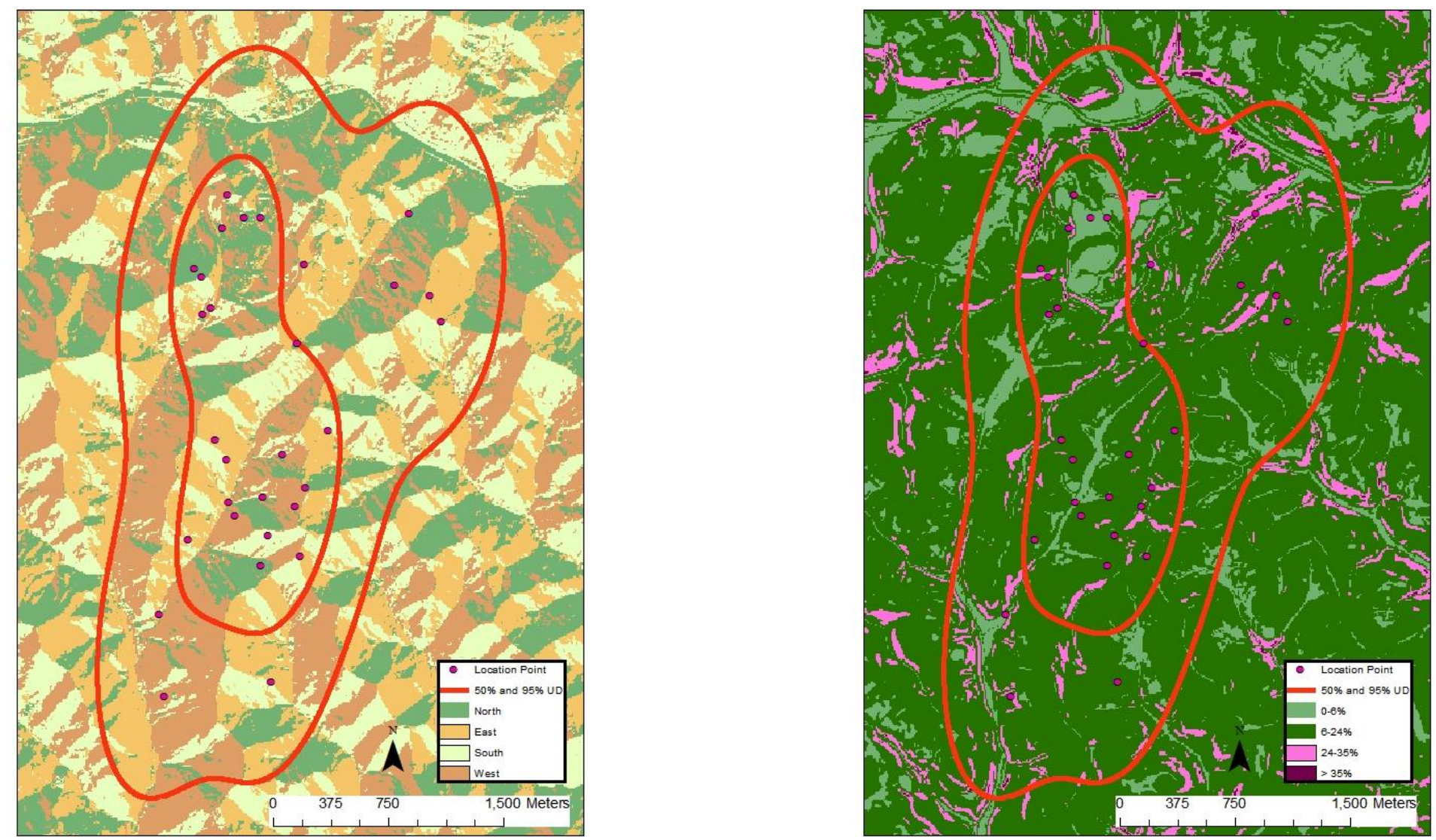
Appendix XXVII $a$. 10016 (adult, spring) - 50\% core and 95\% periphery probability contours of the spring Gaussian fixed kernel home range utilization distributions. Smoothing parameter $(h)$ determined by least squares cross validation, Marion County, West Virginia, 2004-2007 (land use and land cover, land fragmentation maps).
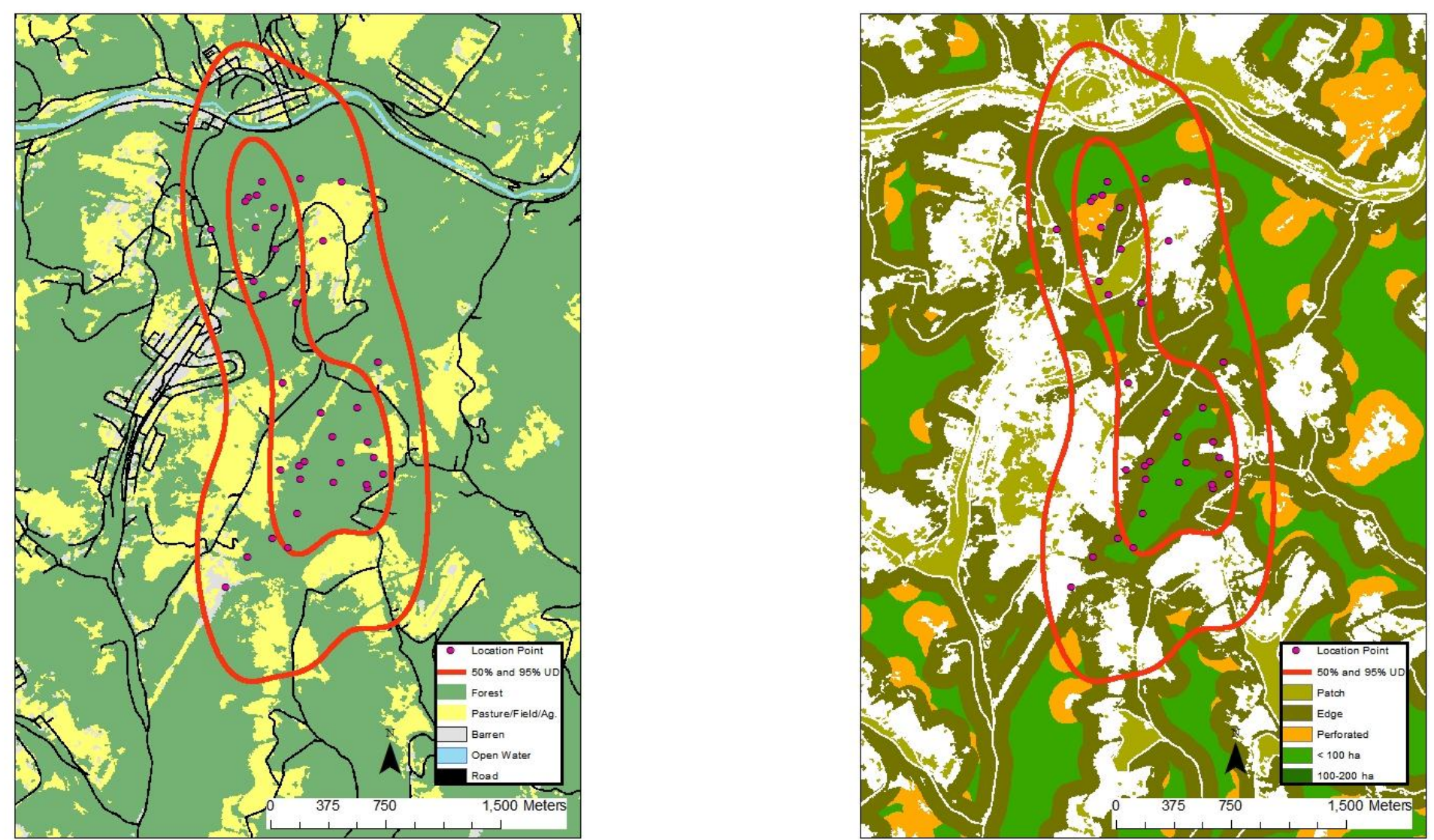
Appendix XXVIIIa. 10016 (adult, spring) - 50\% core and 95\% periphery probability contours of the spring Gaussian fixed kernel home range utilization distributions. Smoothing parameter $(h)$ determined by least squares cross validation, Marion County, West Virginia, 2004-2007 (aspect and slope maps).
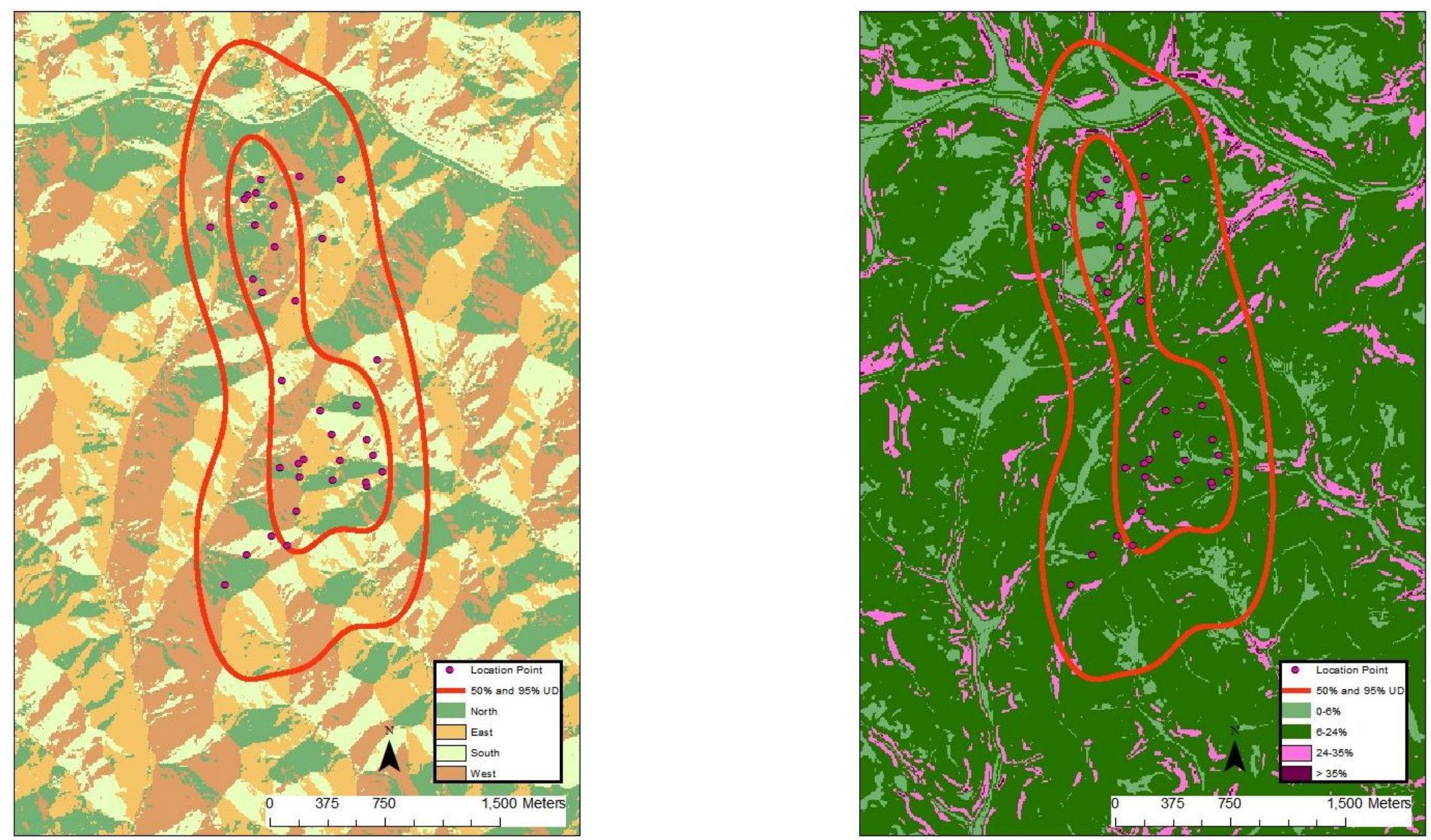
Appendix XXIXa. 10017 (adult, spring-summer) - 50\% core and 95\% periphery probability contours of the spring-summer Gaussian fixed kernel home range utilization distributions. Smoothing parameter $(h)$ determined by least squares cross validation, Marion County, West Virginia, 2004-2007 (land use and land cover, land fragmentation maps).
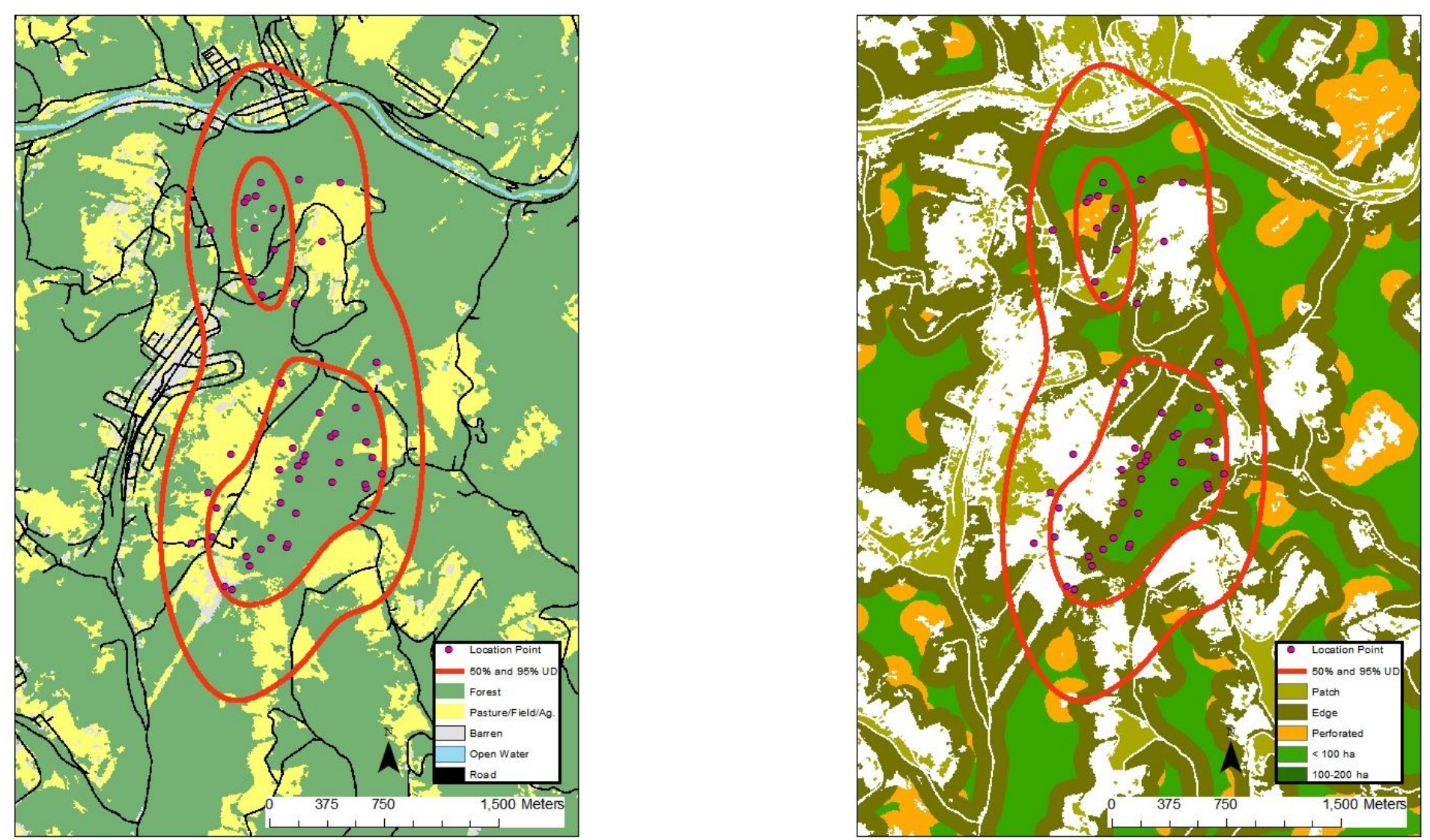
Appendix XXXa. 10017 (adult, spring-summer) - 50\% core and 95\% periphery probability contours of the spring-summer Gaussian fixed kernel home range utilization distributions. Smoothing parameter $(h)$ determined by least squares cross validation, Marion County, West Virginia, 2004-2007 (aspect and slope maps).
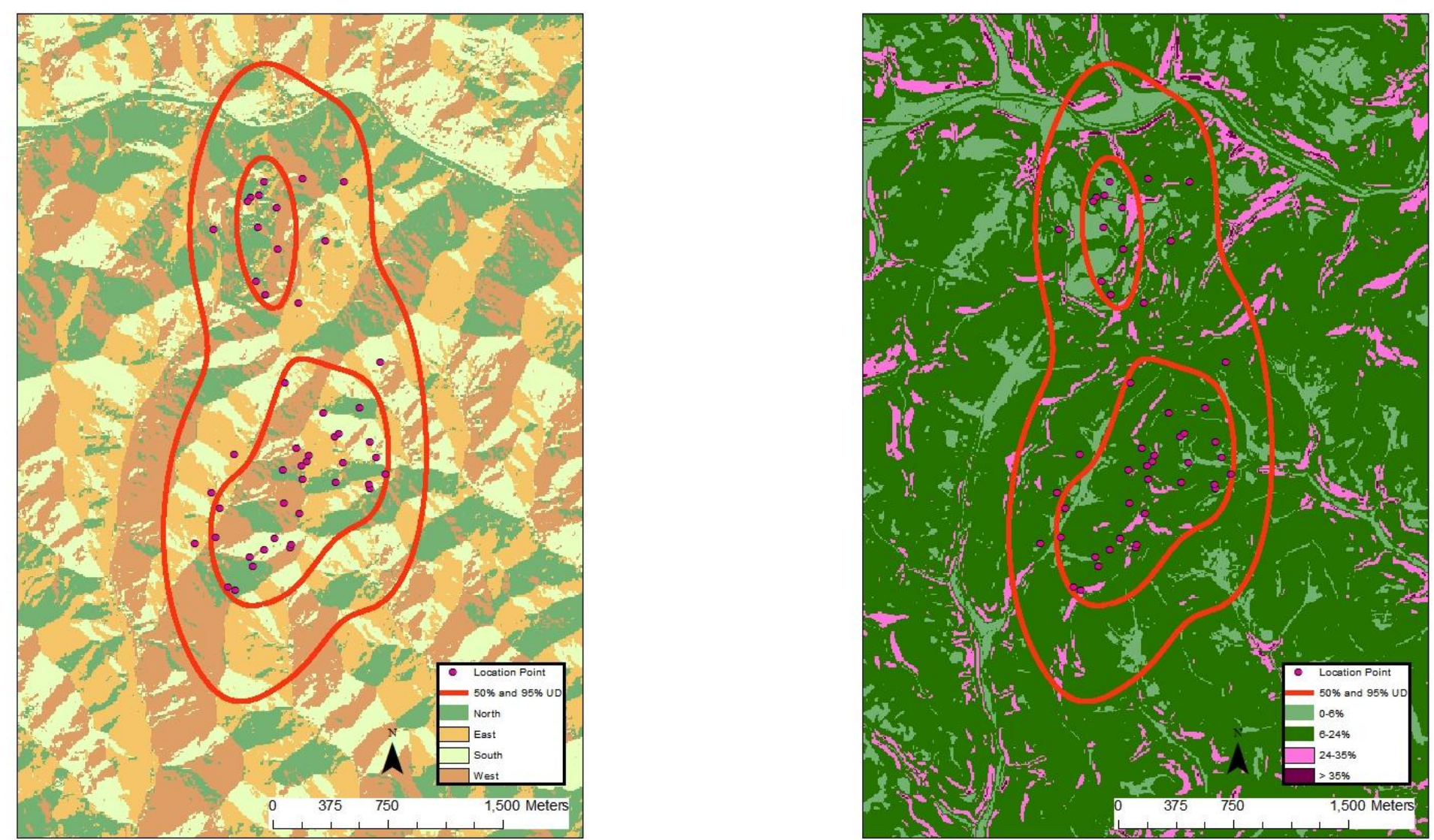
Appendix XXXIa. 10018 (adult, fall-winter) - 50\% core and 95\% periphery probability contours of the fall-winter Gaussian fixed kernel home range utilization distributions. Smoothing parameter $(h)$ determined by least squares cross validation, Marion County, West Virginia, 2004-2007 (land use and land cover, land fragmentation maps).
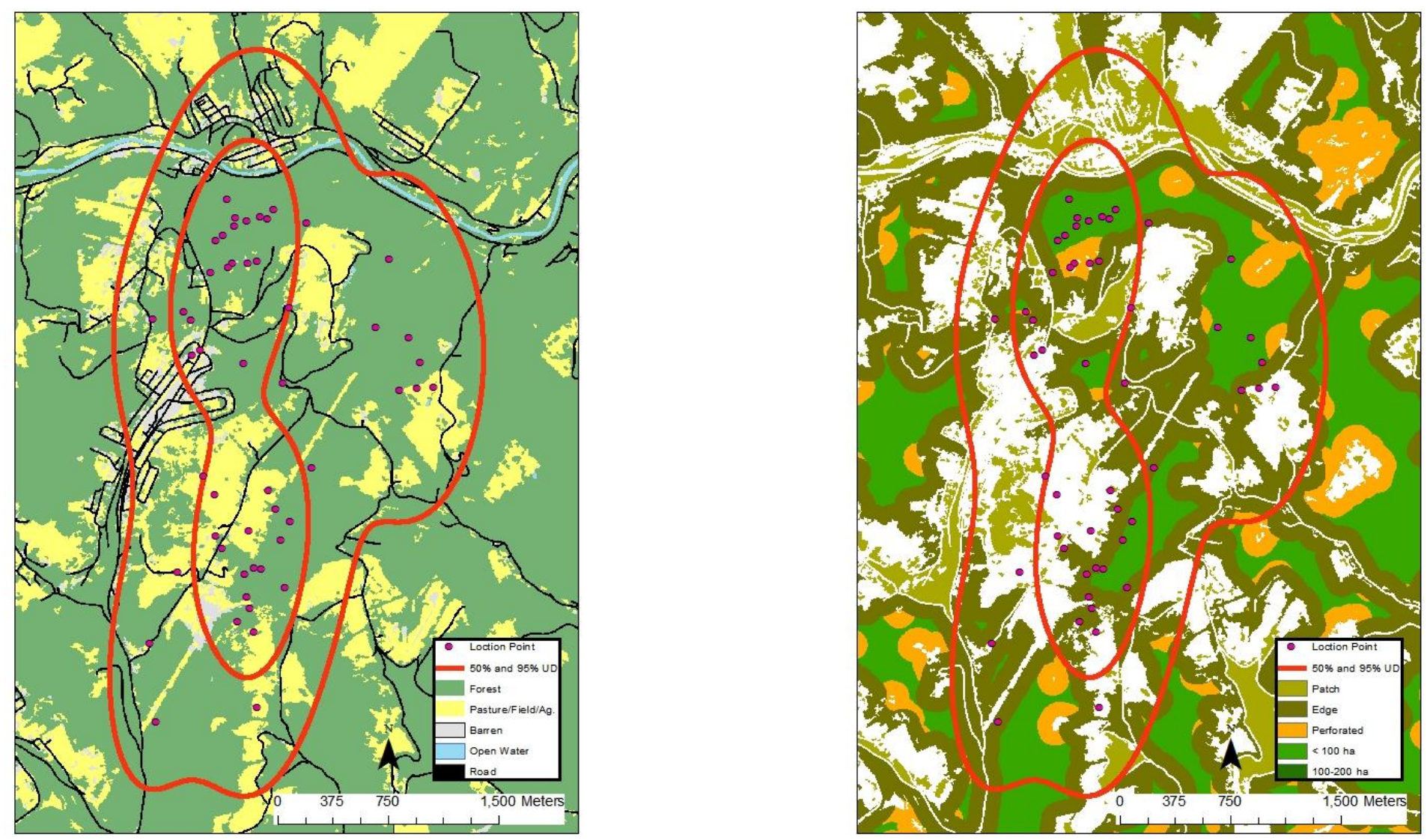
Appendix XXXIIa. 10018 (adult, fall-winter) - 50\% core and 95\% periphery probability contours of the fall-winter Gaussian fixed kernel home range utilization distributions. Smoothing parameter $(h)$ determined by least squares cross validation, Marion County, West Virginia, 2004-2007 (aspect and slope maps).
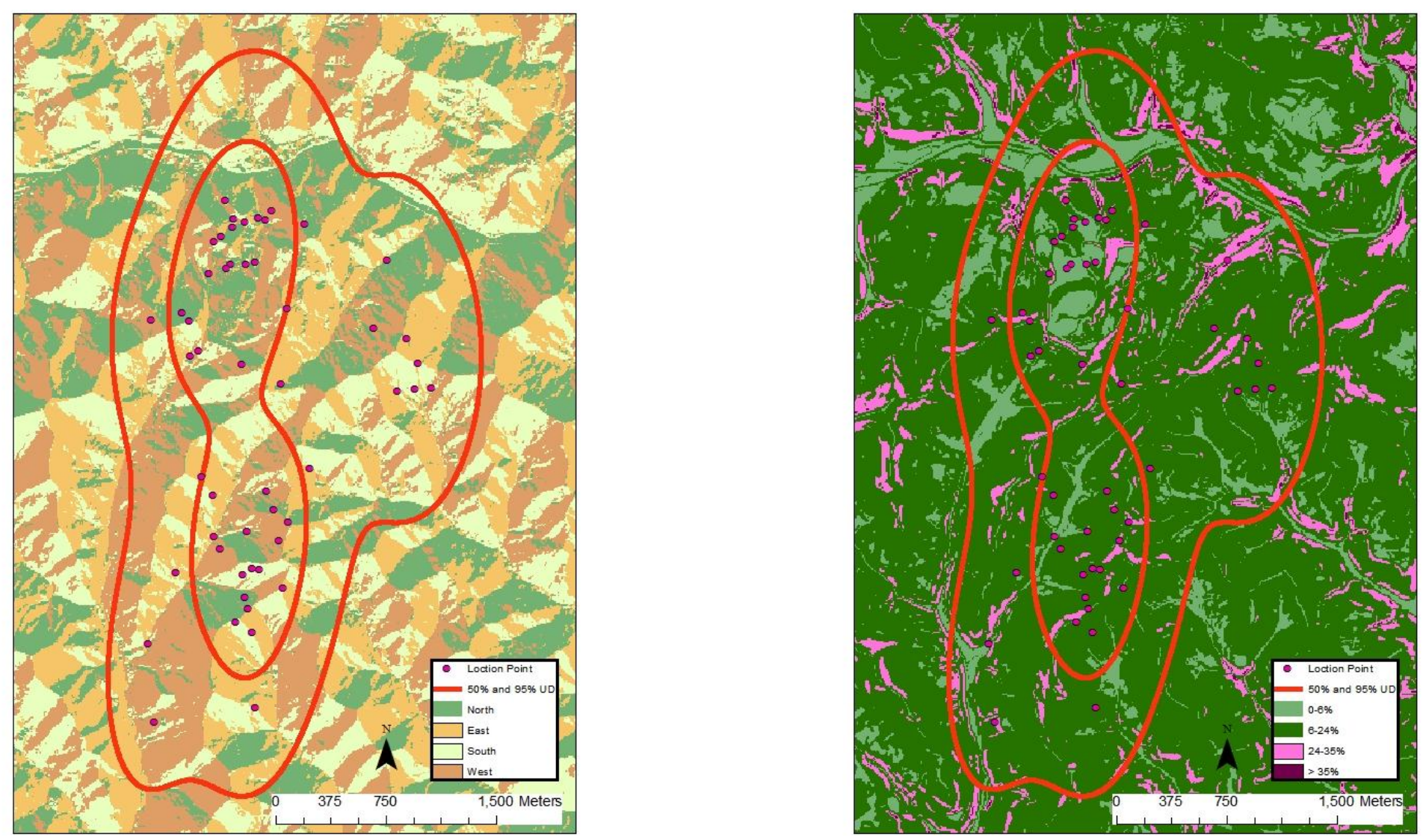
Appendix XXXIII a. 10019 (adult, annual) - 50\% core and 95\% periphery probability contours of the annual Gaussian fixed kernel home range utilization distributions. Smoothing parameter $(h)$ determined by least squares cross validation, Marion County, West Virginia, 2004-2007 (land use and land cover, land fragmentation maps).
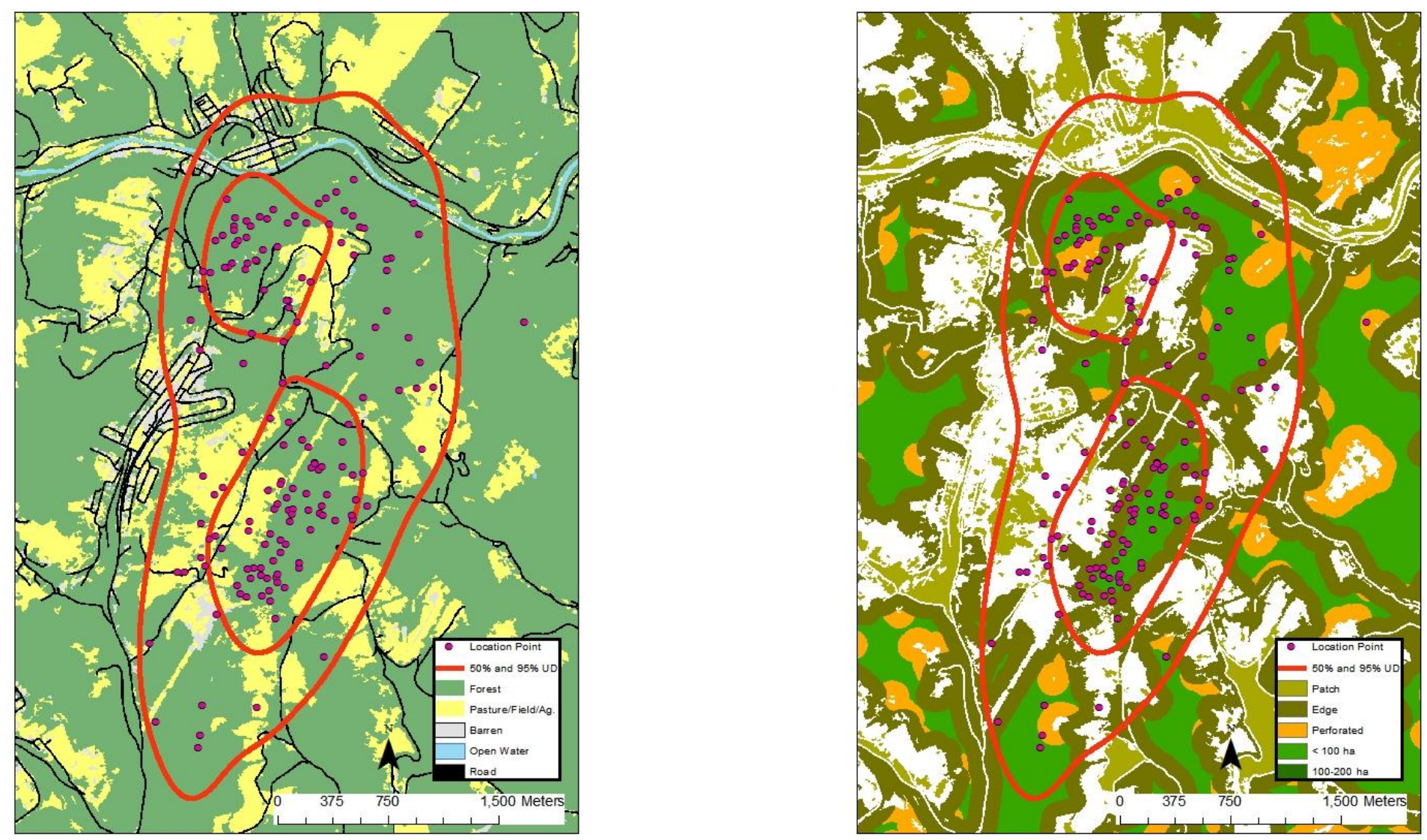
Appendix XXXIVa. 10019 (adult, annual) - 50\% core and 95\% periphery probability contours of the annual Gaussian fixed kernel home range utilization distributions. Smoothing parameter $(h)$ determined by least squares cross validation, Marion County, West Virginia, 2004-2007 (aspect and slope maps).
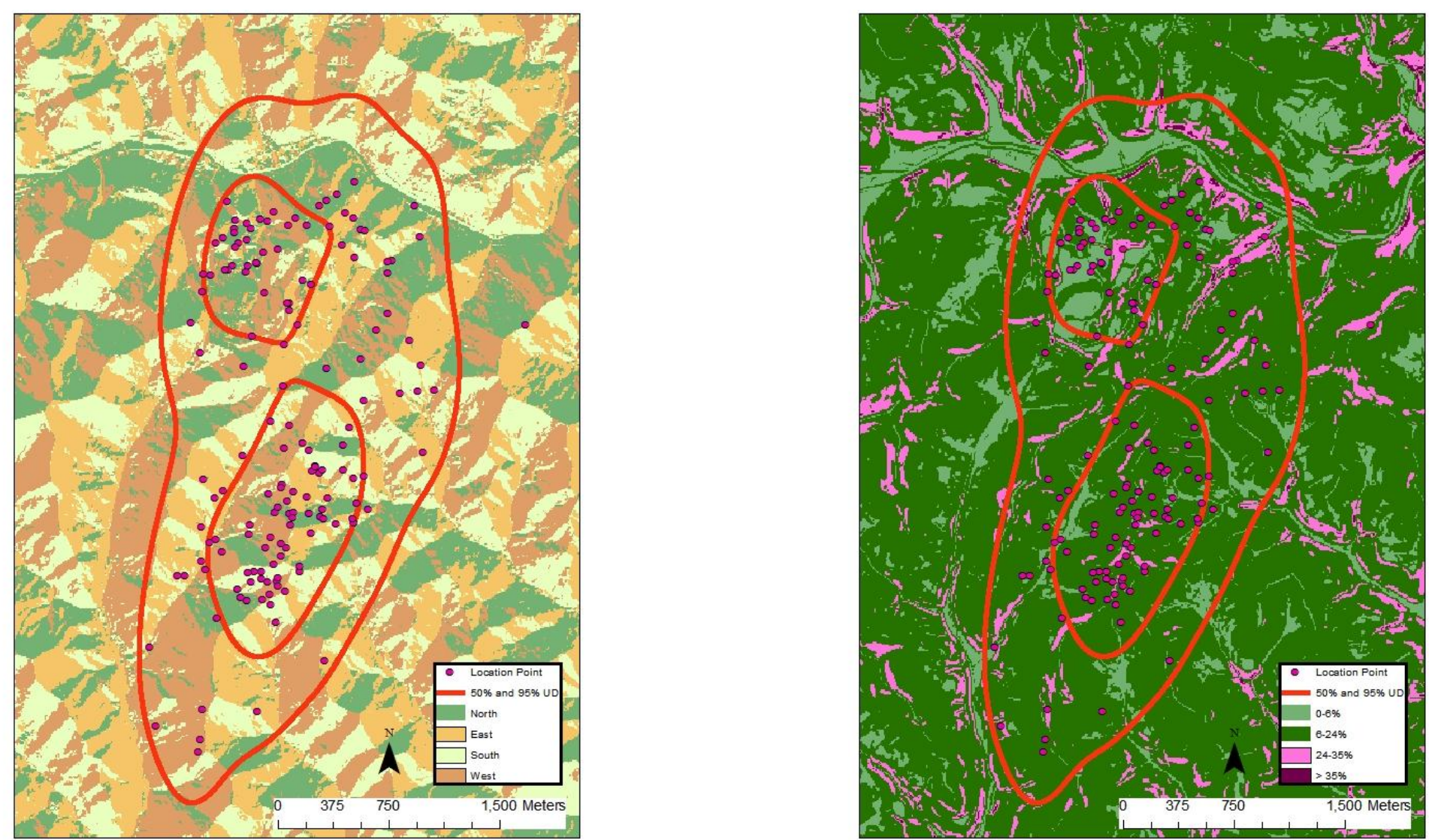
Appendix XXXVa. 10021 (adult, fall) - 50\% core and 95\% periphery probability contours of the fall Gaussian fixed kernel home range utilization distributions. Smoothing parameter $(h)$ determined by least squares cross validation, Marion County, West Virginia, 2004-2007 (land use and land cover, land fragmentation maps).
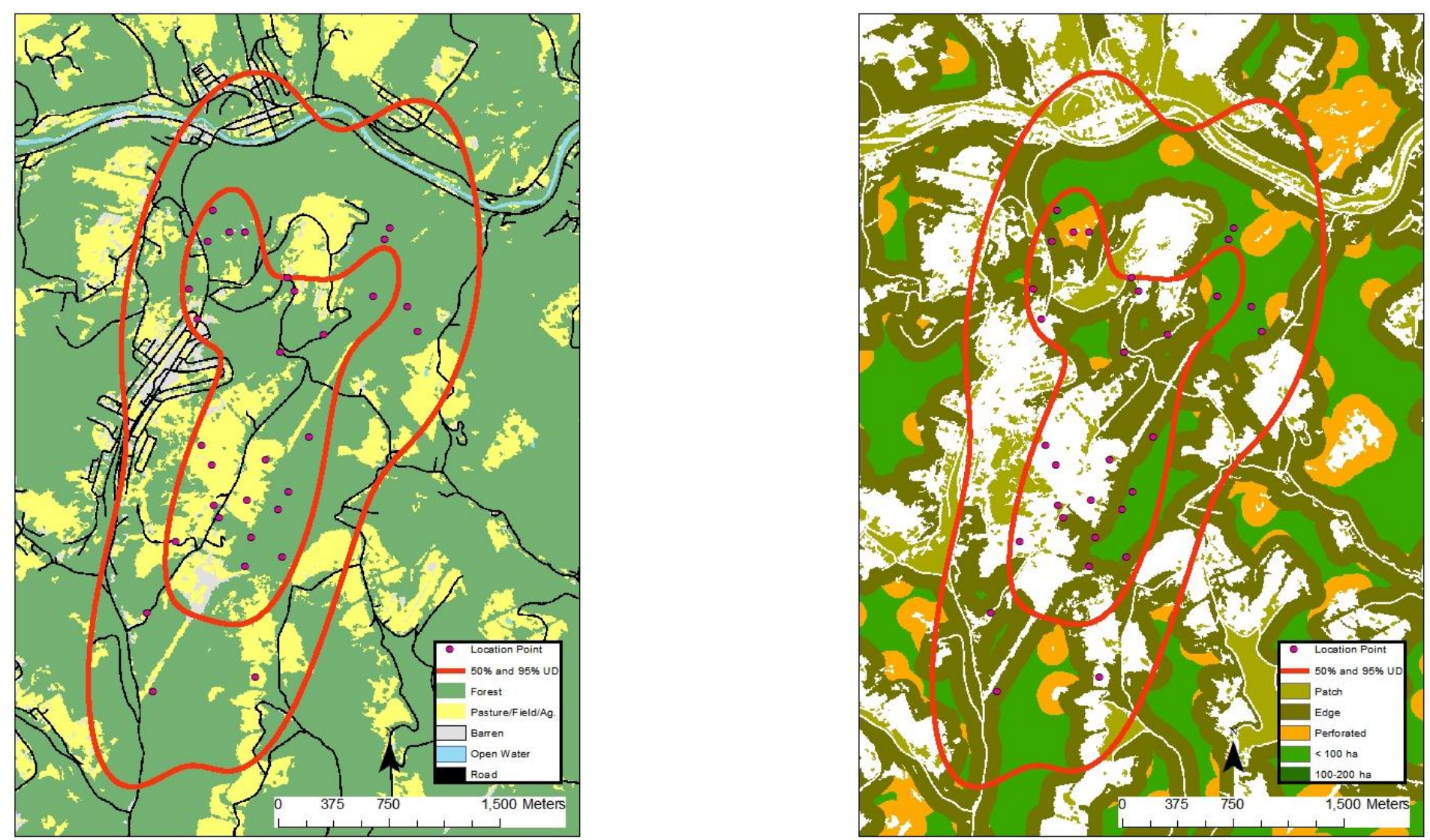
Appendix XXXVIa. 10021 (adult, fall) - 50\% core and 95\% periphery probability contours of the fall Gaussian fixed kernel home range utilization distributions. Smoothing parameter $(h)$ determined by least squares cross validation, Marion County, West Virginia, 2004-2007 (aspect and slope maps).
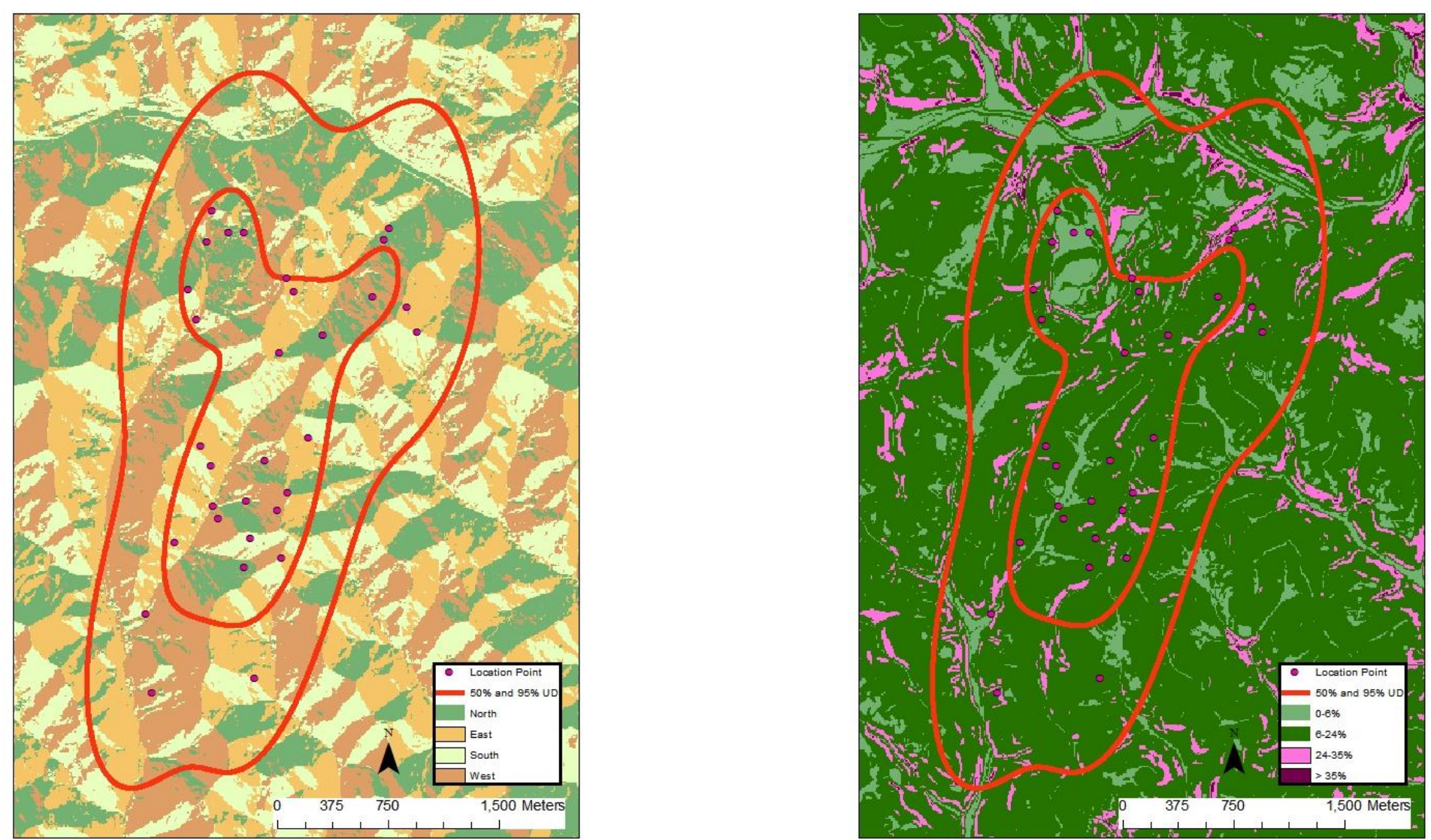
Appendix XXXVII a. 10022 (adult, fall-winter) - 50\% core and 95\% periphery probability contours of the fall-winter Gaussian fixed kernel home range utilization distributions. Smoothing parameter $(h)$ determined by least squares cross validation, Marion County, West Virginia, 2004-2007 (land use and land cover, land fragmentation maps).
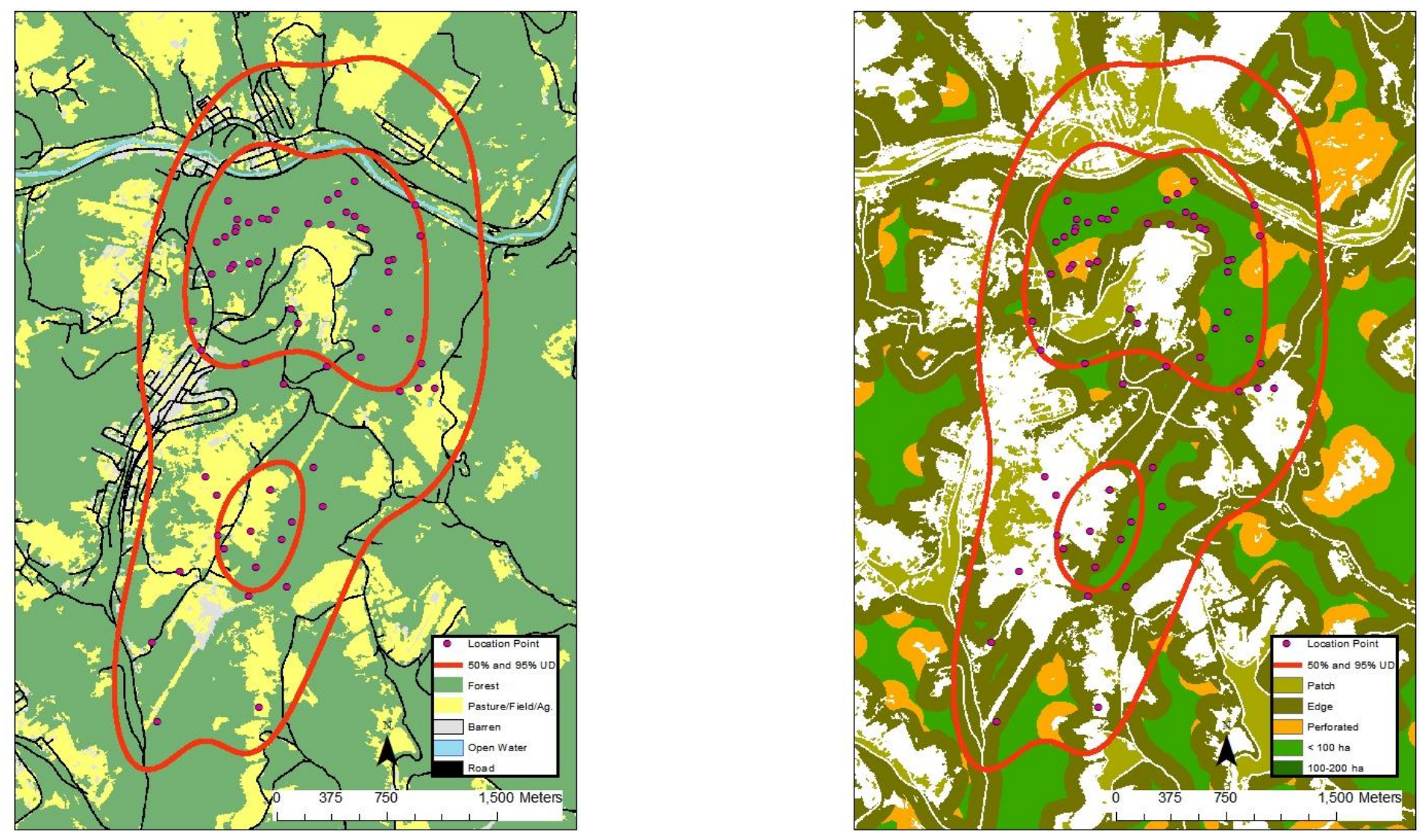
Appendix XXXVIIIa. 10022 (adult, fall-winter) - 50\% core and 95\% periphery probability contours of the fall-winter Gaussian fixed kernel home range utilization distributions. Smoothing parameter $(h)$ determined by least squares cross validation, Marion County, West Virginia, 2004-2007 (aspect and slope maps).
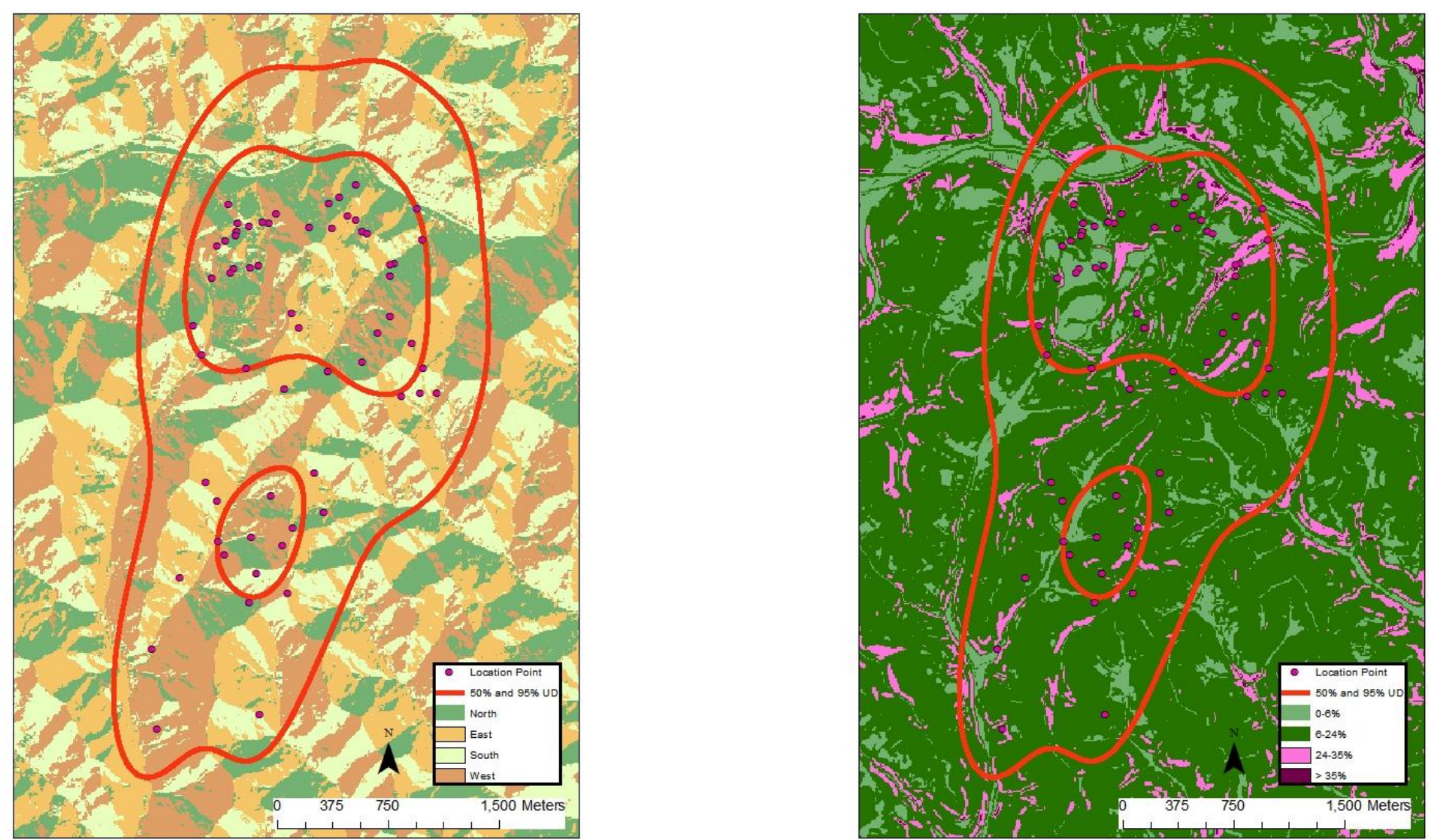
Appendix XXXIXa. 10023 (juvenile, annual) - 50\% core and 95\% periphery probability contours of the annual Gaussian fixed kernel home range utilization distributions. Smoothing parameter $(h)$ determined by least squares cross validation, Marion County, West Virginia, 2004-2007 (land use and land cover, land fragmentation maps).
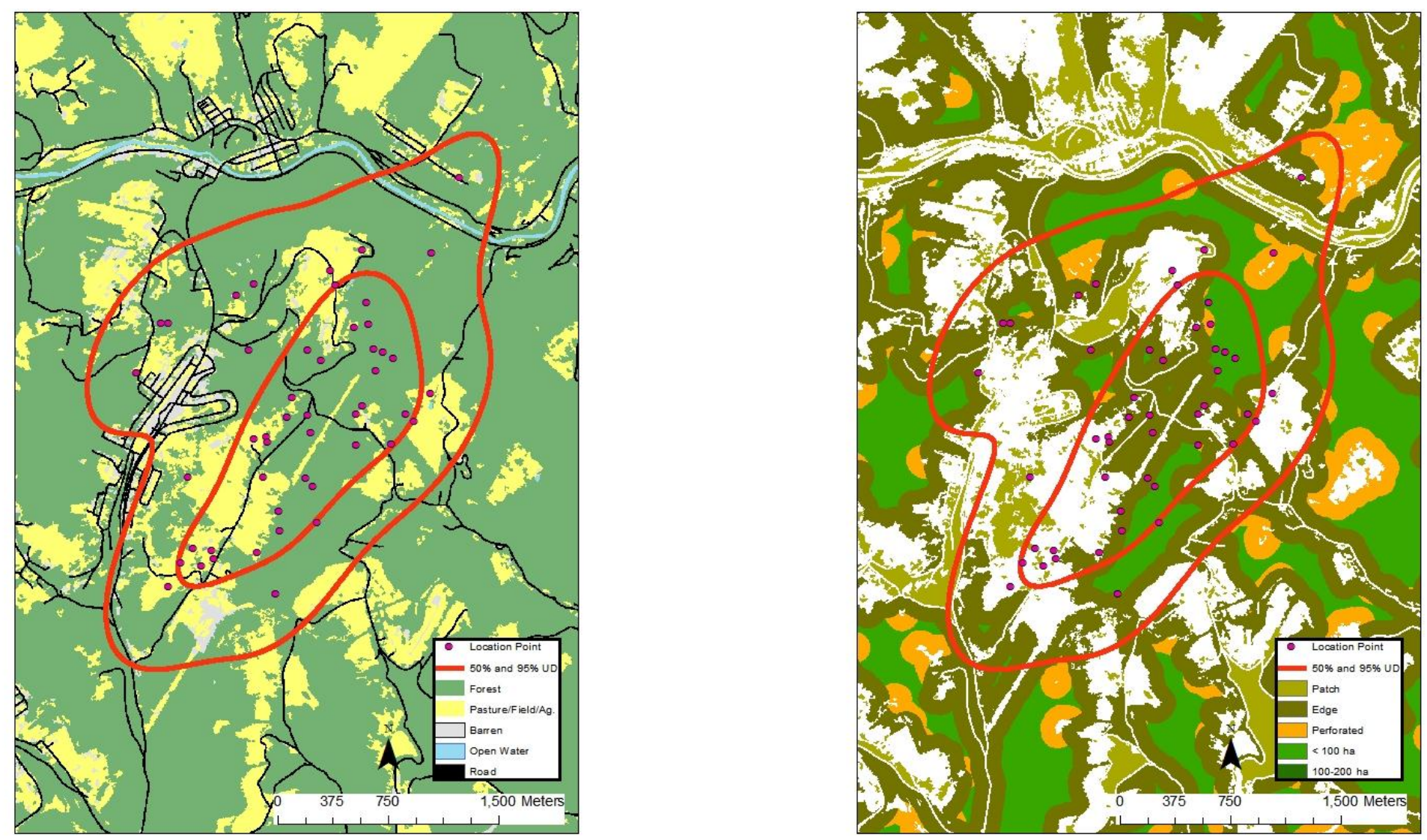
Appendix XLa. 10023 (juvenile, annual) - 50\% core and 95\% periphery probability contours of the annual Gaussian fixed kernel home range utilization distributions. Smoothing parameter $(h)$ determined by least squares cross validation, Marion County, West Virginia, 2004-2007 (aspect and slope maps).
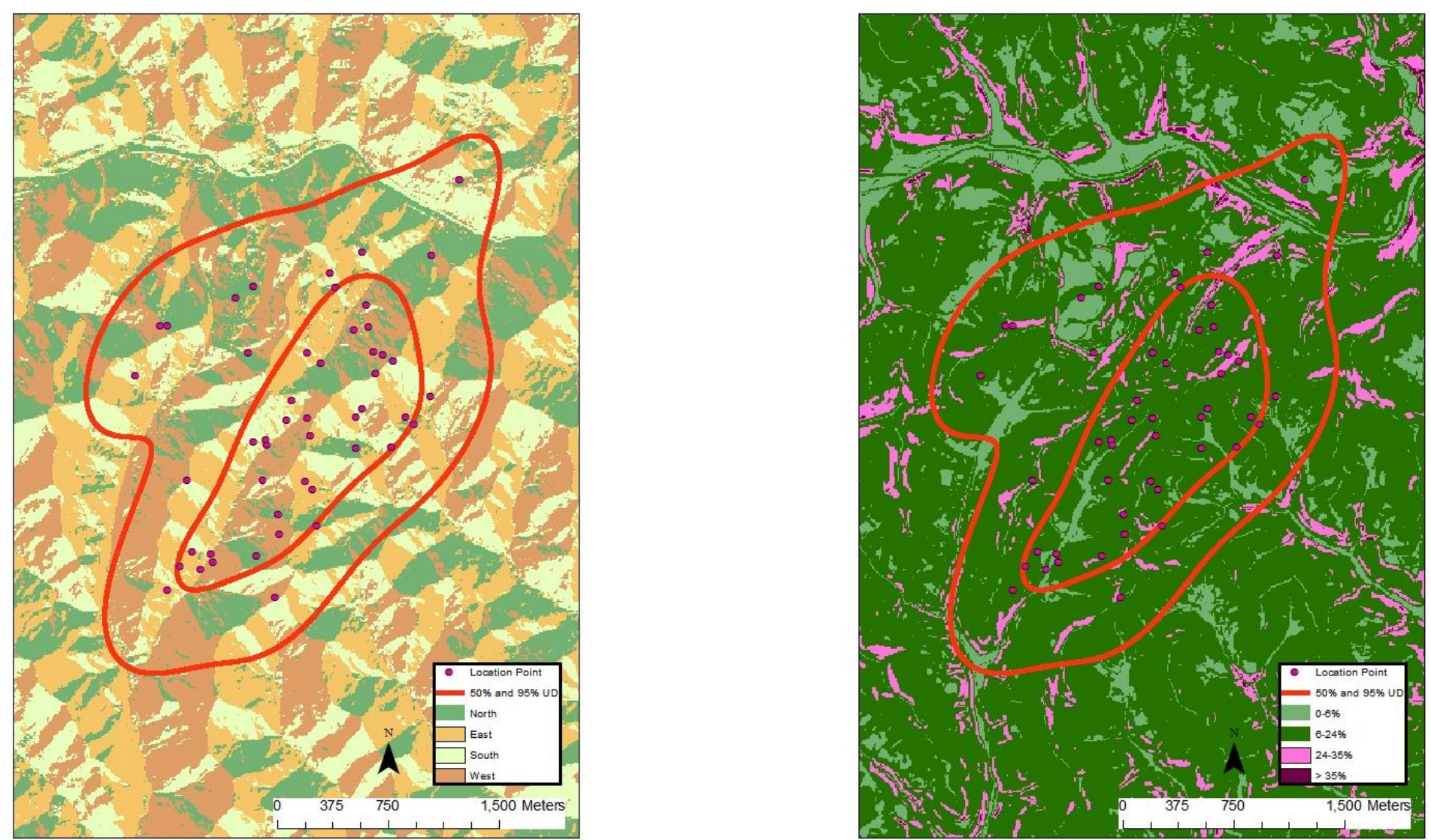
Appendix XLIa. 10024 (adult, spring) - 50\% core and 95\% periphery probability contours of the spring Gaussian fixed kernel home range utilization distributions. Smoothing parameter $(h)$ determined by least squares cross validation, Marion County, West Virginia, 2004-2007 (land use and land cover, land fragmentation maps).
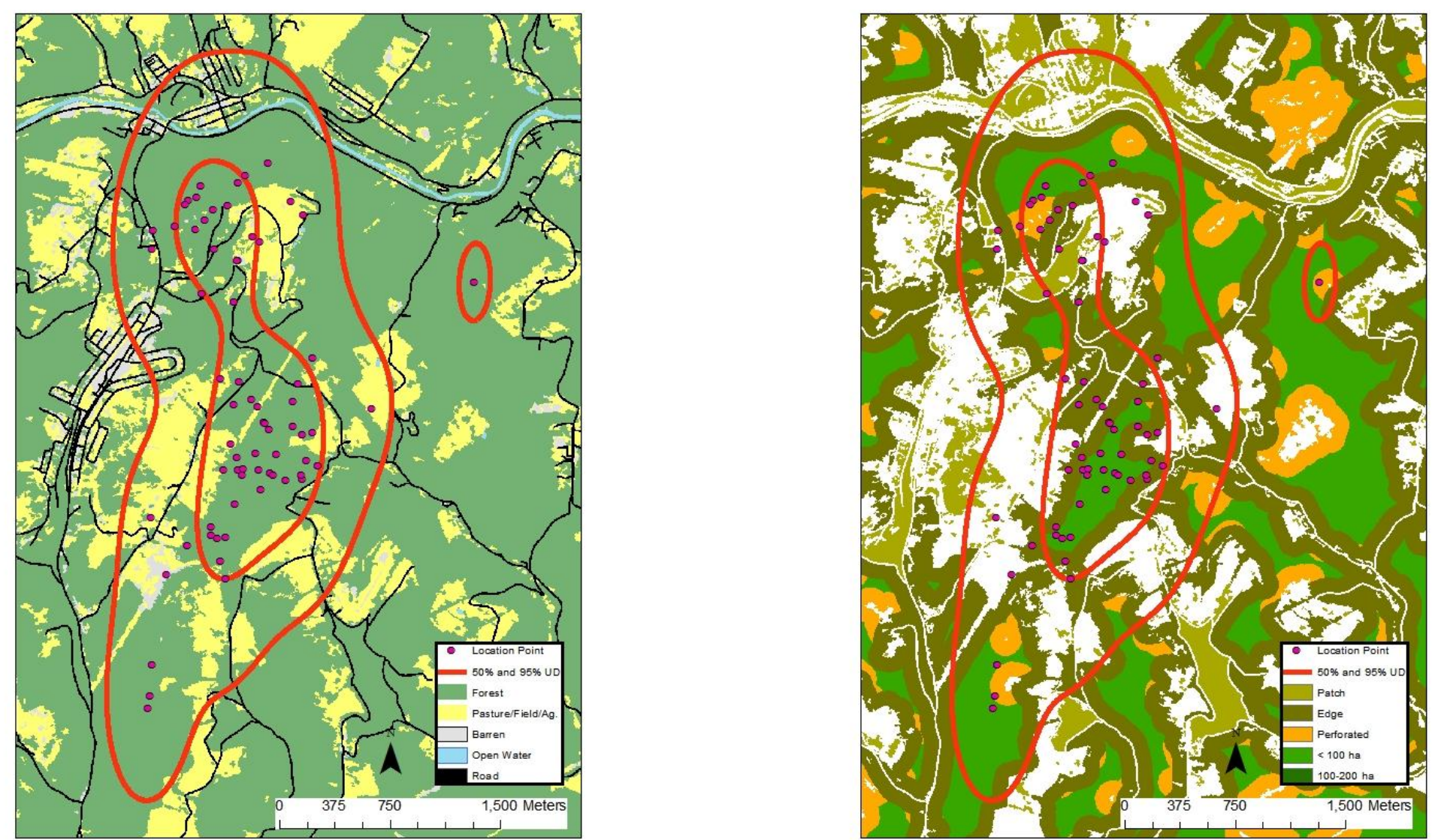
Appendix XLII a. 10024 (adult, spring) - 50\% core and 95\% periphery probability contours of the spring Gaussian fixed kernel home range utilization distributions. Smoothing parameter $(h)$ determined by least squares cross validation, Marion County, West Virginia, 2004-2007 (aspect and slope maps).
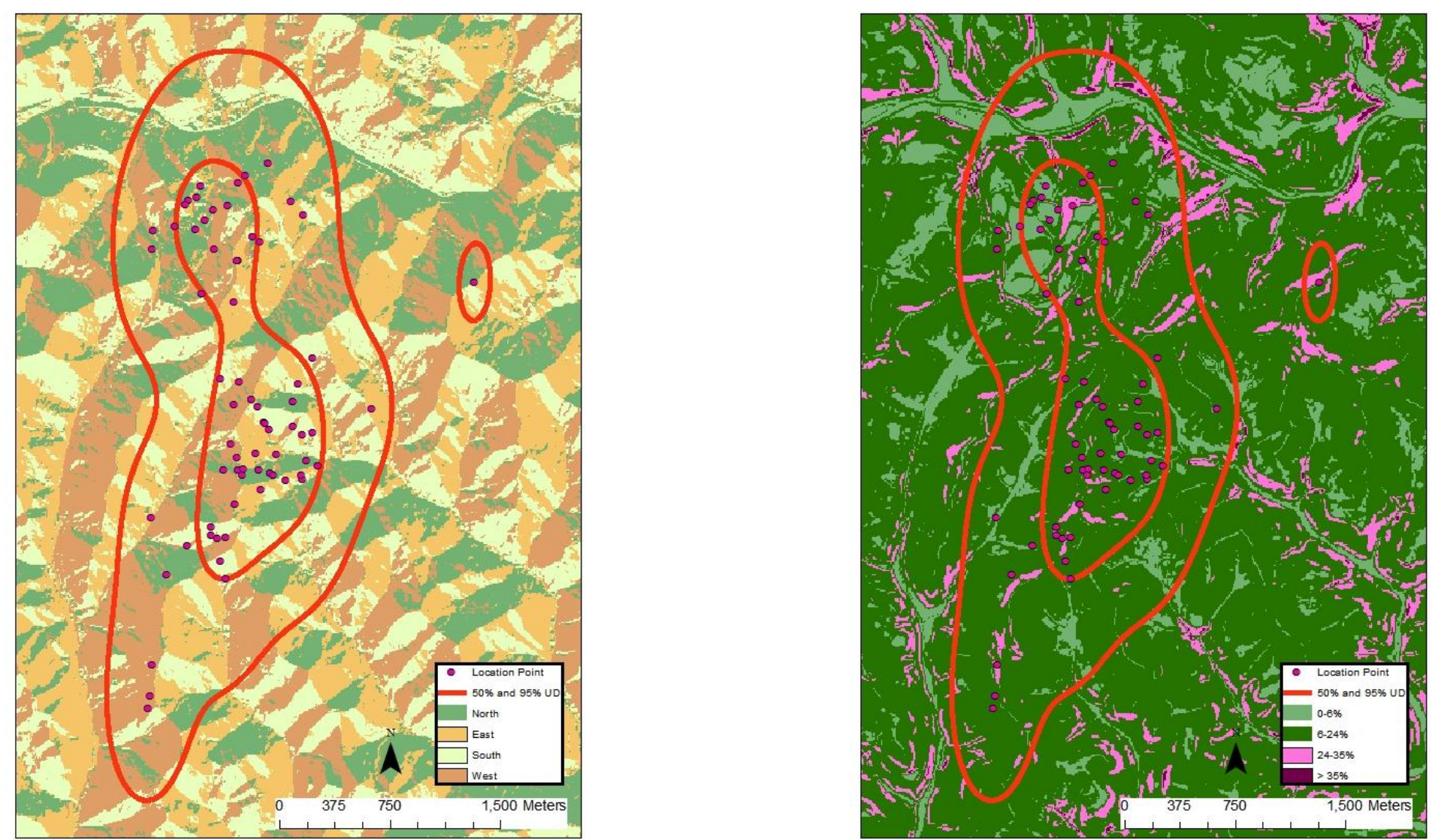
Appendix XLIII a. 10025 (adult, winter) - 50\% core and 95\% periphery probability contours of the winter Gaussian fixed kernel home range utilization distributions. Smoothing parameter $(h)$ determined by least squares cross validation, Marion County, West Virginia, 2004-2007 (land use and land cover, land fragmentation maps).
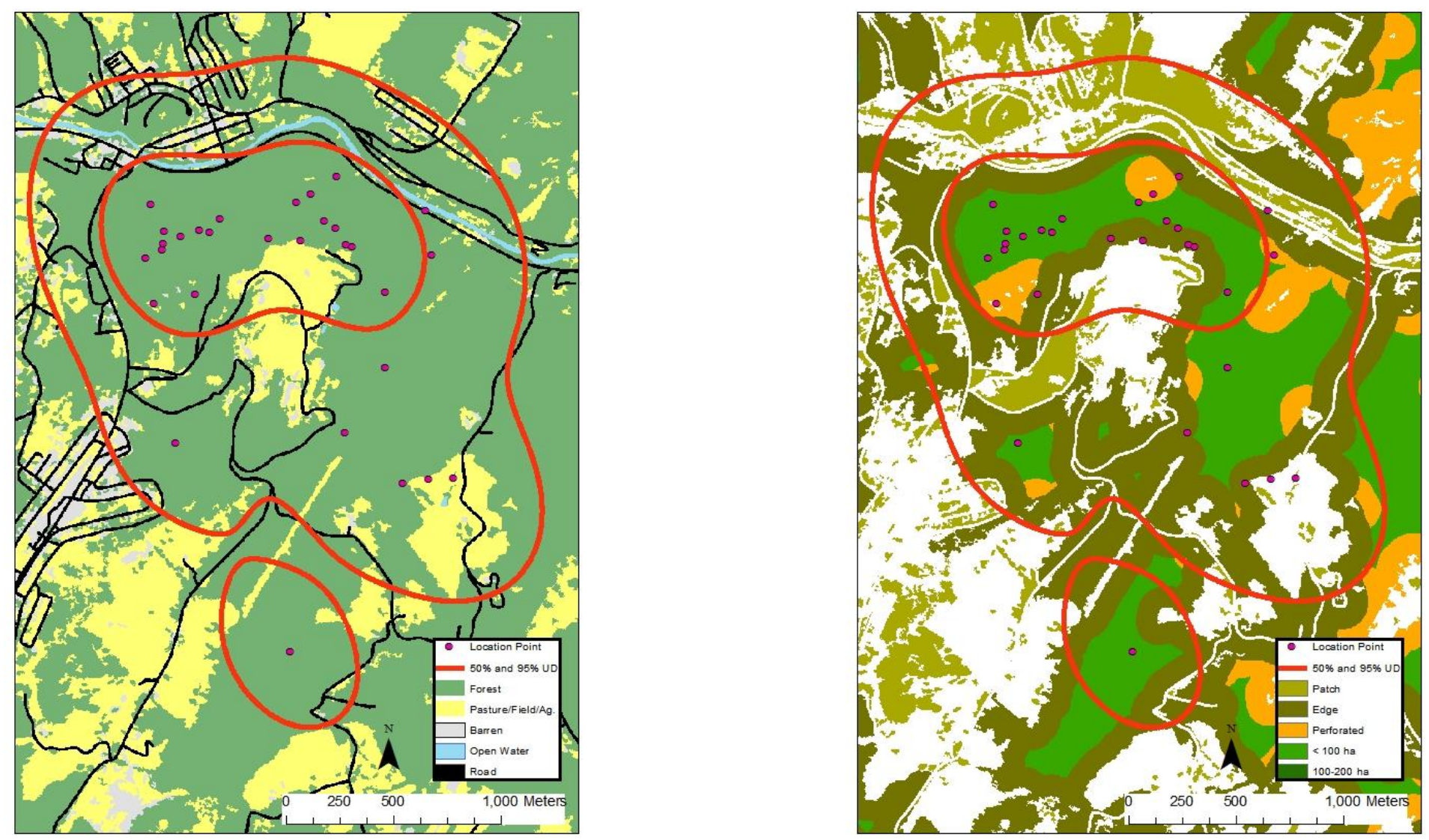
Appendix XLIVa. 10025 (adult, winter) - 50\% core and 95\% periphery probability contours of the winter Gaussian fixed kernel home range utilization distributions. Smoothing parameter $(h)$ determined by least squares cross validation, Marion County, West Virginia, 2004-2007 (aspect and slope maps).
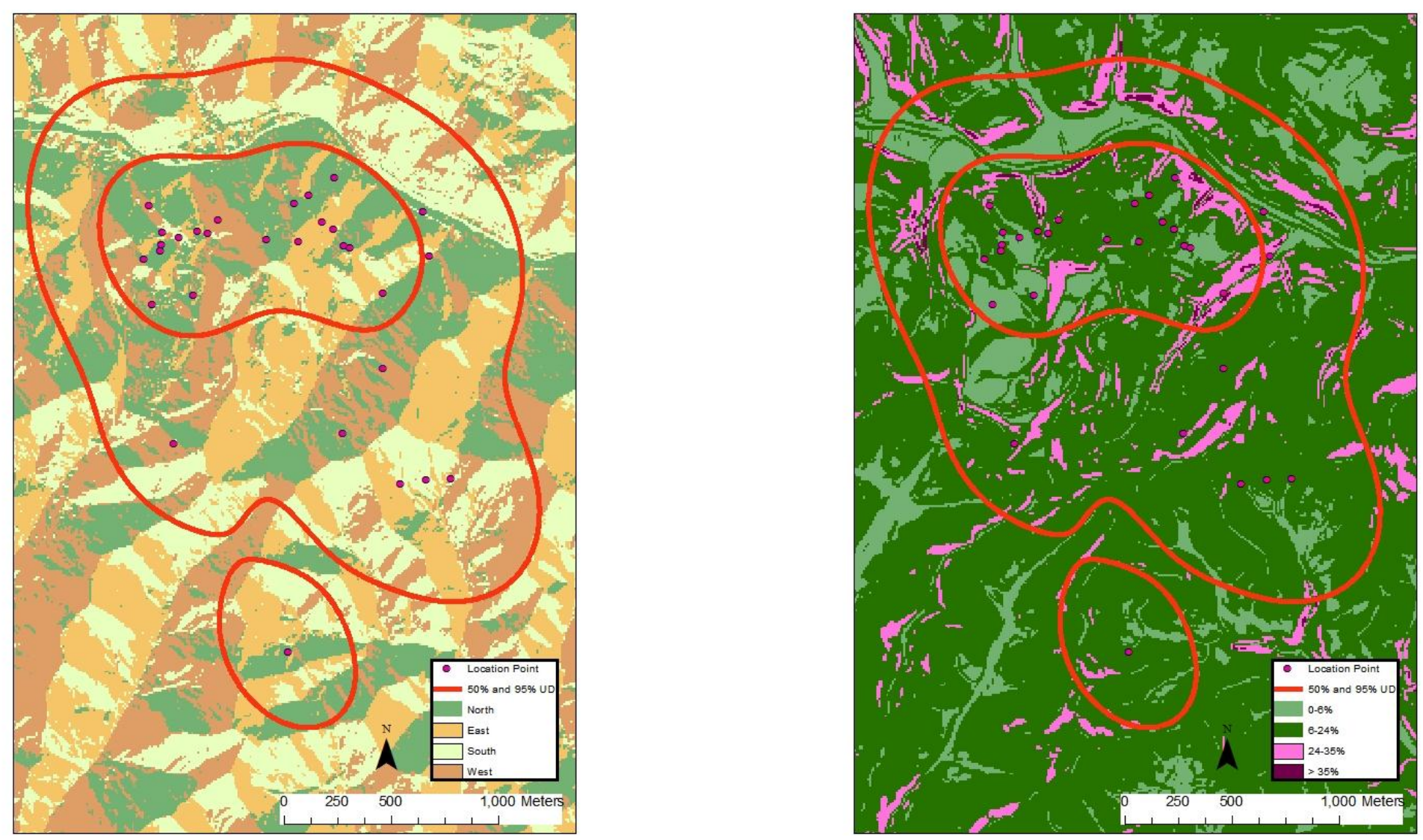
Appendix XLVa. 10026 (adult, annual) - 50\% core and 95\% periphery probability contours of the annual Gaussian fixed kernel home range utilization distributions. Smoothing parameter $(h)$ determined by least squares cross validation, Marion County, West Virginia, 2004-2007 (land use and land cover, land fragmentation maps).
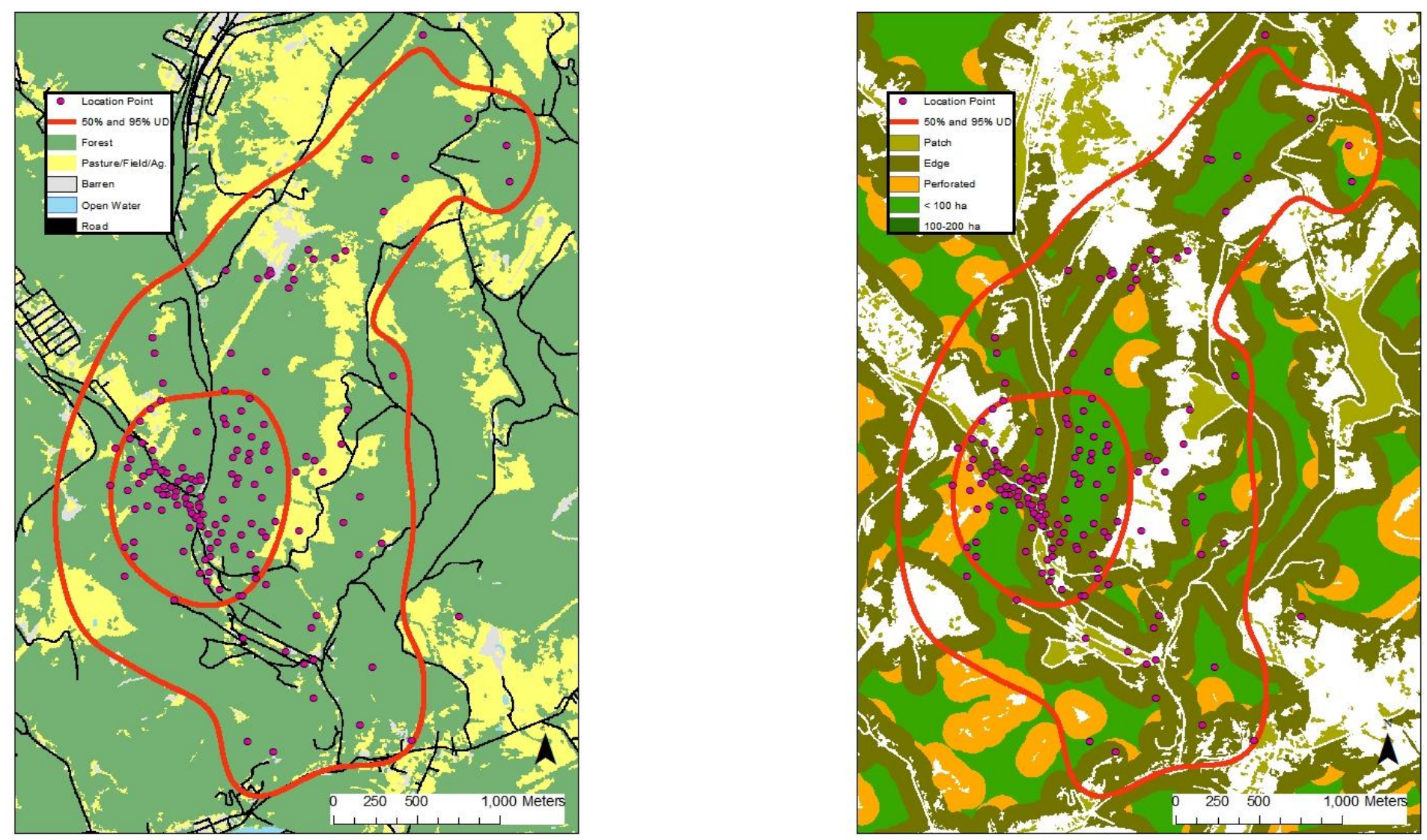
Appendix XLVIa. 10026 (adult, annual) - 50\% core and 95\% periphery probability contours of the annual Gaussian fixed kernel home range utilization distributions. Smoothing parameter $(h)$ determined by least squares cross validation, Marion County, West Virginia, 2004-2007 (aspect and slope maps).
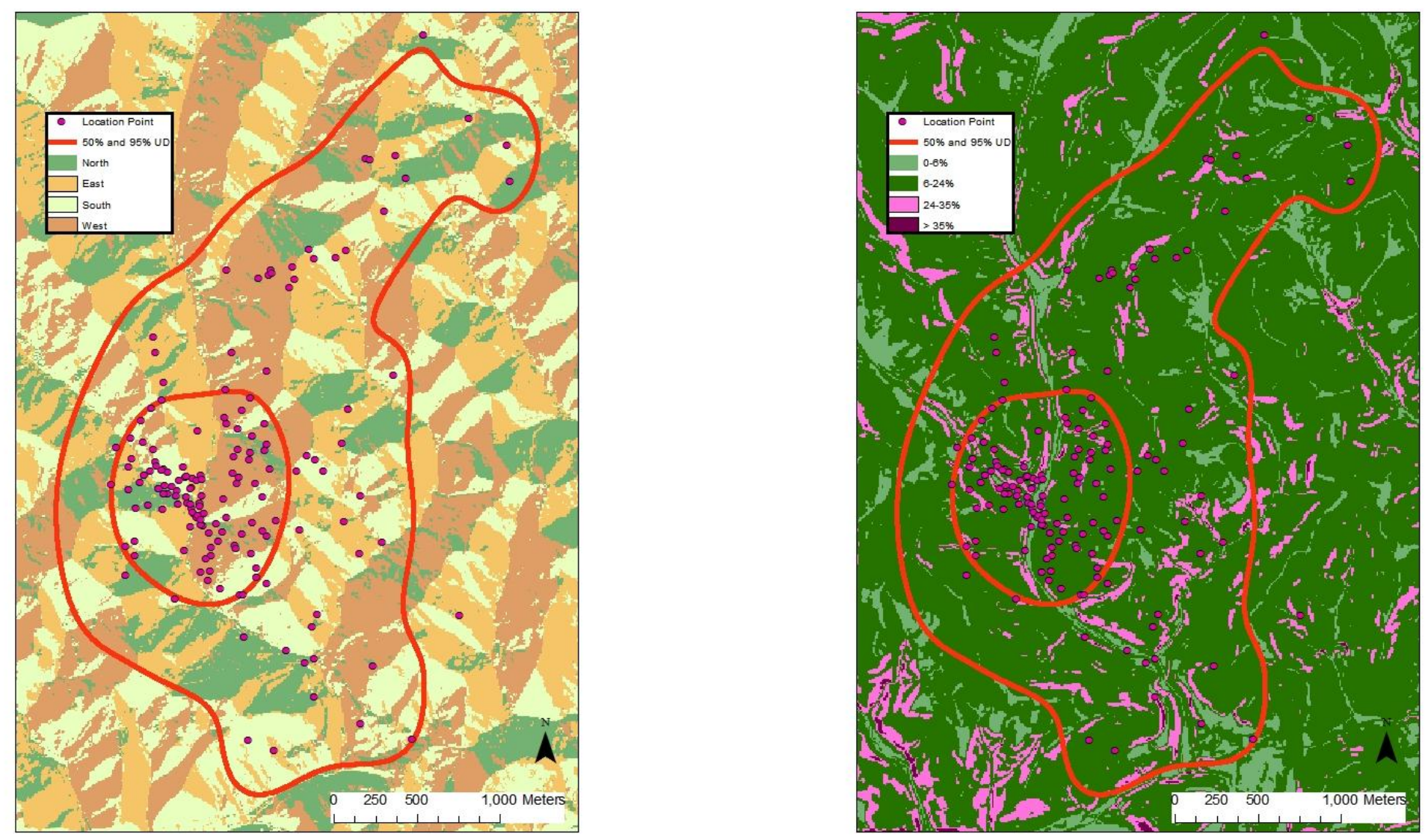
Appendix XLVII a. 10027 (adult, spring-summer) - 50\% core and 95\% periphery probability contours of the spring-summer Gaussian fixed kernel home range utilization distributions. Smoothing parameter $(h)$ determined by least squares cross validation, Marion County, West Virginia, 2004-2007 (land use and land cover, land fragmentation maps).
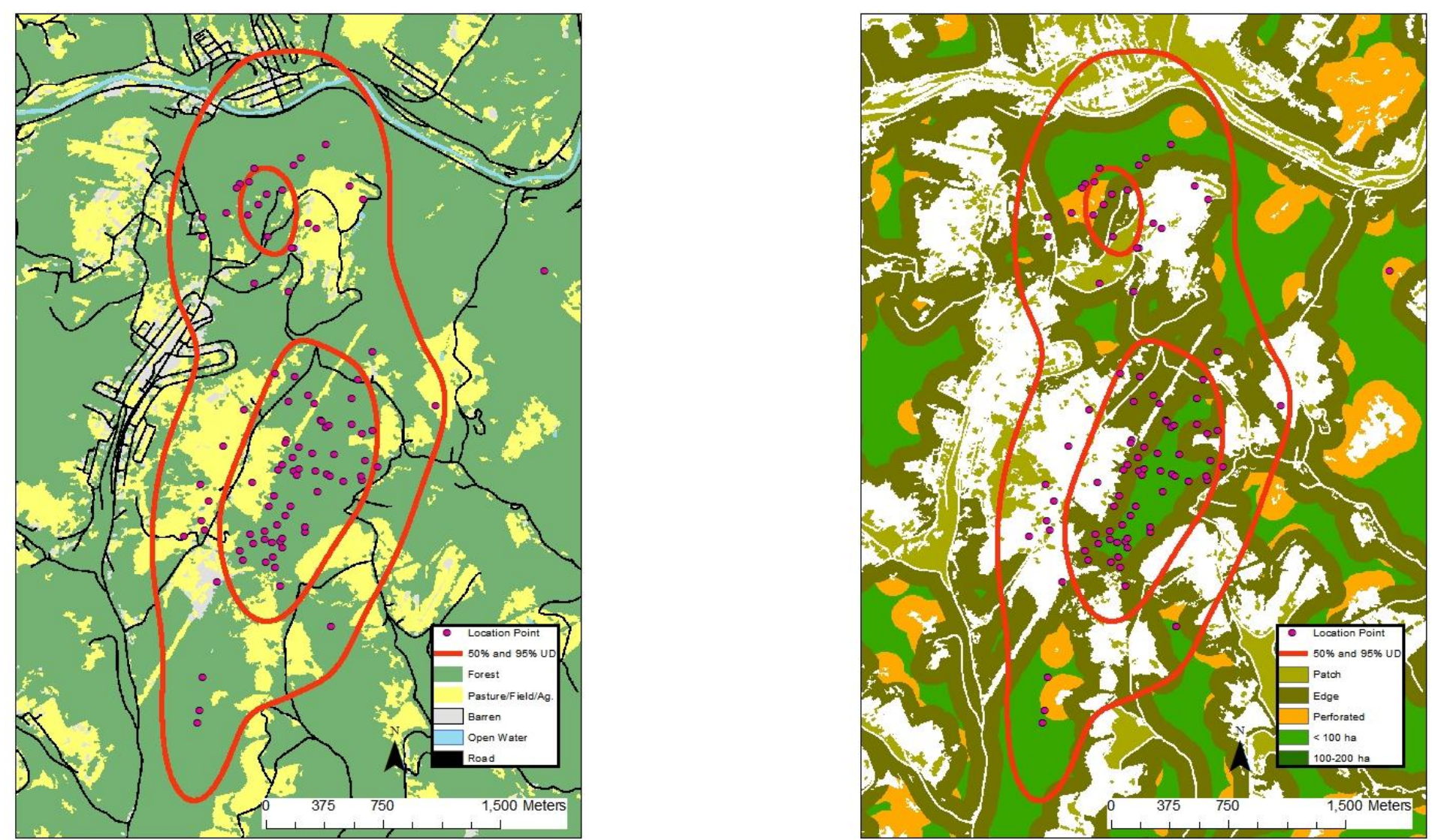
Appendix XLVIII a. 10027 (adult, spring-summer) - 50\% core and 95\% periphery probability contours of the spring-summer Gaussian fixed kernel home range utilization distributions. Smoothing parameter $(h)$ determined by least squares cross validation, Marion County, West Virginia, 2004-2007 (aspect and slope maps).
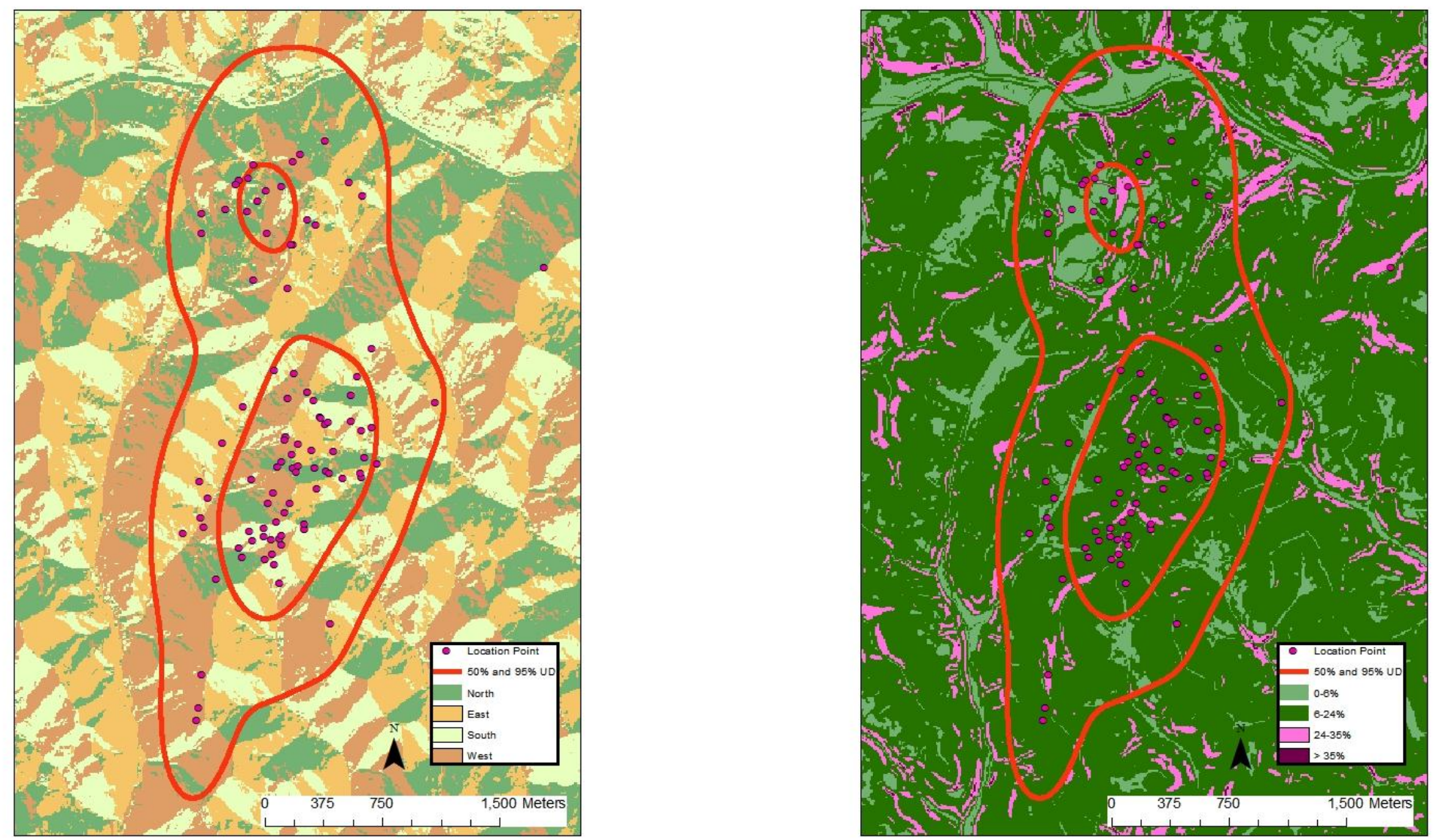
Appendix XLIXa. 10029 (adult, fall) - 50\% core and 95\% periphery probability contours of the fall Gaussian fixed kernel home range utilization distributions. Smoothing parameter $(h)$ determined by least squares cross validation, Marion County, West Virginia, 20042007 (land use and land cover, land fragmentation maps).
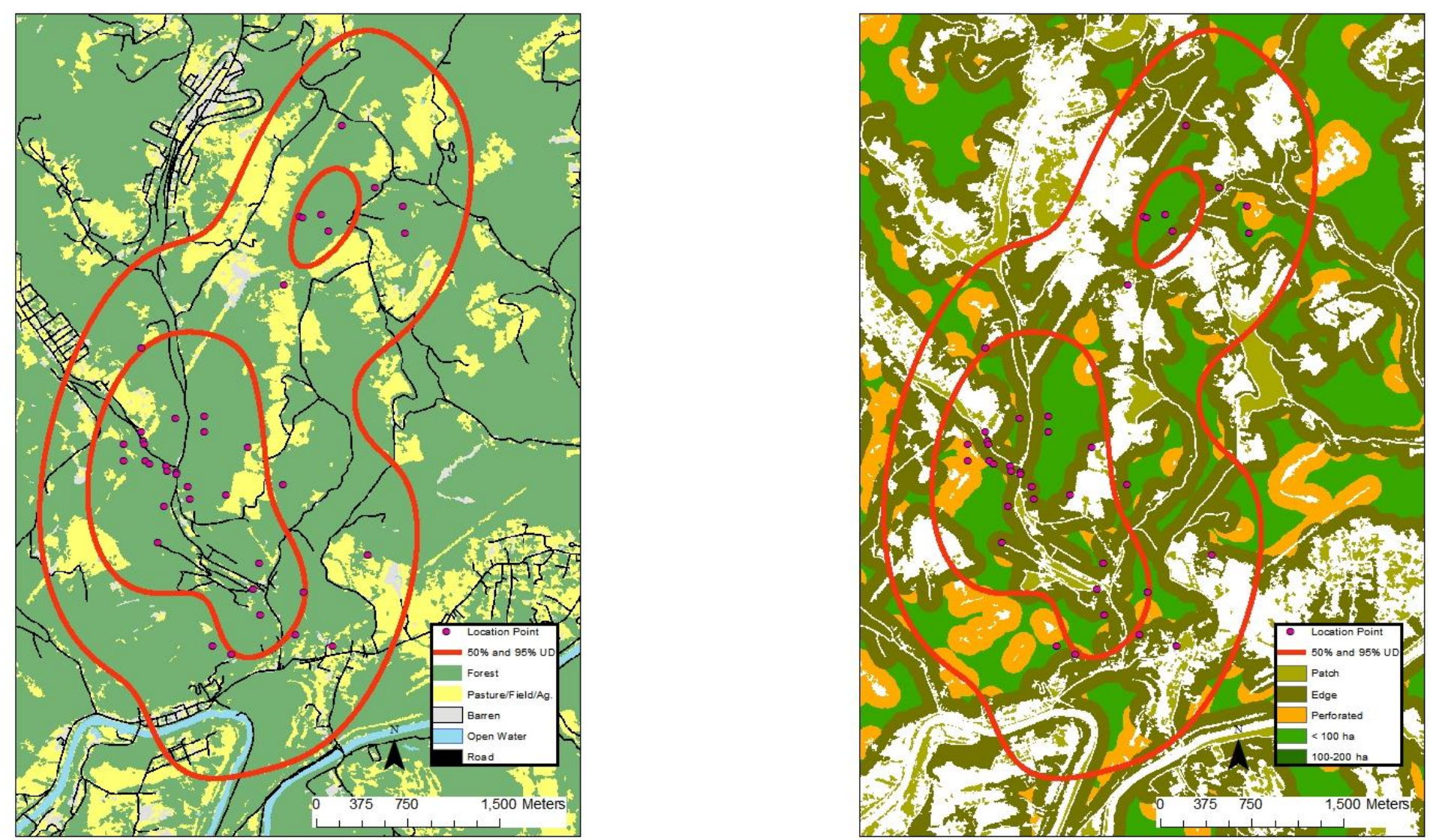
Appendix La. 10029 (adult, fall) - 50\% core and 95\% periphery probability contours of the fall Gaussian fixed kernel home range utilization distributions. Smoothing parameter $(h)$ determined by least squares cross validation, Marion County, West Virginia, 20042007 (aspect and slope maps).
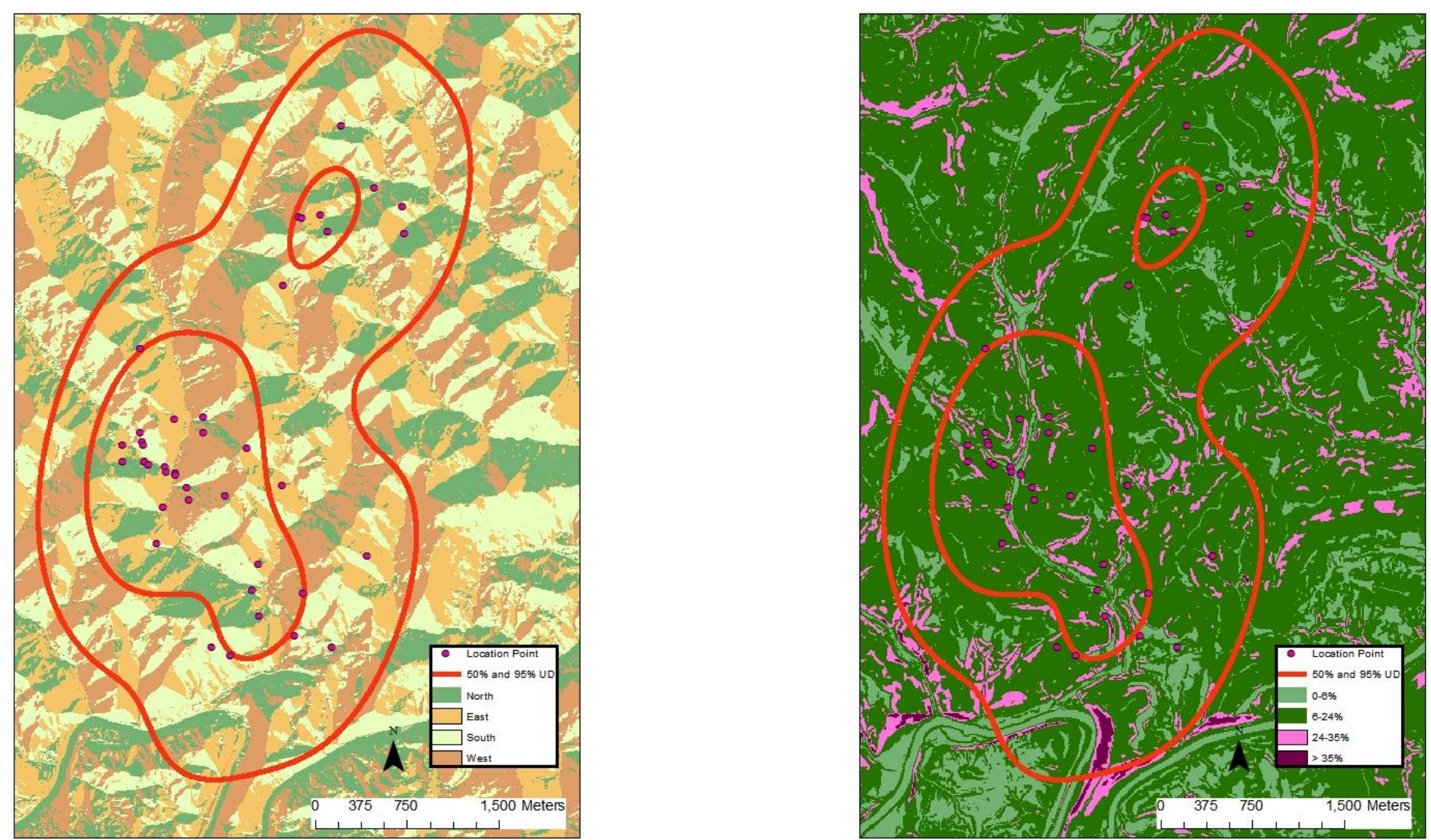
Appendix LIa. 10030 (adult, fall-winter) - 50\% core and 95\% periphery probability contours of the fall-winter Gaussian fixed kernel home range utilization distributions. Smoothing parameter $(h)$ determined by least squares cross validation, Marion County, West Virginia, 2004-2007 (land use and land cover, land fragmentation maps).
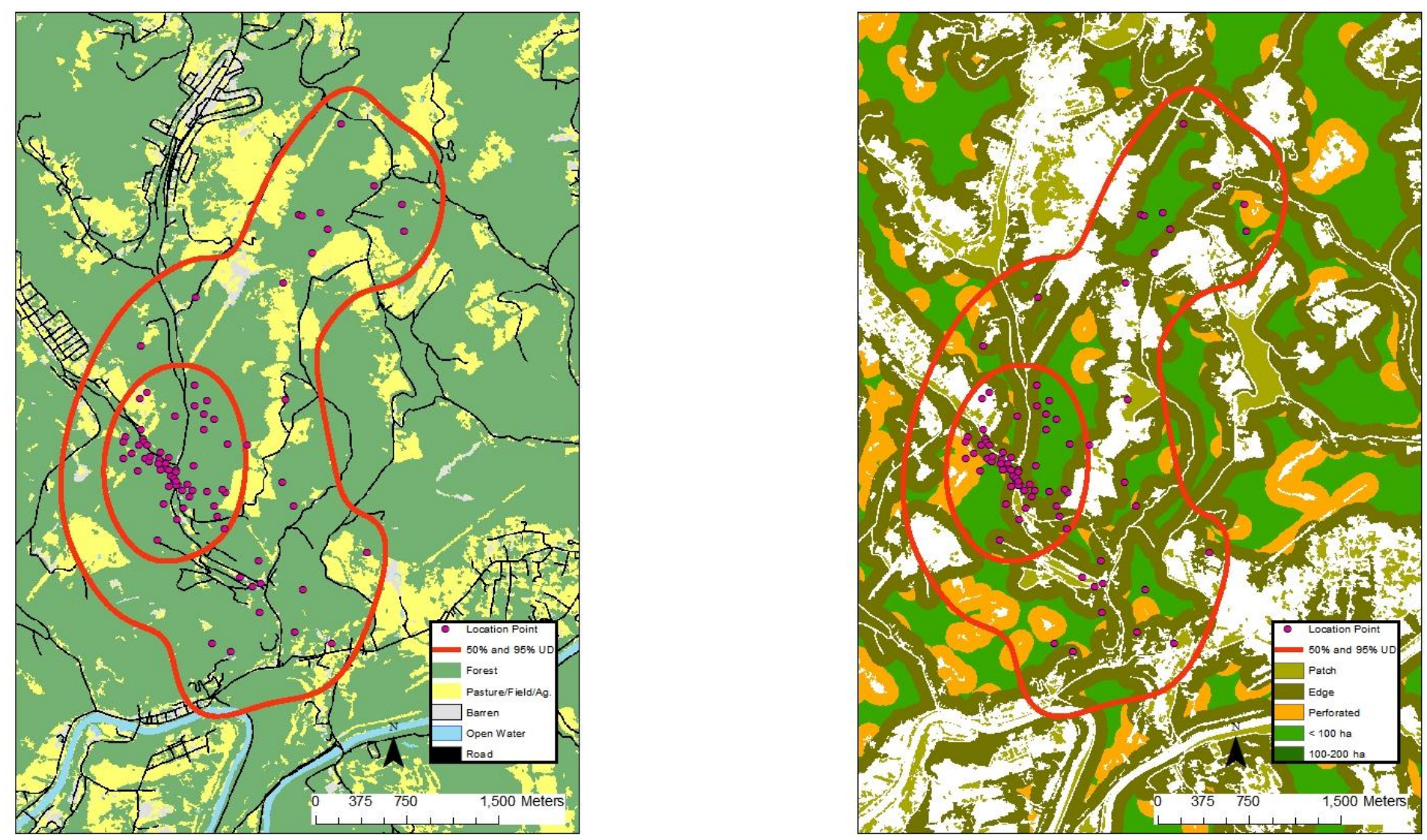
Appendix LII $a .10030$ (adult, fall-winter) - 50\% core and 95\% periphery probability contours of the fall-winter Gaussian fixed kernel home range utilization distributions. Smoothing parameter $(h)$ determined by least squares cross validation, Marion County, West Virginia, 2004-2007 (aspect and slope maps).
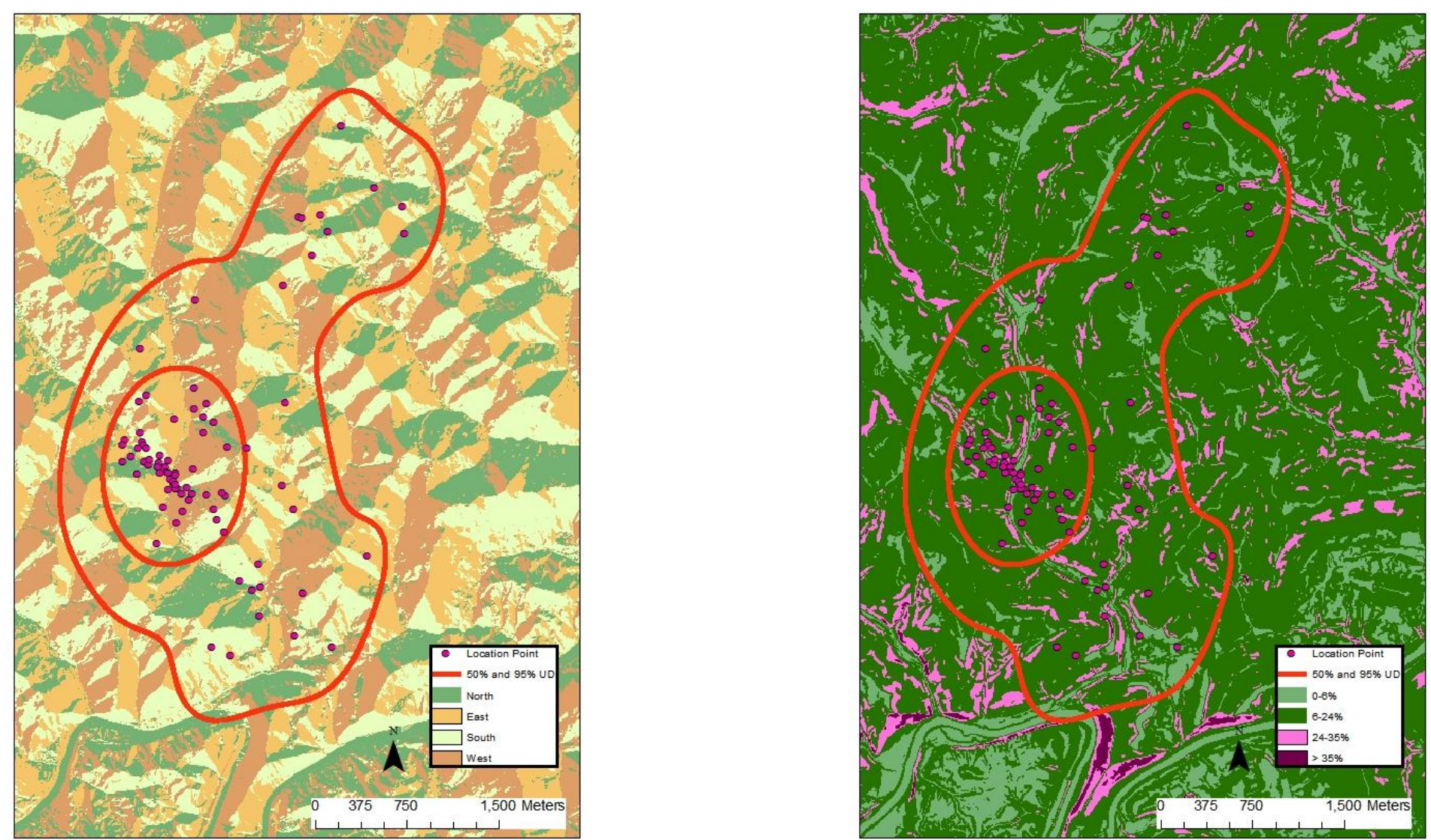
Appendix LIII $a .10031$ (adult, spring) - 50\% core and 95\% periphery probability contours of the spring Gaussian fixed kernel home range utilization distributions. Smoothing parameter $(h)$ determined by least squares cross validation, Marion County, West Virginia, 2004-2007 (land use and land cover, land fragmentation maps).
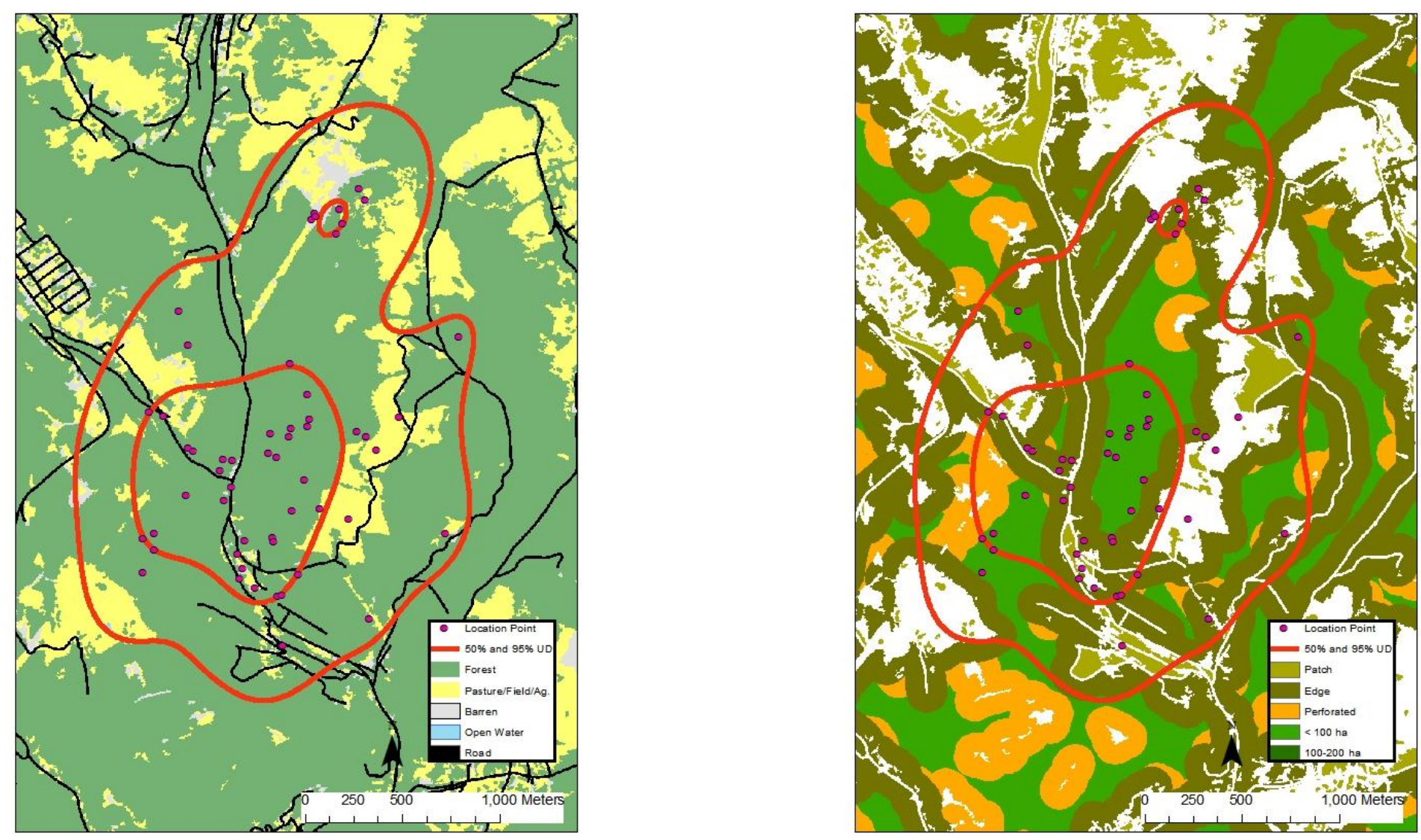
Appendix LIVa. 10031 (adult, spring) - 50\% core and 95\% periphery probability contours of the spring Gaussian fixed kernel home range utilization distributions. Smoothing parameter $(h)$ determined by least squares cross validation, Marion County, West Virginia, 2004-2007 (aspect and slope maps).
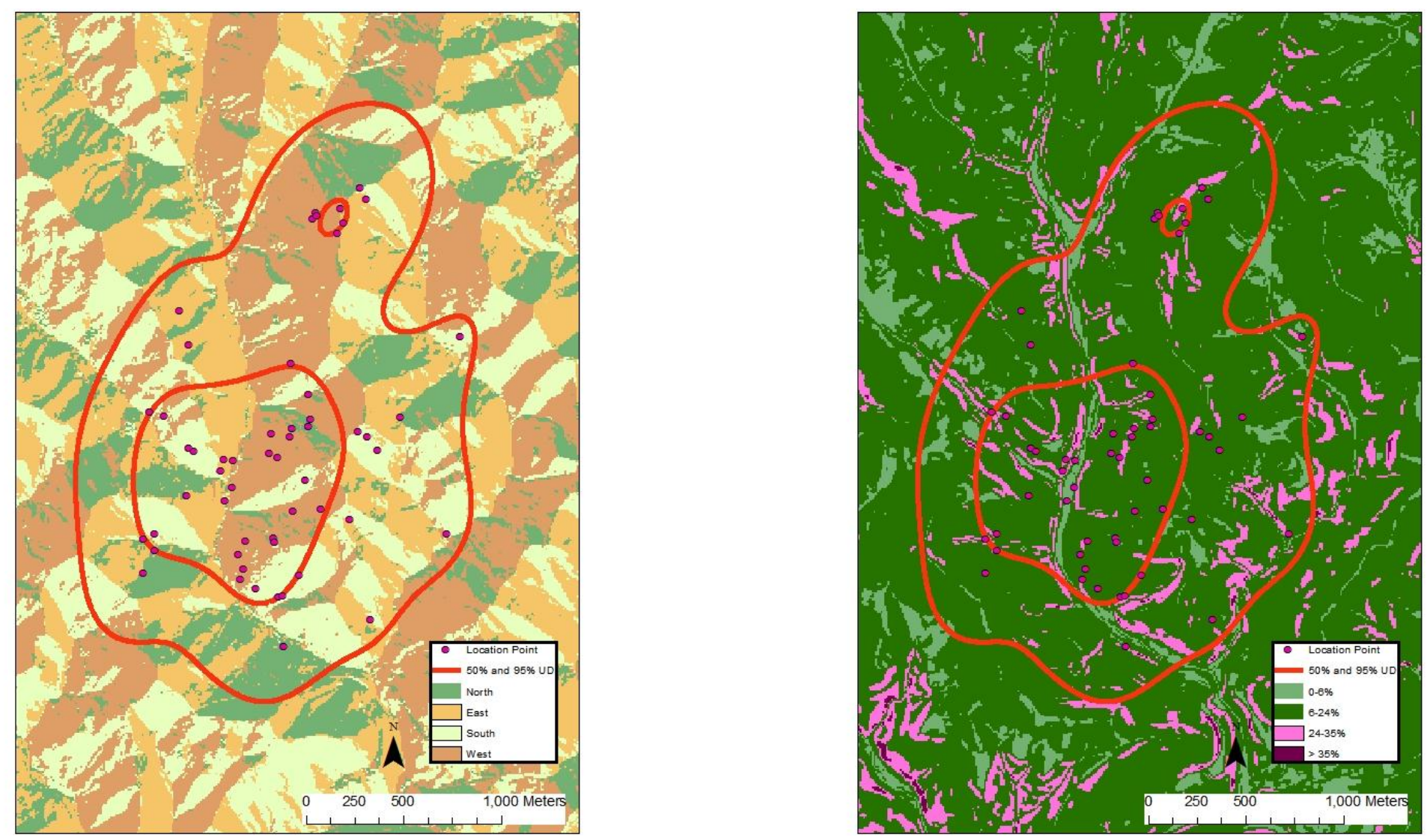
Appendix LVa. 10032 (adult, spring-summer) - 50\% core and 95\% periphery probability contours of the spring-summer Gaussian fixed kernel home range utilization distributions. Smoothing parameter $(h)$ determined by least squares cross validation, Marion County, West Virginia, 2004-2007 (land use and land cover, land fragmentation maps).
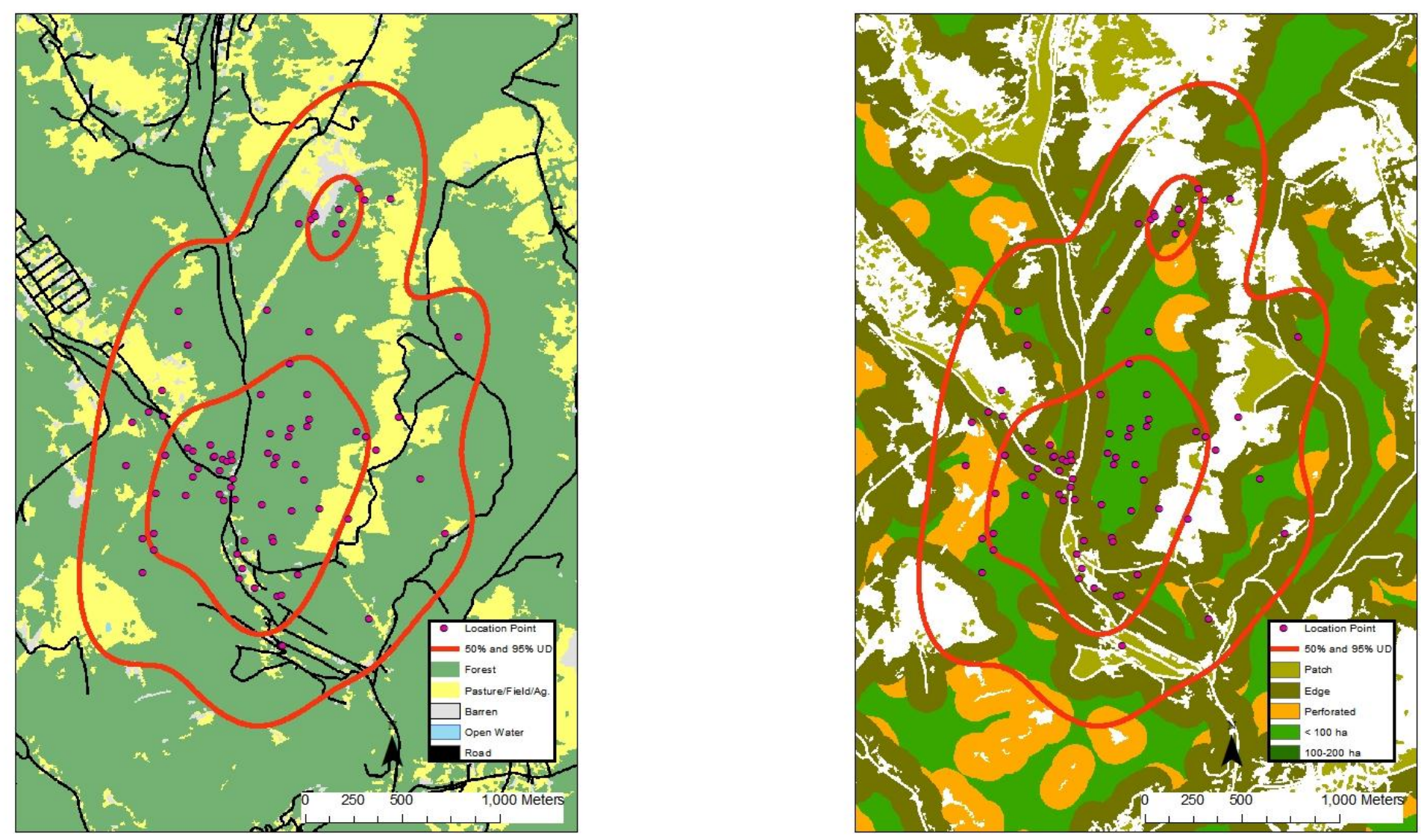
Appendix LVIa. 10032 (adult, spring-summer) - 50\% core and 95\% periphery probability contours of the spring-summer Gaussian fixed kernel home range utilization distributions. Smoothing parameter $(h)$ determined by least squares cross validation, Marion County, West Virginia, 2004-2007 (aspect and slope maps).
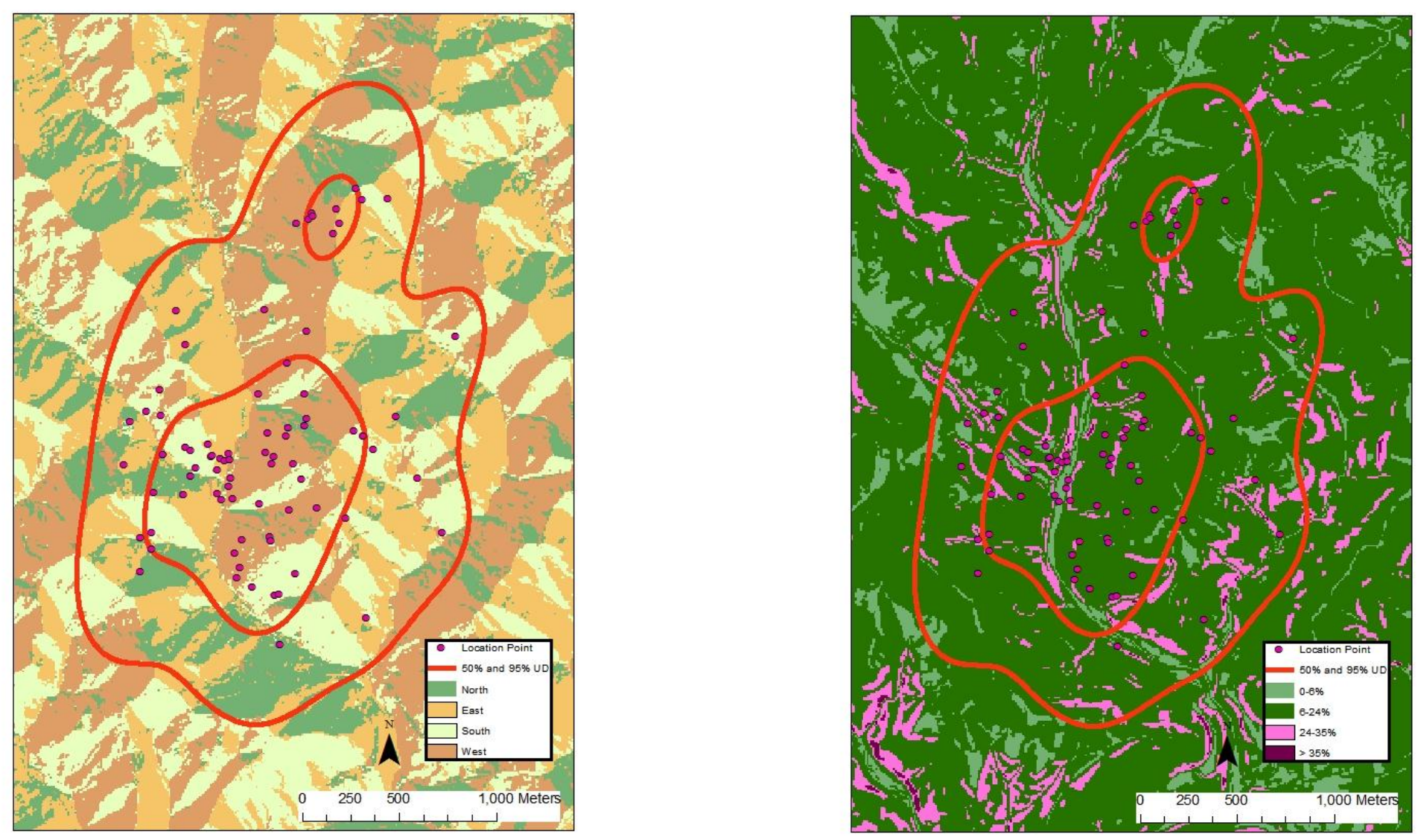
Appendix LVIIa. 10033 (adult, winter) - 50\% core and 95\% periphery probability contours of the winter Gaussian fixed kernel home range utilization distributions. Smoothing parameter $(h)$ determined by least squares cross validation, Marion County, West Virginia, 2004-2007 (land use and land cover, land fragmentation maps).
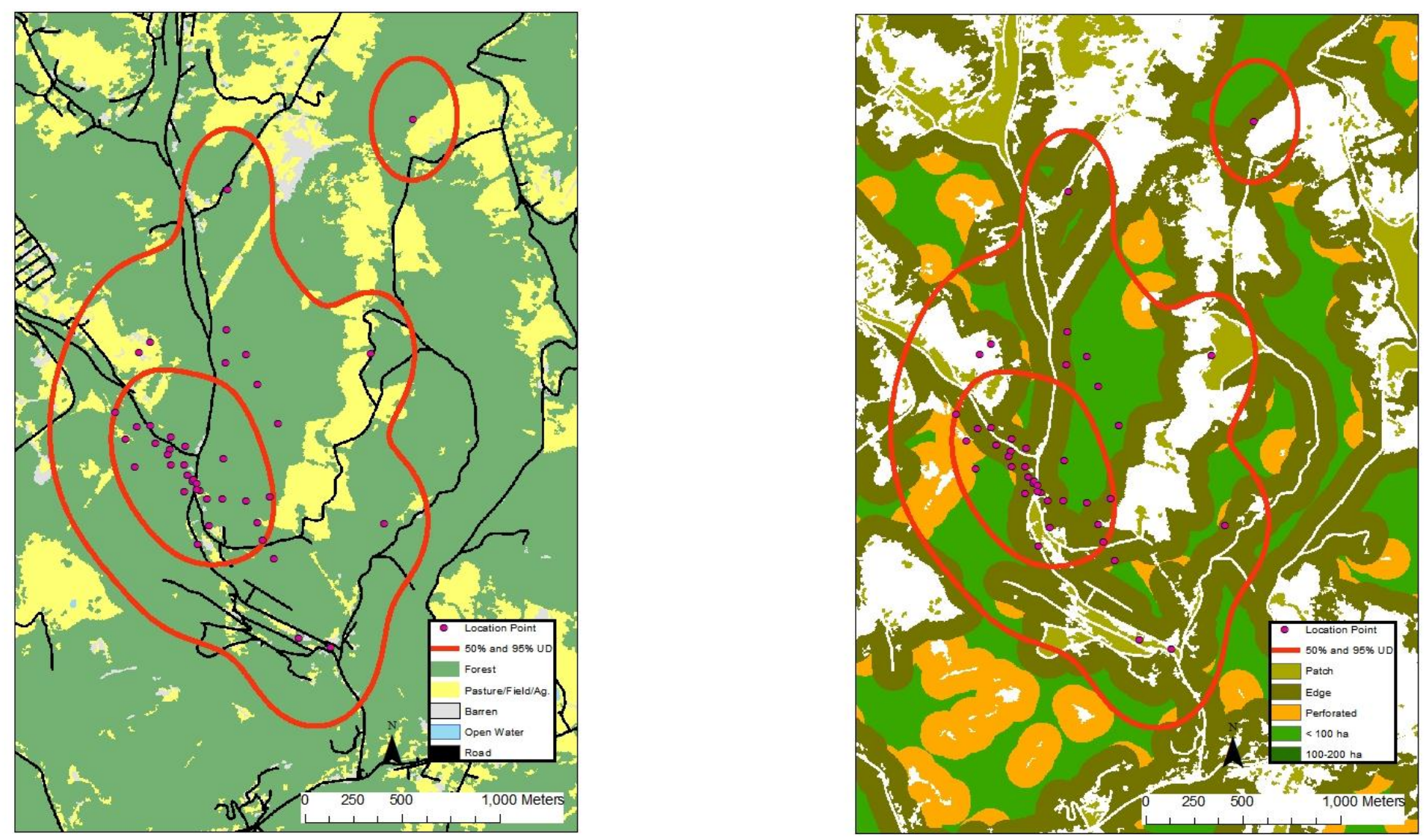
Appendix LVIII a. 10033 (adult, winter) - 50\% core and 95\% periphery probability contours of the winter Gaussian fixed kernel home range utilization distributions. Smoothing parameter $(h)$ determined by least squares cross validation, Marion County, West Virginia, 2004-2007 (aspect and slope maps).
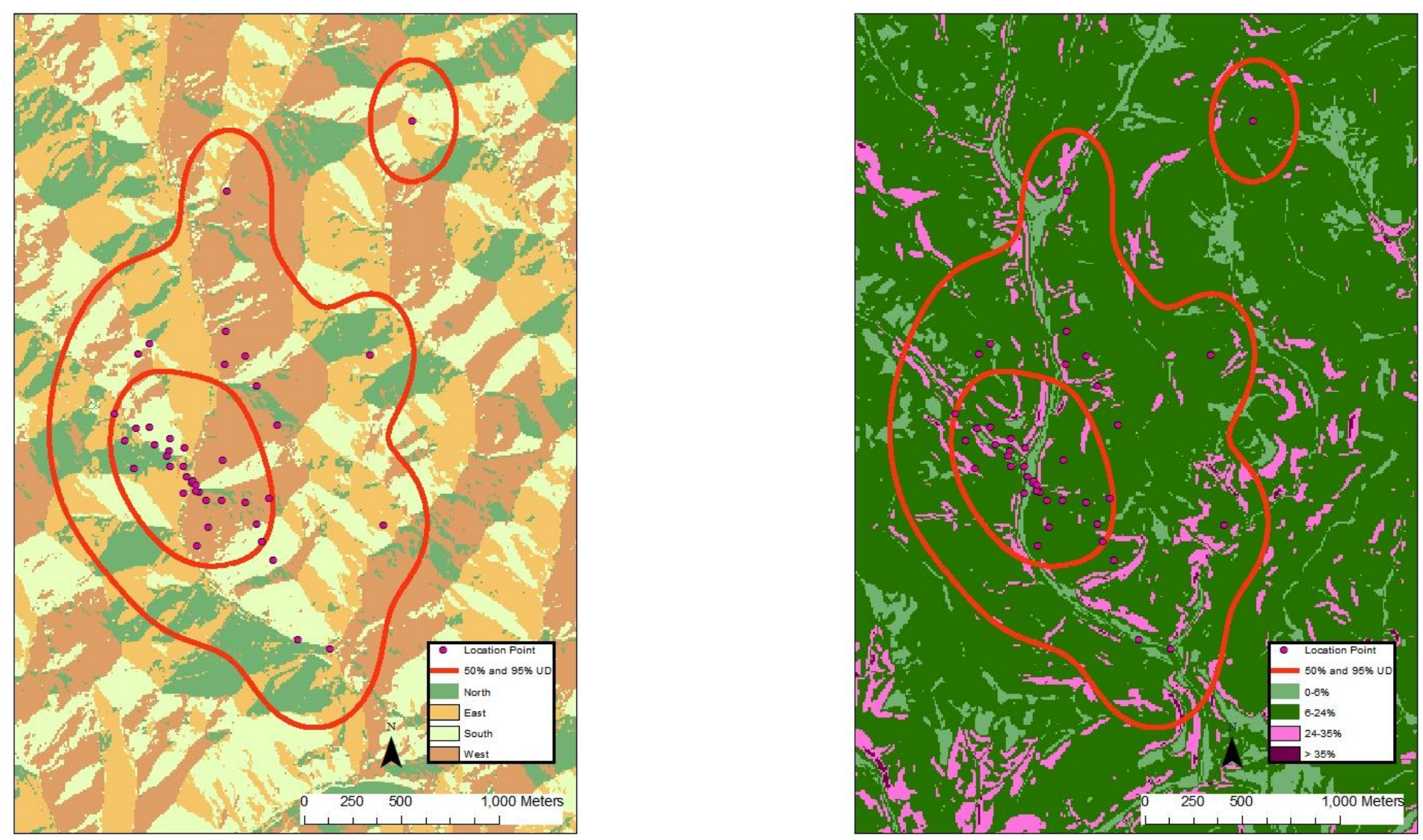
Appendix LIXa. 10034 (adult, annual) - 50\% core and 95\% periphery probability contours of the annual Gaussian fixed kernel home range utilization distributions. Smoothing parameter $(h)$ determined by least squares cross validation, Taylor County, West Virginia, 2004-2007 (land use and land cover, land fragmentation maps).
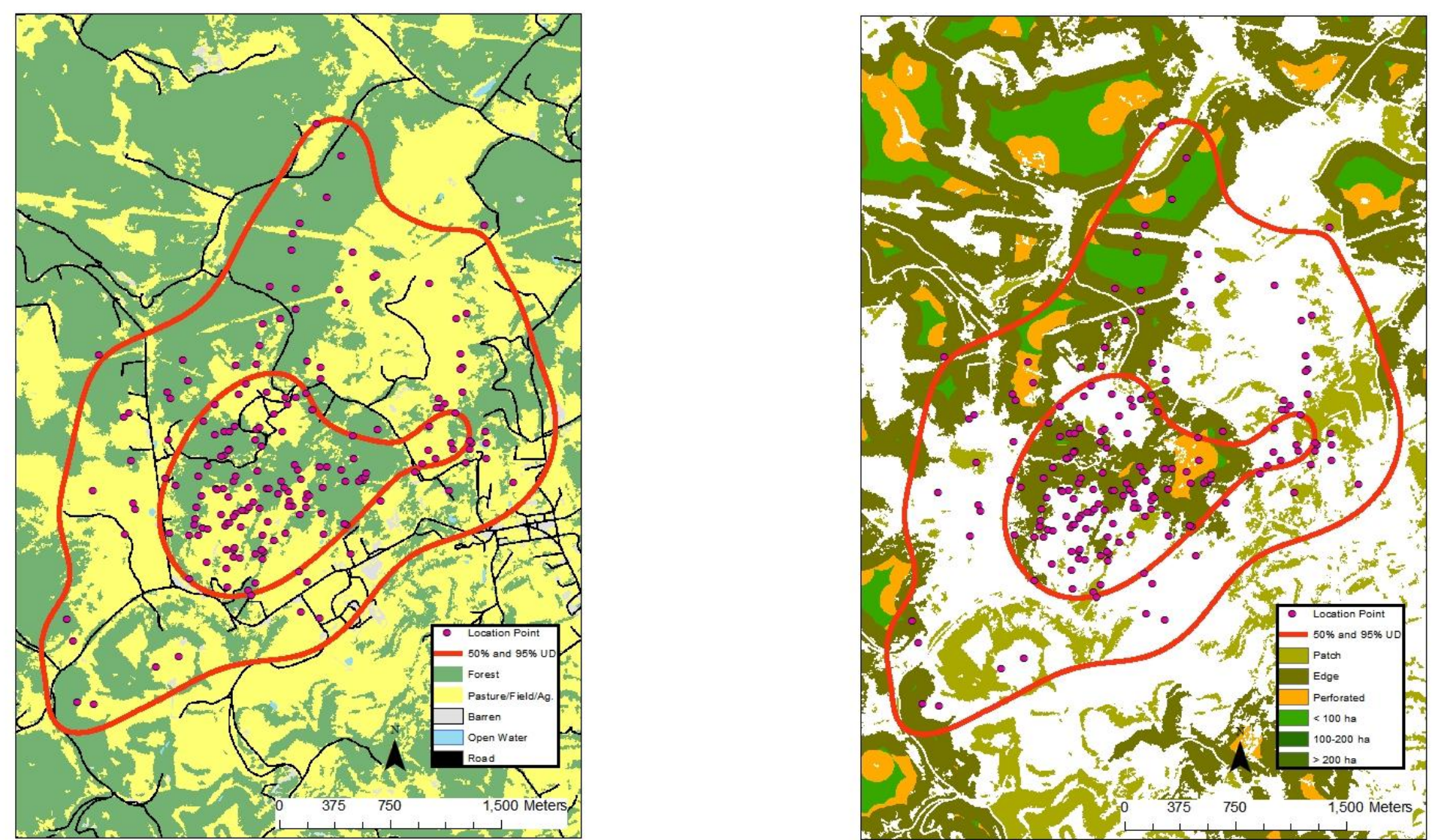
Appendix LXa. 10034 (adult, annual) - 50\% core and 95\% periphery probability contours of the annual Gaussian fixed kernel home range utilization distributions. Smoothing parameter $(h)$ determined by least squares cross validation, Taylor County, West Virginia, 2004-2007 (aspect and slope maps).
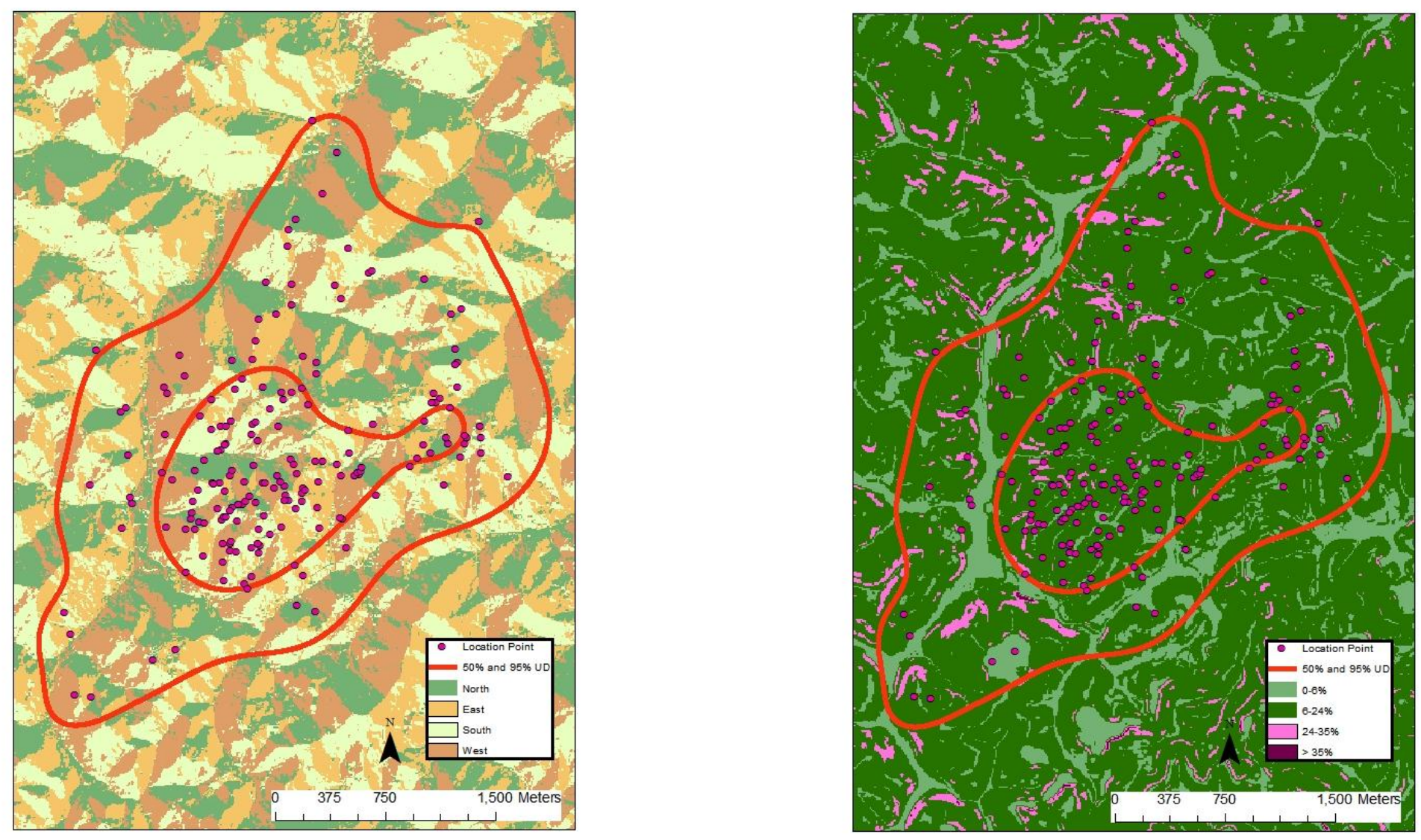
Appendix LXI $a .10036$ (adult, fall) - 50\% core and 95\% periphery probability contours of the fall Gaussian fixed kernel home range utilization distributions. Smoothing parameter $(h)$ determined by least squares cross validation, Taylor County, West Virginia, 2004 2007 (land use and land cover, land fragmentation maps).
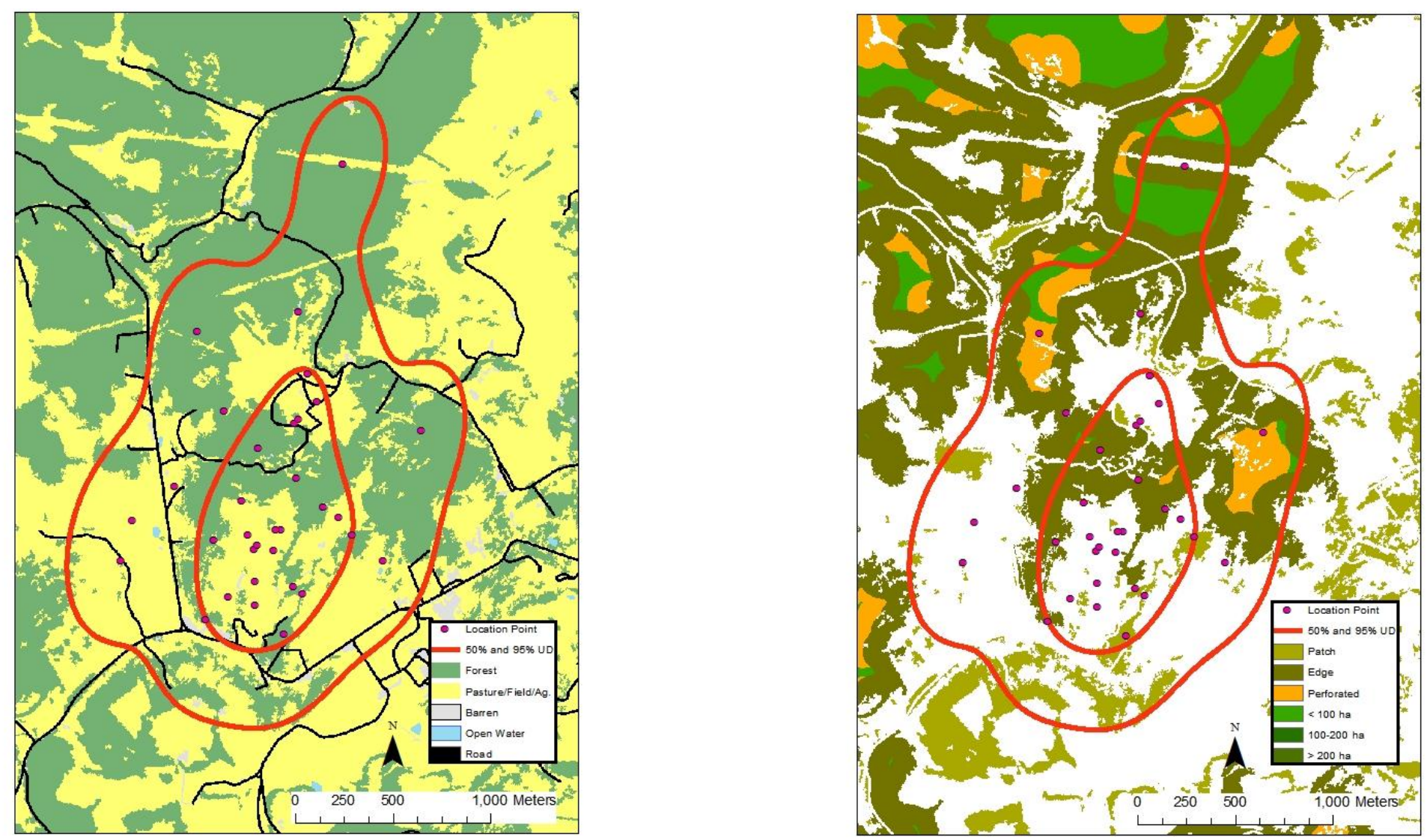
Appendix LXIIa. 10036 (adult, fall) - 50\% core and 95\% periphery probability contours of the fall Gaussian fixed kernel home range utilization distributions. Smoothing parameter $(h)$ determined by least squares cross validation, Taylor County, West Virginia, 20042007 (aspect and slope maps).
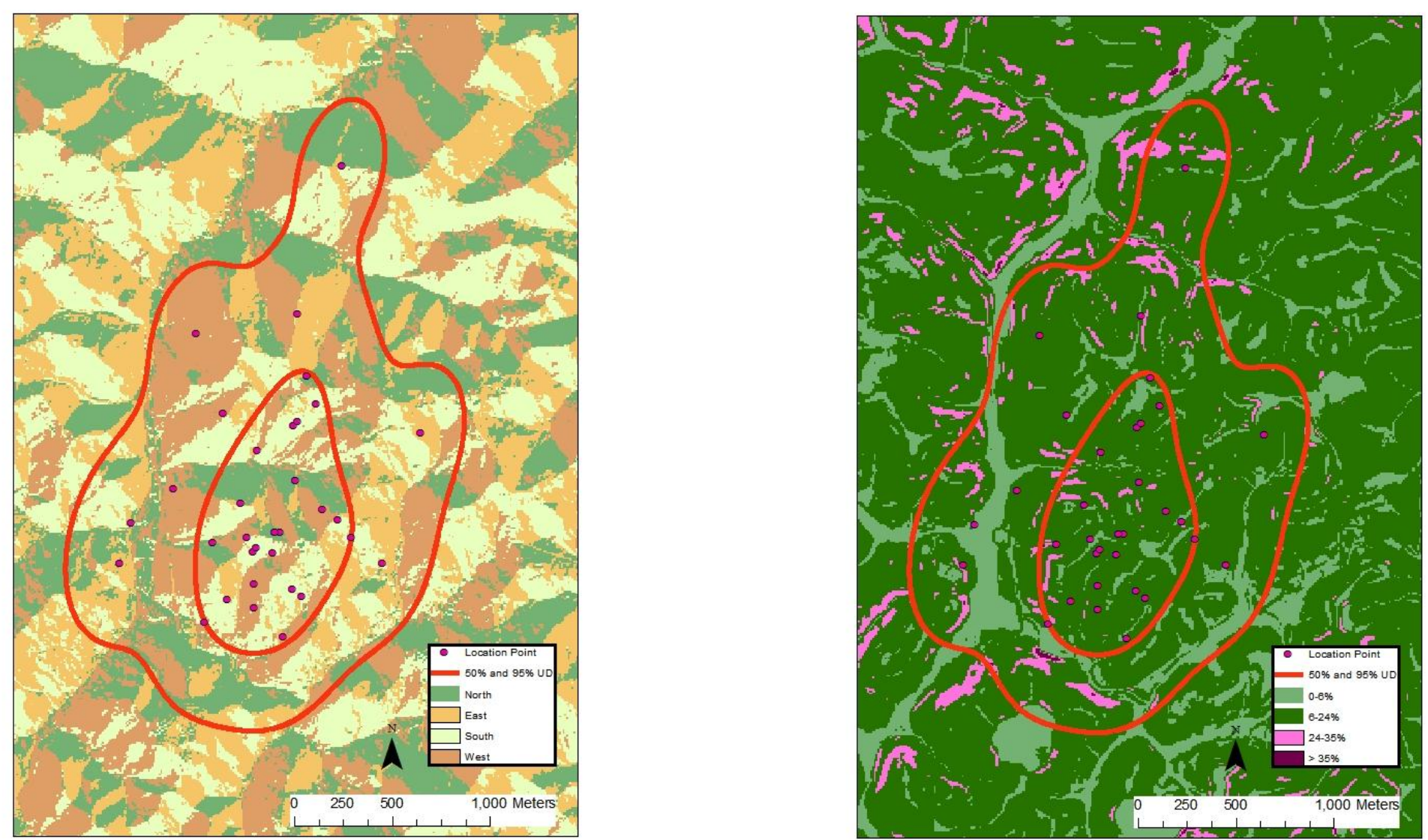
Appendix LXIII a. 10037 (adult, fall-winter) - 50\% core and 95\% periphery probability contours of the fall-winter Gaussian fixed kernel home range utilization distributions. Smoothing parameter $(h)$ determined by least squares cross validation, Taylor County, West Virginia, 2004-2007 (land use and land cover, land fragmentation maps).
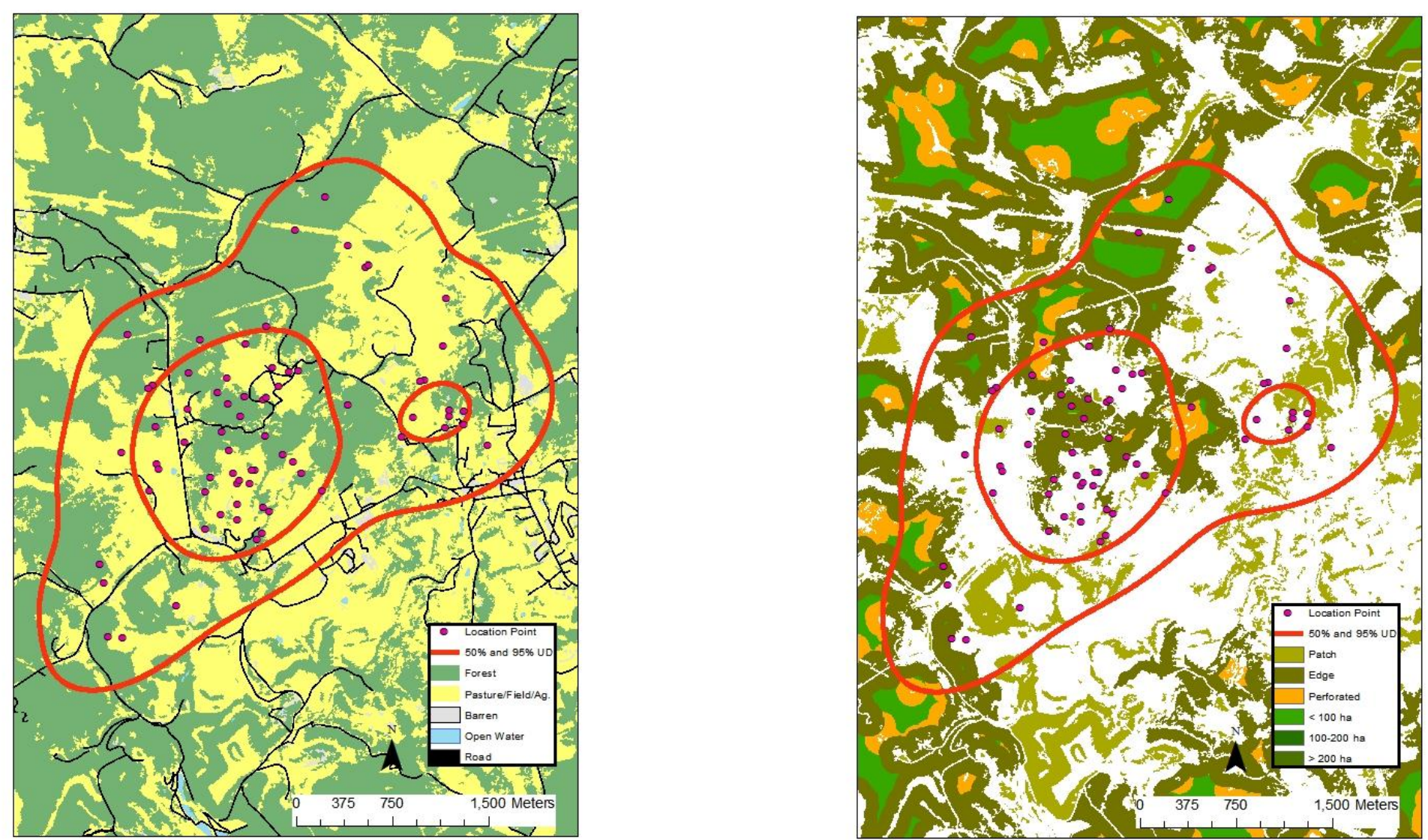
Appendix LXIVa. 10037 (adult, fall-winter) - 50\% core and 95\% periphery probability contours of the fall-winter Gaussian fixed kernel home range utilization distributions. Smoothing parameter $(h)$ determined by least squares cross validation, Taylor County, West Virginia, 2004-2007 (aspect and slope maps).
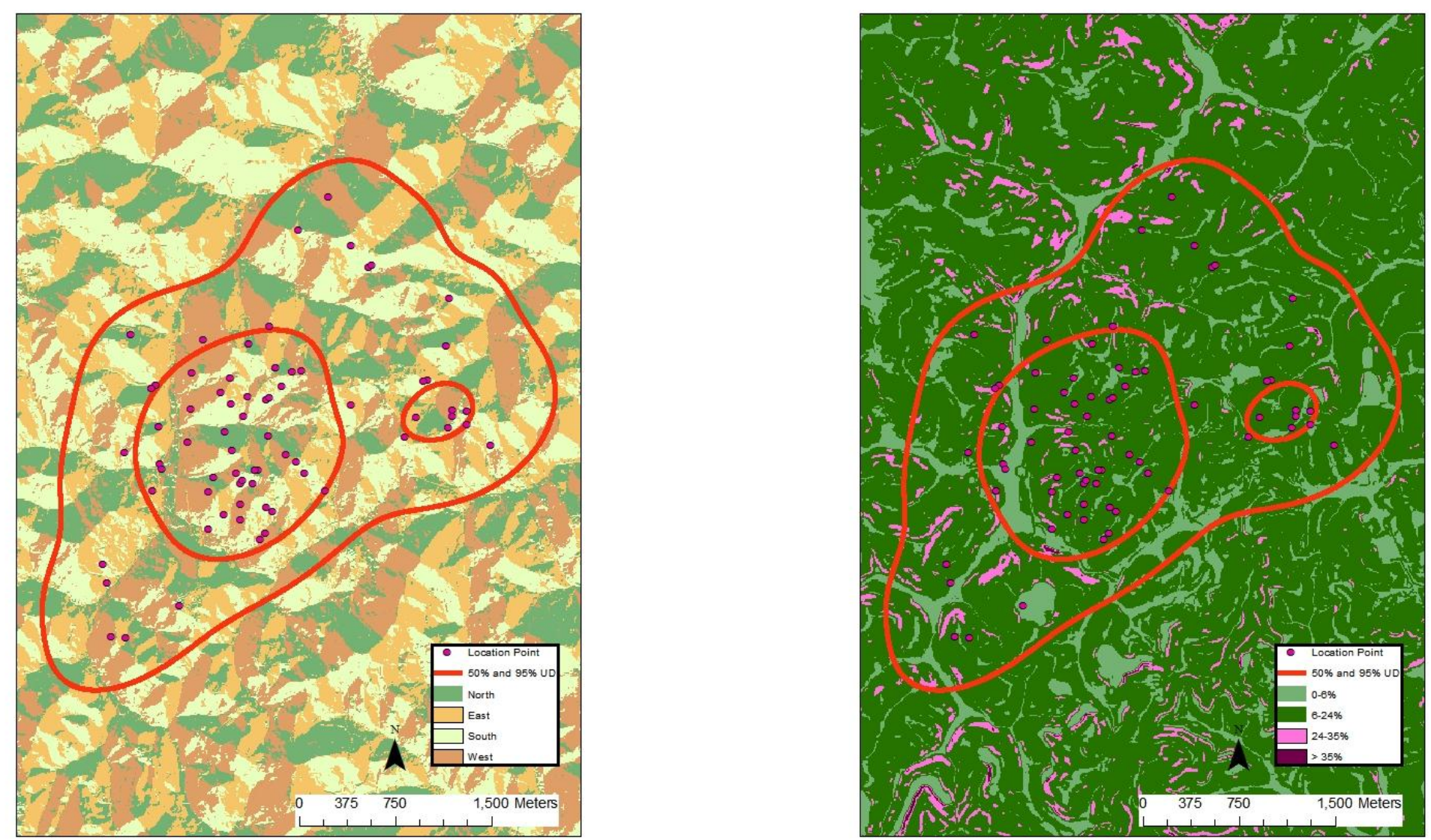
Appendix LXVa. 10038 (adult, spring) - 50\% core and 95\% periphery probability contours of the spring Gaussian fixed kernel home range utilization distributions. Smoothing parameter $(h)$ determined by least squares cross validation, Taylor County, West Virginia, 2004-2007 (land use and land cover, land fragmentation maps).
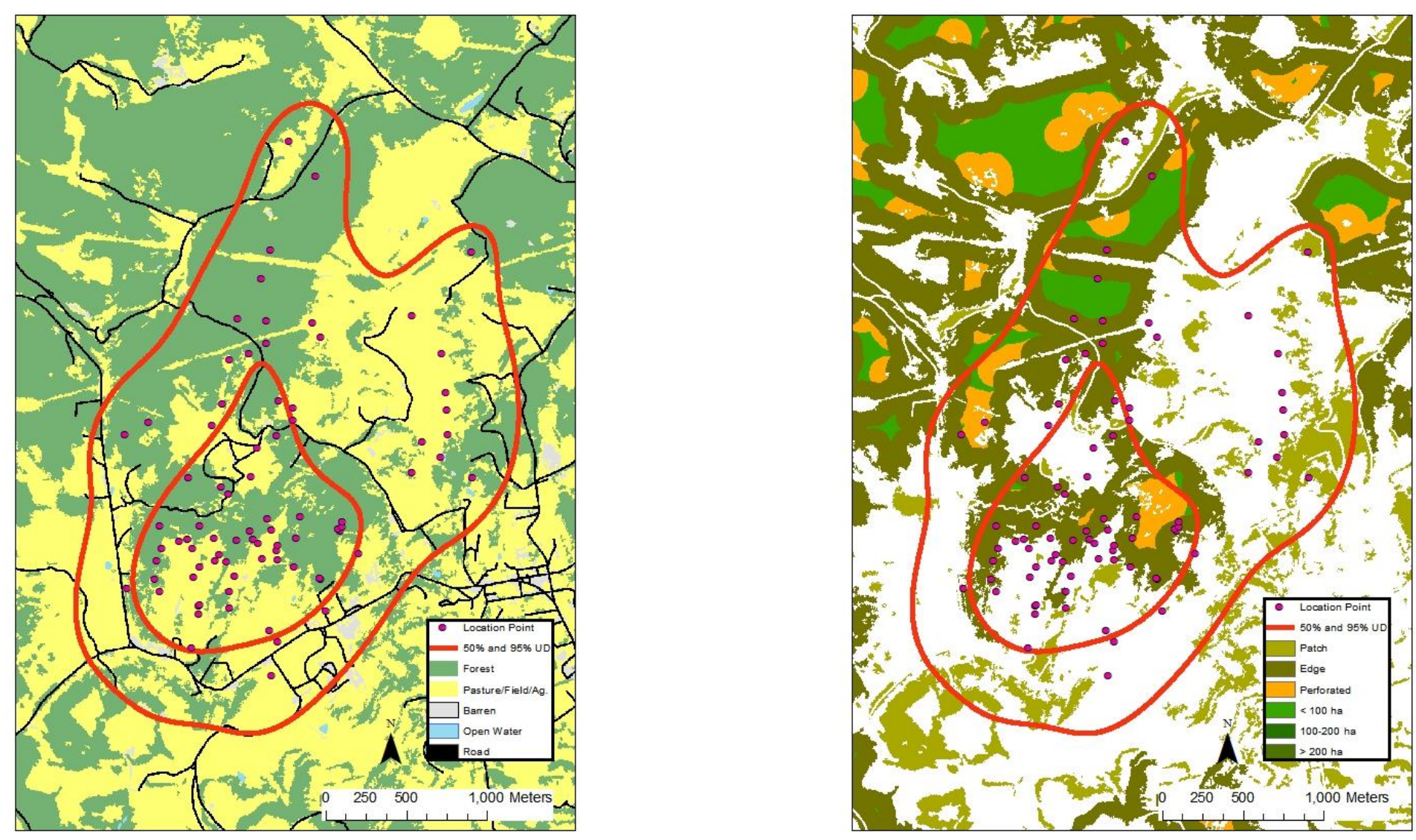
Appendix LXVIa. 10038 (adult, spring) - 50\% core and 95\% periphery probability contours of the spring Gaussian fixed kernel home range utilization distributions. Smoothing parameter $(h)$ determined by least squares cross validation, Taylor County, West Virginia, 2004-2007 (aspect and slope maps).
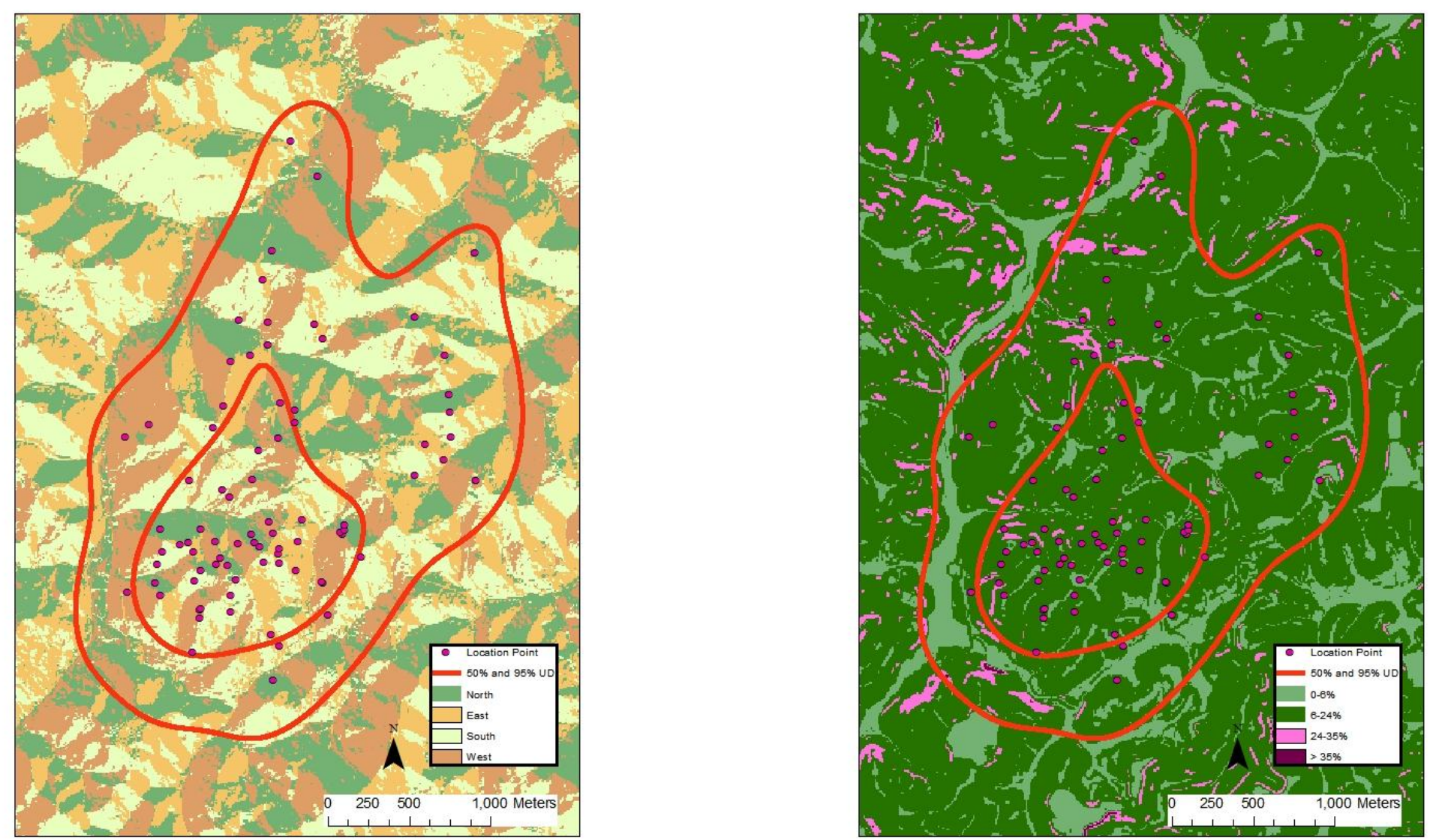
Appendix LXVII a. 10039 (adult, spring-summer) - 50\% core and 95\% periphery probability contours of the spring-summer Gaussian fixed kernel home range utilization distributions. Smoothing parameter $(h)$ determined by least squares cross validation, Taylor County, West Virginia, 2004-2007 (land use and land cover, land fragmentation maps).
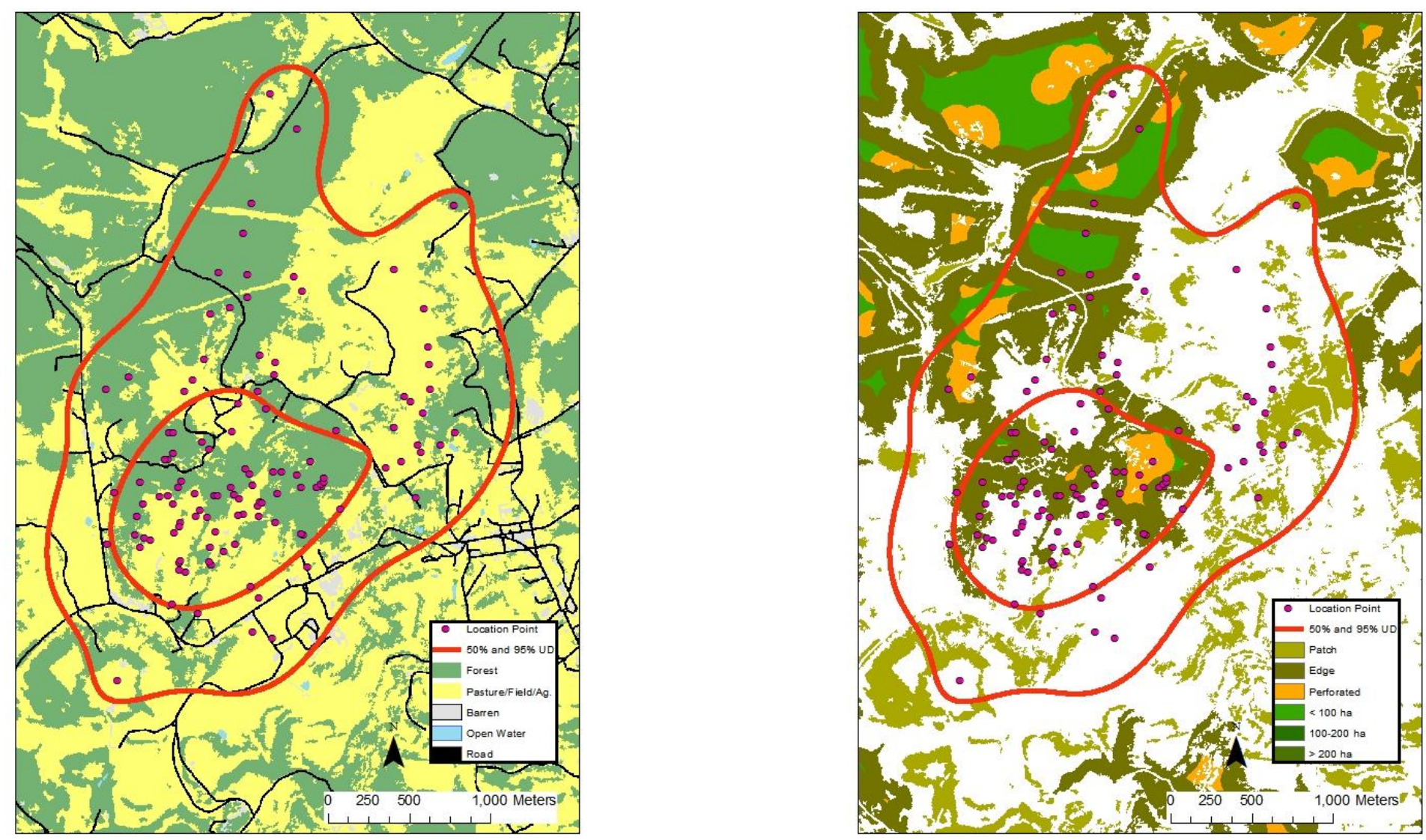
Appendix LXVIII a. 10039 (adult, spring-summer) - 50\% core and 95\% periphery probability contours of the spring-summer Gaussian fixed kernel home range utilization distributions. Smoothing parameter $(h)$ determined by least squares cross validation, Taylor County, West Virginia, 2004-2007 (aspect and slope maps).
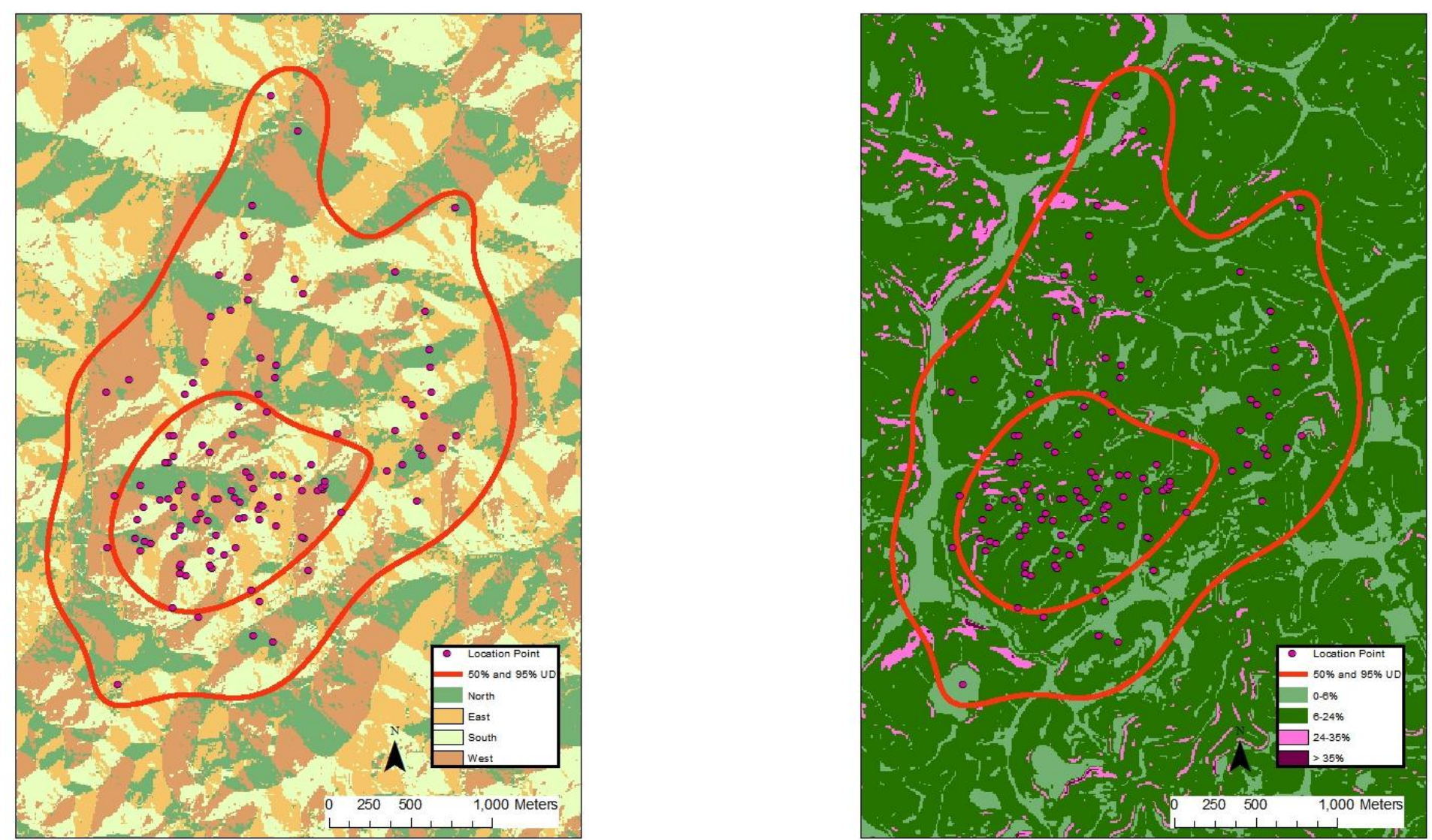
Appendix LXIXa. 10040 (adult, winter) - 50\% core and 95\% periphery probability contours of the winter Gaussian fixed kernel home range utilization distributions. Smoothing parameter $(h)$ determined by least squares cross validation, Taylor County, West Virginia, 2004-2007 (land use and land cover, land fragmentation maps).
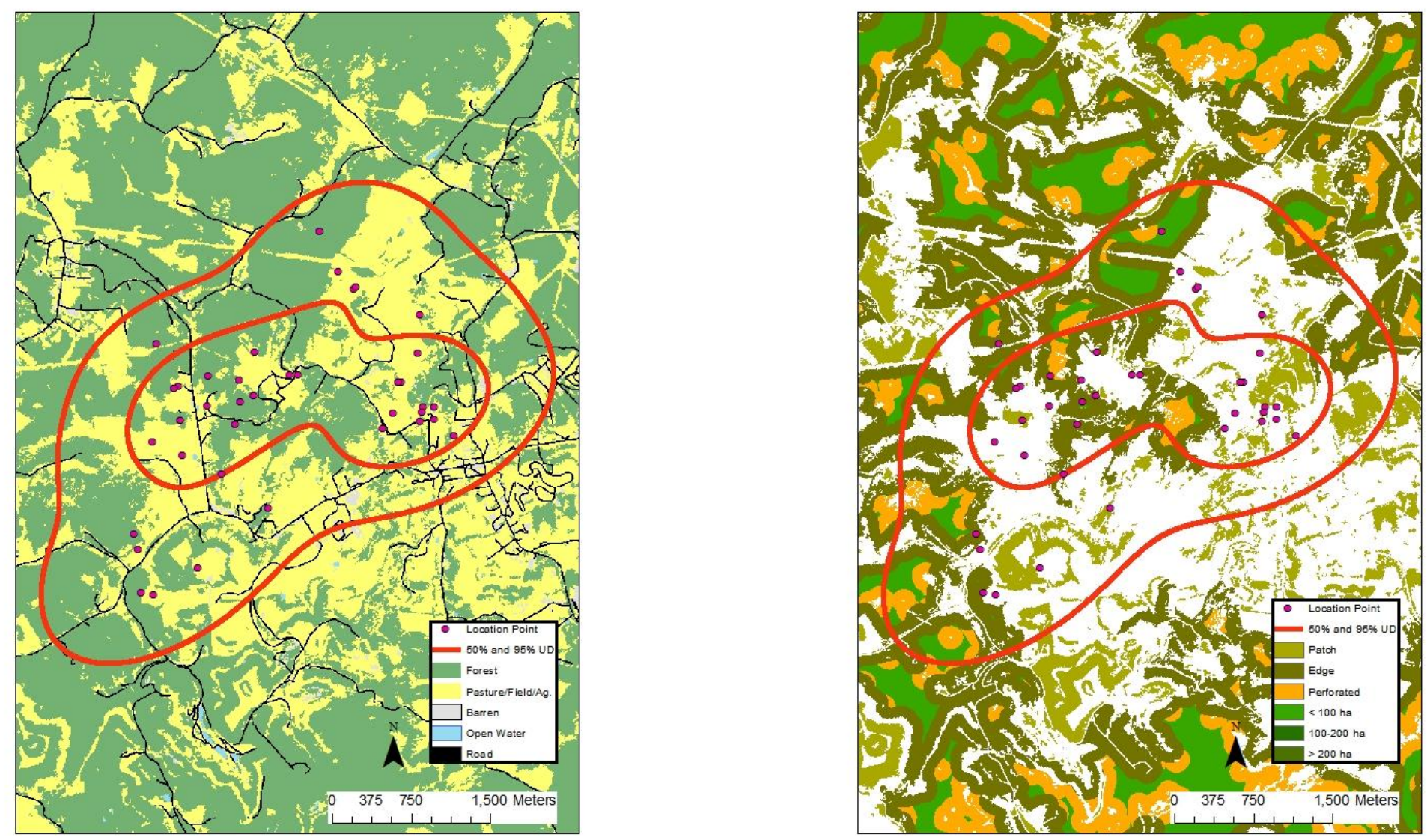
Appendix LXXa. 10040 (adult, winter) - 50\% core and 95\% periphery probability contours of the winter Gaussian fixed kernel home range utilization distributions. Smoothing parameter $(h)$ determined by least squares cross validation, Taylor County, West Virginia, 2004-2007 (aspect and slope maps).
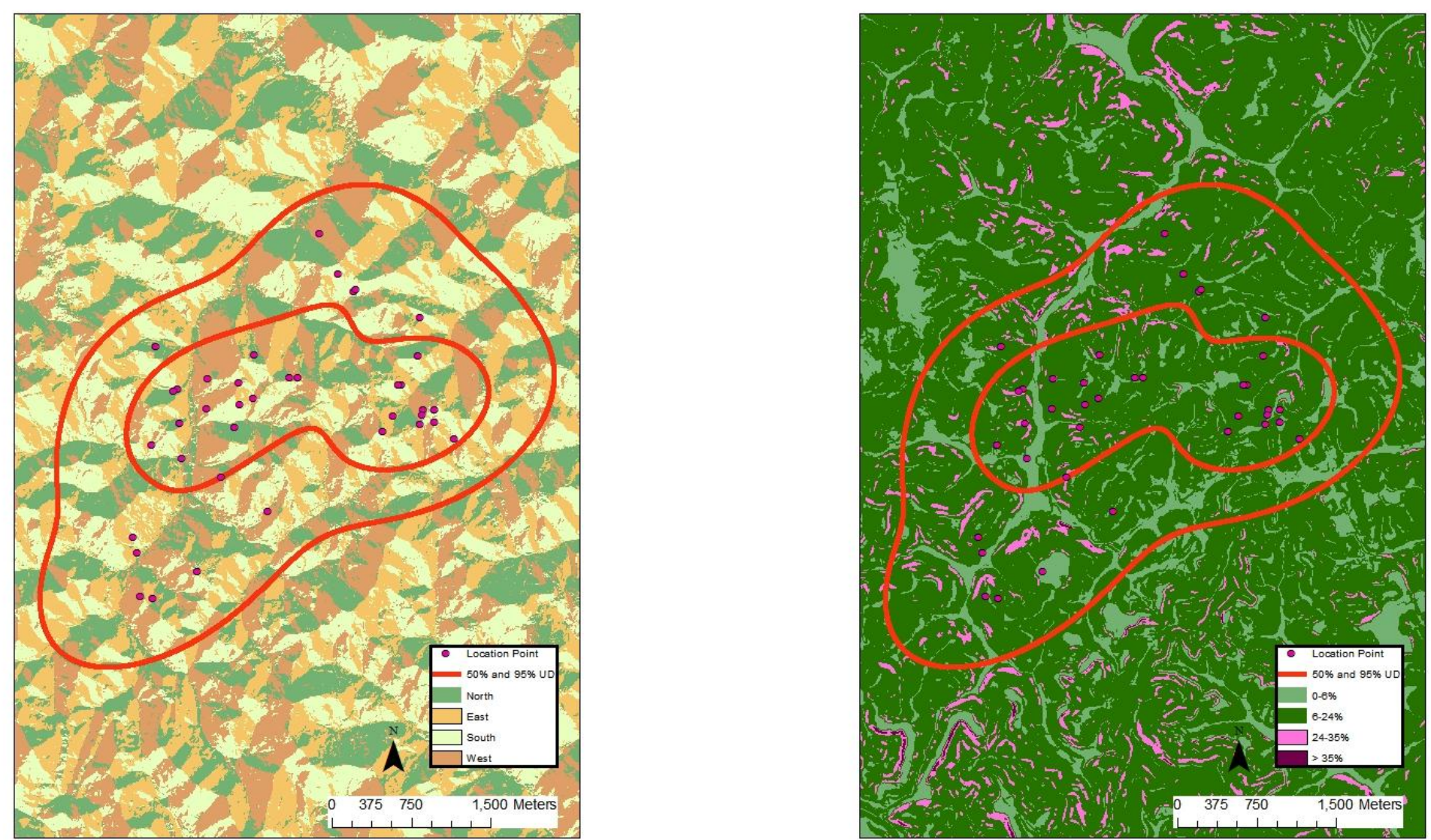
Appendix LXXIa. 10041 (adult, annual) - 50\% core and 95\% periphery probability contours of the annual Gaussian fixed kernel home range utilization distributions. Smoothing parameter $(h)$ determined by least squares cross validation, Taylor County, West Virginia, 2004-2007 (land use and land cover, land fragmentation maps).
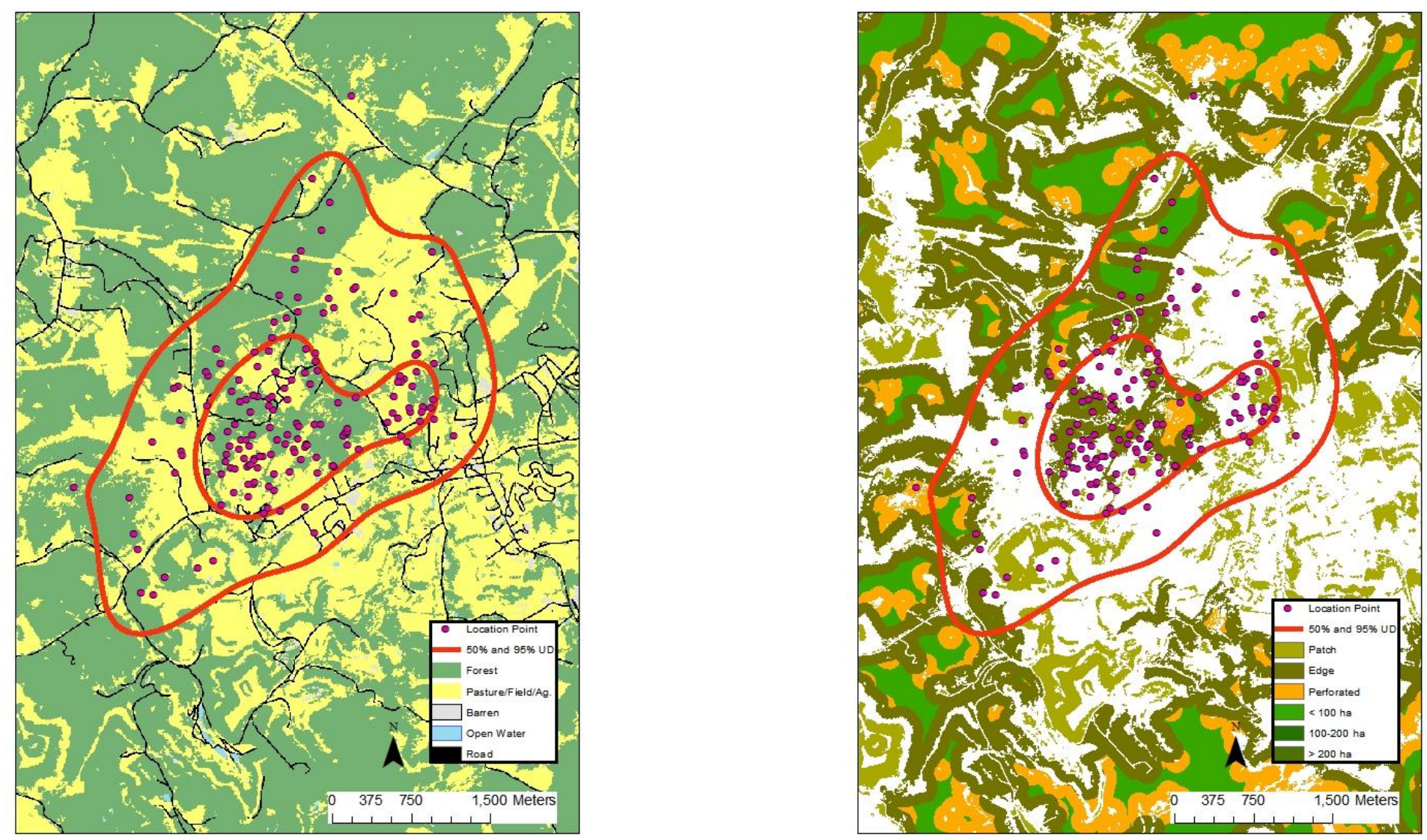
Appendix LXXIIa. 10041 (adult, annual) - 50\% core and 95\% periphery probability contours of the annual Gaussian fixed kernel home range utilization distributions. Smoothing parameter $(h)$ determined by least squares cross validation, Taylor County, West Virginia, 2004-2007 (aspect and slope maps).
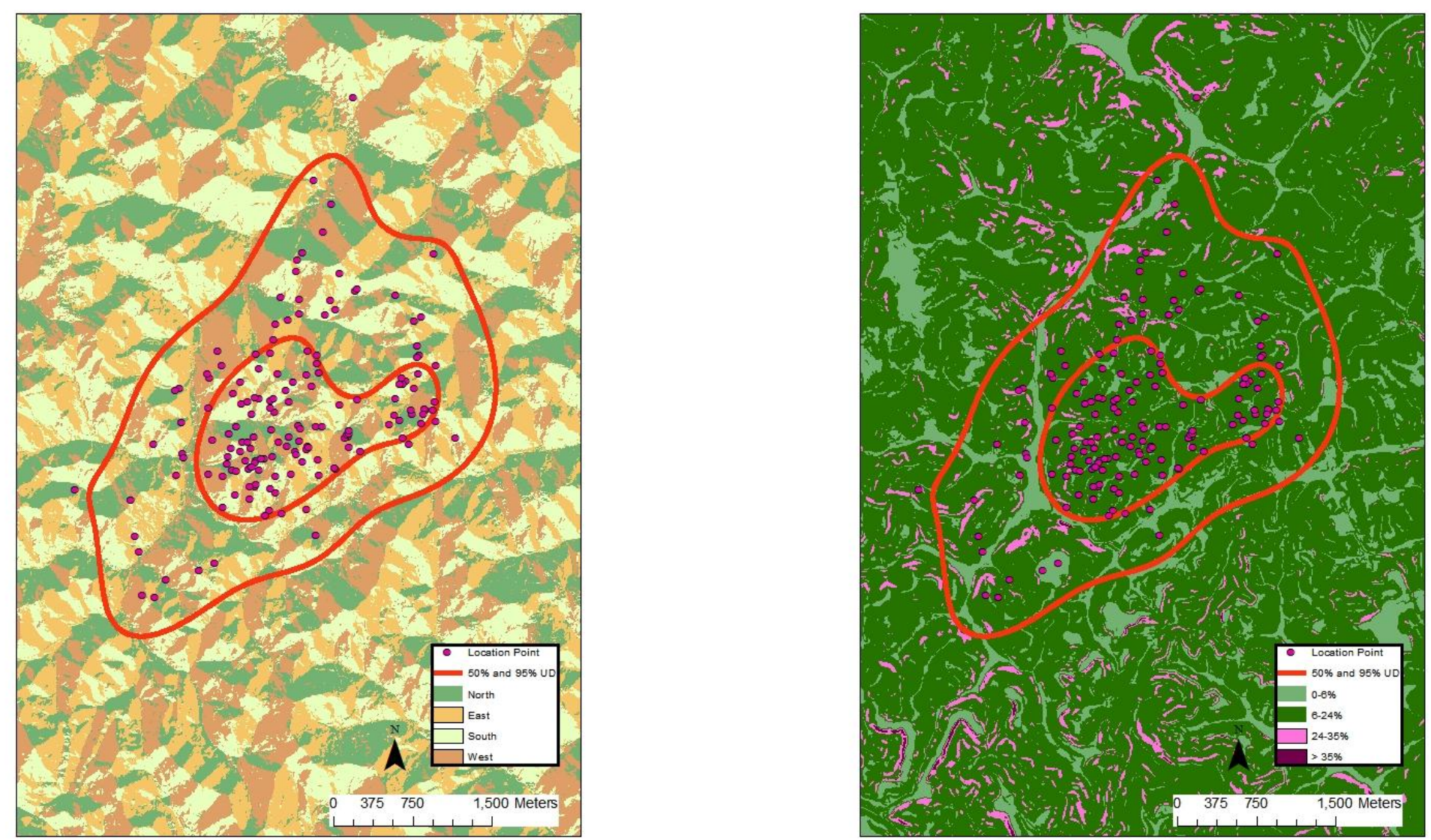
Appendix LXXIIIa. 10043 (adult, fall) - 50\% core and 95\% periphery probability contours of the fall Gaussian fixed kernel home range utilization distributions. Smoothing parameter $(h)$ determined by least squares cross validation, Taylor County, West Virginia, 2004-2007 (land use and land cover, land fragmentation maps).
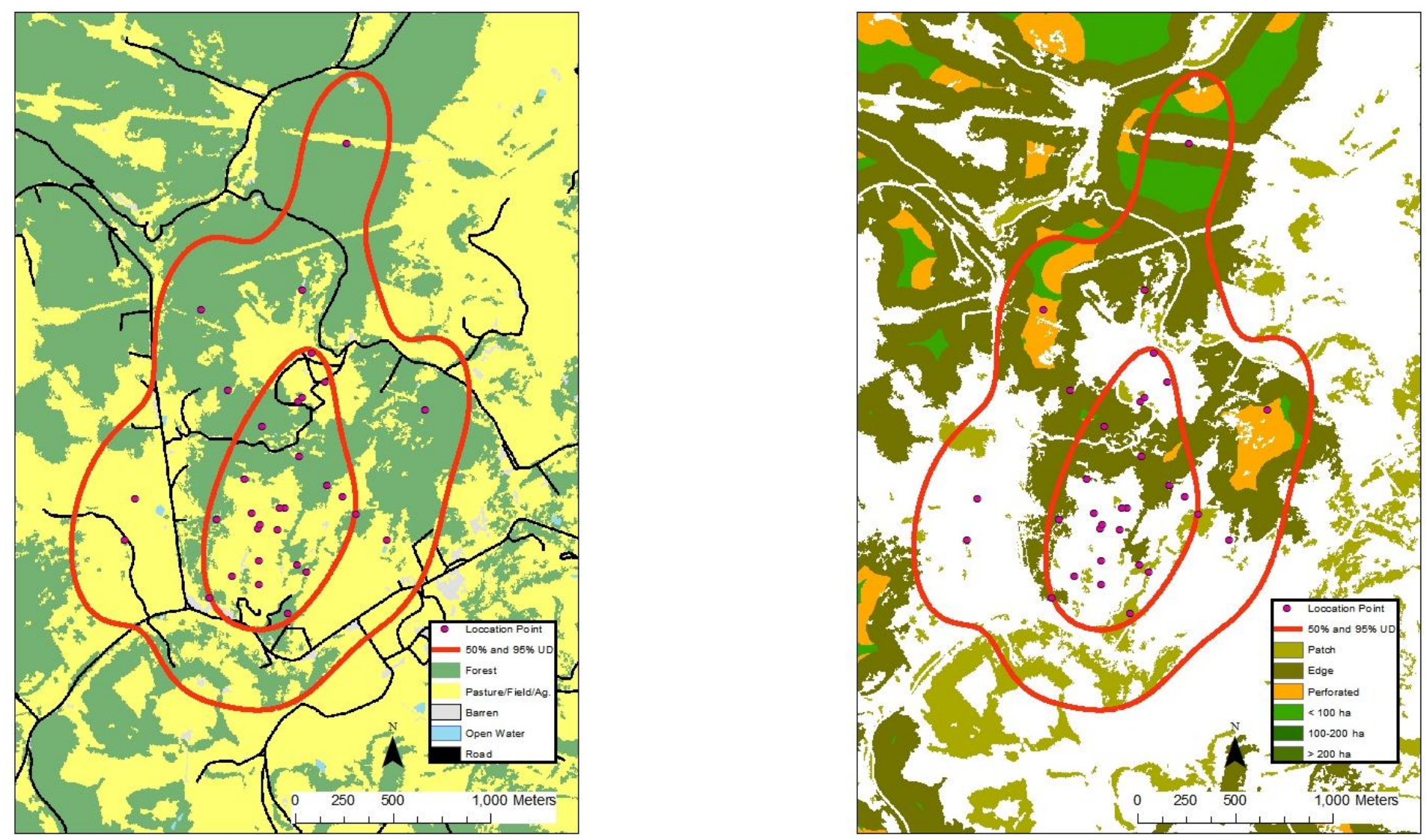
Appendix LXXIVa. 10043 (adult, fall) - 50\% core and 95\% periphery probability contours of the fall Gaussian fixed kernel home range utilization distributions. Smoothing parameter $(h)$ determined by least squares cross validation, Taylor County, West Virginia, 2004-2007 (aspect and slope maps).
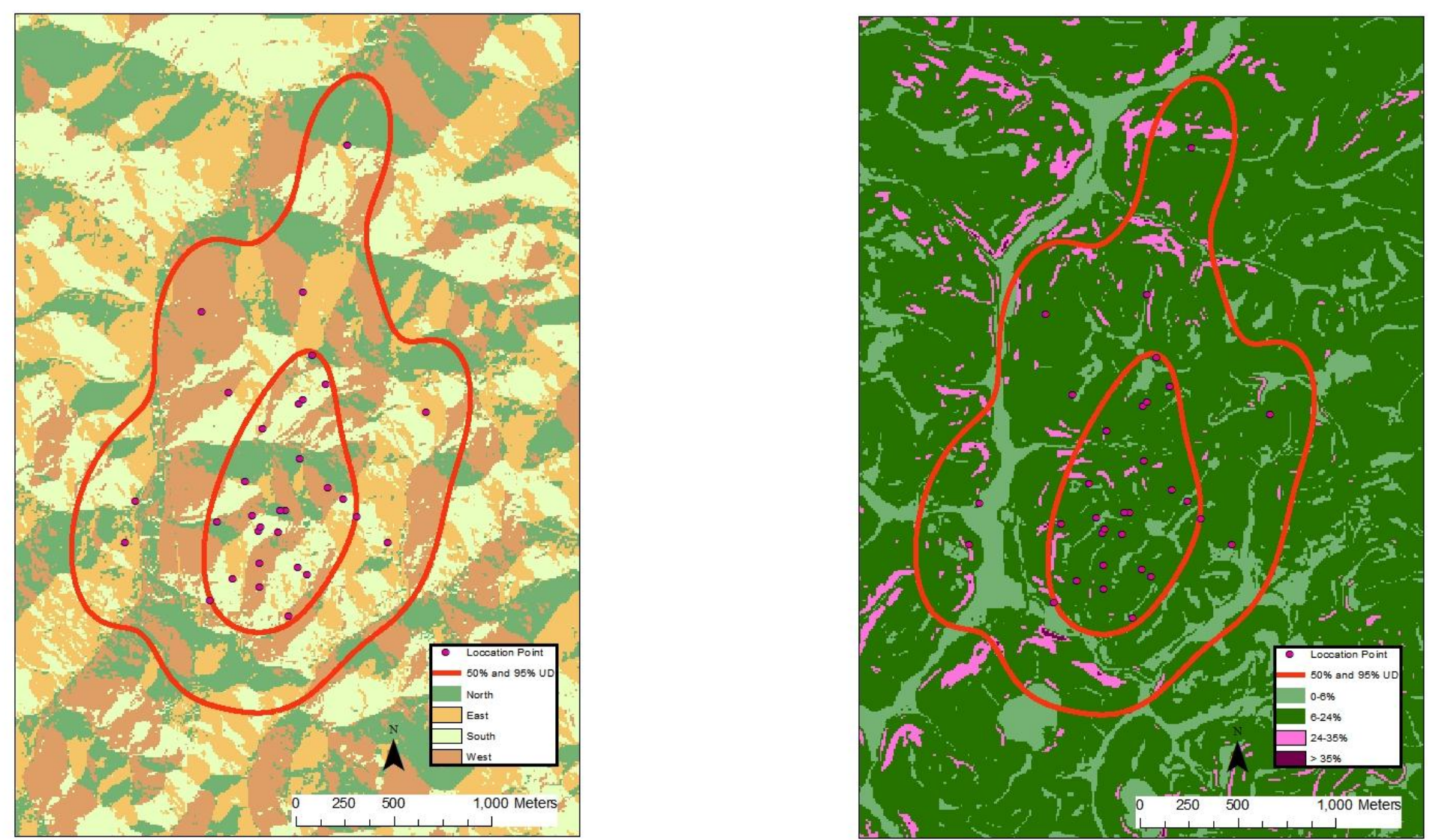
Appendix LXXVa. 10044 (adult, fall-winter) - 50\% core and 95\% periphery probability contours of the fall-winter Gaussian fixed kernel home range utilization distributions. Smoothing parameter $(h)$ determined by least squares cross validation, Taylor County, West Virginia, 2004-2007 (land use and land cover, land fragmentation maps).
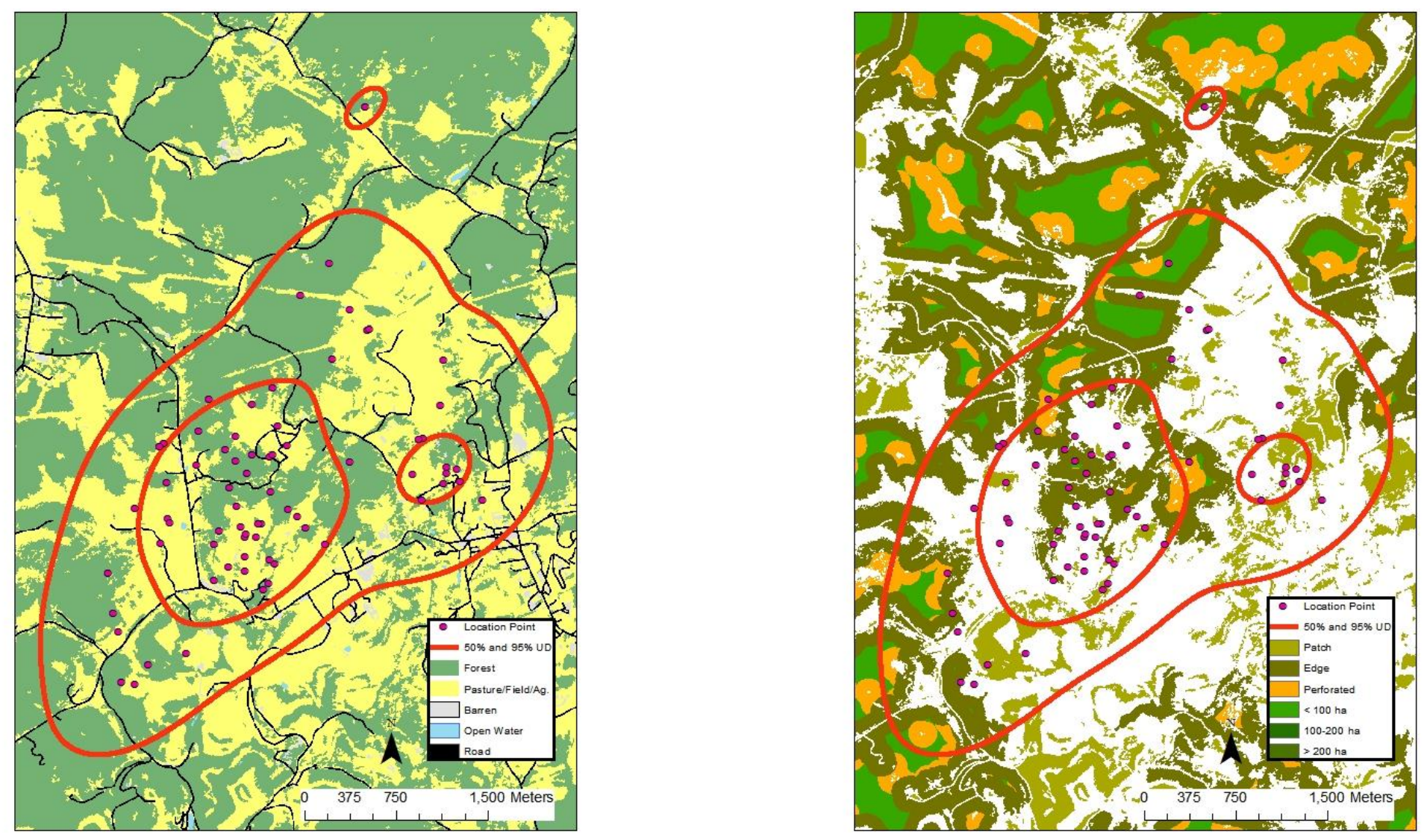
Appendix LXXVIa. 10044 (adult, fall-winter) - 50\% core and 95\% periphery probability contours of the fall-winter Gaussian fixed kernel home range utilization distributions. Smoothing parameter $(h)$ determined by least squares cross validation, Taylor County, West Virginia, 2004-2007 (aspect and slope maps).
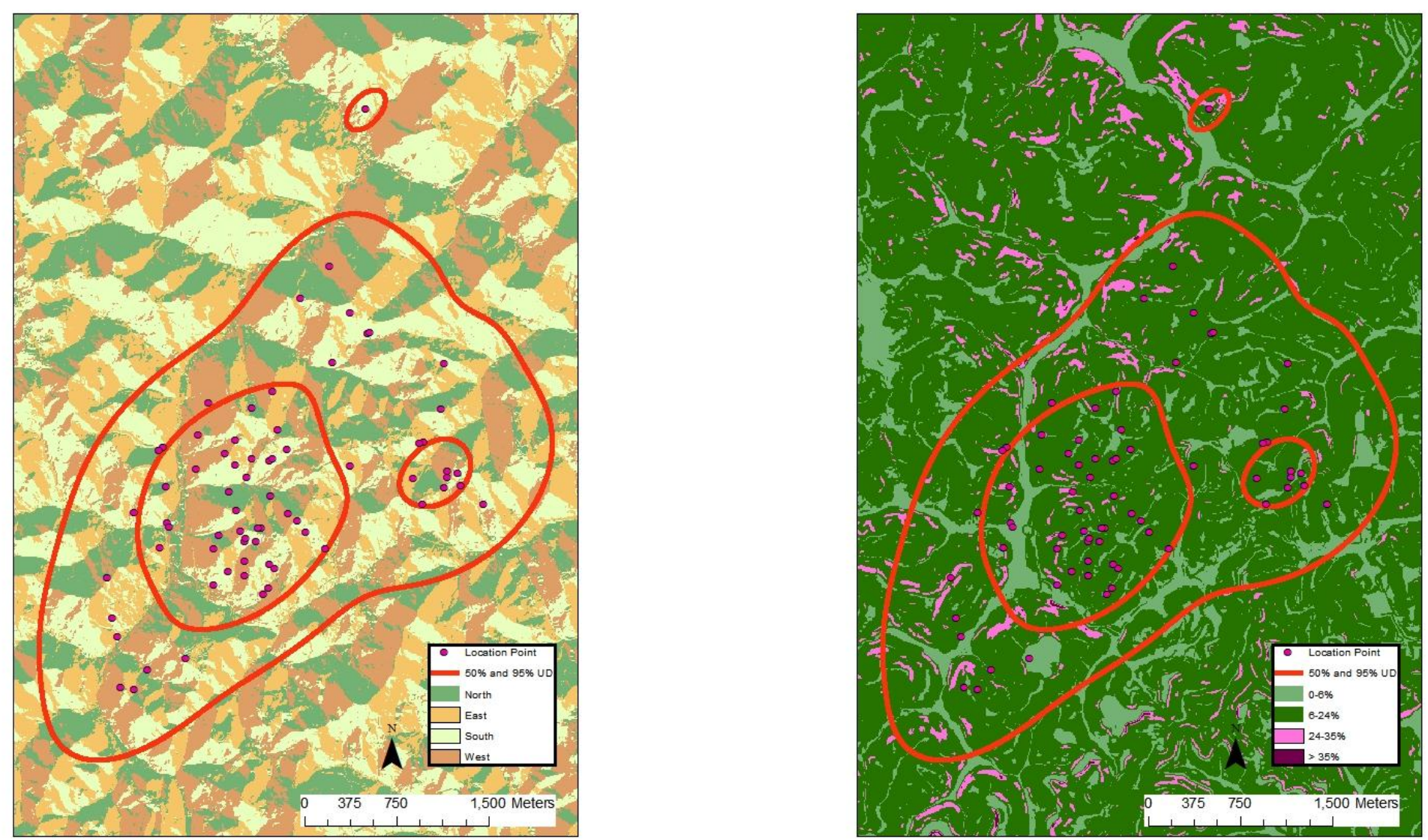
Appendix LXXVIIa. 10045 (adult, spring) - 50\% core and 95\% periphery probability contours of the spring Gaussian fixed kernel home range utilization distributions. Smoothing parameter $(h)$ determined by least squares cross validation, Taylor County, West Virginia, 2004-2007 (land use and land cover, land fragmentation maps).
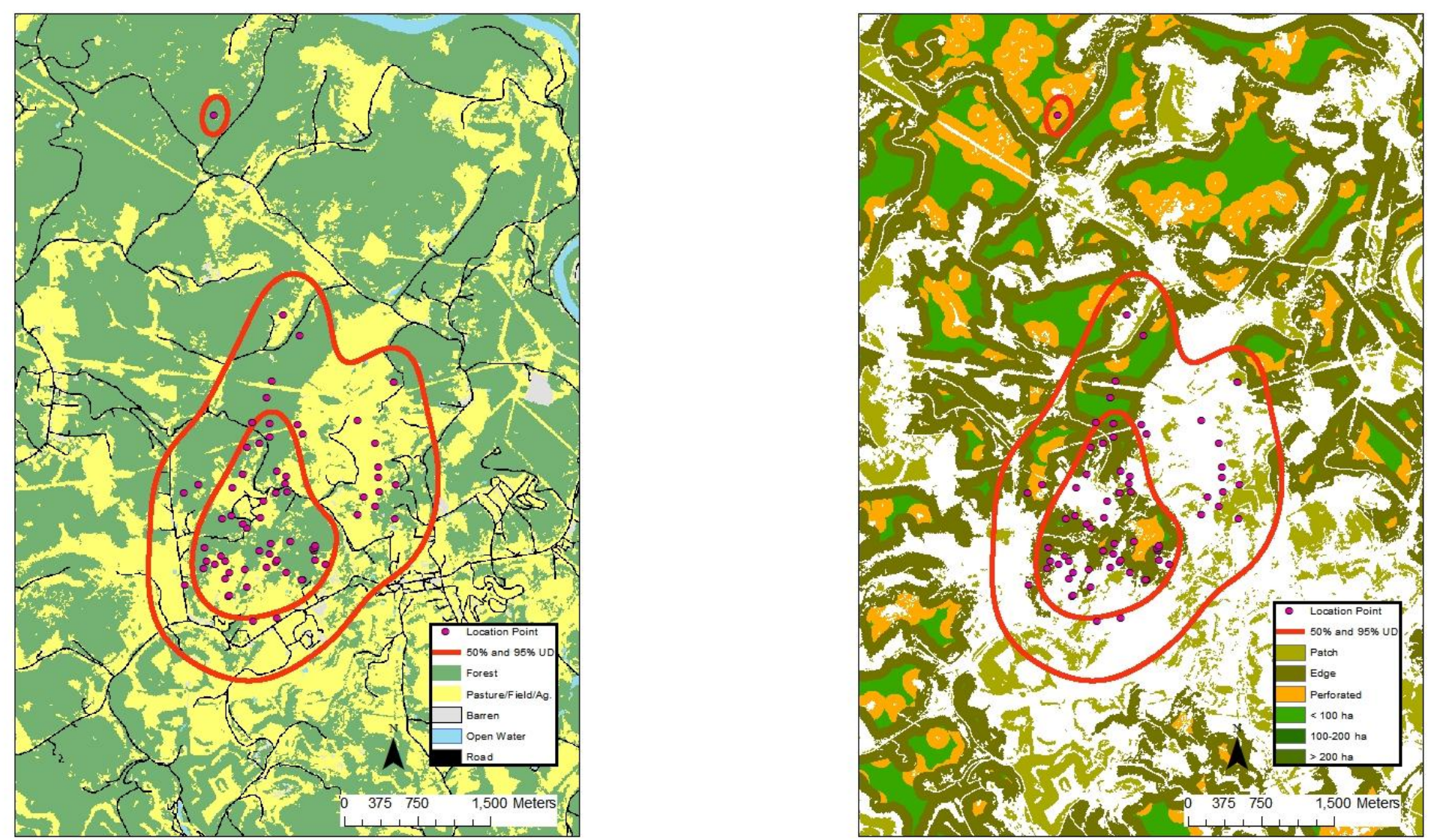
Appendix LXXVIIIa. 10045 (adult, spring) - 50\% core and 95\% periphery probability contours of the spring Gaussian fixed kernel home range utilization distributions. Smoothing parameter $(h)$ determined by least squares cross validation, Taylor County, West Virginia, 2004-2007 (aspect and slope maps).
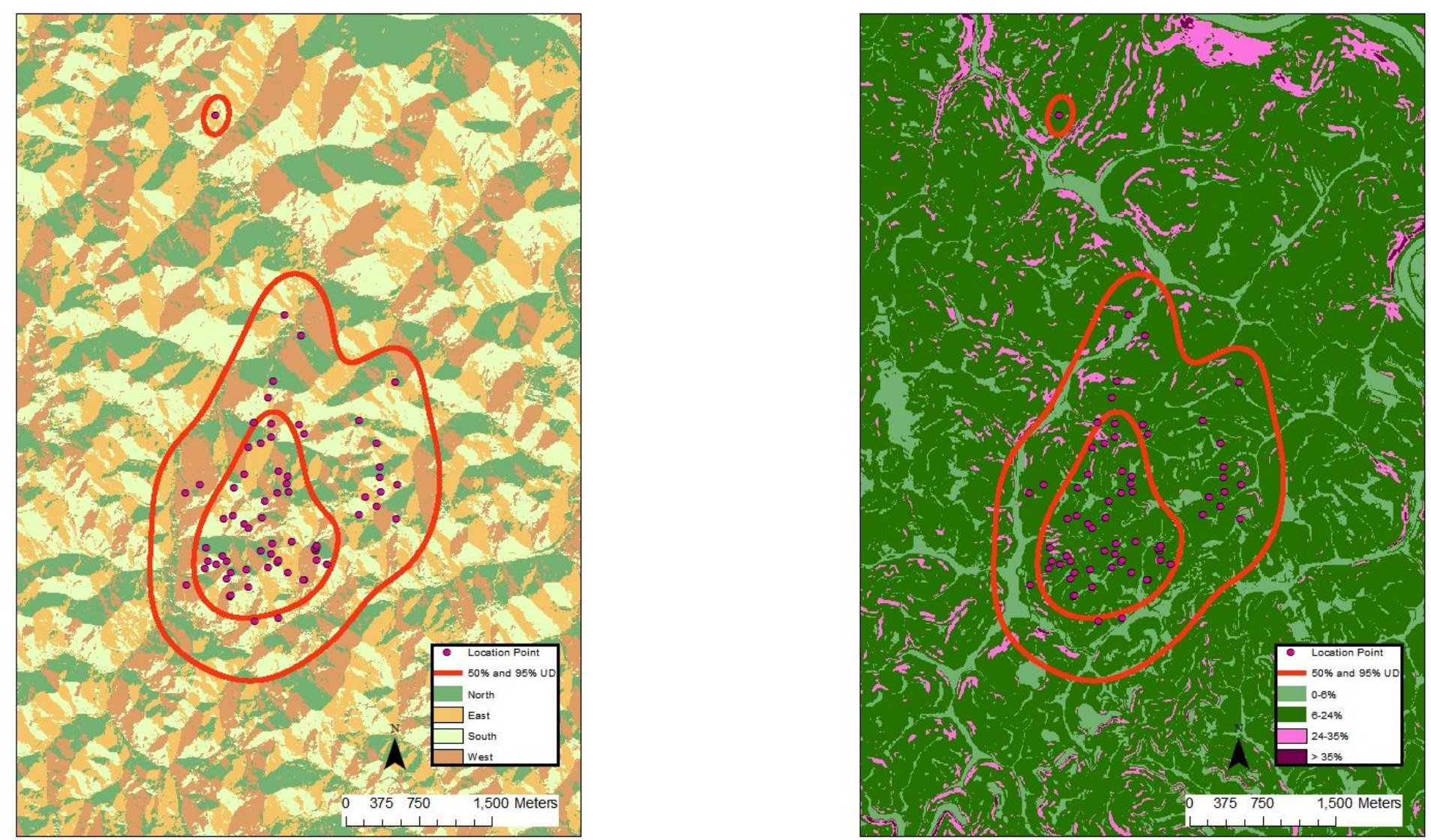
Appendix LXXIXa. 10046 (adult, spring-summer) - 50\% core and 95\% periphery probability contours of the spring-summer Gaussian fixed kernel home range utilization distributions. Smoothing parameter $(h)$ determined by least squares cross validation, Taylor County, West Virginia, 2004-2007 (land use and land cover, land fragmentation maps).
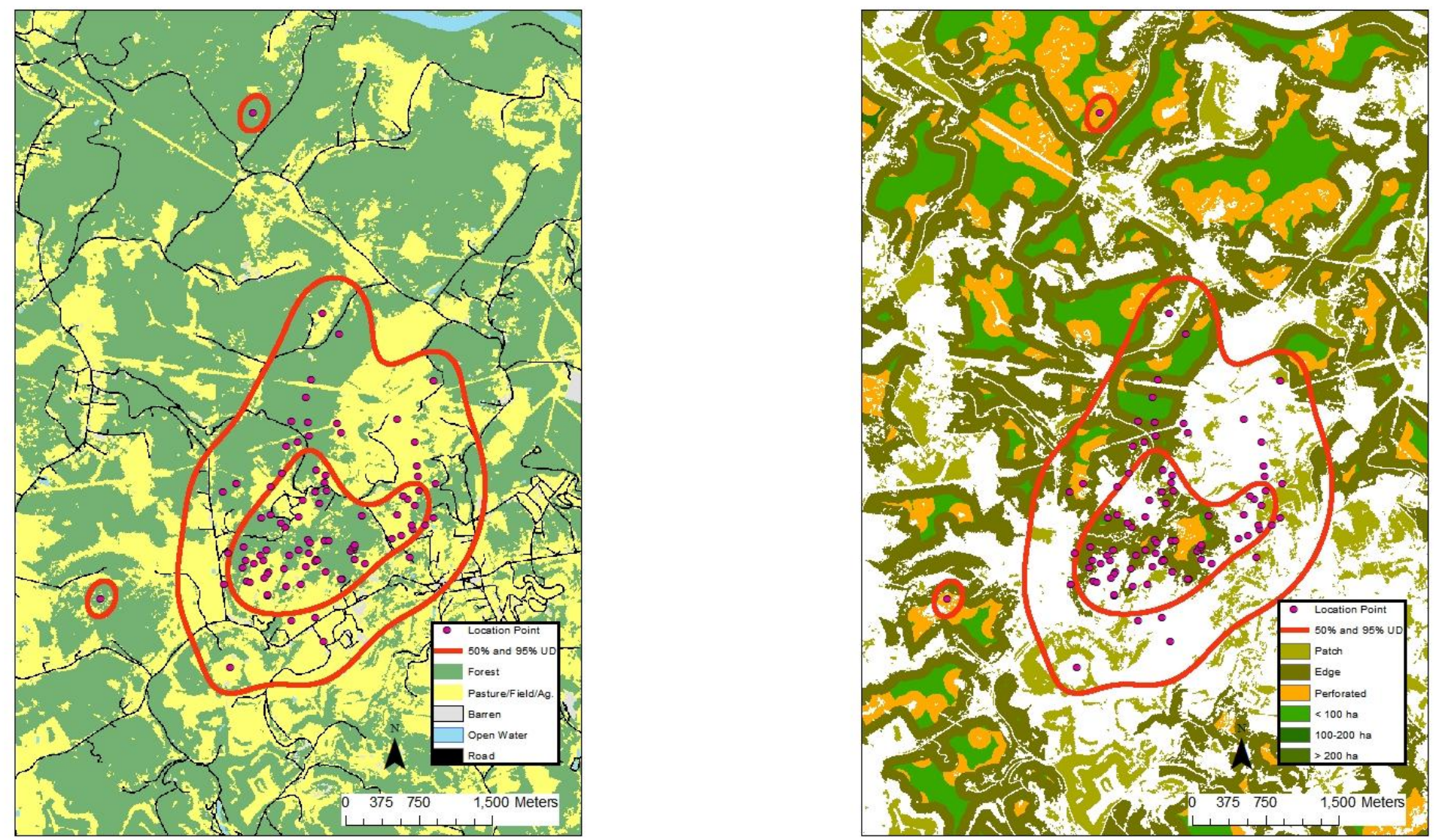
Appendix LXXXa. 10046 (adult, spring-summer) - 50\% core and 95\% periphery probability contours of the spring-summer Gaussian fixed kernel home range utilization distributions. Smoothing parameter $(h)$ determined by least squares cross validation, Taylor County, West Virginia, 2004-2007 (aspect and slope maps).
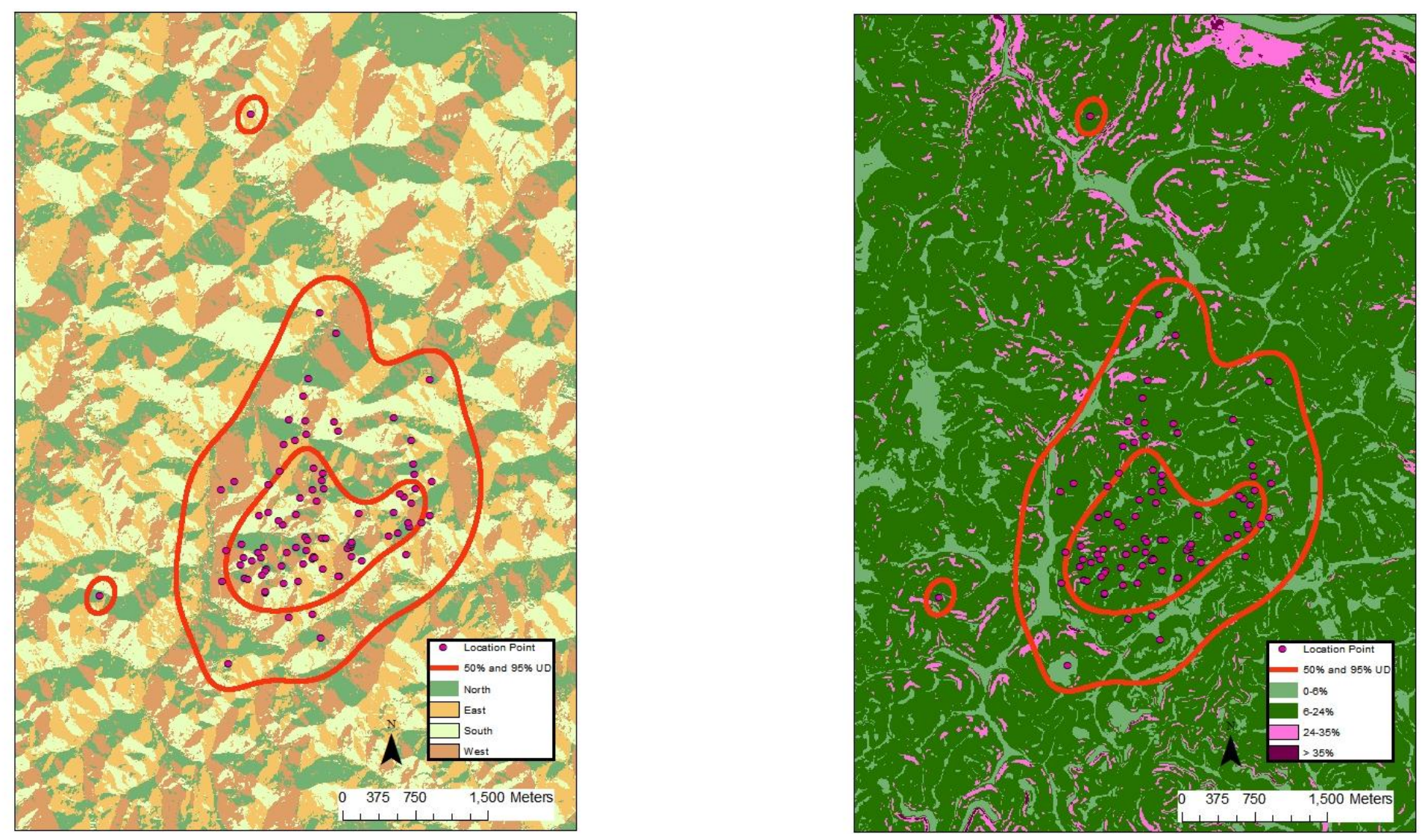
Appendix LXXXIa. 10047 (adult, winter) - 50\% core and 95\% periphery probability contours of the winter Gaussian fixed kernel home range utilization distributions. Smoothing parameter $(h)$ determined by least squares cross validation, Taylor County, West Virginia, 2004-2007 (land use and land cover, land fragmentation maps).
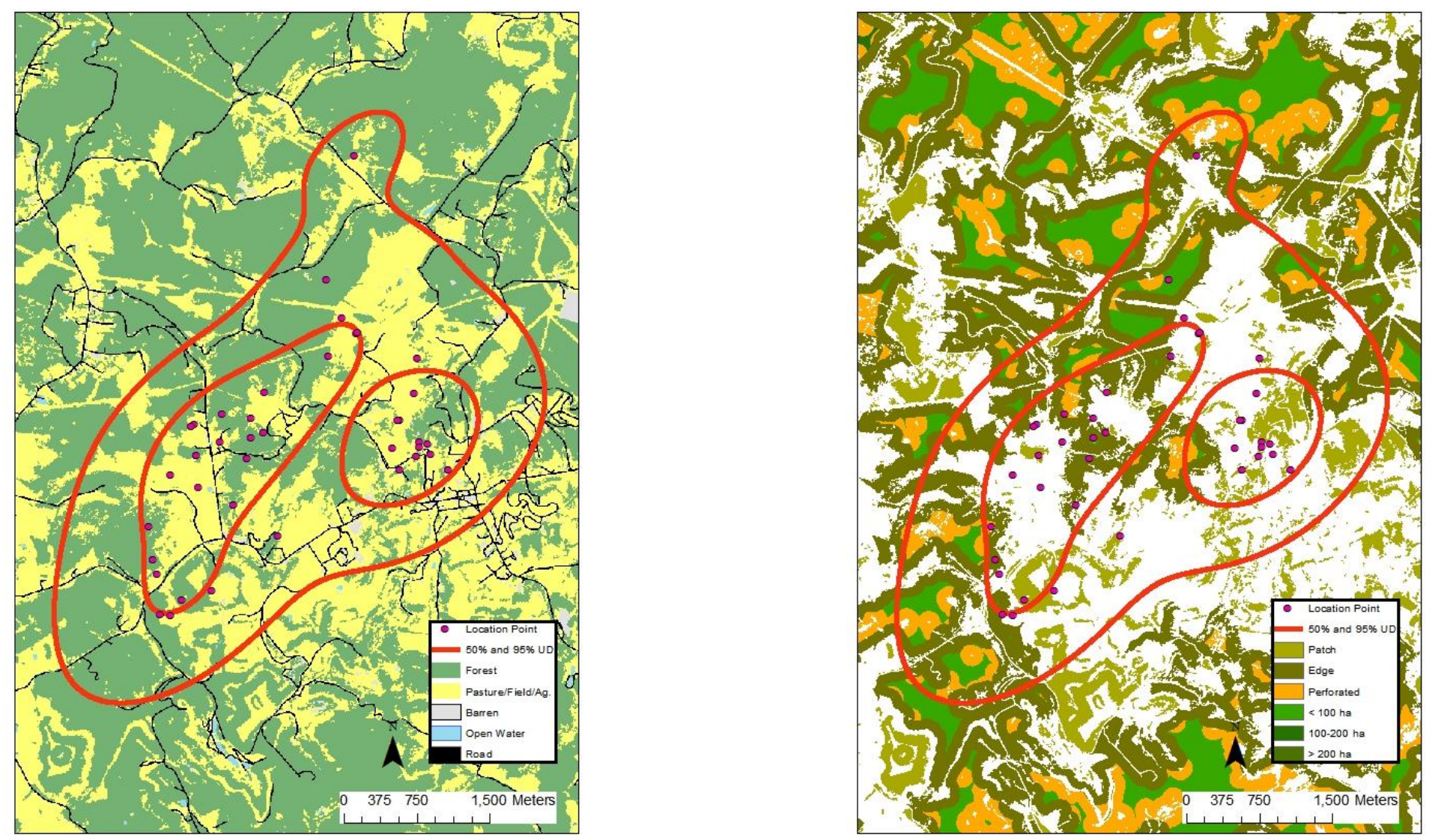
Appendix LXXXIIa. 10047 (adult, winter) - 50\% core and 95\% periphery probability contours of the winter Gaussian fixed kernel home range utilization distributions. Smoothing parameter $(h)$ determined by least squares cross validation, Taylor County, West Virginia, 2004-2007 (aspect and slope maps).
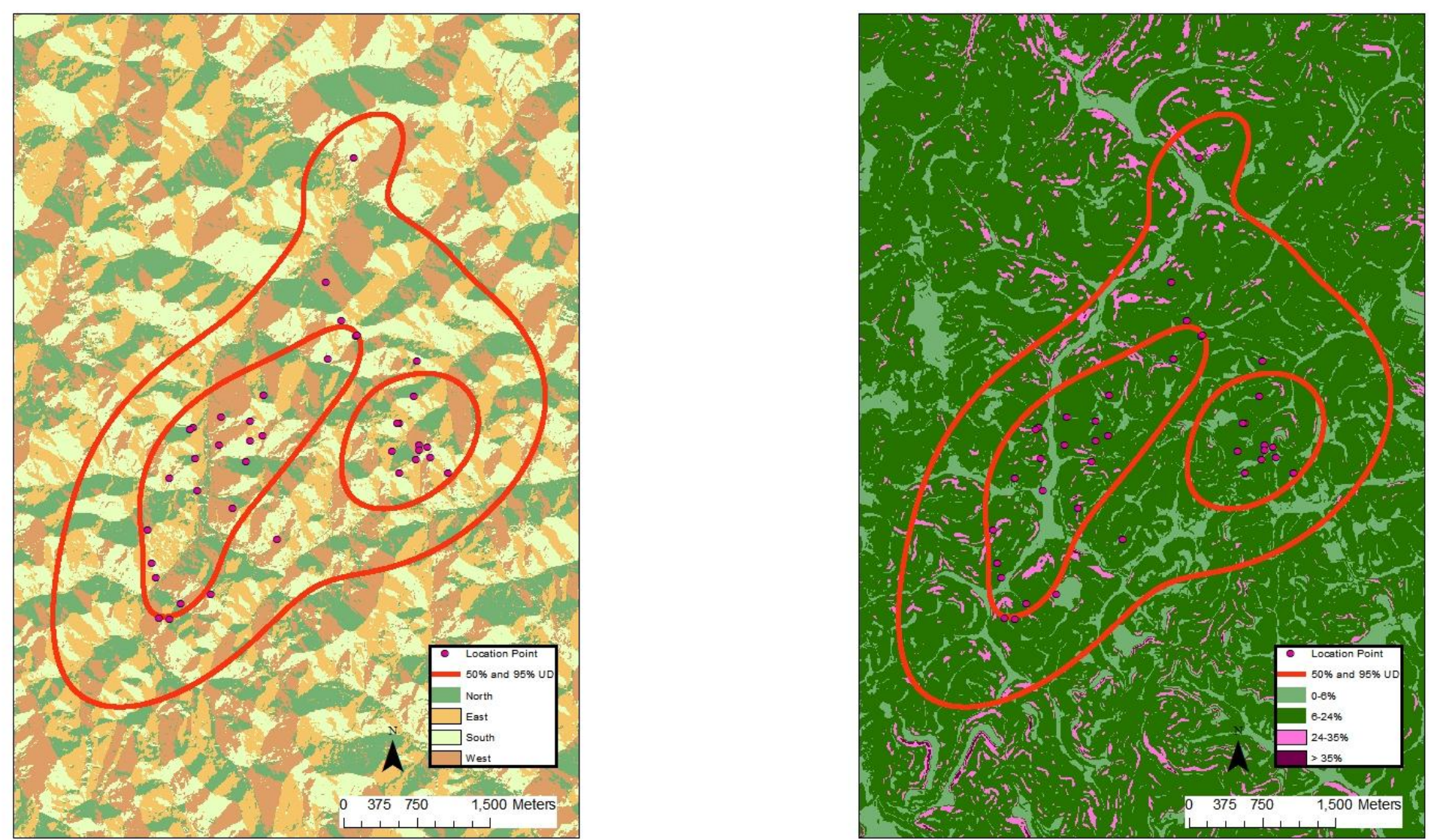
Appendix LXXXIII $a .10048$ (adult, annual) - 50\% core and 95\% periphery probability contours of the annual Gaussian fixed kernel home range utilization distributions. Smoothing parameter $(h)$ determined by least squares cross validation, Taylor County, West Virginia, 2004-2007 (land use and land cover, land fragmentation maps).
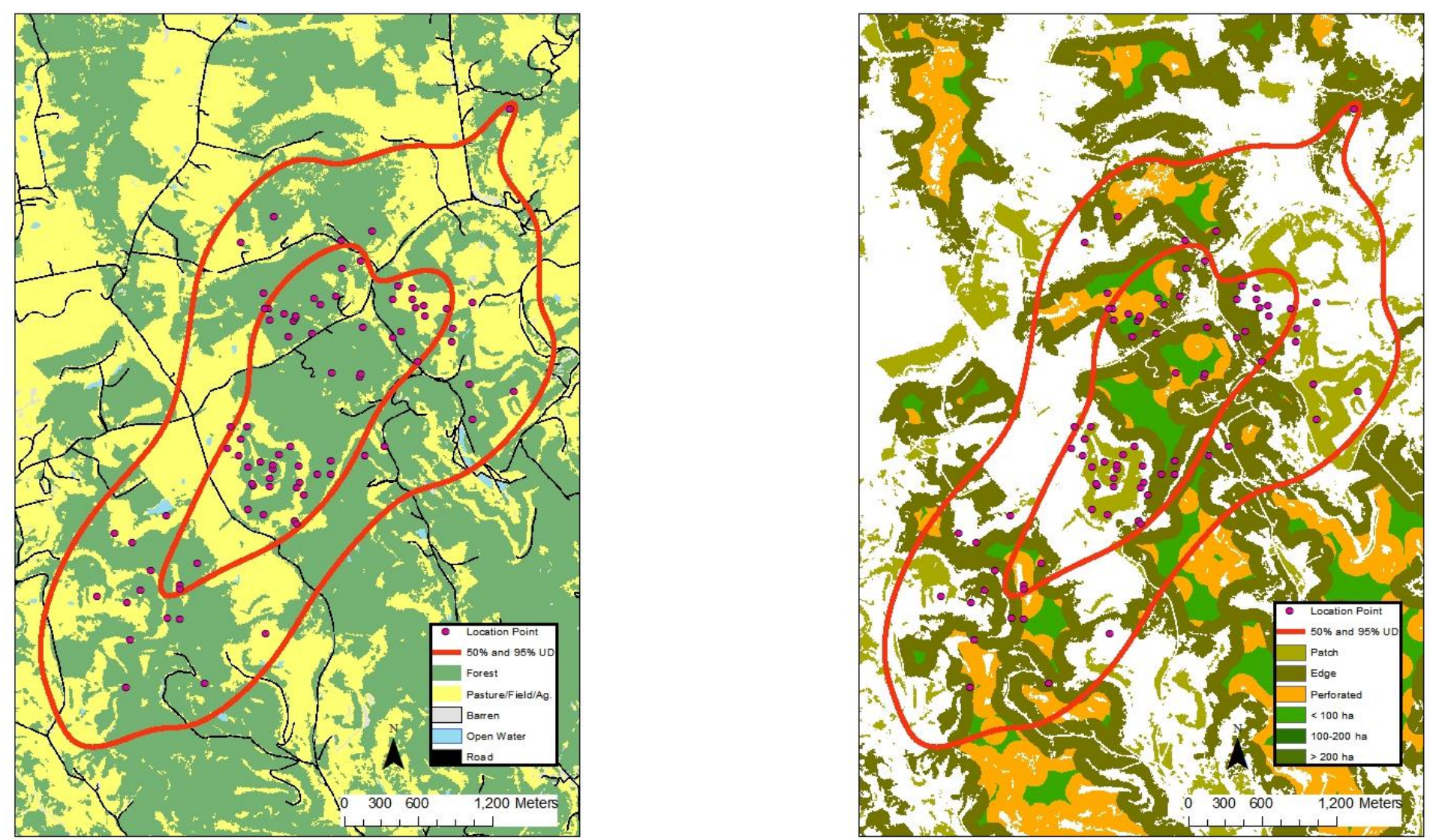
Appendix LXXXIVa. 10048 (adult, annual) - 50\% core and 95\% periphery probability contours of the annual Gaussian fixed kernel home range utilization distributions. Smoothing parameter $(h)$ determined by least squares cross validation, Taylor County, West Virginia, 2004-2007 (aspect and slope maps).
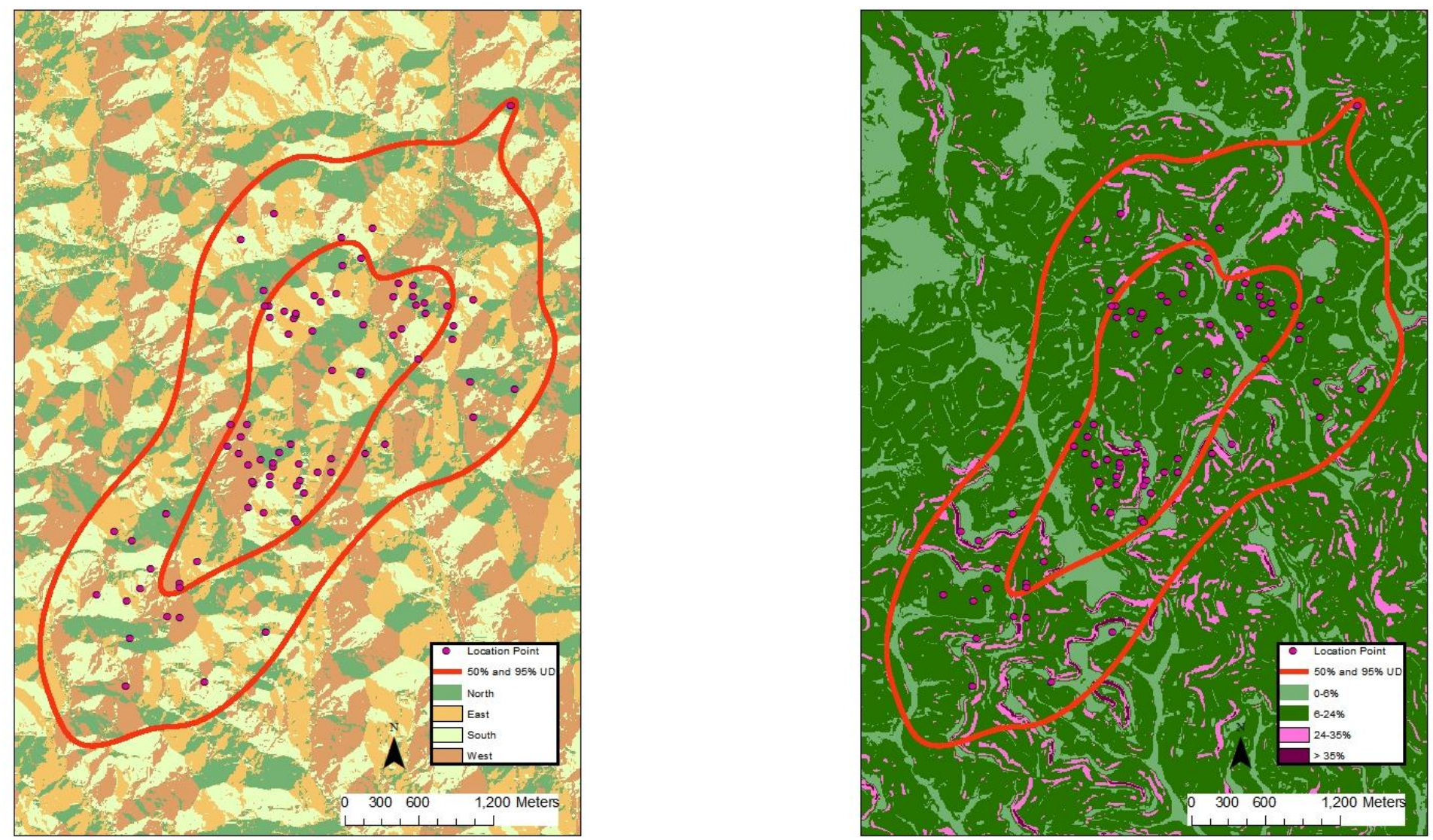
Appendix LXXXVa. 10050 (adult, fall-winter) - 50\% core and 95\% periphery probability contours of the fall-winter Gaussian fixed kernel home range utilization distributions. Smoothing parameter $(h)$ determined by least squares cross validation, Taylor County, West Virginia, 2004-2007 (land use and land cover, land fragmentation maps).
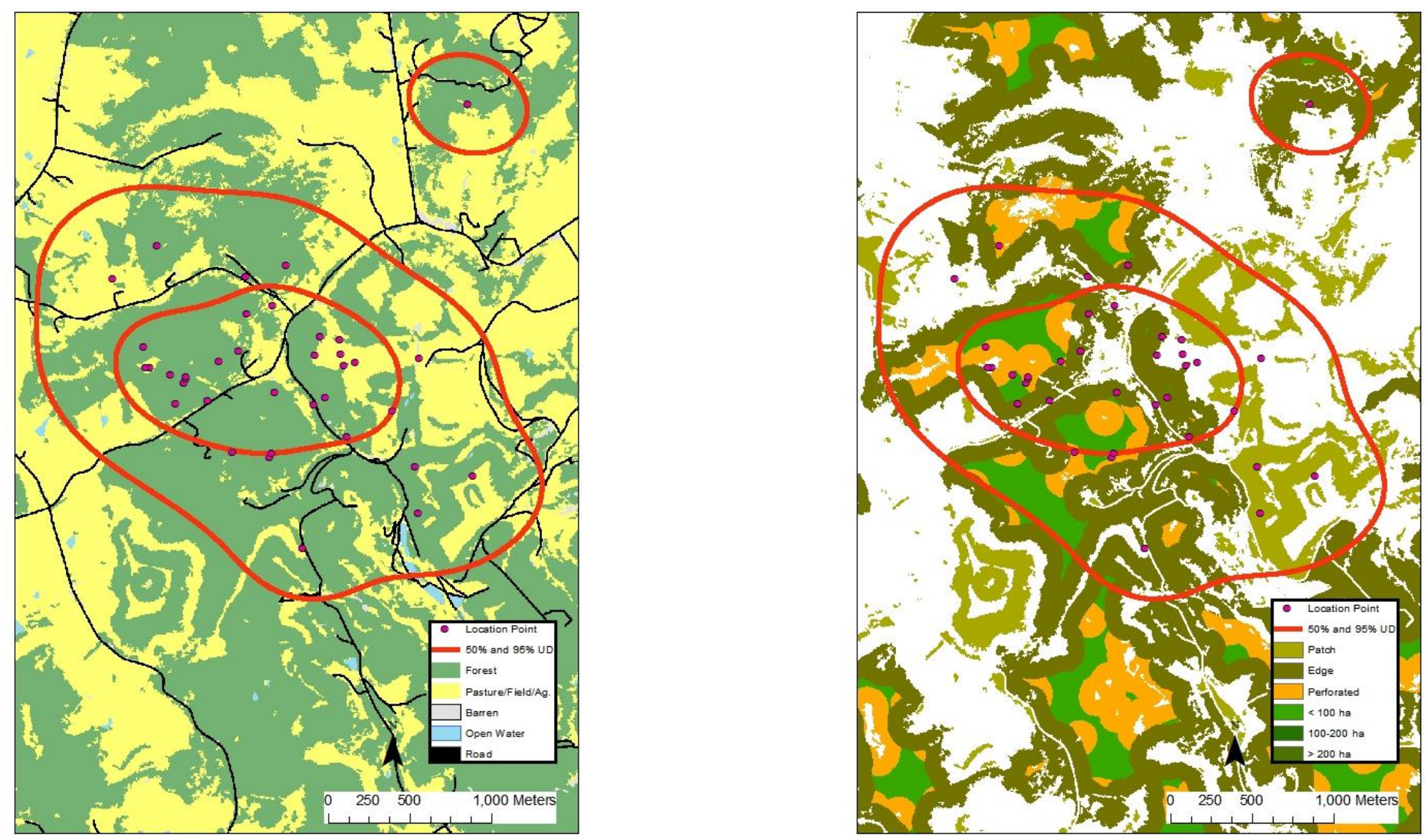
Appendix LXXXVIa. 10050 (adult, fall-winter) - 50\% core and 95\% periphery probability contours of the fall-winter Gaussian fixed kernel home range utilization distributions. Smoothing parameter $(h)$ determined by least squares cross validation, Taylor County, West Virginia, 2004-2007 (aspect and slope maps).
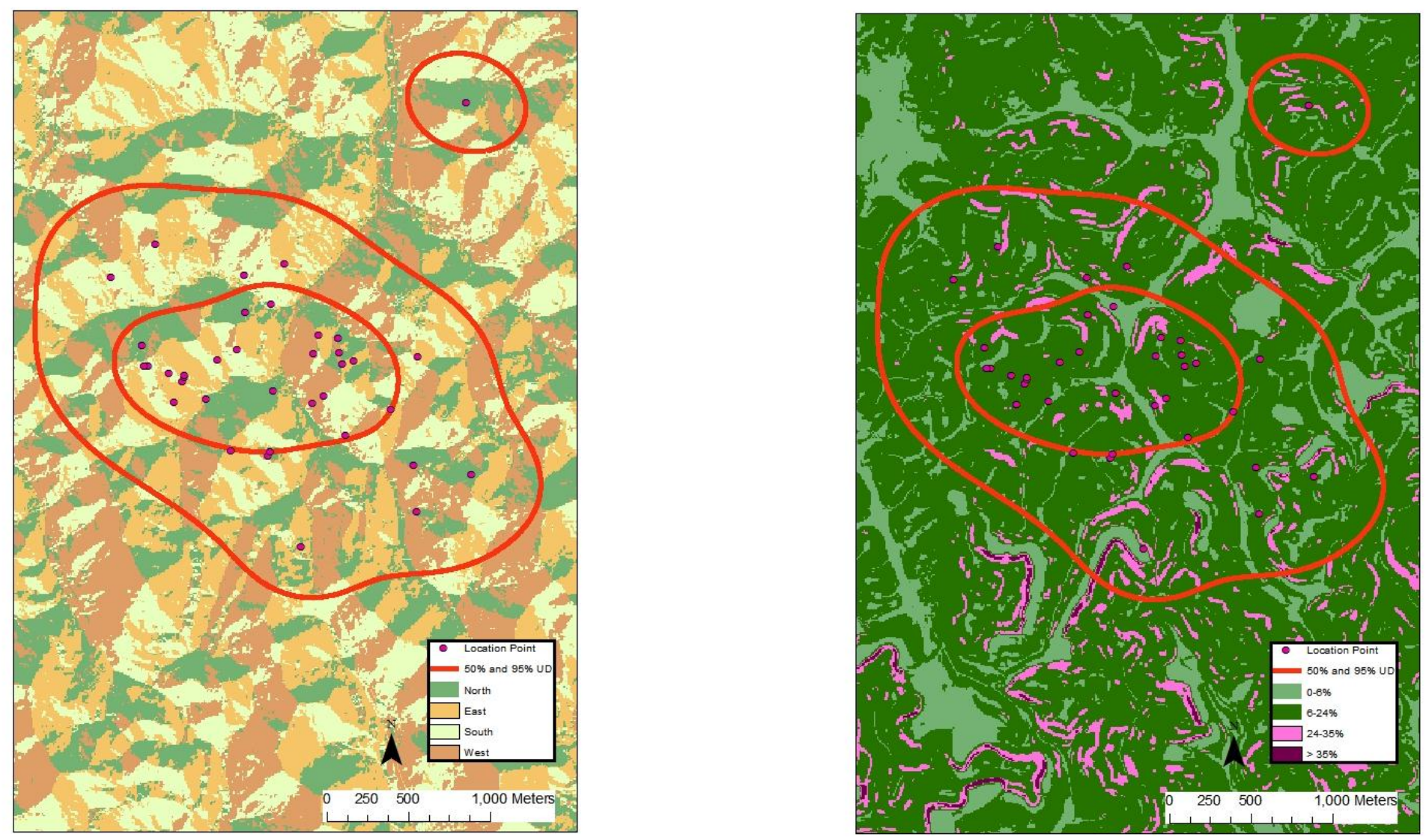
Appendix LXXXVIIa. 10051 (juvenile, annual) - 50\% core and 95\% periphery probability contours of the annual Gaussian fixed kernel home range utilization distributions. Smoothing parameter $(h)$ determined by least squares cross validation, Taylor County, West Virginia, 2004-2007 (land use and land cover, land fragmentation maps).
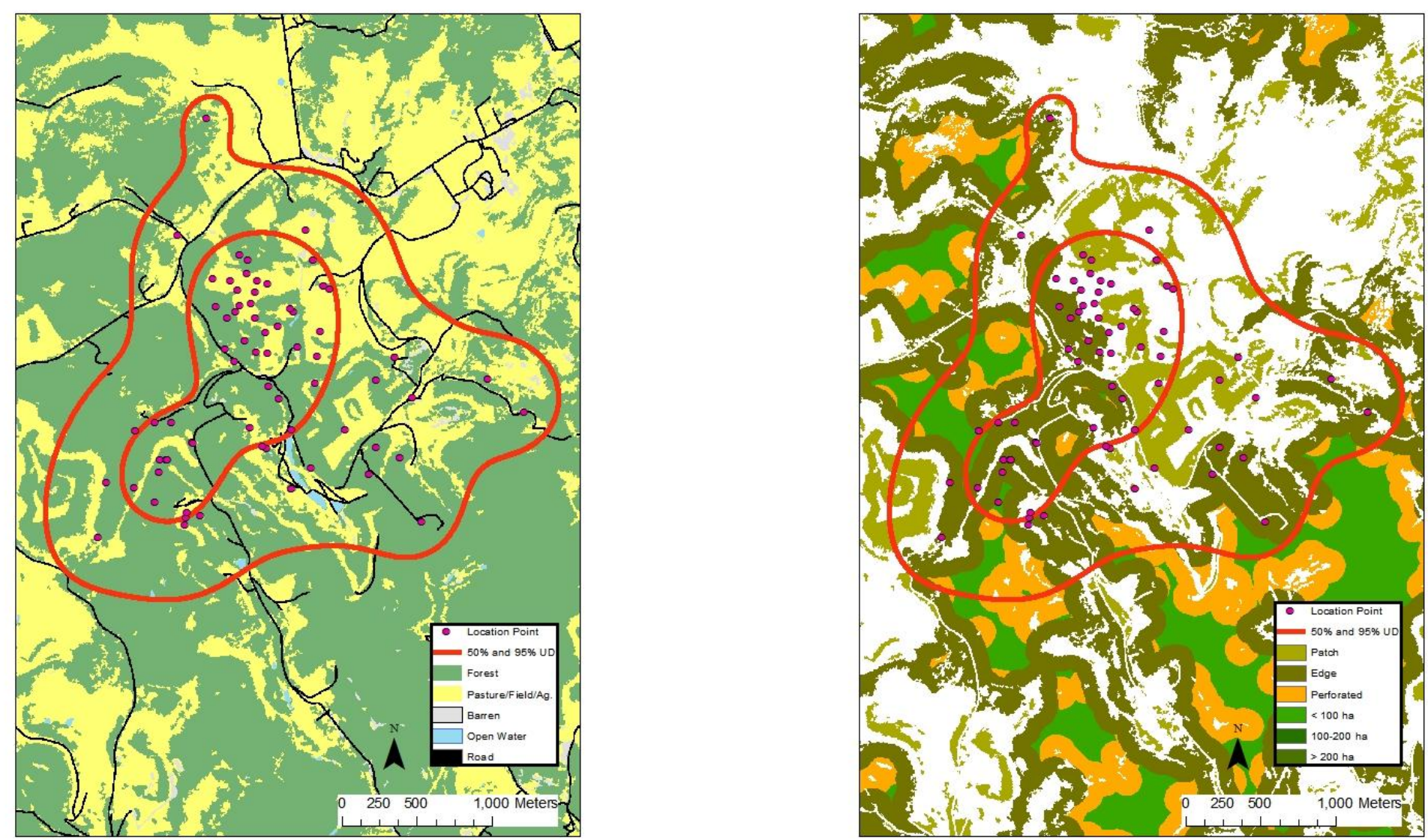
Appendix LXXXVIIa. 10051 (juvenile, annual) - 50\% core and 95\% periphery probability contours of the annual Gaussian fixed kernel home range utilization distributions. Smoothing parameter $(h)$ determined by least squares cross validation, Taylor County, West Virginia, 2004-2007 (aspect and slope maps).
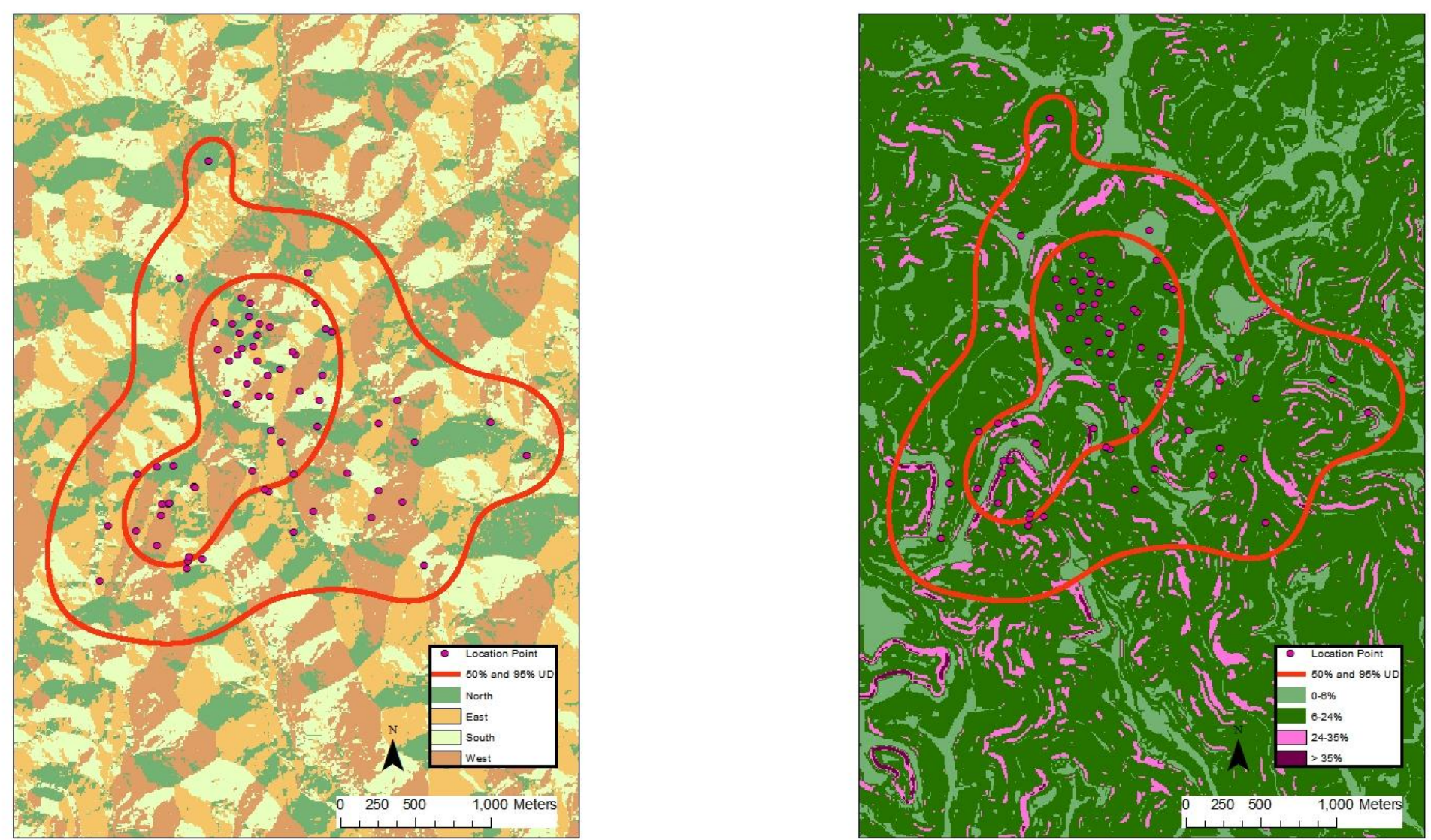
Appendix LXXXIXa. 10053 (juvenile, spring) - 50\% core and 95\% periphery probability contours of the spring Gaussian fixed kernel home range utilization distributions. Smoothing parameter $(h)$ determined by least squares cross validation, Taylor County, West Virginia, 2004-2007 (land use and land cover, land fragmentation maps).
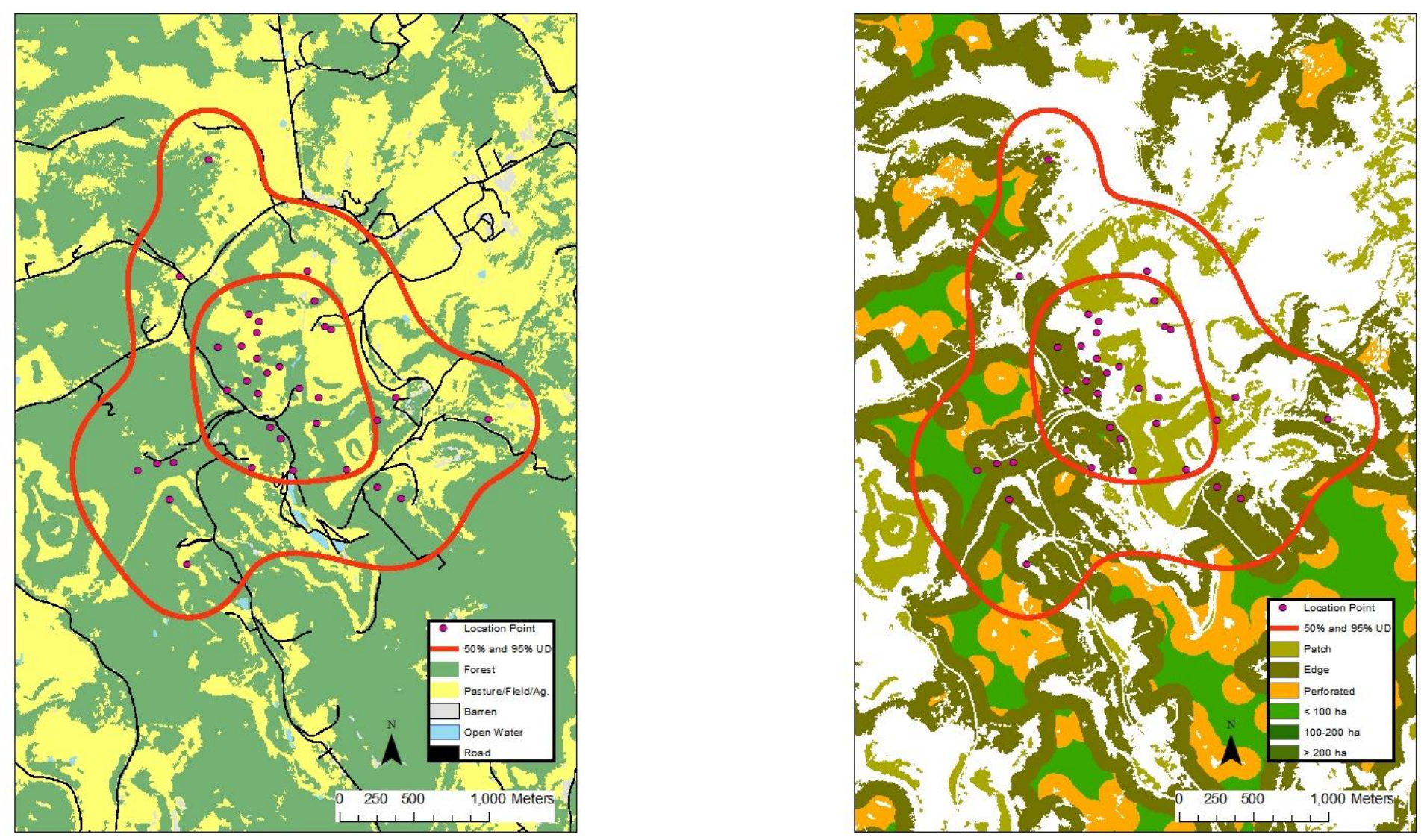
Appendix XCa. 10053 (juvenile, spring) - 50\% core and 95\% periphery probability contours of the spring Gaussian fixed kernel home range utilization distributions. Smoothing parameter $(h)$ determined by least squares cross validation, Taylor County, West Virginia, 2004-2007 (aspect and slope maps).
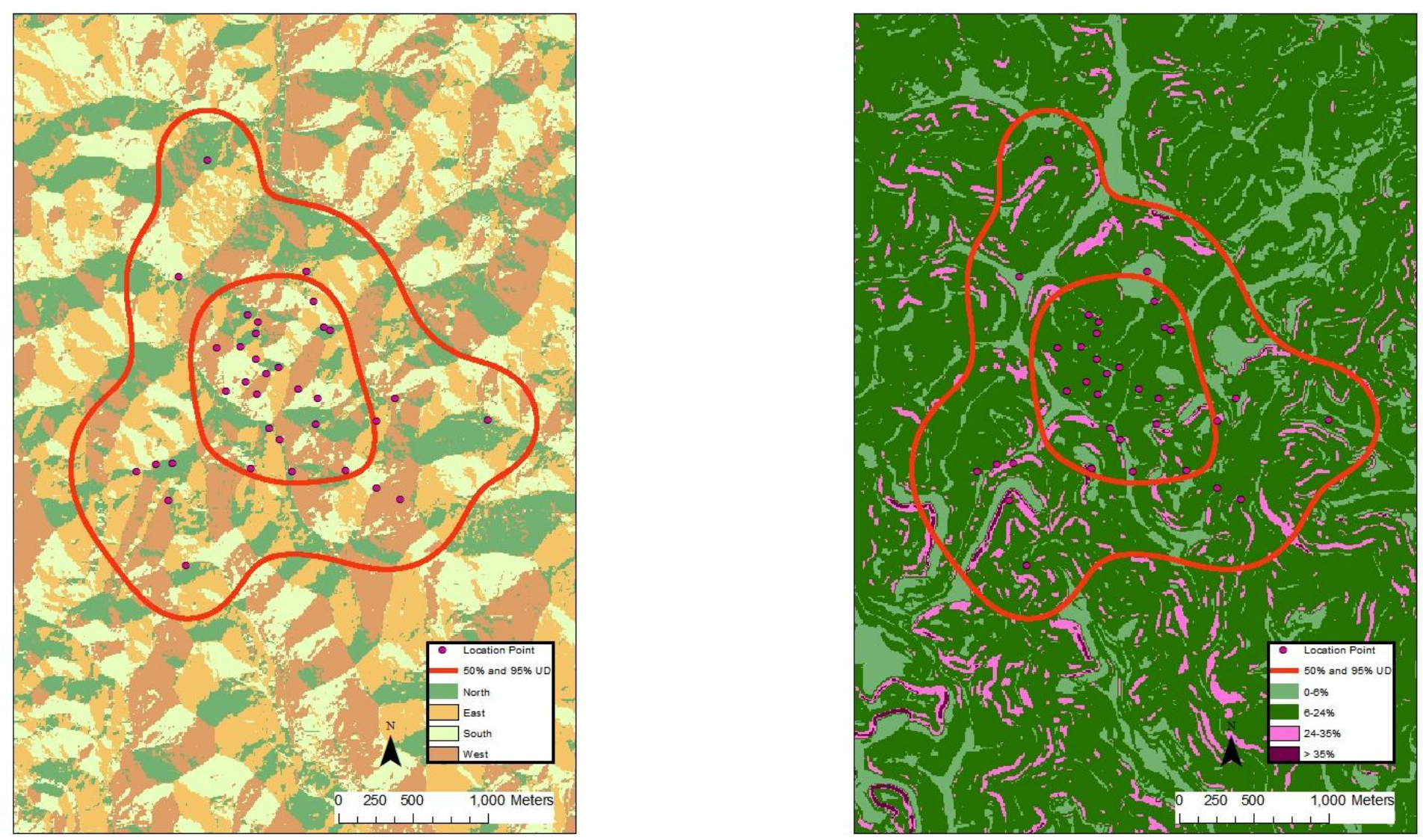
Appendix XCI $a$. 10054 (juvenile, spring-summer) - 50\% core and 95\% periphery probability contours of the spring-summer Gaussian fixed kernel home range utilization distributions. Smoothing parameter $(h)$ determined by least squares cross validation, Taylor County, West Virginia, 2004-2007 (land use and land cover, land fragmentation maps).
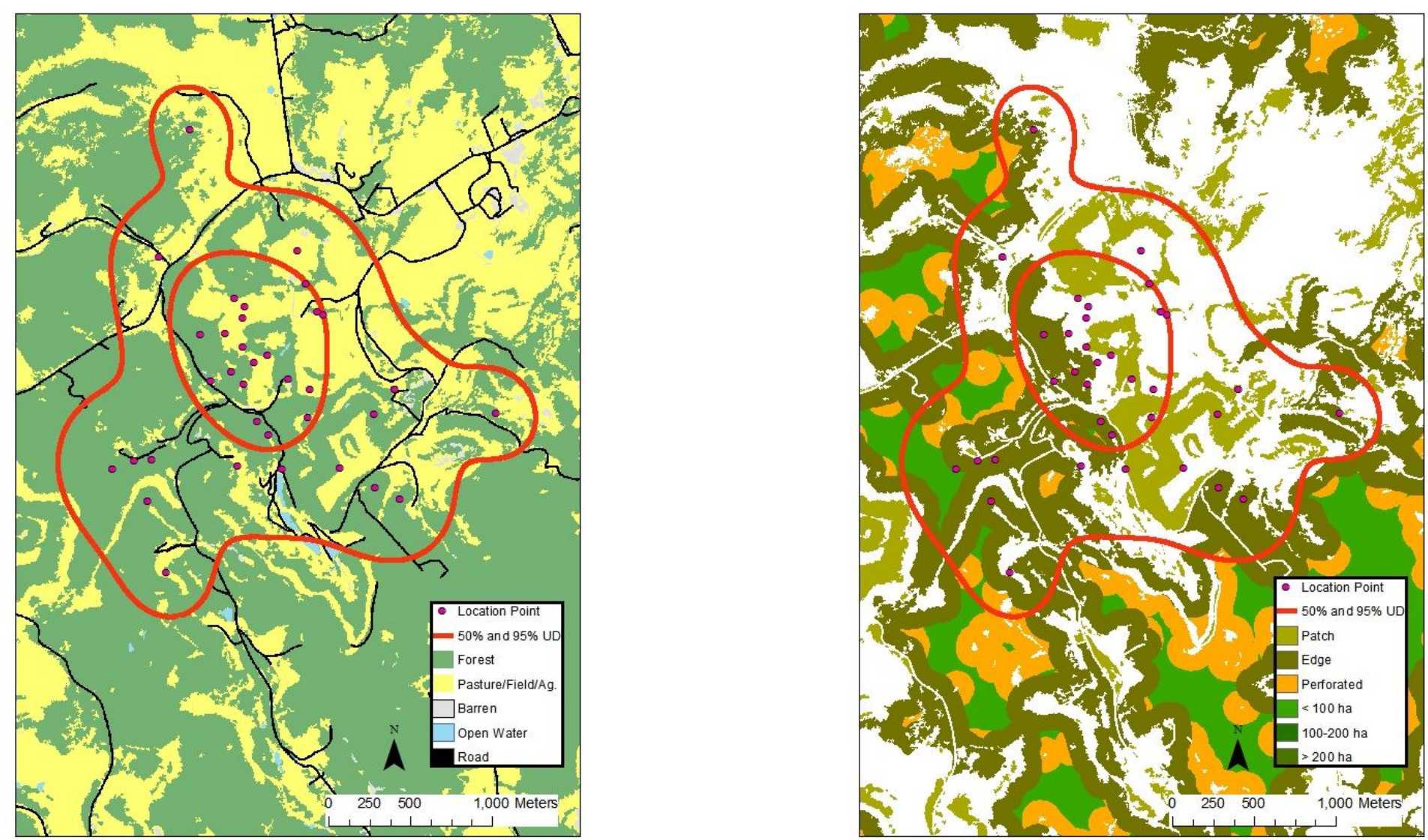
Appendix XCII a. 10054 (juvenile, spring-summer) - 50\% core and 95\% periphery probability contours of the spring-summer Gaussian fixed kernel home range utilization distributions. Smoothing parameter $(h)$ determined by least squares cross validation, Taylor County, West Virginia, 2004-2007 (aspect and slope maps).
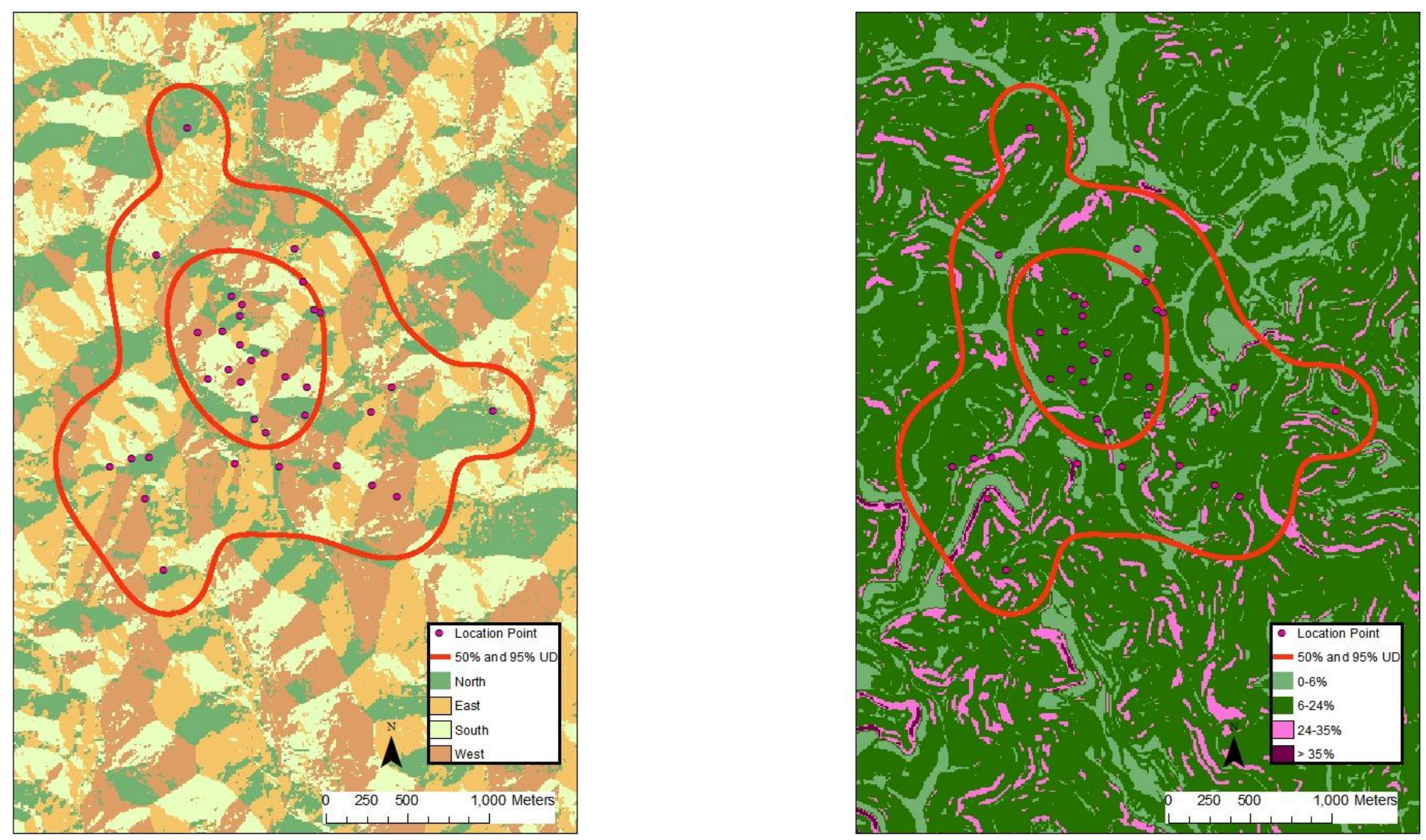
Appendix XCIII a. 10055 (adult, spring) - 50\% core and 95\% periphery probability contours of the spring Gaussian fixed kernel home range utilization distributions. Smoothing parameter $(h)$ determined by least squares cross validation, Taylor County, West Virginia, 2004-2007 (land use and land cover, land fragmentation maps).
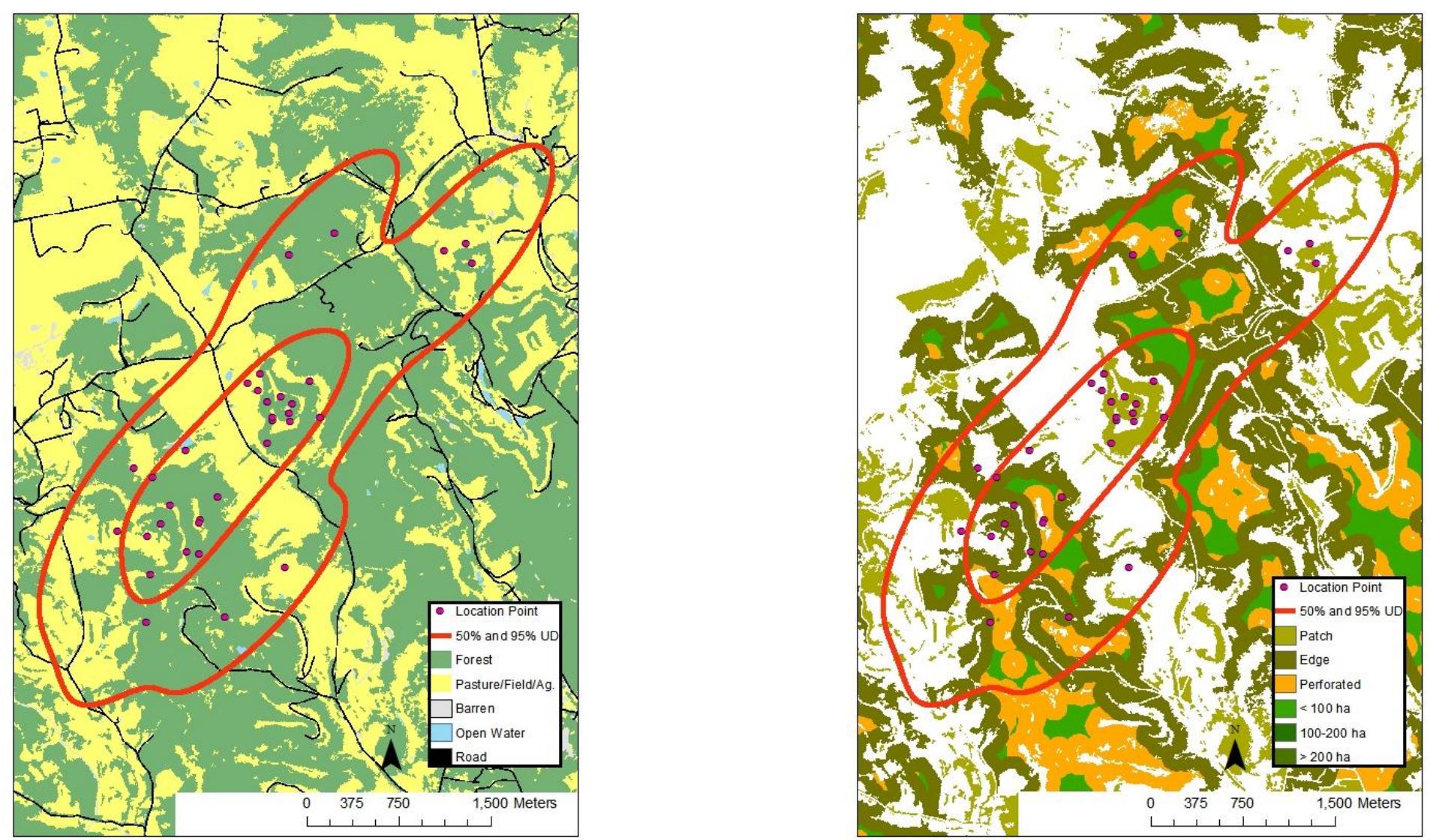
Appendix XCIVa. 10055 (adult, spring) - 50\% core and 95\% periphery probability contours of the spring Gaussian fixed kernel home range utilization distributions. Smoothing parameter $(h)$ determined by least squares cross validation, Taylor County, West Virginia, 2004-2007 (aspect and slope maps).
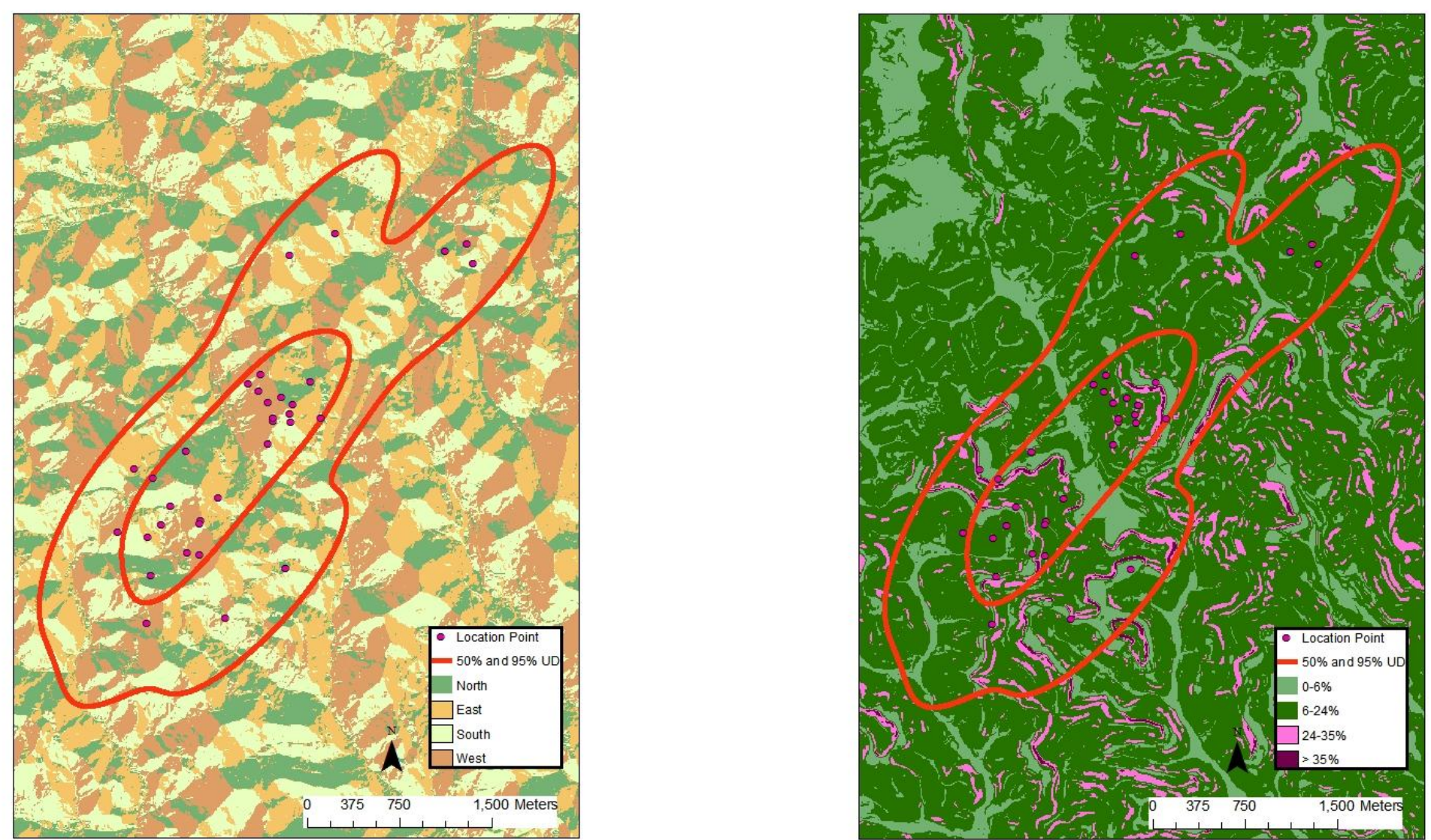
Appendix XCVa. 10056 (adult, spring-summer) - 50\% core and 95\% periphery probability contours of the spring-summer Gaussian fixed kernel home range utilization distributions. Smoothing parameter $(h)$ determined by least squares cross validation, Taylor County, West Virginia, 2004-2007 (land use and land cover, land fragmentation maps).
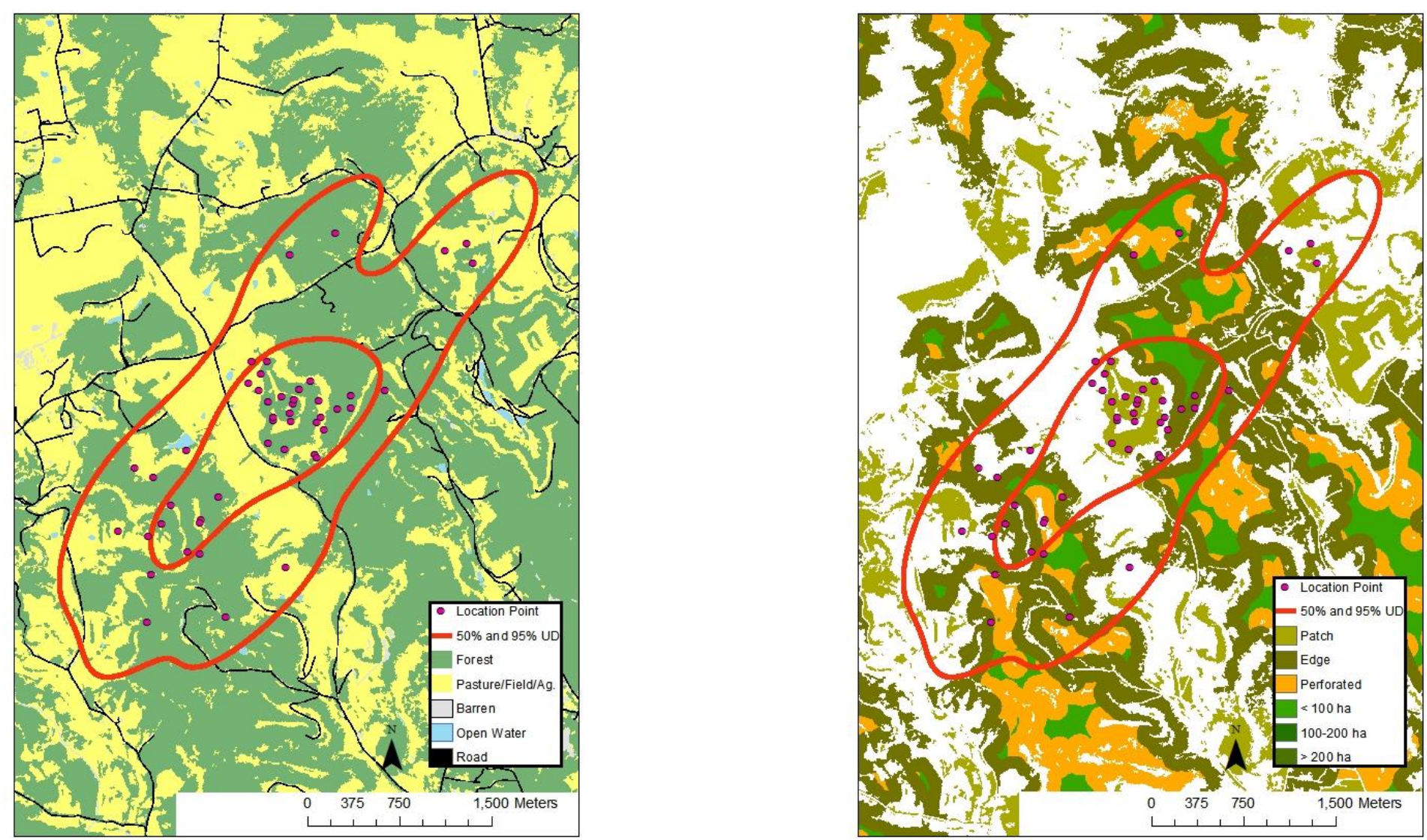
Appendix XCVIa. 10056 (adult, spring-summer) - 50\% core and 95\% periphery probability contours of the spring-summer Gaussian fixed kernel home range utilization distributions. Smoothing parameter $(h)$ determined by least squares cross validation, Taylor County, West Virginia, 2004-2007 (aspect and slope maps).
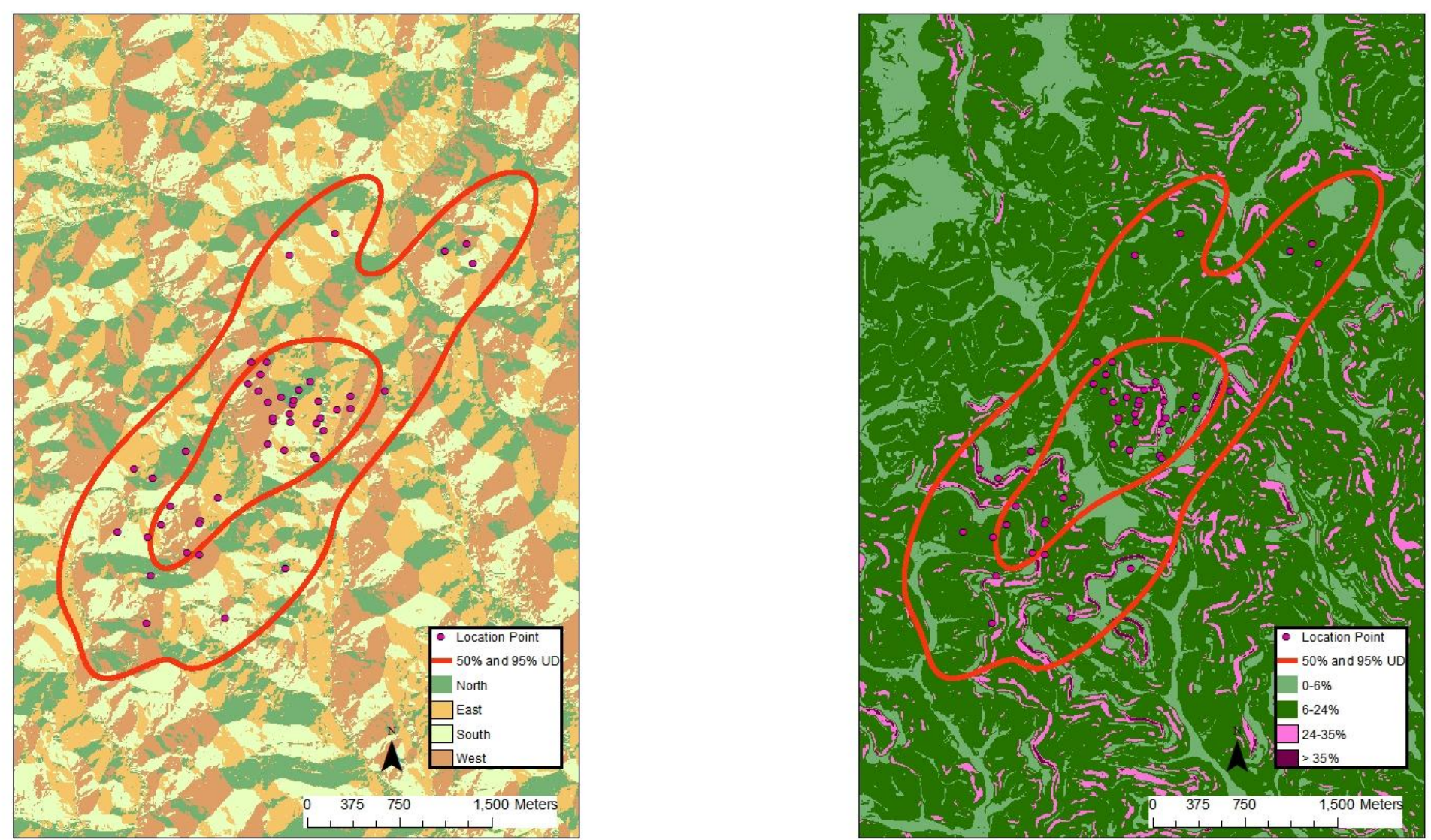
Appendix XCVIIa. 10057 (juvenile, annual) - 50\% core and 95\% periphery probability contours of the annual Gaussian fixed kernel home range utilization distributions. Smoothing parameter $(h)$ determined by least squares cross validation, Marion County, West Virginia, 2004-2007 (land use and land cover, land fragmentation maps).
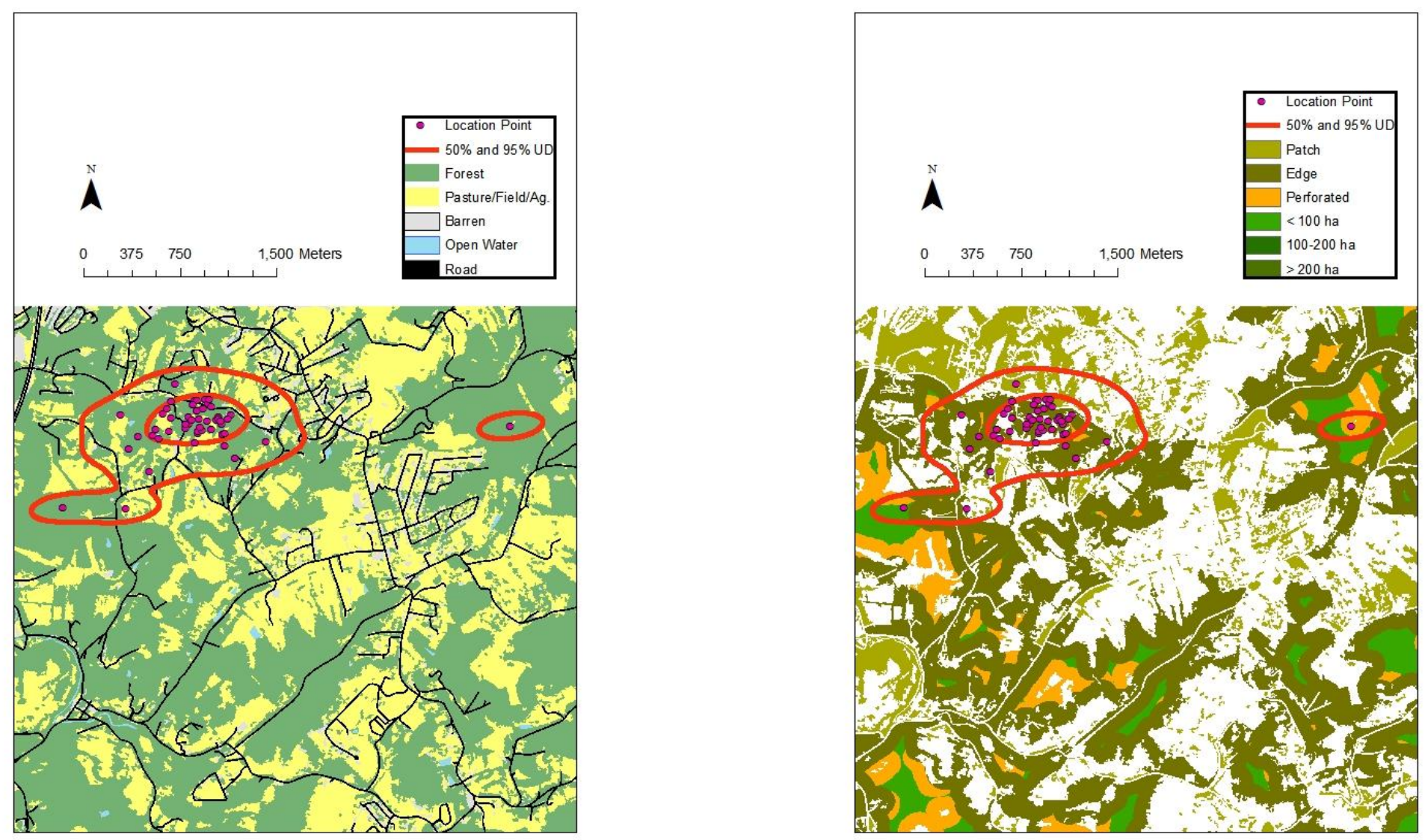
Appendix XCVIII a. 10057 (juvenile, annual) - 50\% core and 95\% periphery probability contours of the annual Gaussian fixed kernel home range utilization distributions. Smoothing parameter $(h)$ determined by least squares cross validation, Marion County, West Virginia, 2004-2007 (aspect and slope maps).
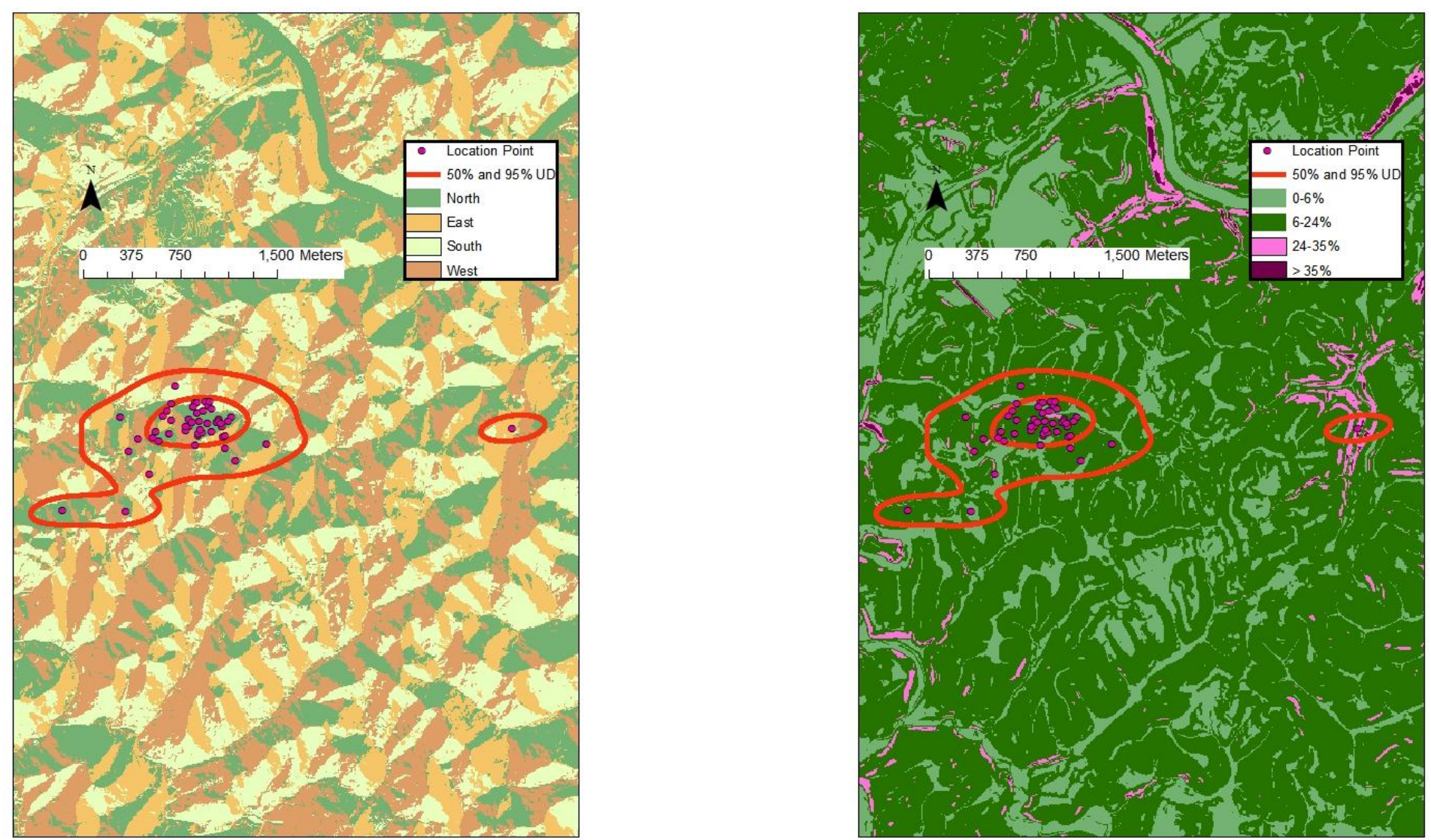
Appendix XCIXa. 10059 (juvenile, spring-summer) - 50\% core and 95\% periphery probability contours of the spring-summer Gaussian fixed kernel home range utilization distributions. Smoothing parameter $(h)$ determined by least squares cross validation, Marion County, West Virginia, 2004-2007 (land use and land cover, land fragmentation maps).
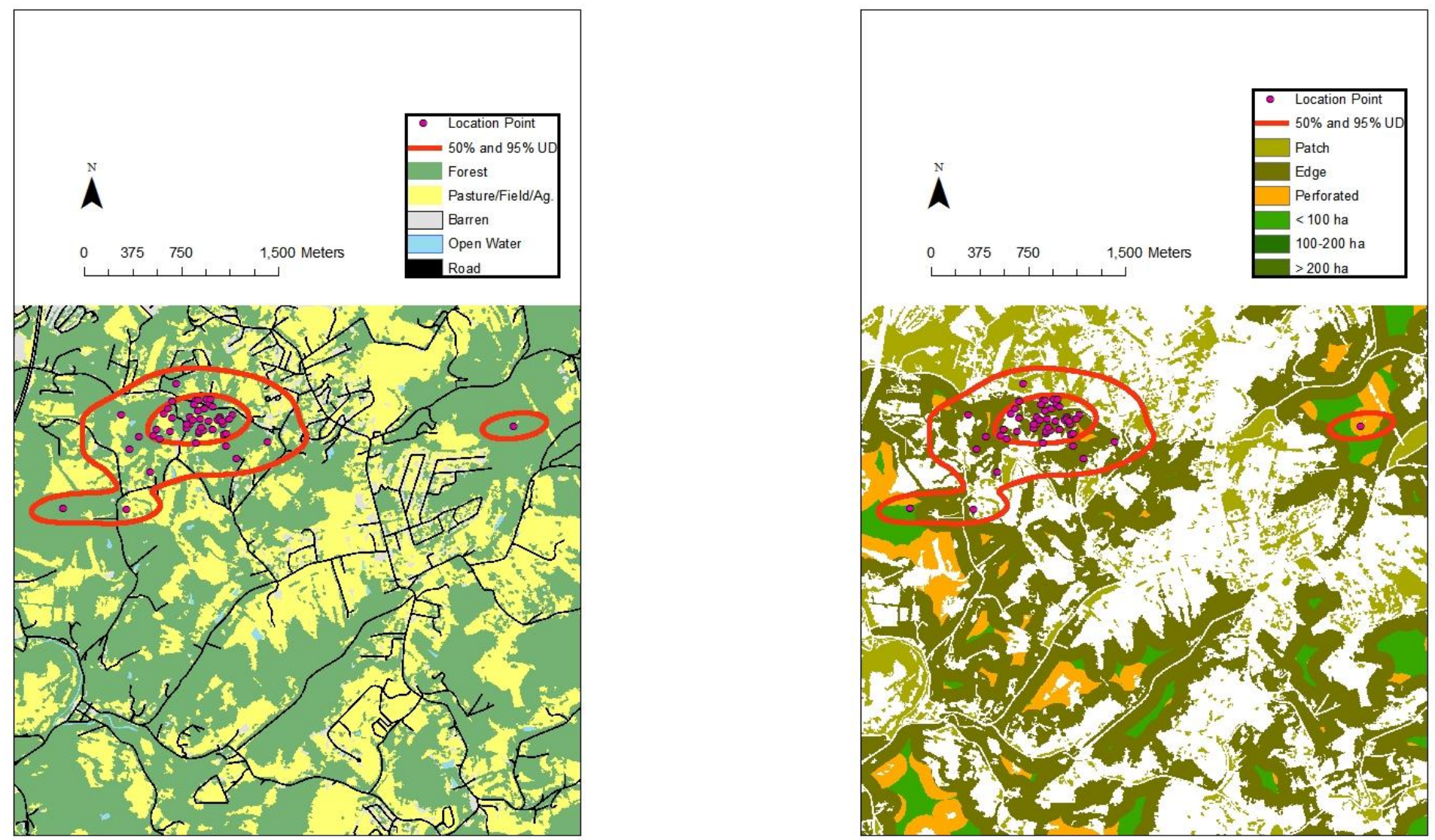
Appendix Ca. 10059 (juvenile, spring-summer) - 50\% core and 95\% periphery probability contours of the spring-summer Gaussian fixed kernel home range utilization distributions. Smoothing parameter $(h)$ determined by least squares cross validation, Marion County, West Virginia, 2004-2007 (aspect and slope maps).
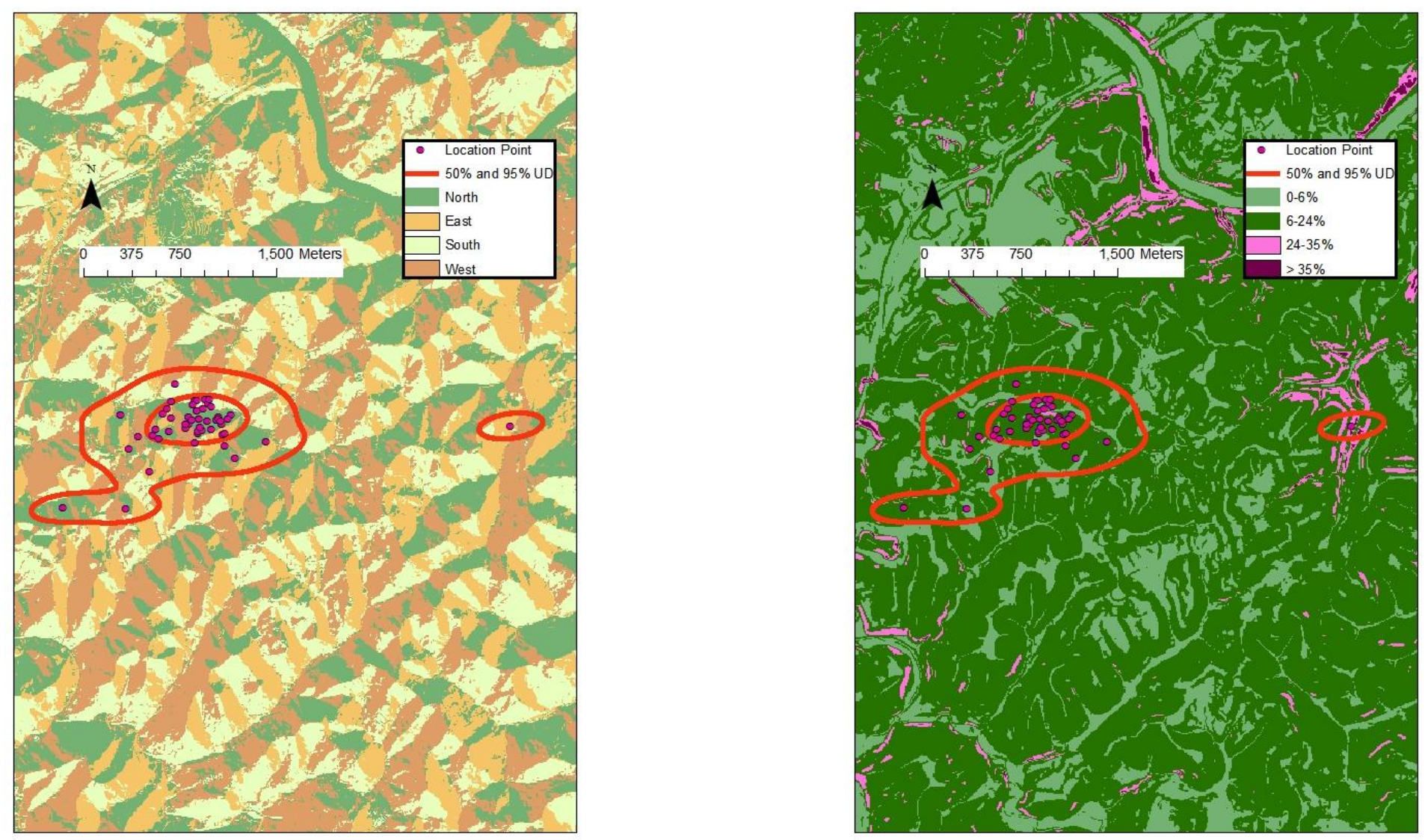
Appendix CI $a .10060$ (juvenile, annual) - 50\% core and 95\% periphery probability contours of the annual Gaussian fixed kernel home range utilization distributions. Smoothing parameter $(h)$ determined by least squares cross validation, Taylor County, West Virginia, 2004-2007 (land use and land cover, land fragmentation maps).
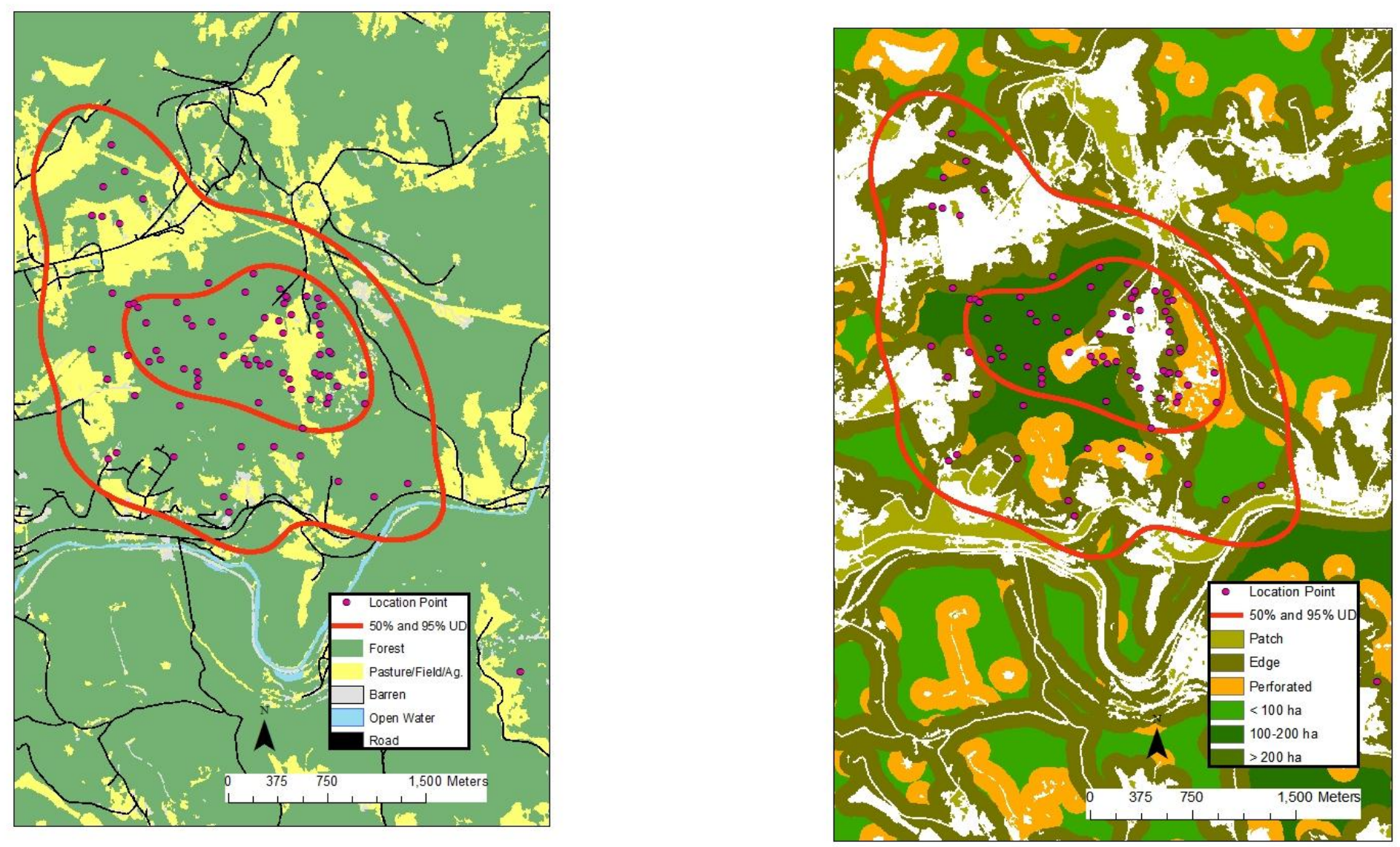
Appendix CII a. 10060 (juvenile, annual) - 50\% core and 95\% periphery probability contours of the annual Gaussian fixed kernel home range utilization distributions. Smoothing parameter $(h)$ determined by least squares cross validation, Taylor County, West Virginia, 2004-2007 (aspect and slope maps).
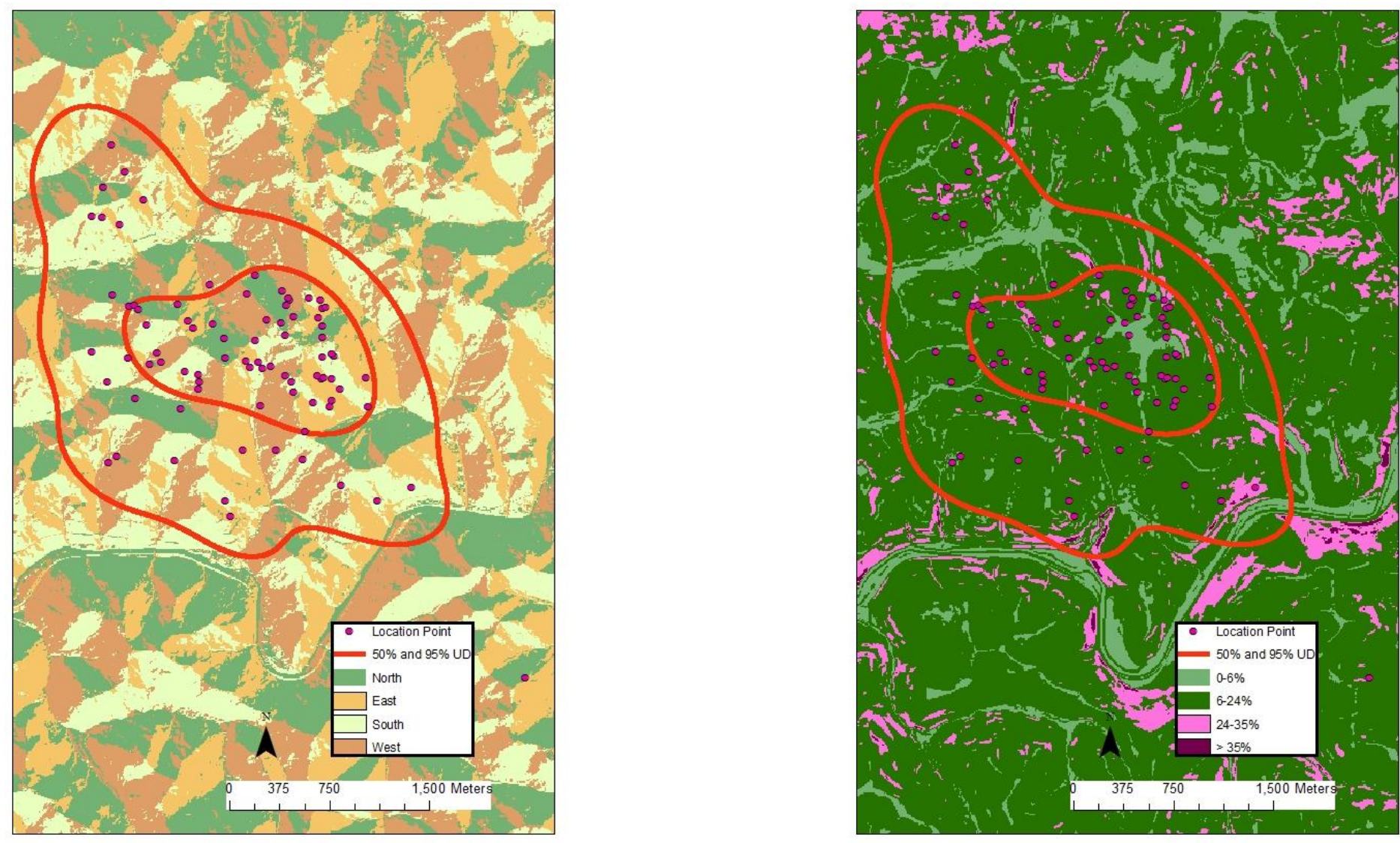
Appendix CIII a. 10061 (juvenile, spring) - 50\% core and 95\% periphery probability contours of the spring Gaussian fixed kernel home range utilization distributions. Smoothing parameter $(h)$ determined by least squares cross validation, Taylor County, West Virginia, 2004-2007 (land use and land cover, land fragmentation maps).
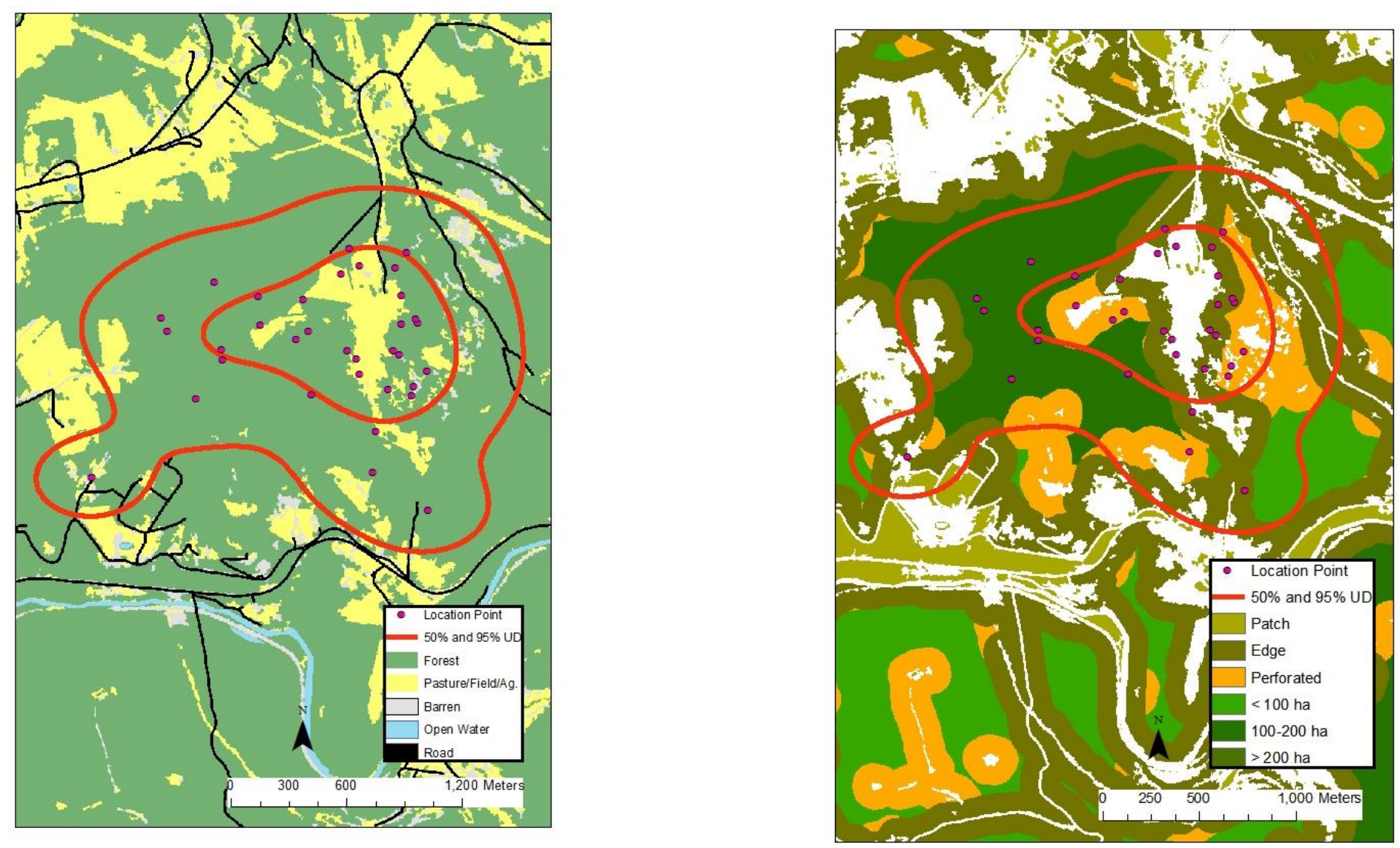
Appendix CIVa. 10061 (juvenile, spring) - 50\% core and 95\% periphery probability contours of the spring Gaussian fixed kernel home range utilization distributions. Smoothing parameter $(h)$ determined by least squares cross validation, Taylor County, West Virginia, 2004-2007 (aspect and slope maps).
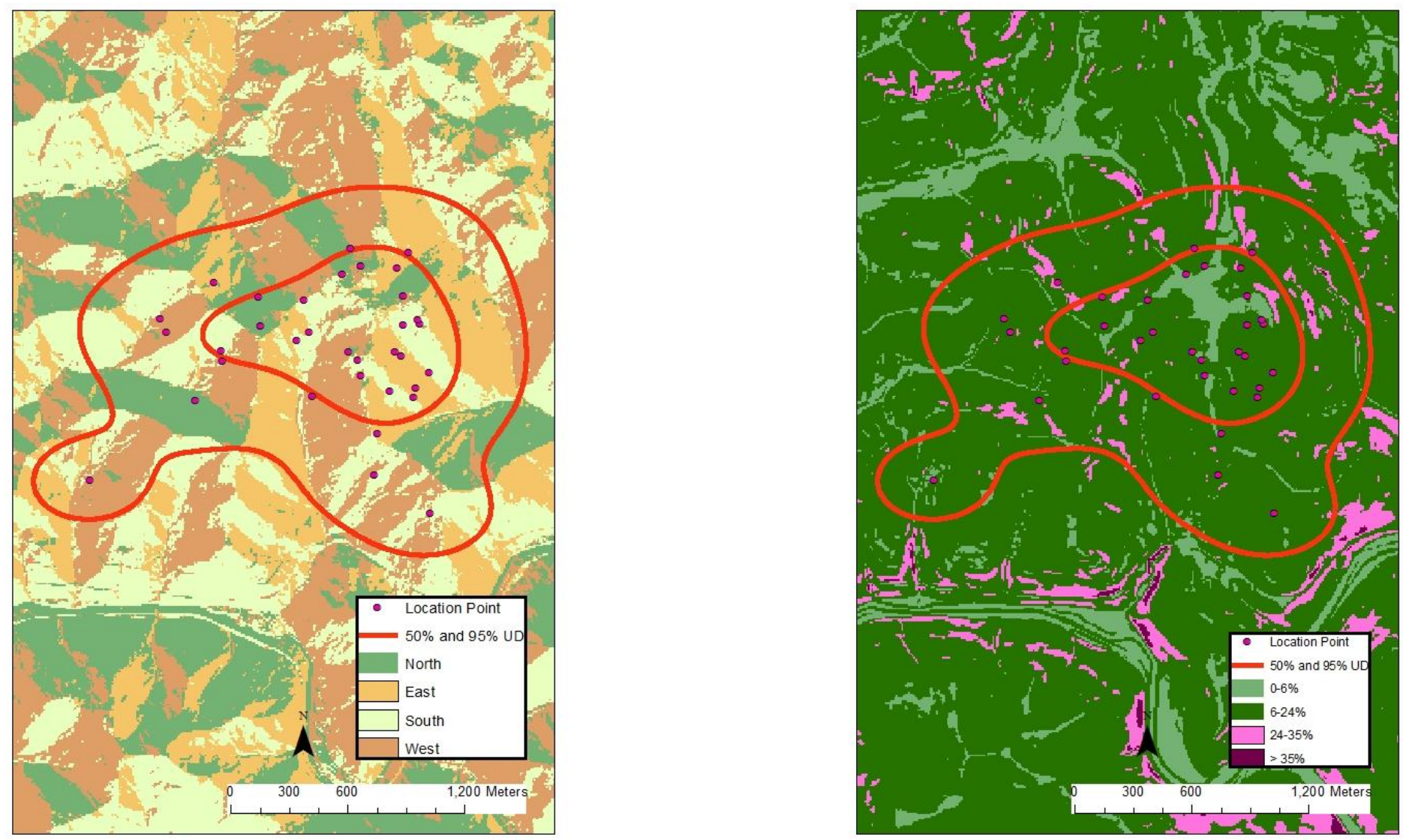
Appendix CVa. 10063 (juvenile, spring-summer) - 50\% core and 95\% periphery probability contours of the spring-summer Gaussian fixed kernel home range utilization distributions. Smoothing parameter $(h)$ determined by least squares cross validation, Taylor County, West Virginia, 2004-2007 (land use and land cover, land fragmentation maps).
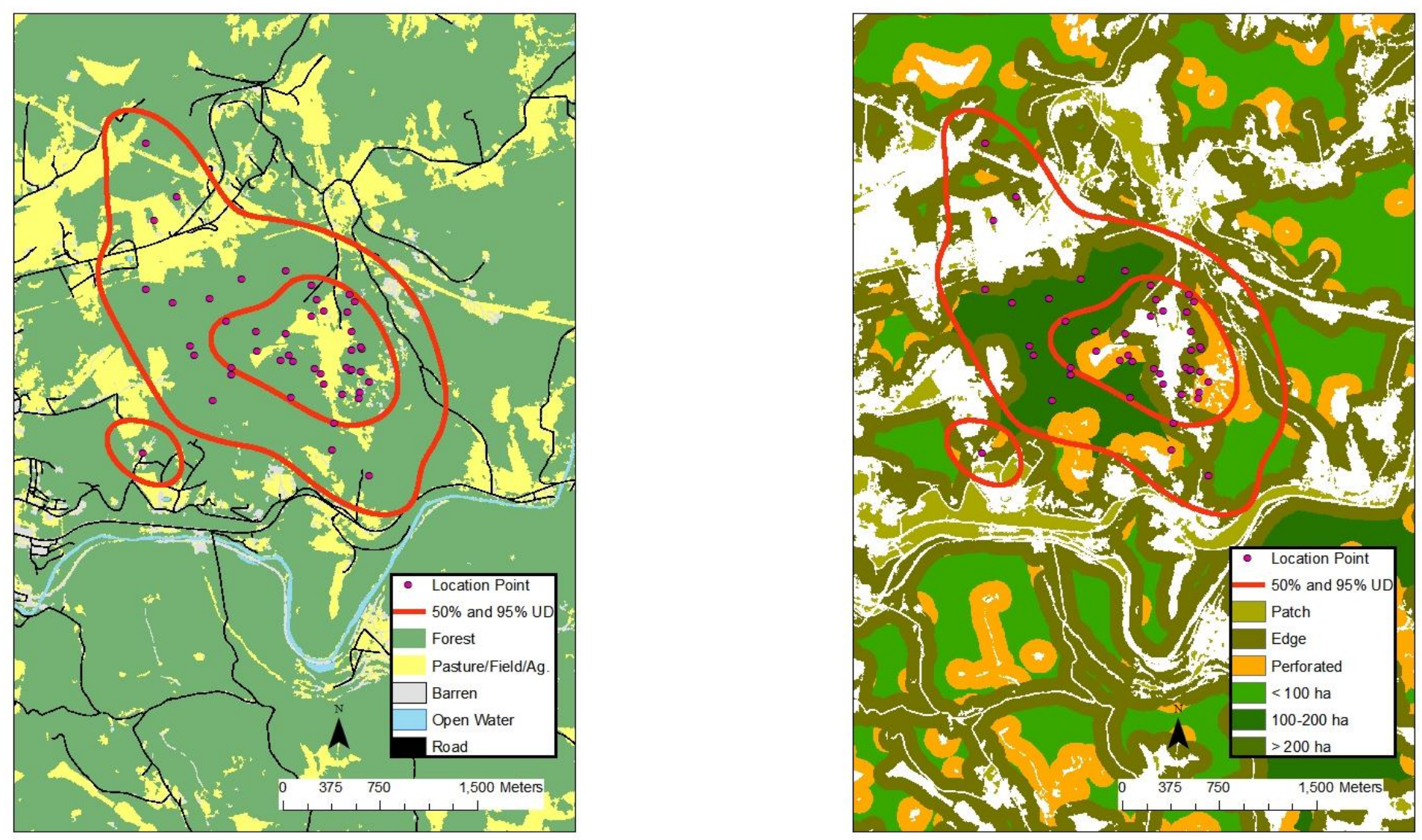
Appendix CVIa. 10063 (juvenile, spring-summer) - 50\% core and 95\% periphery probability contours of the spring-summer Gaussian fixed kernel home range utilization distributions. Smoothing parameter $(h)$ determined by least squares cross validation, Taylor County, West Virginia, 2004-2007 (aspect and slope maps).
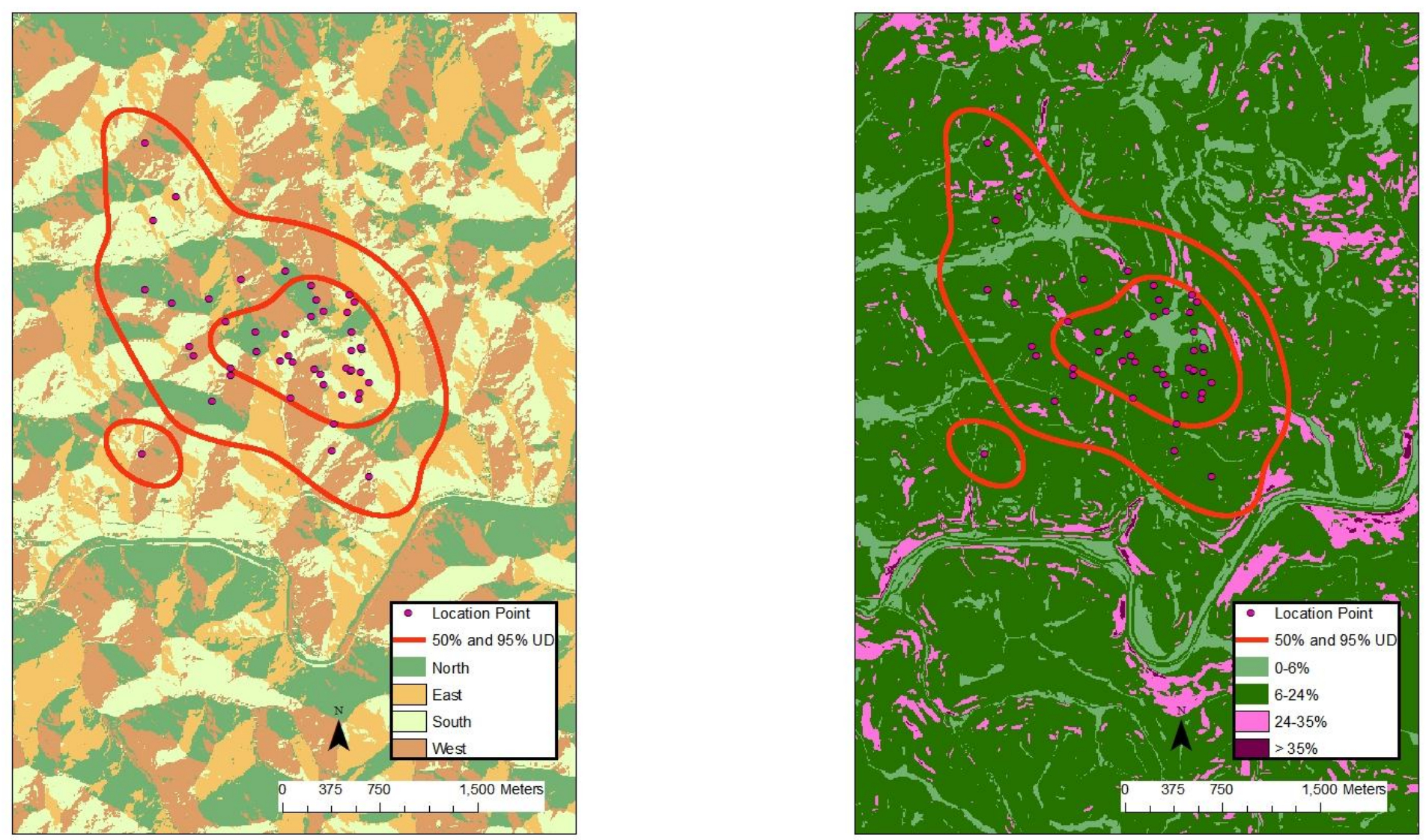
Appendix CVII a. 10064 (juvenile, annual) - 50\% core and 95\% periphery probability contours of the annual Gaussian fixed kernel home range utilization distributions. Smoothing parameter $(h)$ determined by least squares cross validation, Taylor County, West Virginia, 2004-2007 (land use and land cover, land fragmentation maps).
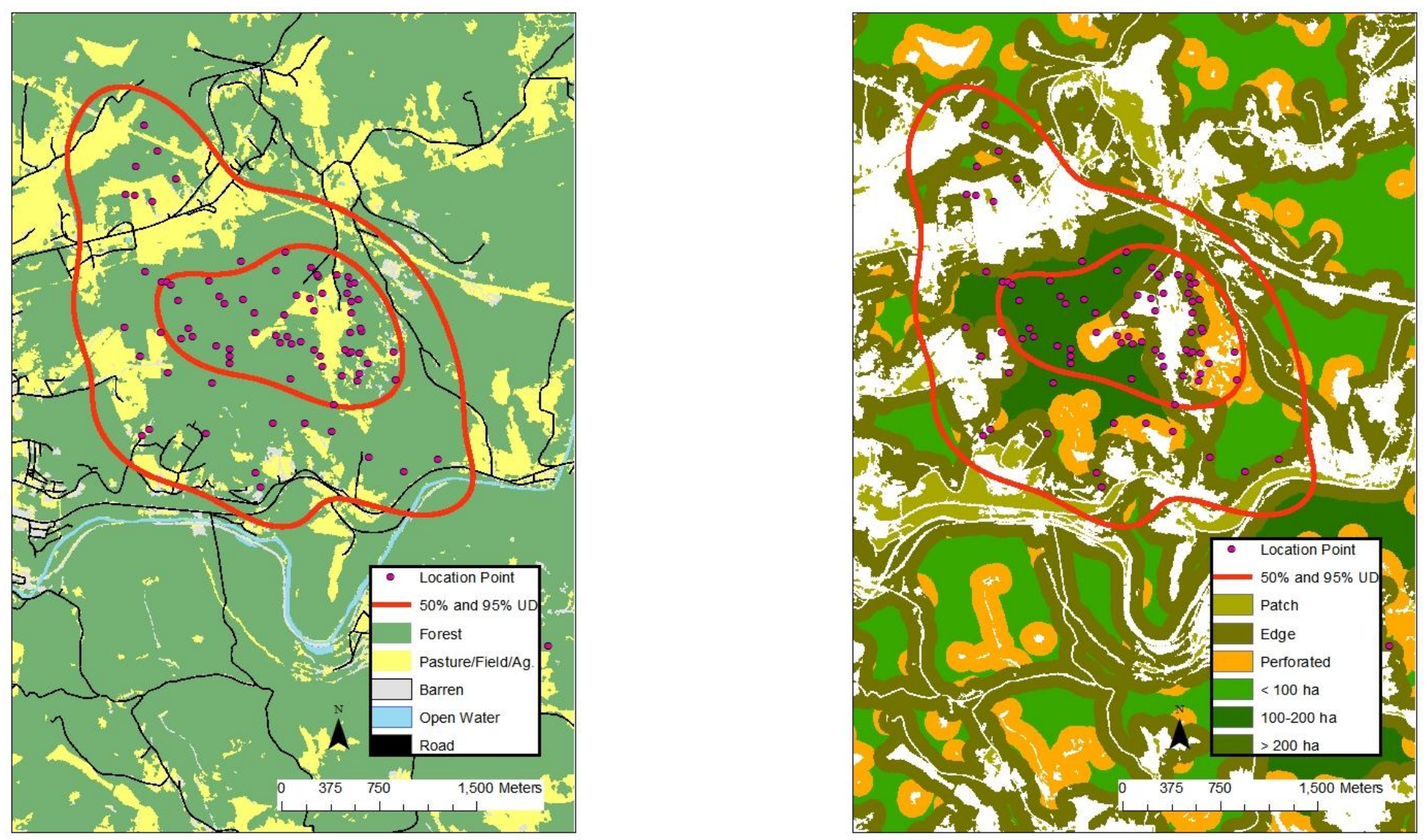
Appendix CVIIIa. 10064 (juvenile, annual) - 50\% core and 95\% periphery probability contours of the annual Gaussian fixed kernel home range utilization distributions. Smoothing parameter $(h)$ determined by least squares cross validation, Taylor County, West Virginia, 2004-2007 (aspect and slope maps).
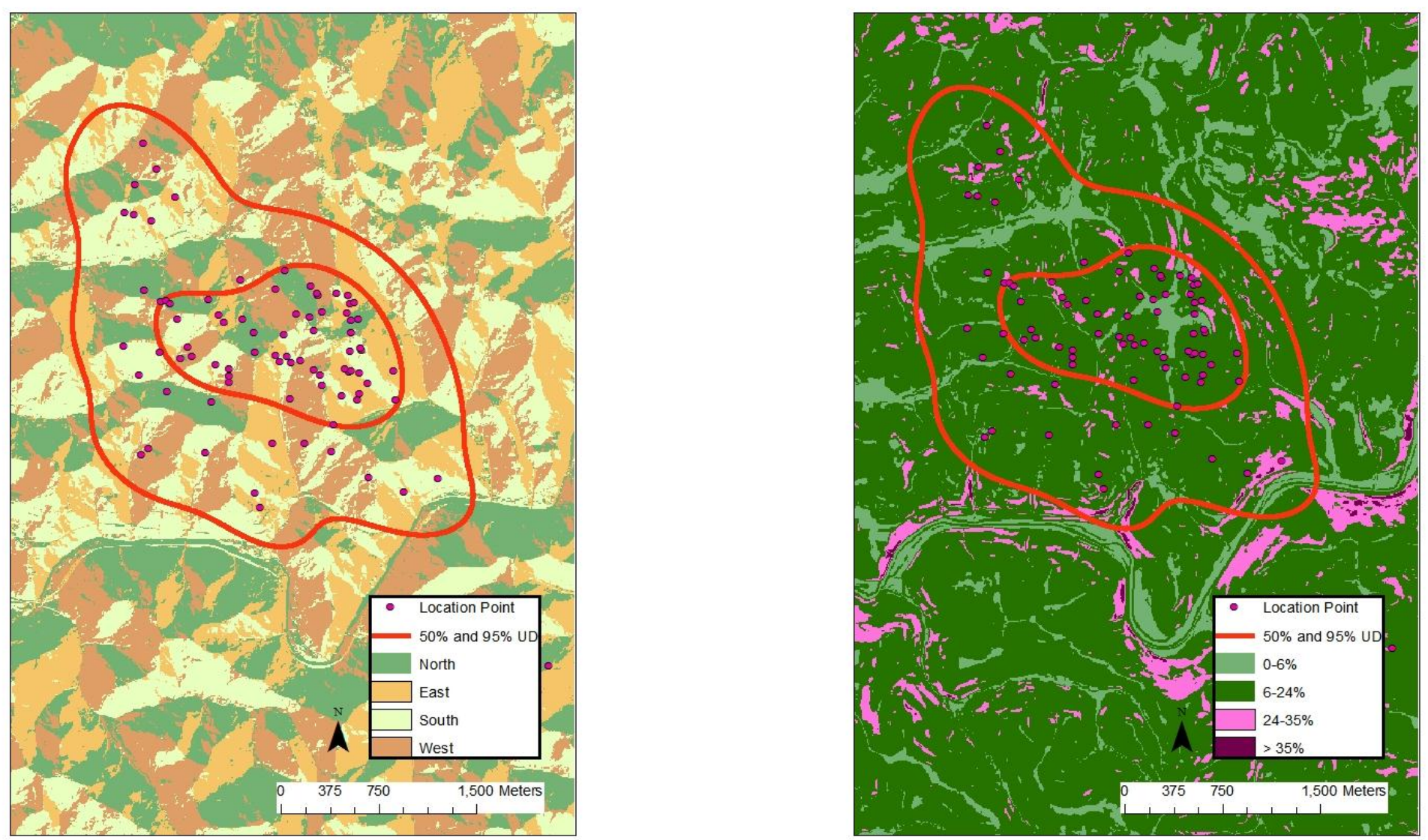
Appendix CIX a. 10066 (juvenile, spring) - 50\% core and 95\% periphery probability contours of the spring Gaussian fixed kernel home range utilization distributions. Smoothing parameter $(h)$ determined by least squares cross validation, Taylor County, West Virginia, 2004-2007 (land use and land cover, land fragmentation maps).
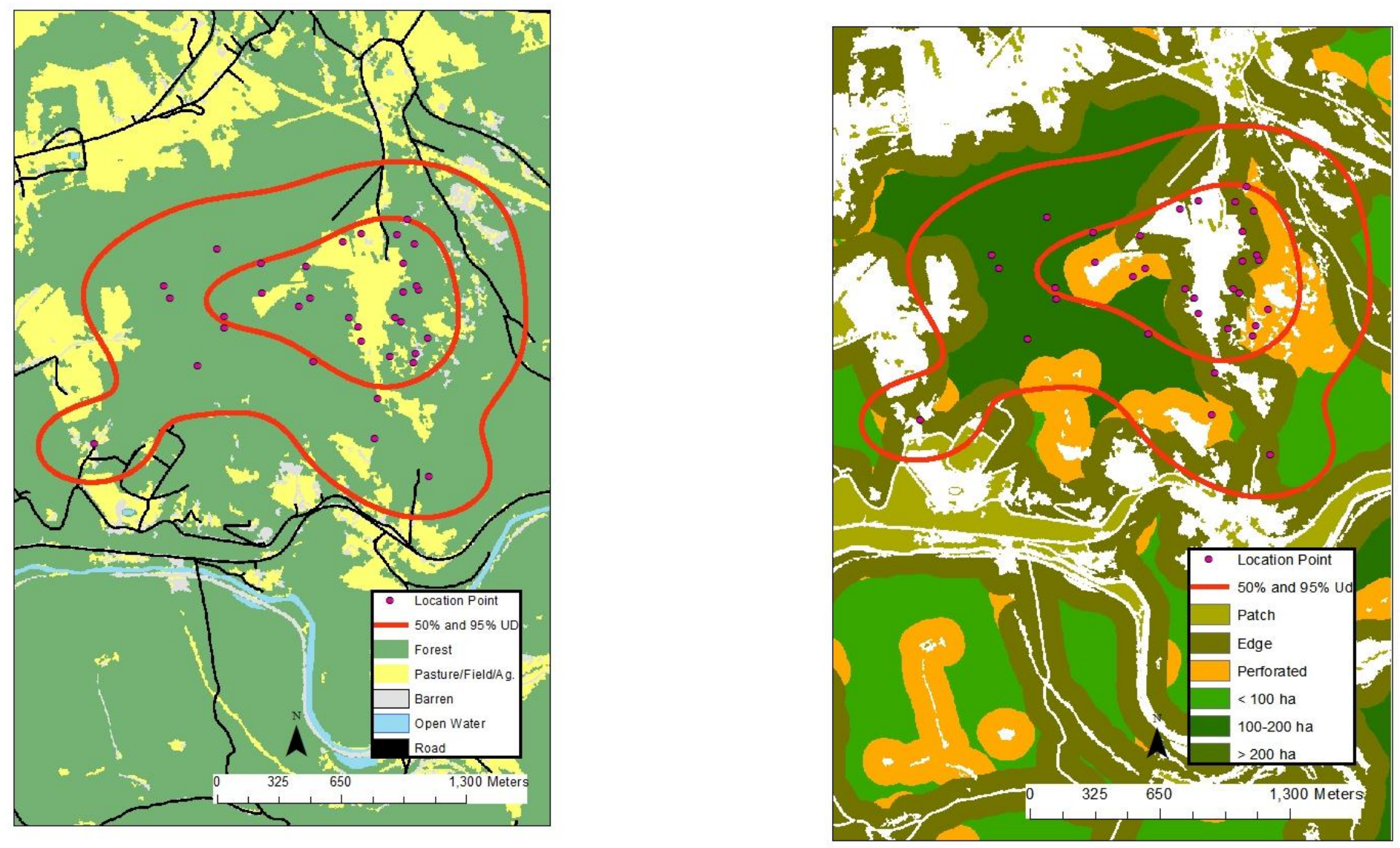
Appendix CXa. 10066 (juvenile, spring) - 50\% core and 95\% periphery probability contours of the spring Gaussian fixed kernel home range utilization distributions. Smoothing parameter $(h)$ determined by least squares cross validation, Taylor County, West Virginia, 2004-2007 (aspect and slope maps).
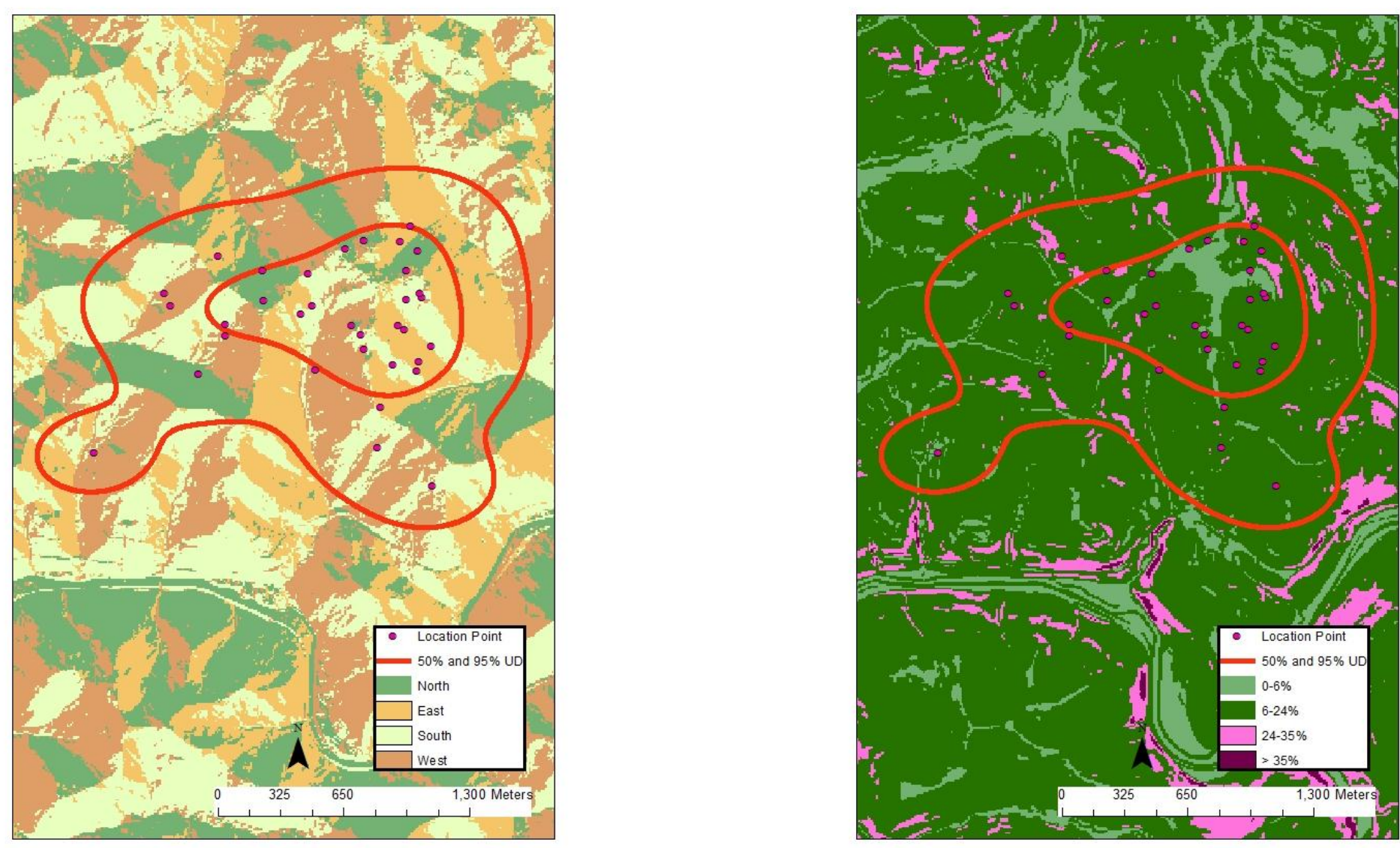
Appendix CXI $a .10067$ (juvenile, spring-summer) - 50\% core and 95\% periphery probability contours of the spring-summer Gaussian fixed kernel home range utilization distributions. Smoothing parameter $(h)$ determined by least squares cross validation, Taylor County, West Virginia, 2004-2007 (land use and land cover, land fragmentation maps).
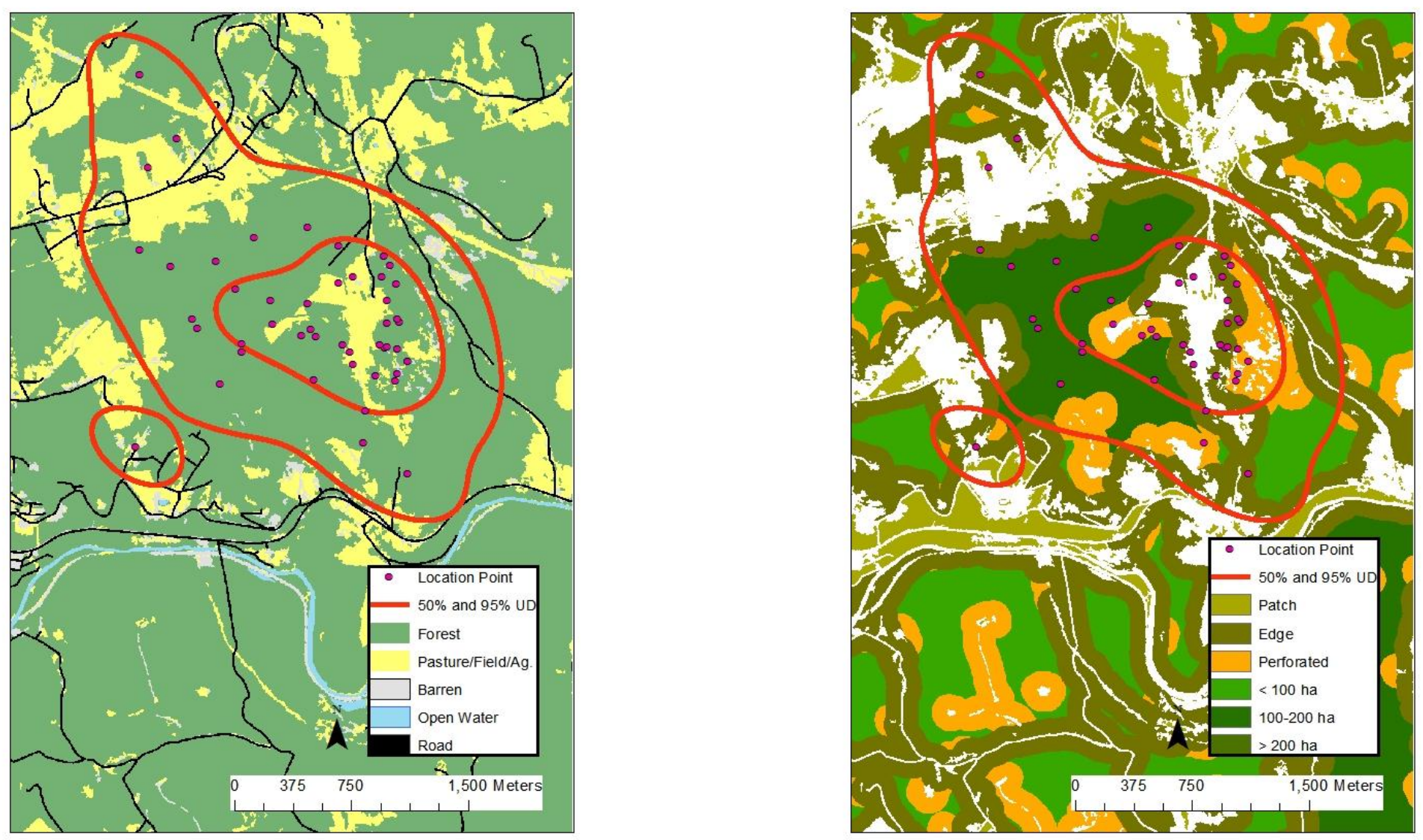
Appendix CXIIa. 10067 (juvenile, spring-summer) - 50\% core and 95\% periphery probability contours of the spring-summer Gaussian fixed kernel home range utilization distributions. Smoothing parameter $(h)$ determined by least squares cross validation, Taylor County, West Virginia, 2004-2007 (aspect and slope maps).
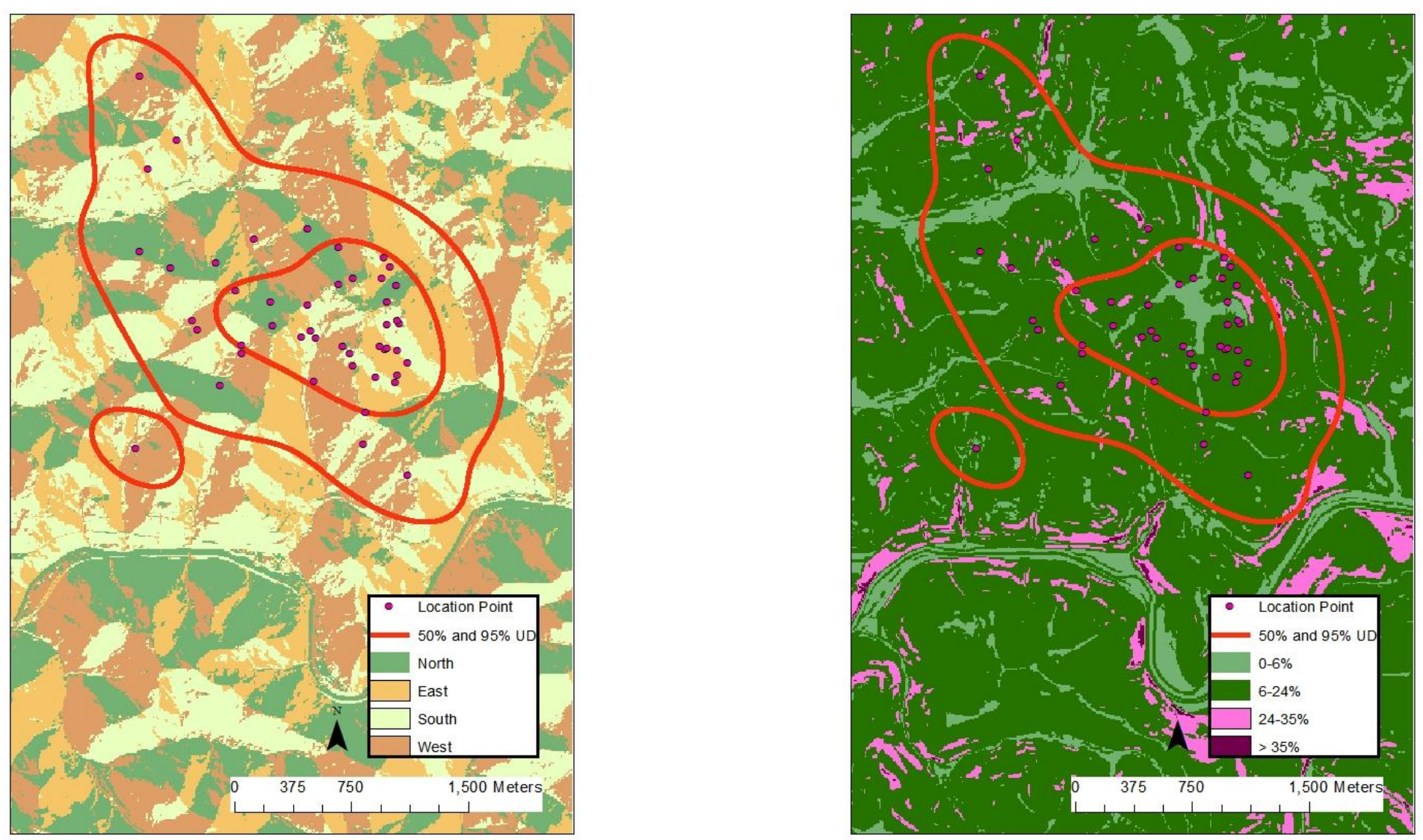
Appendix CXIII $a .10068$ (juvenile, annual) - 50\% core and 95\% periphery probability contours of the annual Gaussian fixed kernel home range utilization distributions. Smoothing parameter $(h)$ determined by least squares cross validation, Marion/Taylor County, West Virginia, 2004-2007 (land use and land cover, land fragmentation maps).
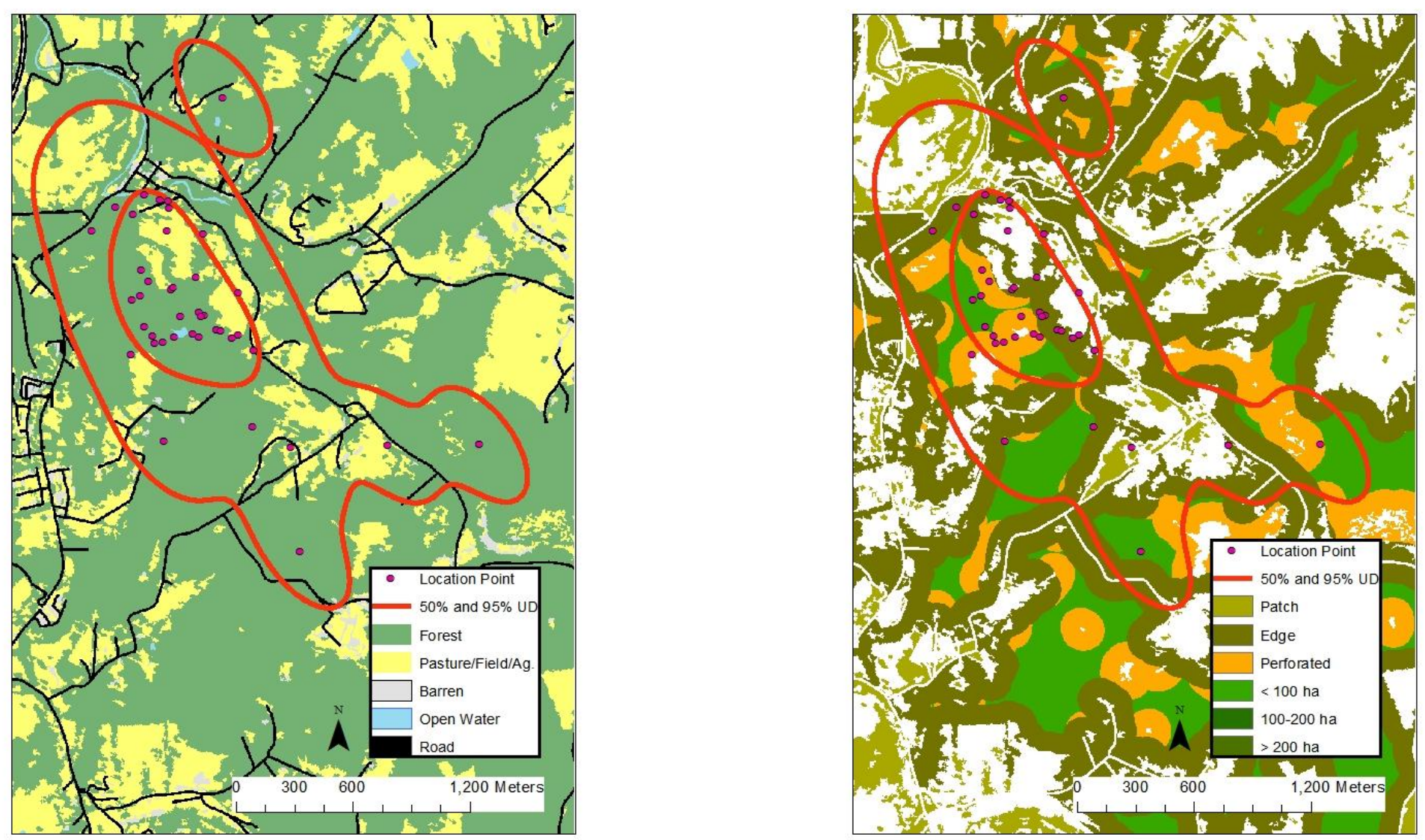
Appendix CXIVa. 10068 (juvenile, annual) - 50\% core and 95\% periphery probability contours of the annual Gaussian fixed kernel home range utilization distributions. Smoothing parameter $(h)$ determined by least squares cross validation, Marion/Taylor County, West Virginia, 2004-2007 (aspect and slope maps).
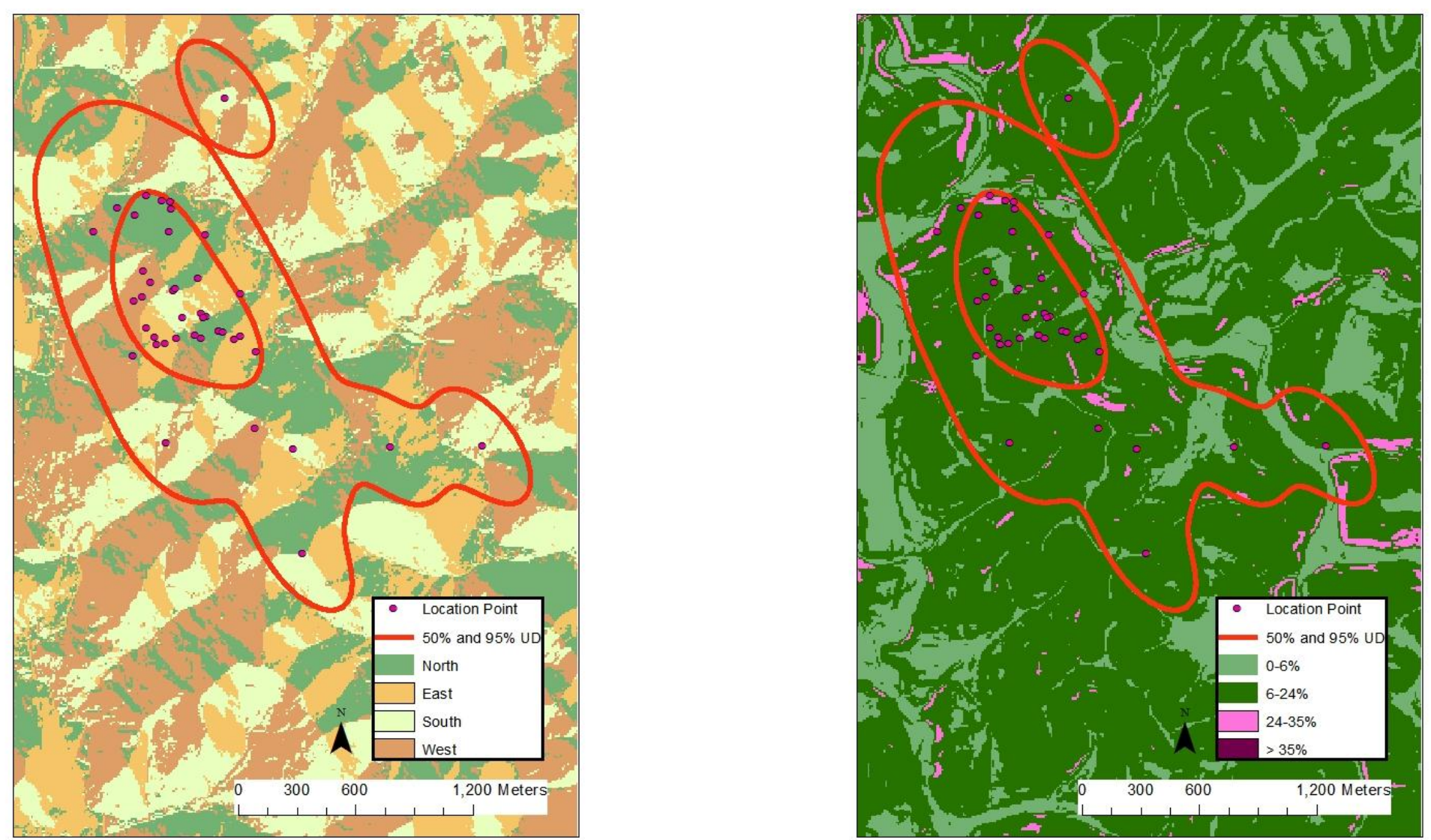
Appendix CXVa. 10069 (juvenile, annual) - 50\% core and 95\% periphery probability contours of the annual Gaussian fixed kernel home range utilization distributions. Smoothing parameter $(h)$ determined by least squares cross validation, Harrison/Marion/Taylor County, West Virginia, 2004-2007 (land use and land cover, land fragmentation maps).
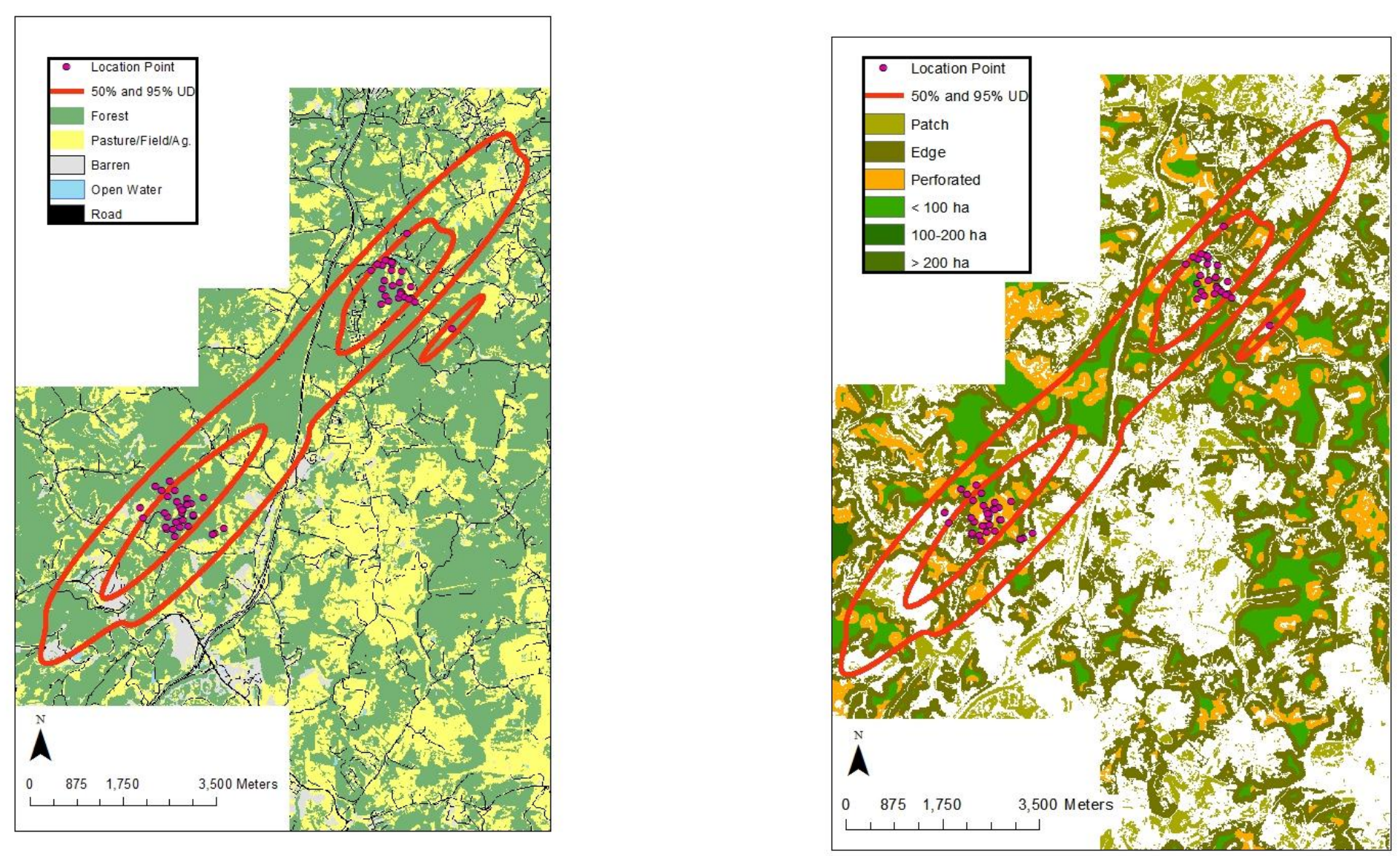
Appendix CXVIa. 10069 (juvenile, annual) - 50\% core and 95\% periphery probability contours of the annual Gaussian fixed kernel home range utilization distributions. Smoothing parameter $(h)$ determined by least squares cross validation, Harrison/Marion/Taylor County, West Virginia, 2004-2007 (aspect and slope maps).
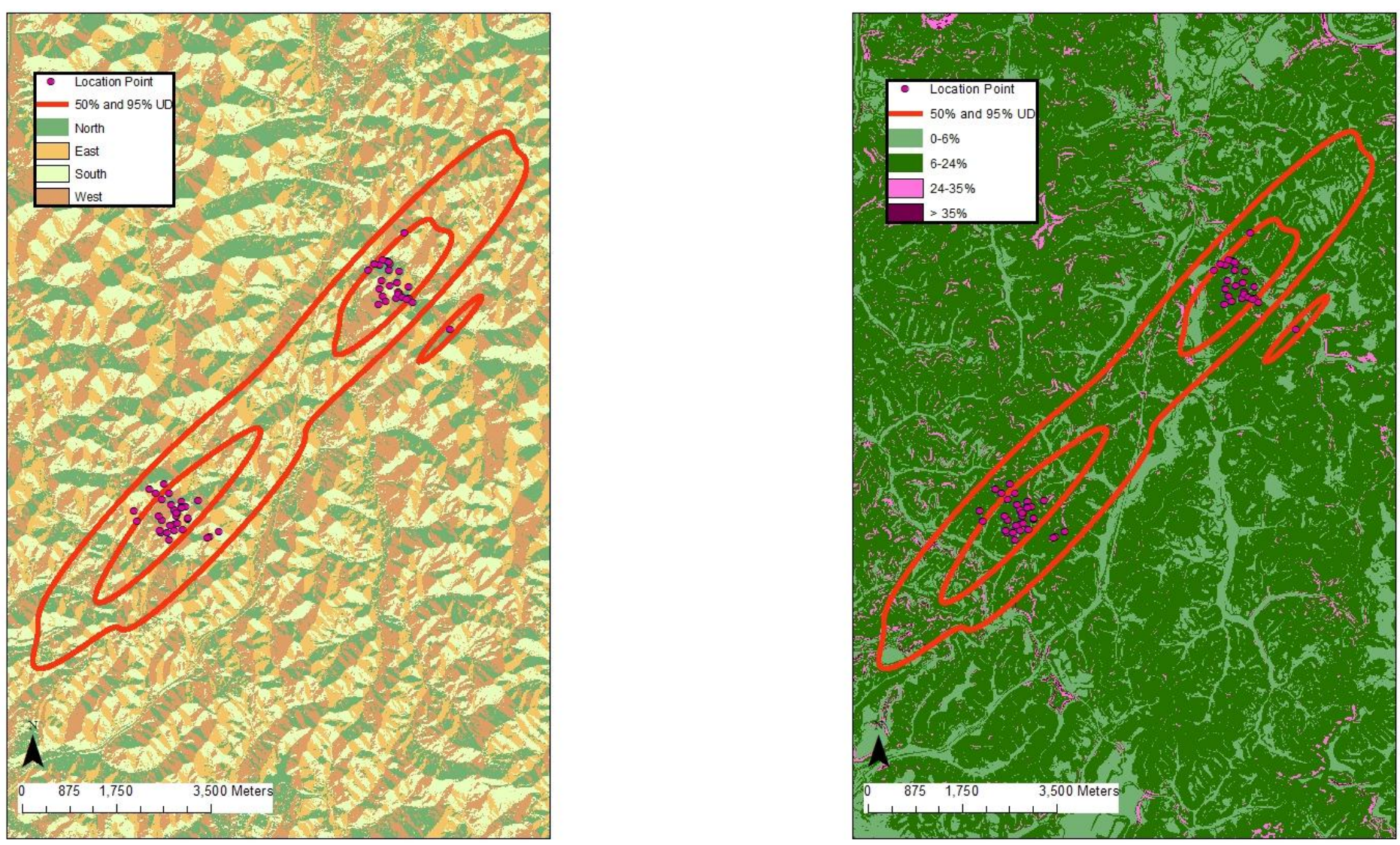
Appendix CXVII $a .10071$ (juvenile, spring) - 50\% core and 95\% periphery probability contours of the spring Gaussian fixed kernel home range utilization distributions. Smoothing parameter $(h)$ determined by least squares cross validation, Harrison/Marrion/Taylor County, West Virginia, 2004-2007 (land use and land cover, land fragmentation maps).
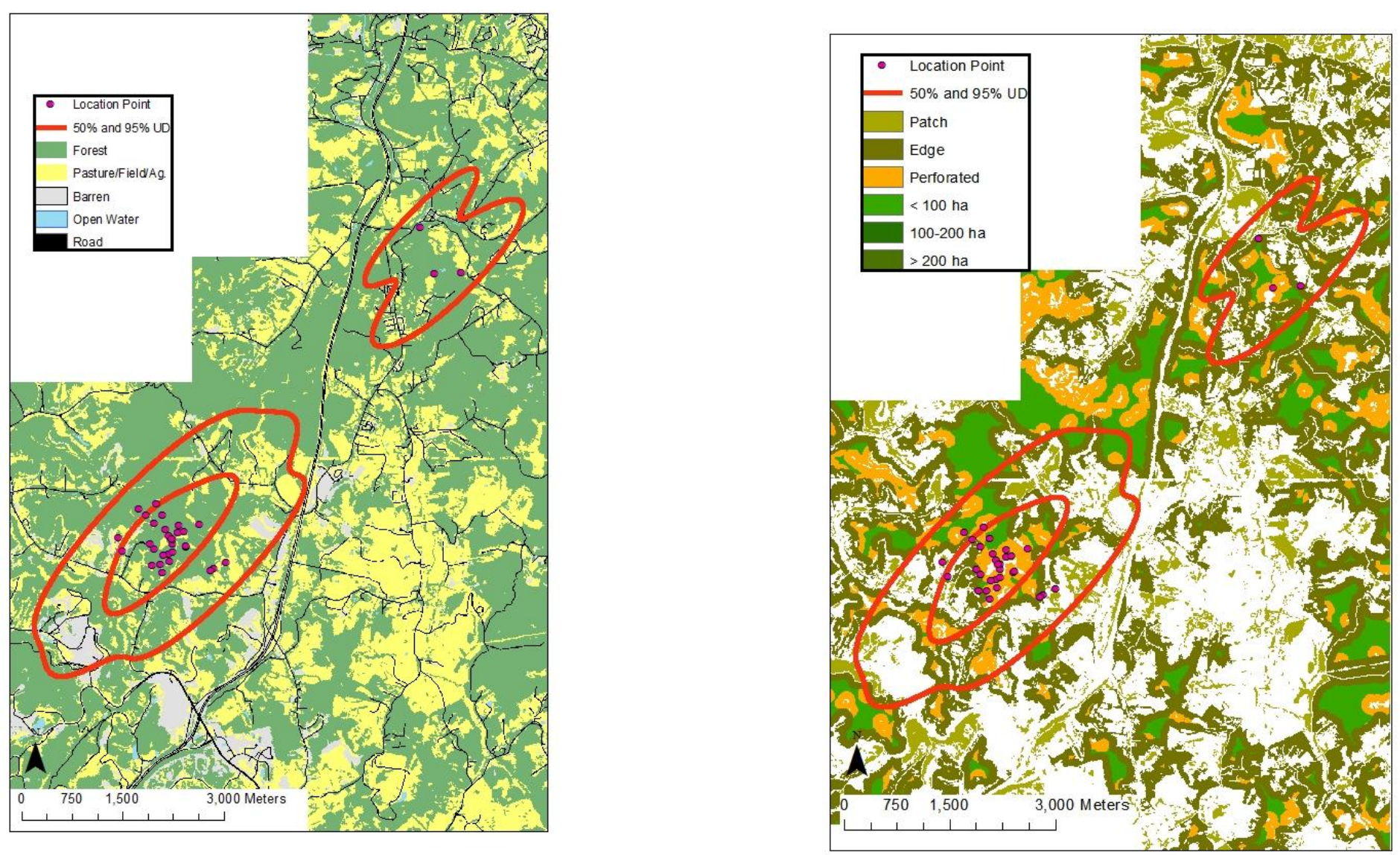
Appendix CXVIII $a$. 10071 (juvenile, spring) - 50\% core and 95\% periphery probability contours of the spring Gaussian fixed kernel home range utilization distributions. Smoothing parameter $(h)$ determined by least squares cross validation, Harrison/Marion/Taylor County, West Virginia, 2004-2007 (aspect and slope maps).
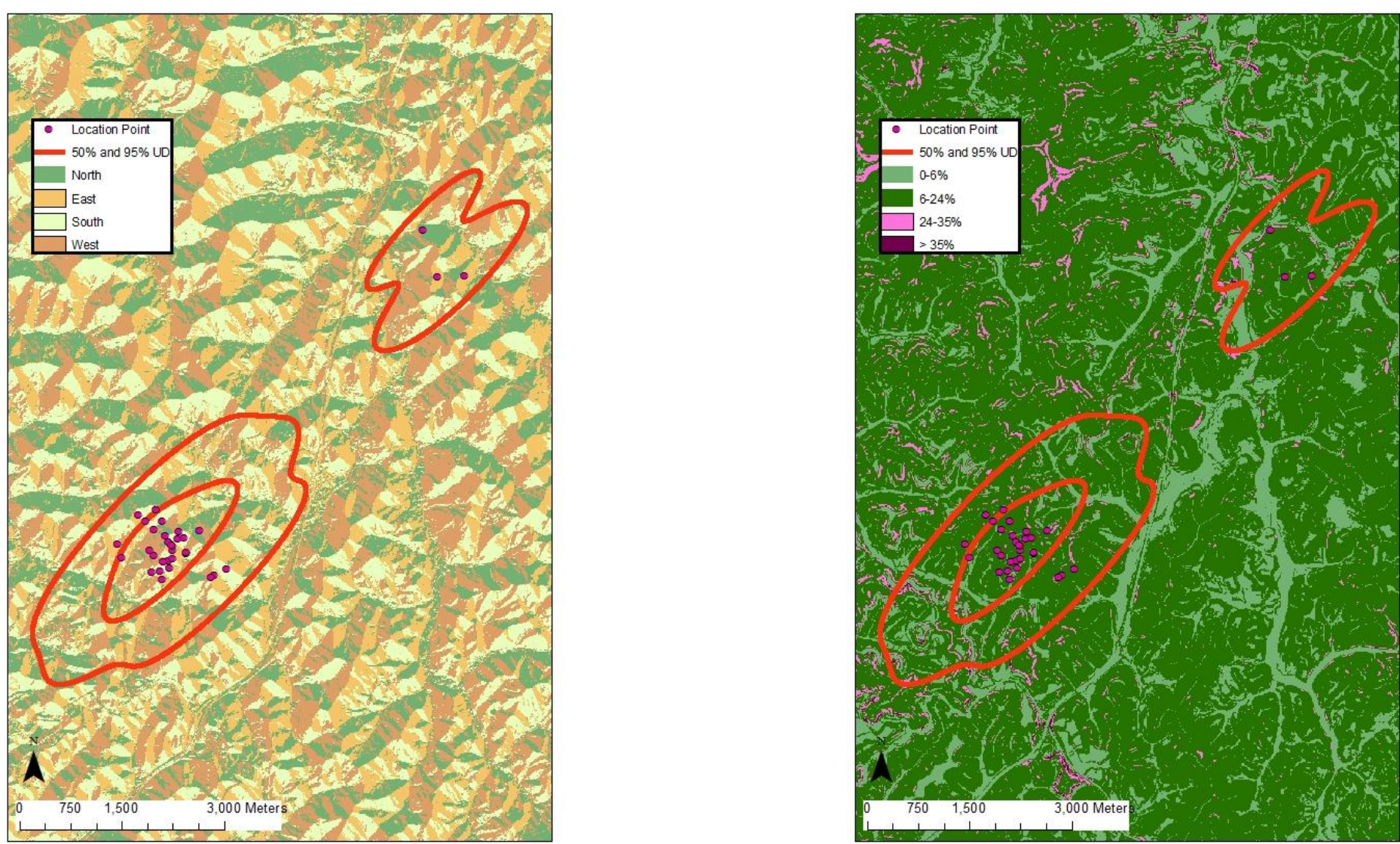
Appendix CXIXa. 10072 (juvenile, annual) - 50\% core and 95\% periphery probability contours of the annual Gaussian fixed kernel home range utilization distributions. Smoothing parameter $(h)$ determined by least squares cross validation, Harrison/Marrion/Taylor County, West Virginia, 2004-2007 (land use and land cover, land fragmentation maps).
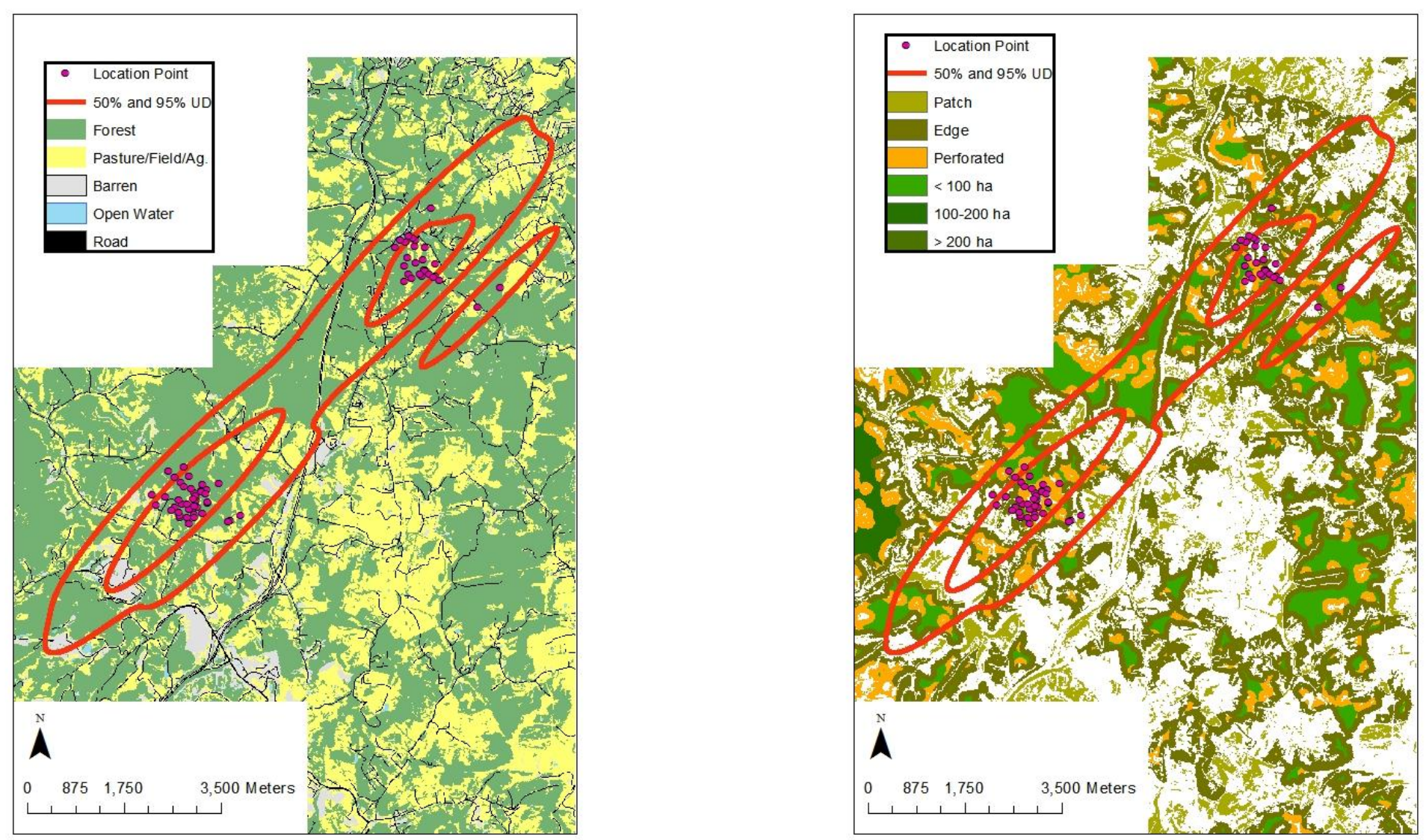
Appendix CXXa. 10072 (juvenile, annual) - 50\% core and 95\% periphery probability contours of the annual Gaussian fixed kernel home range utilization distributions. Smoothing parameter $(h)$ determined by least squares cross validation, Harrison/Marion/Taylor County, West Virginia, 2004-2007 (aspect and slope maps).
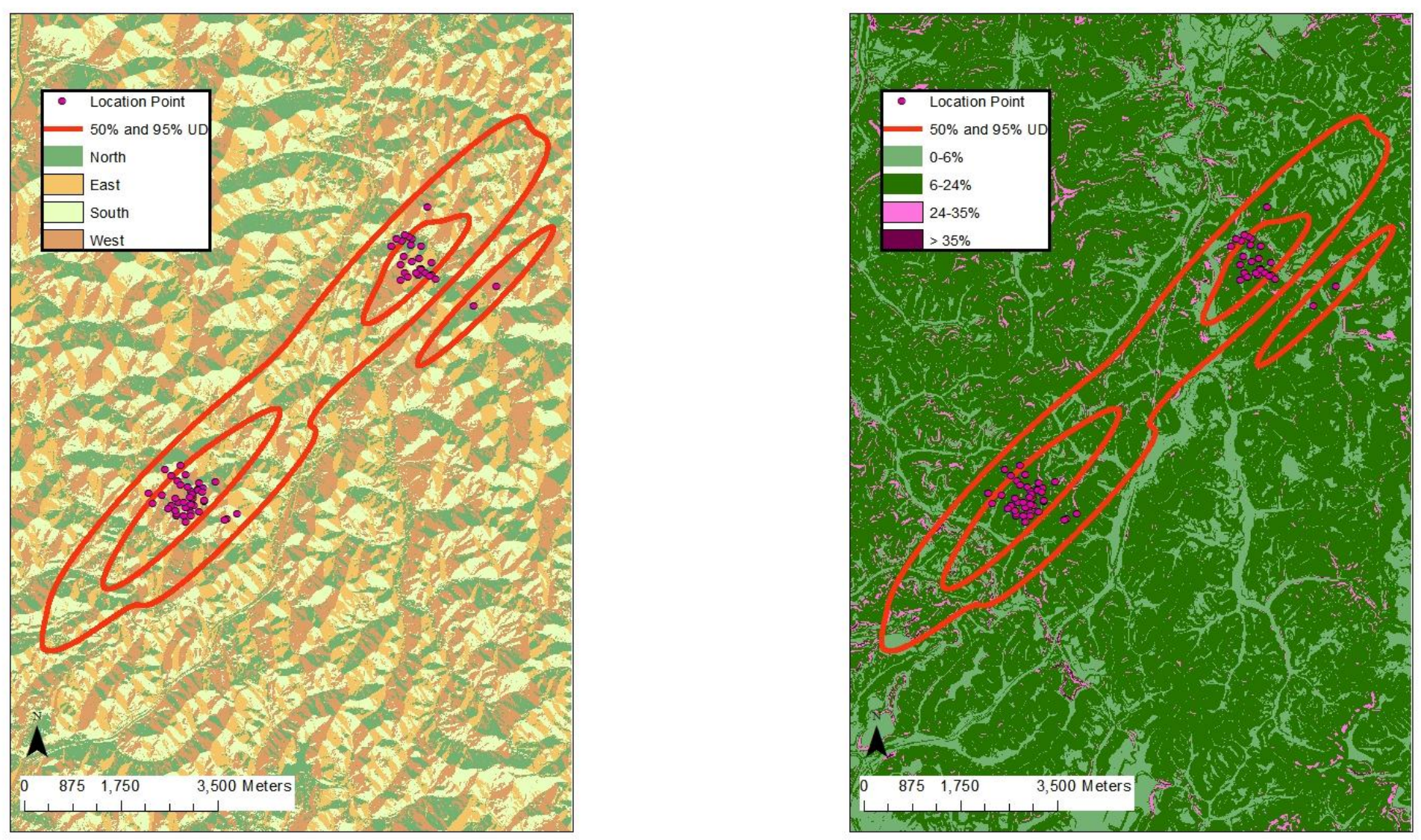
Appendix CXXI $a .10074$ (juvenile, spring) - 50\% core and 95\% periphery probability contours of the spring Gaussian fixed kernel home range utilization distributions. Smoothing parameter $(h)$ determined by least squares cross validation, Harrison/Marrion/Taylor County, West Virginia, 2004-2007 (land use and land cover, land fragmentation maps).
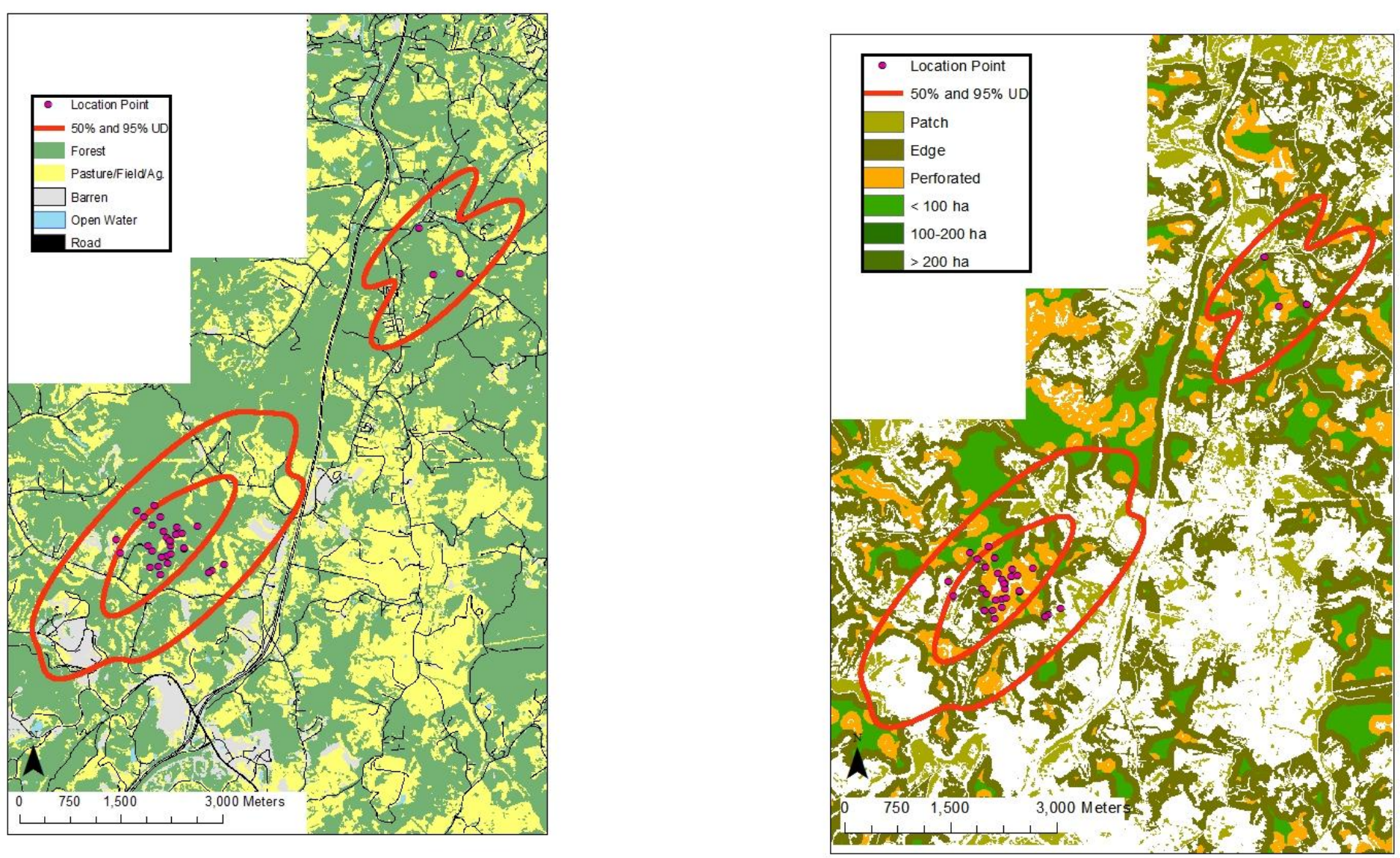
Appendix CXXII $a$. 10074 (juvenile, spring) - 50\% core and 95\% periphery probability contours of the spring Gaussian fixed kernel home range utilization distributions. Smoothing parameter $(h)$ determined by least squares cross validation, Harrison/Marion/Taylor County, West Virginia, 2004-2007 (aspect and slope maps).
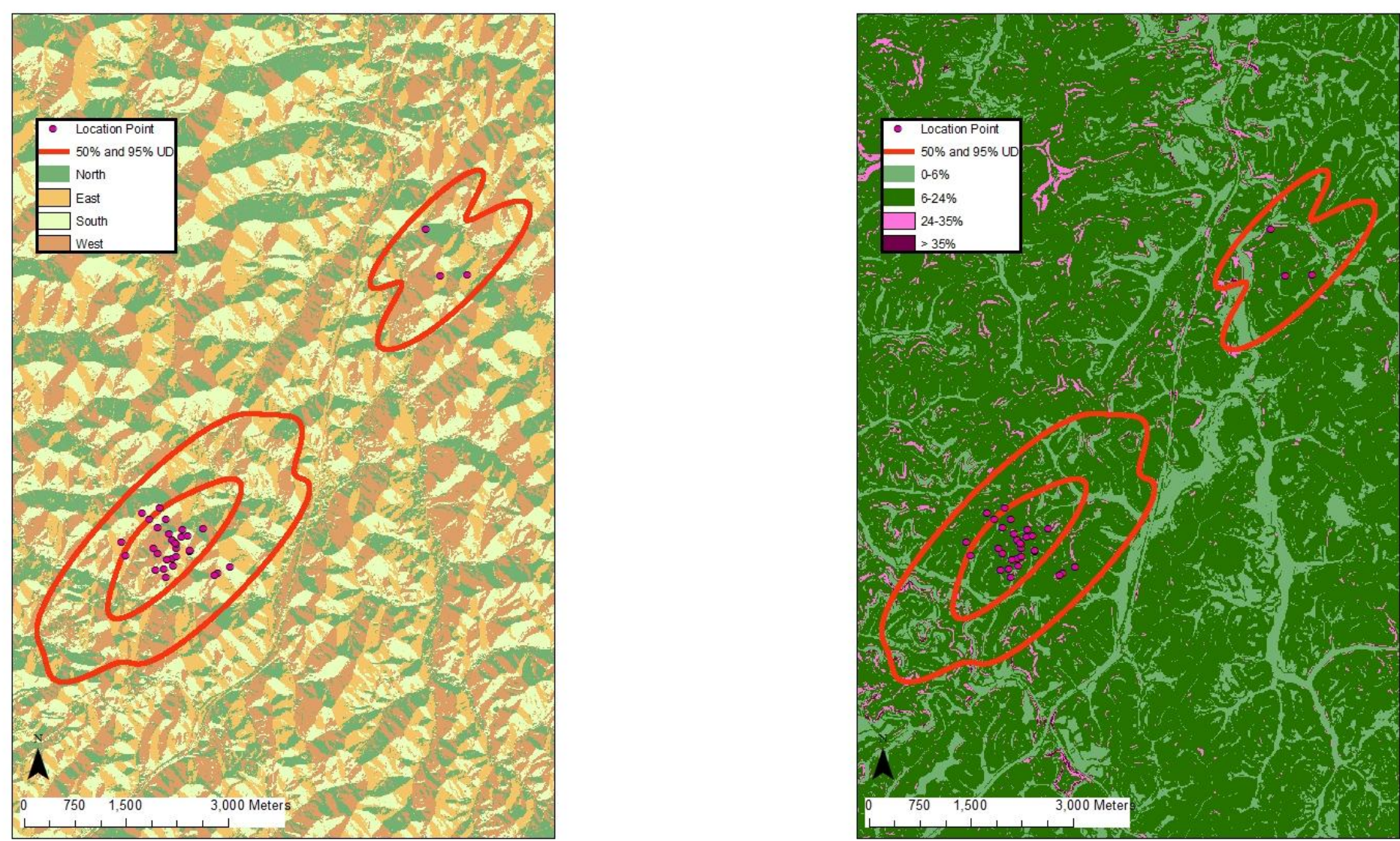
Appendix CXXIII a. 10075 (juvenile, spring-summer) - 50\% core and 95\% periphery probability contours of the spring-summer Gaussian fixed kernel home range utilization distributions. Smoothing parameter $(h)$ determined by least squares cross validation, Harrison/Marion/Taylor County, West Virginia, 2004-2007 (land use and land cover, land fragmentation maps).
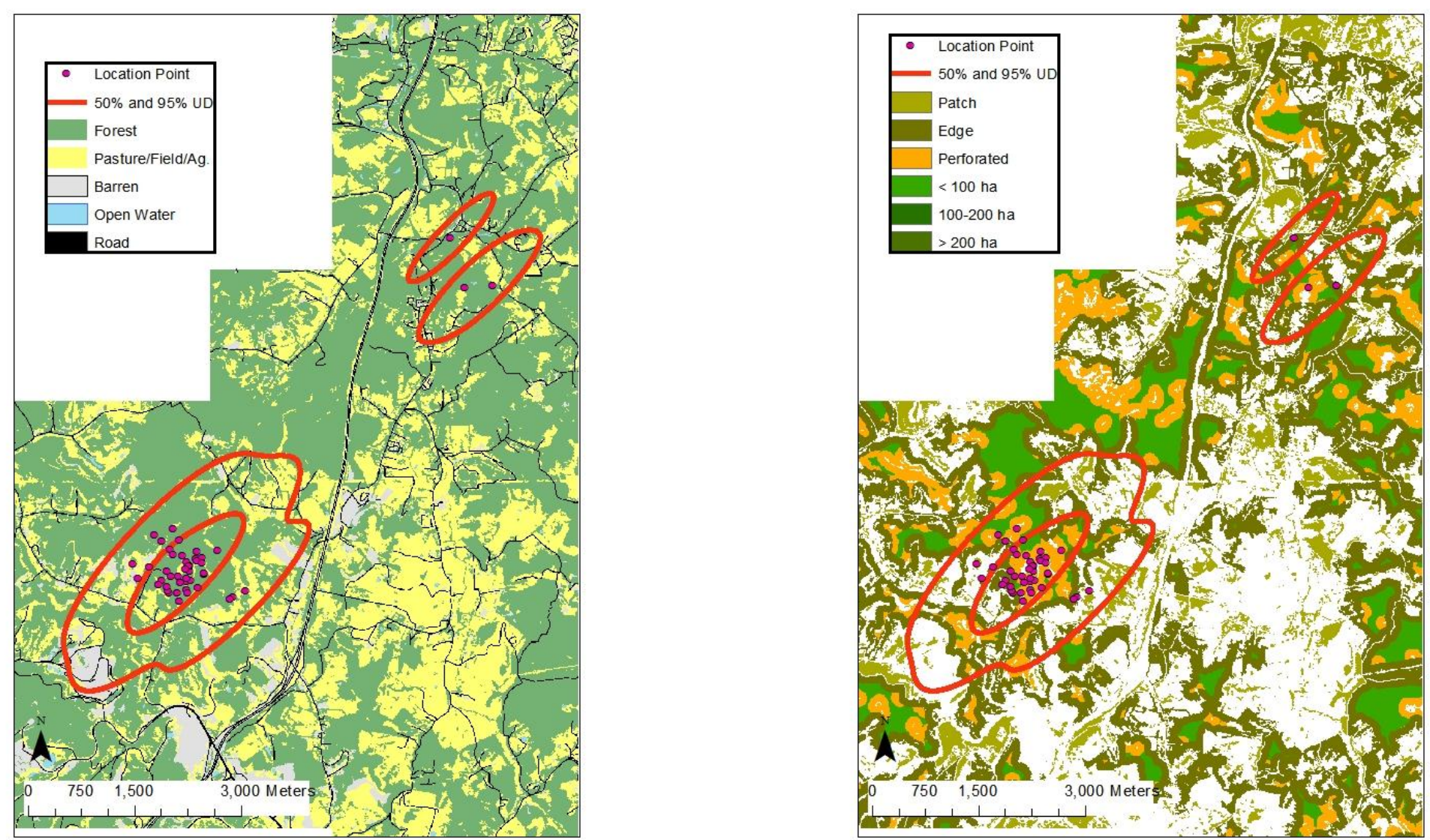
Appendix CXXIVa. 10075 (juvenile, spring-summer) - 50\% core and 95\% periphery probability contours of the spring-summer Gaussian fixed kernel home range utilization distributions. Smoothing parameter $(h)$ determined by least squares cross validation, Harrison/Marion/Taylor County, West Virginia, 2004-2007 (aspect and slope maps).
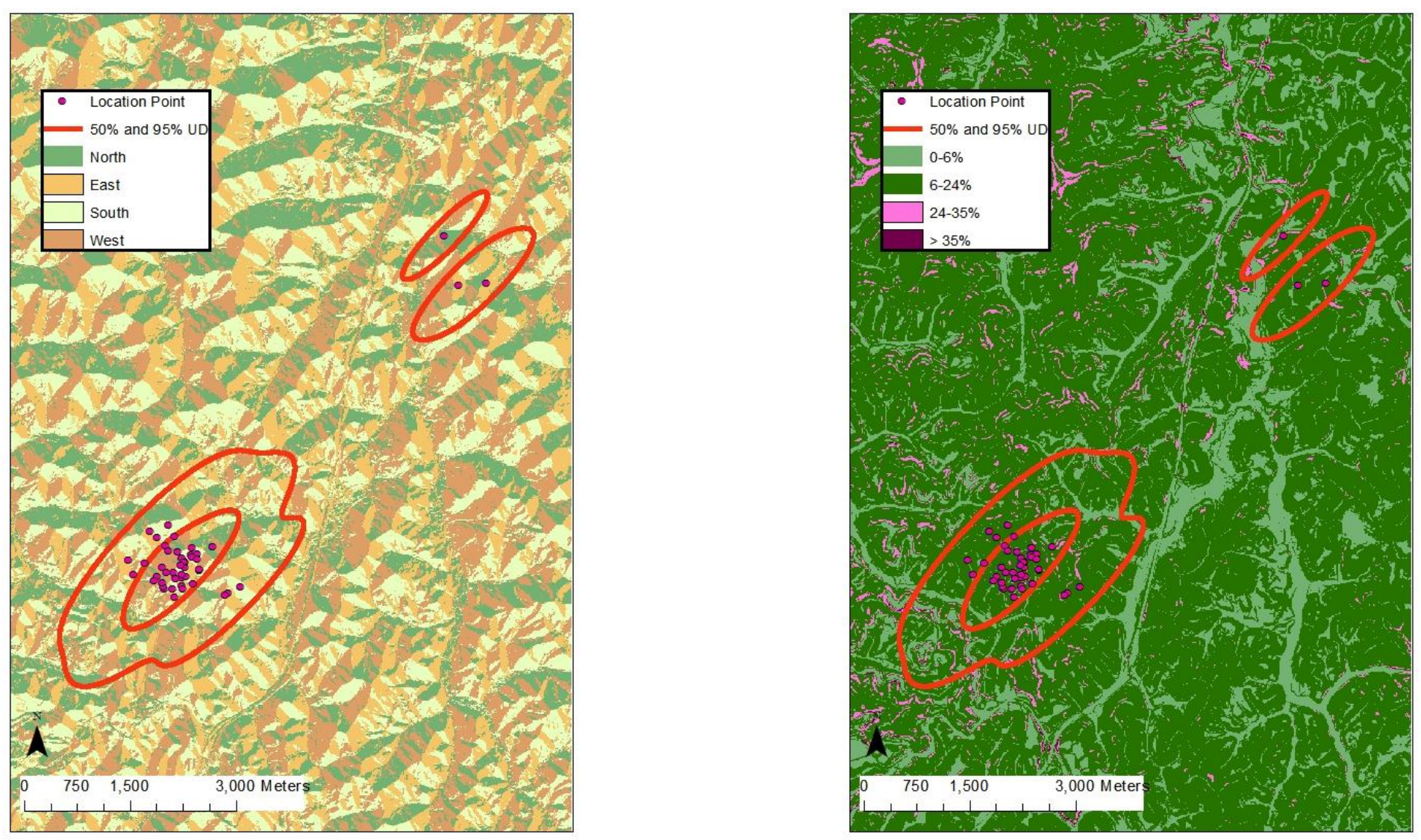
Appendix CXXVa. 10076 (juvenile, annual) - 50\% core and 95\% periphery probability contours of the annual Gaussian fixed kernel home range utilization distributions. Smoothing parameter $(h)$ determined by least squares cross validation, Harrison/Marion/Taylor County, West Virginia, 2004-2007 (land use and land cover, land fragmentation maps).
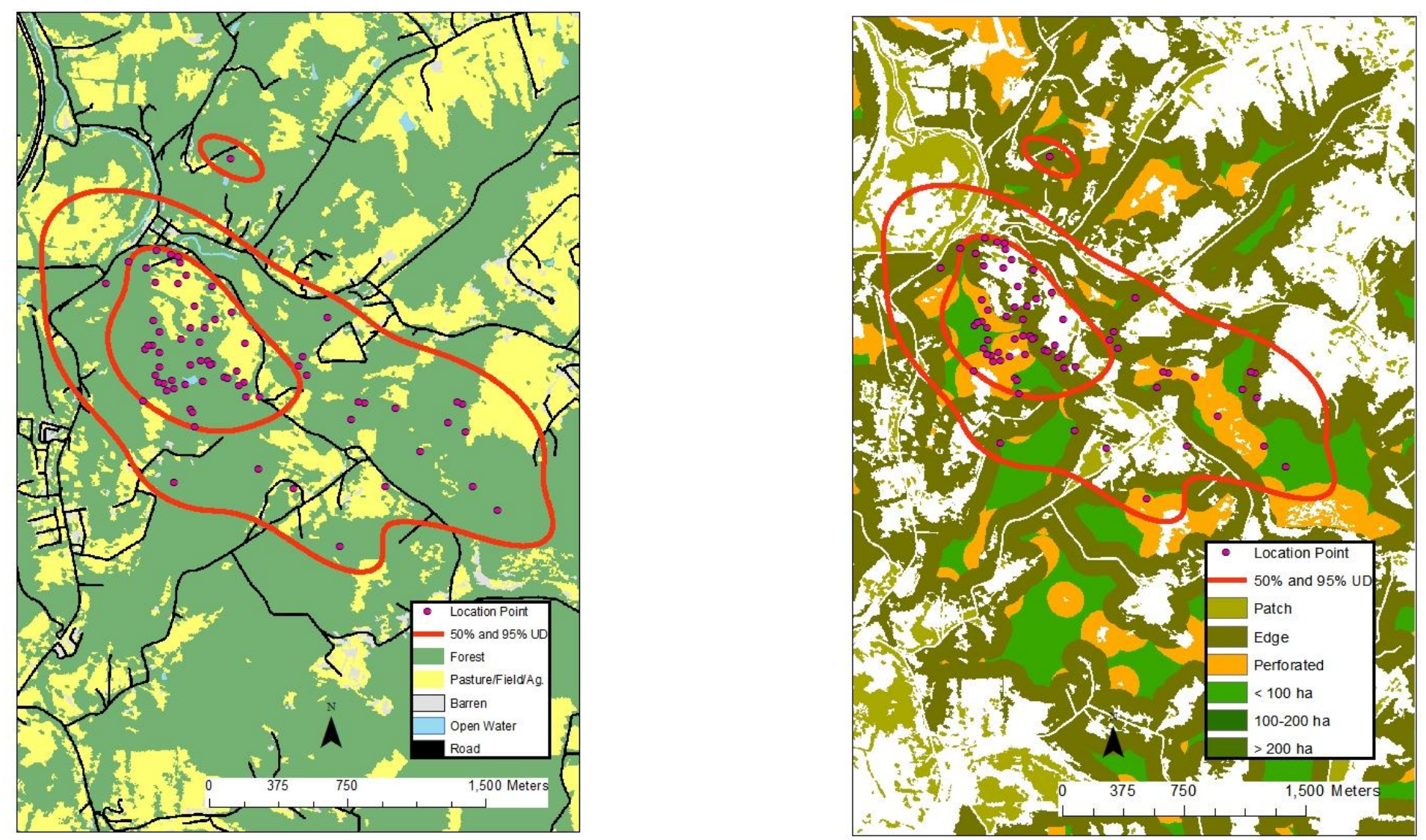
Appendix CXXVIa. 10076 (juvenile, annual) - 50\% core and 95\% periphery probability contours of the annual Gaussian fixed kernel home range utilization distributions. Smoothing parameter $(h)$ determined by least squares cross validation, Harrison/Marion/Taylor County, West Virginia, 2004-2007 (aspect and slope maps).
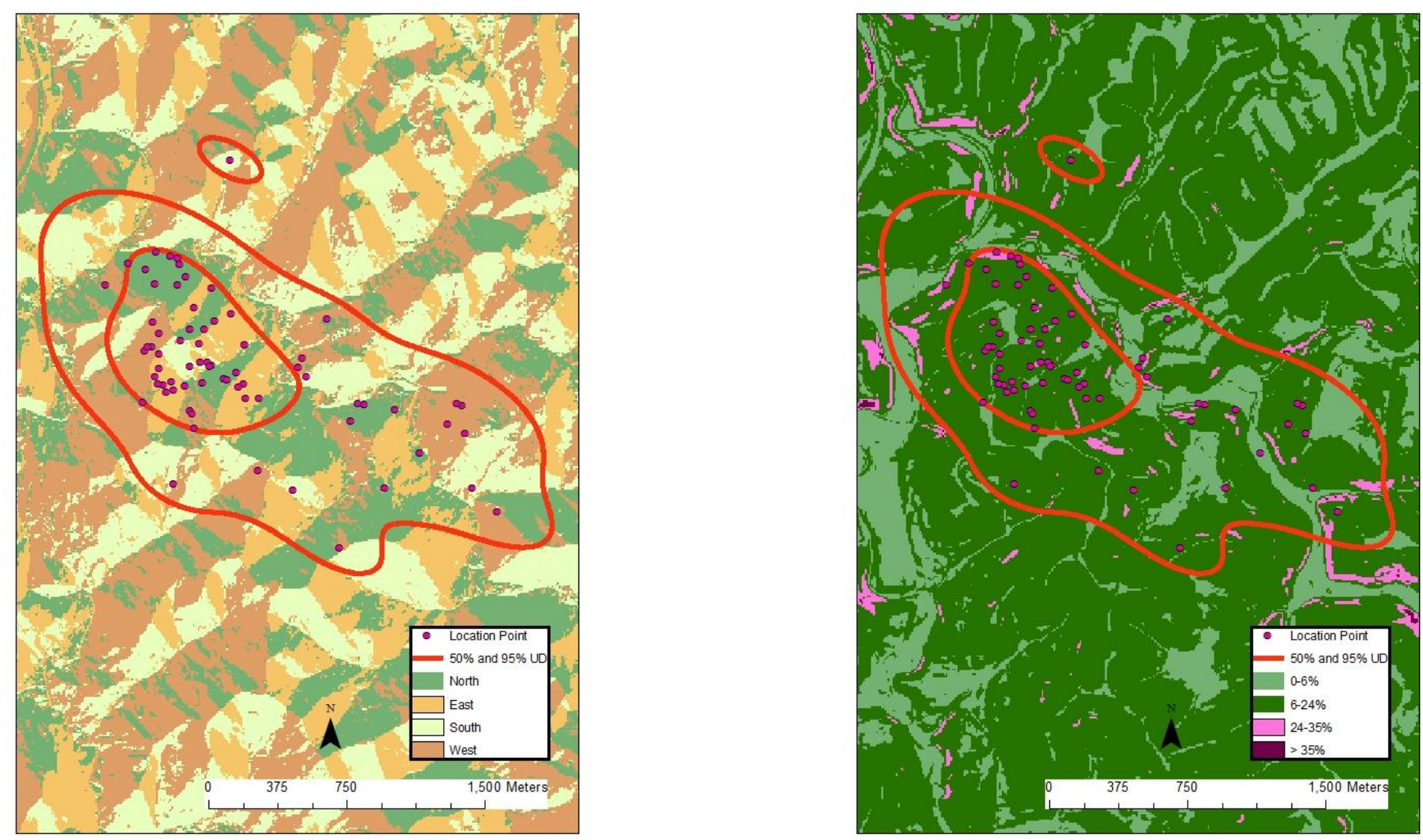
Appendix CXXVII a. 10078 (juvenile, spring) - 50\% core and 95\% periphery probability contours of the spring Gaussian fixed kernel home range utilization distributions. Smoothing parameter $(h)$ determined by least squares cross validation, Harrison/Marion/Taylor County, West Virginia, 2004-2007 (land use and land cover, land fragmentation maps).
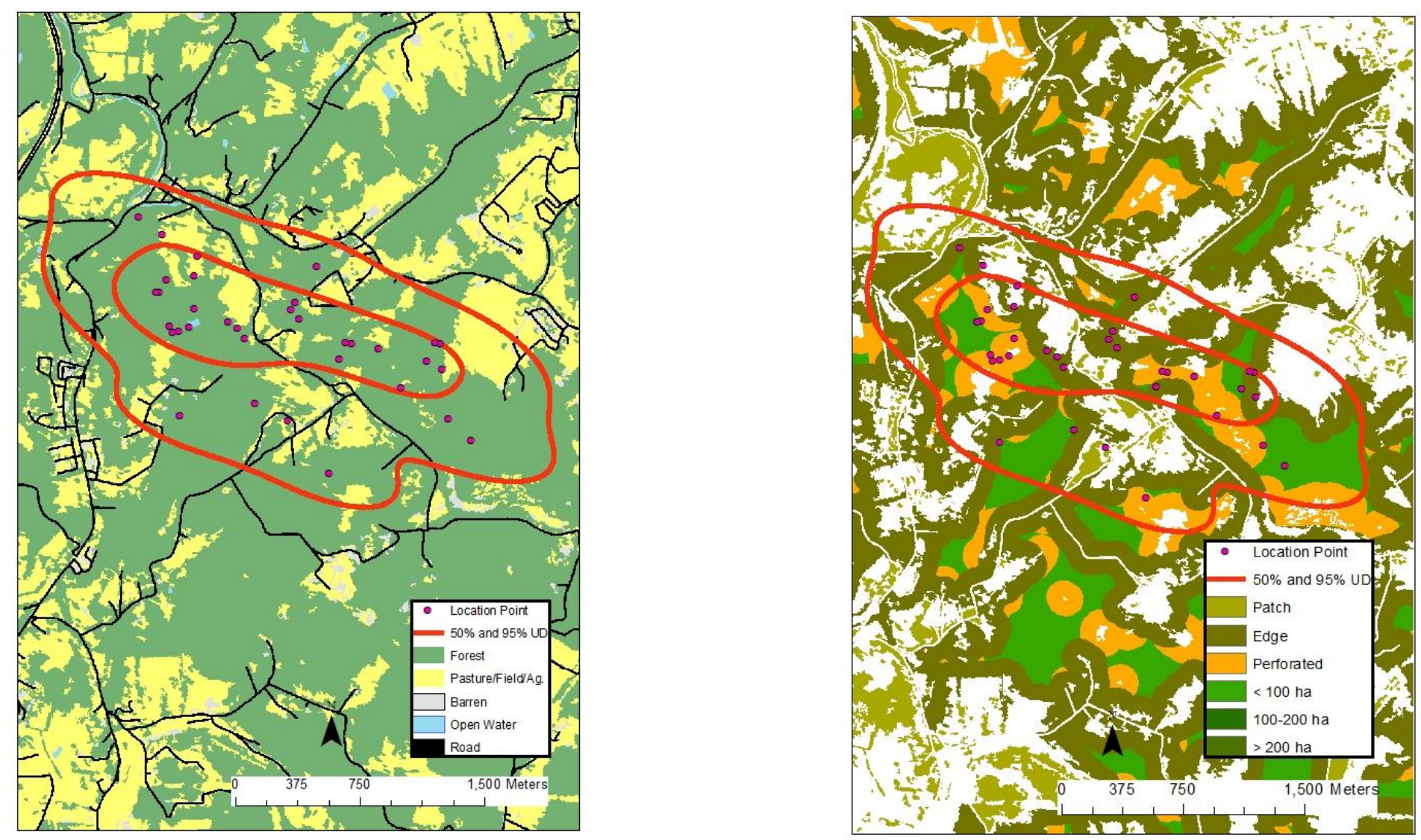
Appendix CXXVIII a. 10078 (juvenile, spring) - 50\% core and 95\% periphery probability contours of the spring Gaussian fixed kernel home range utilization distributions. Smoothing parameter $(h)$ determined by least squares cross validation, Harrison/Marion/Taylor County, West Virginia, 2004-2007 (aspect and slope maps).
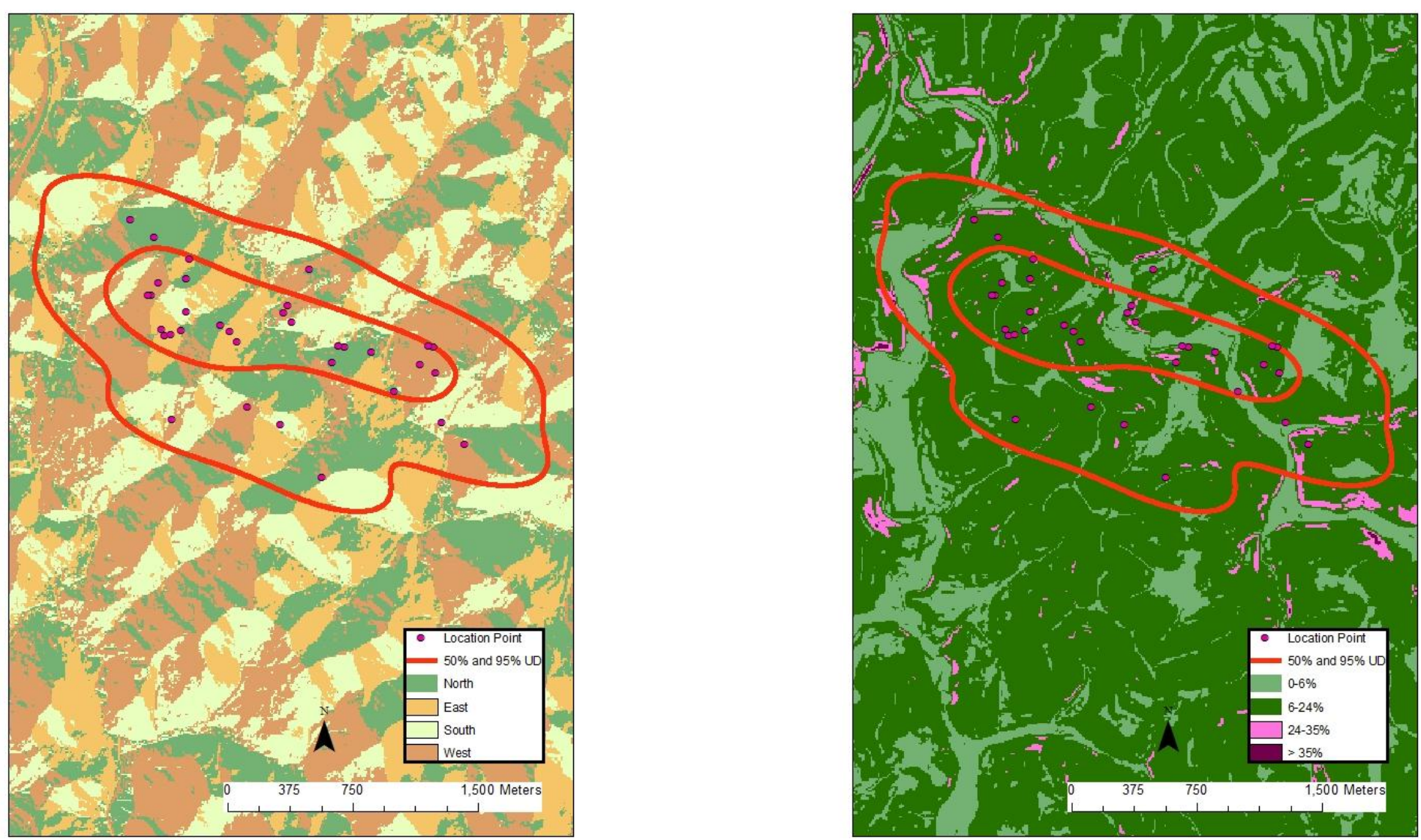
Appendix CXXIXa. 10079 (juvenile, spring-summer) - 50\% core and 95\% periphery probability contours of the spring-summer Gaussian fixed kernel home range utilization distributions. Smoothing parameter $(h)$ determined by least squares cross validation, Harrison/Marion/Taylor County, West Virginia, 2004-2007 (land use and land cover, land fragmentation maps).
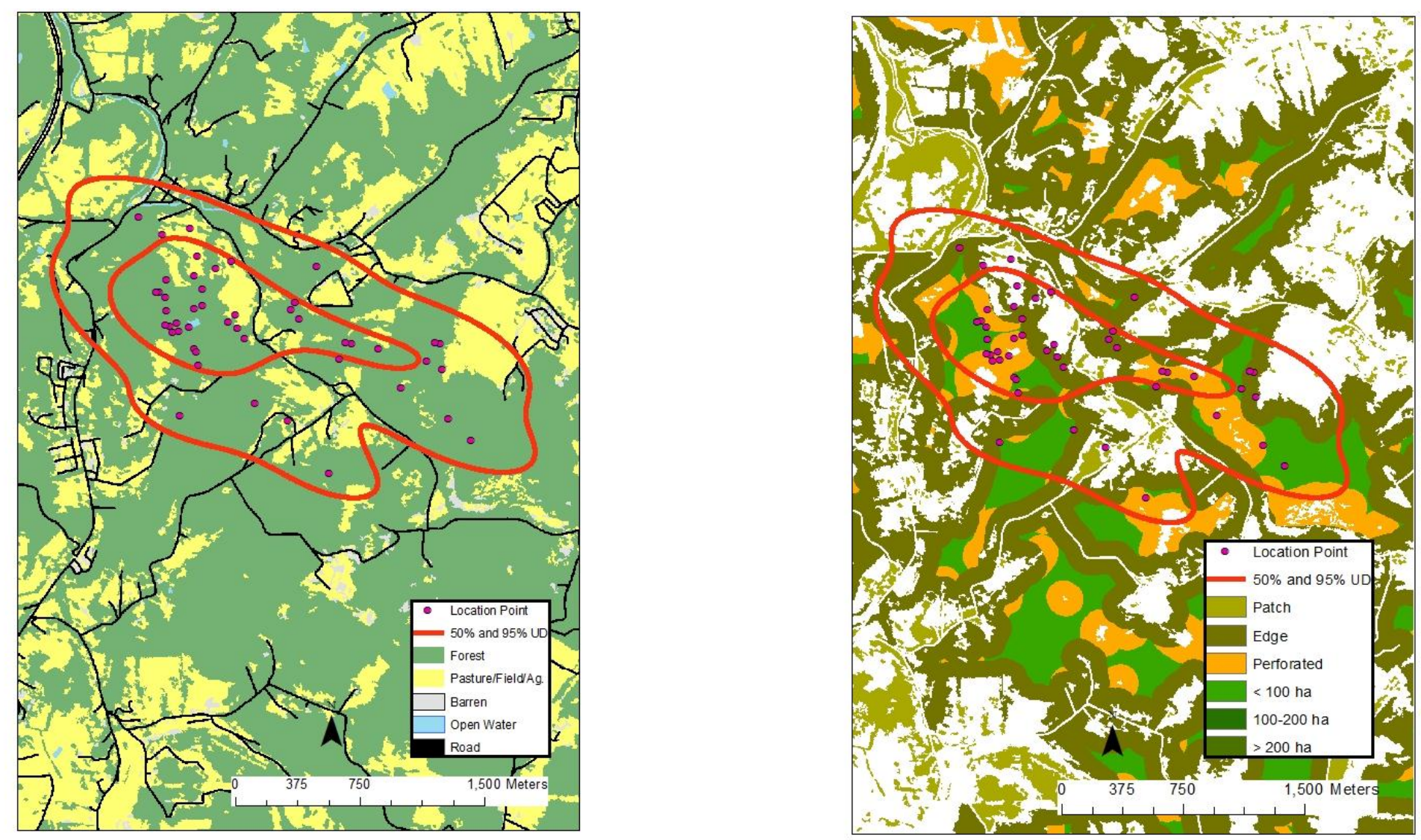
Appendix CXXXa. 10079 (juvenile, spring-summer) - 50\% core and 95\% periphery probability contours of the spring-summer Gaussian fixed kernel home range utilization distributions. Smoothing parameter $(h)$ determined by least squares cross validation, Harrison/Marion/Taylor County, West Virginia, 2004-2007 (aspect and slope maps).
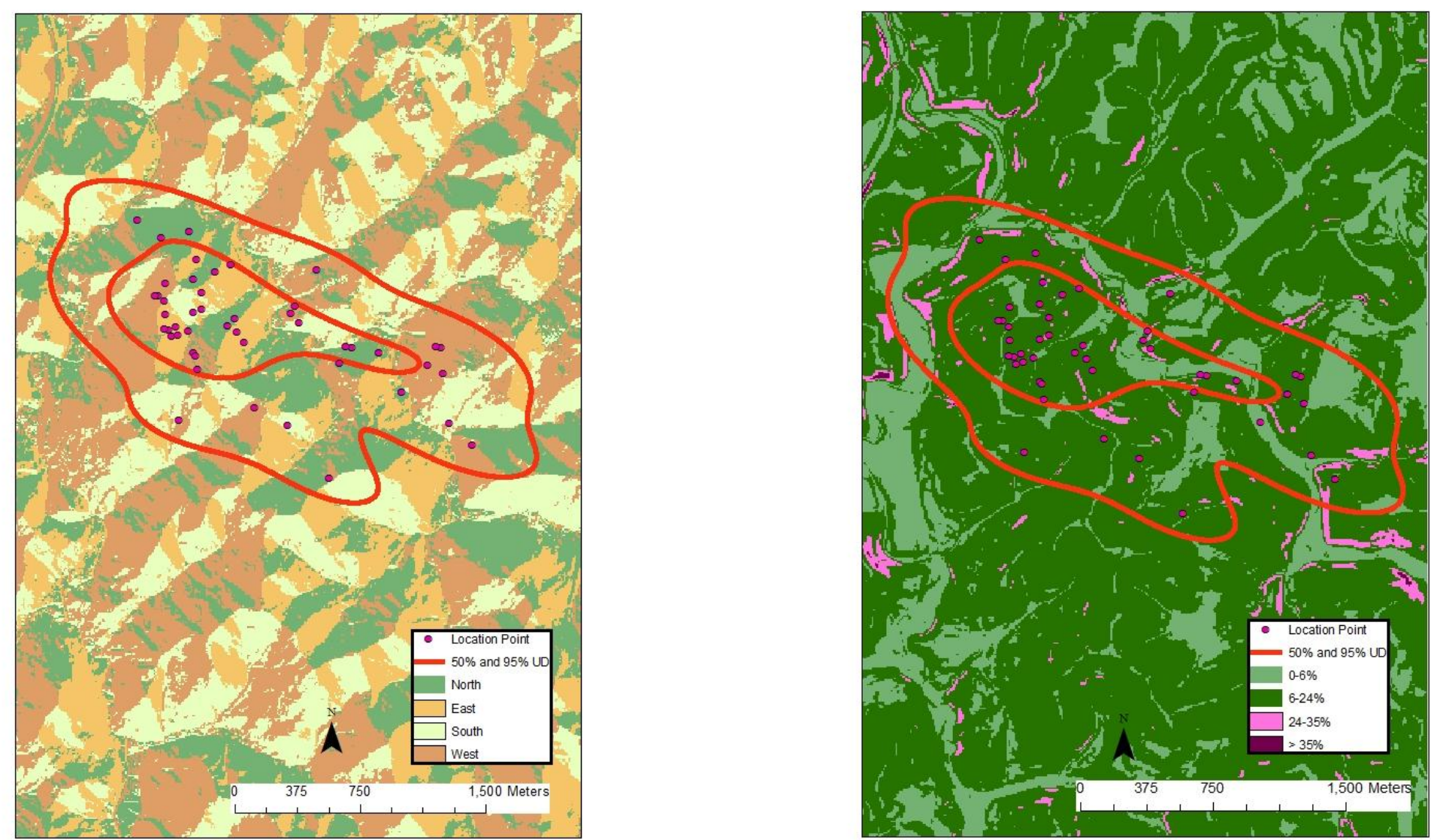
Appendix CXXXIa. 10080 (juvenile, annual) - 50\% core and 95\% periphery probability contours of the annual Gaussian fixed kernel home range utilization distributions. Smoothing parameter $(h)$ determined by least squares cross validation, Harrison/Marion/Taylor County, West Virginia, 2004-2007 (land use and land cover, land fragmentation maps).
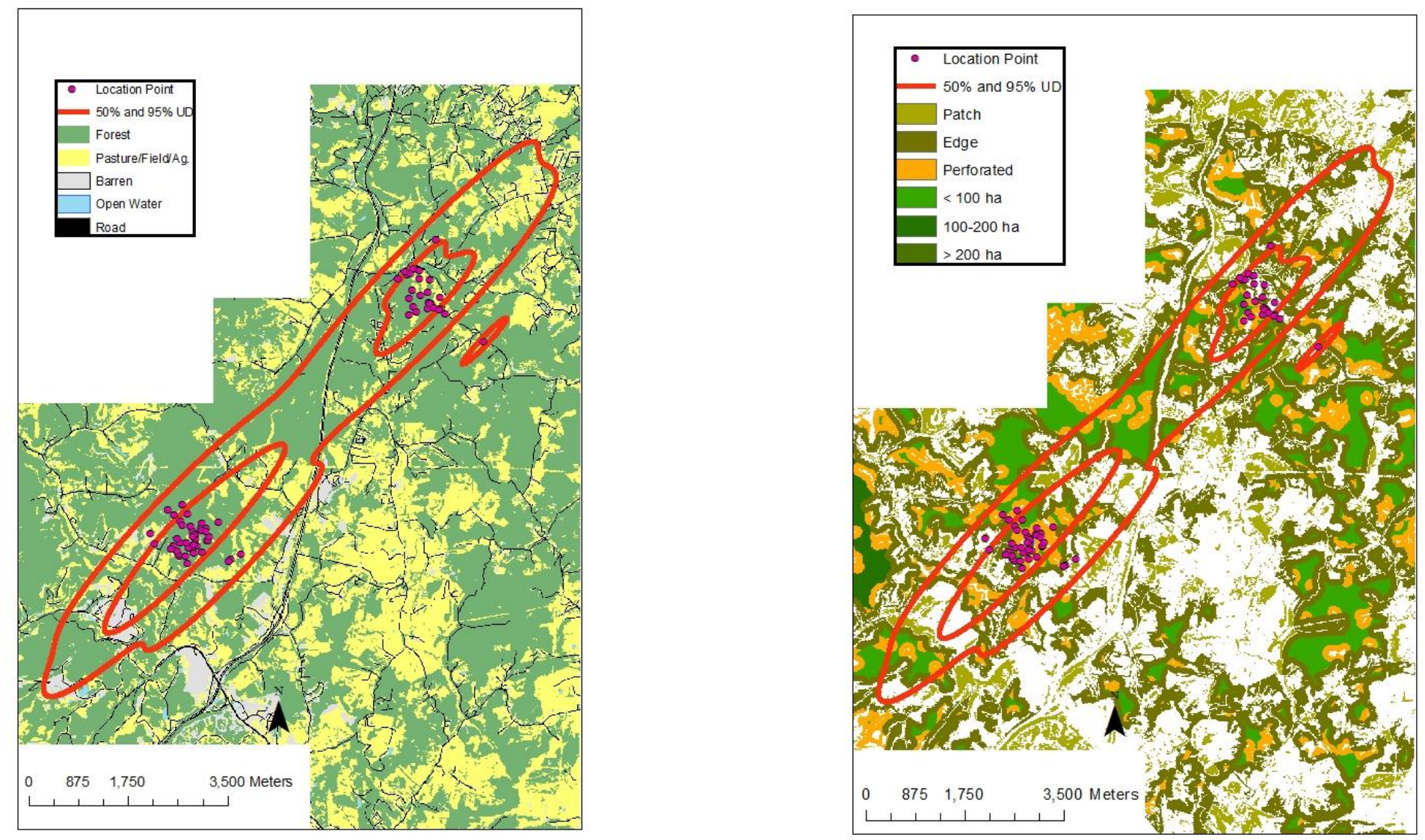
Appendix CXXXII $a$. 10080 (juvenile, annual) - 50\% core and 95\% periphery probability contours of the annual Gaussian fixed kernel home range utilization distributions. Smoothing parameter $(h)$ determined by least squares cross validation, Harrison/Marion/Taylor County, West Virginia, 2004-2007 (aspect and slope maps).
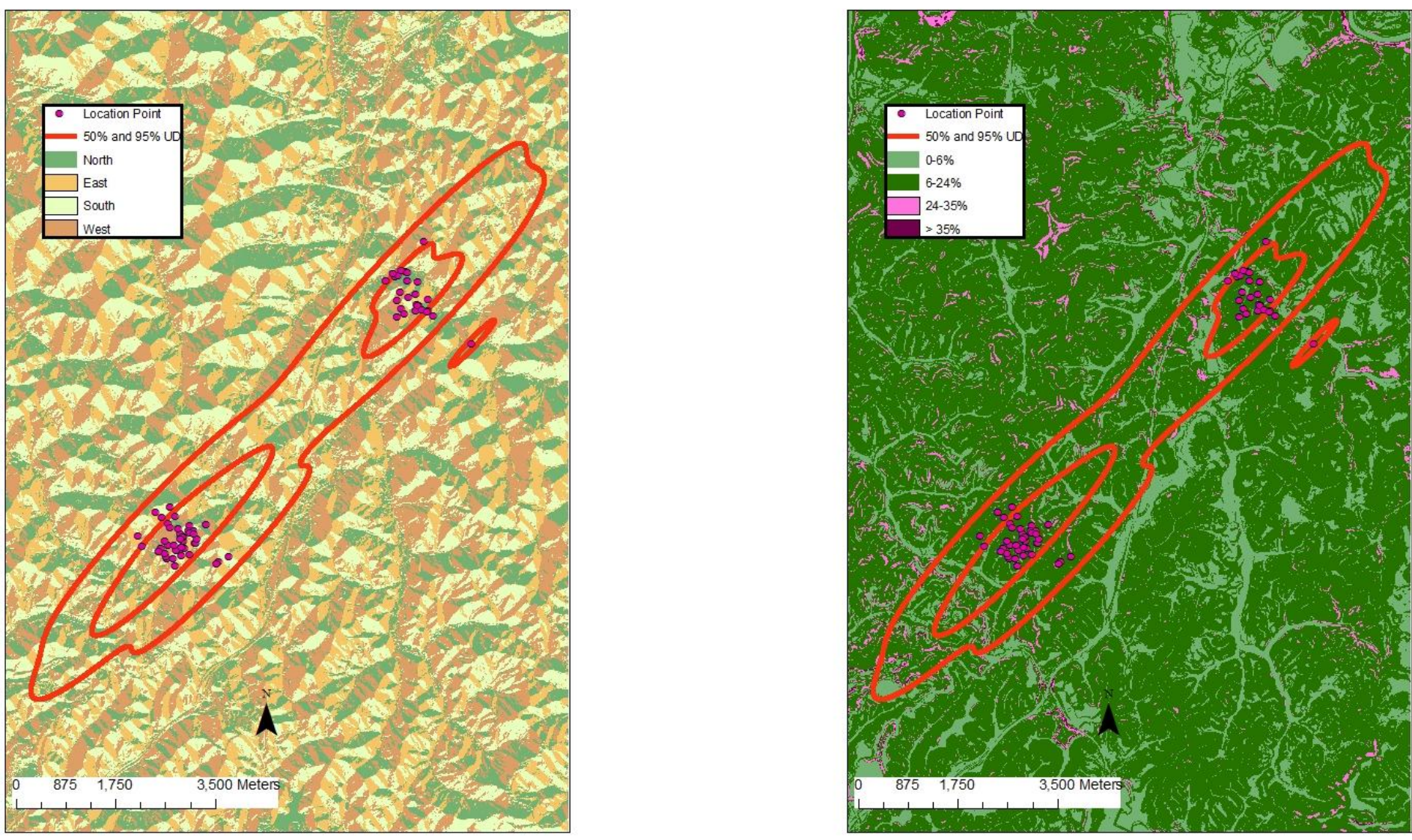
Appendix CXXXIII $a .10082$ (juvenile, spring) - 50\% core and 95\% periphery probability contours of the spring Gaussian fixed kernel home range utilization distributions. Smoothing parameter $(h)$ determined by least squares cross validation, Harrison/Marion/Taylor County, West Virginia, 2004-2007 (land use and land cover, land fragmentation maps).
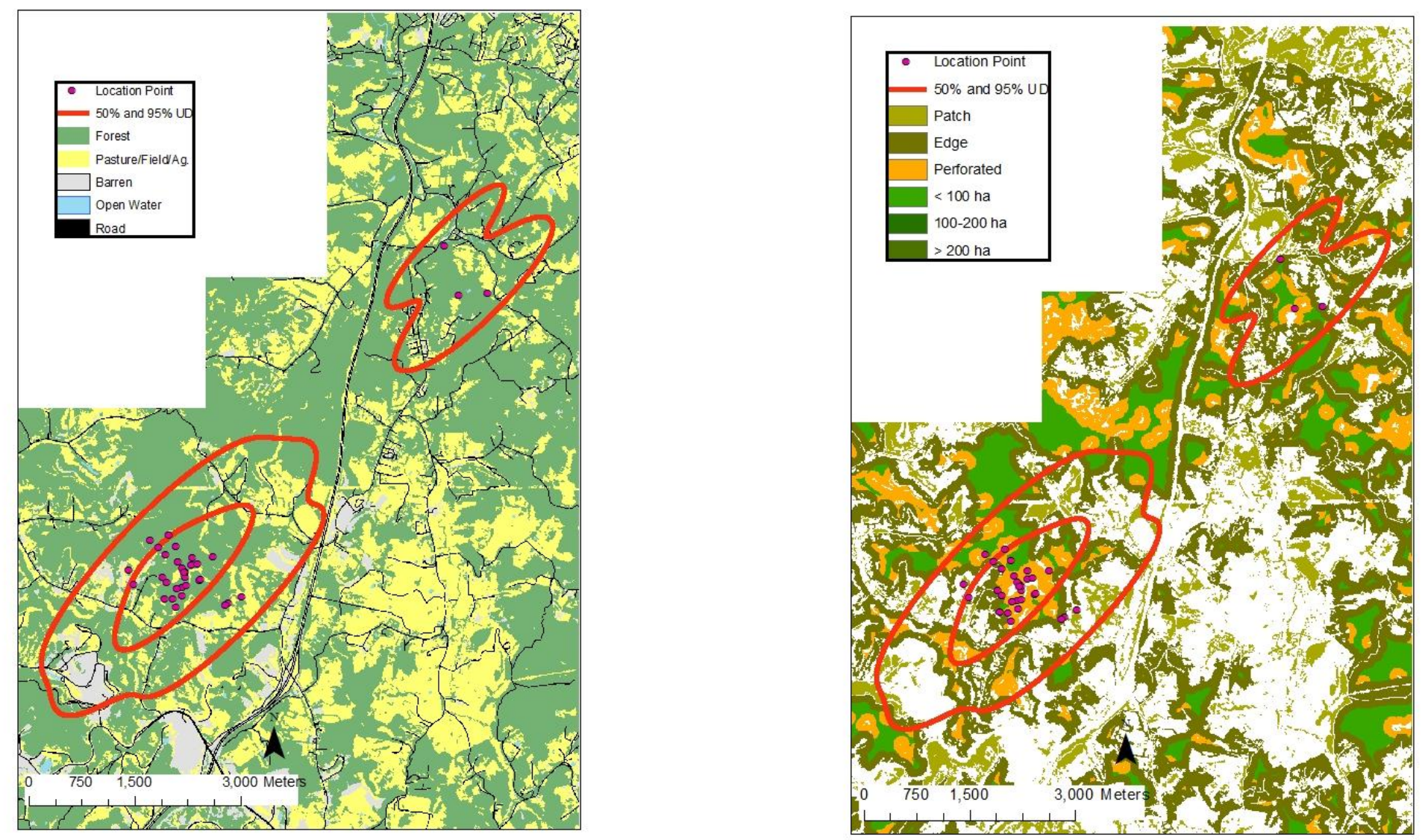
Appendix CXXXIVa. 10082 (juvenile, spring) - 50\% core and 95\% periphery probability contours of the spring Gaussian fixed kernel home range utilization distributions. Smoothing parameter $(h)$ determined by least squares cross validation, Harrison/Marion/Taylor County, West Virginia, 2004-2007 (aspect and slope maps).
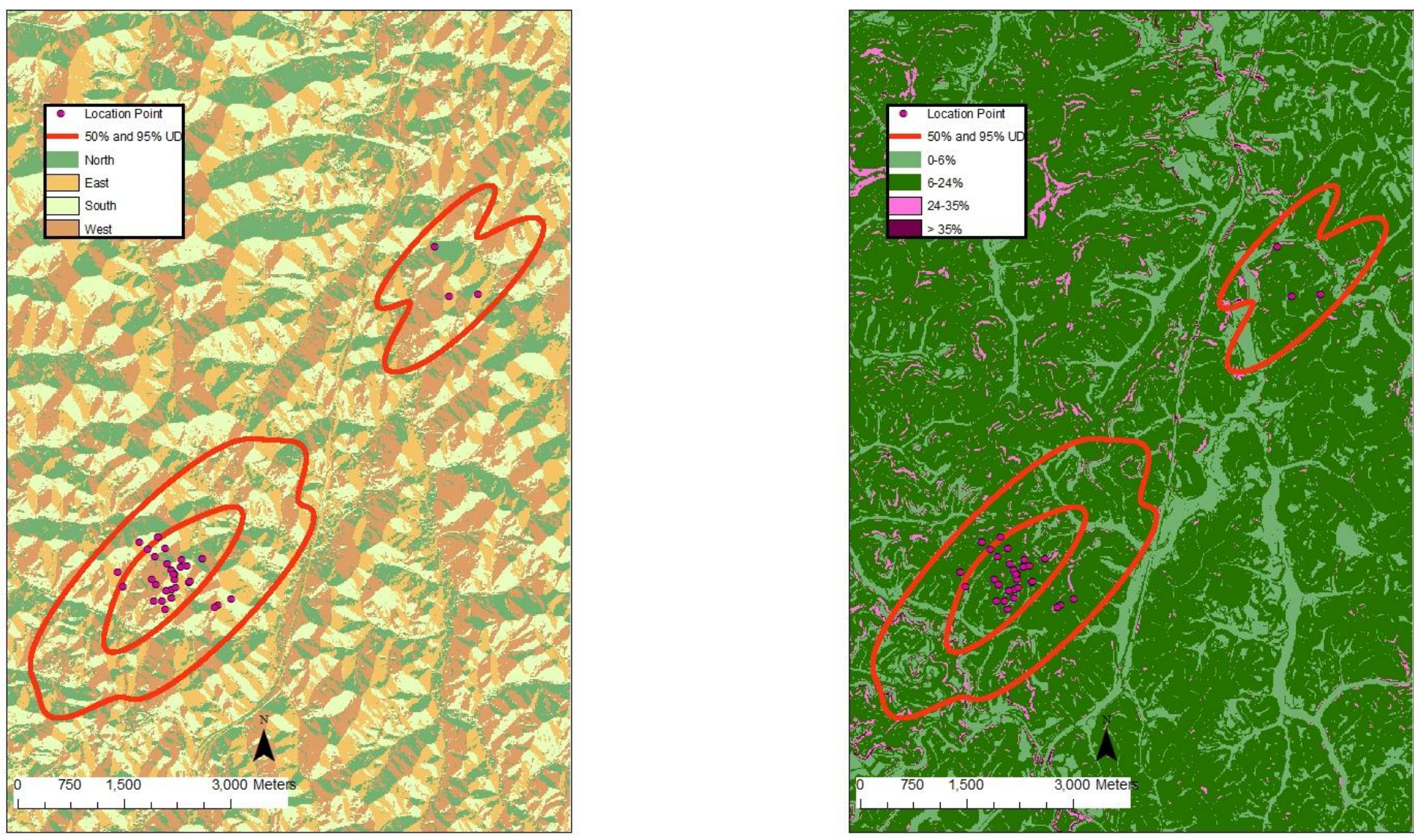
Appendix CXXXVa. 10083 (juvenile, spring-summer) - 50\% core and 95\% periphery probability contours of the spring-summer Gaussian fixed kernel home range utilization distributions. Smoothing parameter $(h)$ determined by least squares cross validation, Harrison/Marion/Taylor County, West Virginia, 2004-2007 (land use and land cover, land fragmentation maps).
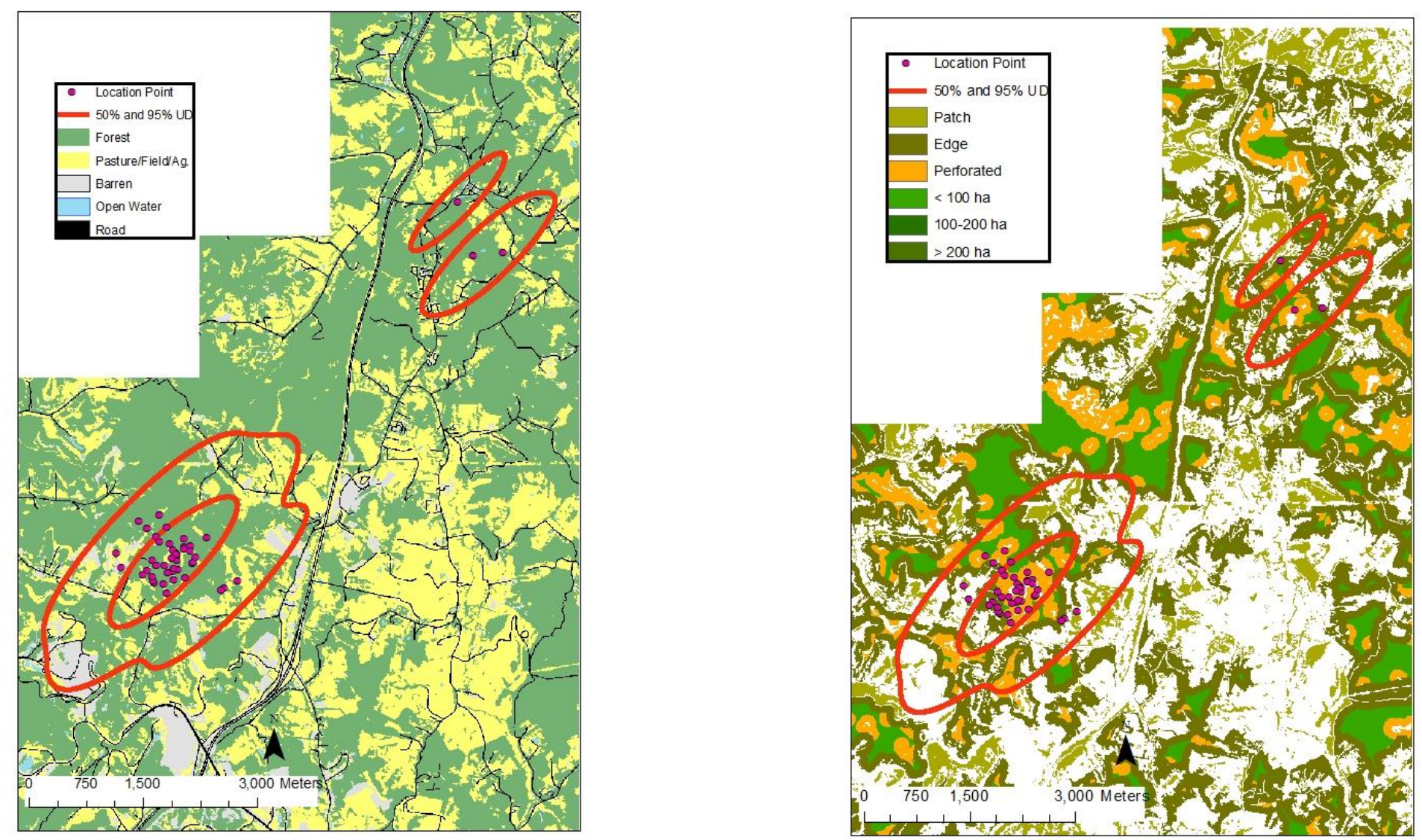
Appendix CXXXVIa. 10083 (juvenile, spring-summer) - 50\% core and 95\% periphery probability contours of the spring-summer Gaussian fixed kernel home range utilization distributions. Smoothing parameter $(h)$ determined by least squares cross validation, Harrison/Marion/Taylor County, West Virginia, 2004-2007 (aspect and slope maps).
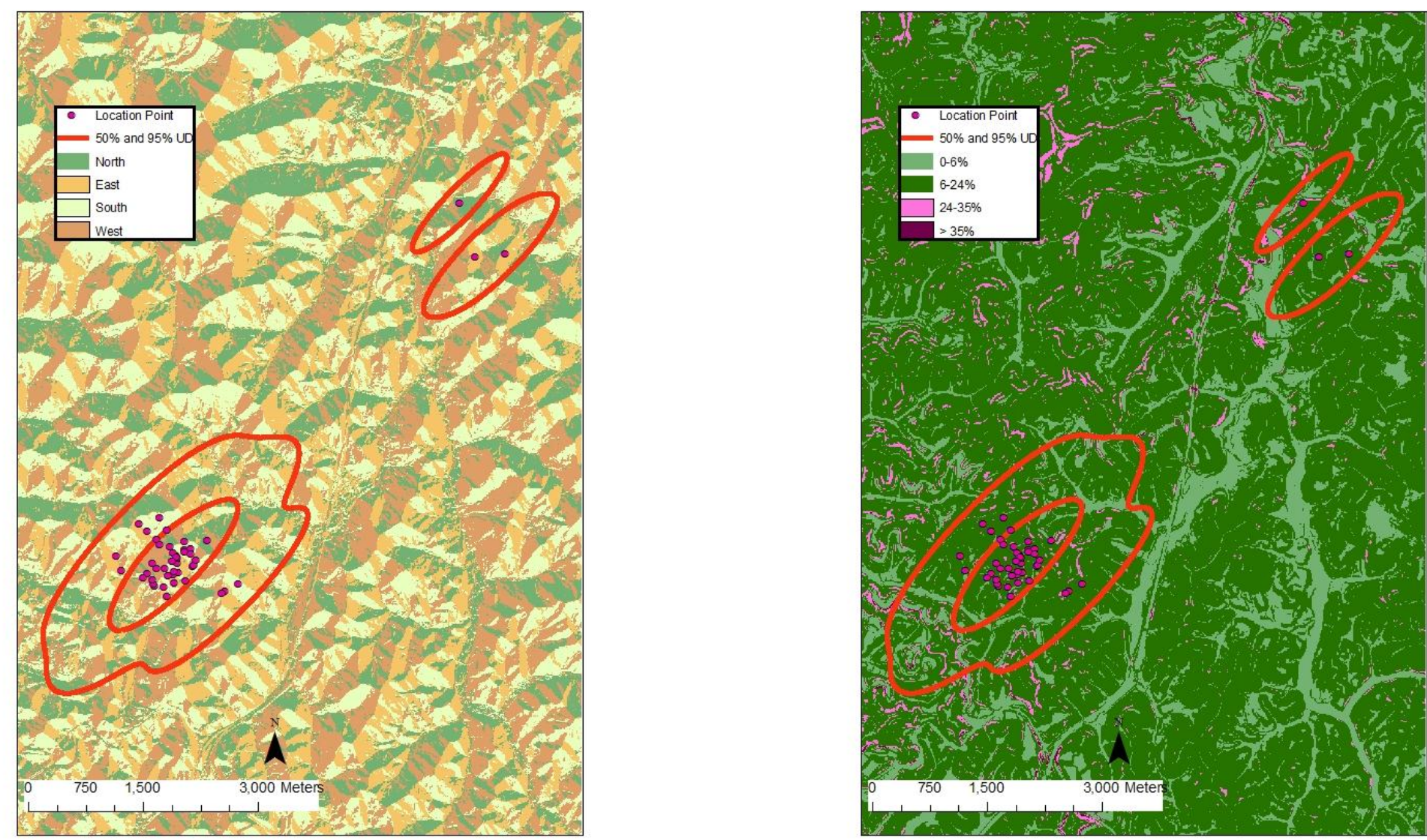
Appendix CXXXVII a. 10085 (juvenile, annual) - 50\% core and 95\% periphery probability contours of the annual Gaussian fixed kernel home range utilization distributions. Smoothing parameter $(h)$ determined by least squares cross validation, Harrison/Marion/Taylor County, West Virginia, 2004-2007 (land use and land cover, land fragmentation maps).
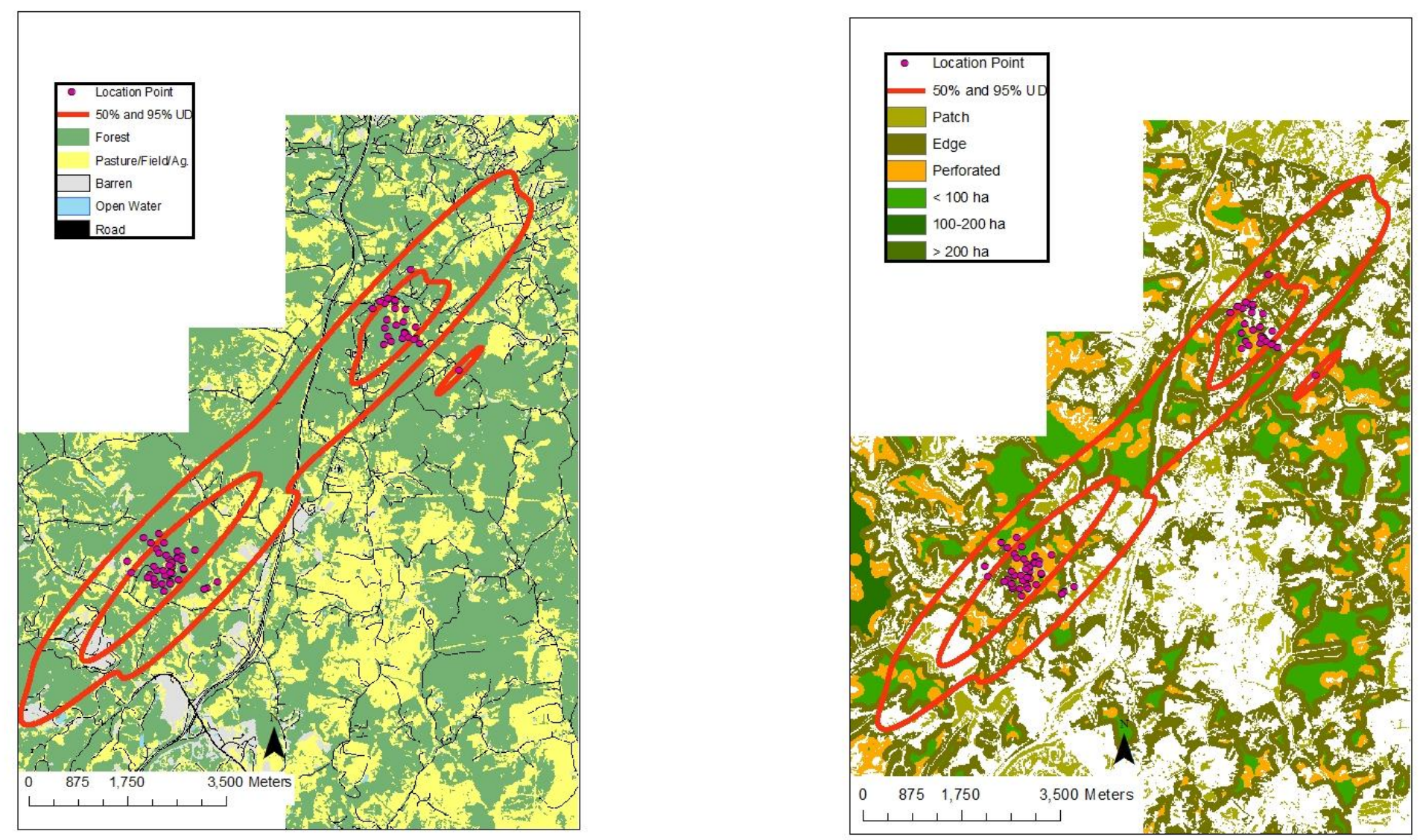
Appendix CXXXVIIIa. 10085 (juvenile, annual) - 50\% core and 95\% periphery probability contours of the annual Gaussian fixed kernel home range utilization distributions. Smoothing parameter $(h)$ determined by least squares cross validation, Harrison/Marion/Taylor County, West Virginia, 2004-2007 (aspect and slope maps).
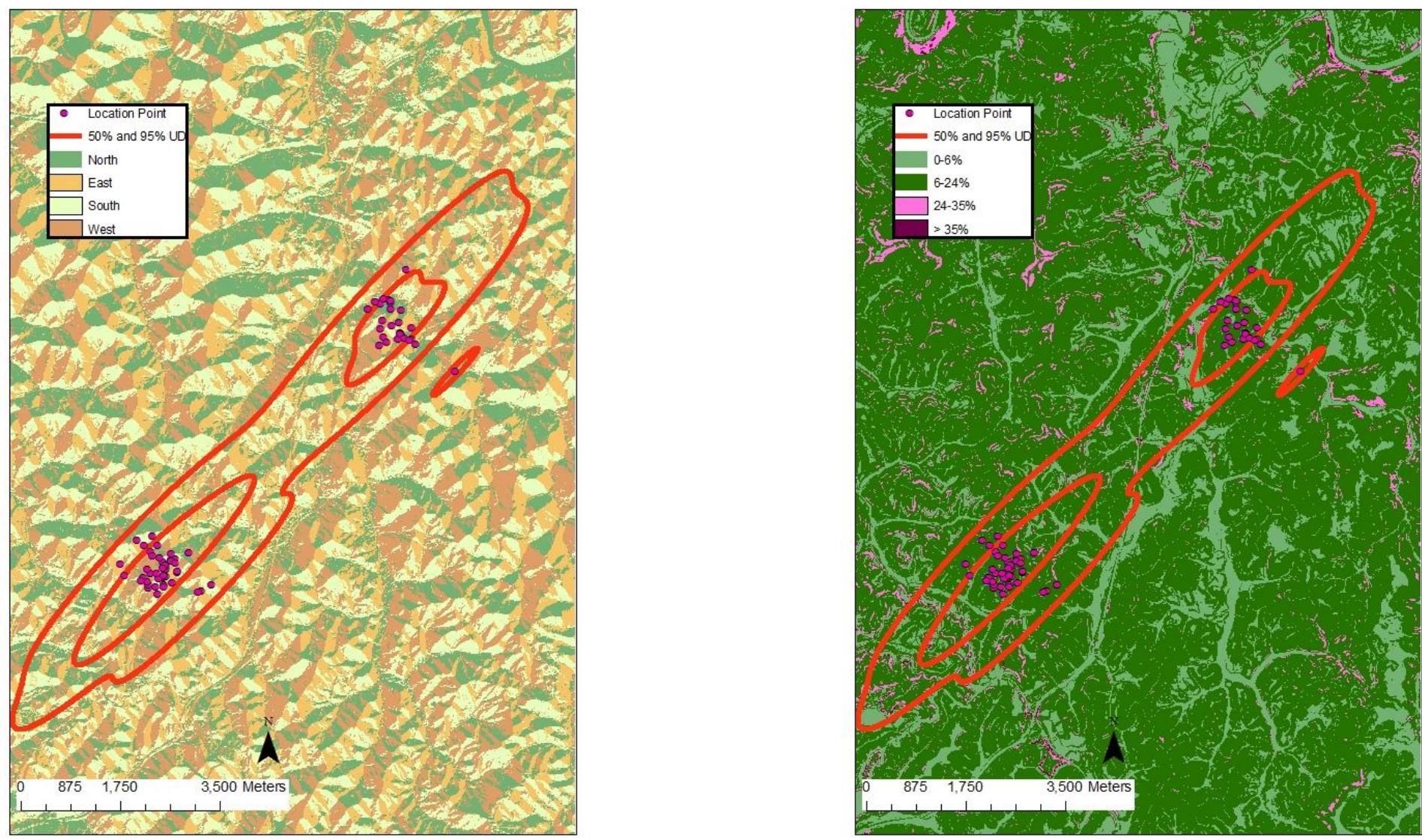
Appendix CXXXIXa. 10086 (juvenile, spring) - 50\% core and 95\% periphery probability contours of the spring Gaussian fixed kernel home range utilization distributions. Smoothing parameter $(h)$ determined by least squares cross validation, Harrison/Marion/Taylor County, West Virginia, 2004-2007 (land use and land cover, land fragmentation maps).
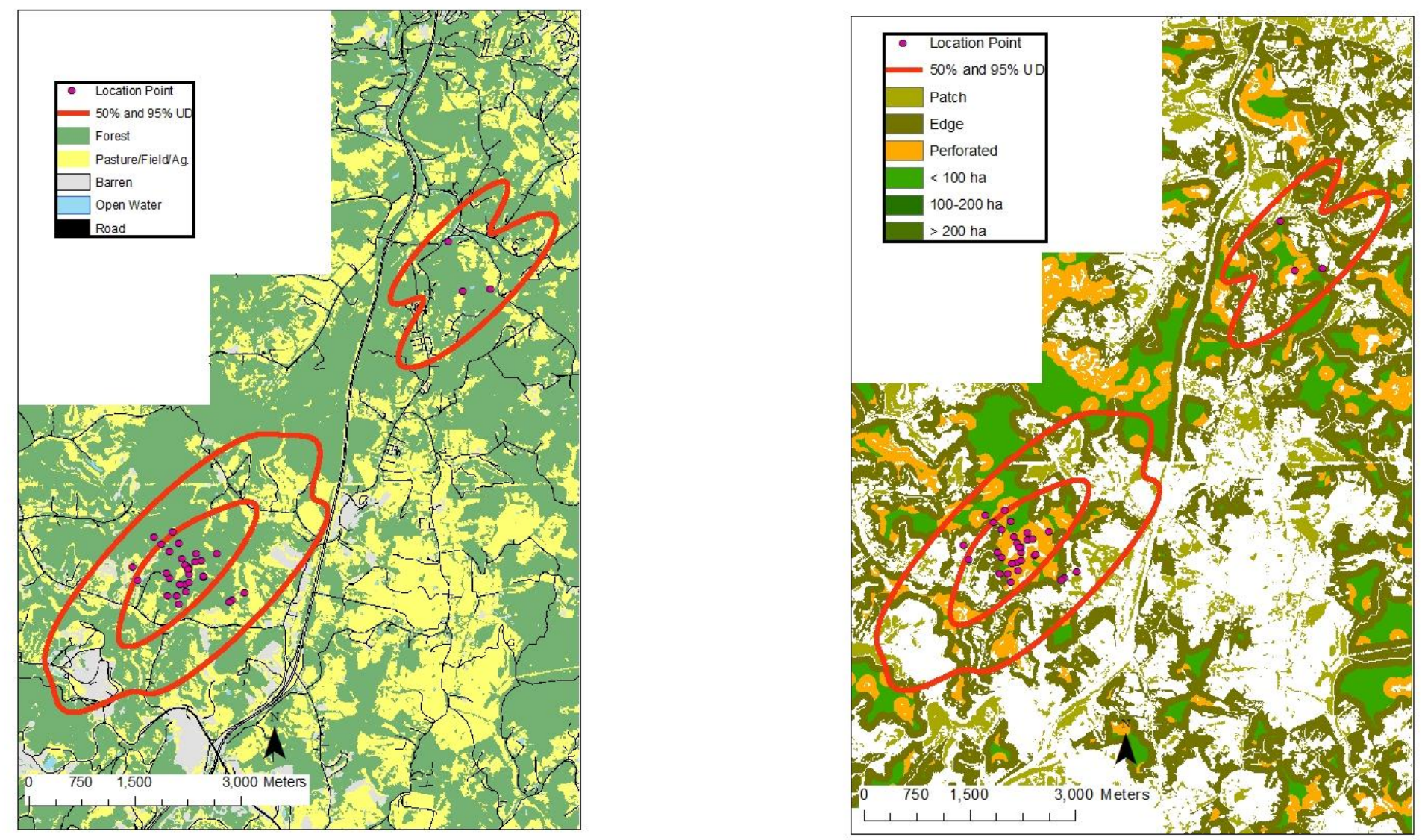
Appendix CXLa. 10086 (juvenile, spring) - 50\% core and 95\% periphery probability contours of the spring Gaussian fixed kernel home range utilization distributions. Smoothing parameter $(h)$ determined by least squares cross validation, Harrison/Marion/Taylor County, West Virginia, 2004-2007 (aspect and slope maps).
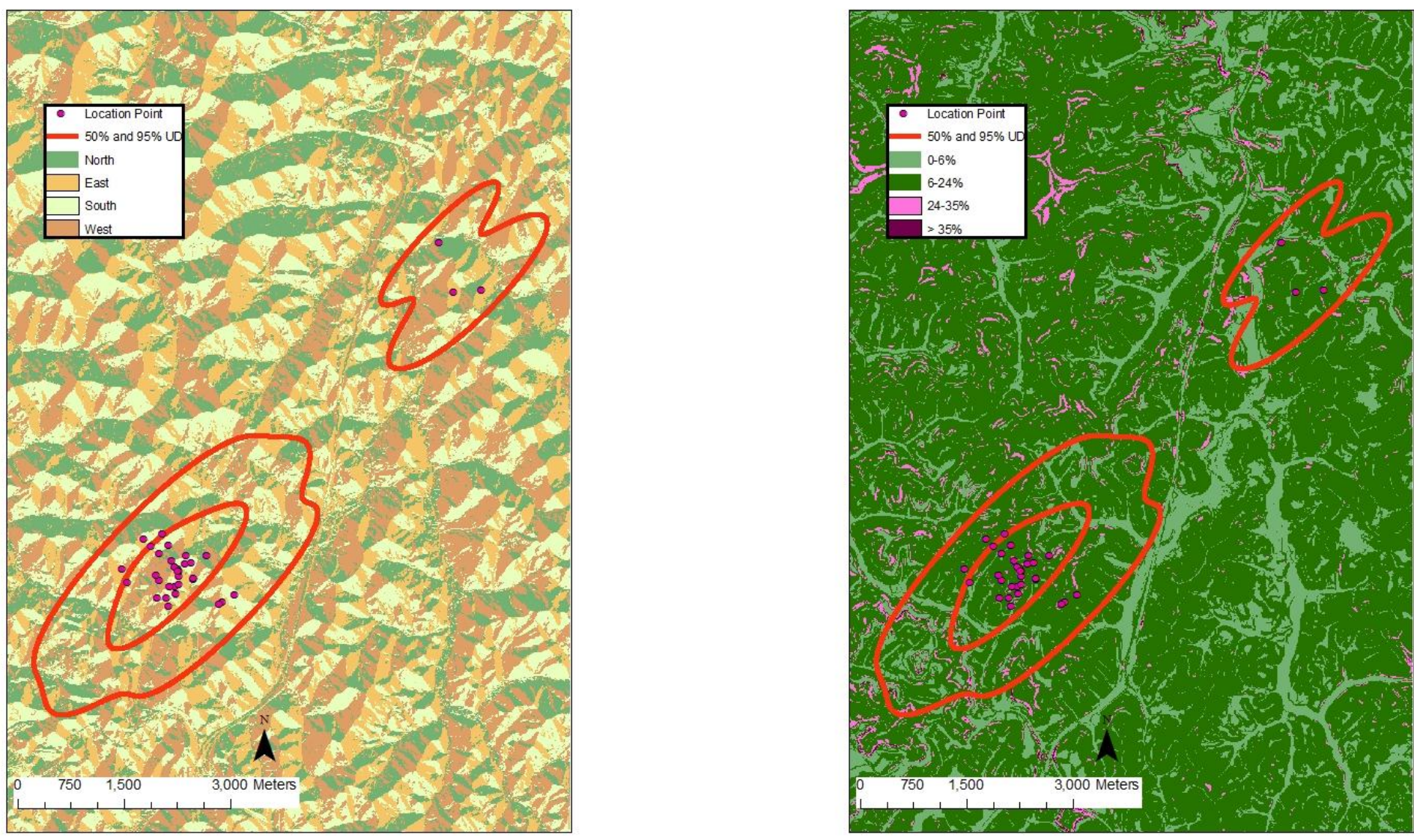
Appendix CXLIa. 10087 (juvenile, spring-summer) - 50\% core and 95\% periphery probability contours of the spring-summer Gaussian fixed kernel home range utilization distributions. Smoothing parameter $(h)$ determined by least squares cross validation, Harrison/Marion/Taylor County, West Virginia, 2004-2007 (land use and land cover, land fragmentation maps).
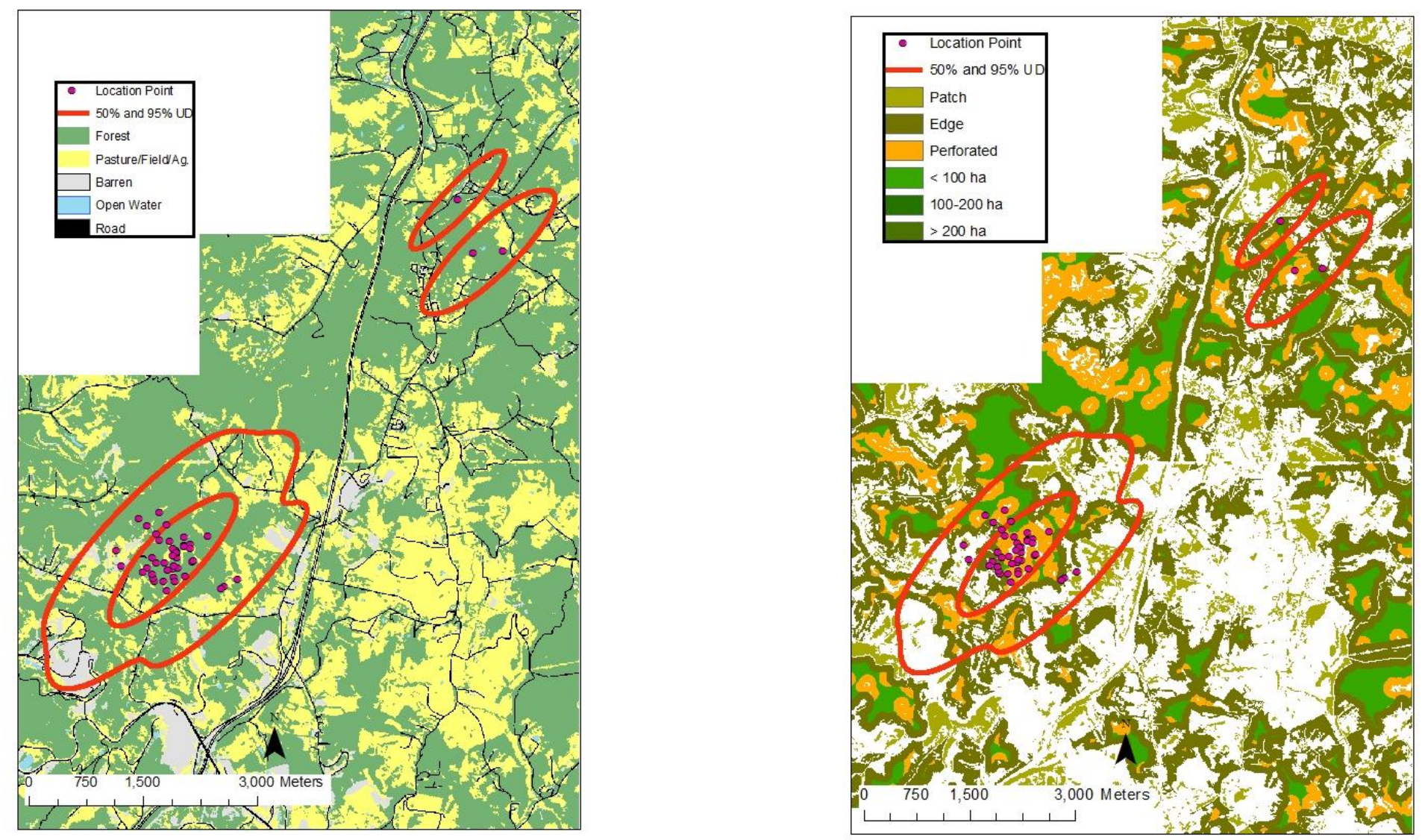
Appendix CXLIIa. 10087 (juvenile, spring-summer) - 50\% core and 95\% periphery probability contours of the spring-summer Gaussian fixed kernel home range utilization distributions. Smoothing parameter $(h)$ determined by least squares cross validation, Harrison/Marion/Taylor County, West Virginia, 2004-2007 (aspect and slope maps).
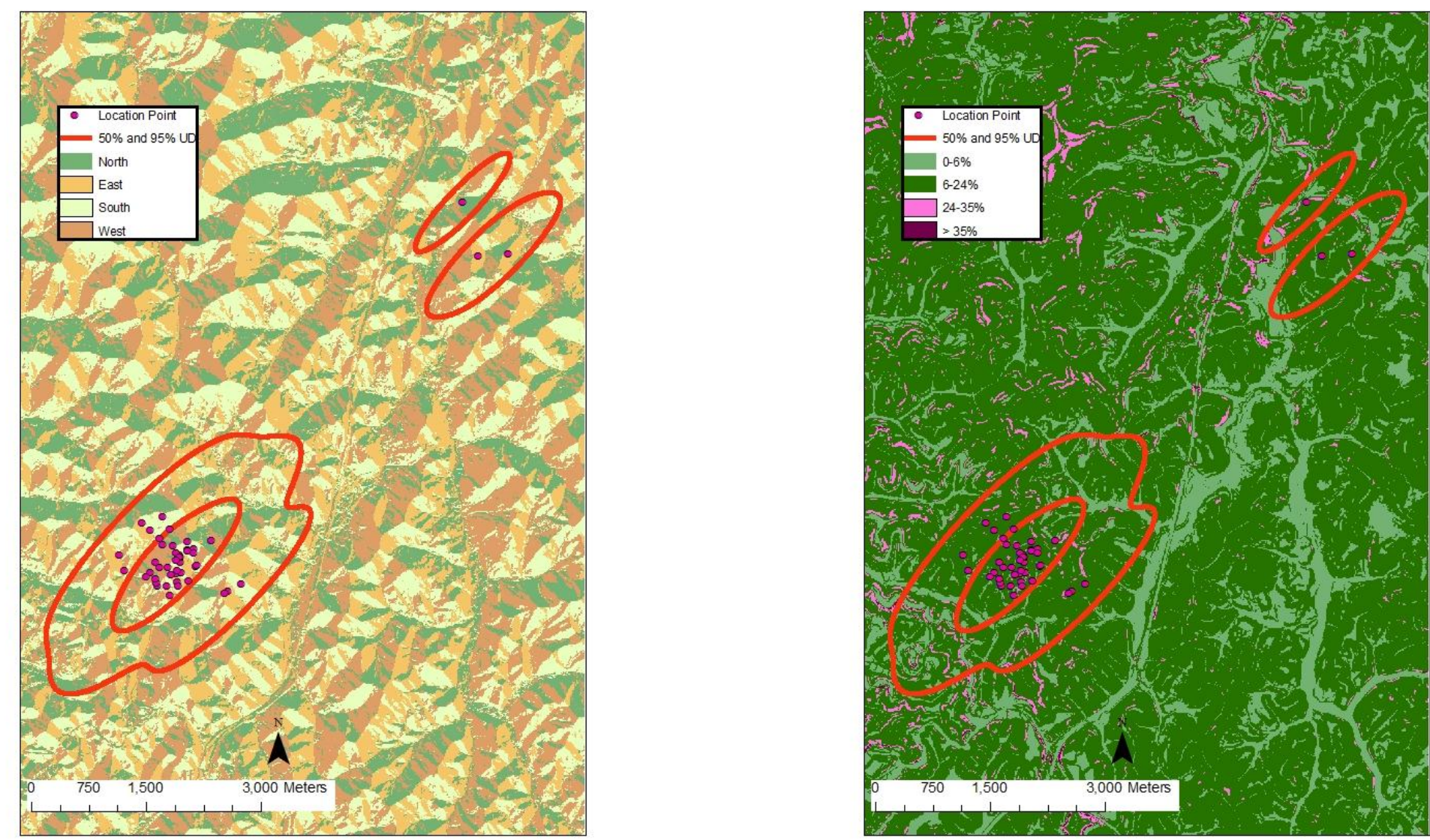
Appendix CXLIII a. 10088 (juvenile, annual) - 50\% core and 95\% periphery probability contours of the annual Gaussian fixed kernel home range utilization distributions. Smoothing parameter $(h)$ determined by least squares cross validation, Harrison/Marion/Taylor County, West Virginia, 2004-2007 (land use and land cover, land fragmentation maps).
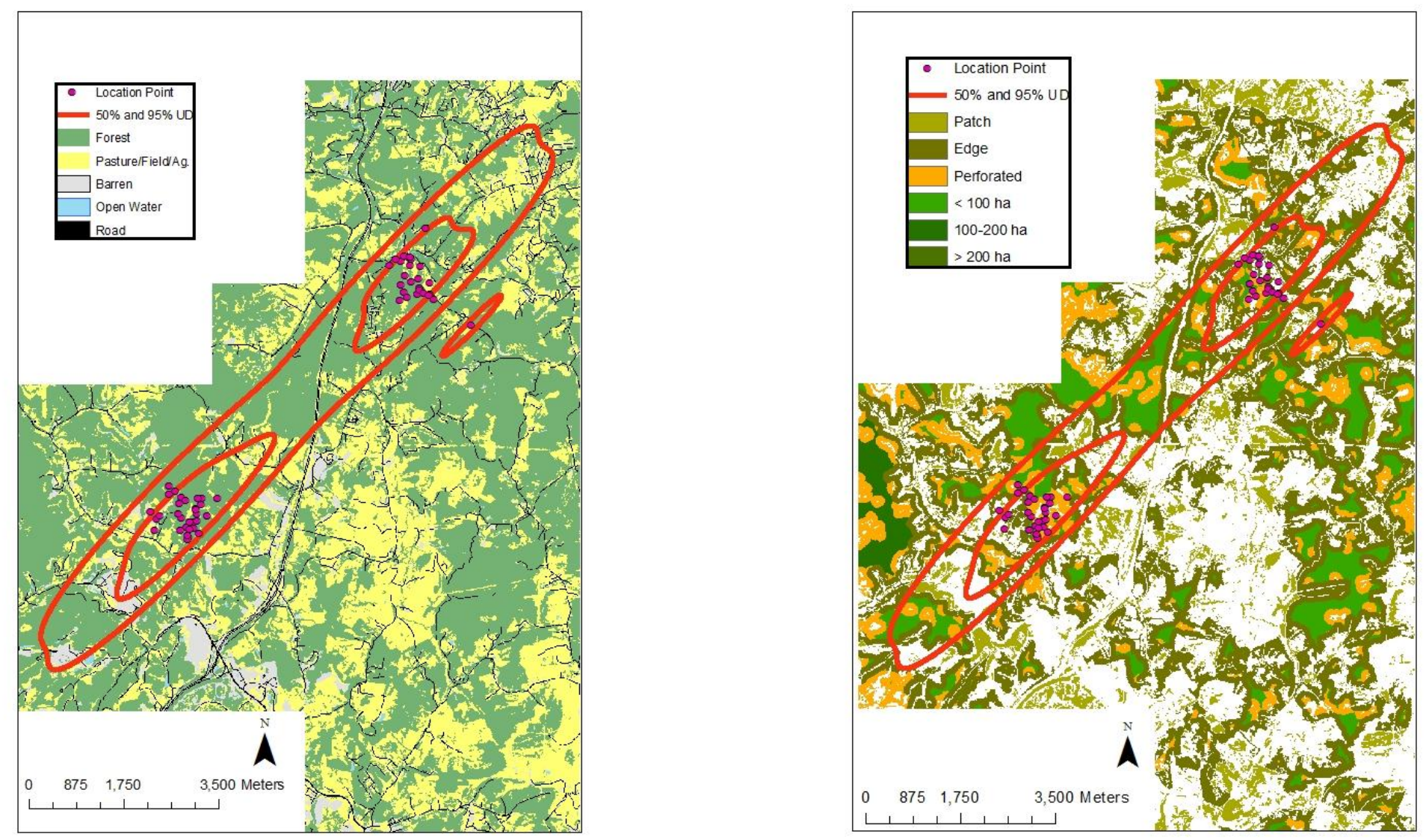
Appendix CXLIVa. 10088 (juvenile, annual) - 50\% core and 95\% periphery probability contours of the annual Gaussian fixed kernel home range utilization distributions. Smoothing parameter $(h)$ determined by least squares cross validation, Harrison/Marion/Taylor County, West Virginia, 2004-2007 (aspect and slope maps).
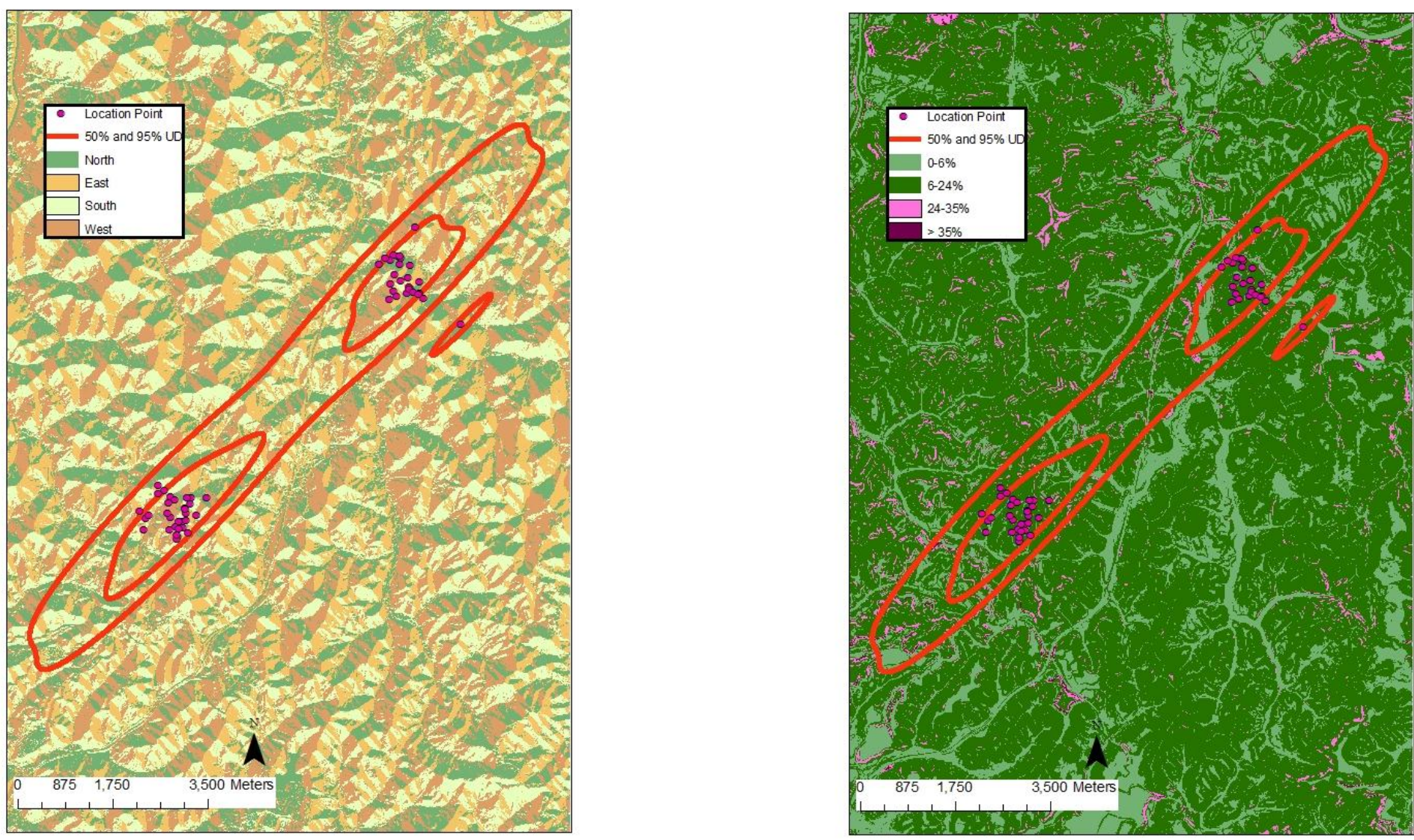
Appendix CXLVa. 10090 (juvenile, spring) - 50\% core and 95\% periphery probability contours of the spring Gaussian fixed kernel home range utilization distributions. Smoothing parameter $(h)$ determined by least squares cross validation, Harrison/Marion/Taylor County, West Virginia, 2004-2007 (land use and land cover, land fragmentation maps).
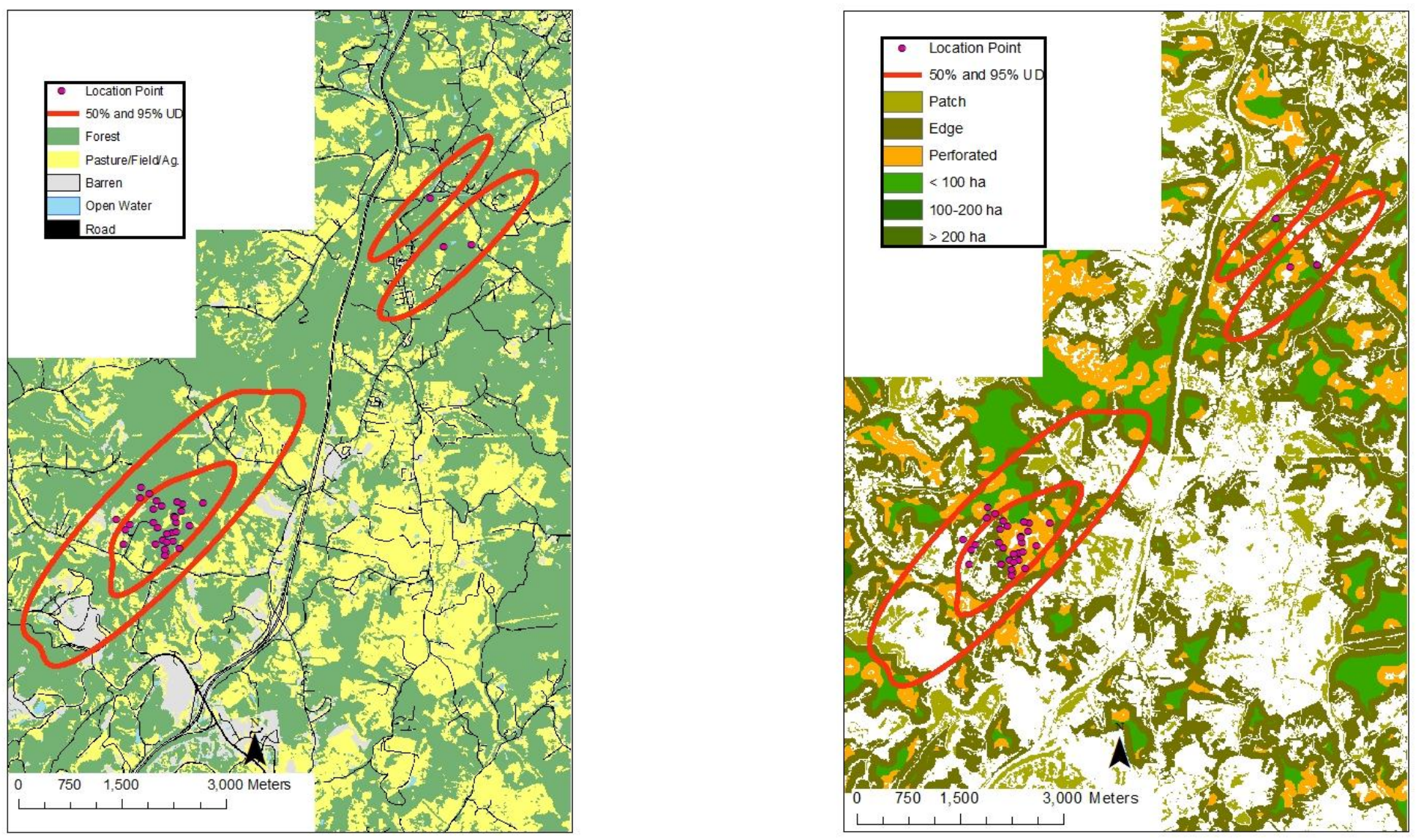
Appendix CXLVIa. 10090 (juvenile, spring) - 50\% core and 95\% periphery probability contours of the spring Gaussian fixed kernel home range utilization distributions. Smoothing parameter $(h)$ determined by least squares cross validation, Harrison/Marion/Taylor County, West Virginia, 2004-2007 (aspect and slope maps).
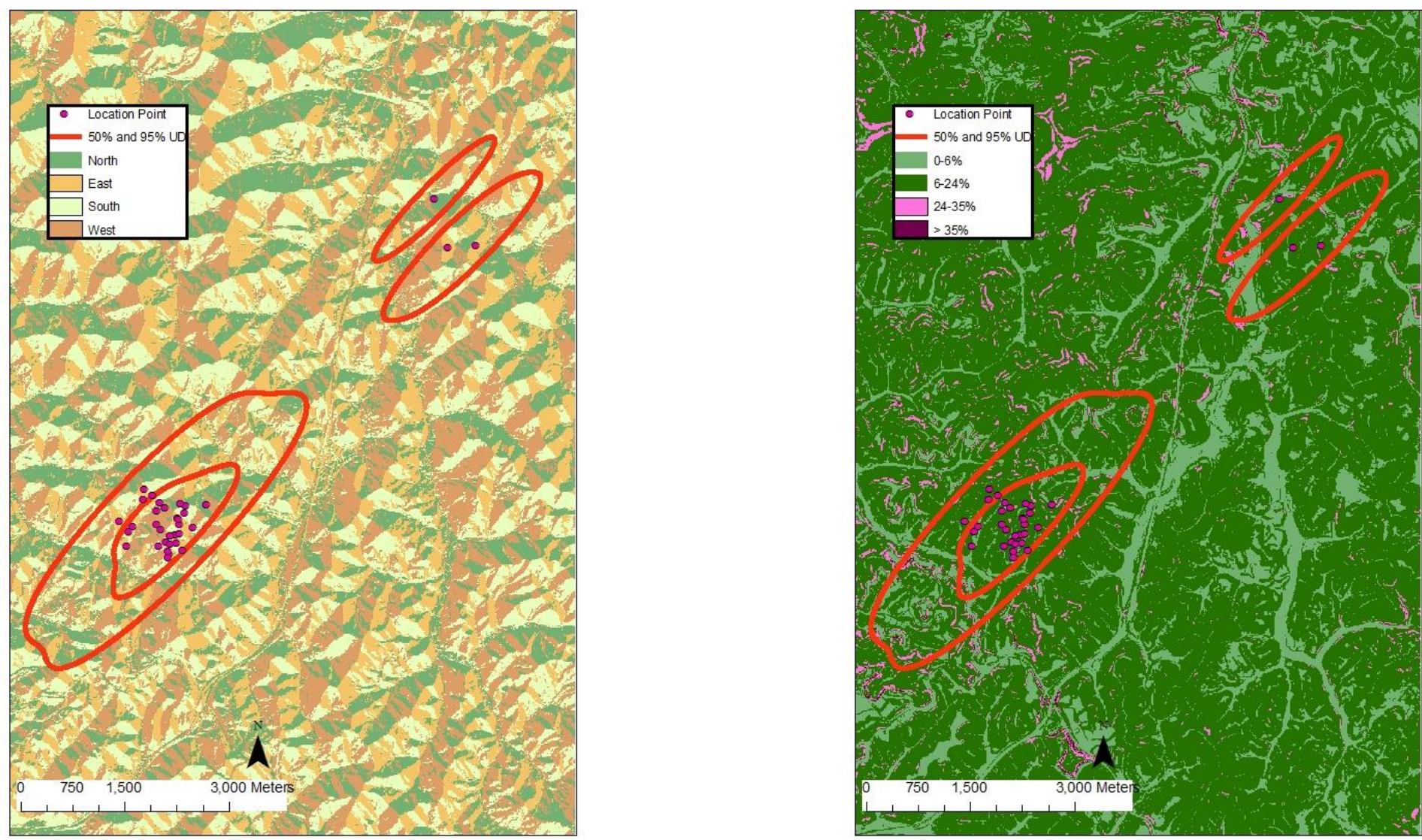
Appendix CXLVII $a .10091$ (juvenile, annual) - 50\% core and 95\% periphery probability contours of the annual Gaussian fixed kernel home range utilization distributions. Smoothing parameter $(h)$ determined by least squares cross validation, Harrison/Marion/Taylor County, West Virginia, 2004-2007 (land use and land cover, land fragmentation maps).
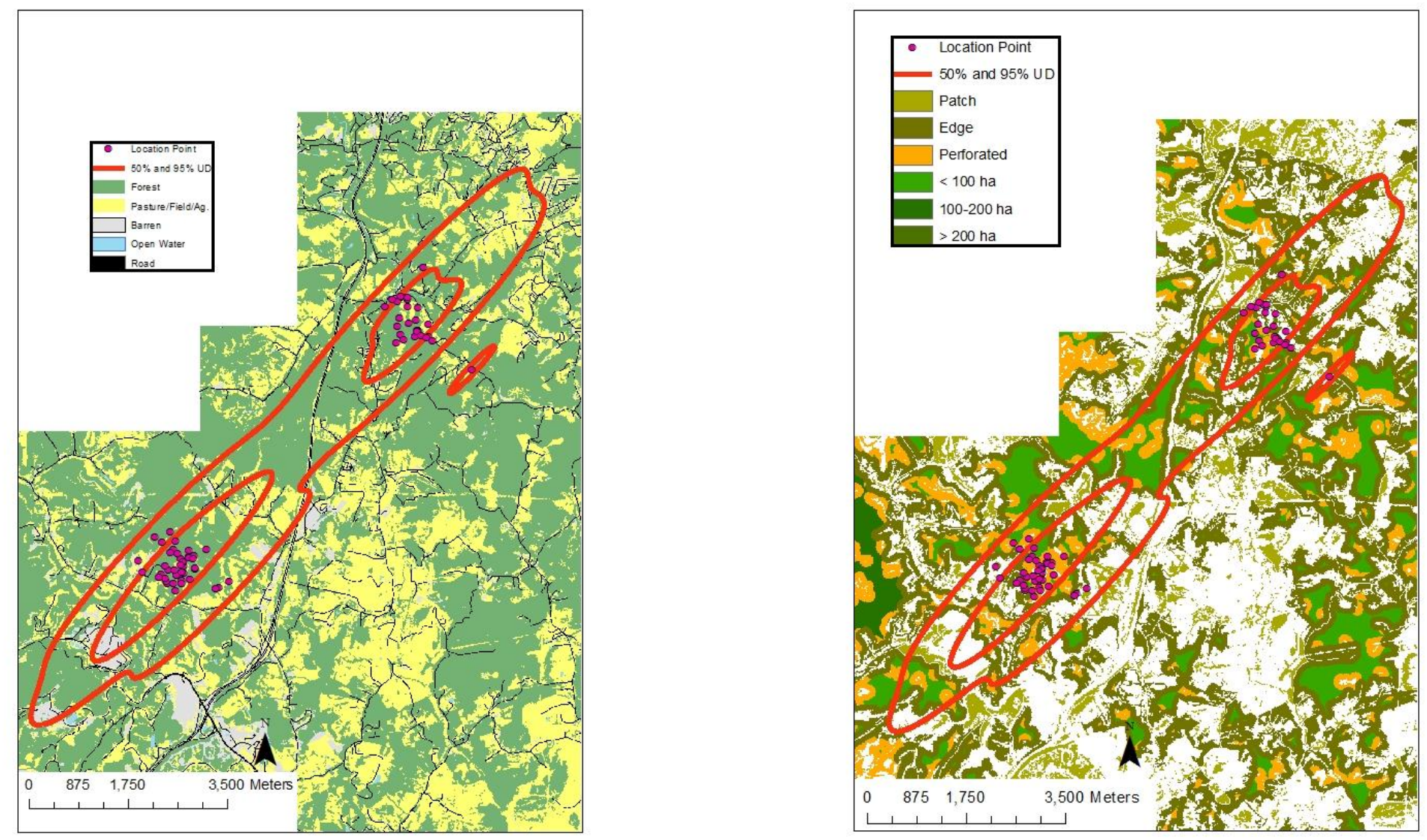
Appendix CXLVIIIa. 10091 (juvenile, annual) - 50\% core and 95\% periphery probability contours of the annual Gaussian fixed kernel home range utilization distributions. Smoothing parameter $(h)$ determined by least squares cross validation, Harrison/Marion/Taylor County, West Virginia, 2004-2007 (aspect and slope maps).
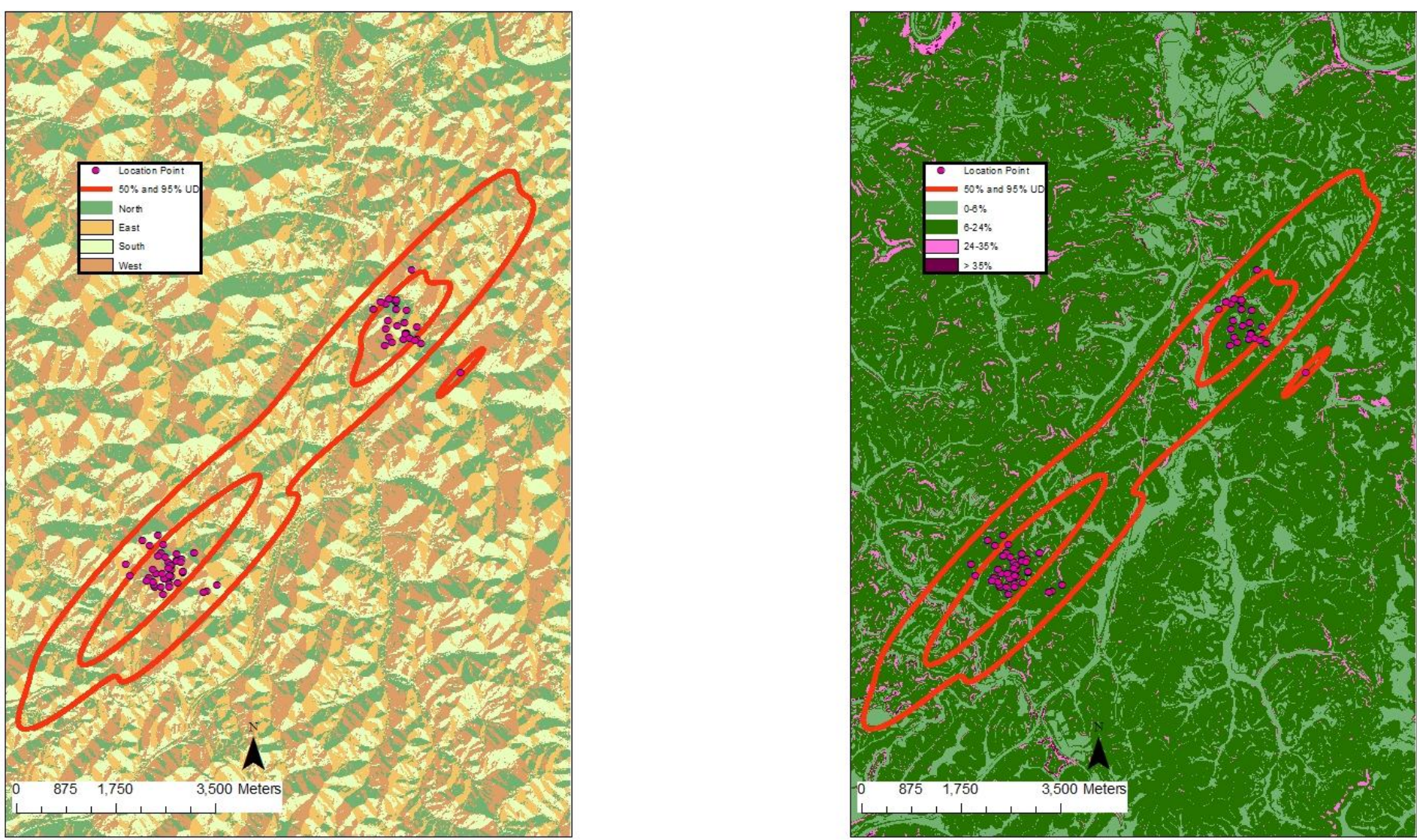
Appendix CXLIXa. 10093 (juvenile, spring) - 50\% core and 95\% periphery probability contours of the spring Gaussian fixed kernel home range utilization distributions. Smoothing parameter $(h)$ determined by least squares cross validation, Harrison/Marion/Taylor County, West Virginia, 2004-2007 (land use and land cover, land fragmentation maps).
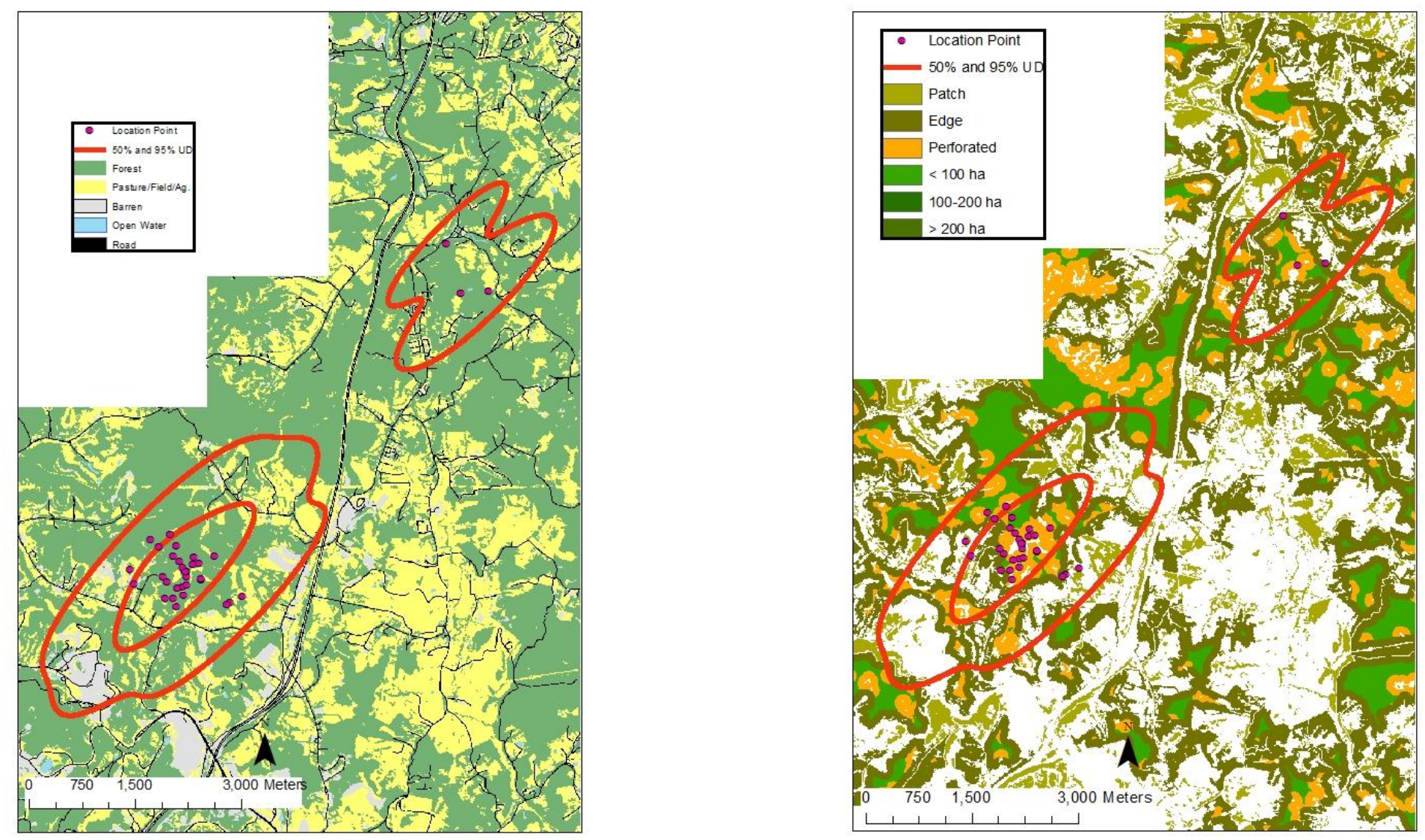
Appendix CLa. 10093 (juvenile, spring) - 50\% core and 95\% periphery probability contours of the spring Gaussian fixed kernel home range utilization distributions. Smoothing parameter $(h)$ determined by least squares cross validation, Harrison/Marion/Taylor County, West Virginia, 2004-2007 (aspect and slope maps).
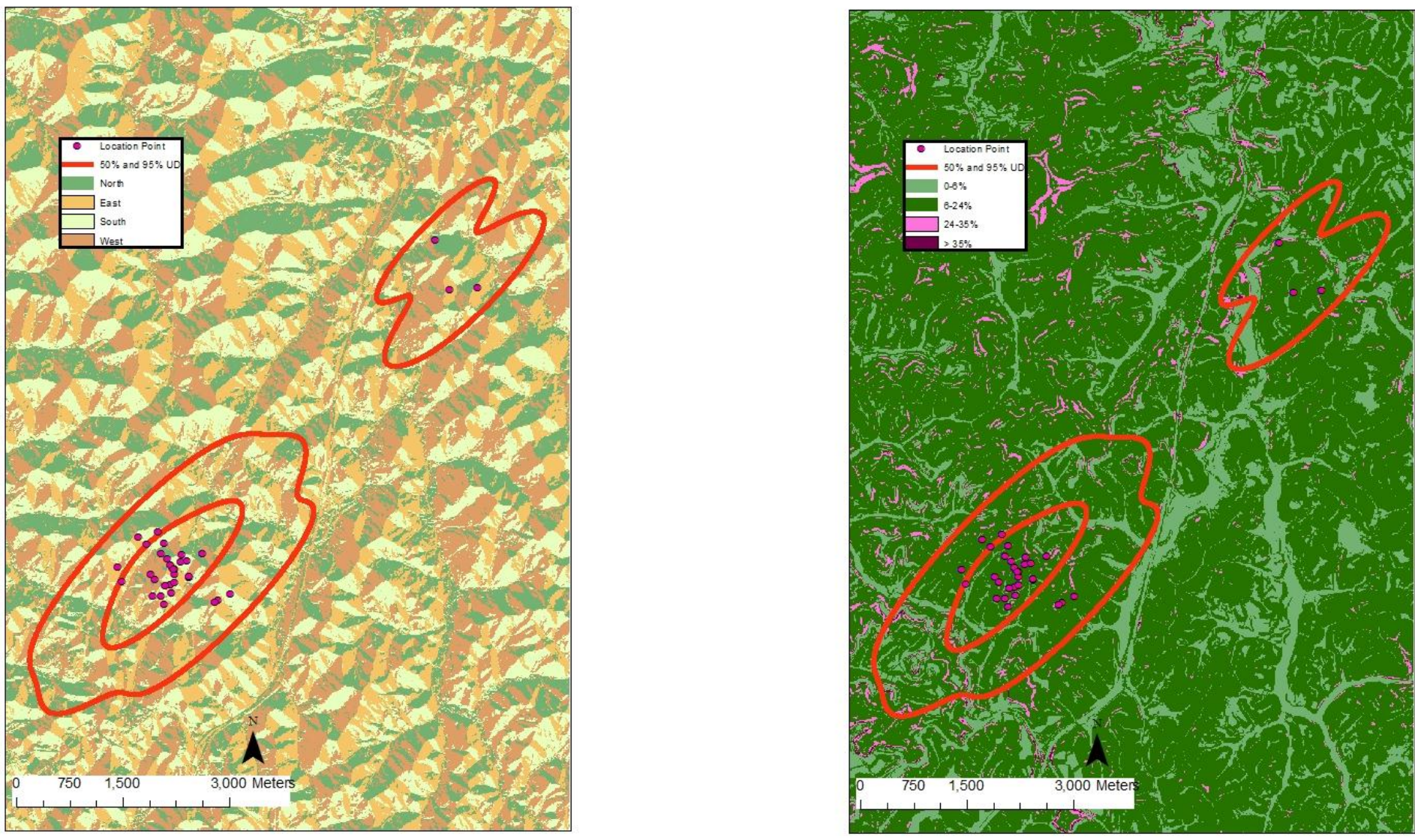
Appendix CLI $a .10094$ (juvenile, spring-summer) - 50\% core and 95\% periphery probability contours of the spring-summer Gaussian fixed kernel home range utilization distributions. Smoothing parameter $(h)$ determined by least squares cross validation, Harrison/Marion/Taylor County, West Virginia, 2004-2007 (land use and land cover, land fragmentation maps).
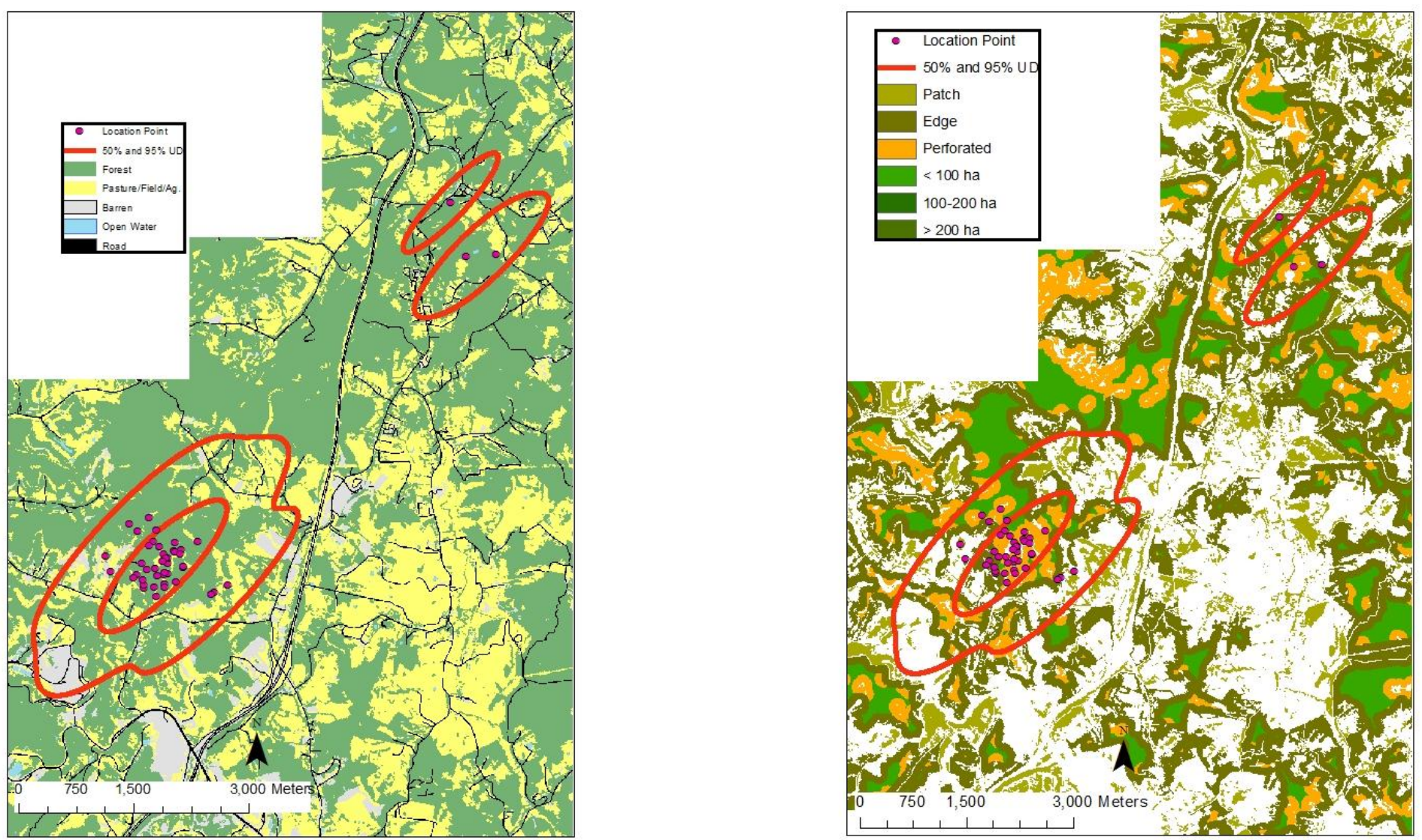
Appendix CLII a. 10094 (juvenile, spring-summer) - 50\% core and 95\% periphery probability contours of the spring-summer Gaussian fixed kernel home range utilization distributions. Smoothing parameter $(h)$ determined by least squares cross validation, Harrison/Marion/Taylor County, West Virginia, 2004-2007 (aspect and slope maps).
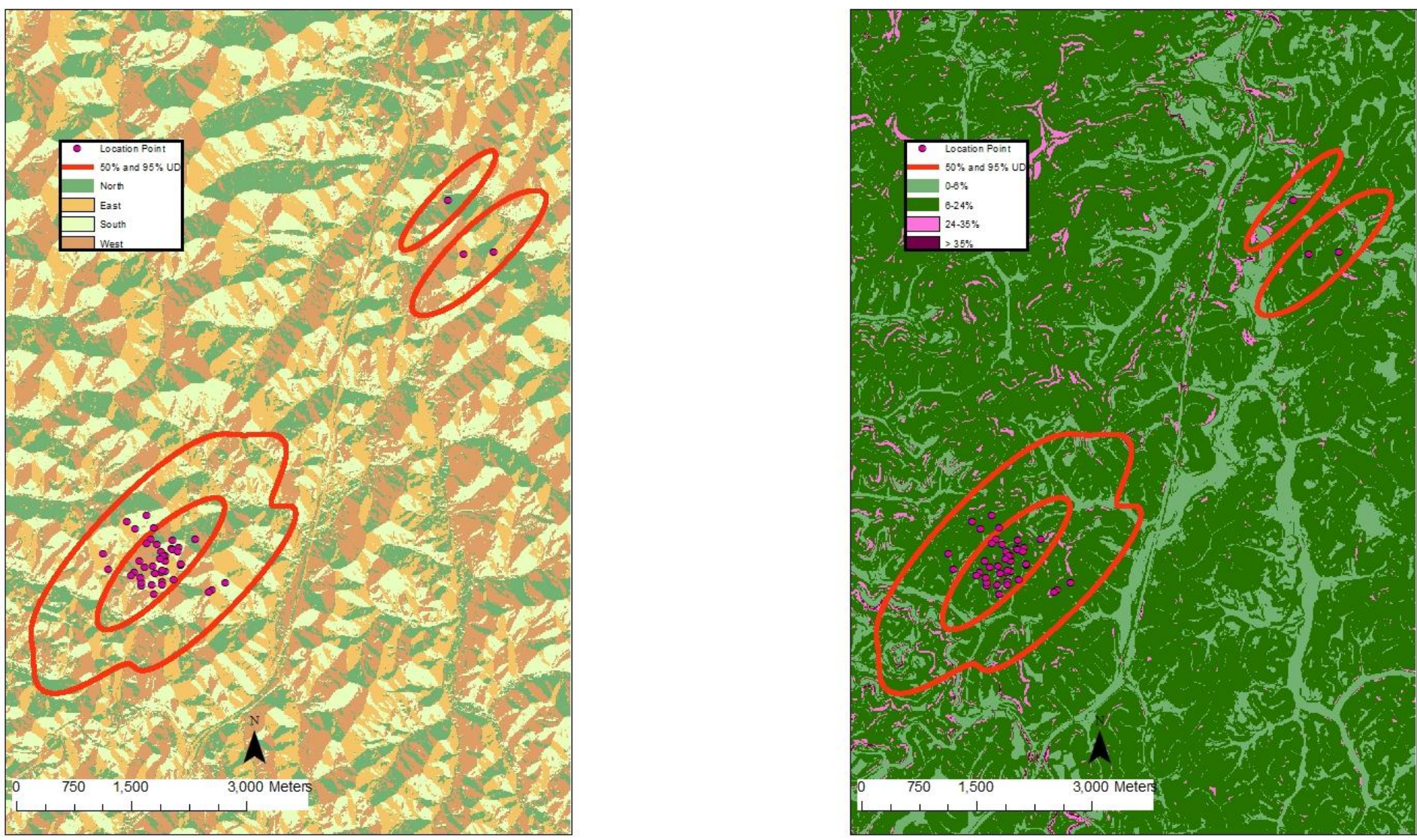
Appendix CLIIIa. 10095 (juvenile, annual) - 50\% core and 95\% periphery probability contours of the annual Gaussian fixed kernel home range utilization distributions. Smoothing parameter $(h)$ determined by least squares cross validation, Marion/Taylor County, West Virginia, 2004-2007 (land use and land cover, land fragmentation maps).
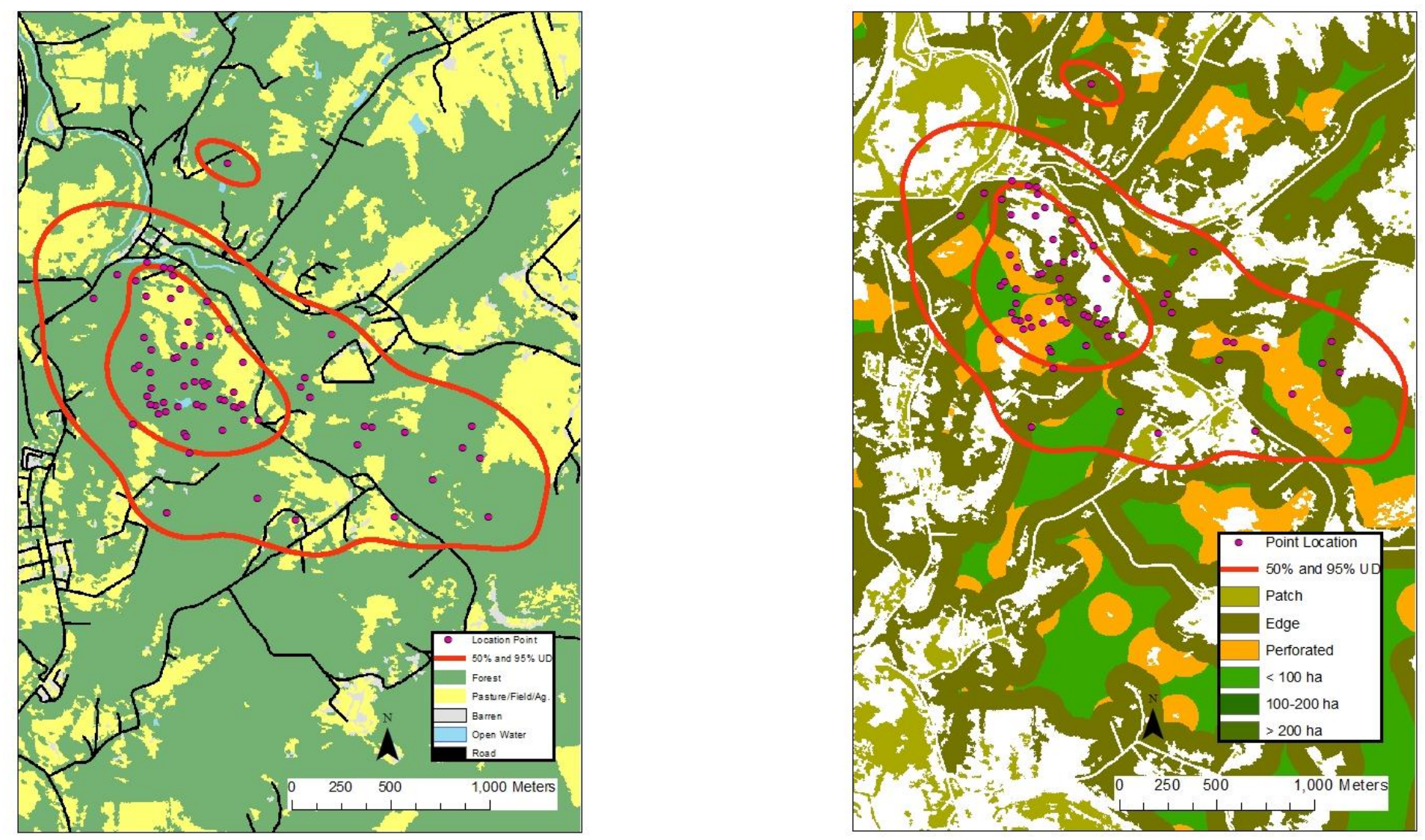
Appendix CLIVa. 10095 (juvenile, annual) - 50\% core and 95\% periphery probability contours of the annual Gaussian fixed kernel home range utilization distributions. Smoothing parameter $(h)$ determined by least squares cross validation, Harrison/Marion/Taylor County, West Virginia, 2004-2007 (aspect and slope maps).
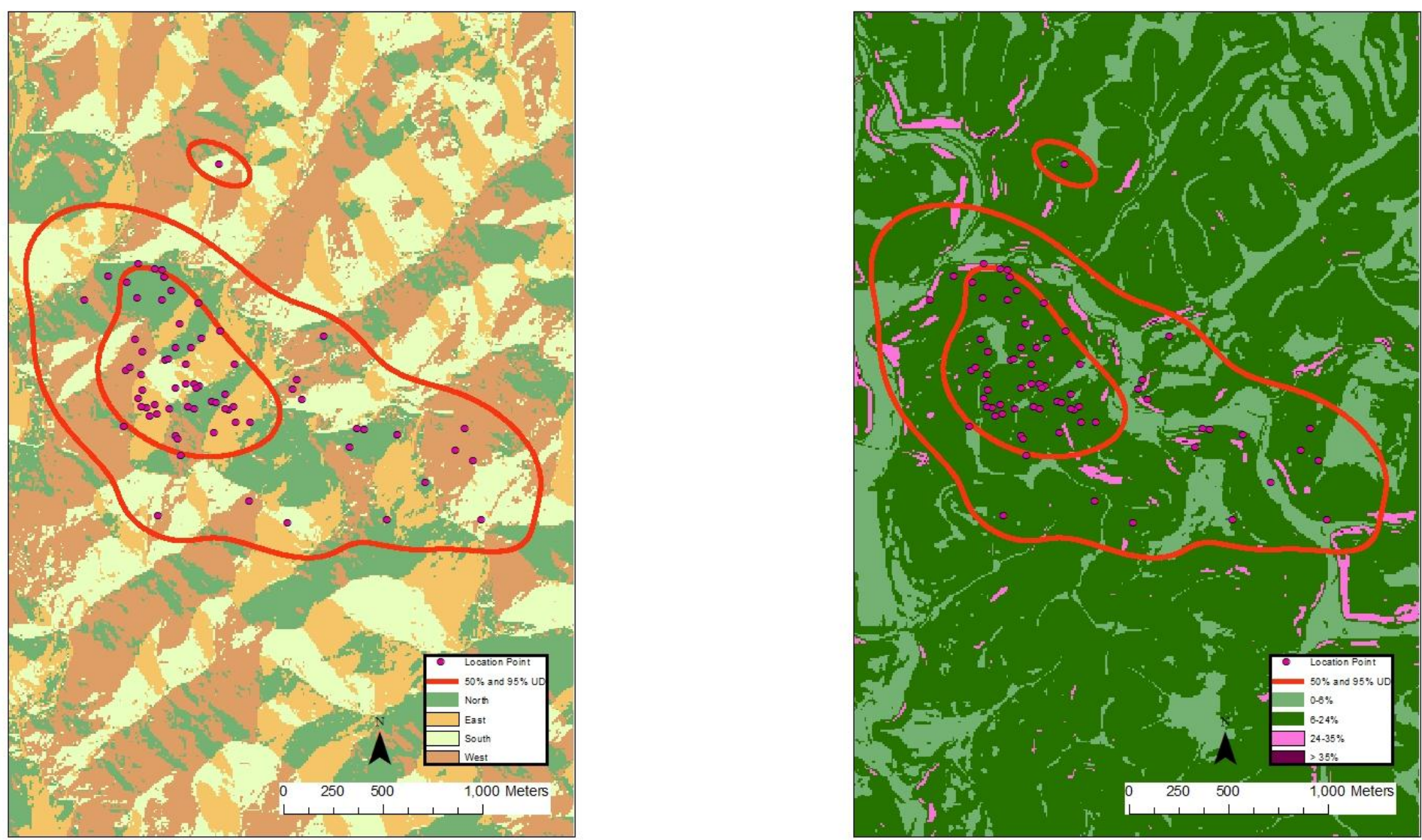
Appendix CLVa. 10097 (juvenile, spring) - 50\% core and 95\% periphery probability contours of the spring Gaussian fixed kernel home range utilization distributions. Smoothing parameter $(h)$ determined by least squares cross validation, Marion/Taylor County, West Virginia, 2004-2007 (land use and land cover, land fragmentation maps).
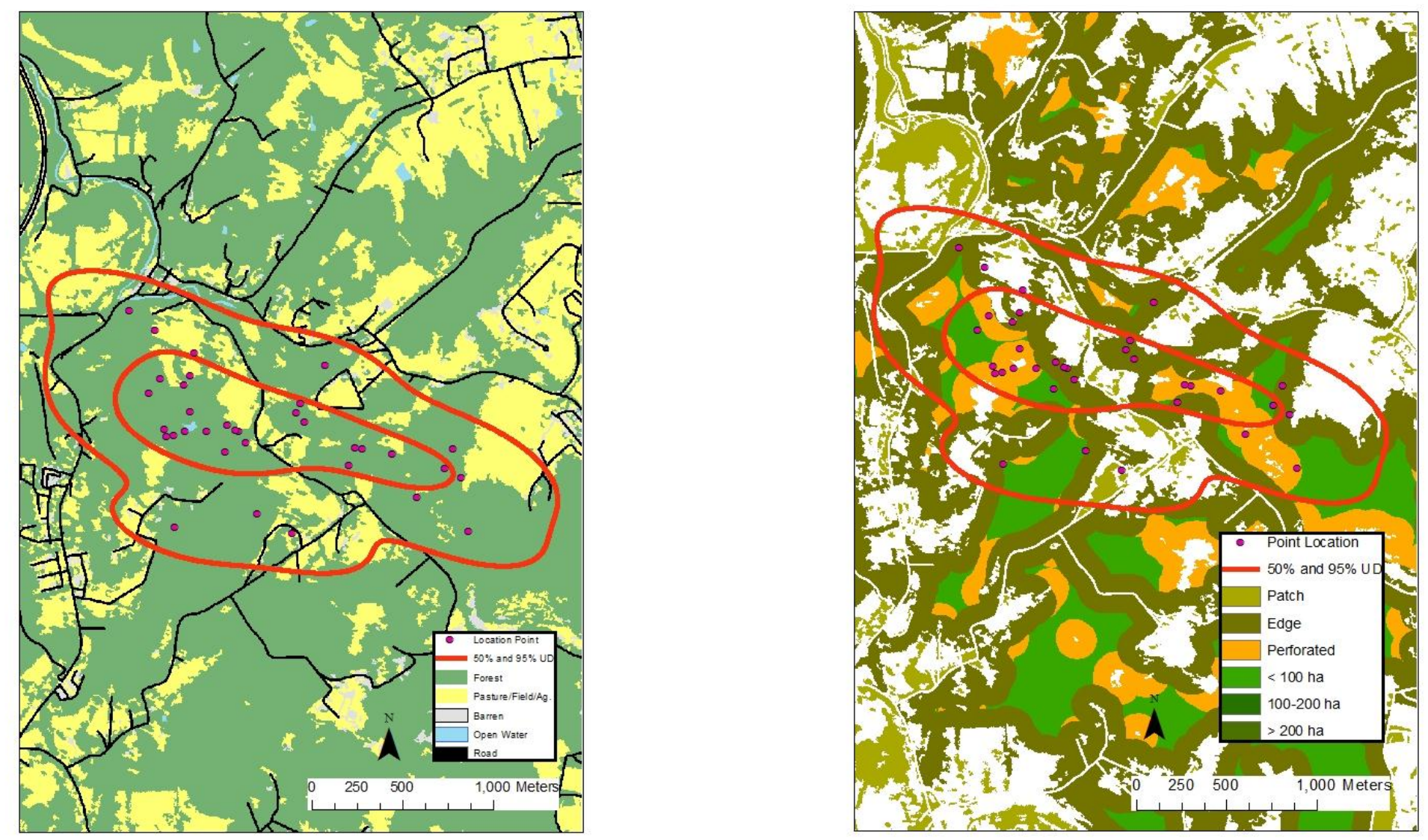
Appendix CLVIa. 10097 (juvenile, spring) - 50\% core and 95\% periphery probability contours of the spring Gaussian fixed kernel home range utilization distributions. Smoothing parameter $(h)$ determined by least squares cross validation, Marion/Taylor County, West Virginia, 2004-2007 (aspect and slope maps).
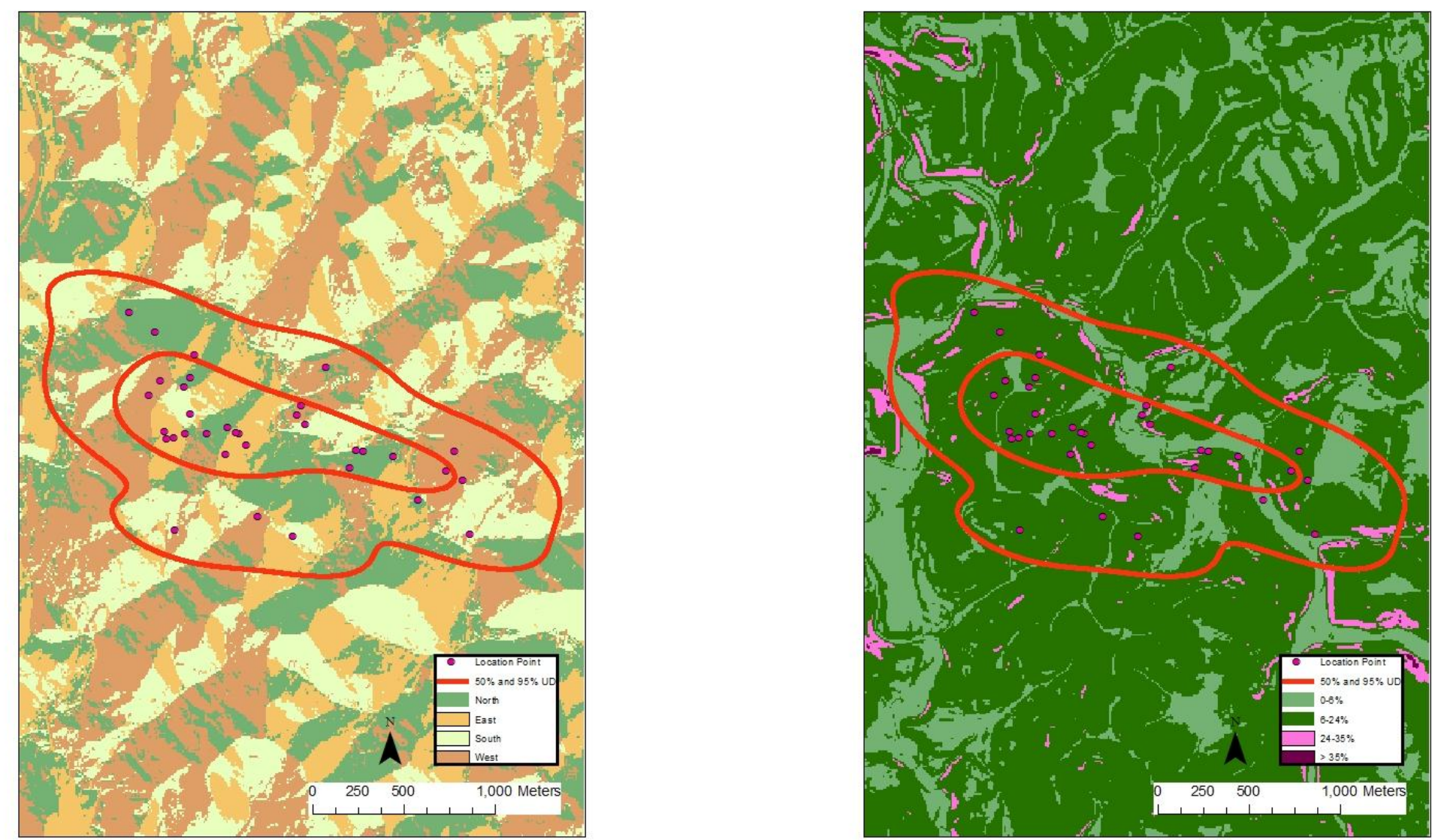
Appendix CLVIIa. 10098 (juvenile, spring-summer) - 50\% core and 95\% periphery probability contours of the spring-summer Gaussian fixed kernel home range utilization distributions. Smoothing parameter $(h)$ determined by least squares cross validation, Marion/Taylor County, West Virginia, 2004-2007 (land use and land cover, land fragmentation maps).
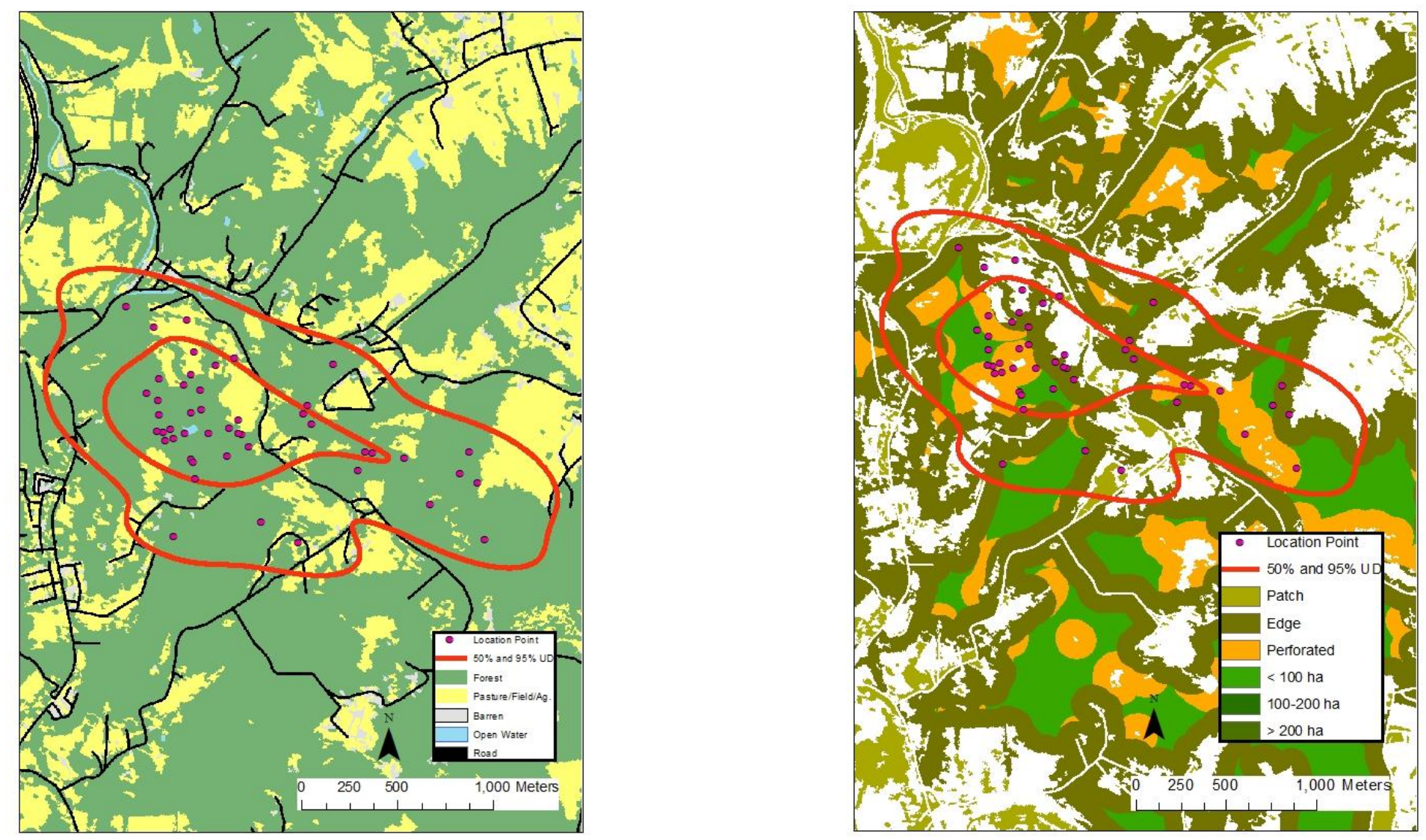
Appendix CLVIIIa. 10098 (juvenile, spring-summer) - 50\% core and 95\% periphery probability contours of the spring-summer Gaussian fixed kernel home range utilization distributions. Smoothing parameter $(h)$ determined by least squares cross validation, Marion/Taylor County, West Virginia, 2004-2007 (aspect and slope maps).
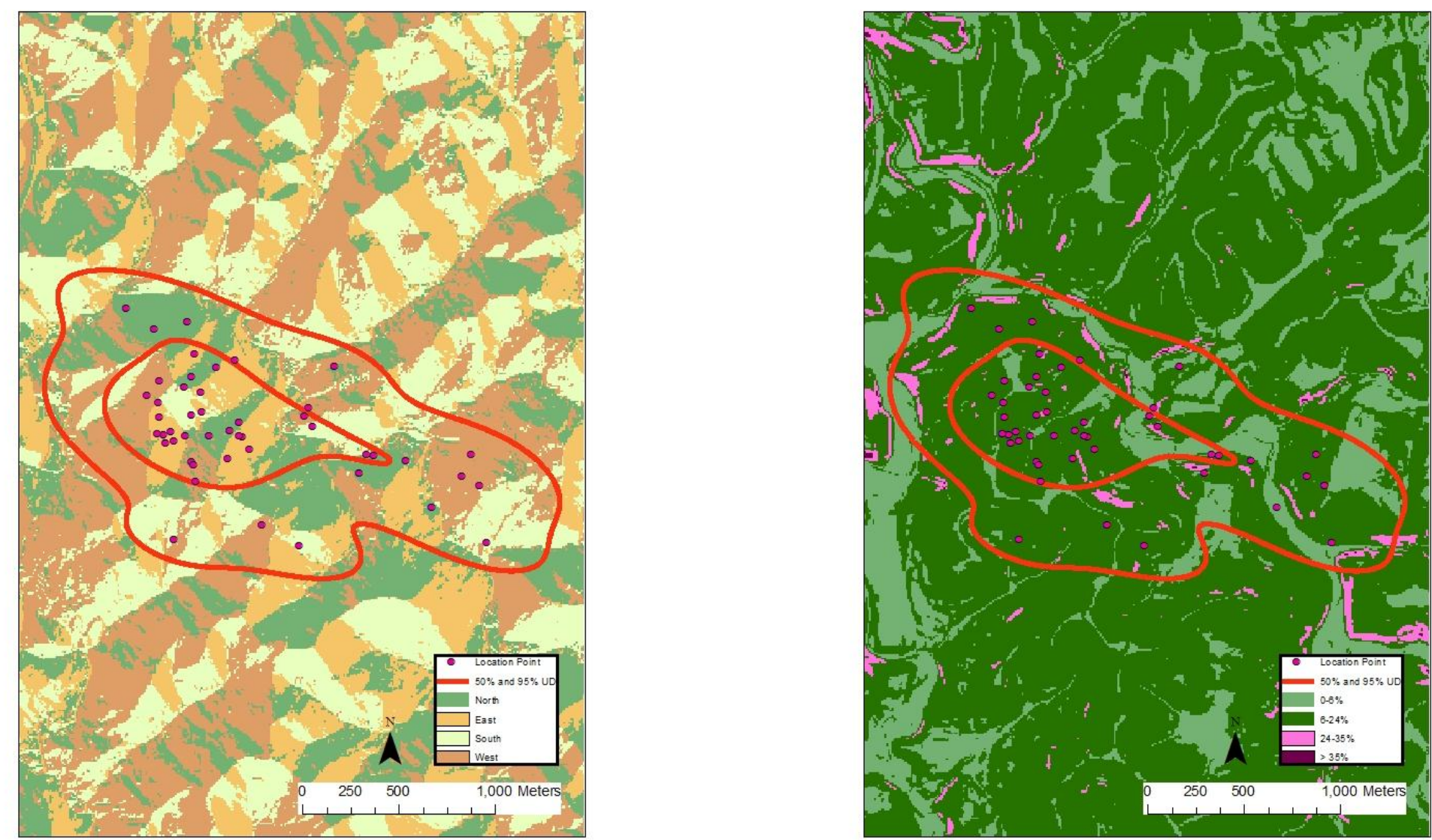
Appendix CLIXa. 10099 (adult, annual) - 50\% core and 95\% periphery probability contours of the annual Gaussian fixed kernel home range utilization distributions. Smoothing parameter $(h)$ determined by least squares cross validation, Pendleton County, West Virginia, 2004-2007 (land use and land cover, land fragmentation maps).
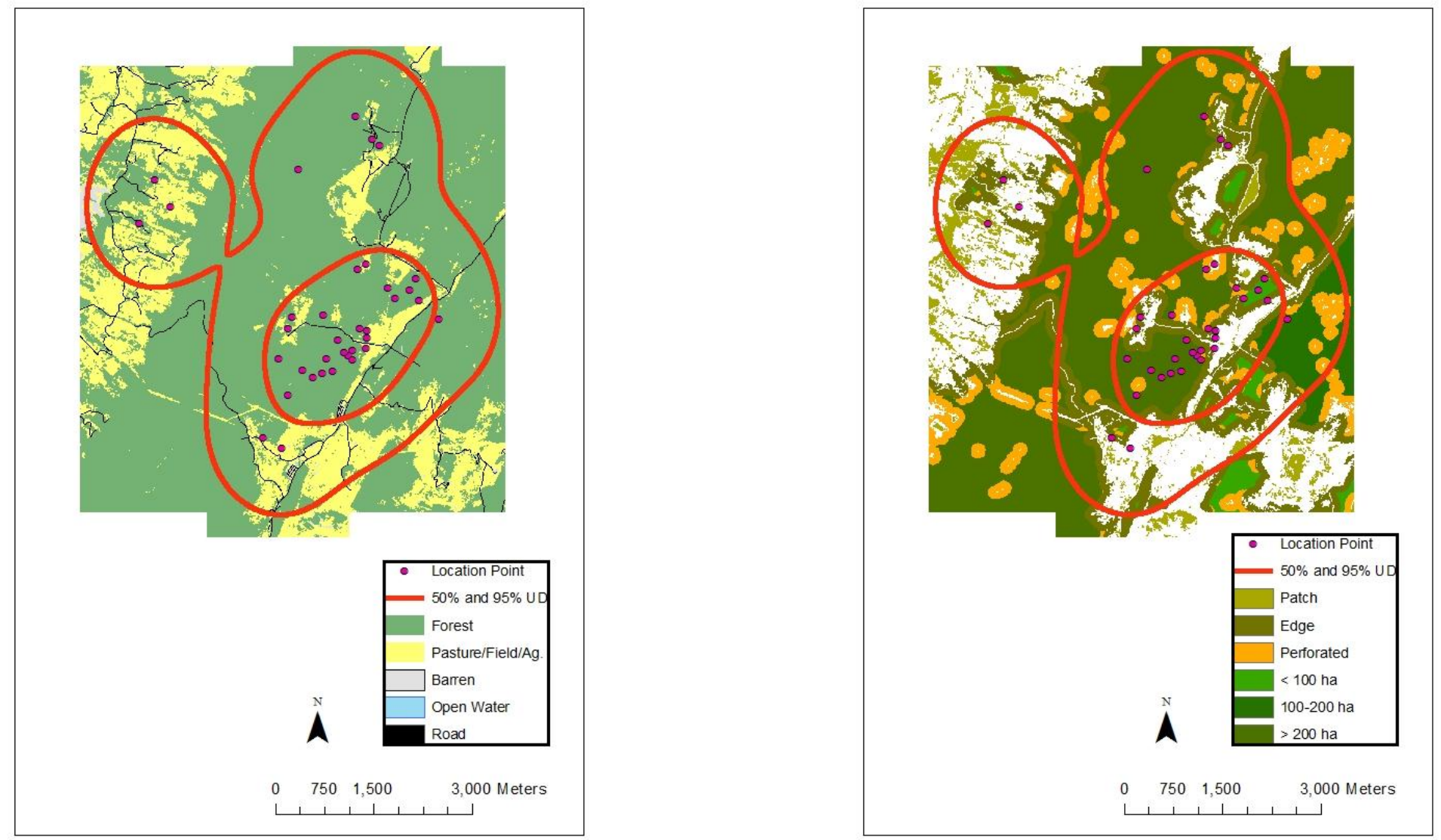
Appendix CLXa. 10099 (adult, annual) - 50\% core and 95\% periphery probability contours of the annual Gaussian fixed kernel home range utilization distributions. Smoothing parameter $(h)$ determined by least squares cross validation, Pendleton County, West Virginia, 2004-2007 (aspect and slope maps).
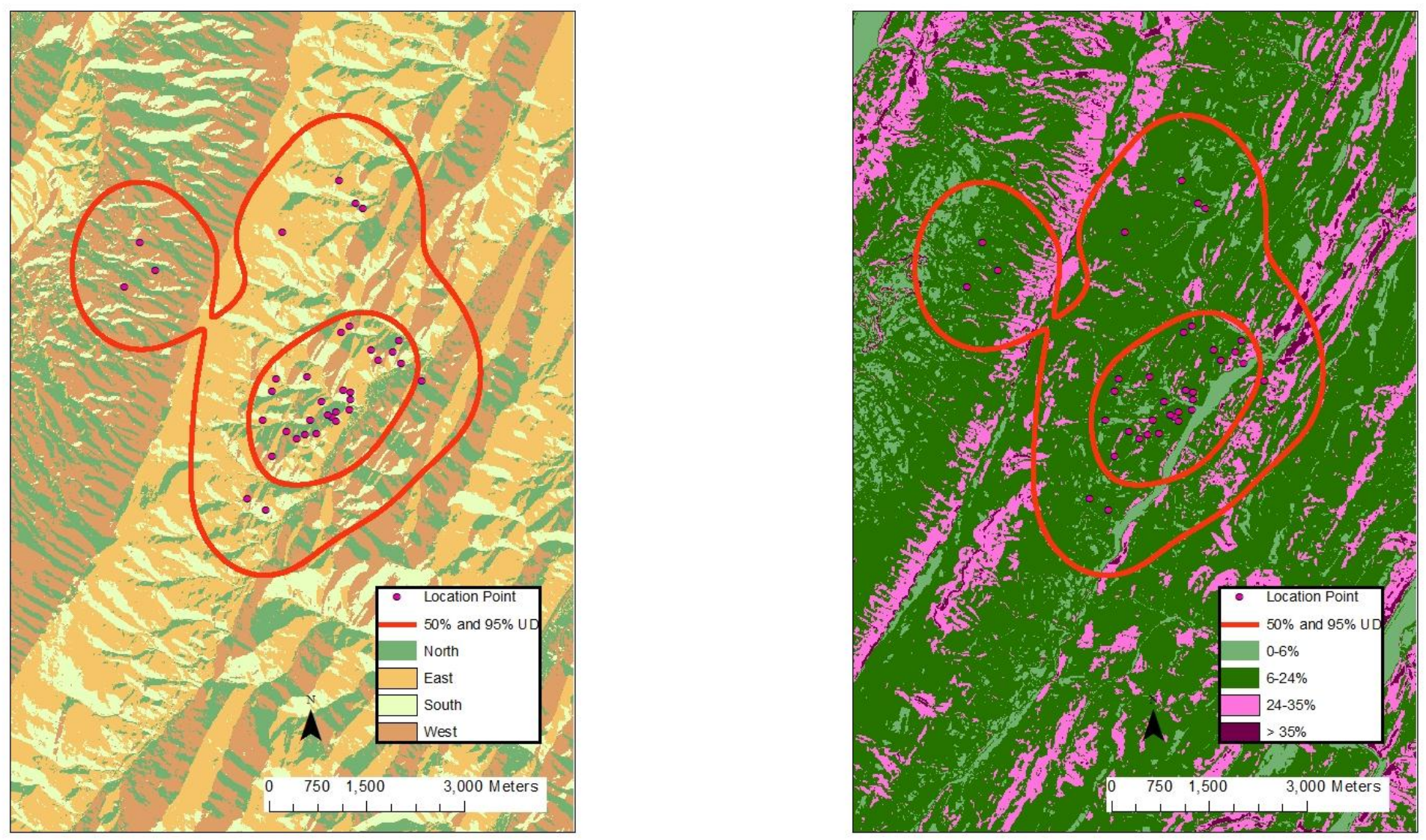
Appendix CLXIa. 10100 (adult, annual) - 50\% core and 95\% periphery probability contours of the annual Gaussian fixed kernel home range utilization distributions. Smoothing parameter $(h)$ determined by least squares cross validation, Hardy County, West Virginia, 2004-2007 (land use and land cover, land fragmentation maps).
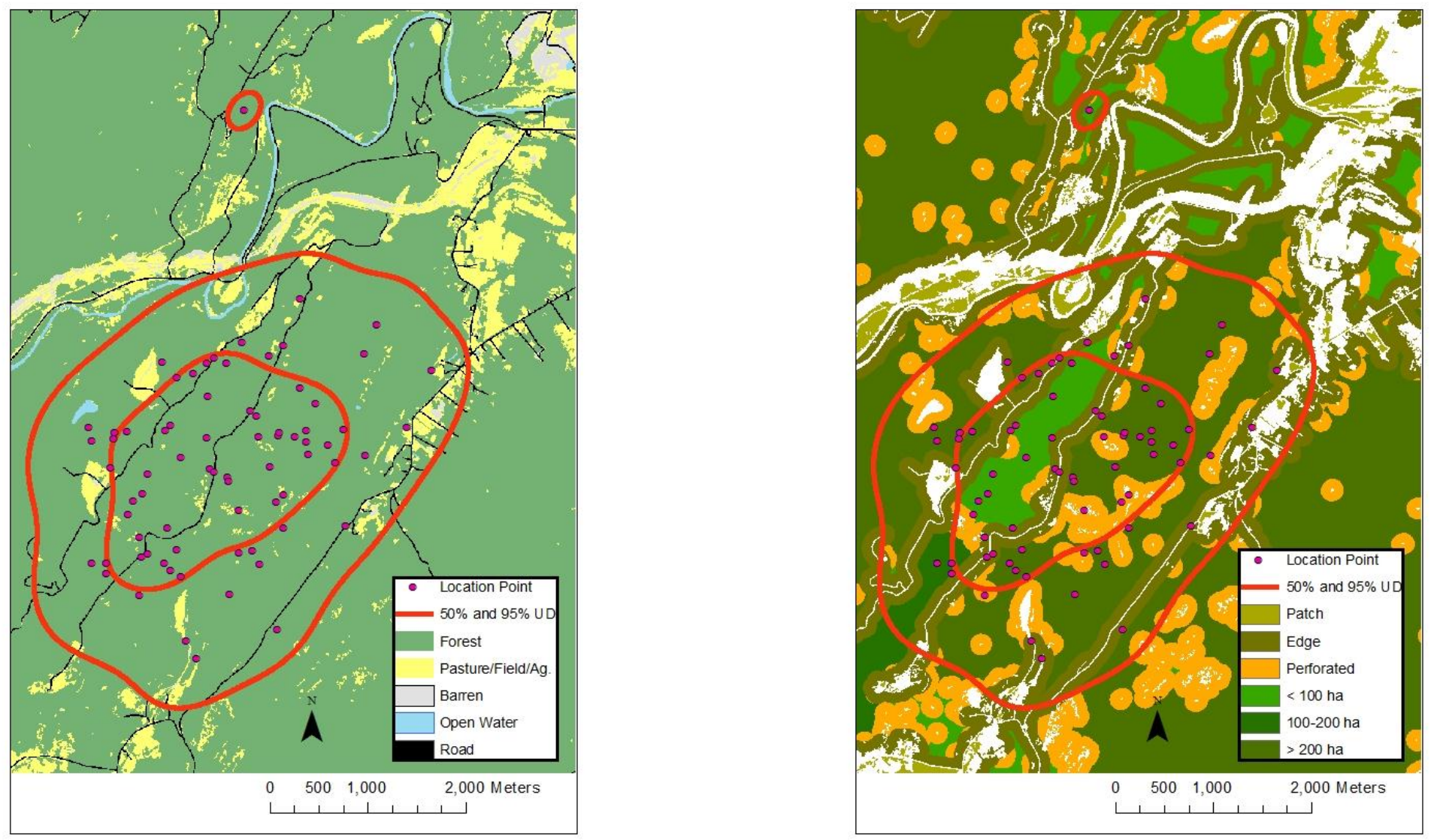
Appendix CLXIIa. 10100 (adult, annual) - 50\% core and 95\% periphery probability contours of the annual Gaussian fixed kernel home range utilization distributions. Smoothing parameter $(h)$ determined by least squares cross validation, Hardy County, West Virginia, 2004-2007 (aspect and slope maps).
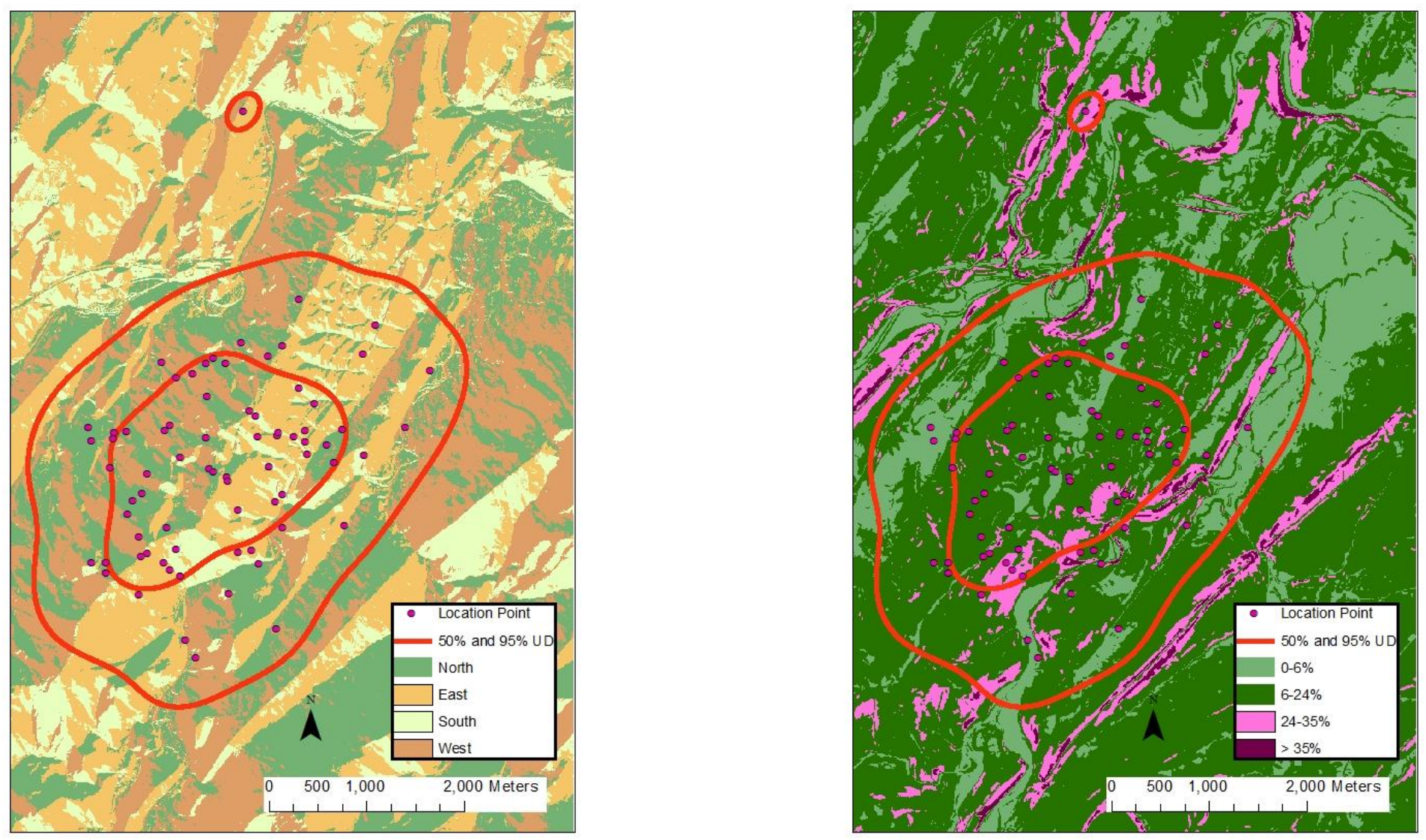
Appendix CLXIII a. 10101 (adult, annual) - 50\% core and 95\% periphery probability contours of the annual Gaussian fixed kernel home range utilization distributions. Smoothing parameter $(h)$ determined by least squares cross validation, Lewis County, West Virginia, 2004-2007 (land use and land cover, land fragmentation maps).
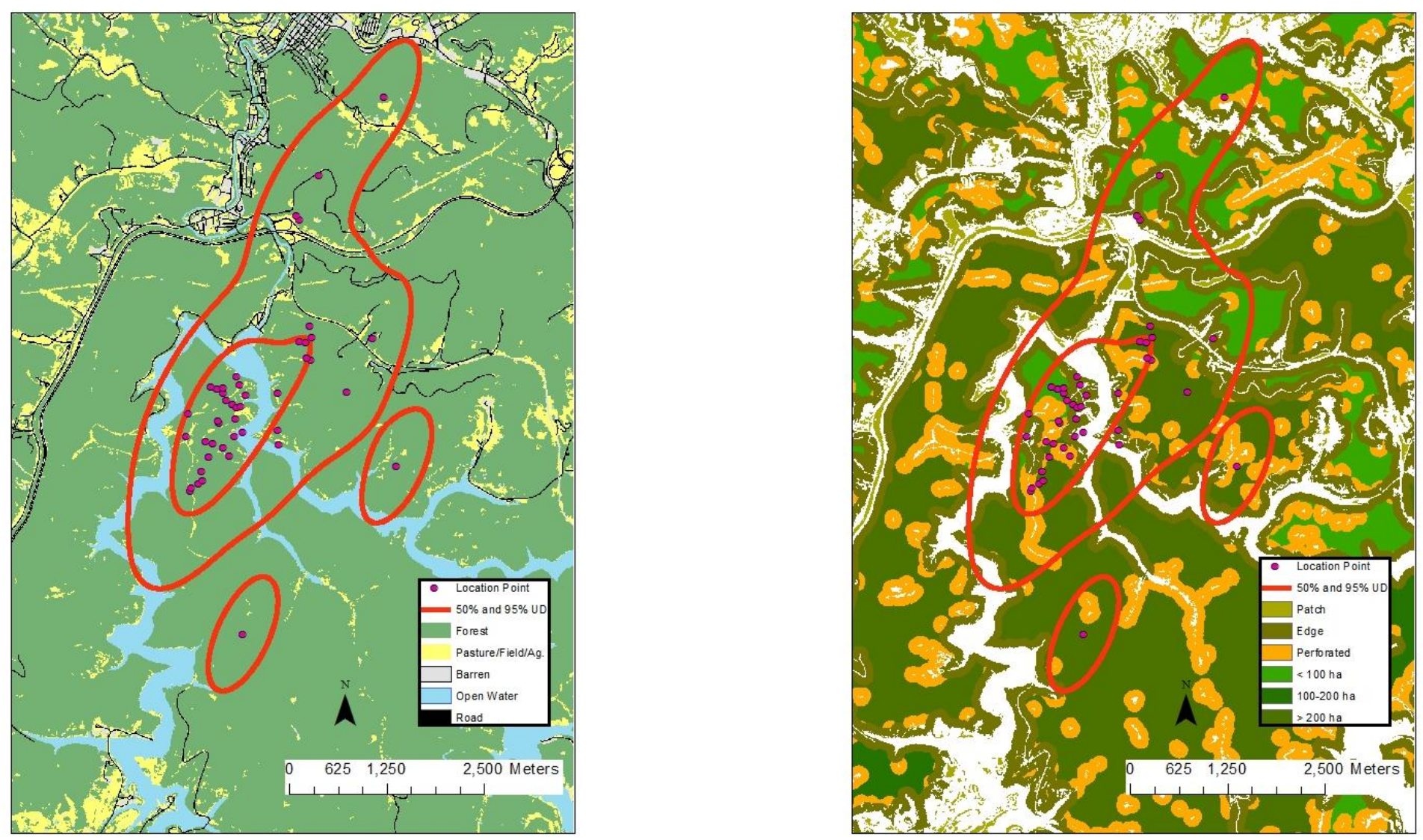
Appendix CLXIVa. 10101 (adult, annual) - 50\% core and 95\% periphery probability contours of the annual Gaussian fixed kernel home range utilization distributions. Smoothing parameter $(h)$ determined by least squares cross validation, Lewis County, West Virginia, 2004-2007 (aspect and slope maps).
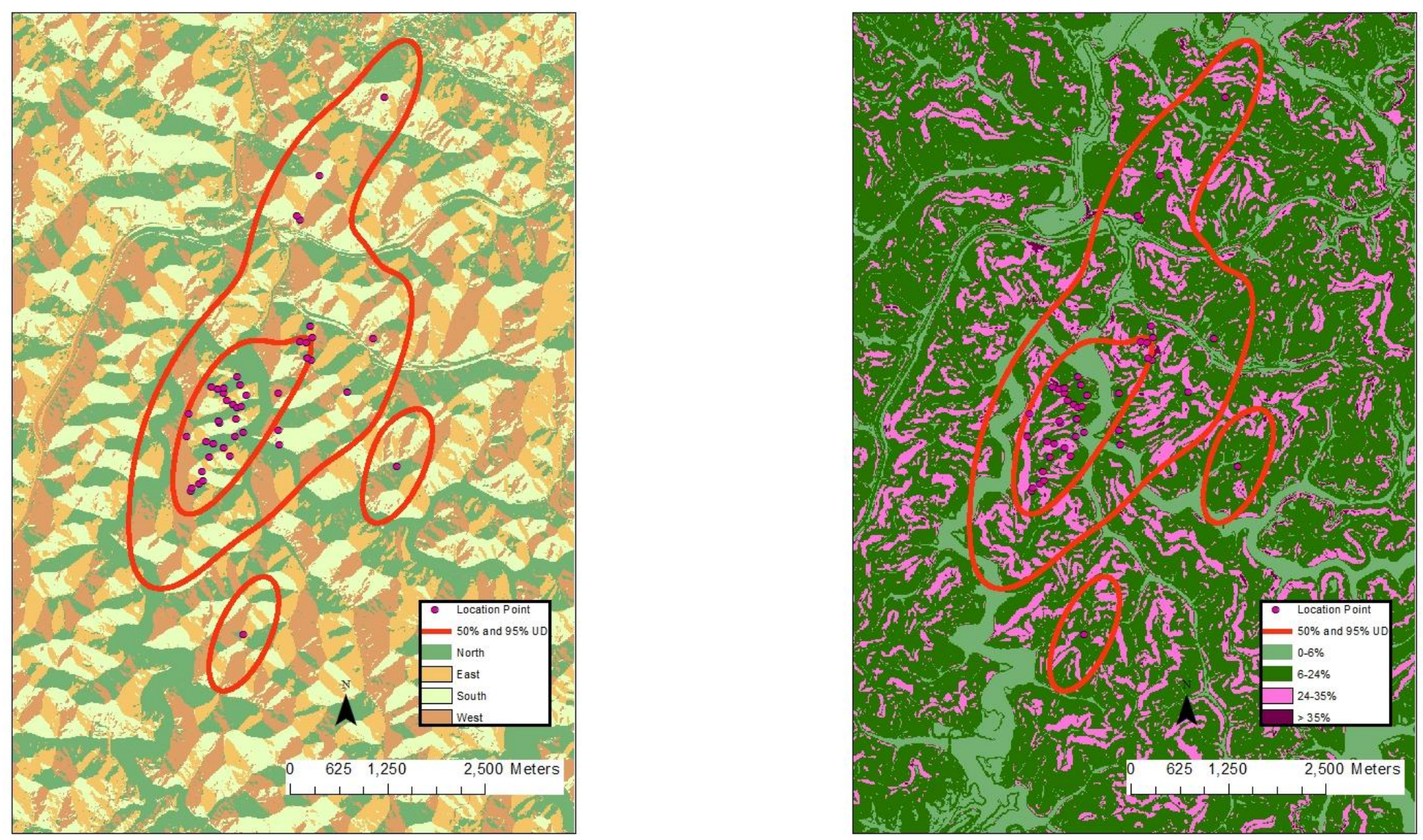
Appendix CLXVa. 10102 (juvenile, annual) - 50\% core and 95\% periphery probability contours of the annual Gaussian fixed kernel home range utilization distributions. Smoothing parameter $(h)$ determined by least squares cross validation, Hardy County, West Virginia, 2004-2007 (land use and land cover, land fragmentation maps).
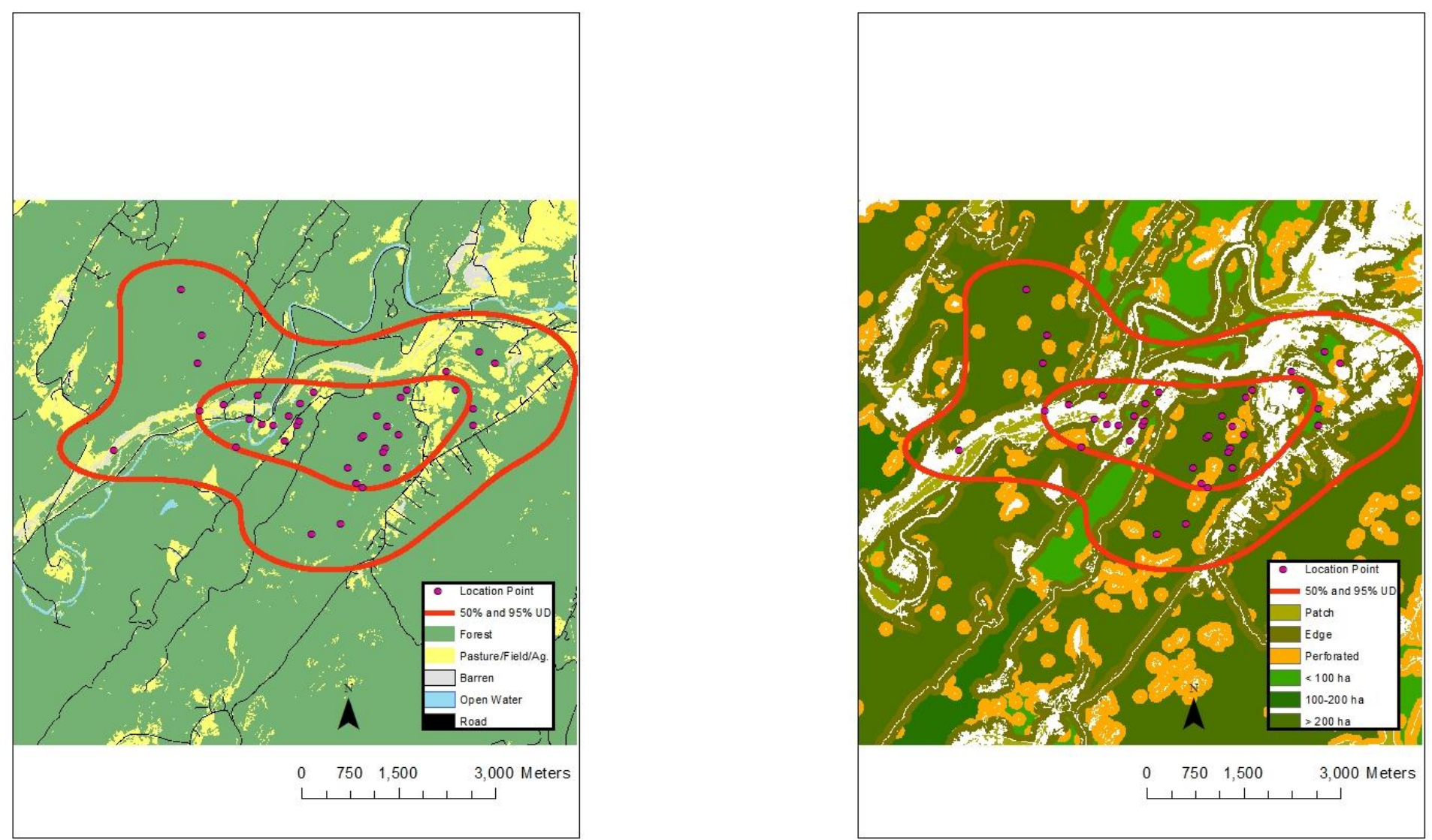
Appendix CLXVIa. 10102 (juvenile, annual) - 50\% core and 95\% periphery probability contours of the annual Gaussian fixed kernel home range utilization distributions. Smoothing parameter $(h)$ determined by least squares cross validation, Hardy County, West Virginia, 2004-2007 (aspect and slope maps).
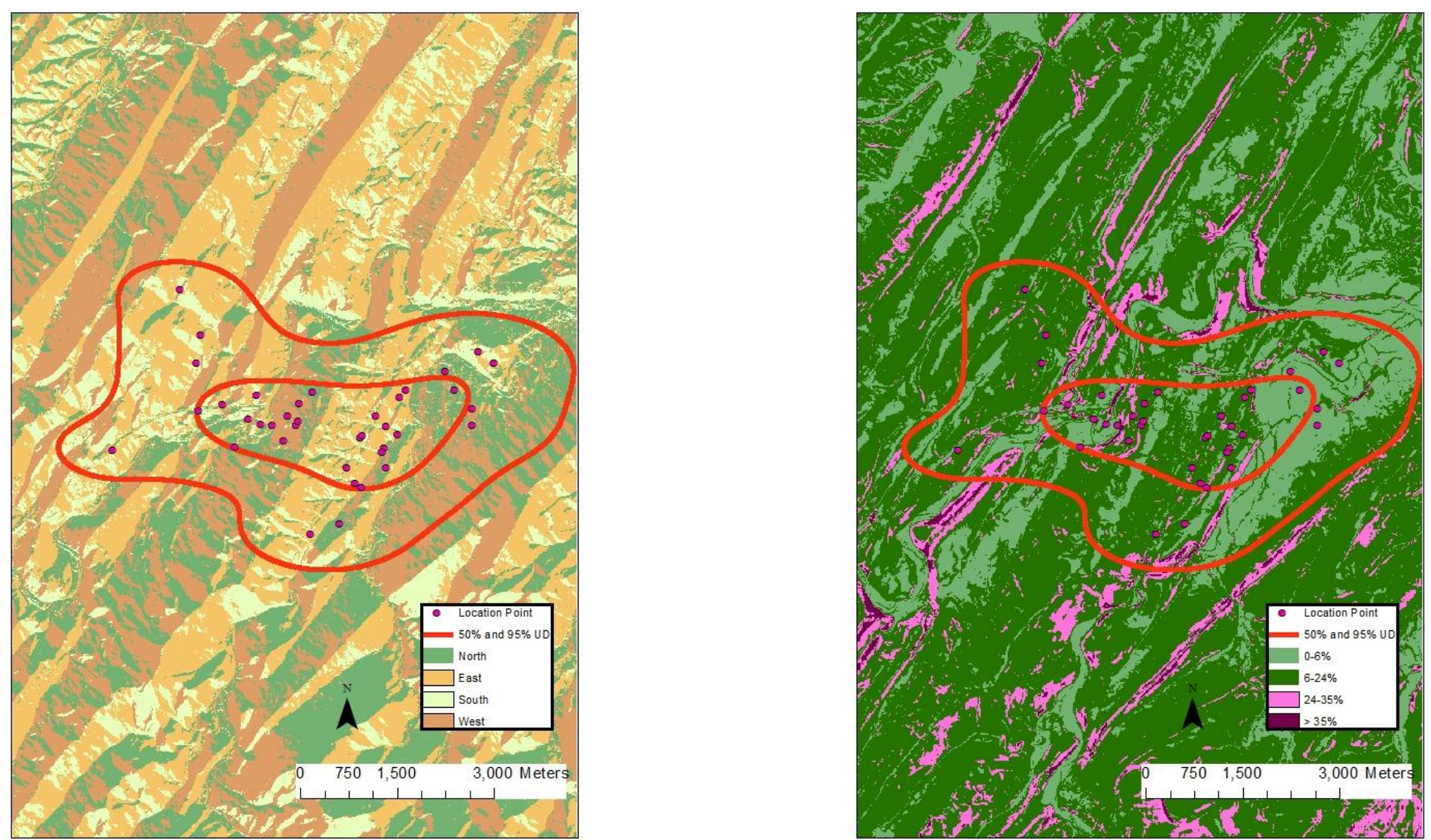
Appendix CLXVIIa. 10103 (adult, spring-summer) - 50\% core and 95\% periphery probability contours of the spring-summer Gaussian fixed kernel home range utilization distributions. Smoothing parameter $(h)$ determined by least squares cross validation, Hardy County, West Virginia, 2004-2007 (land use and land cover, land fragmentation maps).
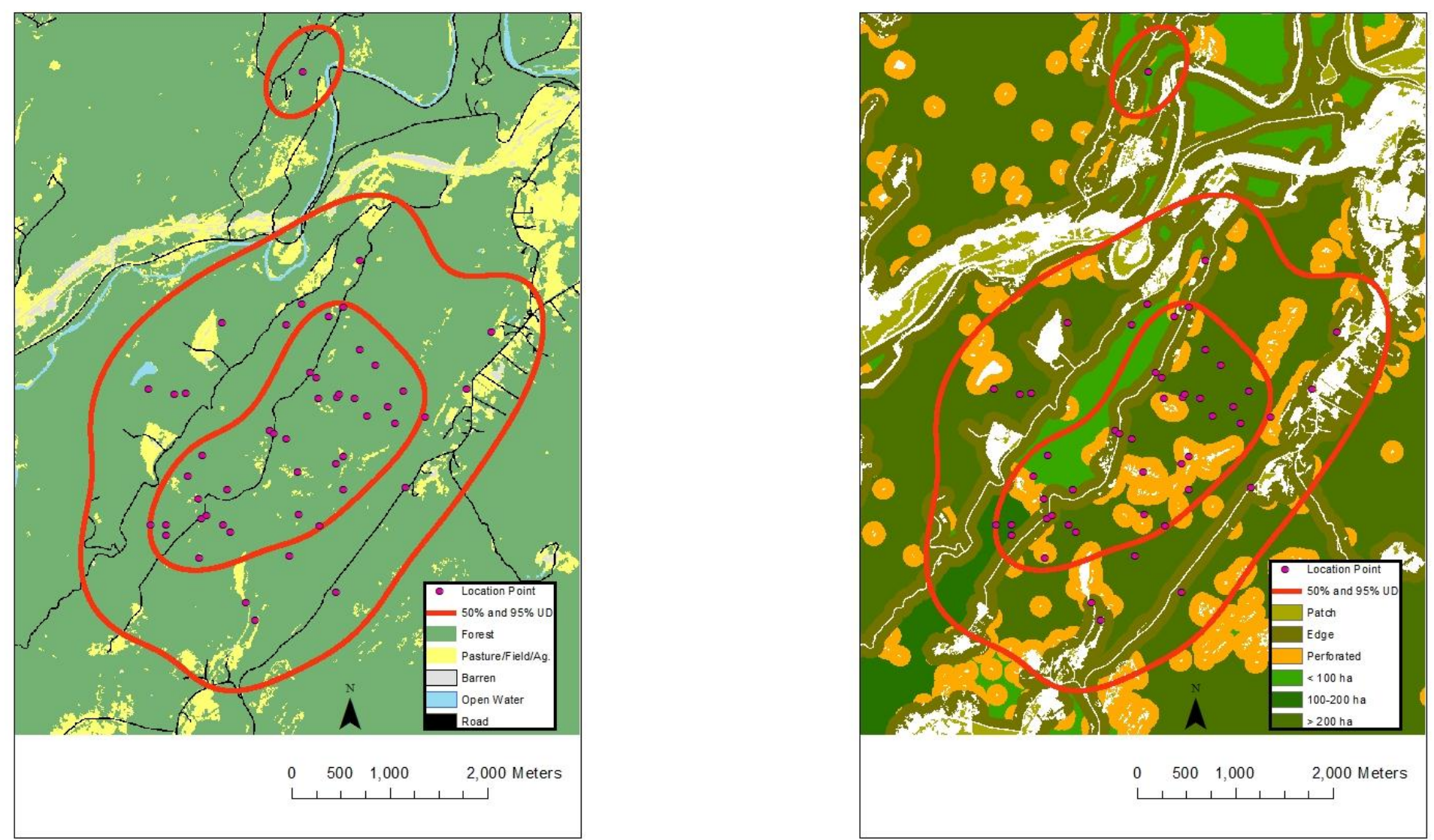
Appendix CLXVIIIa. 10103 (adult, spring-summer) - 50\% core and 95\% periphery probability contours of the spring-summer Gaussian fixed kernel home range utilization distributions. Smoothing parameter $(h)$ determined by least squares cross validation, Hardy County, West Virginia, 2004-2007 (aspect and slope maps).
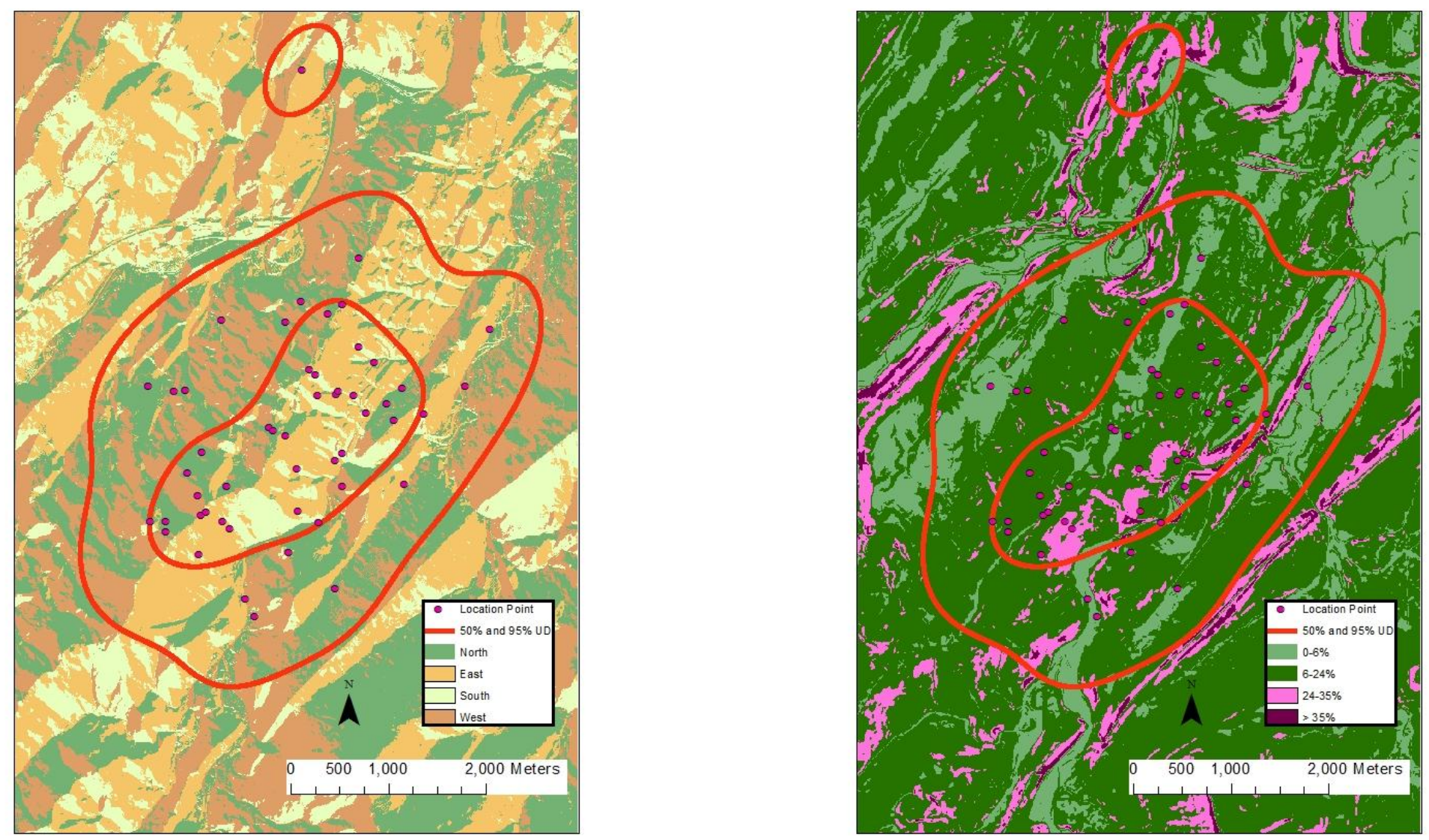
Appendix CLXIXa. 10104 (adult, annual) - 50\% core and 95\% periphery probability contours of the annual Gaussian fixed kernel home range utilization distributions. Smoothing parameter $(h)$ determined by least squares cross validation, Lewis County, West Virginia, 2004-2007 (land use and land cover, land fragmentation maps).
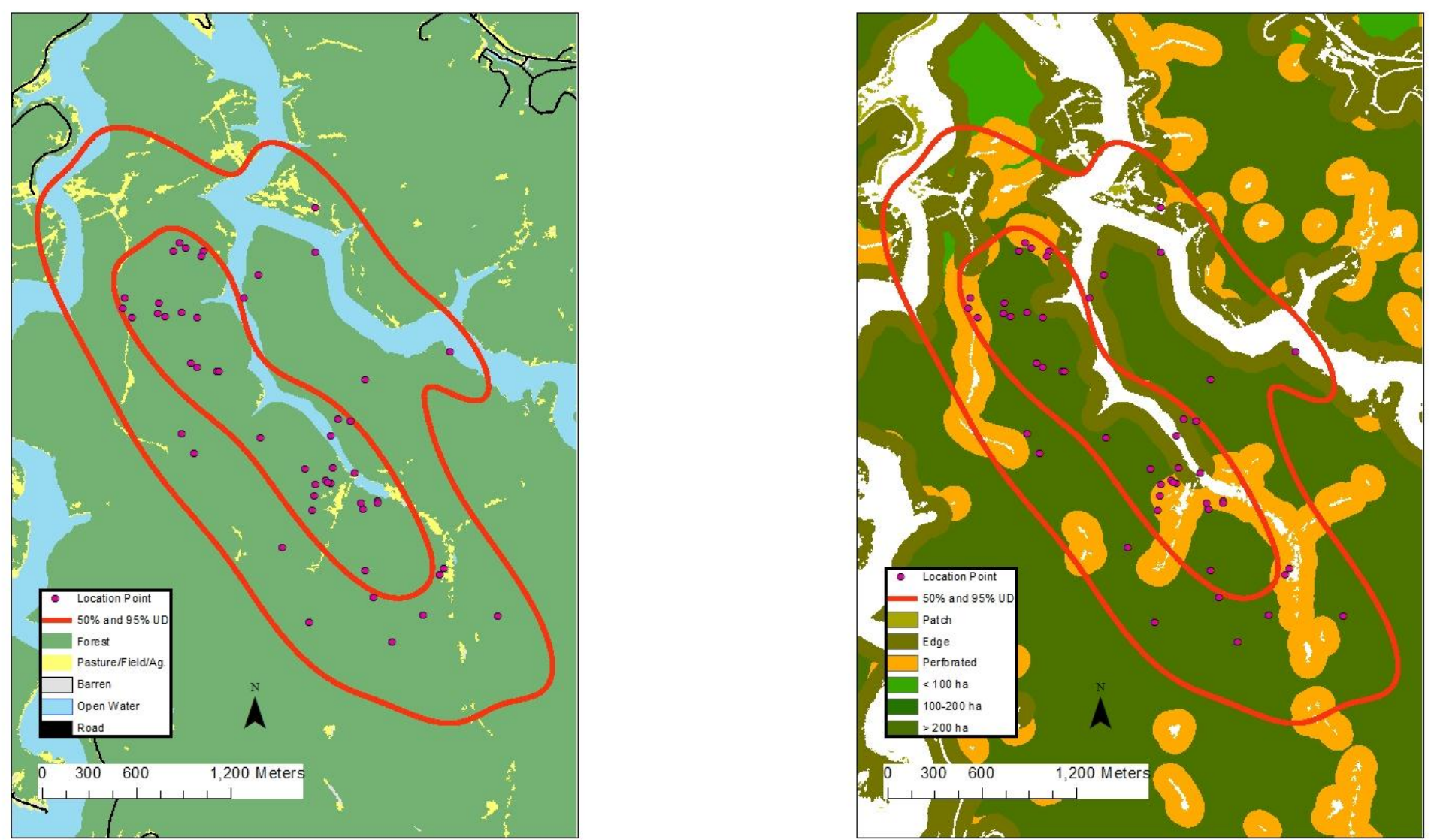
Appendix CLXXa. 10104 (adult, annual) - 50\% core and 95\% periphery probability contours of the annual Gaussian fixed kernel home range utilization distributions. Smoothing parameter $(h)$ determined by least squares cross validation, Lewis County, West Virginia, 2004-2007 (aspect and slope maps).
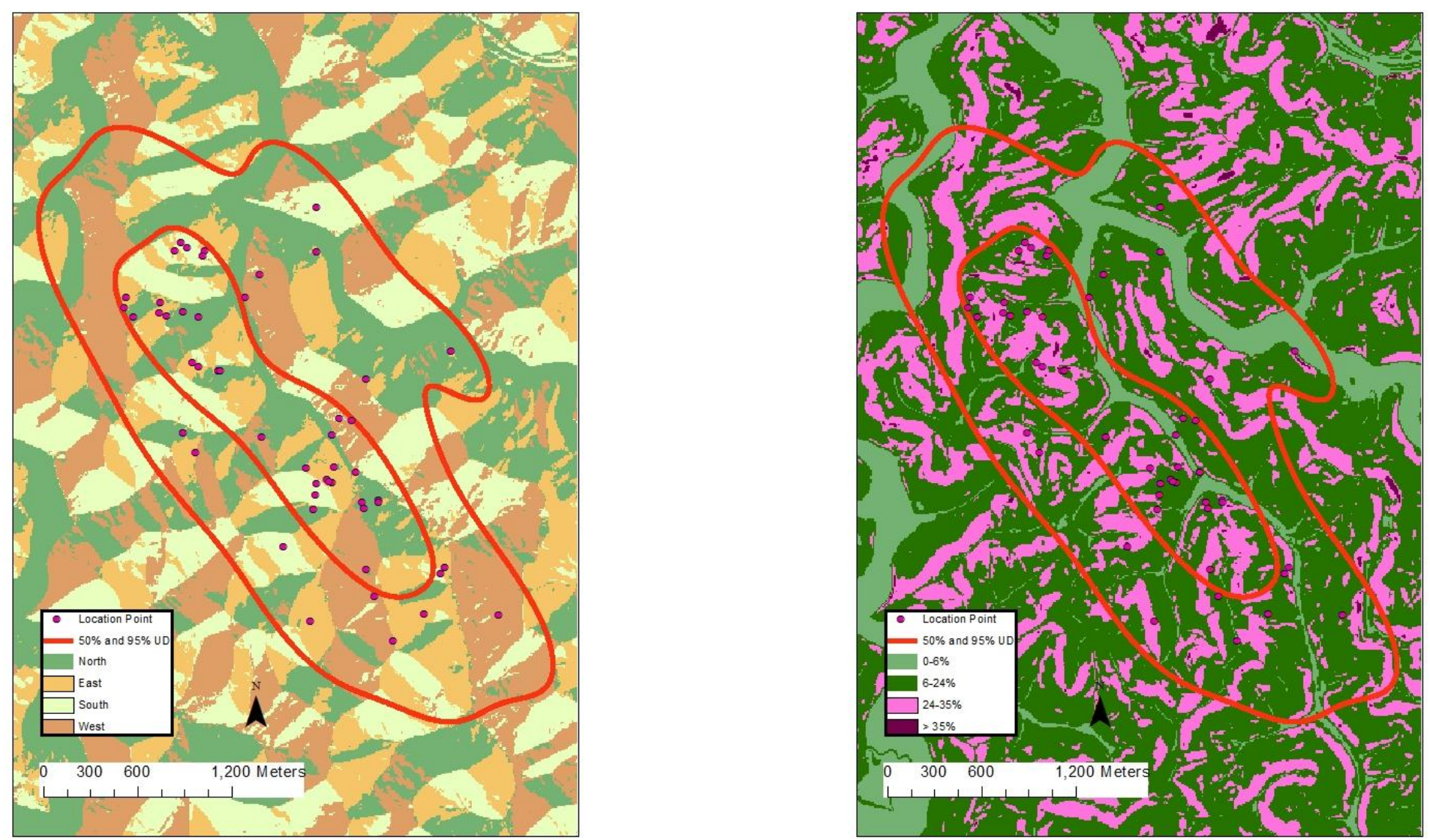
Appendix CLXXIa. 10105 (adult, annual) - 50\% core and 95\% periphery probability contours of the annual Gaussian fixed kernel home range utilization distributions. Smoothing parameter $(h)$ determined by least squares cross validation, Lewis County, West Virginia, 2004-2007 (land use and land cover, land fragmentation maps).
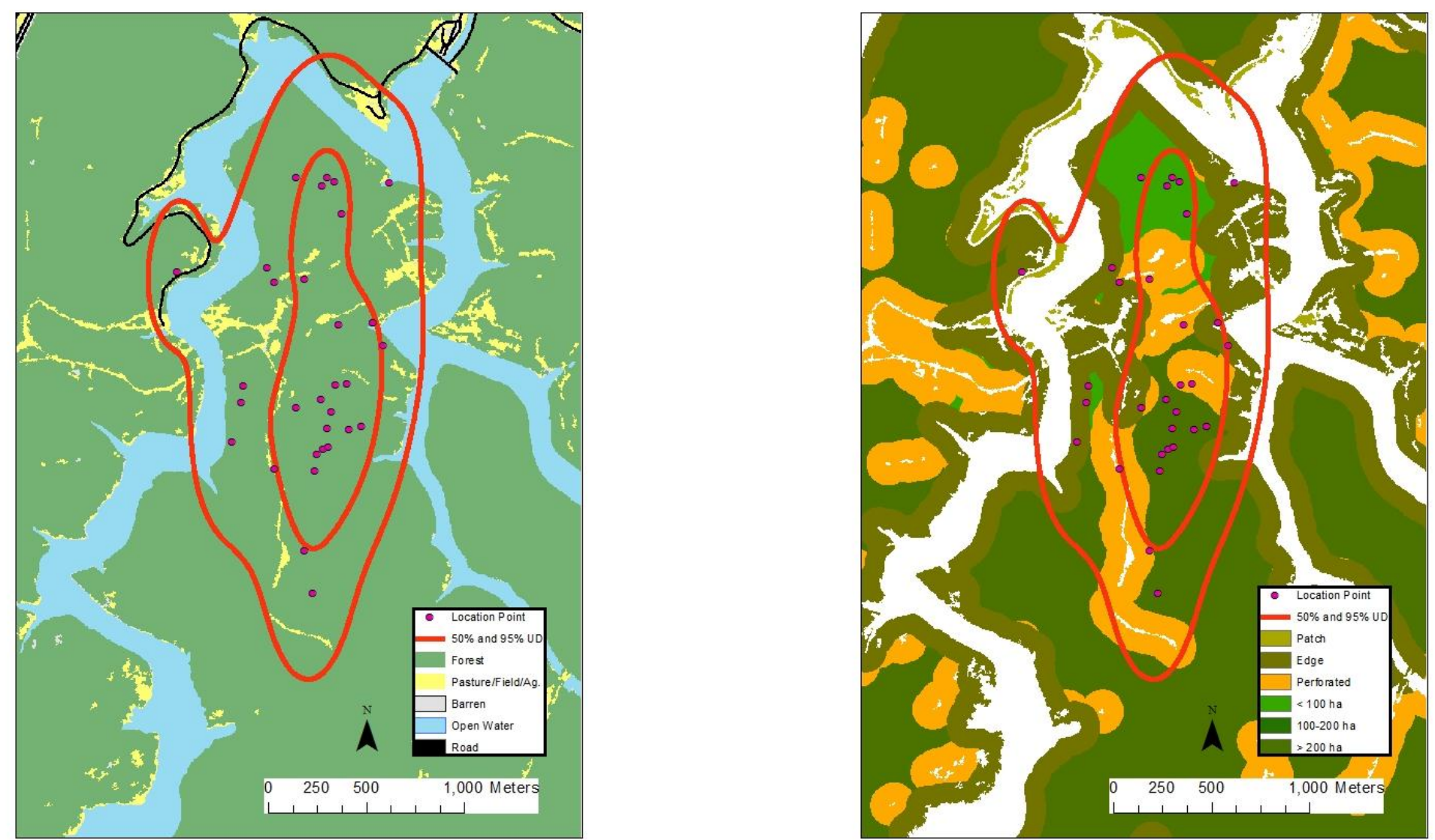
Appendix CLXXIIa. 10105 (adult, annual) - 50\% core and 95\% periphery probability contours of the annual Gaussian fixed kernel home range utilization distributions. Smoothing parameter $(h)$ determined by least squares cross validation, Lewis County, West Virginia, 2004-2007 (aspect and slope maps).
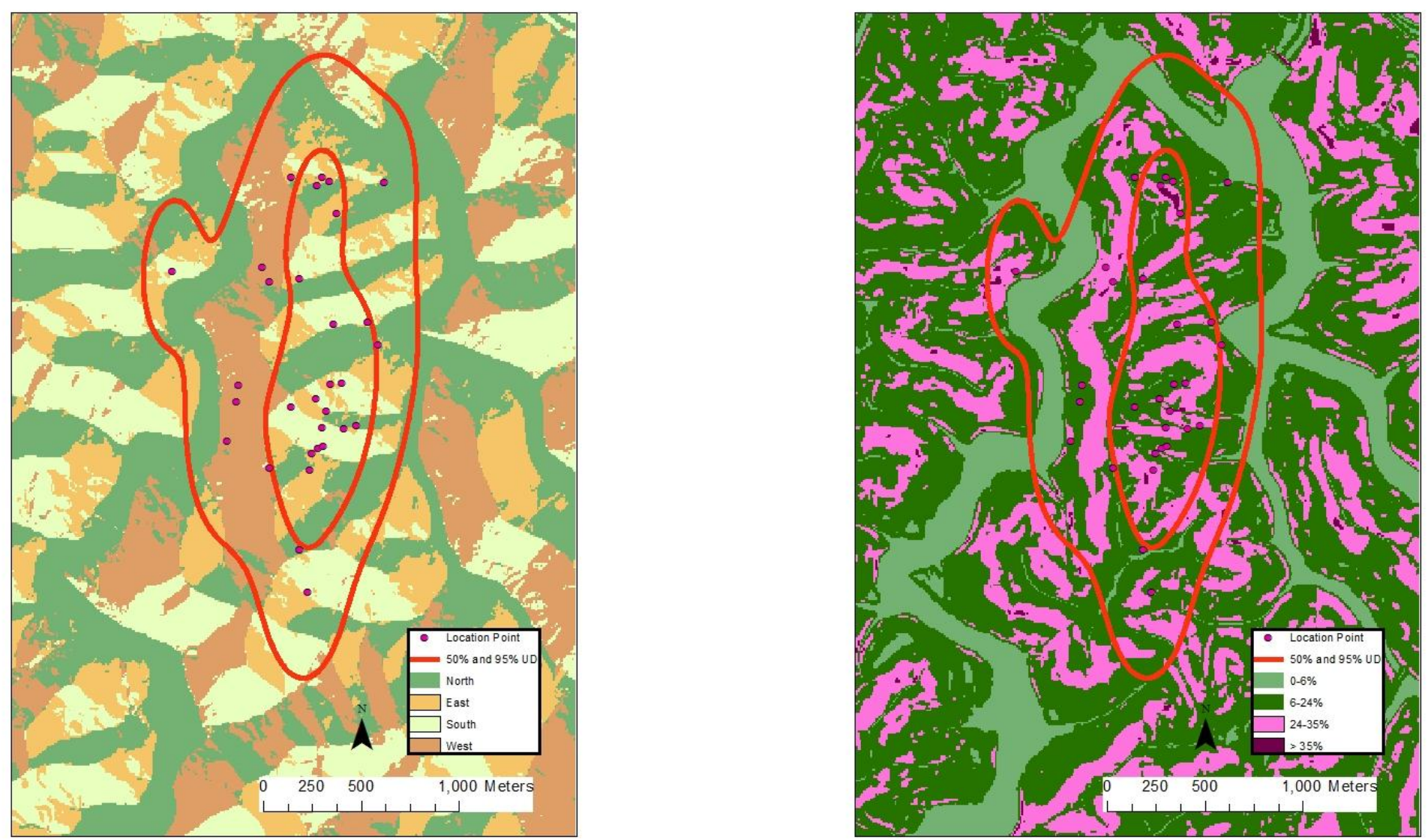
Appendix CLXXIII a. 10106 (adult, annual) - 50\% core and 95\% periphery probability contours of the annual Gaussian fixed kernel home range utilization distributions. Smoothing parameter $(h)$ determined by least squares cross validation, Lewis County, West Virginia, 2004-2007 (land use and land cover, land fragmentation maps).
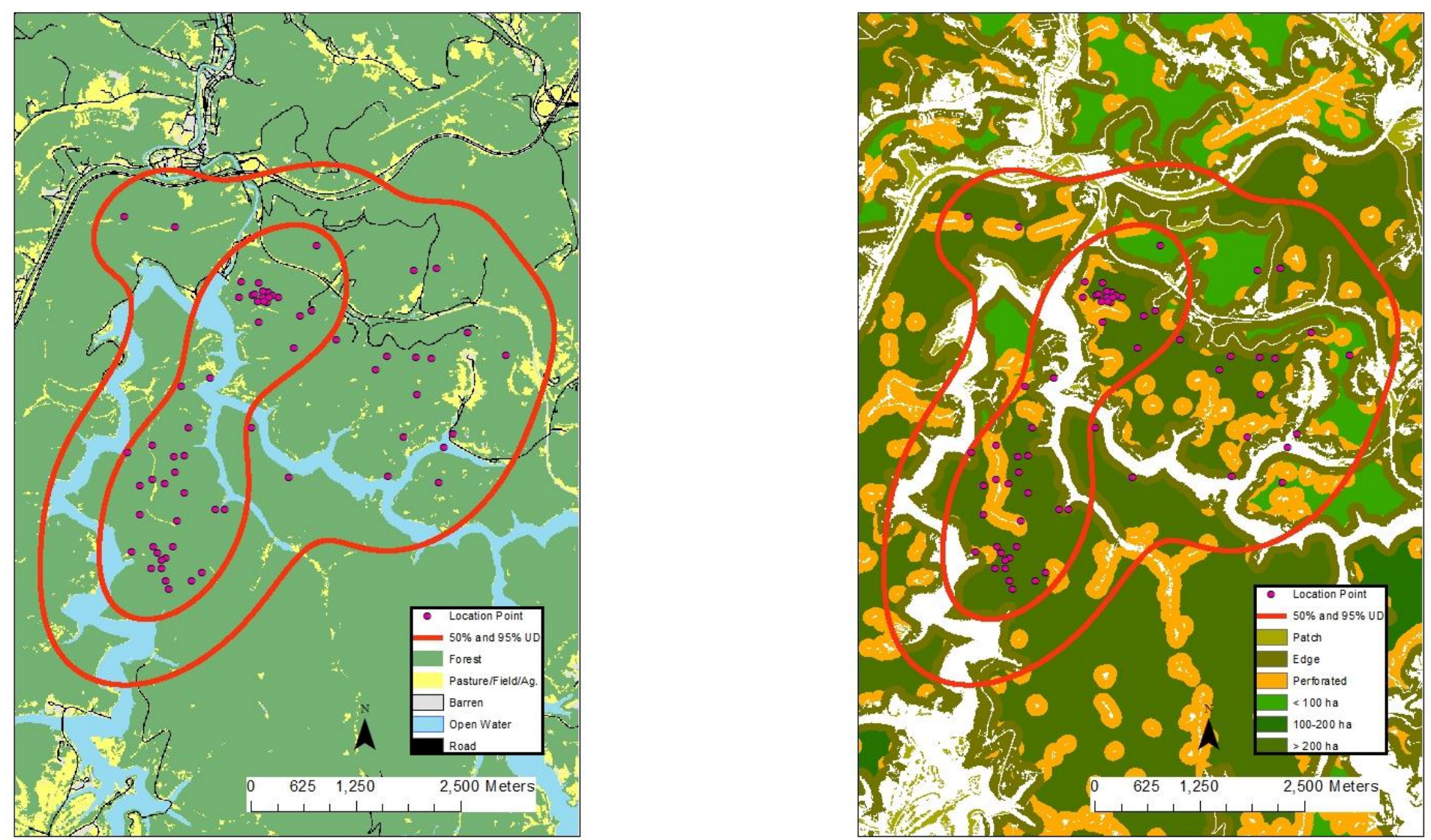
Appendix CLXXIIa. 10106 (adult, annual) - 50\% core and 95\% periphery probability contours of the annual Gaussian fixed kernel home range utilization distributions. Smoothing parameter $(h)$ determined by least squares cross validation, Lewis County, West Virginia, 2004-2007 (aspect and slope maps).
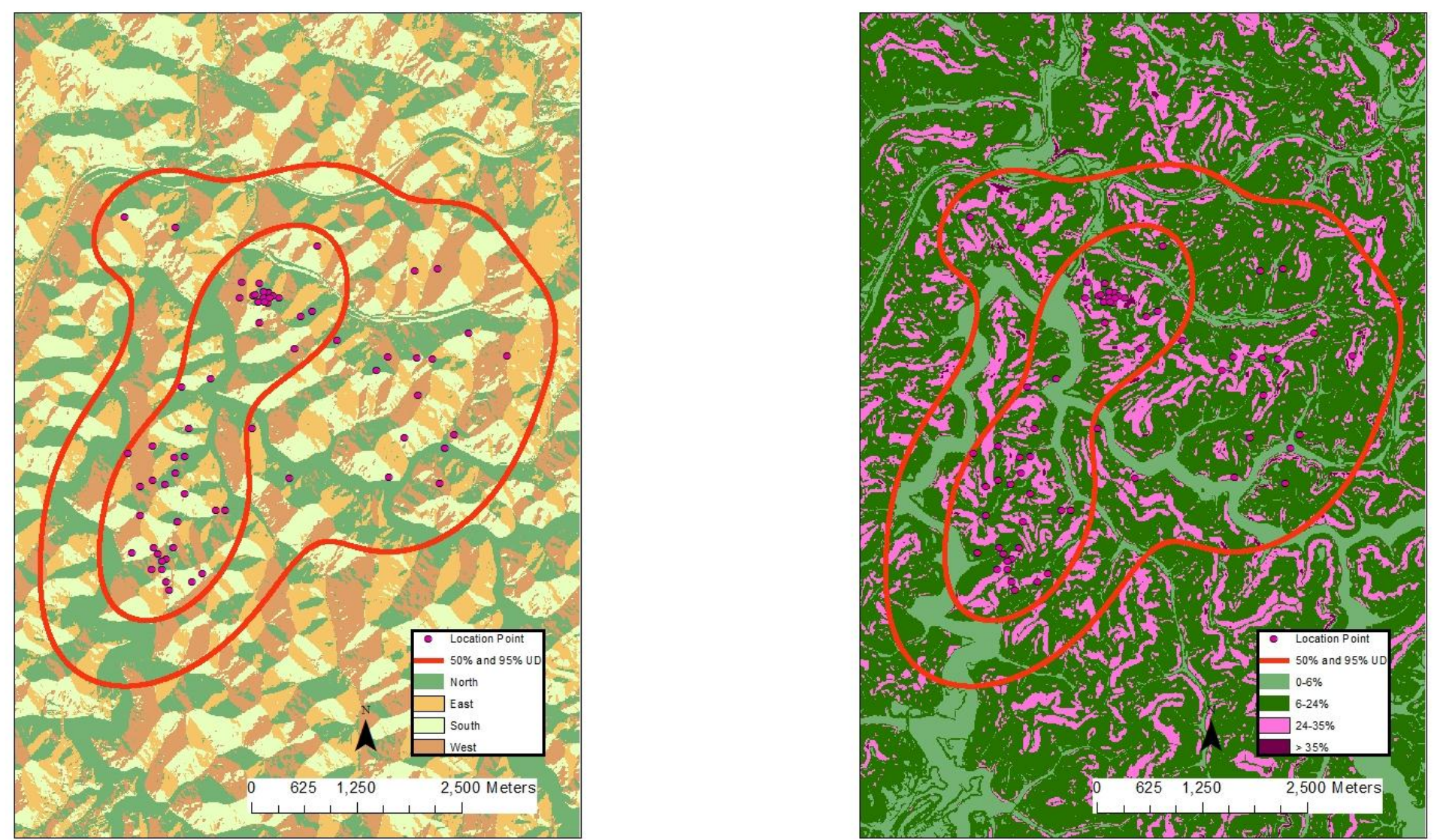
Appendix CLXXVa. 10107 (adult, fall-winter) - 50\% core and 95\% periphery probability contours of the fall-winter Gaussian fixed kernel home range utilization distributions. Smoothing parameter $(h)$ determined by least squares cross validation, Lewis County, West Virginia, 2004-2007 (land use and land cover, land fragmentation maps).
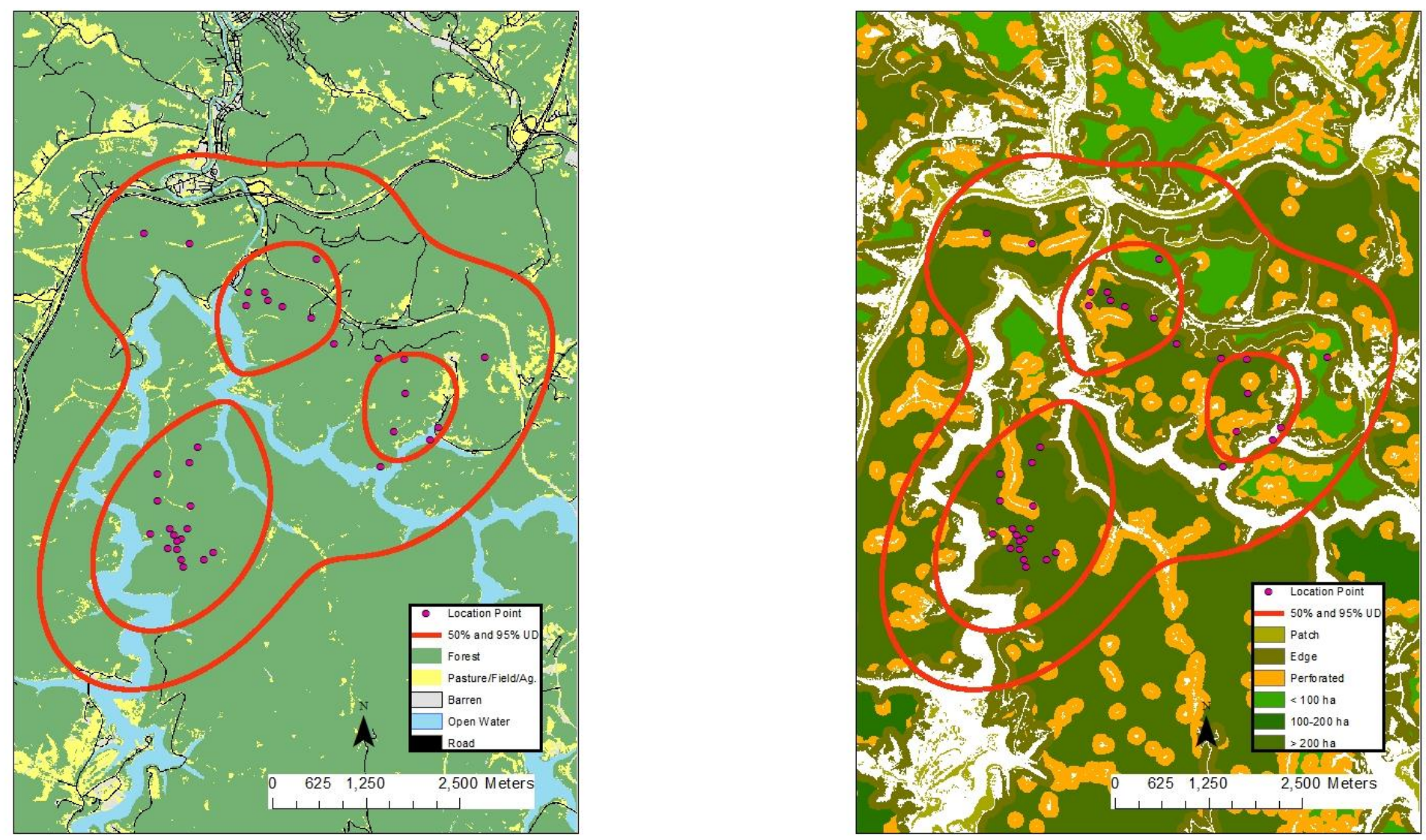
Appendix CLXXVIa. 10107 (adult, fall-winter) - 50\% core and 95\% periphery probability contours of the fall-winter Gaussian fixed kernel home range utilization distributions. Smoothing parameter $(h)$ determined by least squares cross validation, Lewis County, West Virginia, 2004-2007 (aspect and slope maps).
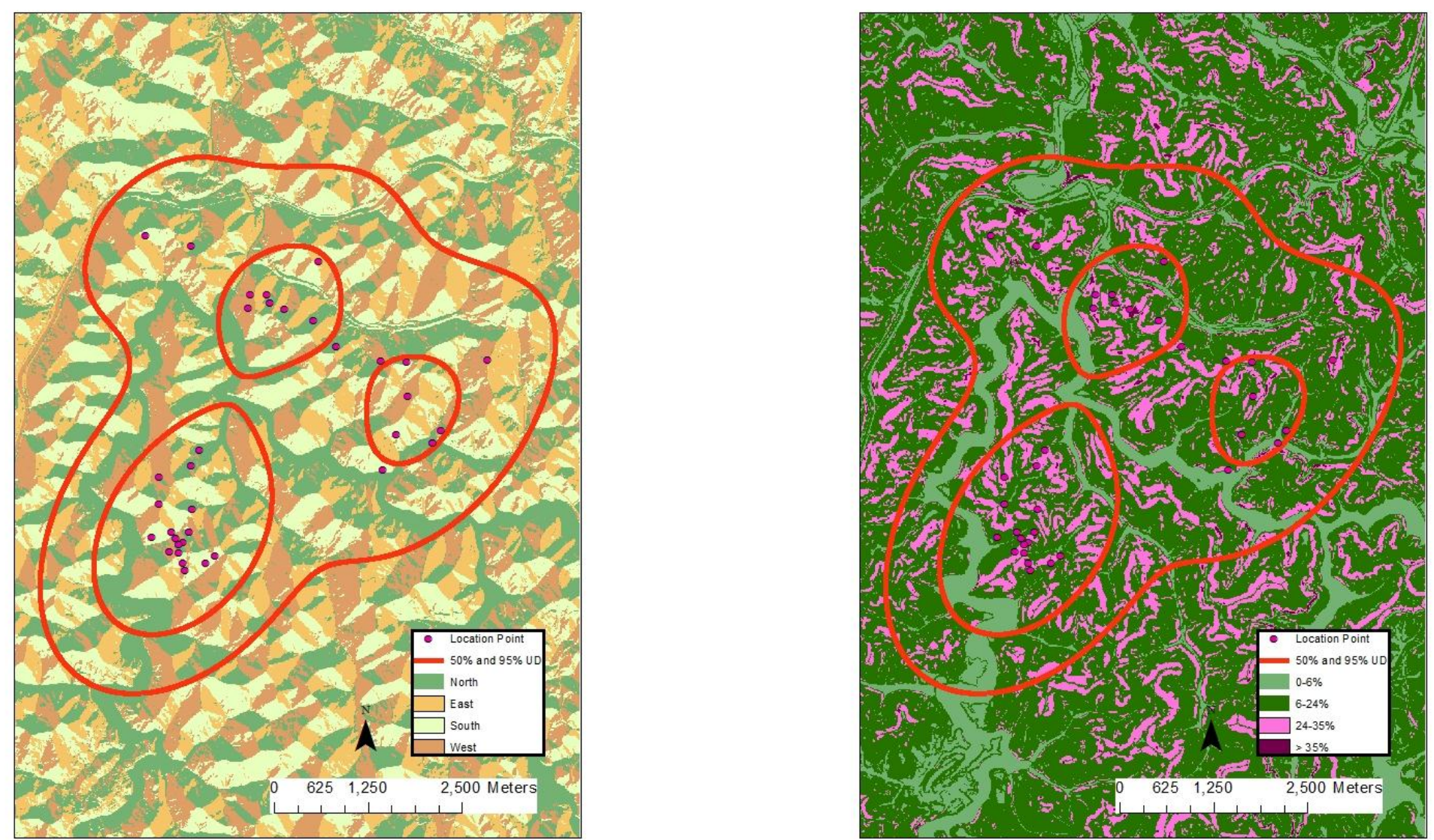
Appendix CLXXVIIa. 10108 (adult, spring-summer) - 50\% core and 95\% periphery probability contours of the spring-summer Gaussian fixed kernel home range utilization distributions. Smoothing parameter $(h)$ determined by least squares cross validation, Lewis County, West Virginia, 2004-2007 (land use and land cover, land fragmentation maps).
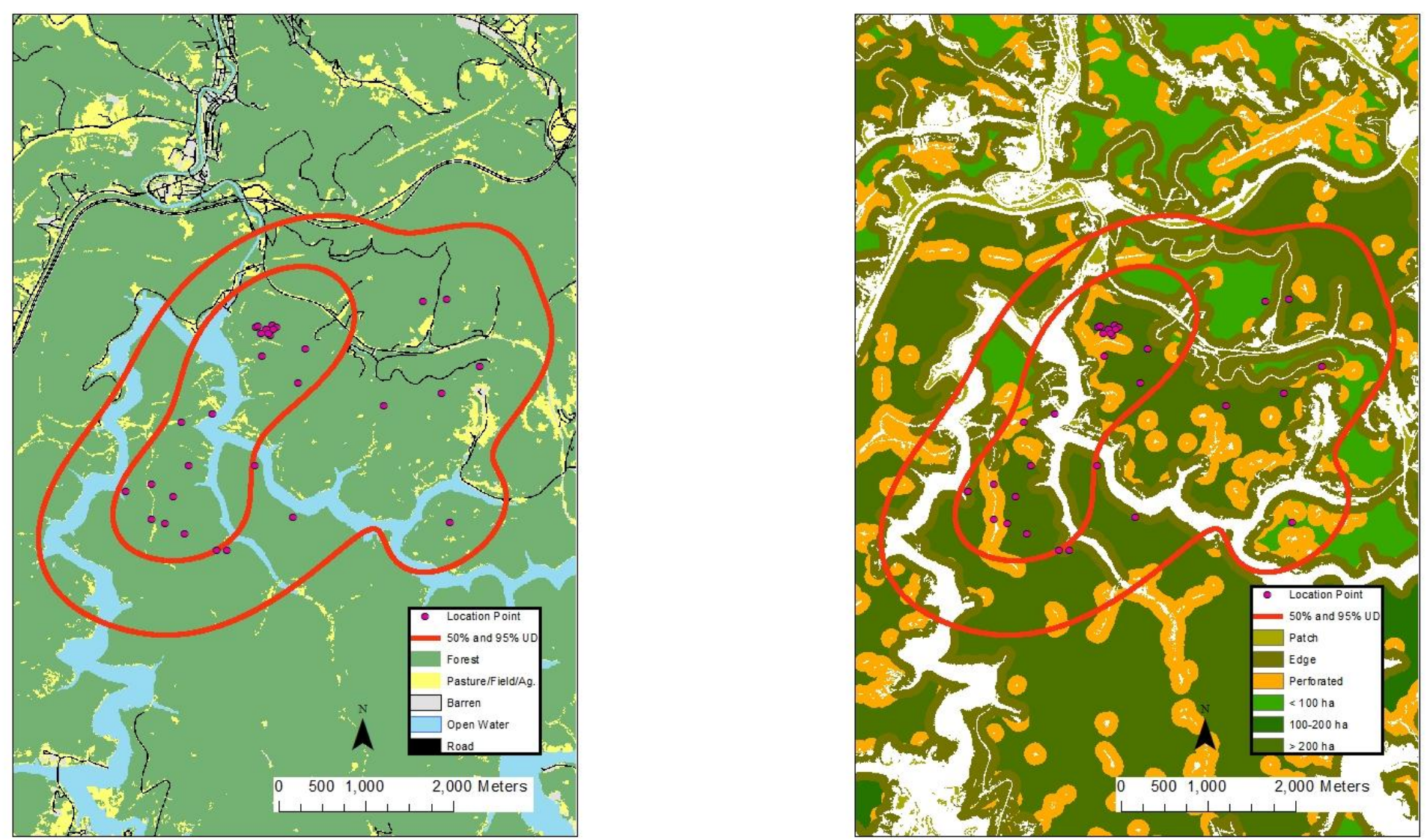
Appendix CLXXVIIIa. 10108 (adult, spring-summer) - 50\% core and 95\% periphery probability contours of the spring-summer Gaussian fixed kernel home range utilization distributions. Smoothing parameter $(h)$ determined by least squares cross validation, Lewis County, West Virginia, 2004-2007 (aspect and slope maps).
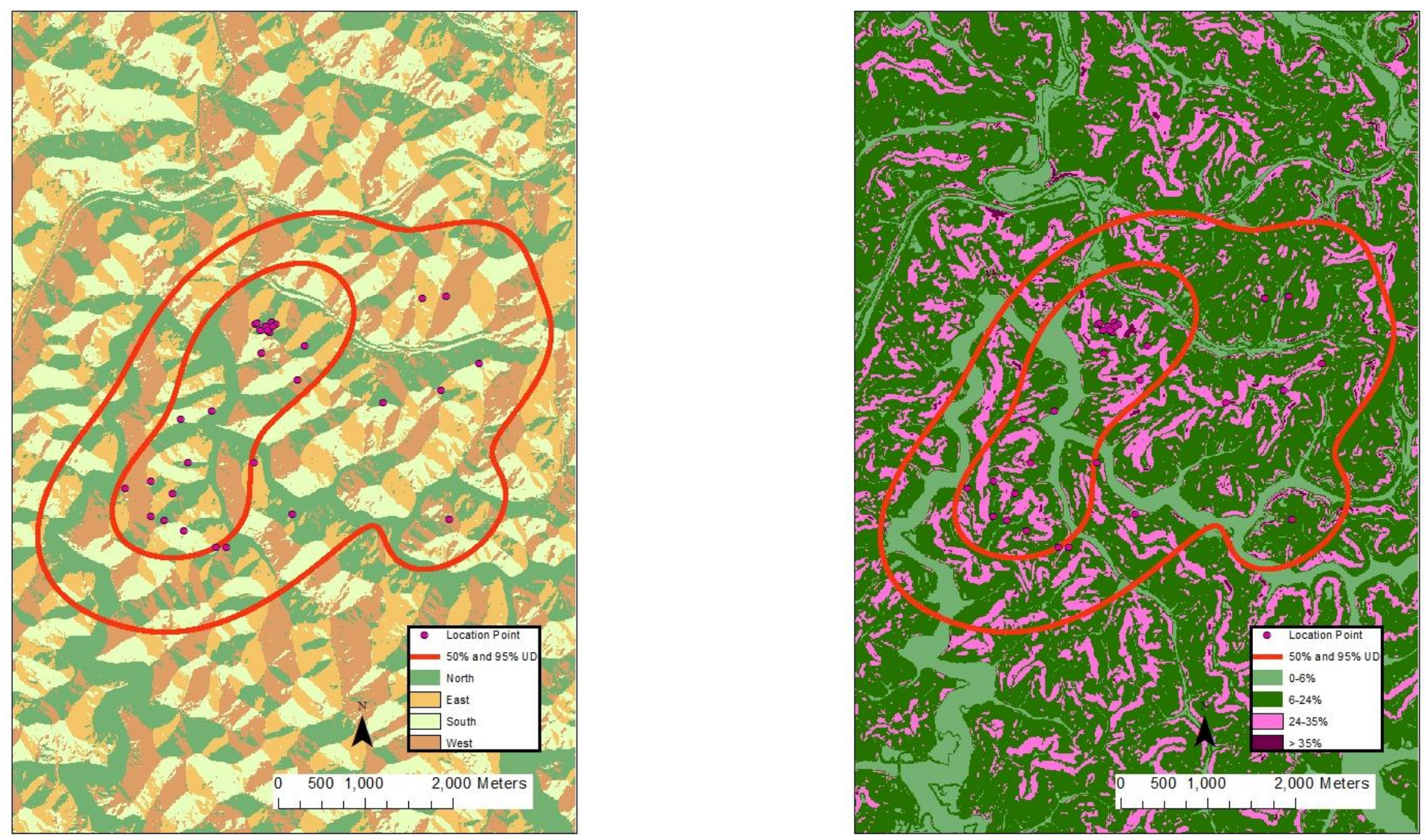
Appendix CLXXIXa. 10109 (adult, annual) - 50\% core and 95\% periphery probability contours of the annual Gaussian fixed kernel home range utilization distributions. Smoothing parameter $(h)$ determined by least squares cross validation, Lewis County, West Virginia, 2004-2007 (land use and land cover, land fragmentation maps).
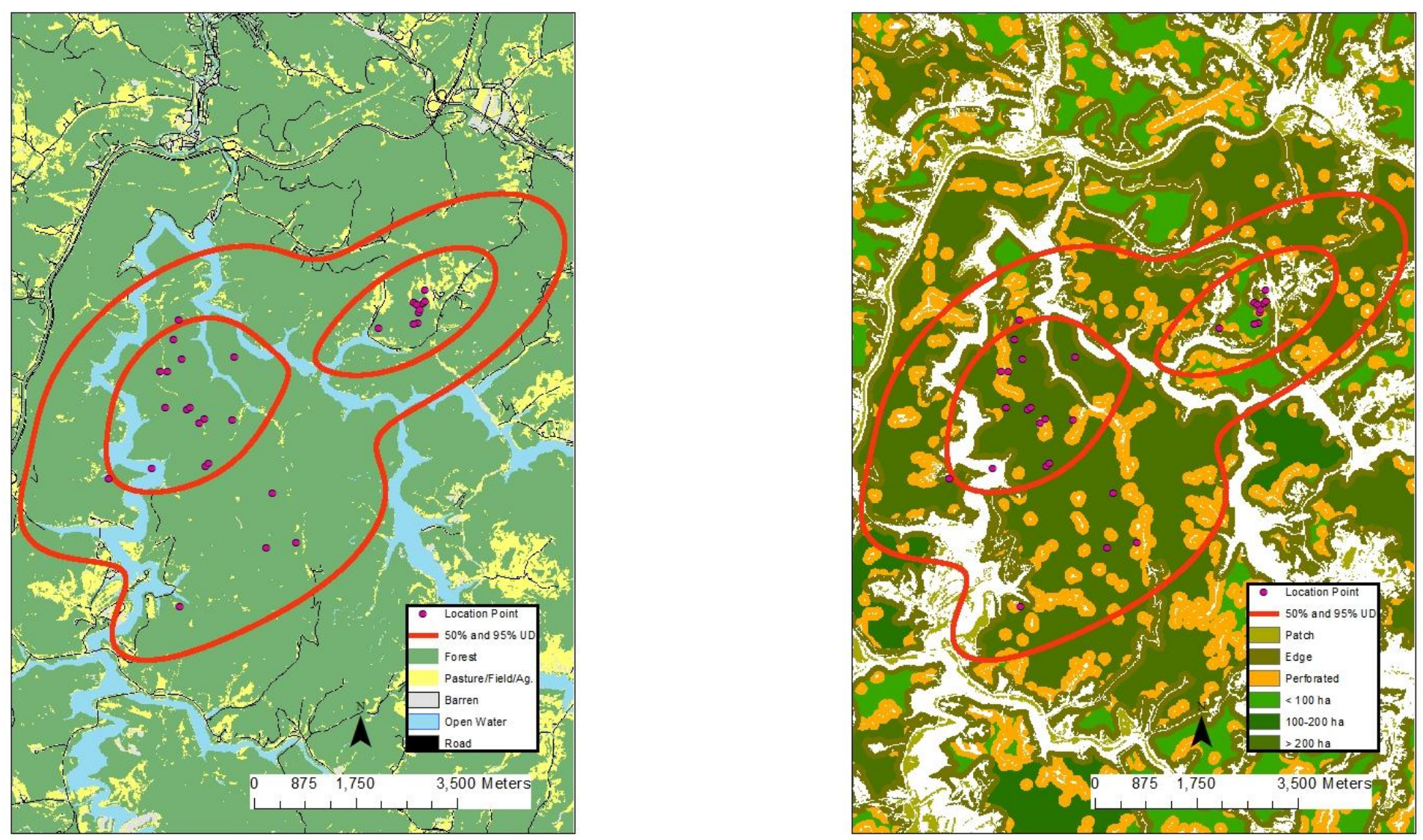
Appendix CLXXXa. 10109 (adult, annual) - 50\% core and 95\% periphery probability contours of the annual Gaussian fixed kernel home range utilization distributions. Smoothing parameter $(h)$ determined by least squares cross validation, Lewis County, West Virginia, 2004-2007 (aspect and slope maps).
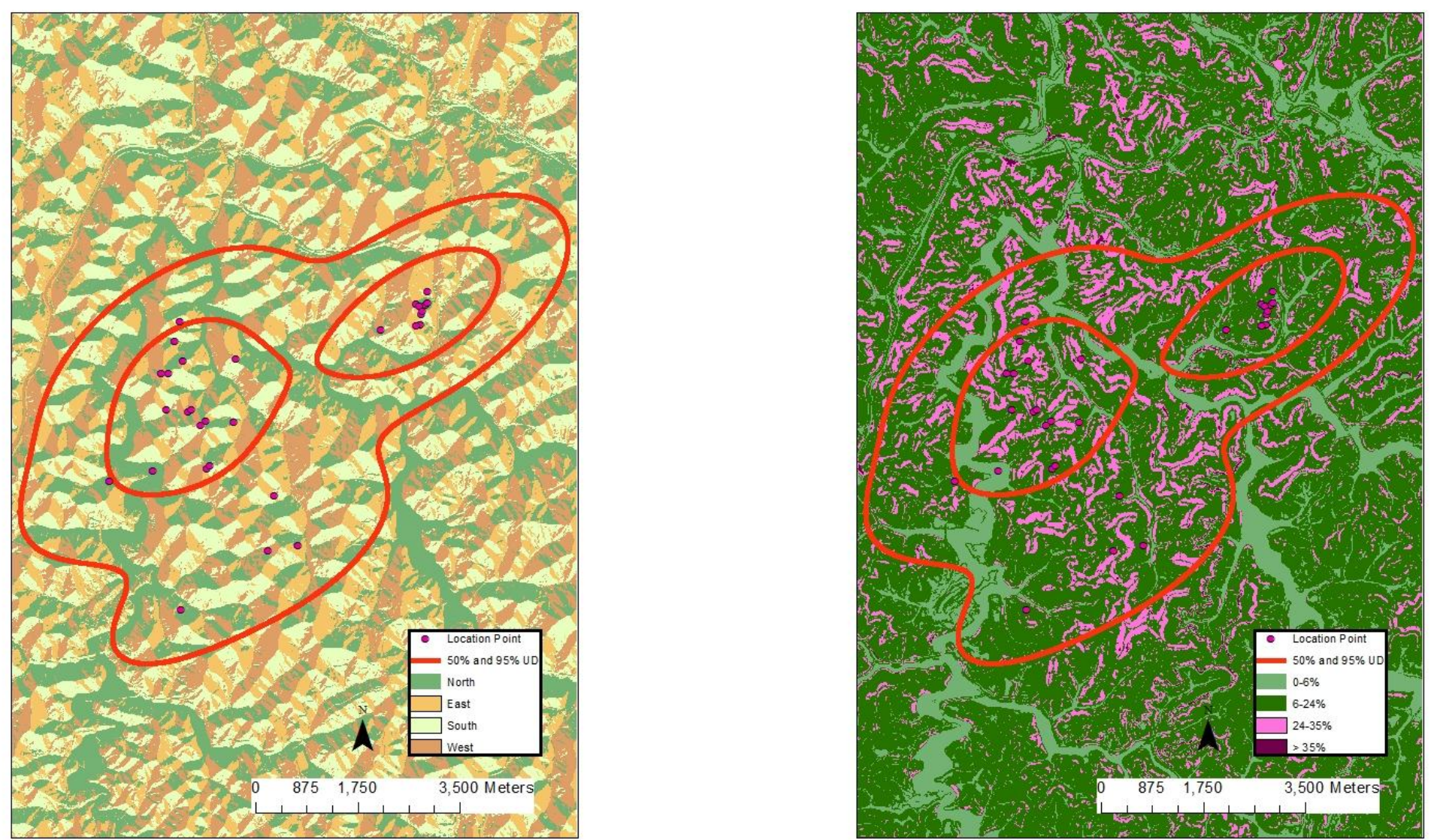
Appendix CLXXXIa. 10110 (juvenile, annual) - 50\% core and 95\% periphery probability contours of the annual Gaussian fixed kernel home range utilization distributions. Smoothing parameter $(h)$ determined by least squares cross validation, Lewis County, West Virginia, 2004-2007 (land use and land cover, land fragmentation maps).
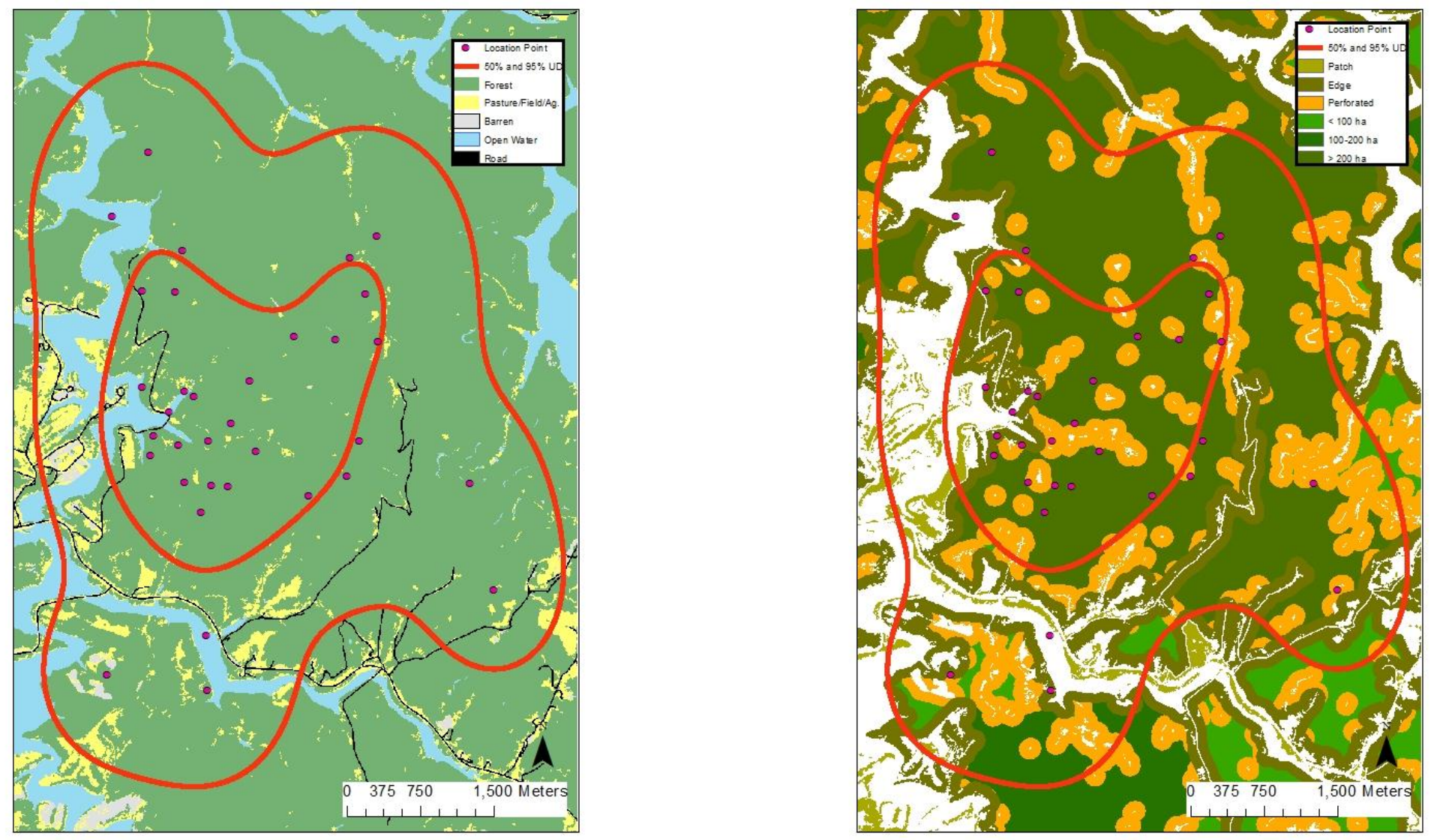
Appendix CLXXXIIa. 10110 (juvenile, annual) - 50\% core and 95\% periphery probability contours of the annual Gaussian fixed kernel home range utilization distributions. Smoothing parameter $(h)$ determined by least squares cross validation, Lewis County, West Virginia, 2004-2007 (aspect and slope maps).
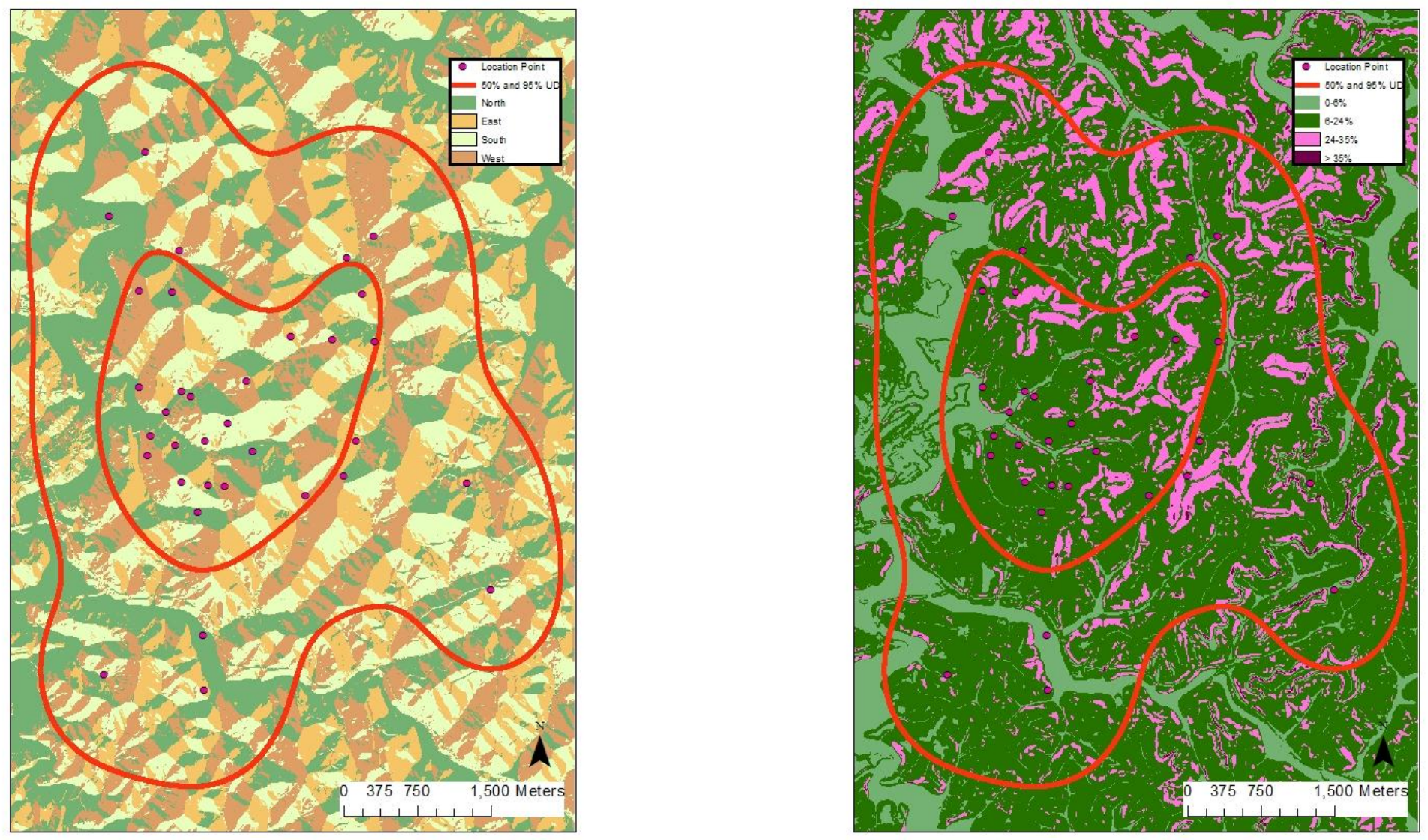
Appendix CLXXXIII a. 10111 (adult, annual) - 50\% core and 95\% periphery probability contours of the annual Gaussian fixed kernel home range utilization distributions. Smoothing parameter $(h)$ determined by least squares cross validation, Lewis County, West Virginia, 2004-2007 (land use and land cover, land fragmentation maps).
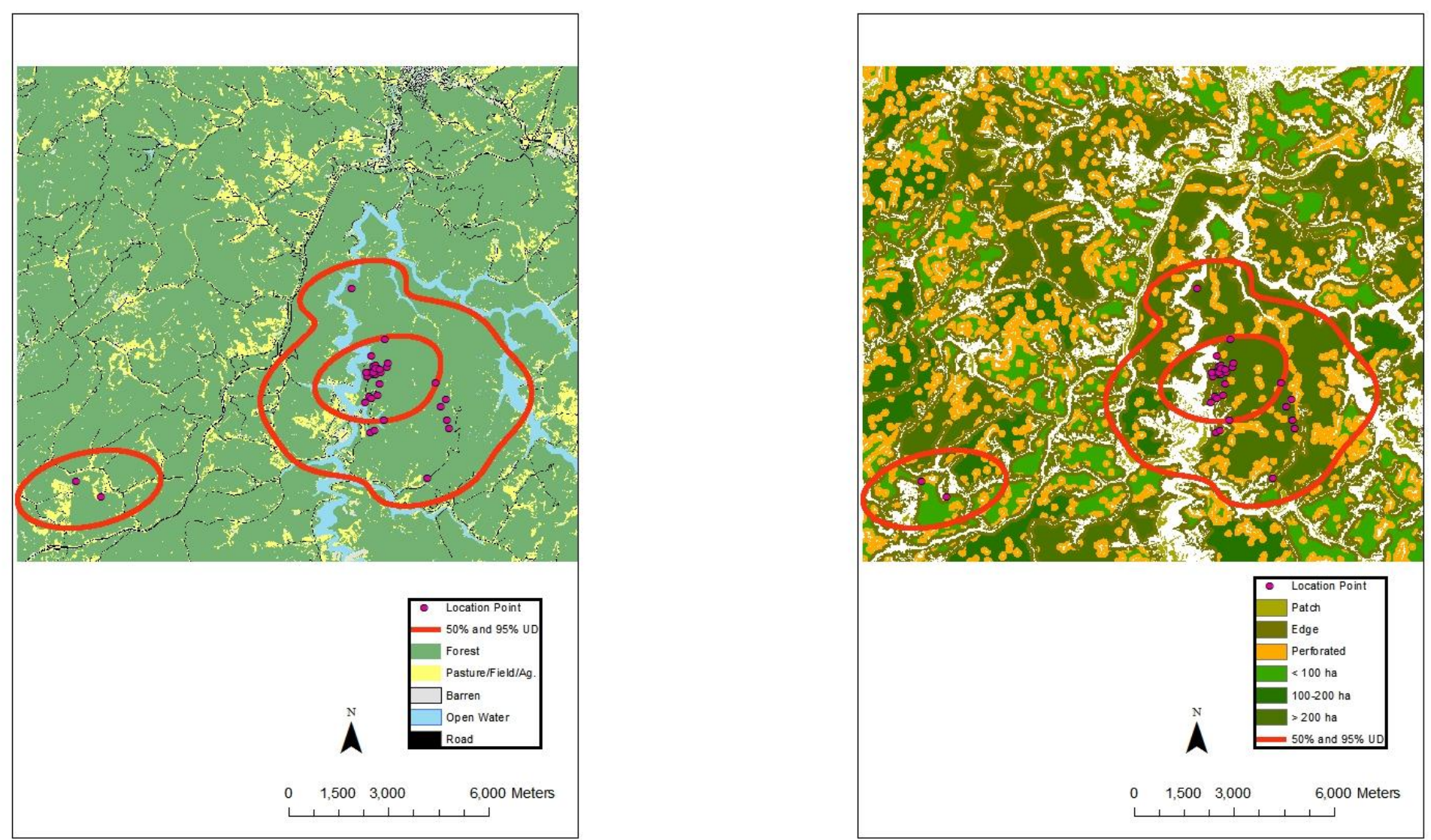
Appendix CLXXXIVa. 10111 (adult, annual) - 50\% core and 95\% periphery probability contours of the annual Gaussian fixed kernel home range utilization distributions. Smoothing parameter $(h)$ determined by least squares cross validation, Lewis County, West Virginia, 2004-2007 (aspect and slope maps).
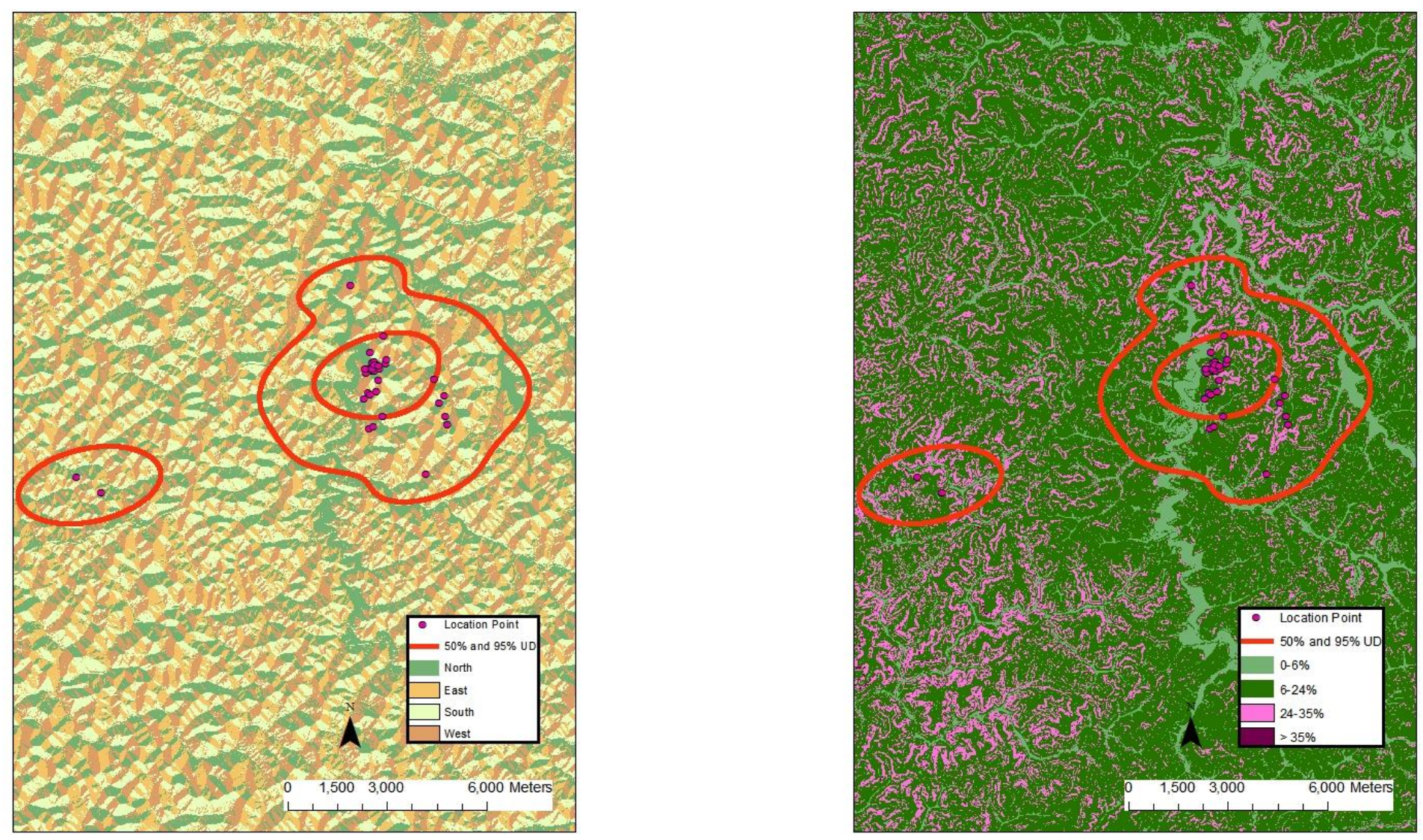
Appendix CLXXXVa. 10112 (adult, annual) - 50\% core and 95\% periphery probability contours of the annual Gaussian fixed kernel home range utilization distributions. Smoothing parameter $(h)$ determined by least squares cross validation, Greenbrier County, West Virginia, 2004-2007 (land use and land cover, land fragmentation maps).
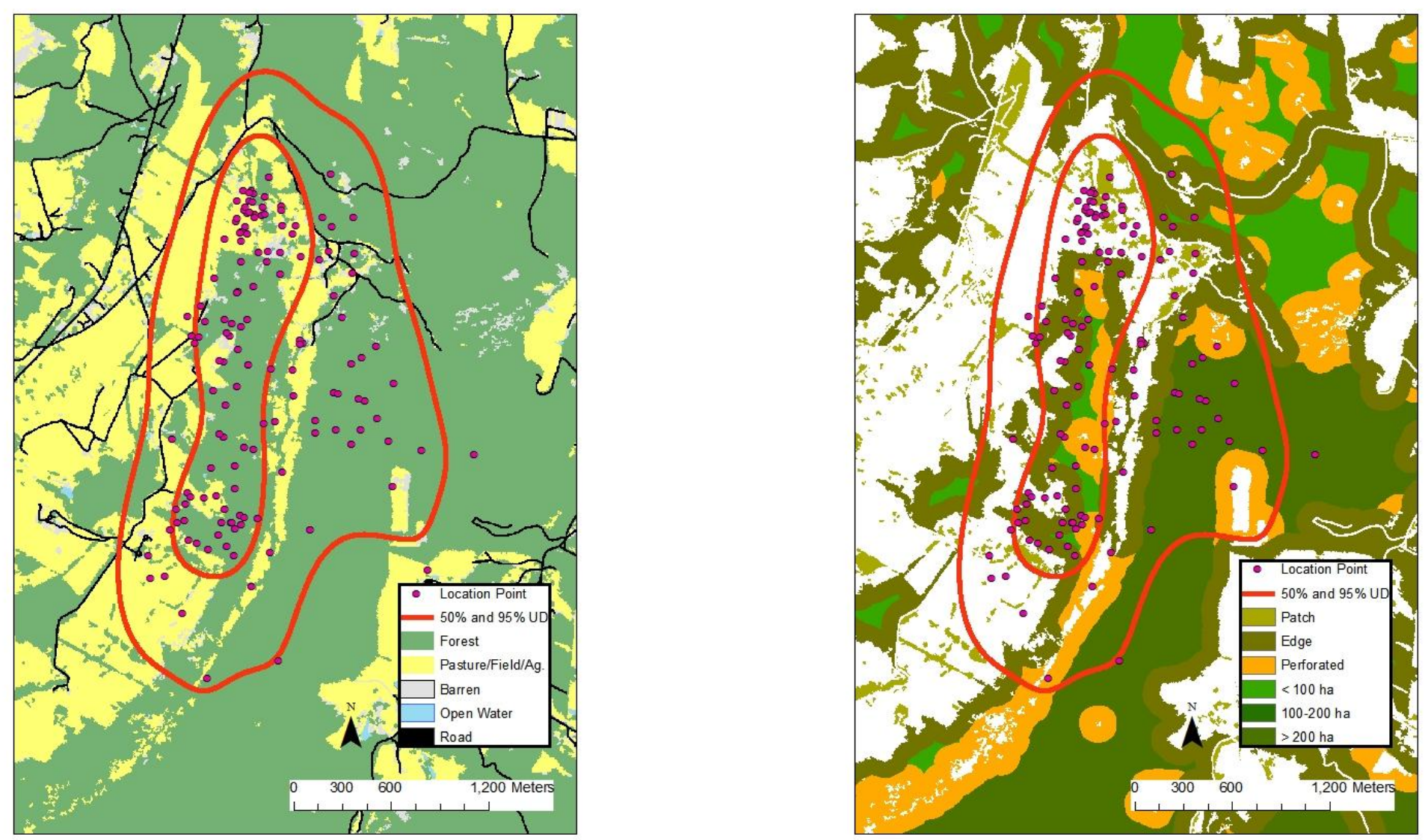
Appendix CLXXXVIa. 10112 (adult, annual) - 50\% core and 95\% periphery probability contours of the annual Gaussian fixed kernel home range utilization distributions. Smoothing parameter $(h)$ determined by least squares cross validation, Greenbrier County, West Virginia, 2004-2007 (aspect and slope maps).
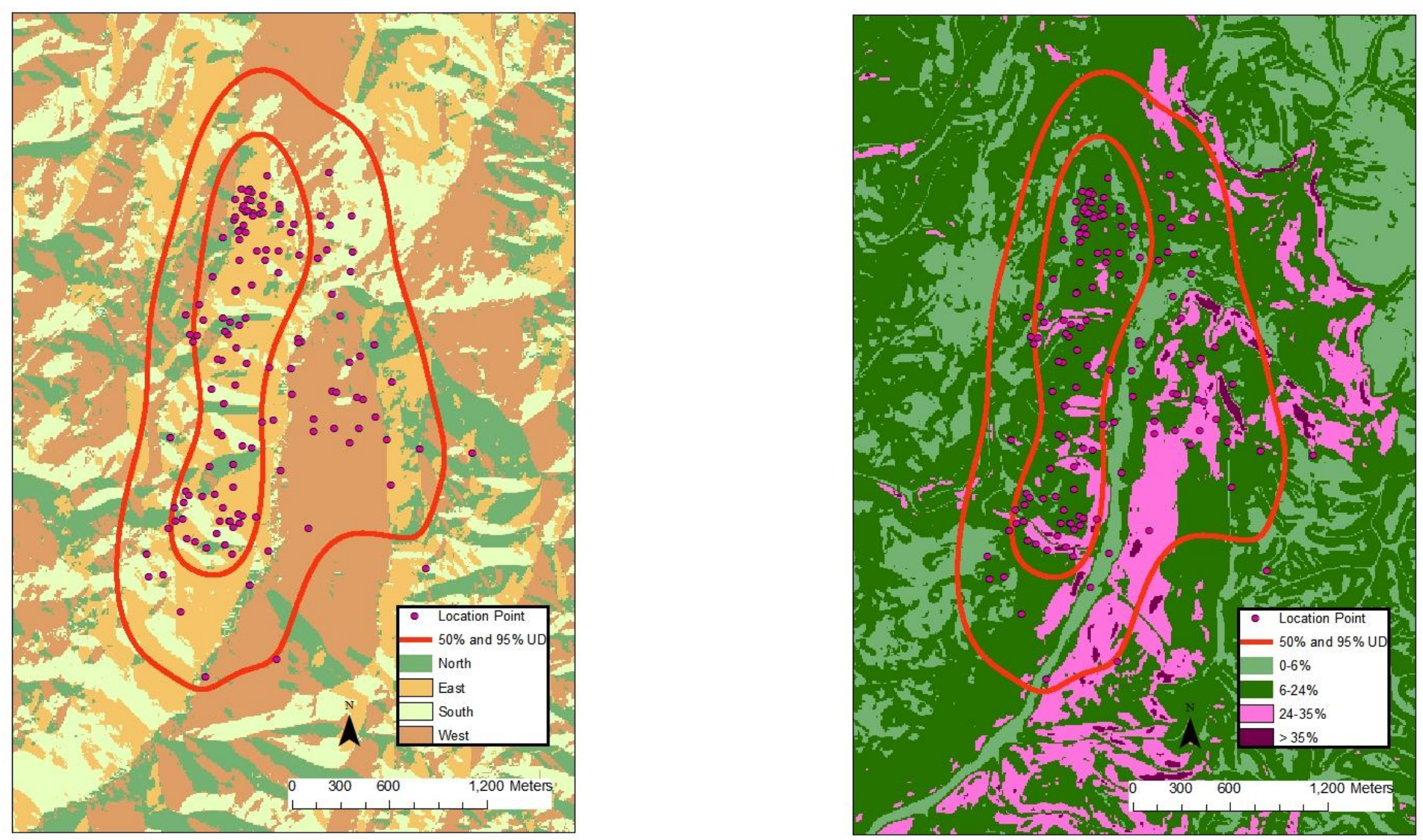
Appendix CLXXXVII a. 10113 (adult, fall) - 50\% core and 95\% periphery probability contours of the annual Gaussian fixed kernel home range utilization distributions. Smoothing parameter $(h)$ determined by least squares cross validation, Greenbrier County, West Virginia, 2004-2007 (land use and land cover, land fragmentation maps).
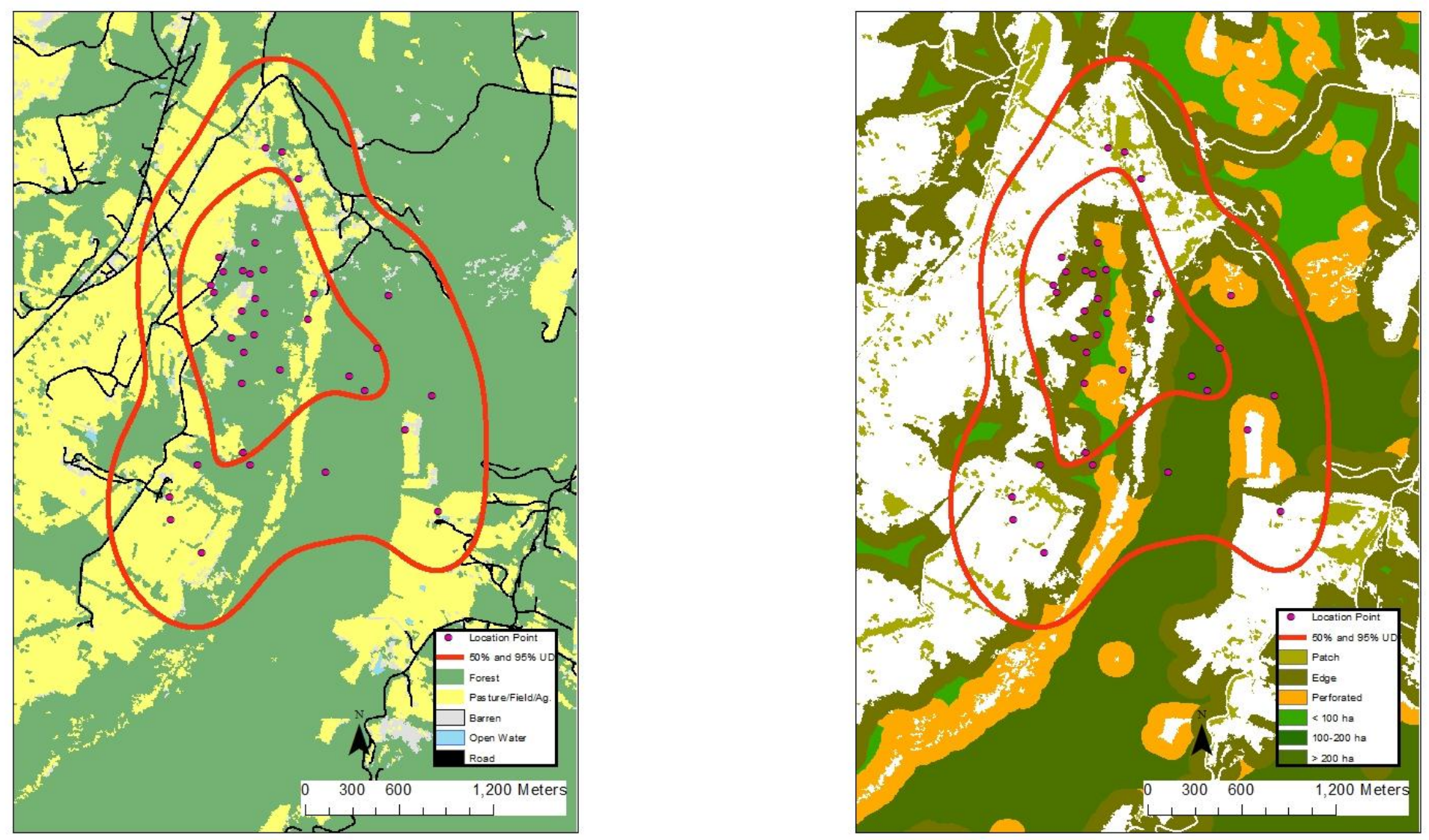
Appendix CLXXXVIIIa. 10113 (adult, fall) - 50\% core and 95\% periphery probability contours of the annual Gaussian fixed kernel home range utilization distributions. Smoothing parameter $(h)$ determined by least squares cross validation, Greenbrier County, West Virginia, 2004-2007 (aspect and slope maps).
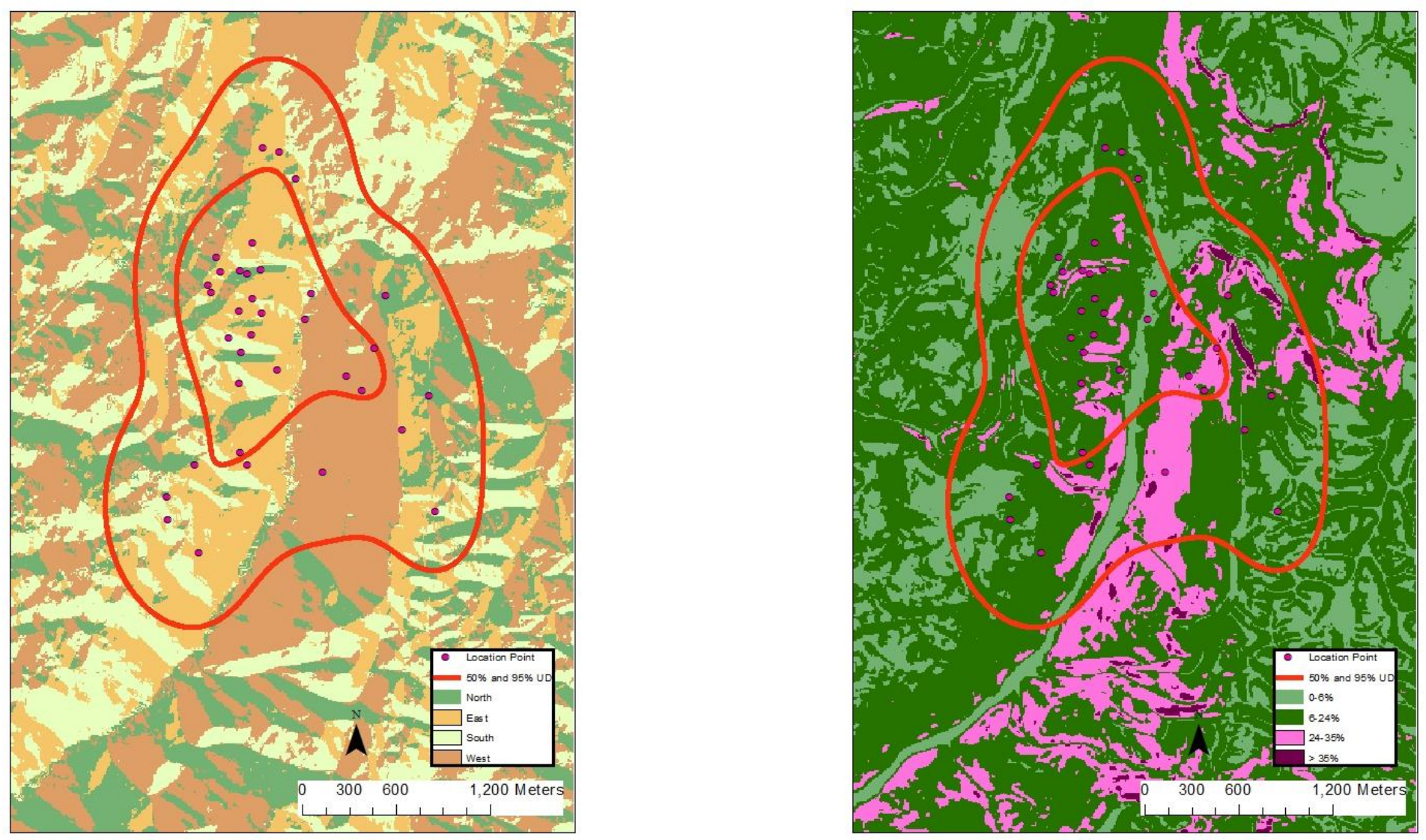
Appendix CLXXXIXa. 10114 (adult, fall-winter) - 50\% core and 95\% periphery probability contours of the annual Gaussian fixed kernel home range utilization distributions. Smoothing parameter $(h)$ determined by least squares cross validation, Greenbrier County, West Virginia, 2004-2007 (land use and land cover, land fragmentation maps).
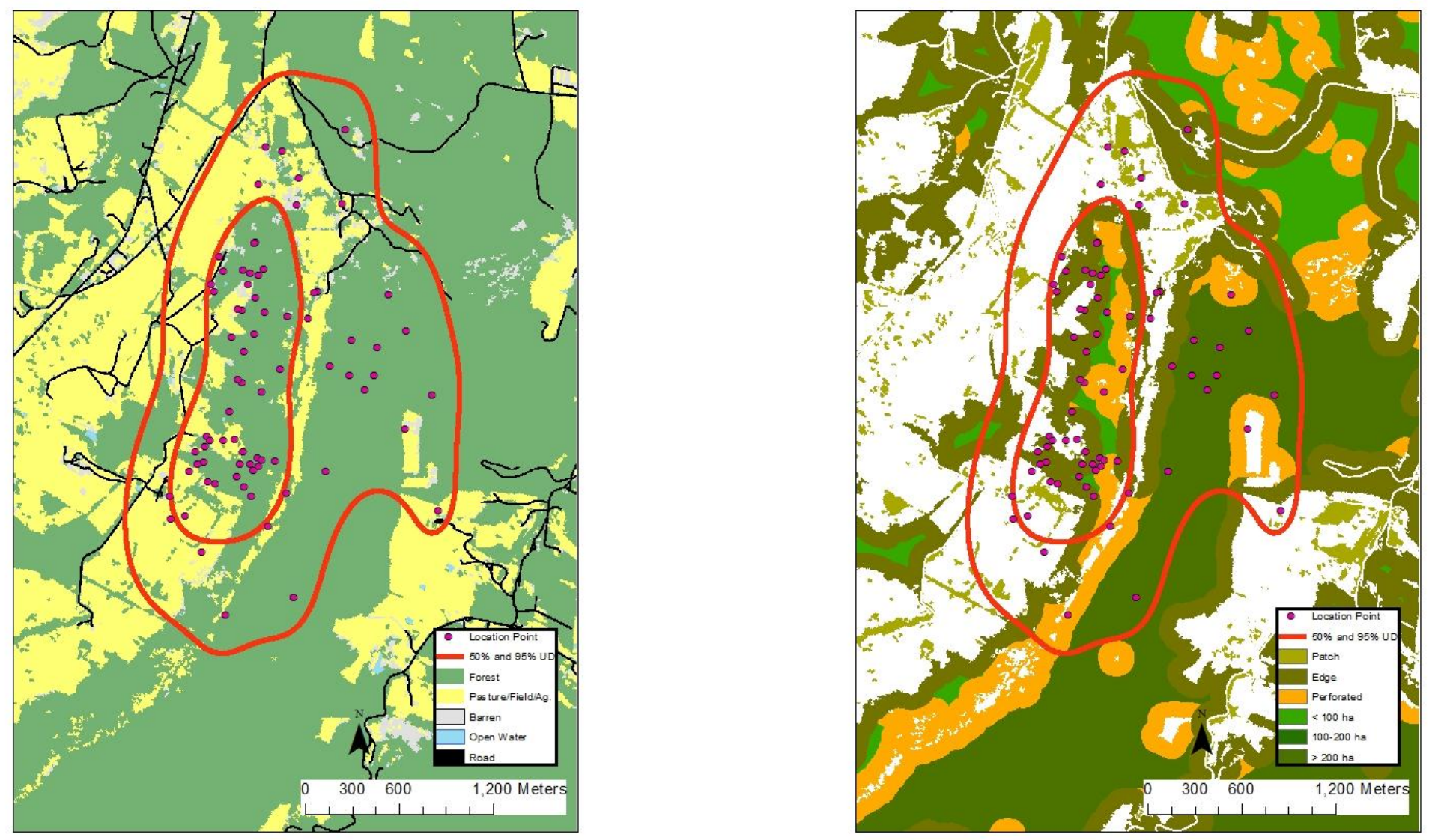
Appendix CXCa. 10114 (adult, fall-winter) - 50\% core and 95\% periphery probability contours of the annual Gaussian fixed kernel home range utilization distributions. Smoothing parameter $(h)$ determined by least squares cross validation, Greenbrier County, West Virginia, 2004-2007 (aspect and slope maps).
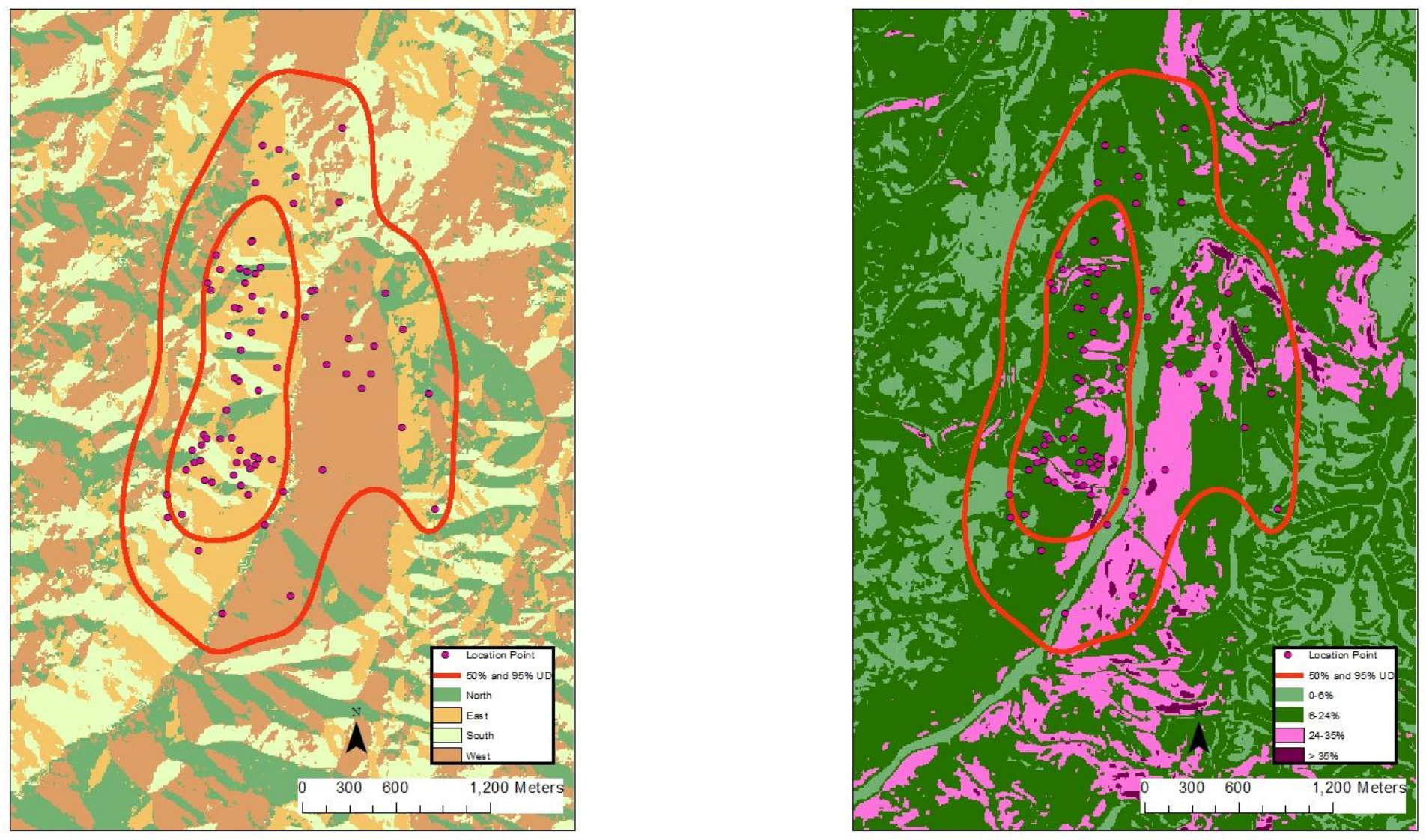
Appendix CXCIa. 10115 (adult, spring) - 50\% core and 95\% periphery probability contours of the annual Gaussian fixed kernel home range utilization distributions. Smoothing parameter $(h)$ determined by least squares cross validation, Greenbrier County, West Virginia, 2004-2007 (land use and land cover, land fragmentation maps).
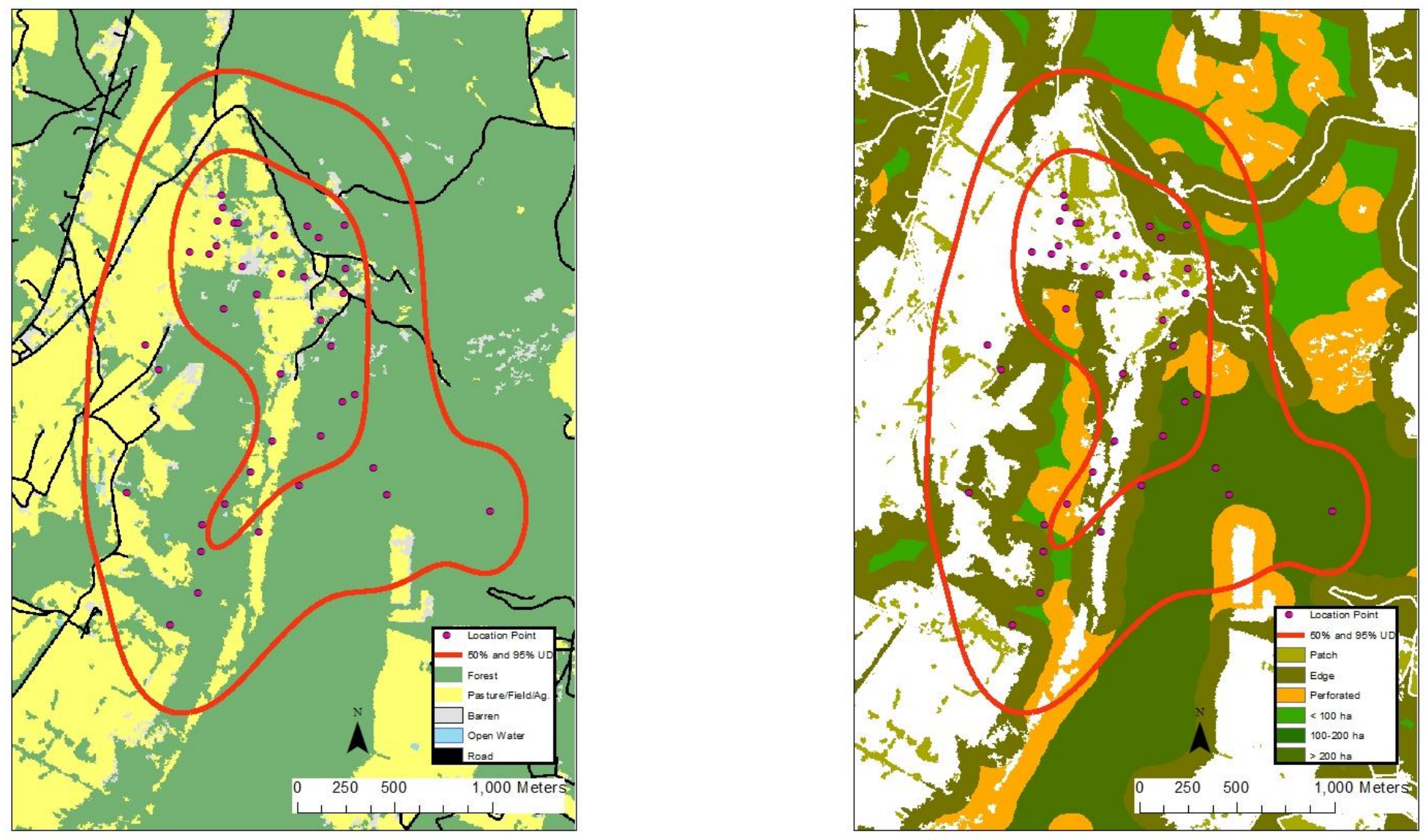
Appendix CXCIIa. 10115 (adult, spring) - 50\% core and 95\% periphery probability contours of the annual Gaussian fixed kernel home range utilization distributions. Smoothing parameter $(h)$ determined by least squares cross validation, Greenbrier County, West Virginia, 2004-2007 (aspect and slope maps).
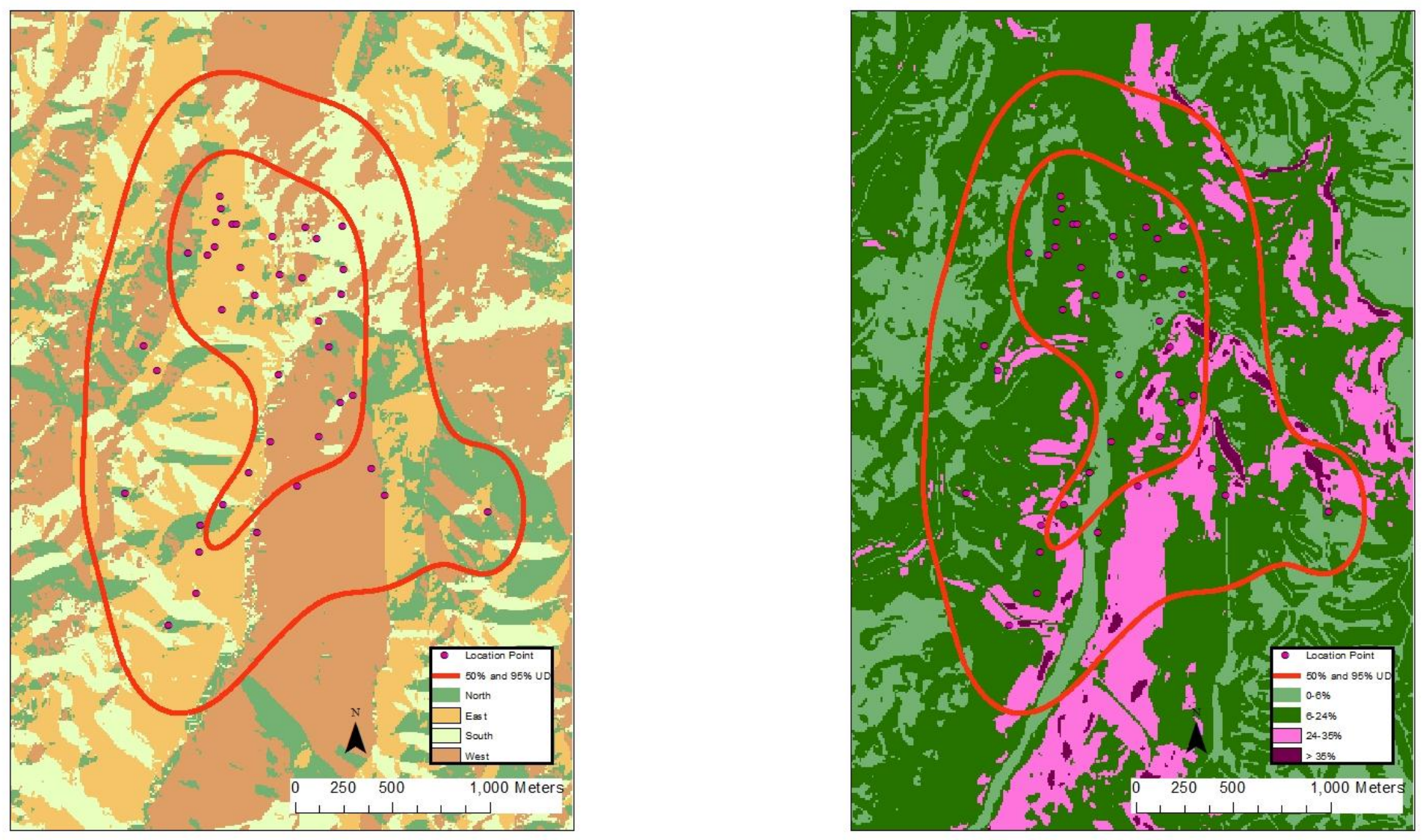
Appendix CXCIIIa. 10116 (adult, spring-summer) - 50\% core and 95\% periphery probability contours of the annual Gaussian fixed kernel home range utilization distributions. Smoothing parameter $(h)$ determined by least squares cross validation, Greenbrier County, West Virginia, 2004-2007 (land use and land cover, land fragmentation maps).
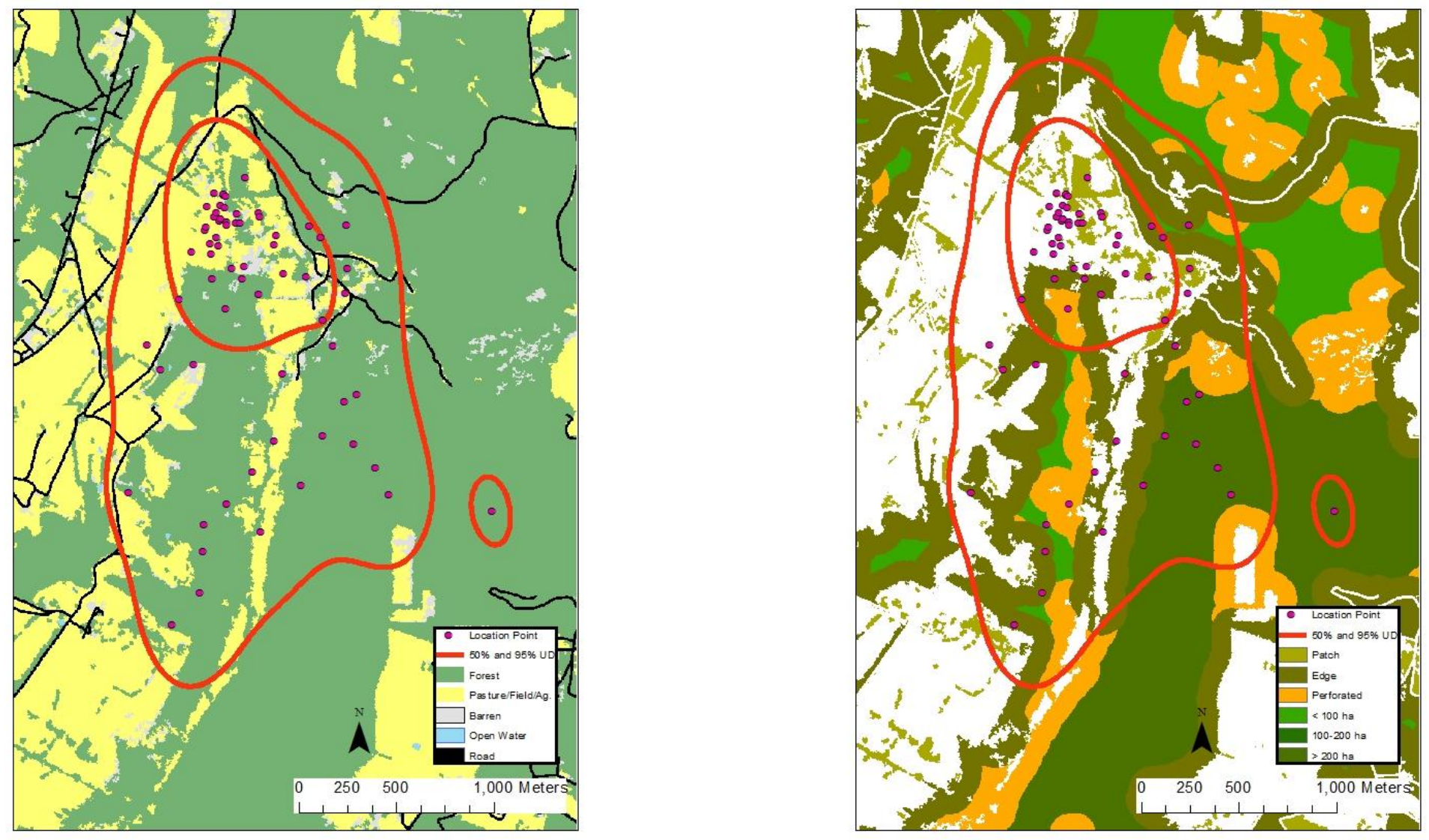
Appendix CXCIVa. 10116 (adult, spring-summer) - 50\% core and 95\% periphery probability contours of the annual Gaussian fixed kernel home range utilization distributions. Smoothing parameter $(h)$ determined by least squares cross validation, Greenbrier County, West Virginia, 2004-2007 (aspect and slope maps).
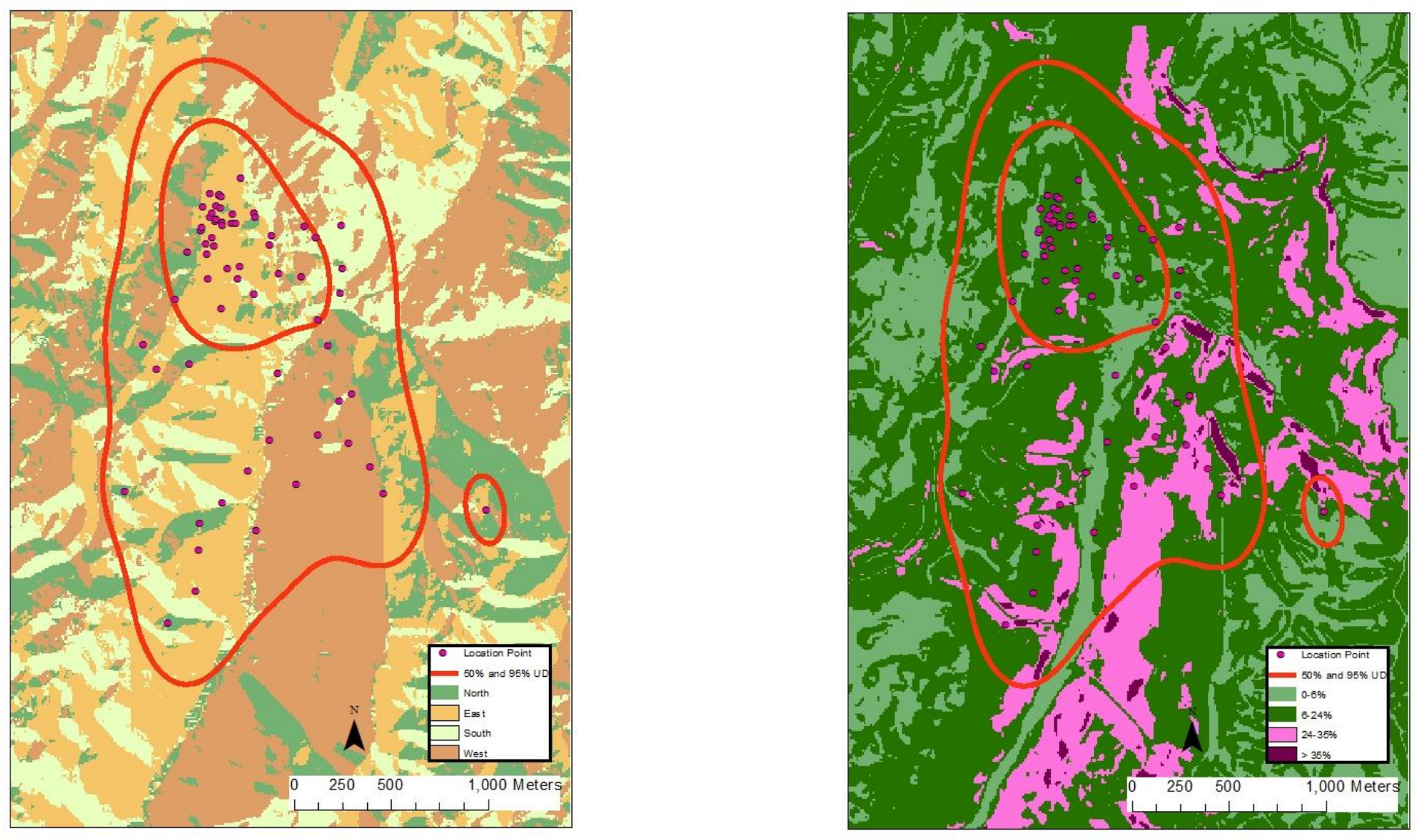
Appendix CXCVa. 10117 (adult, winter) - 50\% core and 95\% periphery probability contours of the annual Gaussian fixed kernel home range utilization distributions. Smoothing parameter $(h)$ determined by least squares cross validation, Greenbrier County, West Virginia, 2004-2007 (land use and land cover, land fragmentation maps).
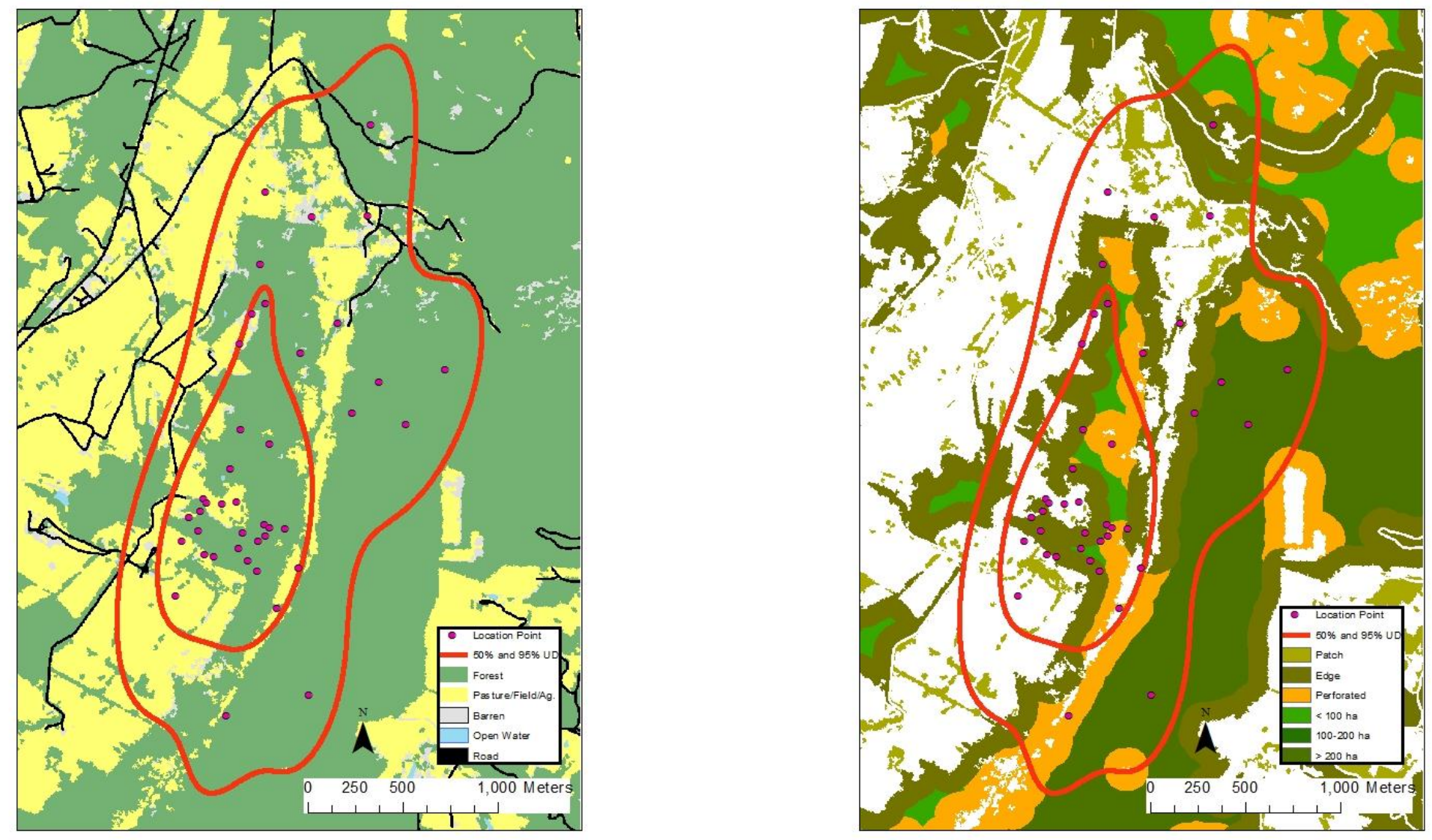
Appendix CXCVIa. 10117 (adult, winter) - 50\% core and 95\% periphery probability contours of the annual Gaussian fixed kernel home range utilization distributions. Smoothing parameter $(h)$ determined by least squares cross validation, Greenbrier County, West Virginia, 2004-2007 (aspect and slope maps).
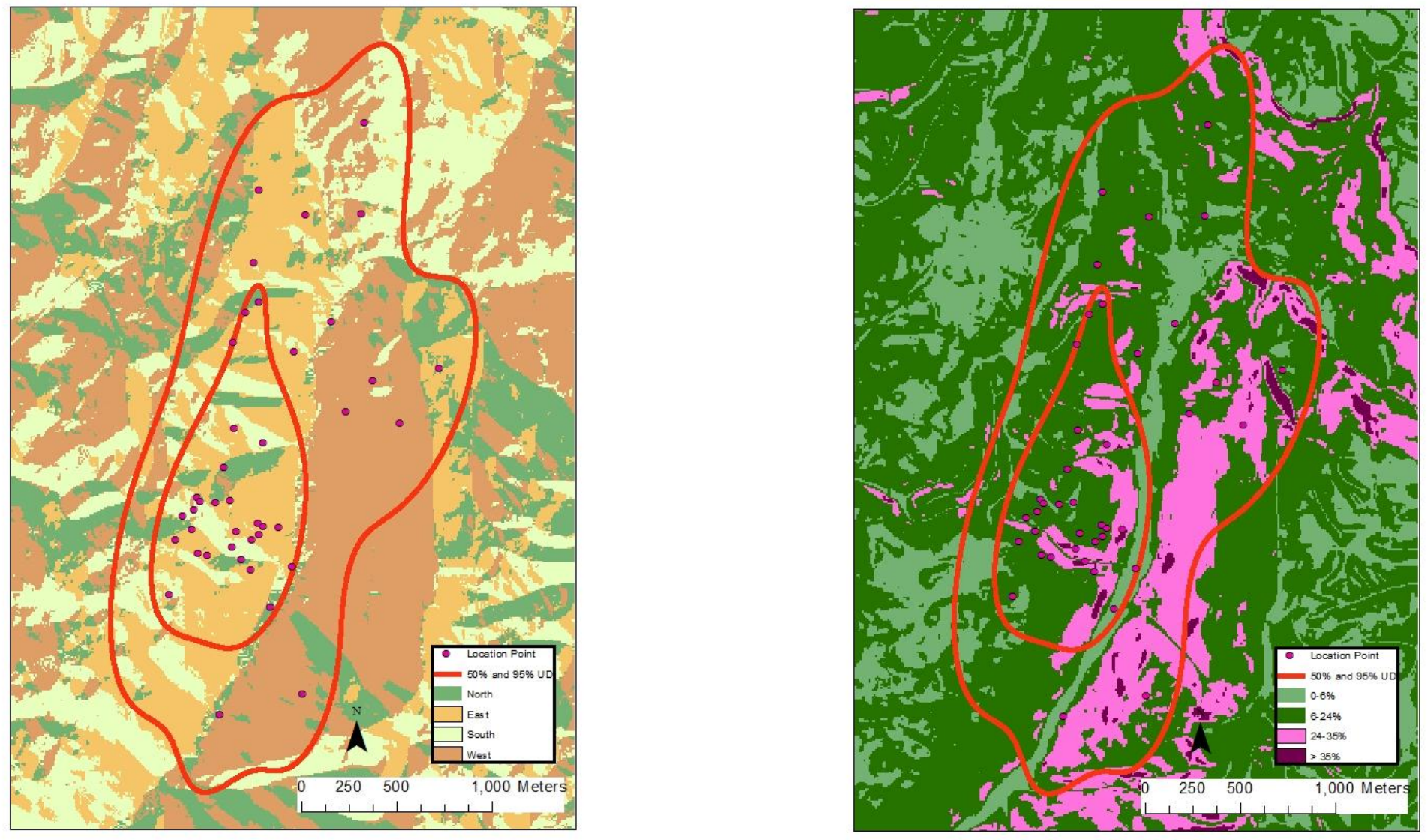
Appendix CXCVIIa. 10118 (adult, annual) - 50\% core and 95\% periphery probability contours of the annual Gaussian fixed kernel home range utilization distributions. Smoothing parameter $(h)$ determined by least squares cross validation, Greenbrier County, West Virginia, 2004-2007 (land use and land cover, land fragmentation maps).
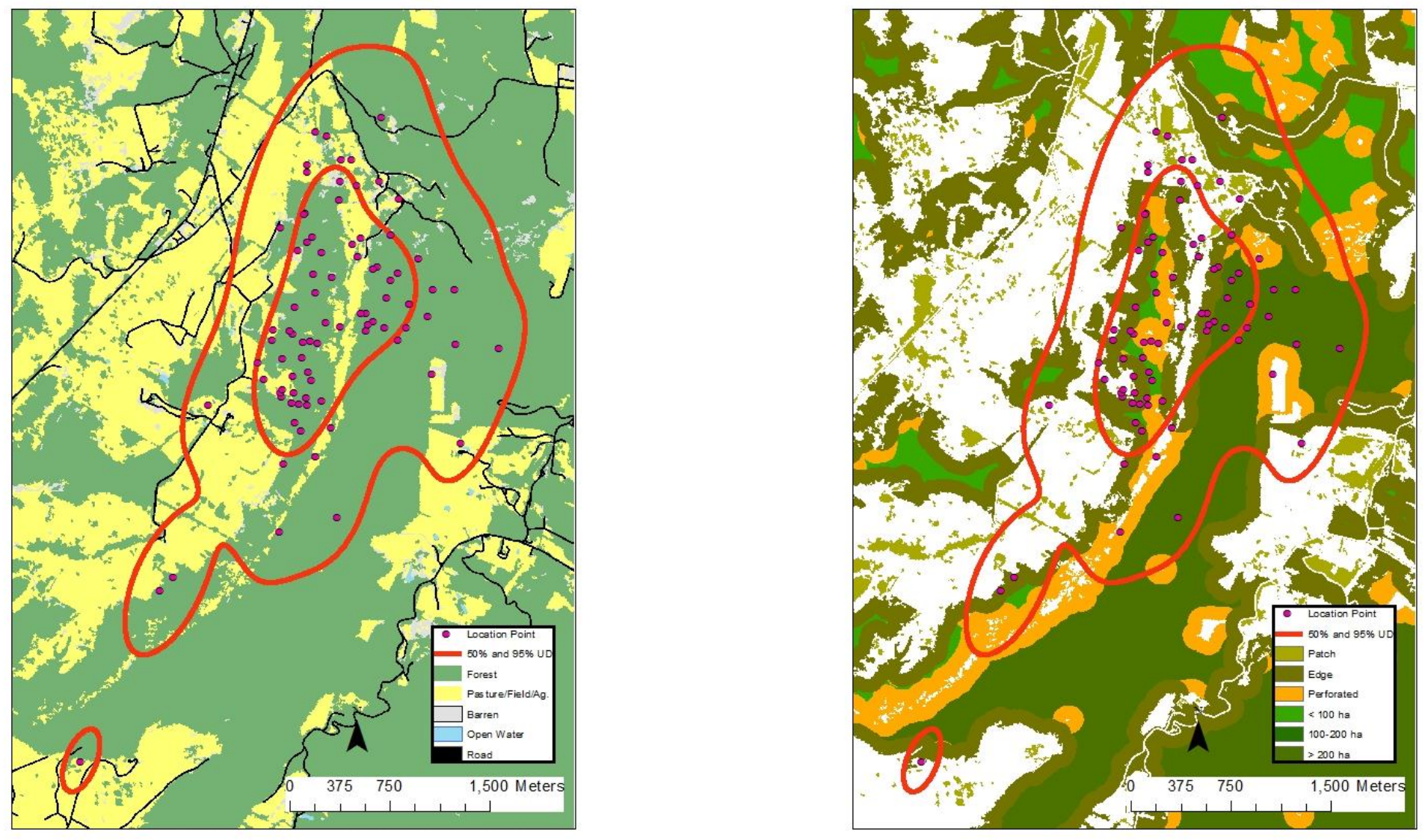
Appendix CXCVIII a. 10118 (adult, annual) - 50\% core and 95\% periphery probability contours of the annual Gaussian fixed kernel home range utilization distributions. Smoothing parameter $(h)$ determined by least squares cross validation, Greenbrier County, West Virginia, 2004-2007 (aspect and slope maps).
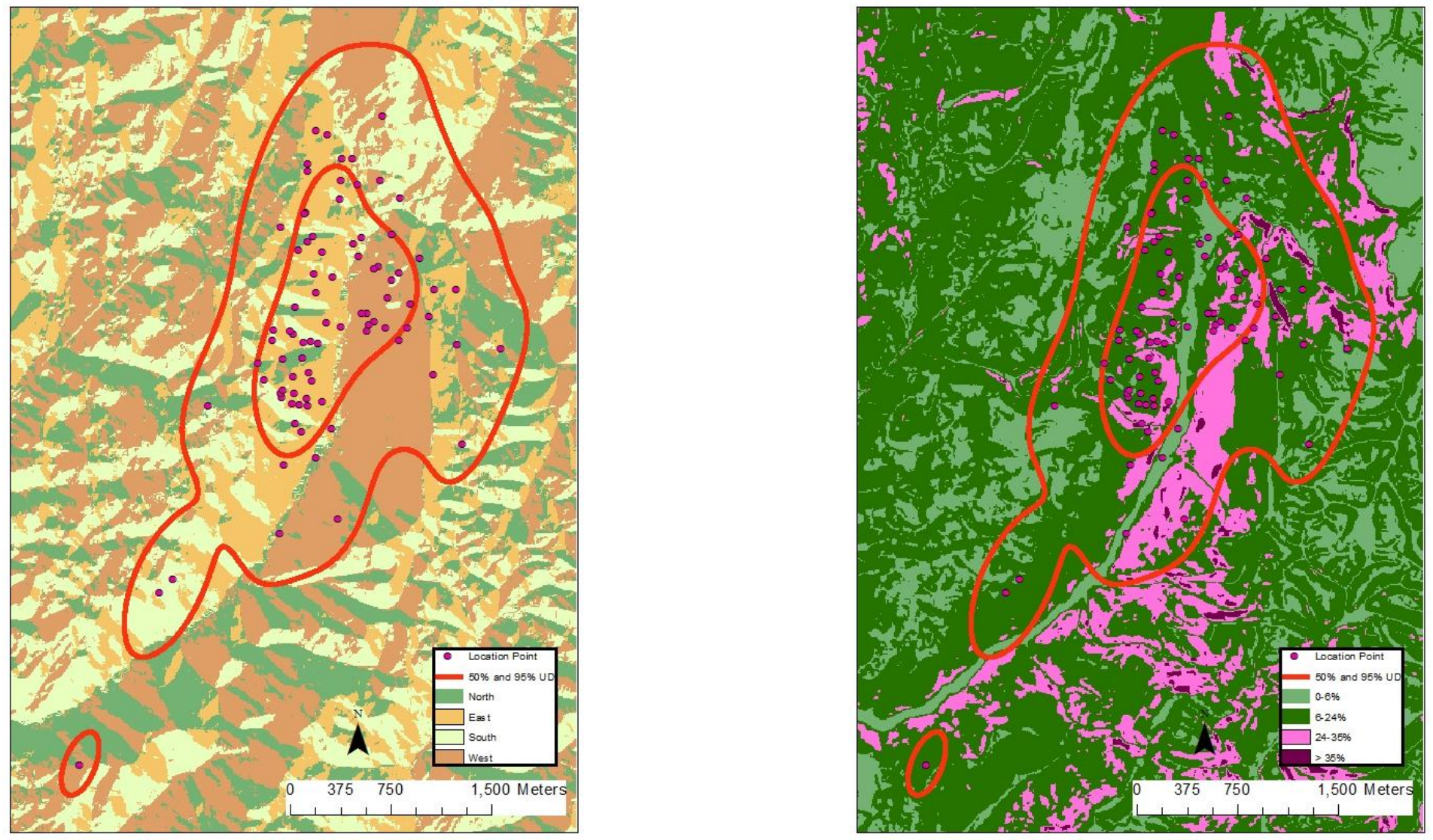
Appendix CXCIXa. 10119 (adult, fall-winter) - 50\% core and 95\% periphery probability contours of the annual Gaussian fixed kernel home range utilization distributions. Smoothing parameter $(h)$ determined by least squares cross validation, Greenbrier County, West Virginia, 2004-2007 (land use and land cover, land fragmentation maps).
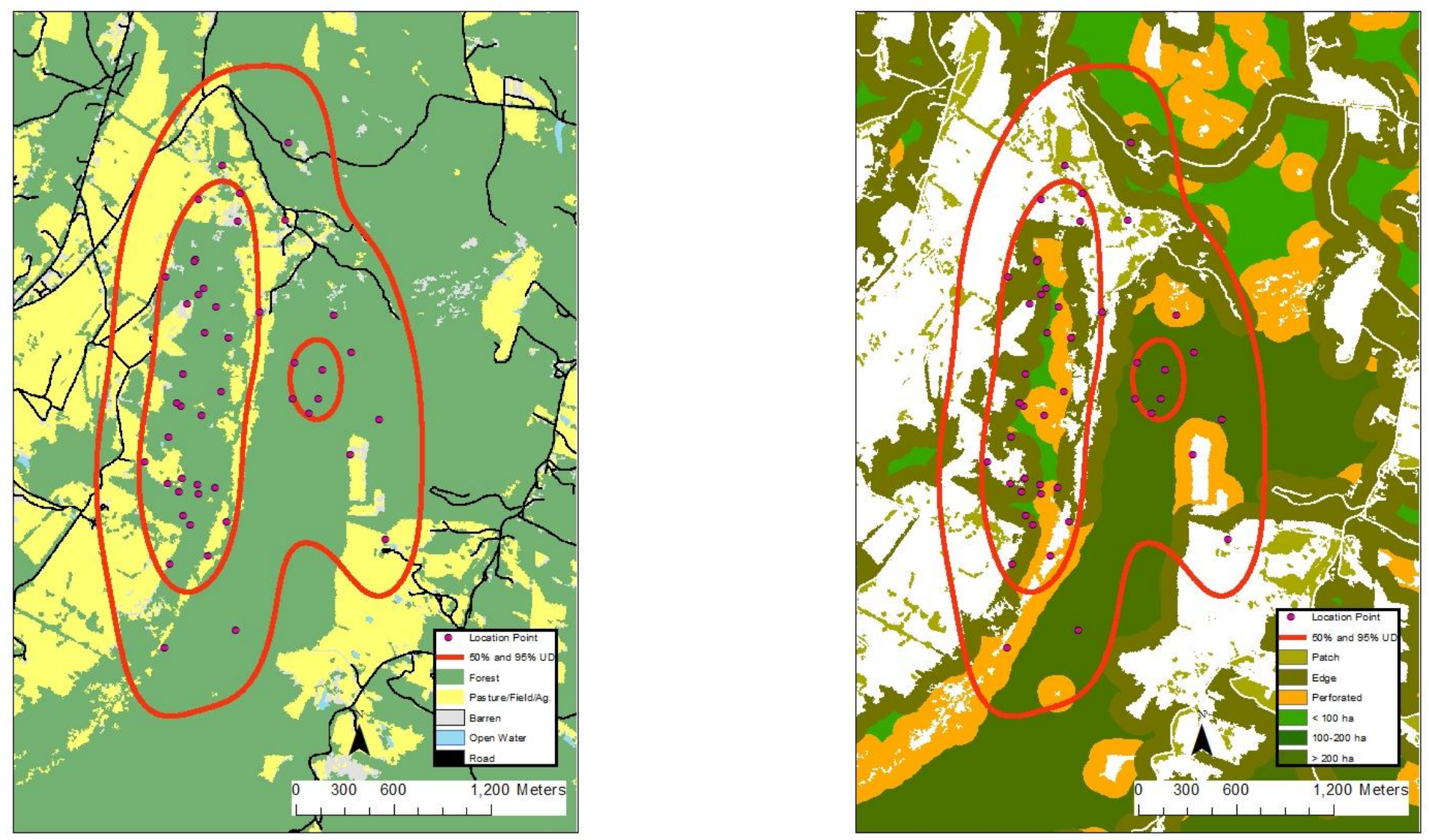
Appendix CCa. 10119 (adult, fall-winter) - 50\% core and 95\% periphery probability contours of the annual Gaussian fixed kernel home range utilization distributions. Smoothing parameter $(h)$ determined by least squares cross validation, Greenbrier County, West Virginia, 2004-2007 (aspect and slope maps).
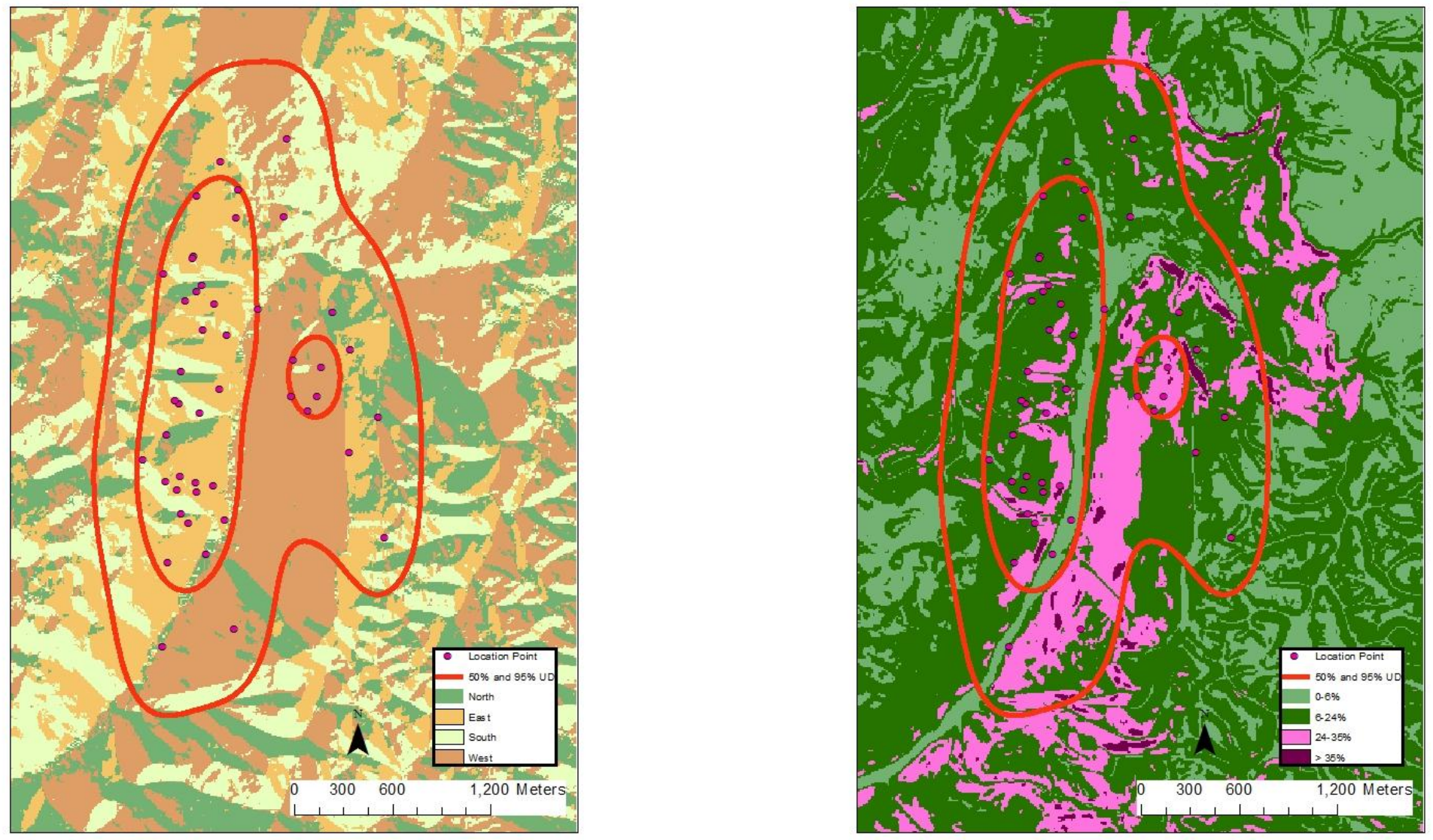
Appendix CCIa. 10120 (adult, spring-summer) - 50\% core and 95\% periphery probability contours of the annual Gaussian fixed kernel home range utilization distributions. Smoothing parameter $(h)$ determined by least squares cross validation, Greenbrier County, West Virginia, 2004-2007 (land use and land cover, land fragmentation maps).
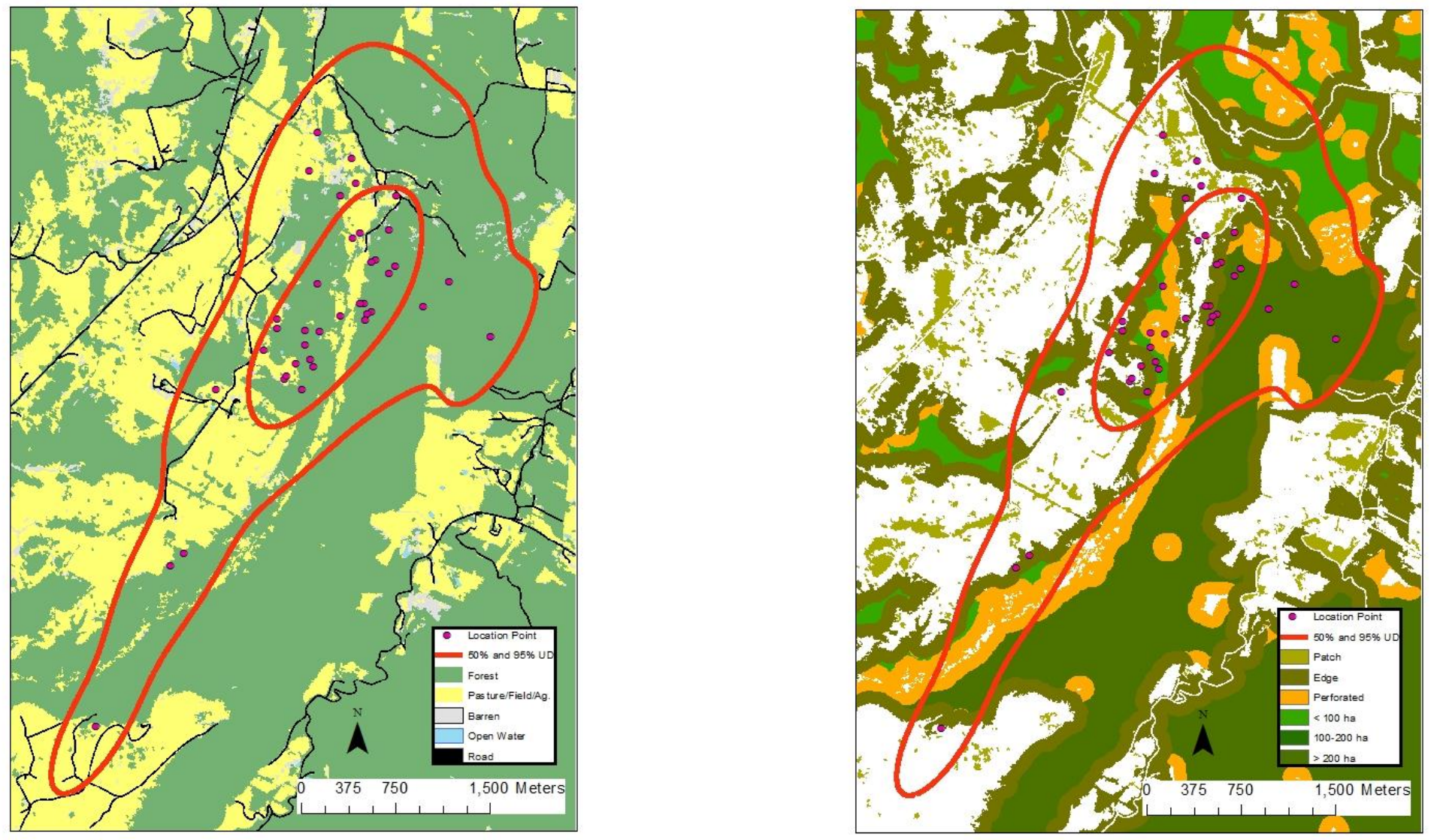
Appendix CCIIa. 10120 (adult, spring-summer) - 50\% core and 95\% periphery probability contours of the annual Gaussian fixed kernel home range utilization distributions. Smoothing parameter $(h)$ determined by least squares cross validation, Greenbrier County, West Virginia, 2004-2007 (aspect and slope maps).
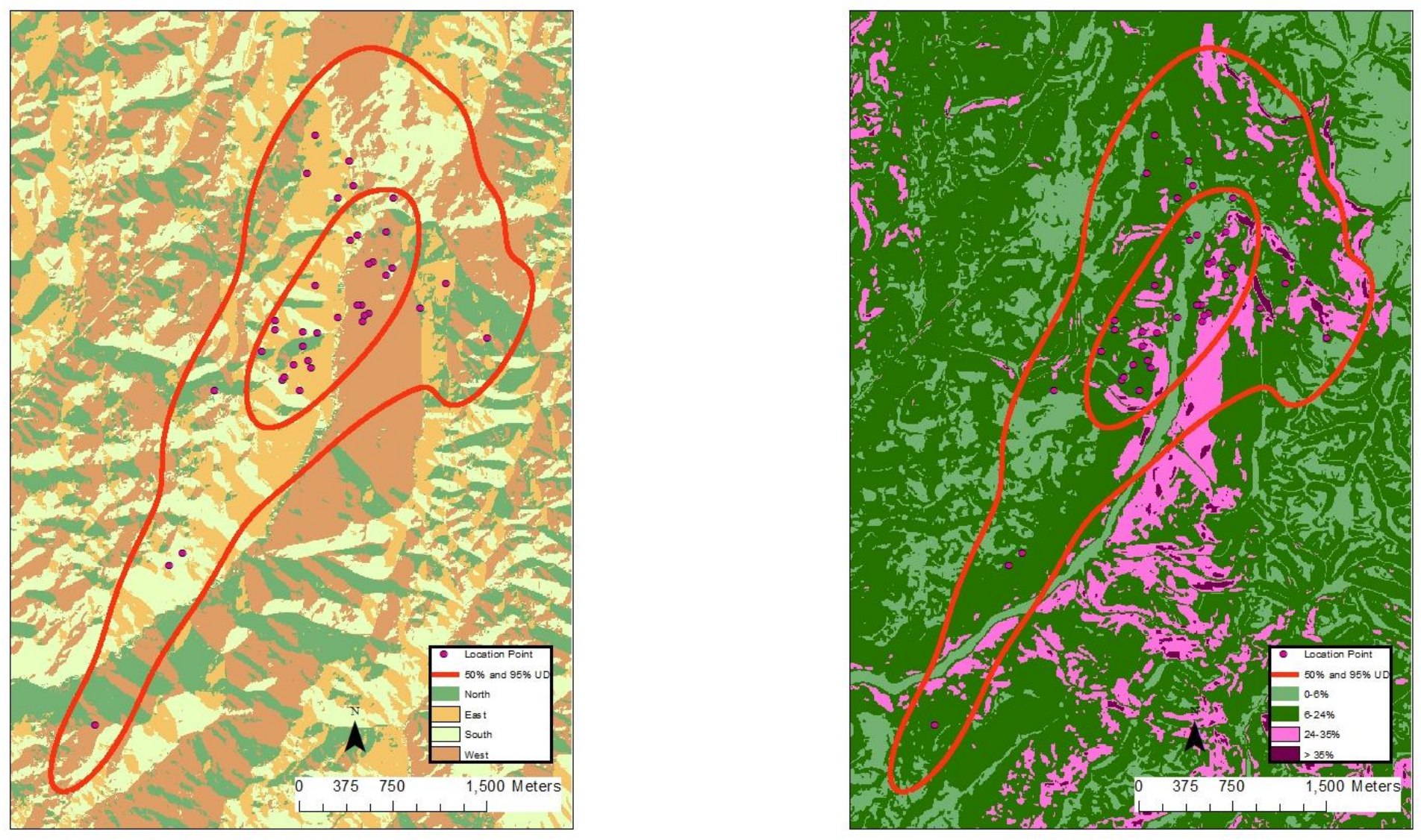
Appendix CCIII $a .10121$ (adult, annual) - 50\% core and 95\% periphery probability contours of the annual Gaussian fixed kernel home range utilization distributions. Smoothing parameter $(h)$ determined by least squares cross validation, Greenbrier County, West Virginia, 2004-2007 (land use and land cover, land fragmentation maps).
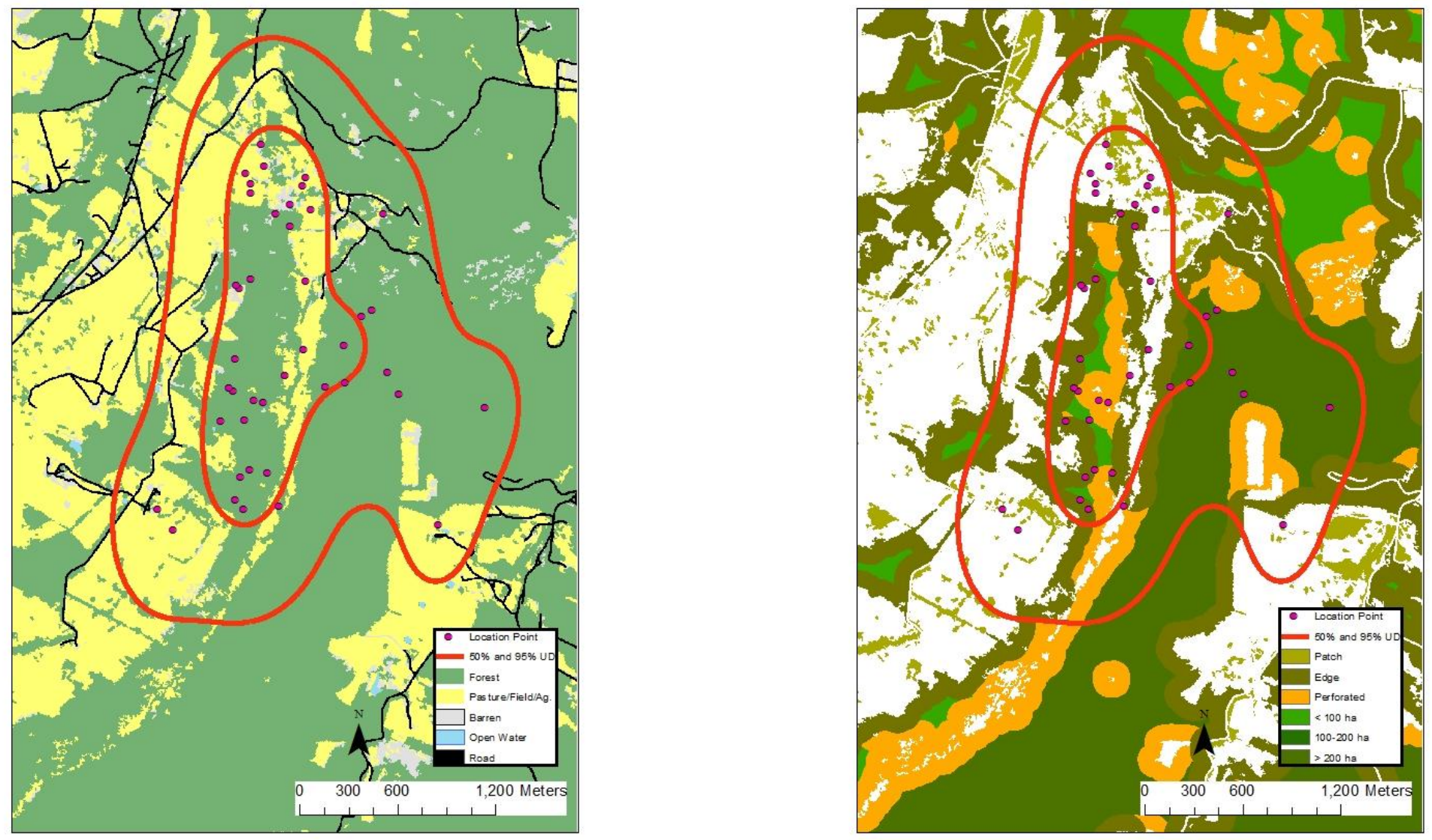
Appendix CCIVa. 10121 (adult, annual) - 50\% core and 95\% periphery probability contours of the annual Gaussian fixed kernel home range utilization distributions. Smoothing parameter $(h)$ determined by least squares cross validation, Greenbrier County, West Virginia, 2004-2007 (aspect and slope maps).
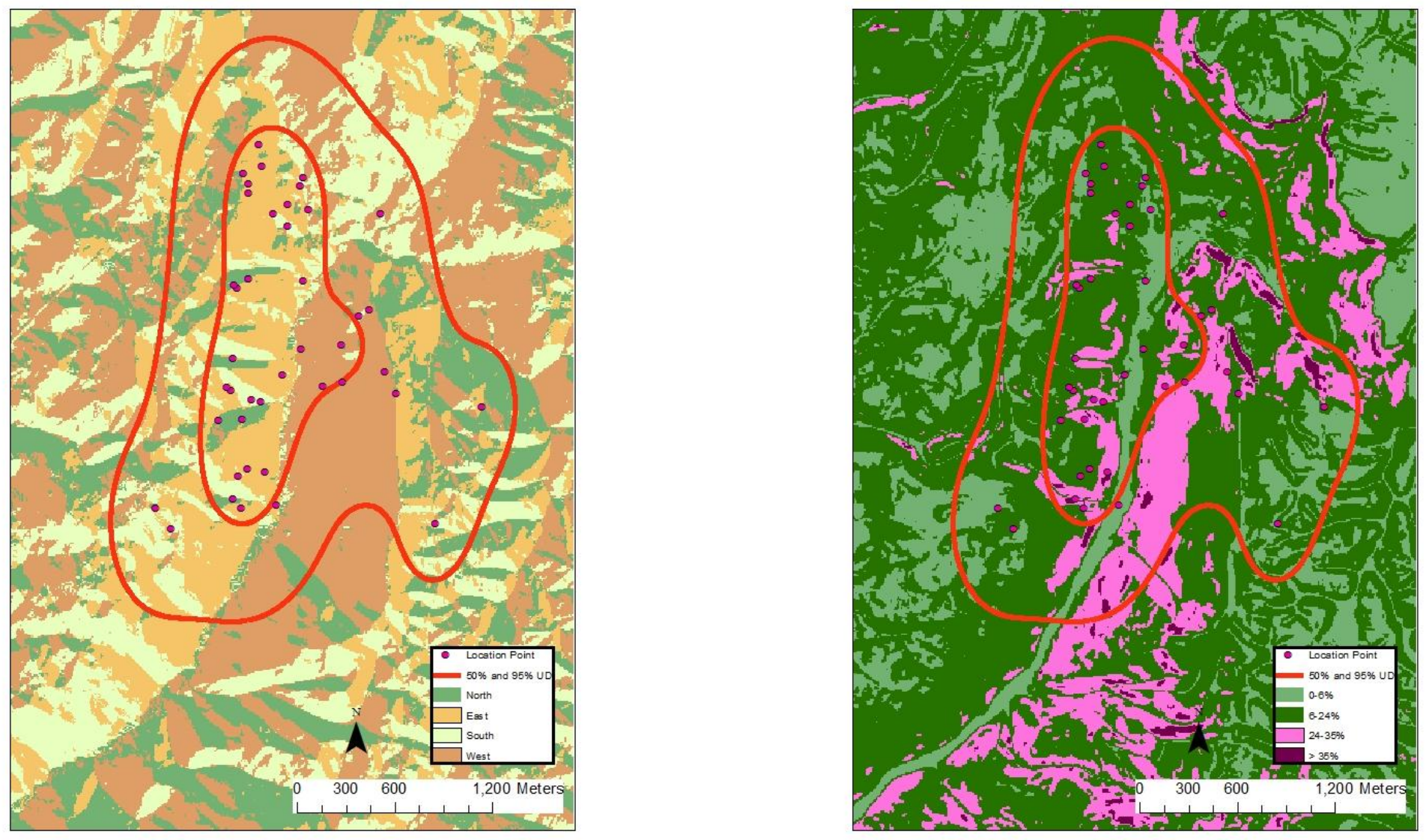
Appendix CCVa. 10122 (juvenile, annual) - 50\% core and 95\% periphery probability contours of the annual Gaussian fixed kernel home range utilization distributions. Smoothing parameter $(h)$ determined by least squares cross validation, Summers County, West Virginia, 2004-2007 (land use and land cover, land fragmentation maps).
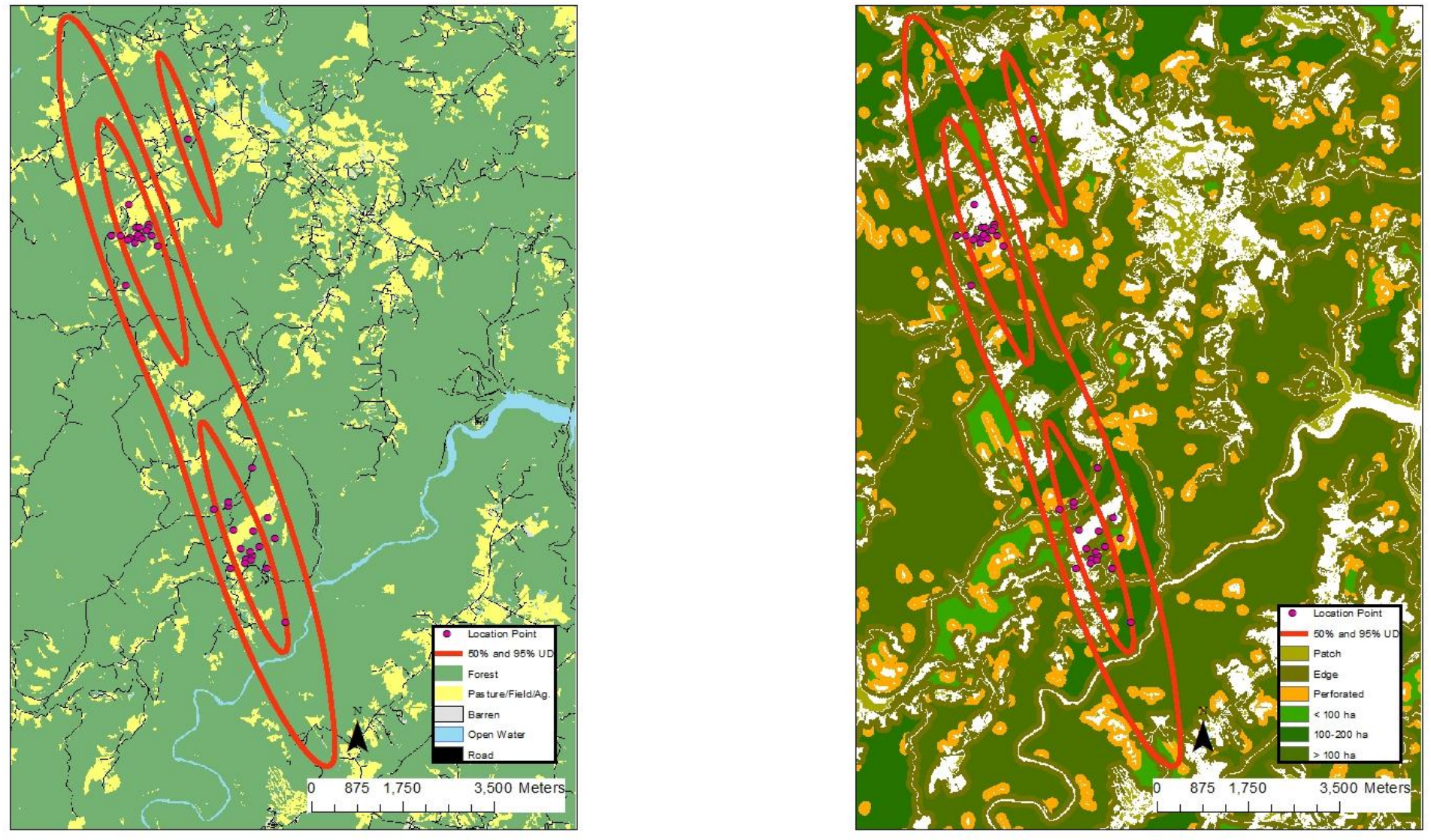
Appendix CCVIa. 10122 (juvenile, annual) - 50\% core and 95\% periphery probability contours of the annual Gaussian fixed kernel home range utilization distributions. Smoothing parameter $(h)$ determined by least squares cross validation, Summers County, West Virginia, 2004-2007 (aspect and slope maps).
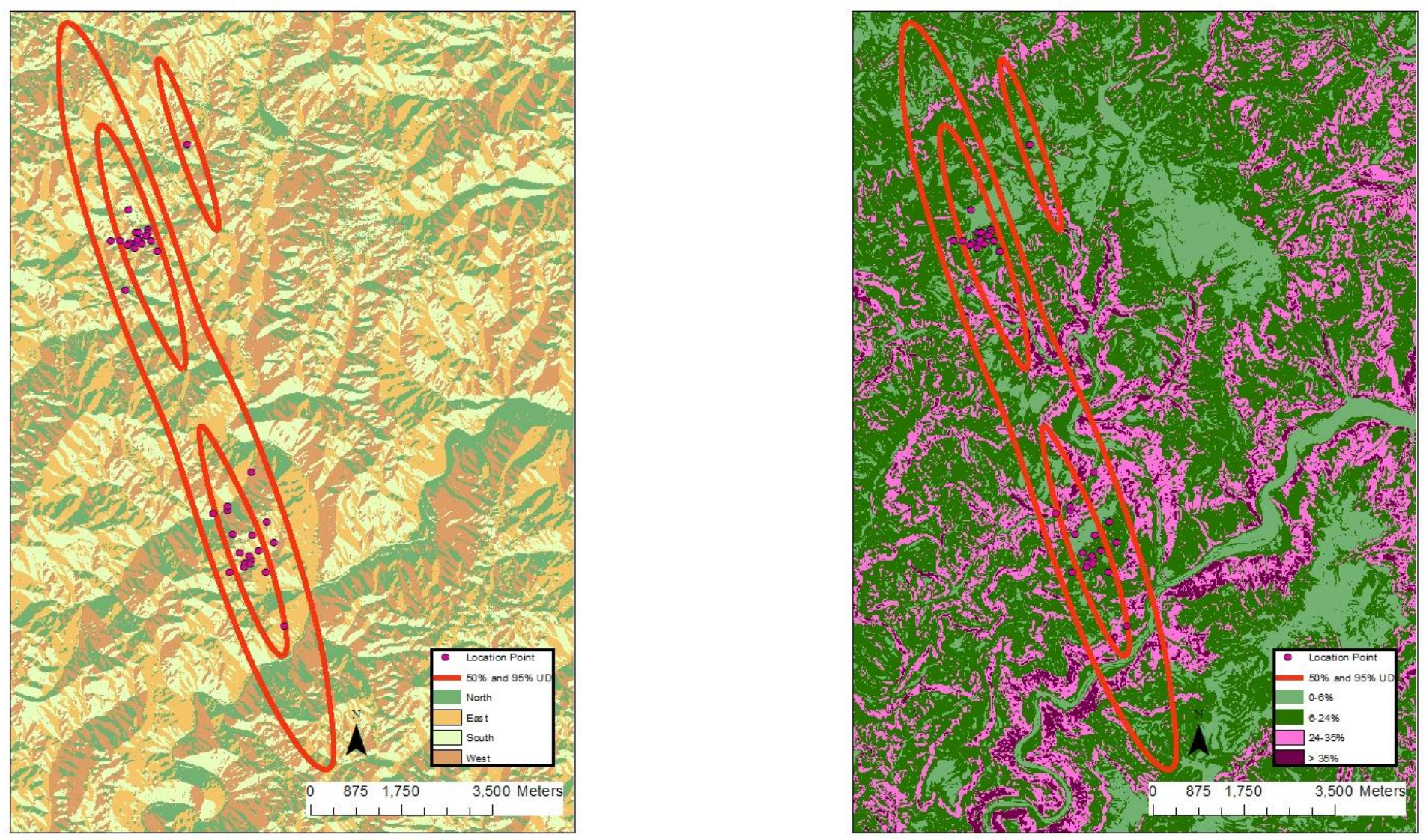
Appendix CCVII a. 10123 (adult, spring-summer) - 50\% core and 95\% periphery probability contours of the annual Gaussian fixed kernel home range utilization distributions. Smoothing parameter $(h)$ determined by least squares cross validation, Summers County, West Virginia, 2004-2007 (land use and land cover, land fragmentation maps).
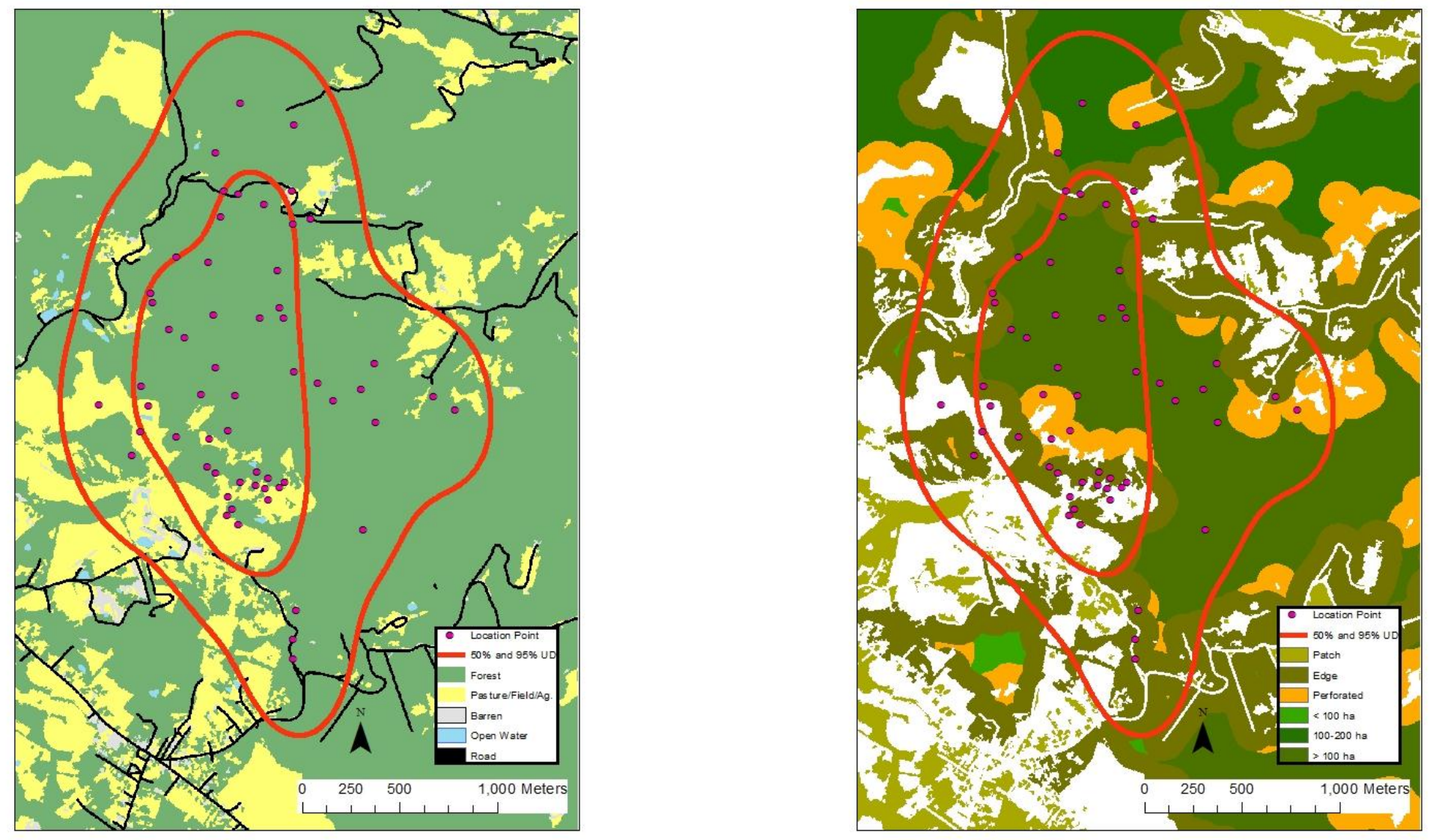
Appendix CCVIIIa. 10123 (adult, spring-summer) - 50\% core and 95\% periphery probability contours of the annual Gaussian fixed kernel home range utilization distributions. Smoothing parameter $(h)$ determined by least squares cross validation, Summers County, West Virginia, 2004-2007 (aspect and slope maps).
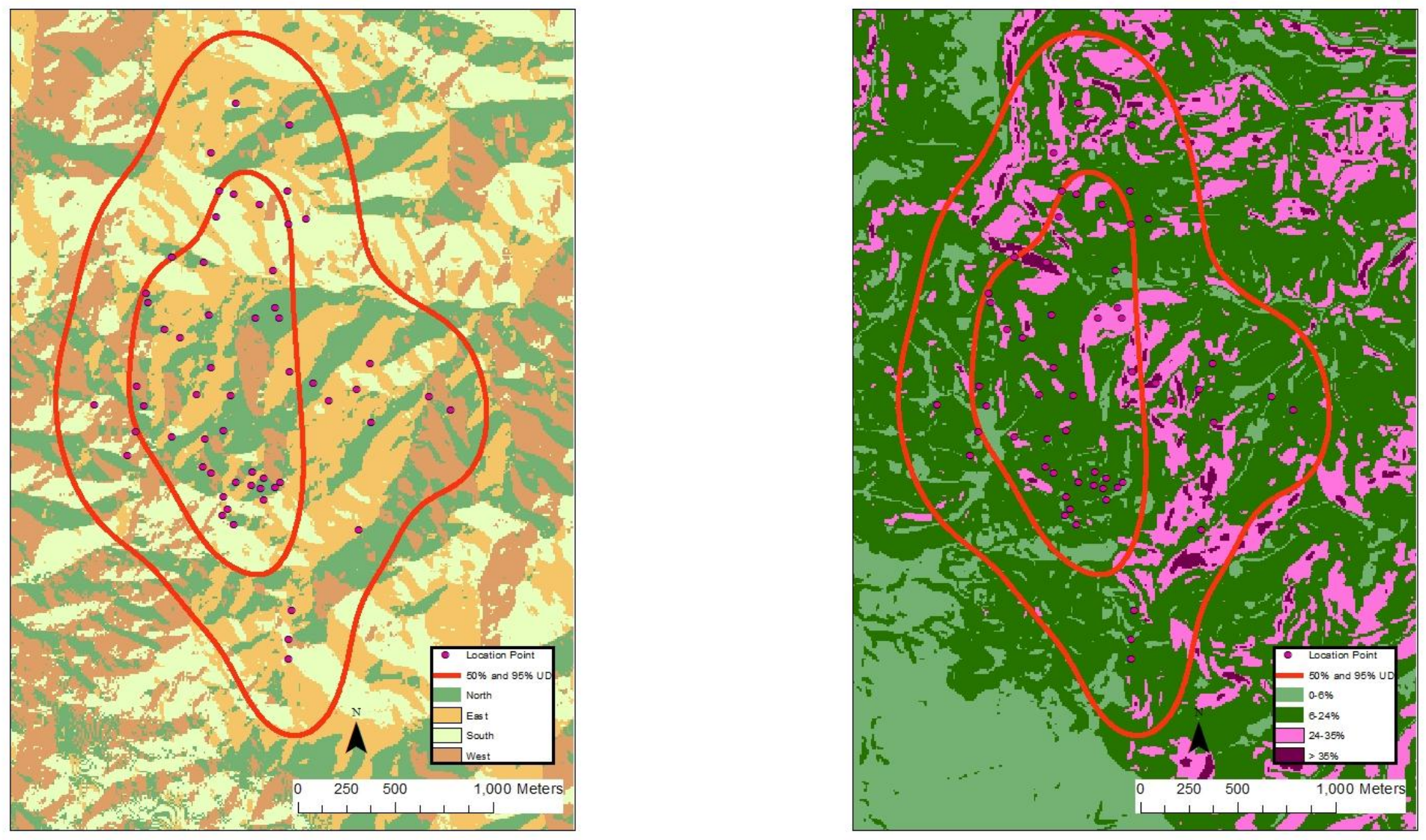
Appendix CCIXa. 10124 (adult, fall-winter) - 50\% core and 95\% periphery probability contours of the annual Gaussian fixed kernel home range utilization distributions. Smoothing parameter $(h)$ determined by least squares cross validation, Summers County, West Virginia, 2004-2007 (land use and land cover, land fragmentation maps).
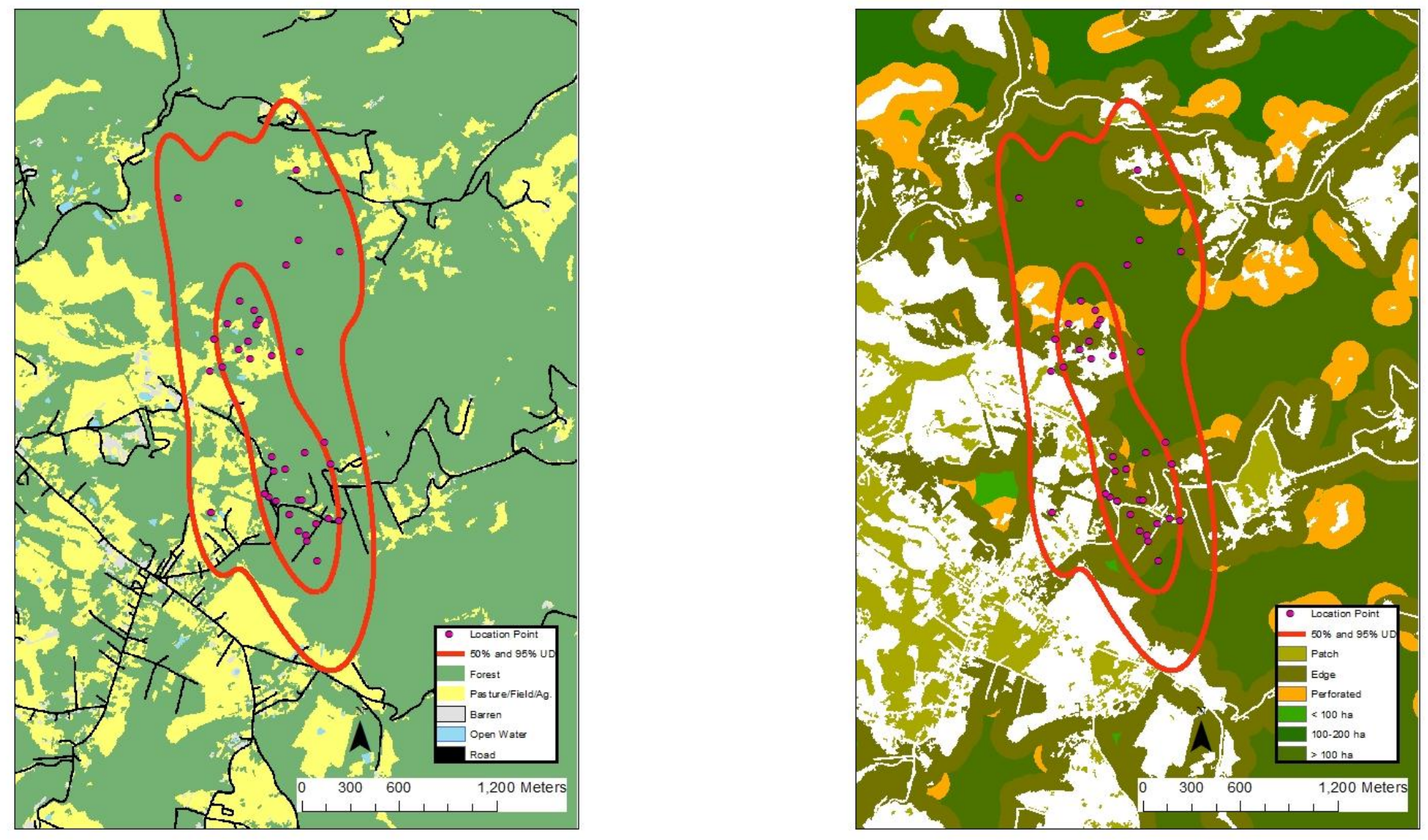
Appendix CCXa. 10124 (adult, fall-winter) - 50\% core and 95\% periphery probability contours of the annual Gaussian fixed kernel home range utilization distributions. Smoothing parameter $(h)$ determined by least squares cross validation, Summers County, West Virginia, 2004-2007 (aspect and slope maps).
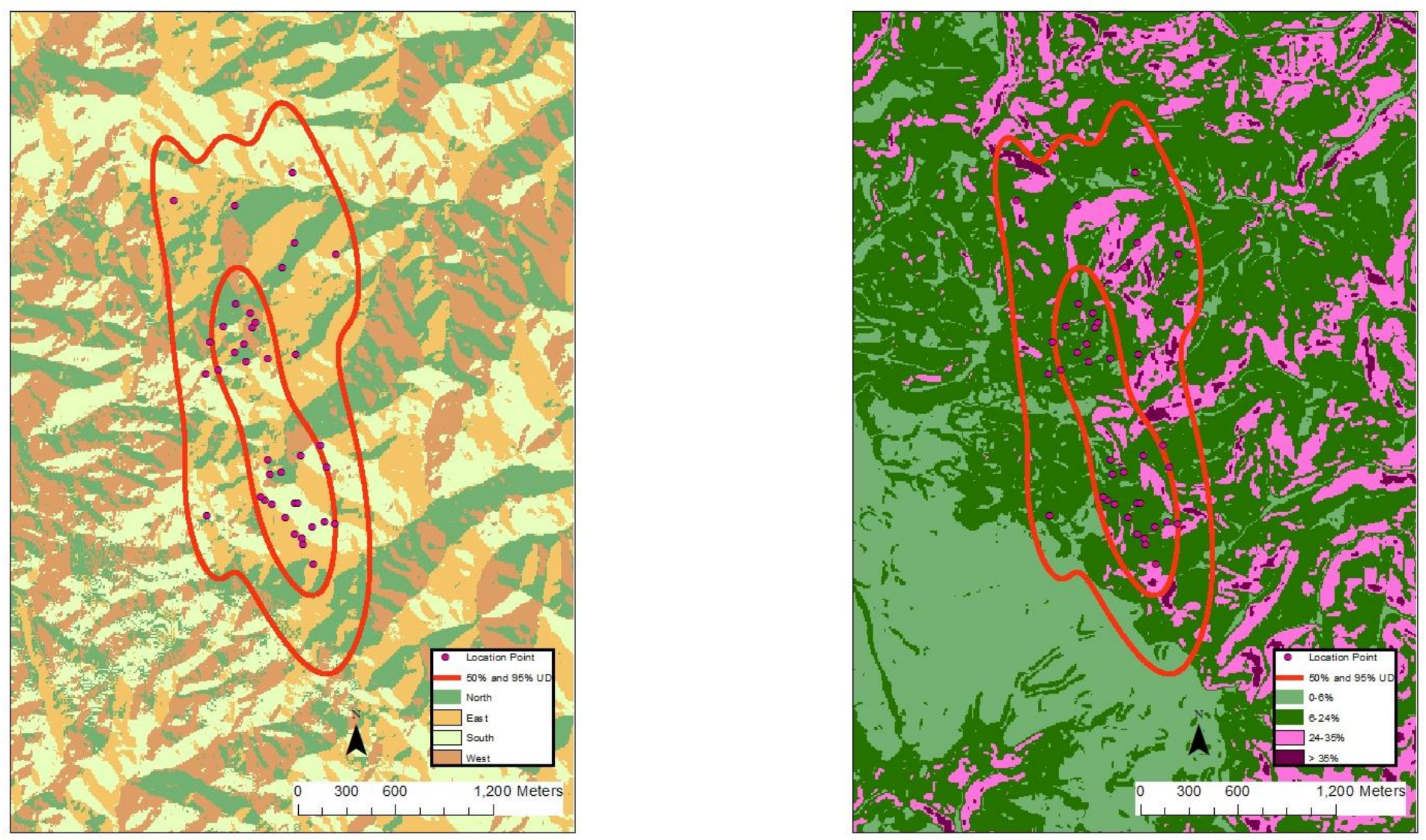
Appendix CCXI $a .10125$ (adult, annual) - 50\% core and 95\% periphery probability contours of the annual Gaussian fixed kernel home range utilization distributions. Smoothing parameter $(h)$ determined by least squares cross validation, Summers County, West Virginia, 2004-2007 (land use and land cover, land fragmentation maps).
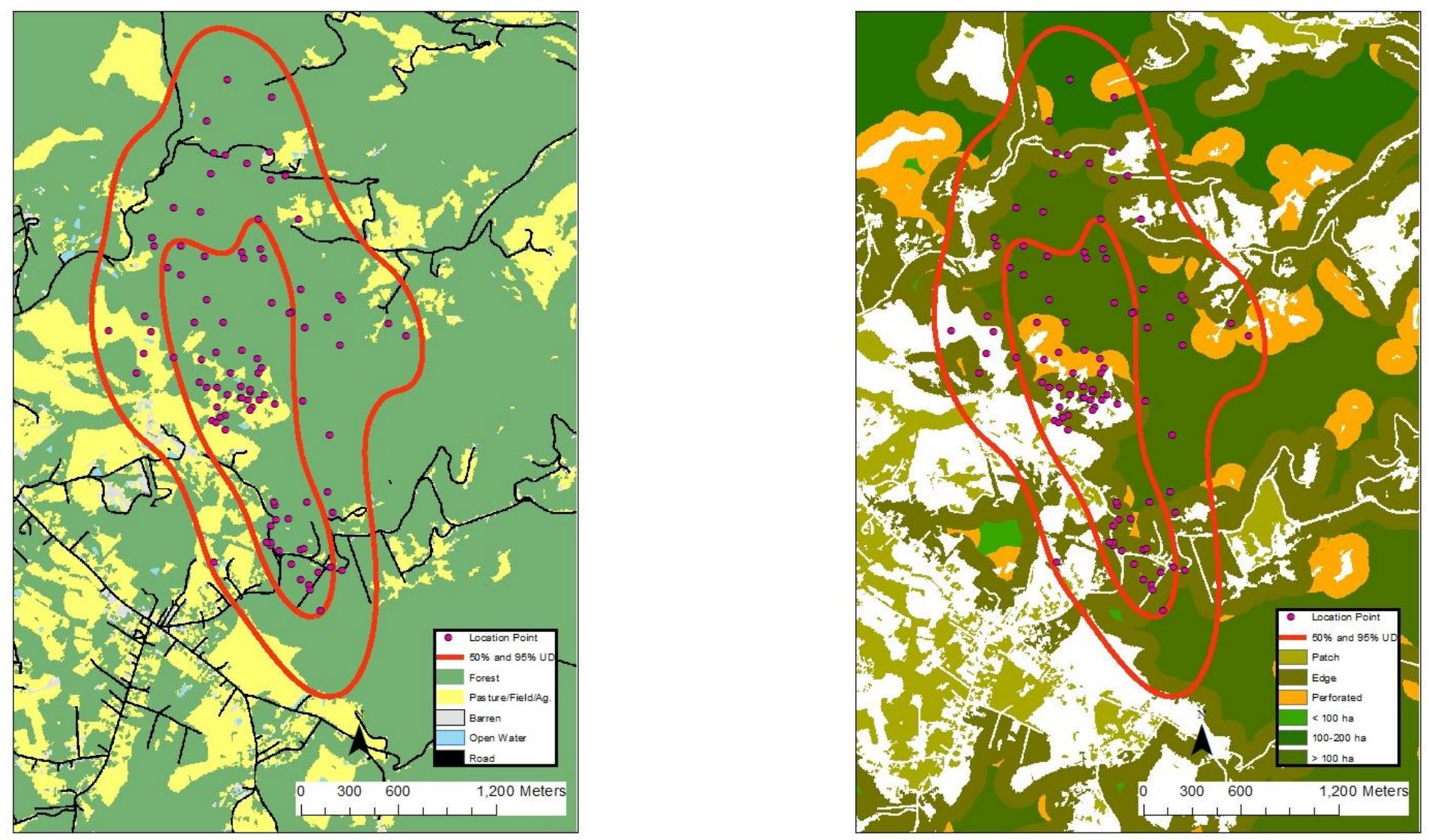
Appendix CCXIIa. 10125 (adult, annual) - 50\% core and 95\% periphery probability contours of the annual Gaussian fixed kernel home range utilization distributions. Smoothing parameter $(h)$ determined by least squares cross validation, Summers County, West Virginia, 2004-2007 (aspect and slope maps).
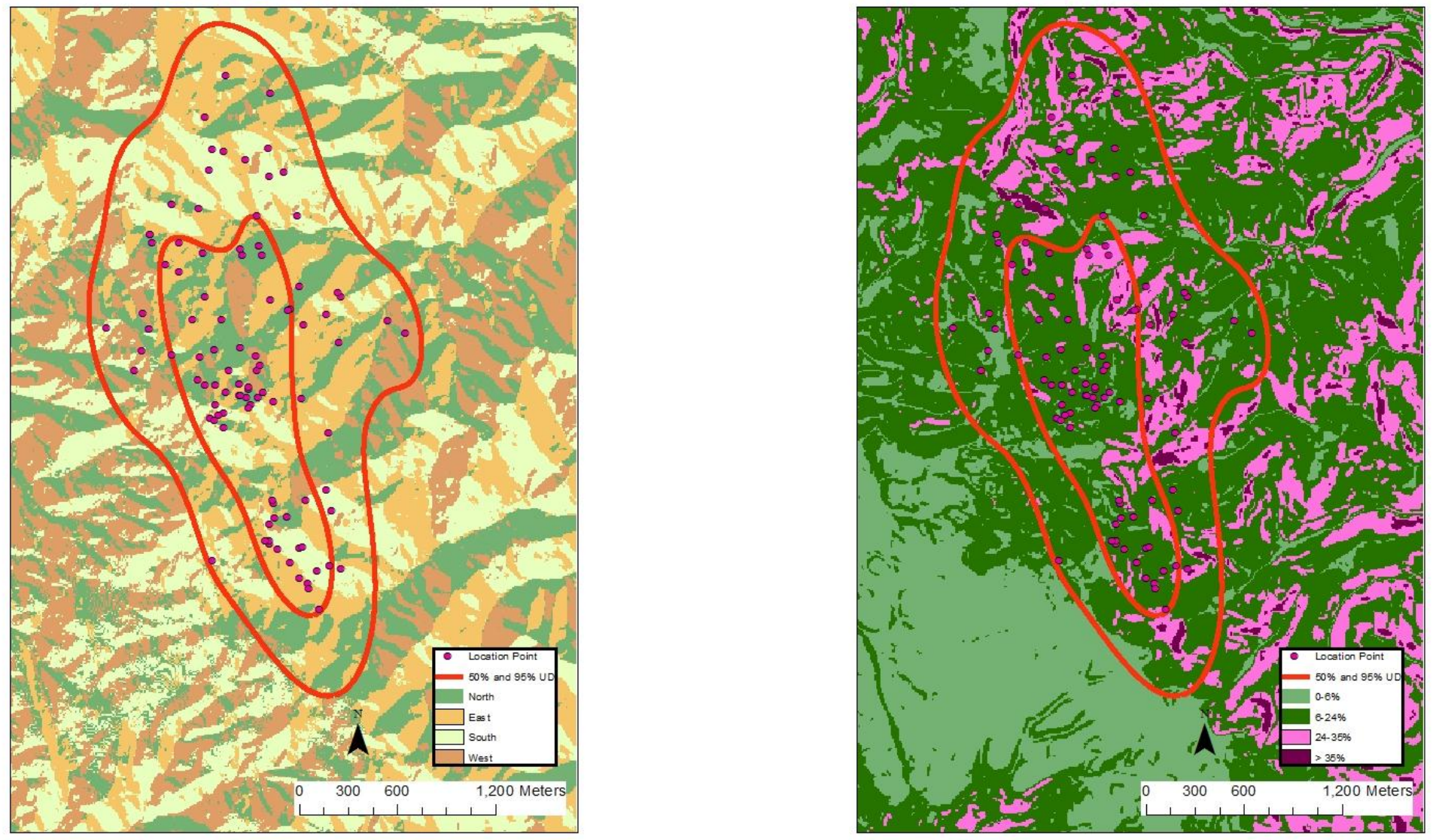
Appendix CCXIII a. 10126 (adult, annual) - 50\% core and 95\% periphery probability contours of the annual Gaussian fixed kernel home range utilization distributions. Smoothing parameter $(h)$ determined by least squares cross validation, Summers County, West Virginia, 2004-2007 (land use and land cover, land fragmentation maps).
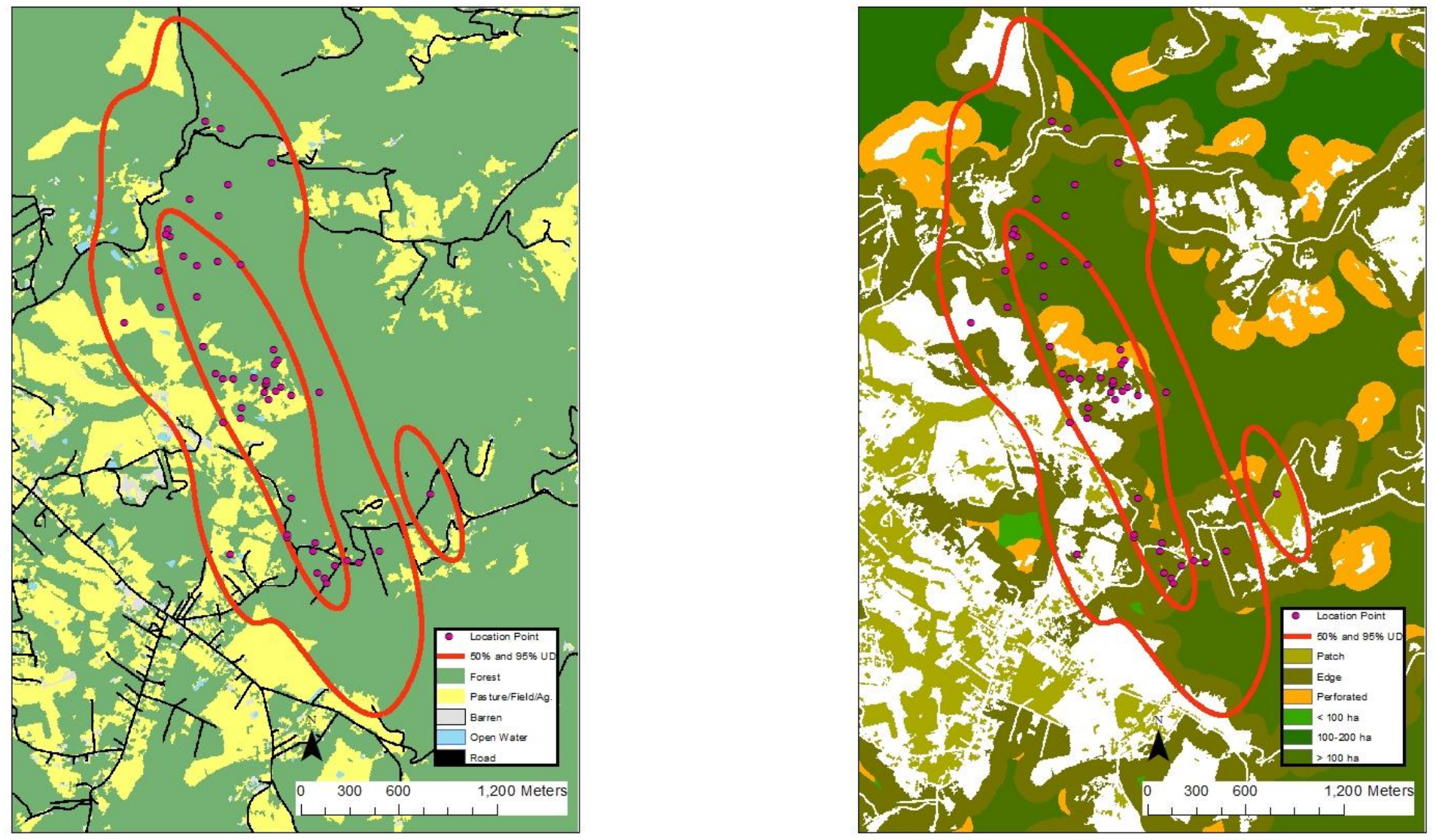
Appendix CCXIVa. 10126 (adult, annual) - 50\% core and 95\% periphery probability contours of the annual Gaussian fixed kernel home range utilization distributions. Smoothing parameter $(h)$ determined by least squares cross validation, Summers County, West Virginia, 2004-2007 (aspect and slope maps).
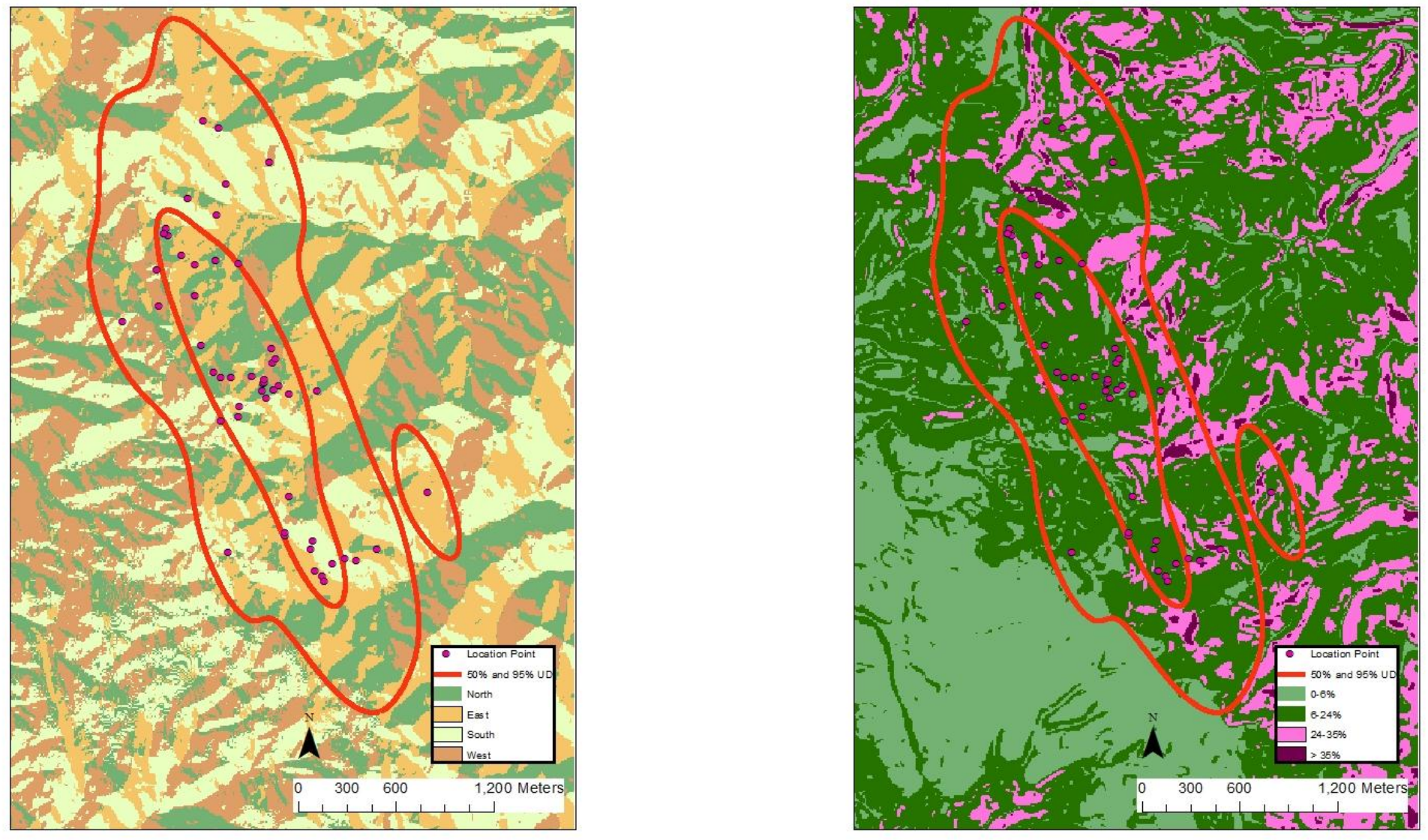
Appendix CCXVa. 10127 (adult, annual) - 50\% core and 95\% periphery probability contours of the annual Gaussian fixed kernel home range utilization distributions. Smoothing parameter $(h)$ determined by least squares cross validation, Summers County, West Virginia, 2004-2007 (land use and land cover, land fragmentation maps).
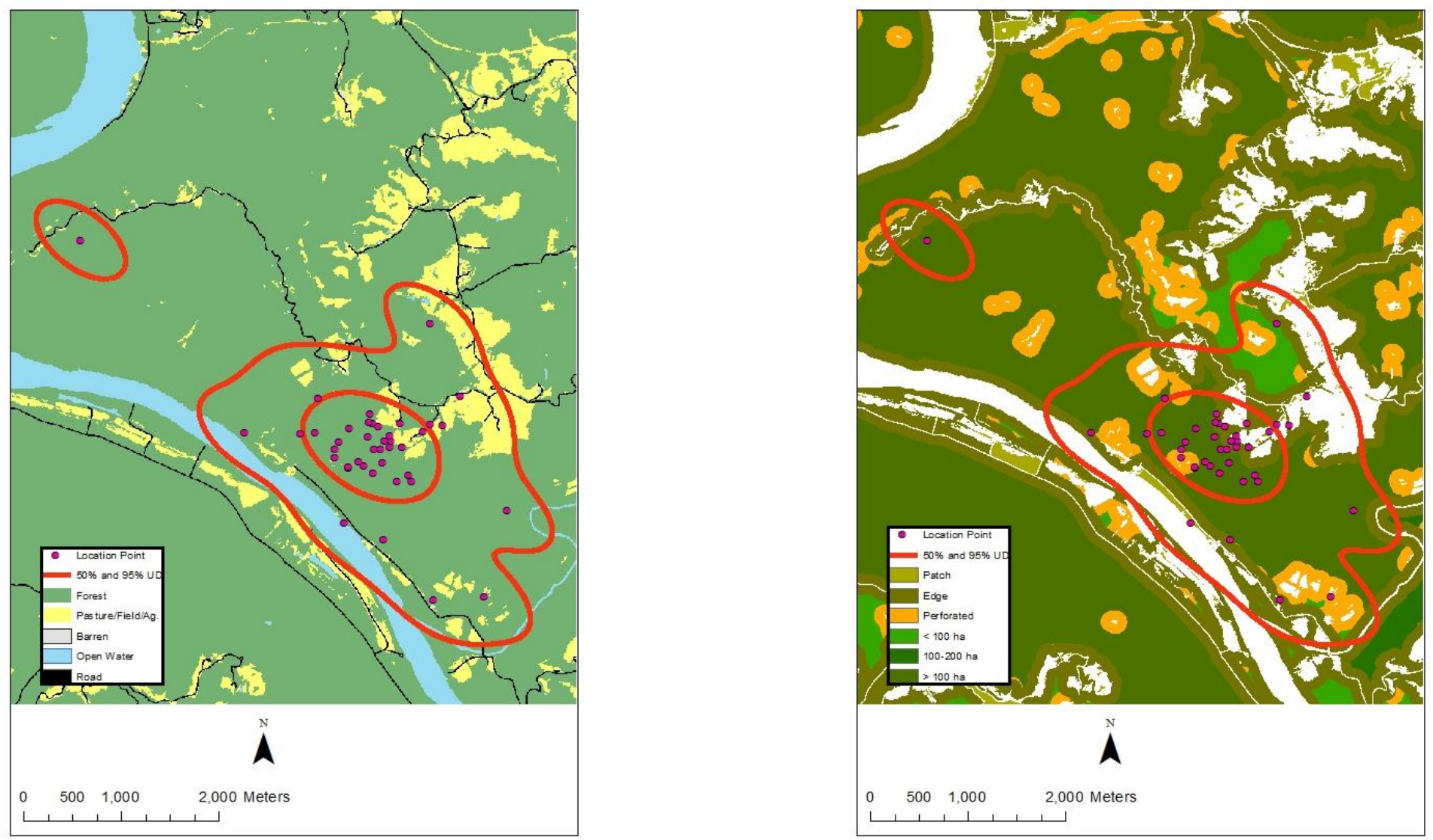
Appendix CCXVIa. 10127 (adult, annual) - 50\% core and 95\% periphery probability contours of the annual Gaussian fixed kernel home range utilization distributions. Smoothing parameter $(h)$ determined by least squares cross validation, Summers County, West Virginia, 2004-2007 (aspect and slope maps).
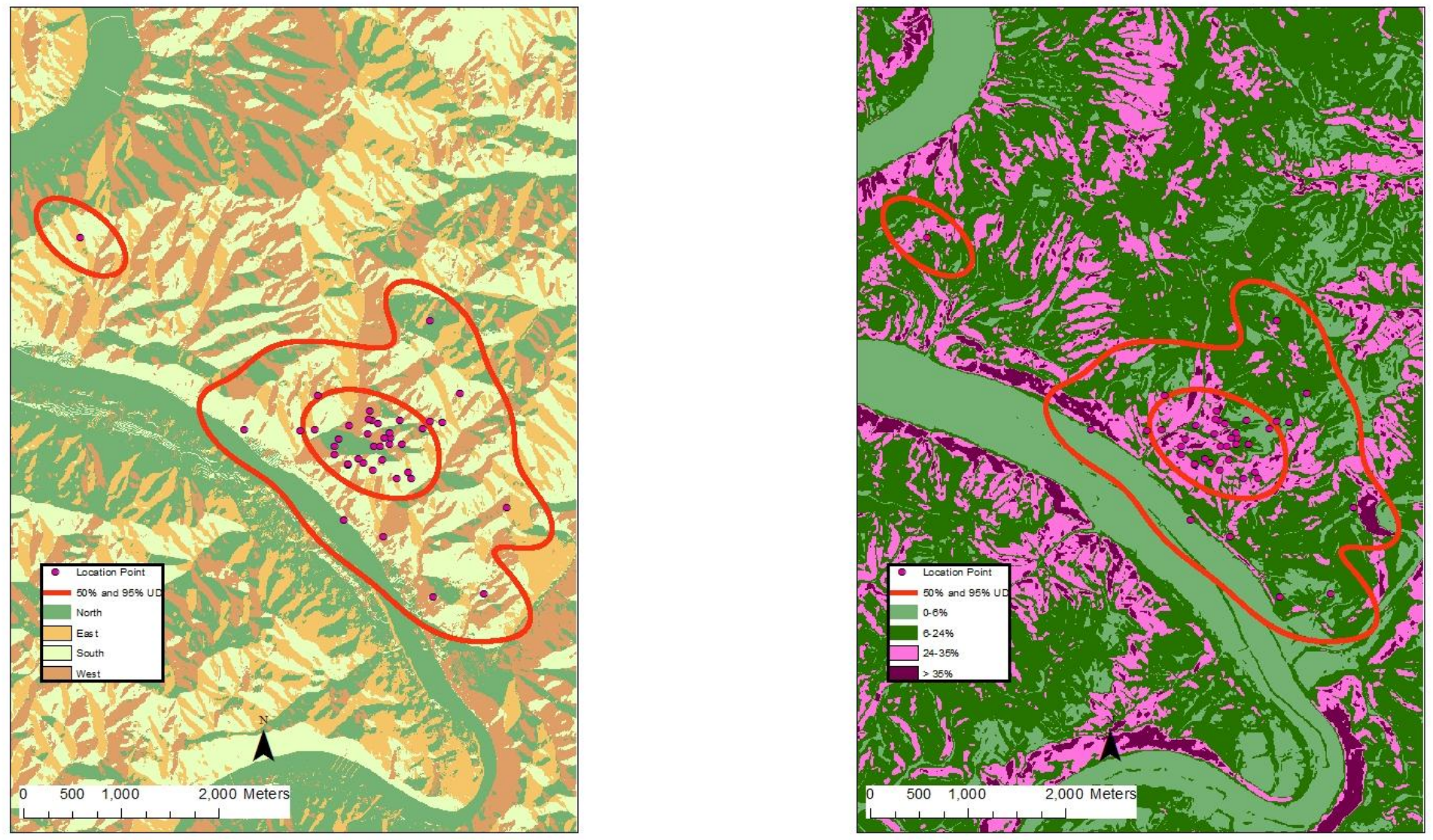
Appendix CCXVIIa. 10128 (adult, annual) - 50\% core and 95\% periphery probability contours of the annual Gaussian fixed kernel home range utilization distributions. Smoothing parameter $(h)$ determined by least squares cross validation, Summers County, West Virginia, 2004-2007 (land use and land cover, land fragmentation maps).
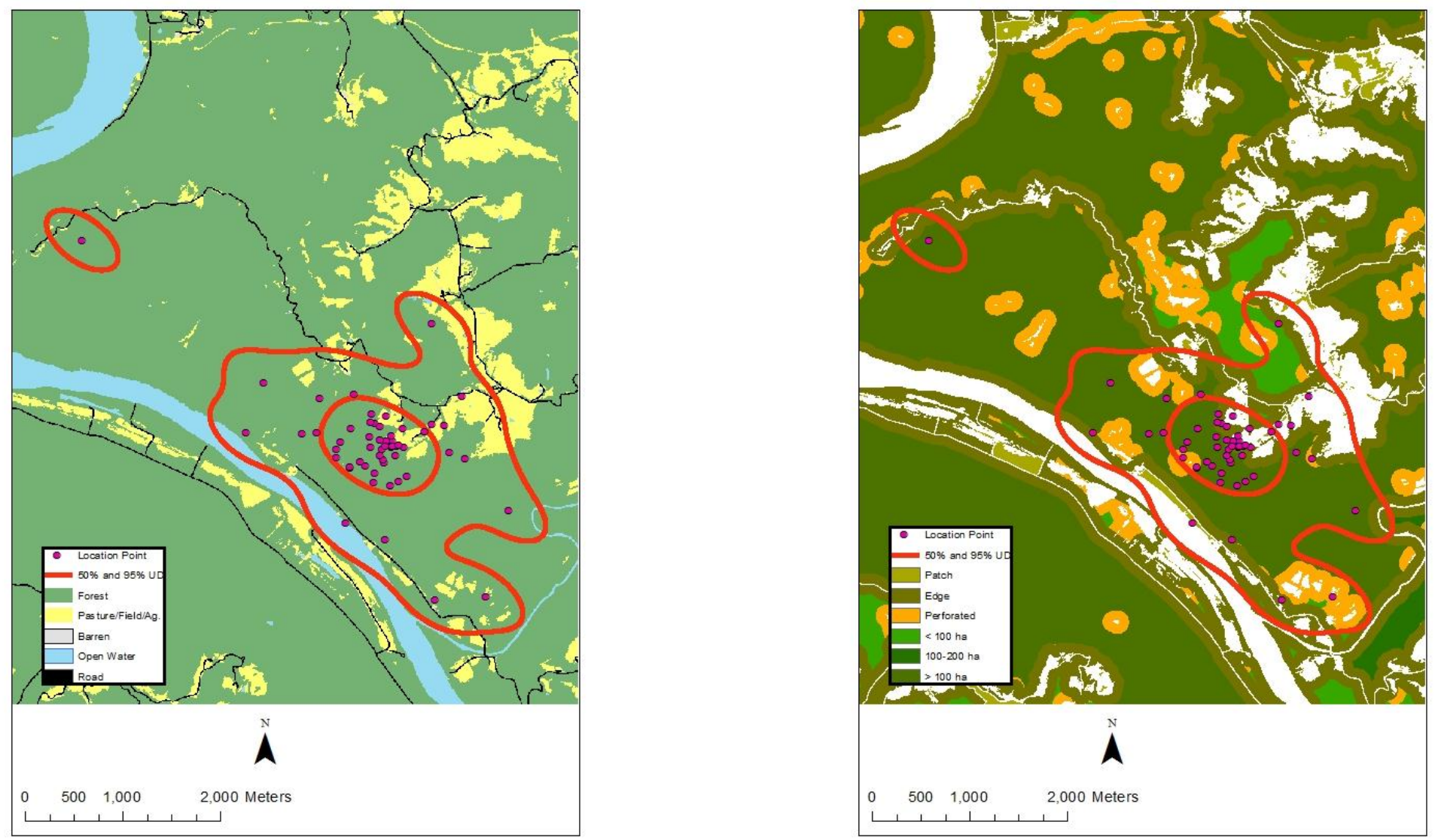
Appendix CCXVIII a. 10128 (adult, annual) - 50\% core and 95\% periphery probability contours of the annual Gaussian fixed kernel home range utilization distributions. Smoothing parameter $(h)$ determined by least squares cross validation, Summers County, West Virginia, 2004-2007 (aspect and slope maps).
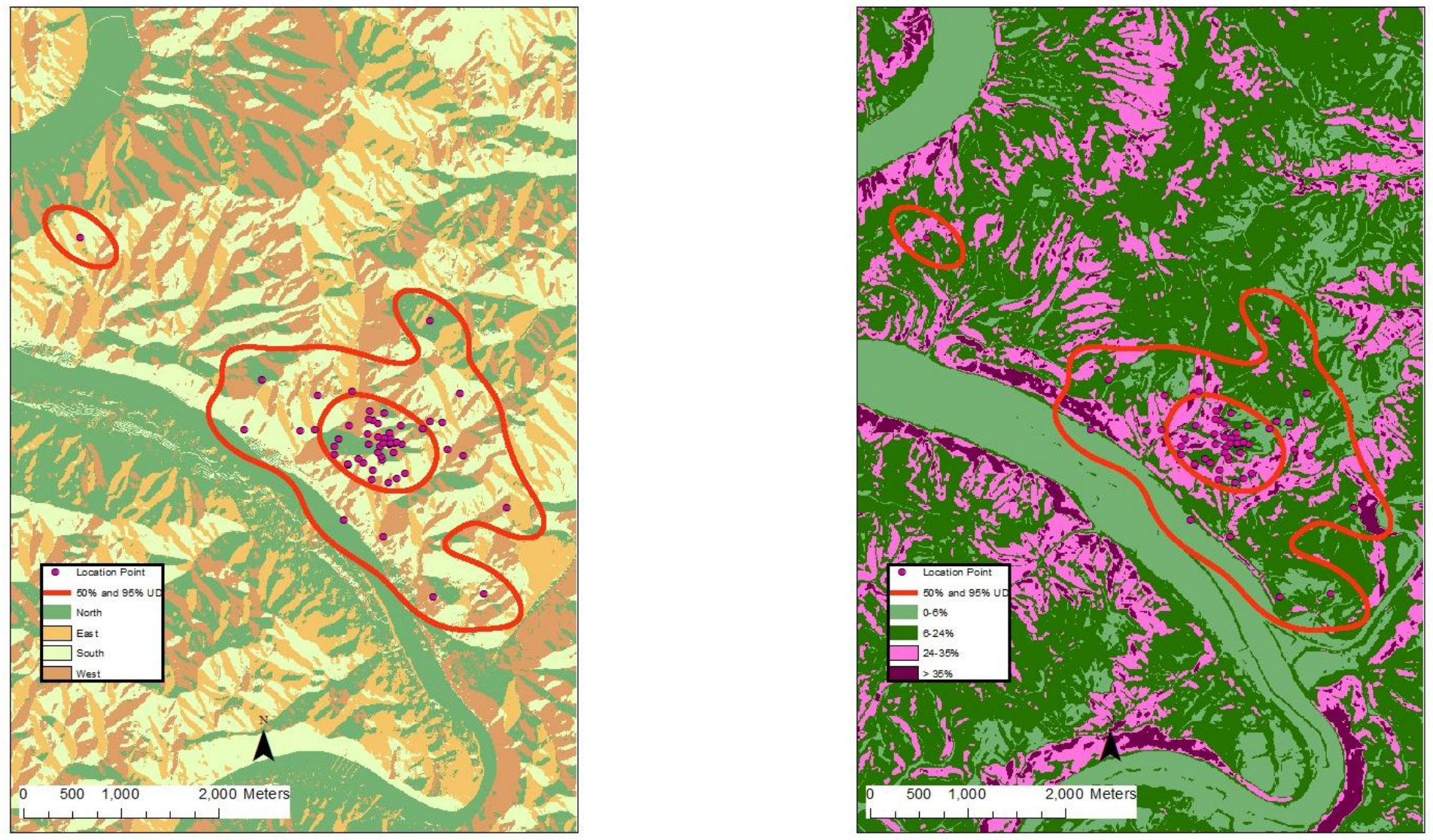
Appendix CCXIXa. 10129 (adult, annual) - 50\% core and 95\% periphery probability contours of the annual Gaussian fixed kernel home range utilization distributions. Smoothing parameter $(h)$ determined by least squares cross validation, Summers County, West Virginia, 2004-2007 (land use and land cover, land fragmentation maps).
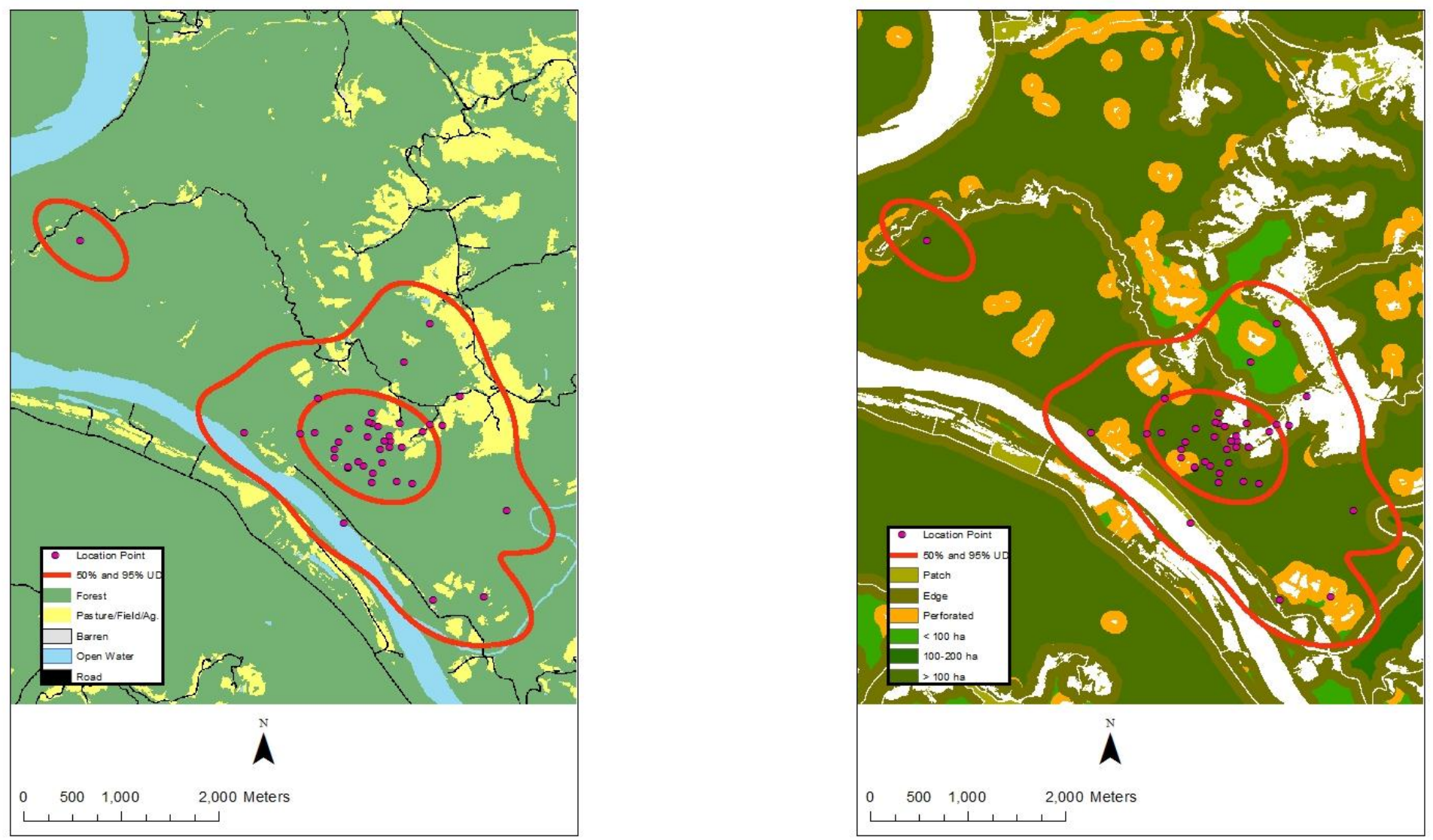
Appendix CCXXa. 10129 (adult, annual) - 50\% core and 95\% periphery probability contours of the annual Gaussian fixed kernel home range utilization distributions. Smoothing parameter $(h)$ determined by least squares cross validation, Summers County, West Virginia, 2004-2007 (aspect and slope maps).
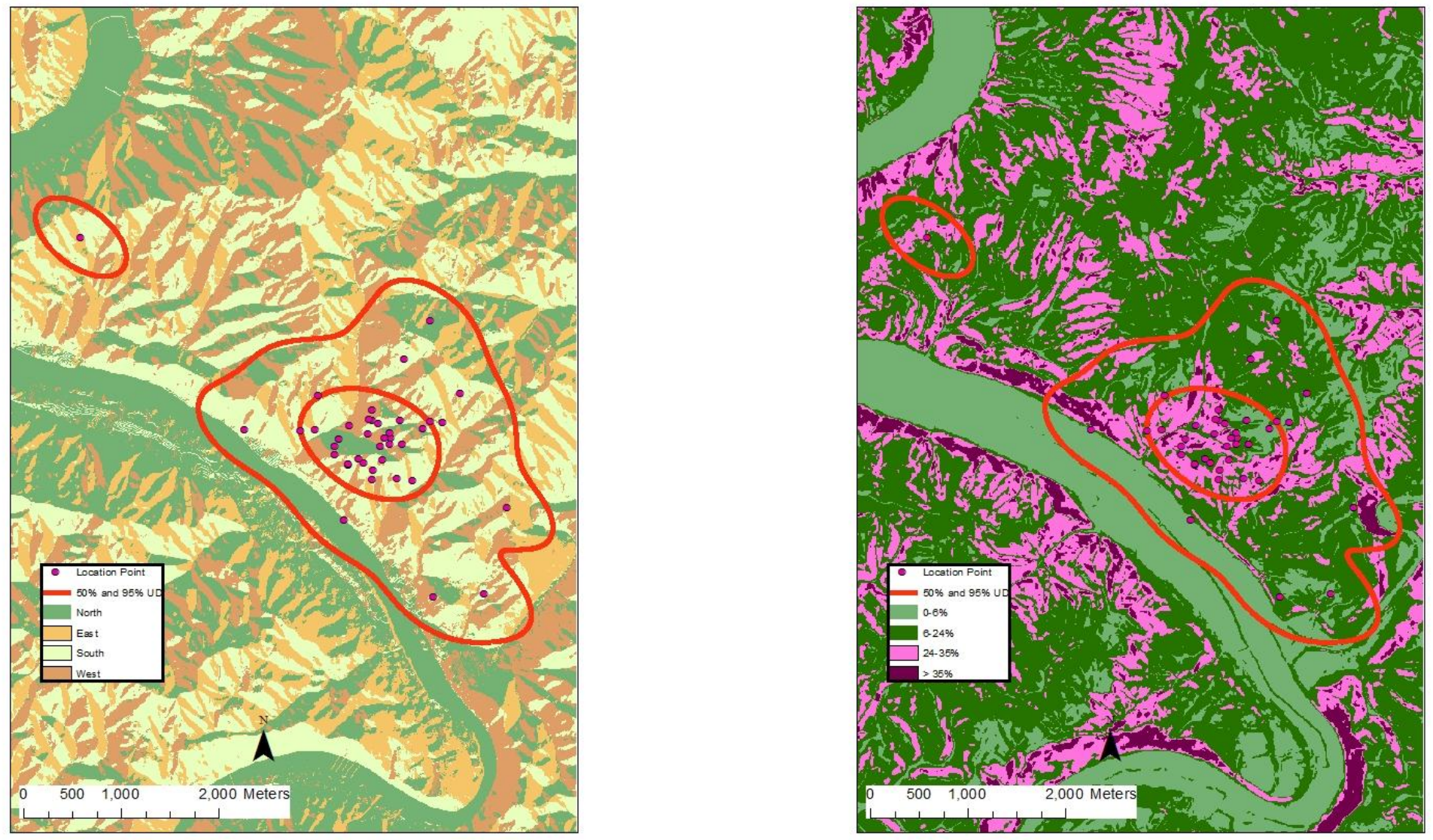
Appendix CCXXI $a$. 10130 (adult, fall-winter) - 50\% core and 95\% periphery probability contours of the annual Gaussian fixed kernel home range utilization distributions. Smoothing parameter $(h)$ determined by least squares cross validation, Lincoln County, West Virginia, 2004-2007 (land use and land cover, land fragmentation maps).
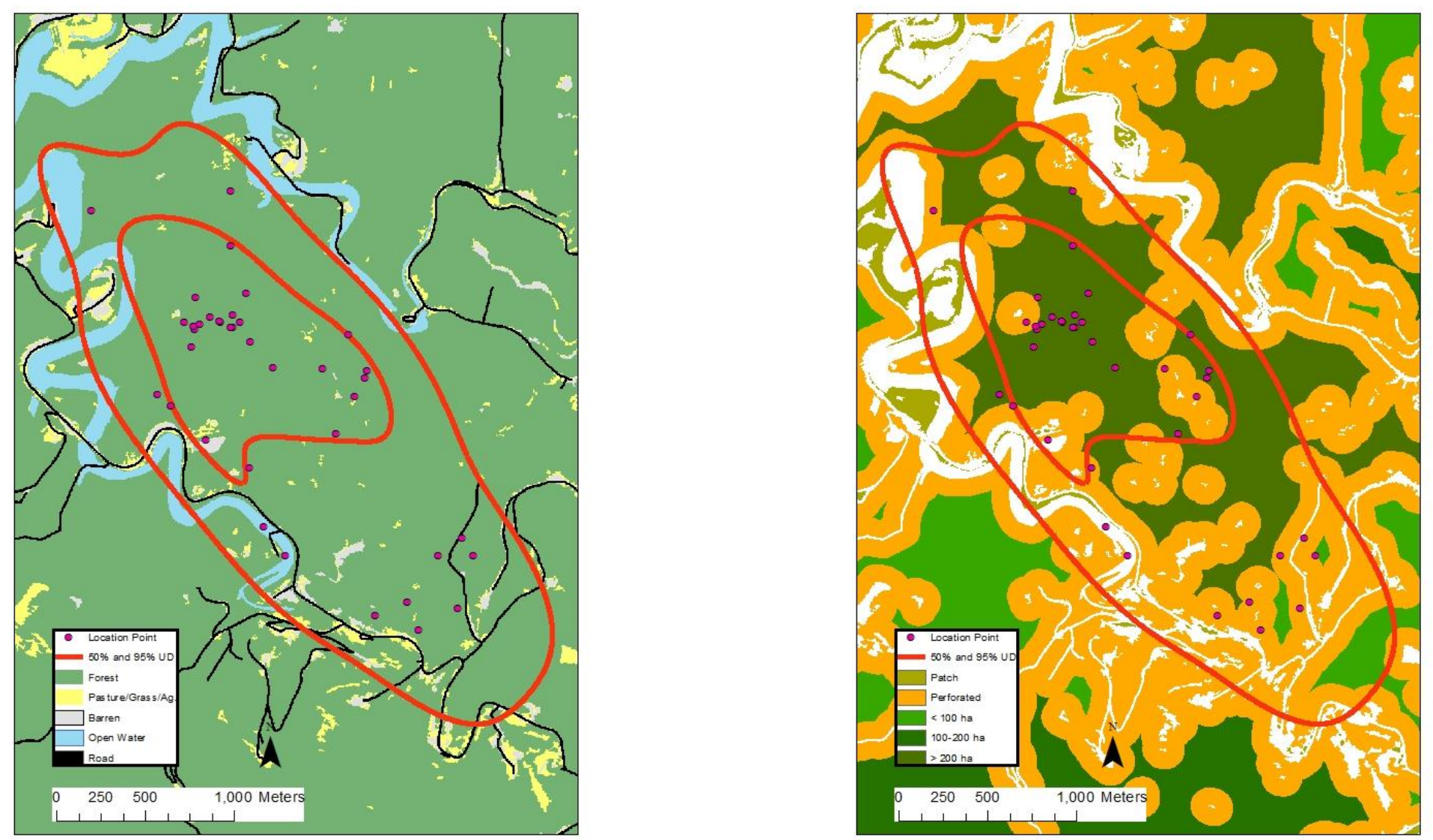
Appendix CCXXIIa. 10130 (adult, fall-winter) - 50\% core and 95\% periphery probability contours of the annual Gaussian fixed kernel home range utilization distributions. Smoothing parameter $(h)$ determined by least squares cross validation, Lincoln County, West Virginia, 2004-2007 (aspect and slope maps).
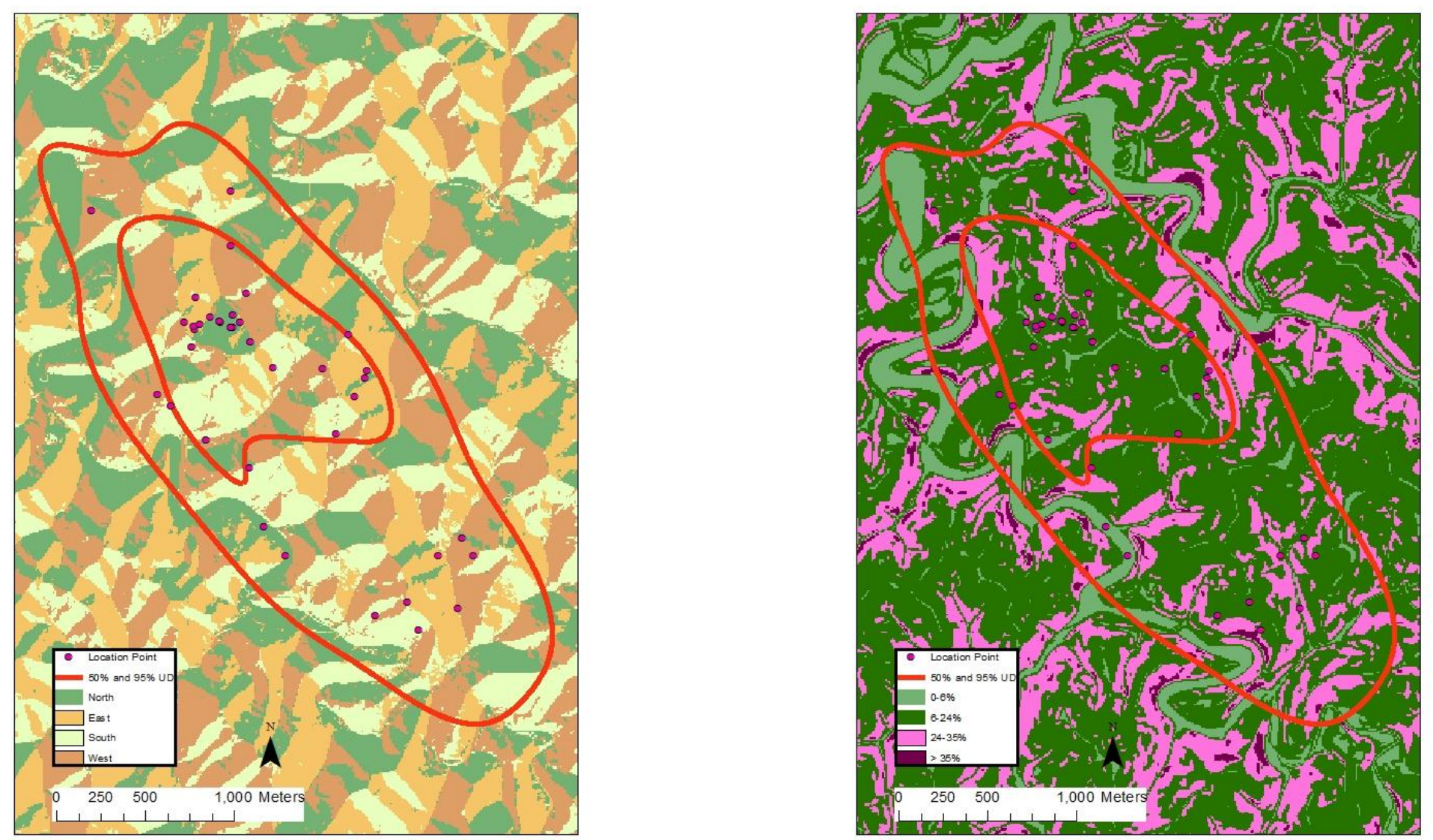
Appendix CCXXIII a. 10131 (adult, annual) - 50\% core and 95\% periphery probability contours of the annual Gaussian fixed kernel home range utilization distributions. Smoothing parameter $(h)$ determined by least squares cross validation, Lincoln County, West Virginia, 2004-2007 (land use and land cover, land fragmentation maps).
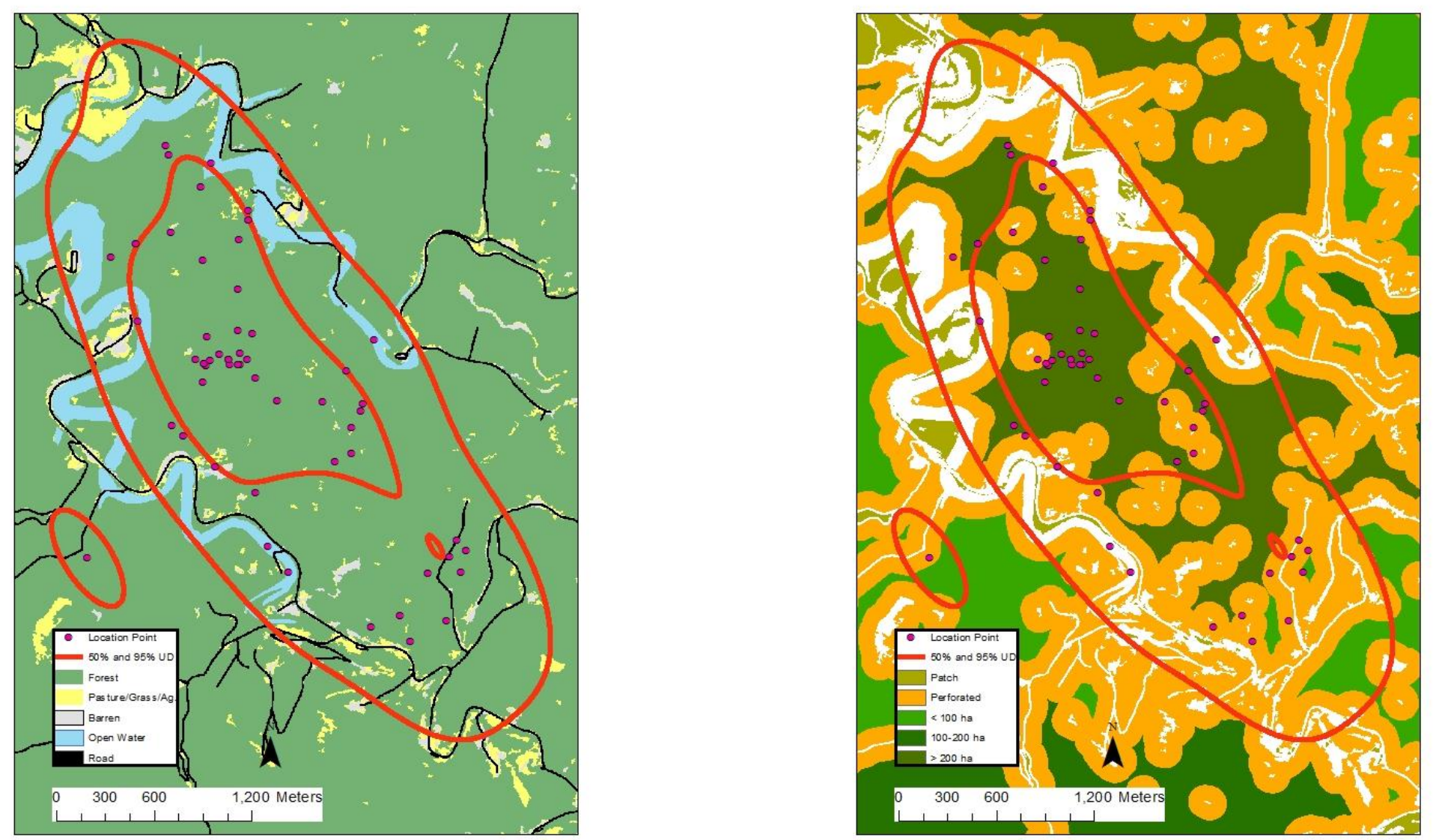
Appendix CCXXIVa. 10131 (adult, annual) - 50\% core and 95\% periphery probability contours of the annual Gaussian fixed kernel home range utilization distributions. Smoothing parameter $(h)$ determined by least squares cross validation, Lincoln County, West Virginia, 2004-2007 (aspect and slope maps).
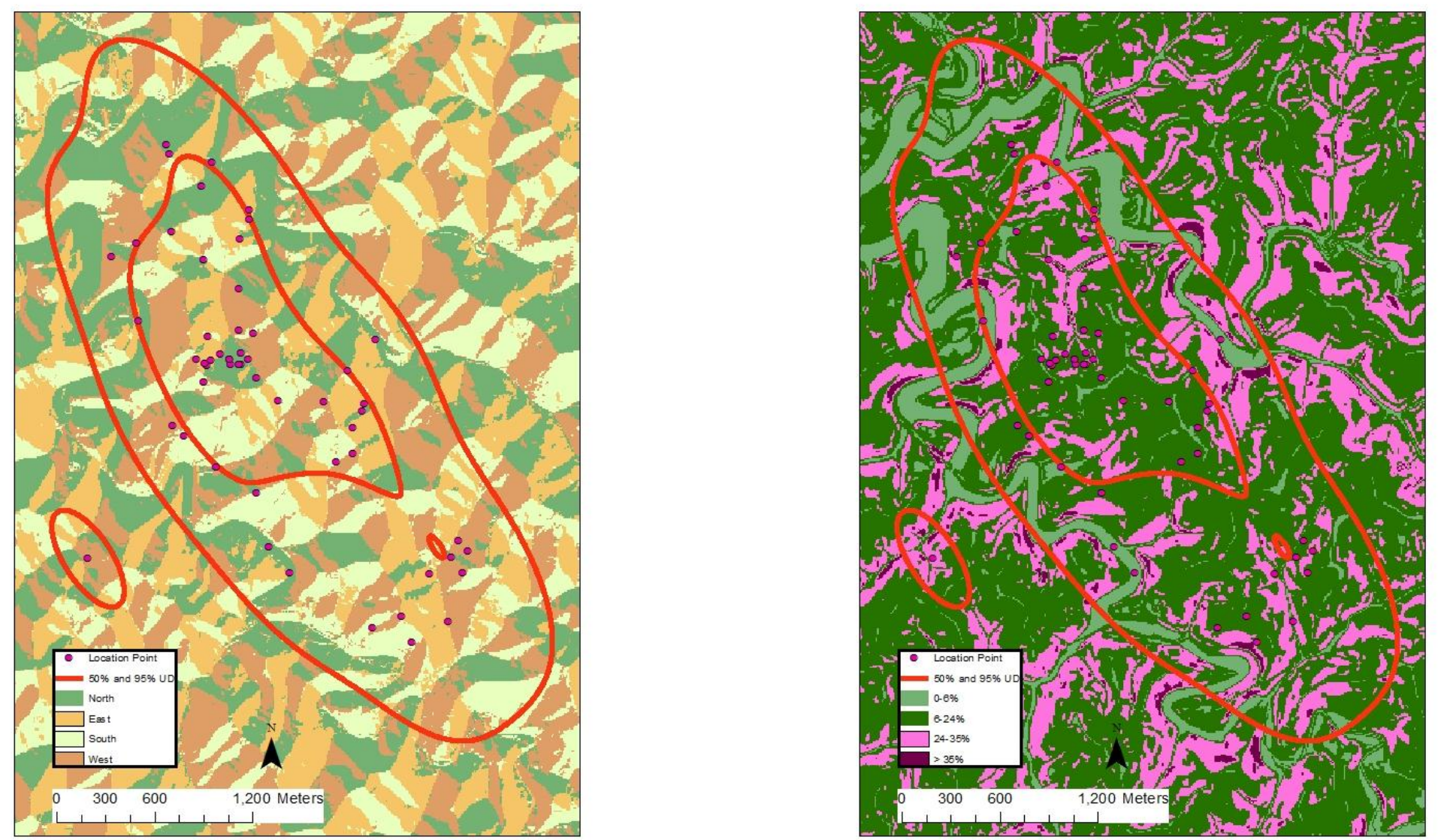
Appendix CCXXVa. 10132 (adult, spring-summer) - 50\% core and 95\% periphery probability contours of the annual Gaussian fixed kernel home range utilization distributions. Smoothing parameter $(h)$ determined by least squares cross validation, Summers County, West Virginia, 2004-2007 (land use and land cover, land fragmentation maps).
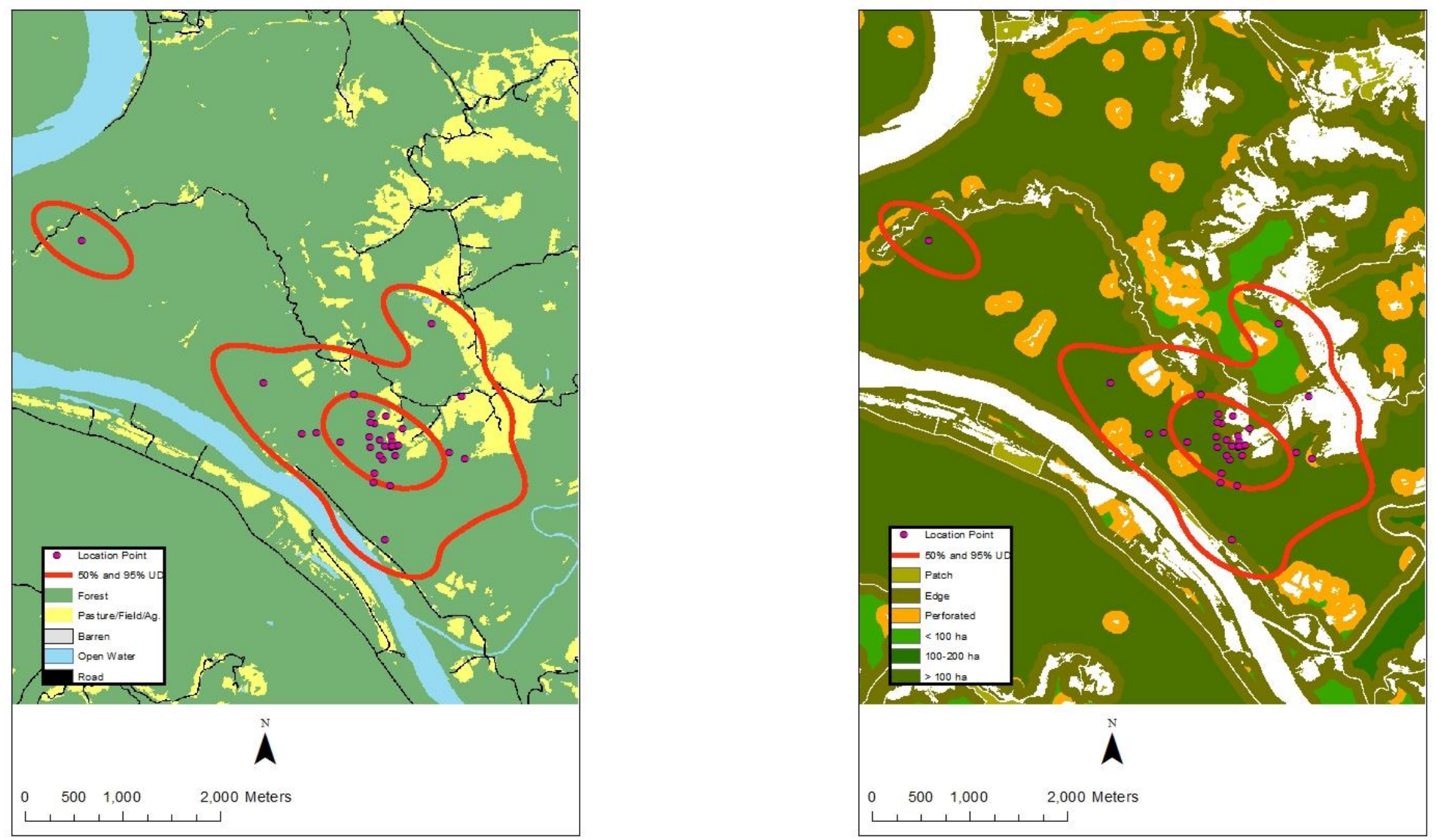
Appendix CCXXVIa. 10132 (adult, spring-summer) - 50\% core and 95\% periphery probability contours of the annual Gaussian fixed kernel home range utilization distributions. Smoothing parameter $(h)$ determined by least squares cross validation, Summers County, West Virginia, 2004-2007 (aspect and slope maps).
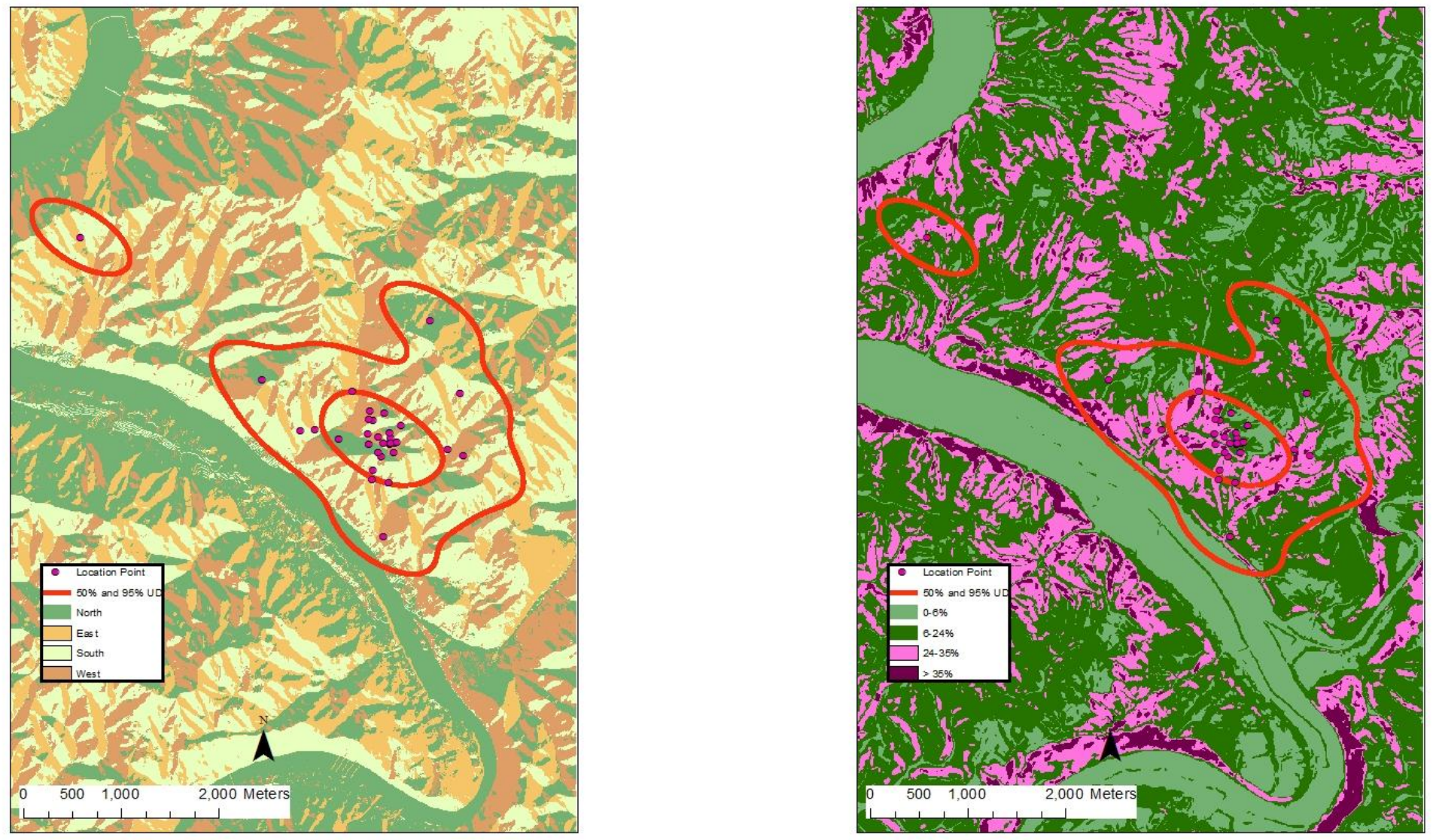
Appendix CCXXVII a. 10133 (adult, annual) - 50\% core and 95\% periphery probability contours of the annual Gaussian fixed kernel home range utilization distributions. Smoothing parameter $(h)$ determined by least squares cross validation, Mason County, West Virginia, 2004-2007 (land use and land cover, land fragmentation maps).
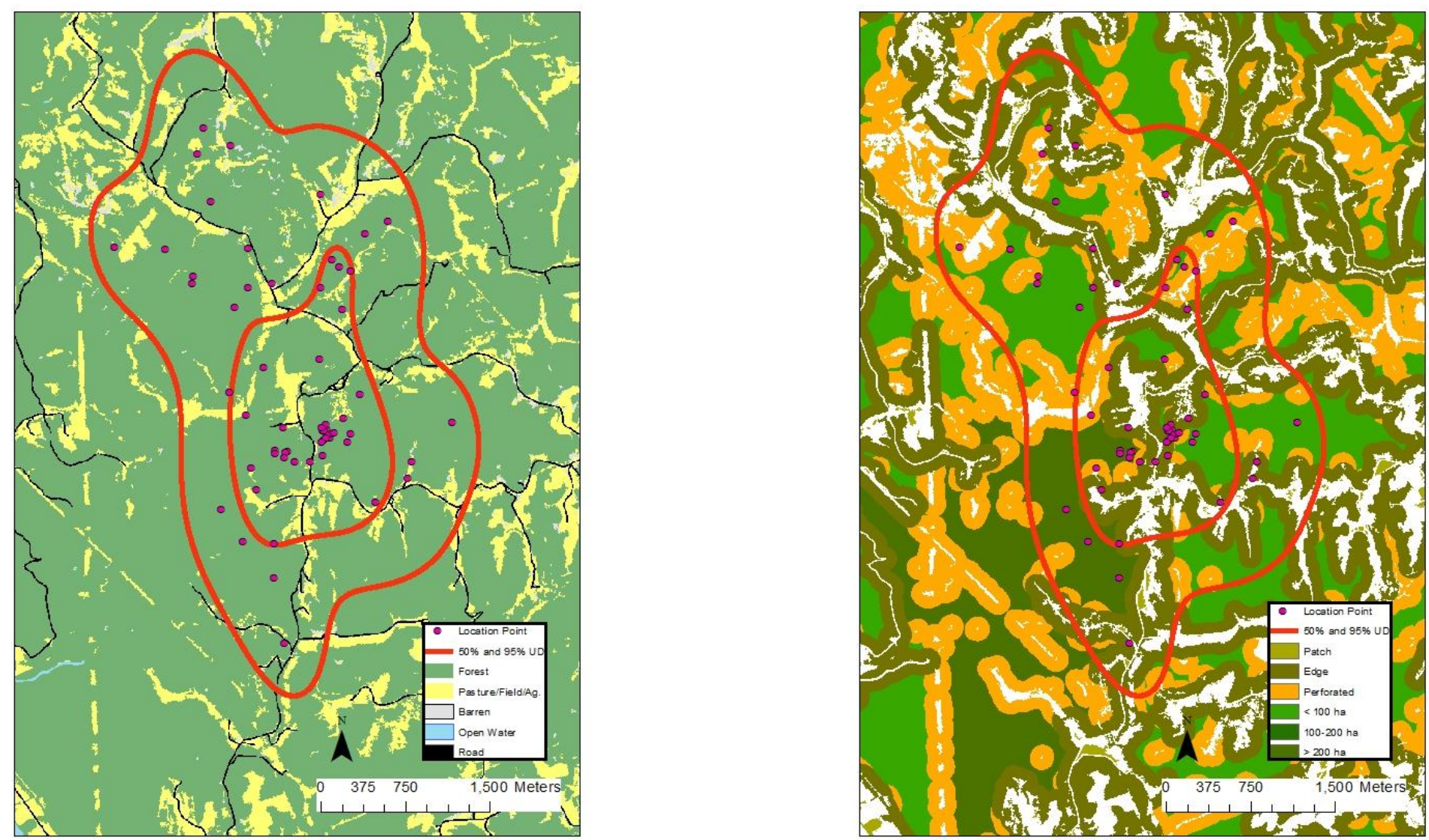
Appendix CCXXVIII a. 10133 (adult, annual) - 50\% core and 95\% periphery probability contours of the annual Gaussian fixed kernel home range utilization distributions. Smoothing parameter $(h)$ determined by least squares cross validation, Mason County, West Virginia, 2004-2007 (aspect and slope maps).
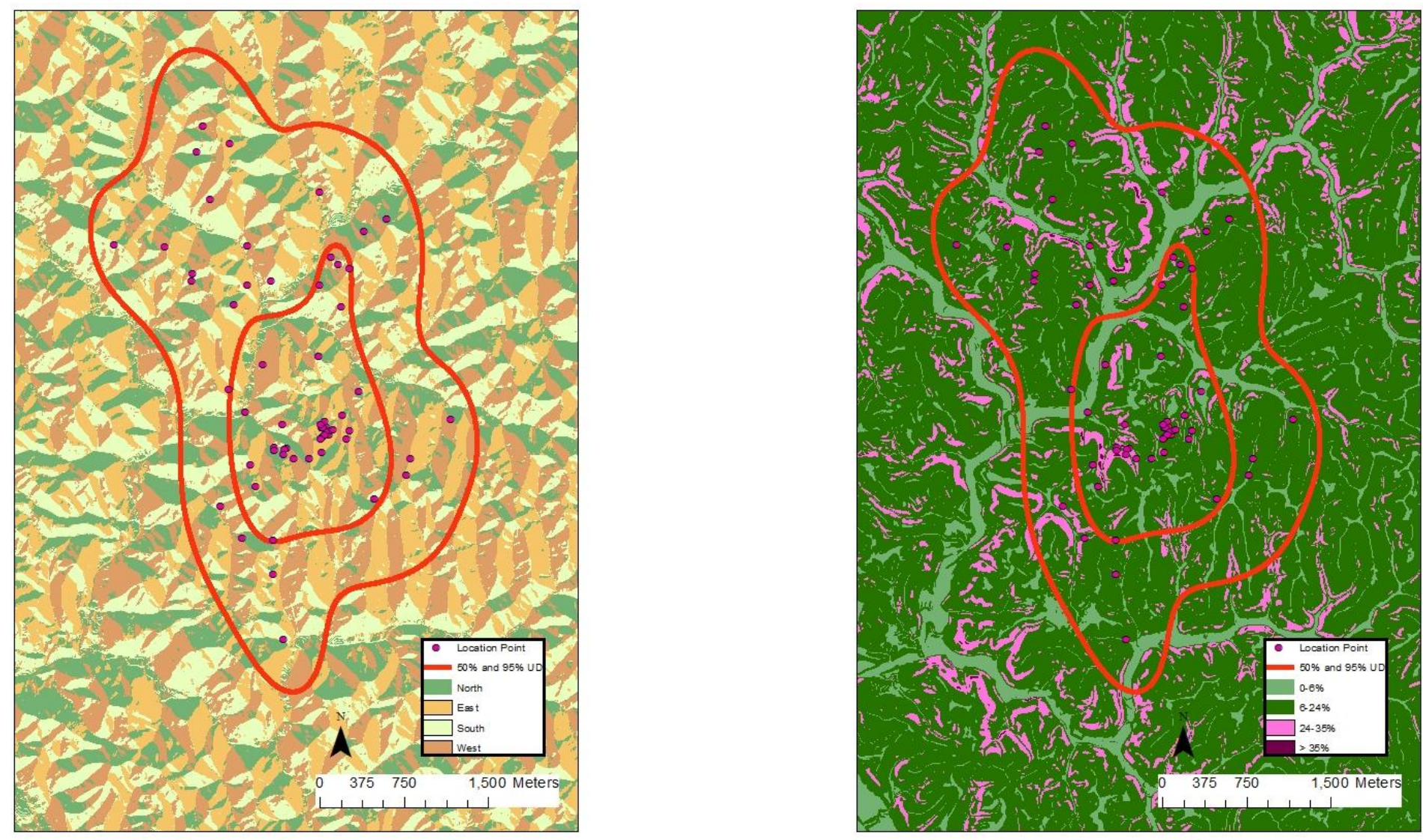
Appendix CCXXIXa. 10134 (adult, fall-winter) - 50\% core and 95\% periphery probability contours of the annual Gaussian fixed kernel home range utilization distributions. Smoothing parameter $(h)$ determined by least squares cross validation, Mason County, West Virginia, 2004-2007 (land use and land cover, land fragmentation maps).
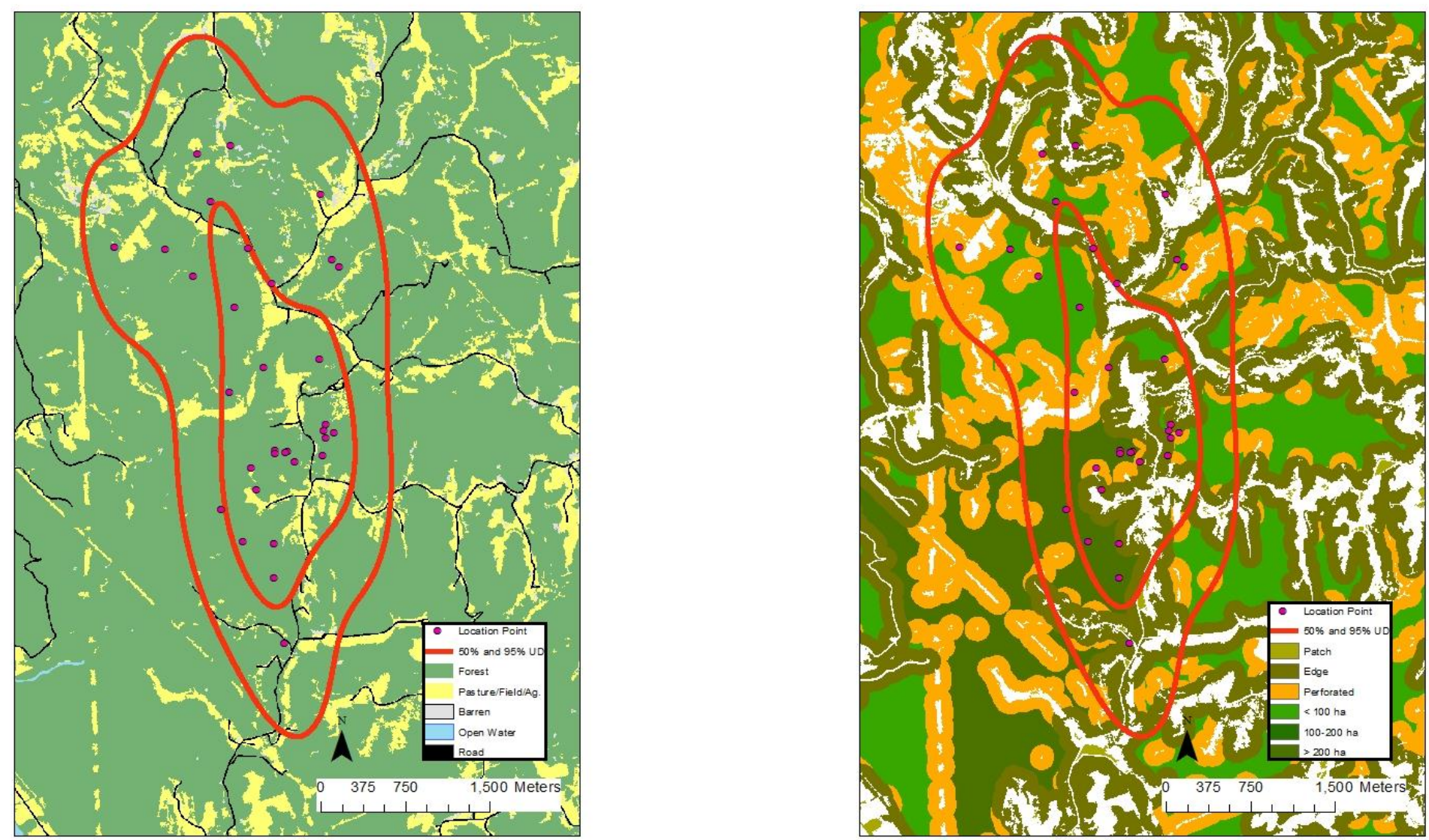
Appendix CCXXXa. 10134 (adult, fall-winter) - 50\% core and 95\% periphery probability contours of the annual Gaussian fixed kernel home range utilization distributions. Smoothing parameter $(h)$ determined by least squares cross validation, Mason County, West Virginia, 2004-2007 (aspect and slope maps).
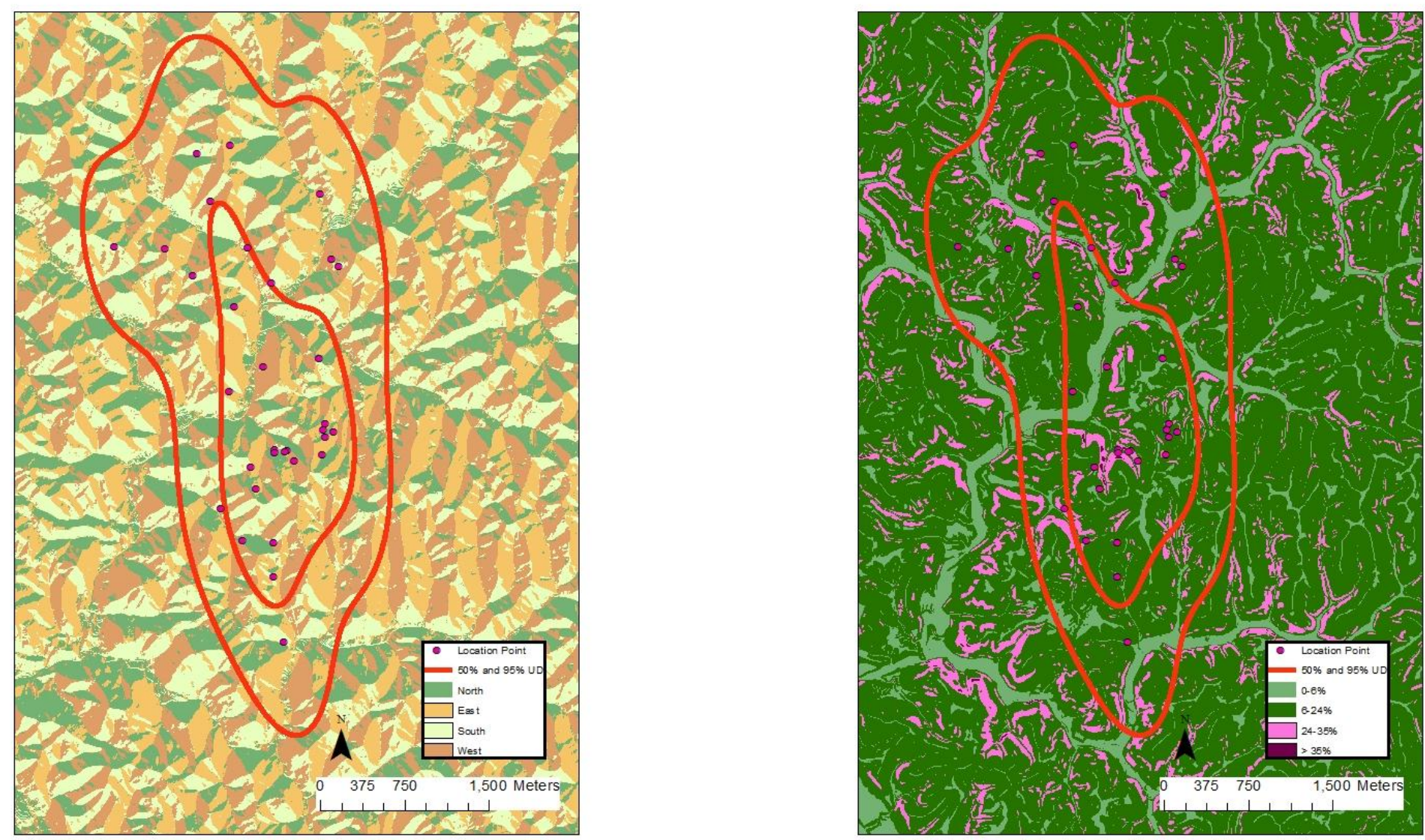
Appendix CCXXXIa. 10135 (adult, annual) - 50\% core and 95\% periphery probability contours of the annual Gaussian fixed kernel home range utilization distributions. Smoothing parameter $(h)$ determined by least squares cross validation, Mason County, West Virginia, 2004-2007 (land use and land cover, land fragmentation maps).
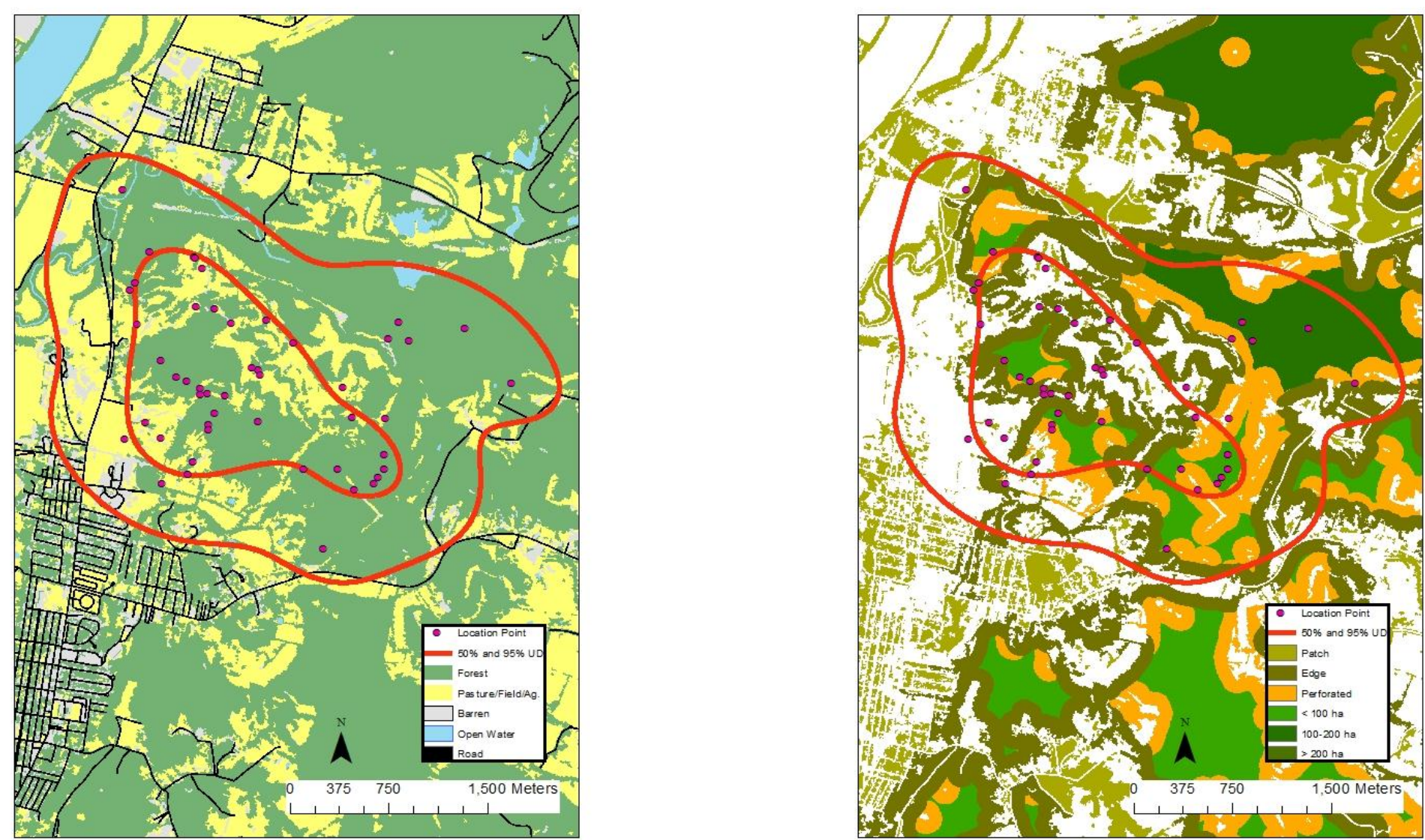
Appendix CCXXXII $a .10135$ (adult, annual) - 50\% core and 95\% periphery probability contours of the annual Gaussian fixed kernel home range utilization distributions. Smoothing parameter $(h)$ determined by least squares cross validation, Mason County, West Virginia, 2004-2007 (aspect and slope maps).
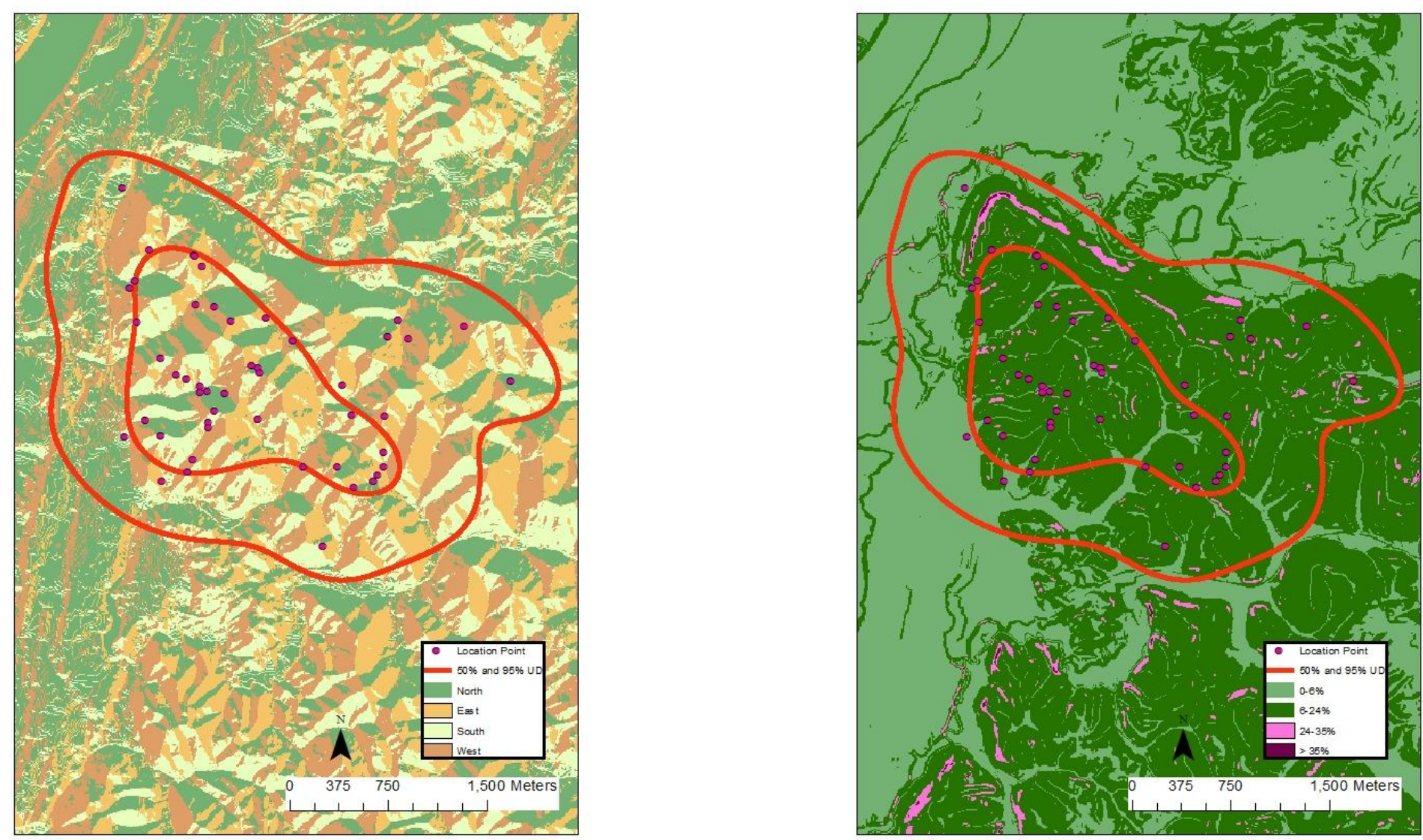
Appendix CCXXXIII a. 10136 (juvenile, annual) - 50\% core and 95\% periphery probability contours of the annual Gaussian fixed kernel home range utilization distributions. Smoothing parameter $(h)$ determined by least squares cross validation, Mason County, West Virginia, 2004-2007 (land use and land cover, land fragmentation maps).
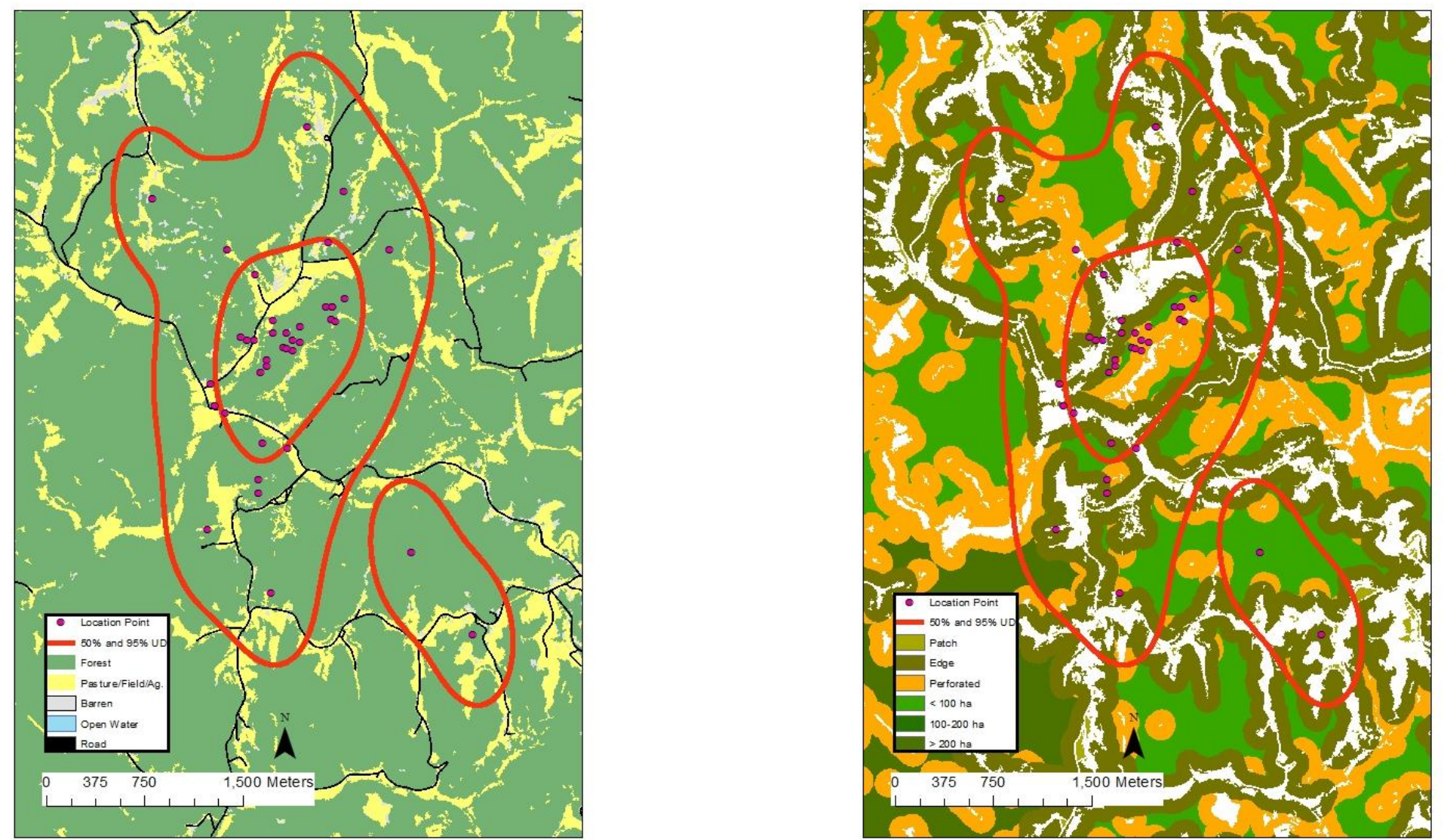
Appendix CCXXXIVa. 10136 (juvenile, annual) - 50\% core and 95\% periphery probability contours of the annual Gaussian fixed kernel home range utilization distributions. Smoothing parameter $(h)$ determined by least squares cross validation, Mason County, West Virginia, 2004-2007 (aspect and slope maps).
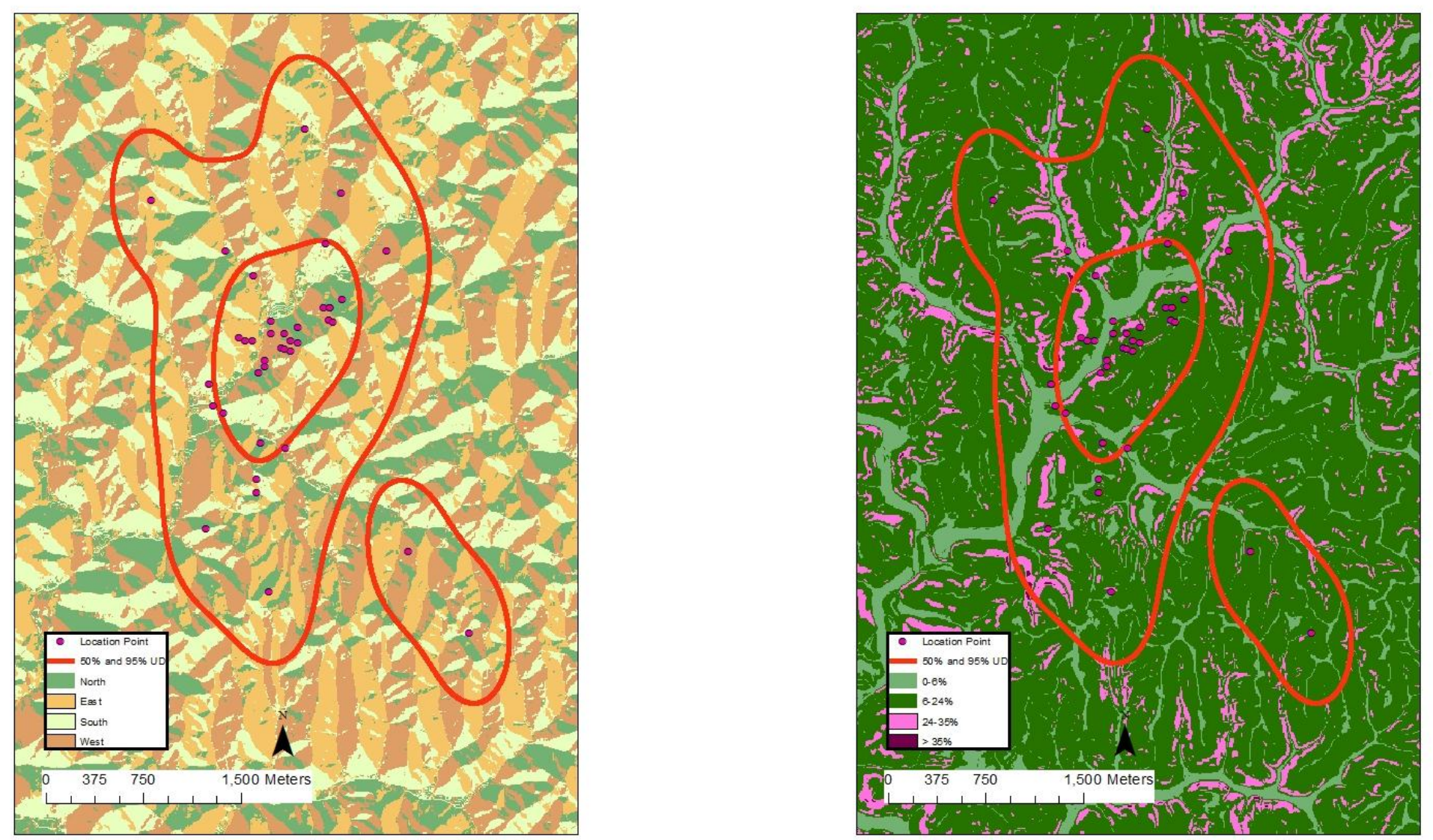
Appendix CCXXXVa. 10137 (adult, annual) - 50\% core and 95\% periphery probability contours of the annual Gaussian fixed kernel home range utilization distributions. Smoothing parameter $(h)$ determined by least squares cross validation, Mason County, West Virginia, 2004-2007 (land use and land cover, land fragmentation maps).
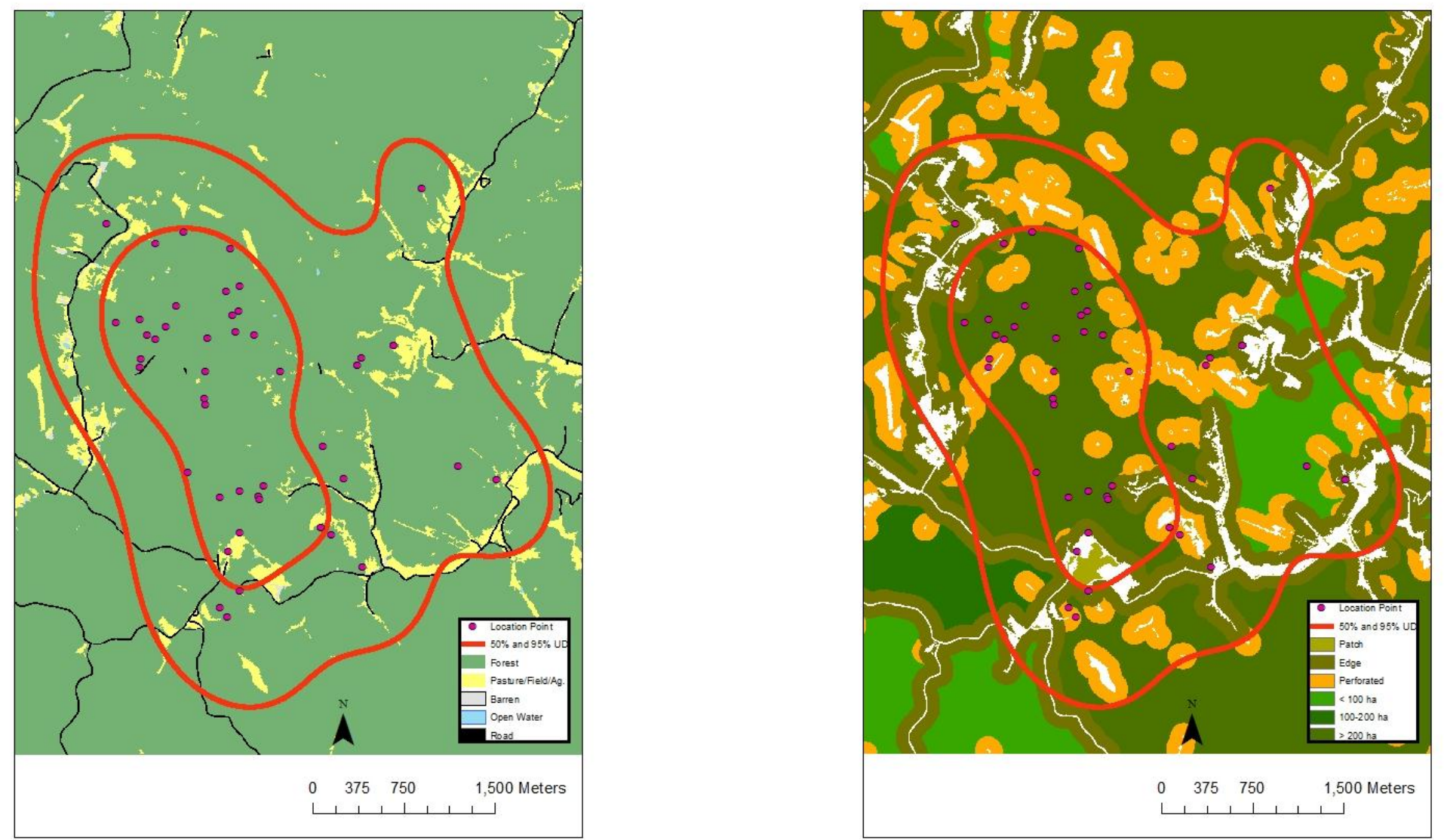
Appendix CCXXXVIa. 10137 (adult, annual) - 50\% core and 95\% periphery probability contours of the annual Gaussian fixed kernel home range utilization distributions. Smoothing parameter $(h)$ determined by least squares cross validation, Mason County, West Virginia, 2004-2007 (aspect and slope maps).
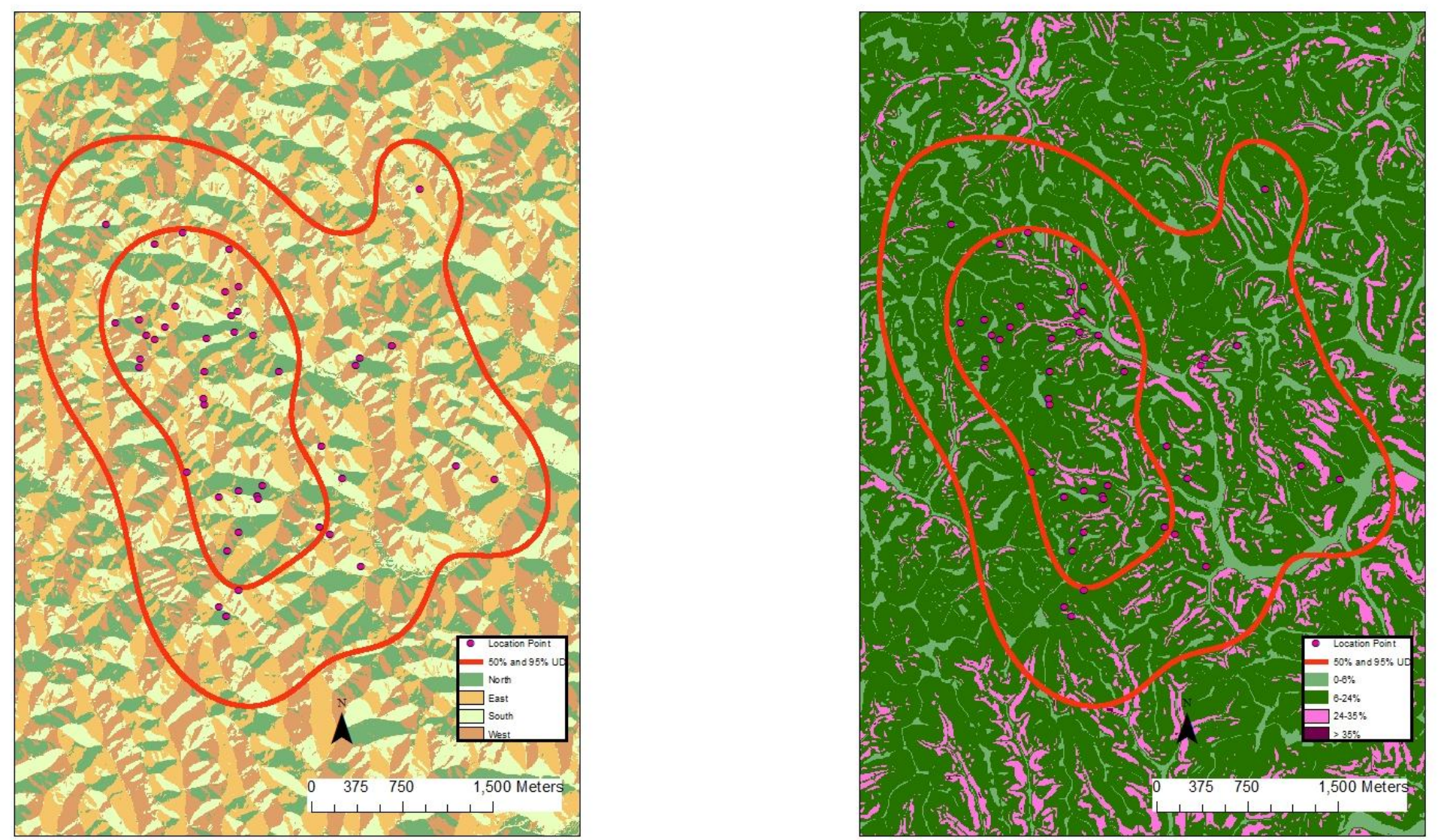
Appendix CCXXXVII a. 10138 (adult, annual) - 50\% core and 95\% periphery probability contours of the annual Gaussian fixed kernel home range utilization distributions. Smoothing parameter $(h)$ determined by least squares cross validation, Mason County, West Virginia, 2004-2007 (land use and land cover, land fragmentation maps).
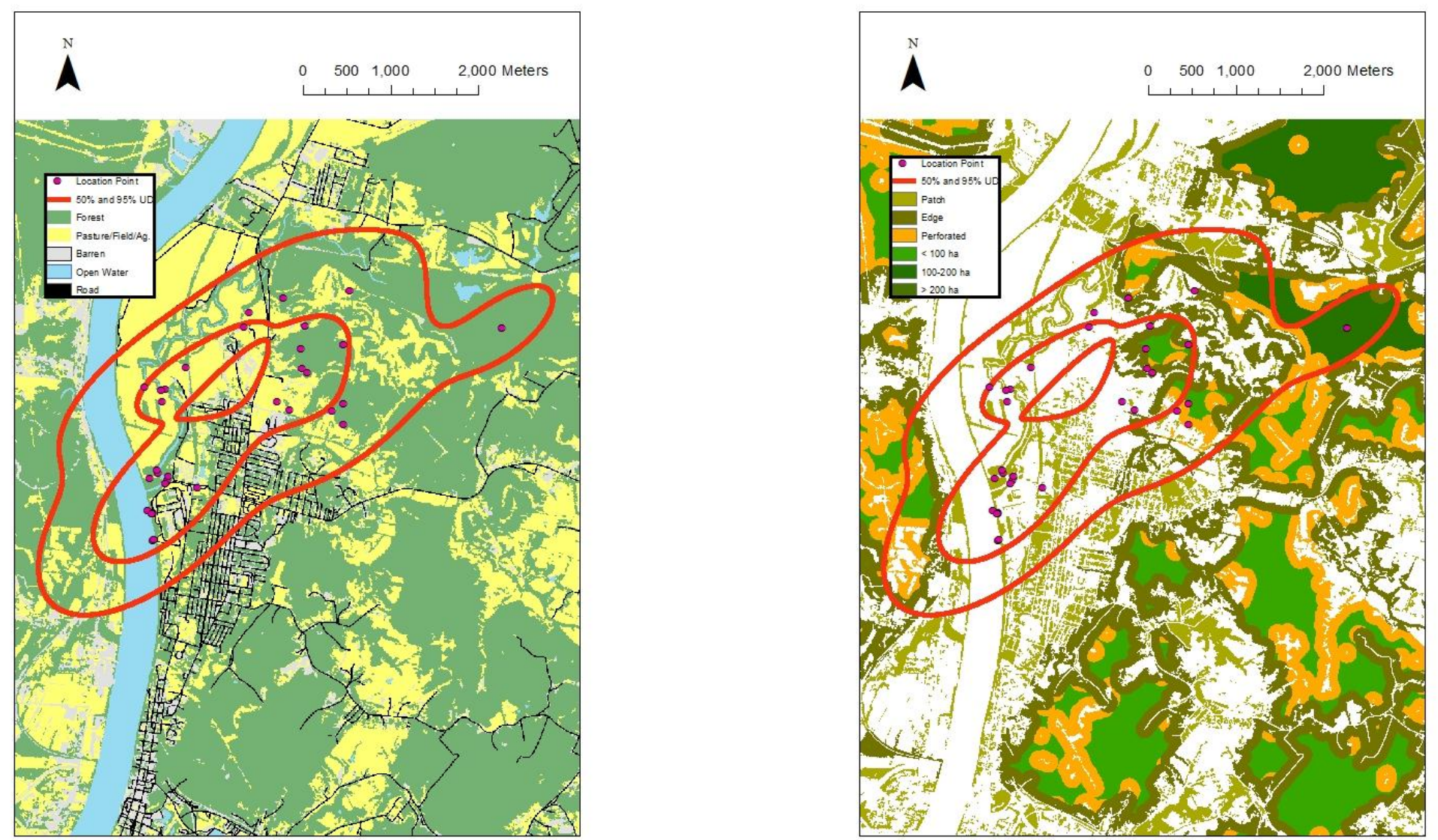
Appendix CCXXXVIIIa. 10138 (adult, annual) - 50\% core and 95\% periphery probability contours of the annual Gaussian fixed kernel home range utilization distributions. Smoothing parameter $(h)$ determined by least squares cross validation, Mason County, West Virginia, 2004-2007 (aspect and slope maps).
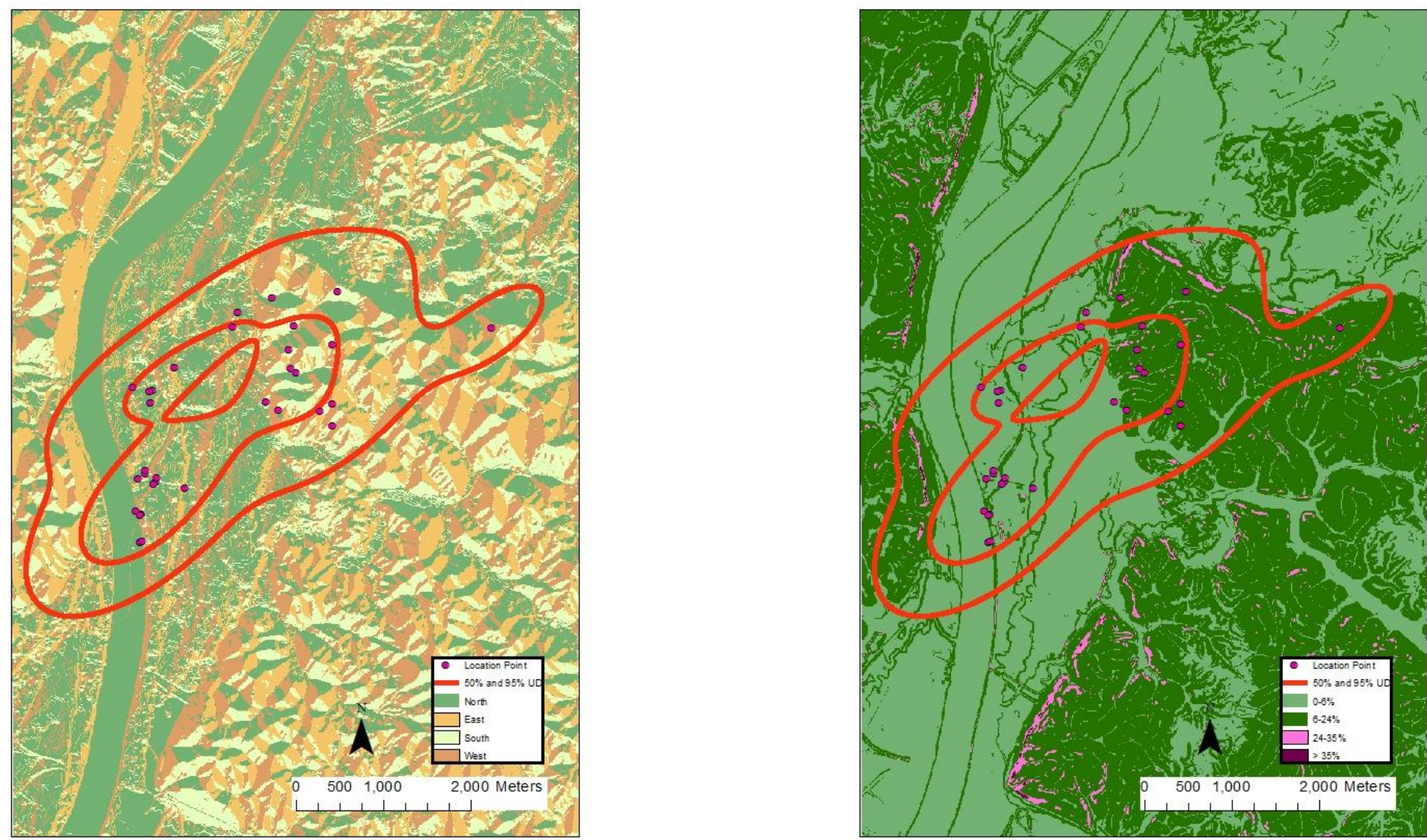
Appendix CCXXXIXa. 10139 (juvenile, annual) - 50\% core and 95\% periphery probability contours of the annual Gaussian fixed kernel home range utilization distributions. Smoothing parameter $(h)$ determined by least squares cross validation, Randolph County, West Virginia, 2004-2007 (land use and land cover, land fragmentation maps).
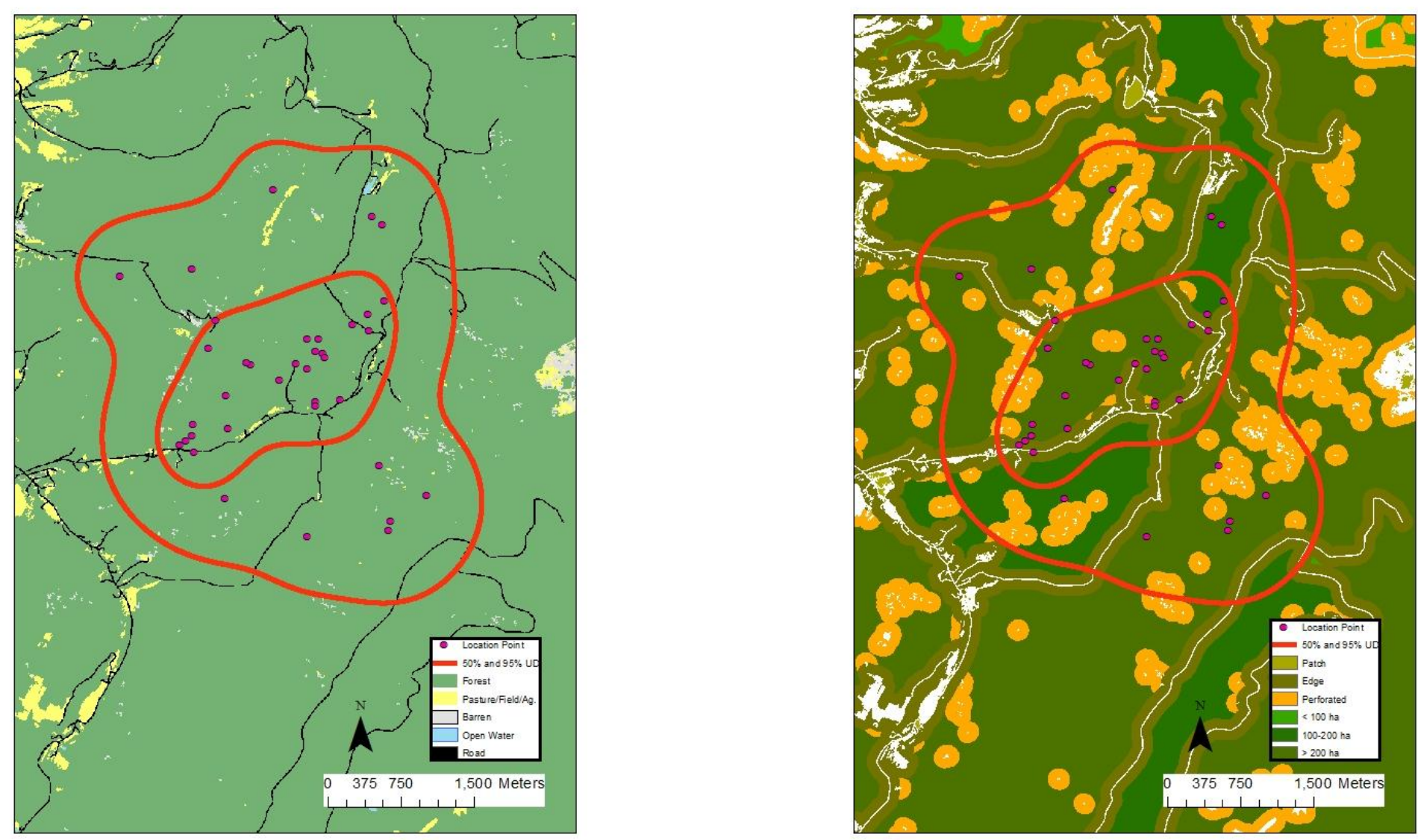
Appendix CCXLa. 10139 (juvenile, annual) - 50\% core and 95\% periphery probability contours of the annual Gaussian fixed kernel home range utilization distributions. Smoothing parameter $(h)$ determined by least squares cross validation, Randolph County, West Virginia, 2004-2007 (aspect and slope maps).
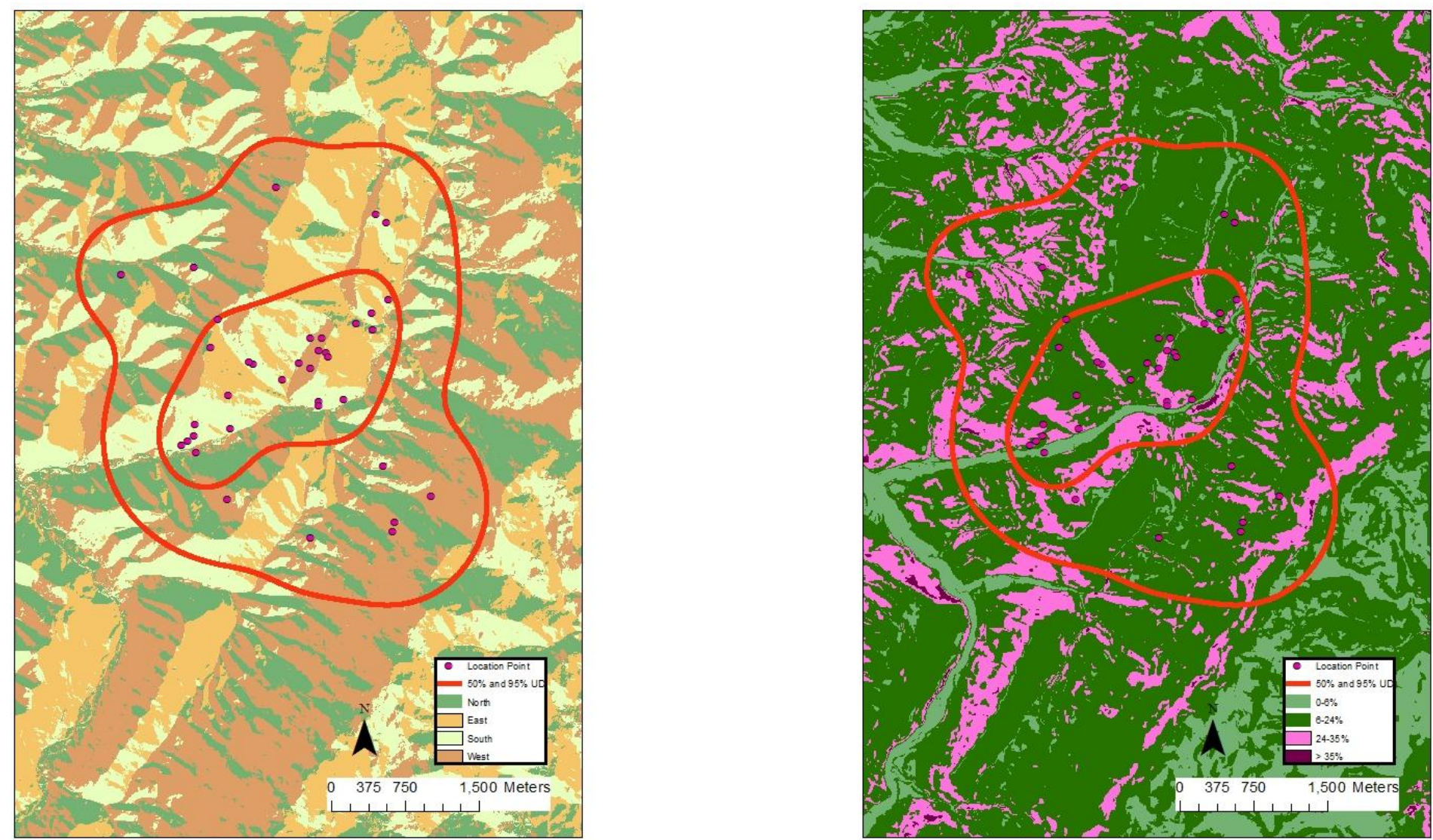
Appendix CCXLIa. 10140 (juvenile, annual) - 50\% core and 95\% periphery probability contours of the annual Gaussian fixed kernel home range utilization distributions. Smoothing parameter $(h)$ determined by least squares cross validation, Randolph County, West Virginia, 2004-2007 (land use and land cover, land fragmentation maps).
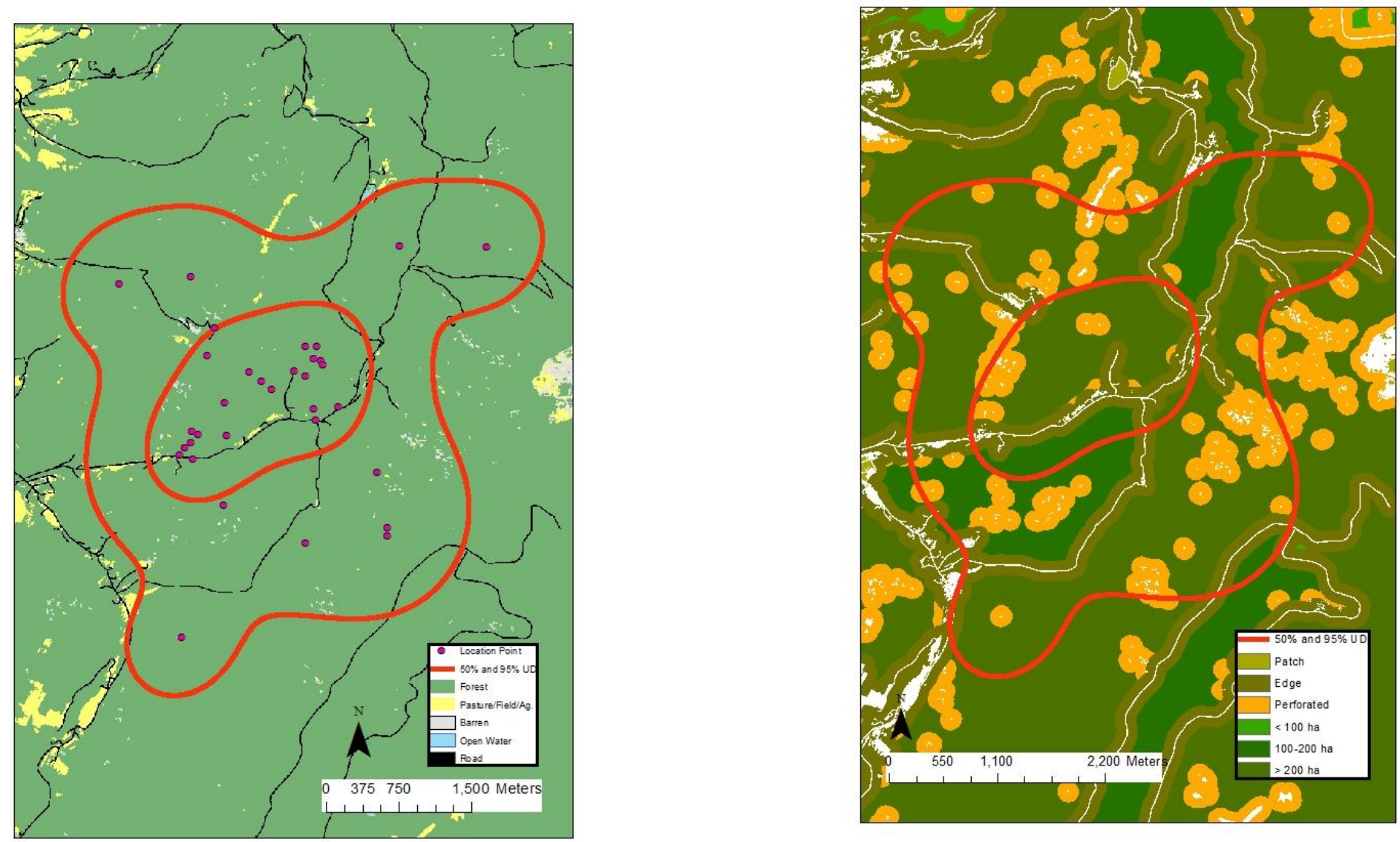
Appendix CCXLII $a .10140$ (juvenile, annual) - 50\% core and 95\% periphery probability contours of the annual Gaussian fixed kernel home range utilization distributions. Smoothing parameter $(h)$ determined by least squares cross validation, Randolph County, West Virginia, 2004-2007 (aspect and slope maps).
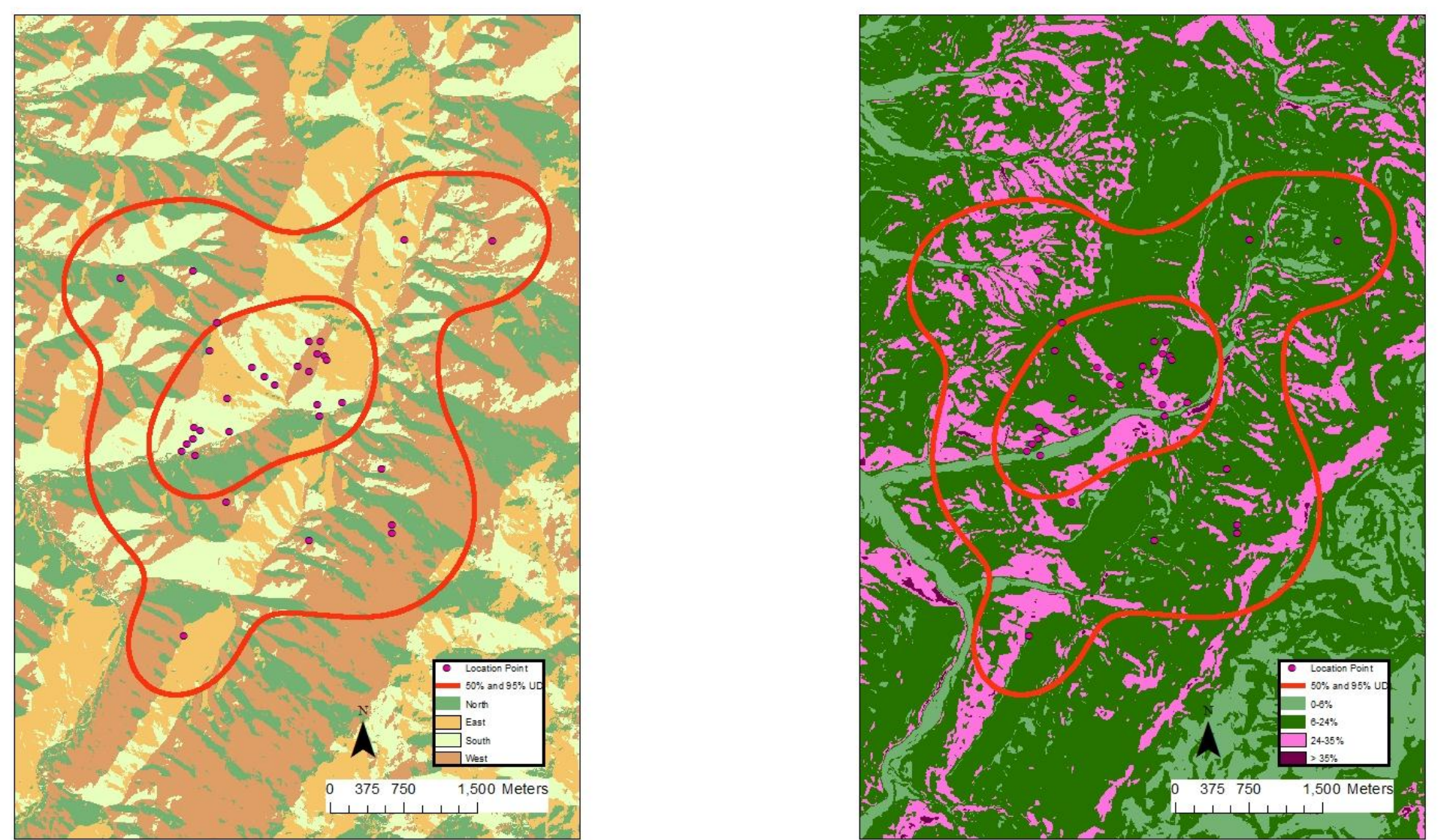
Appendix CCXLIII a. 10141 (adult, annual) - 50\% core and 95\% periphery probability contours of the annual Gaussian fixed kernel home range utilization distributions. Smoothing parameter $(h)$ determined by least squares cross validation, Randolph County, West Virginia, 2004-2007 (land use and land cover, land fragmentation maps).
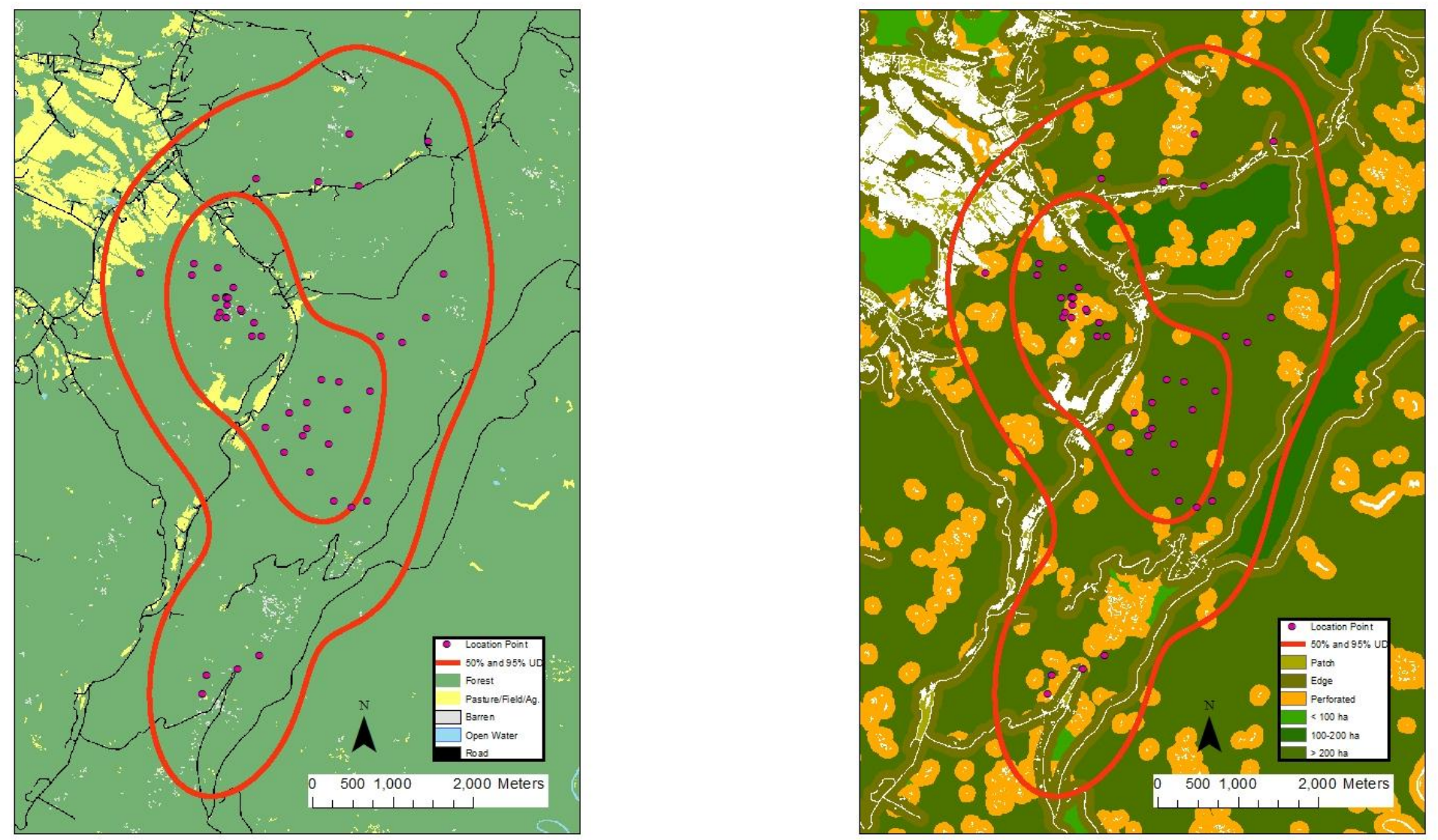
Appendix CCXLIVa. 10141 (adult, annual) - 50\% core and 95\% periphery probability contours of the annual Gaussian fixed kernel home range utilization distributions. Smoothing parameter $(h)$ determined by least squares cross validation, Randolph County, West Virginia, 2004-2007 (aspect and slope maps).
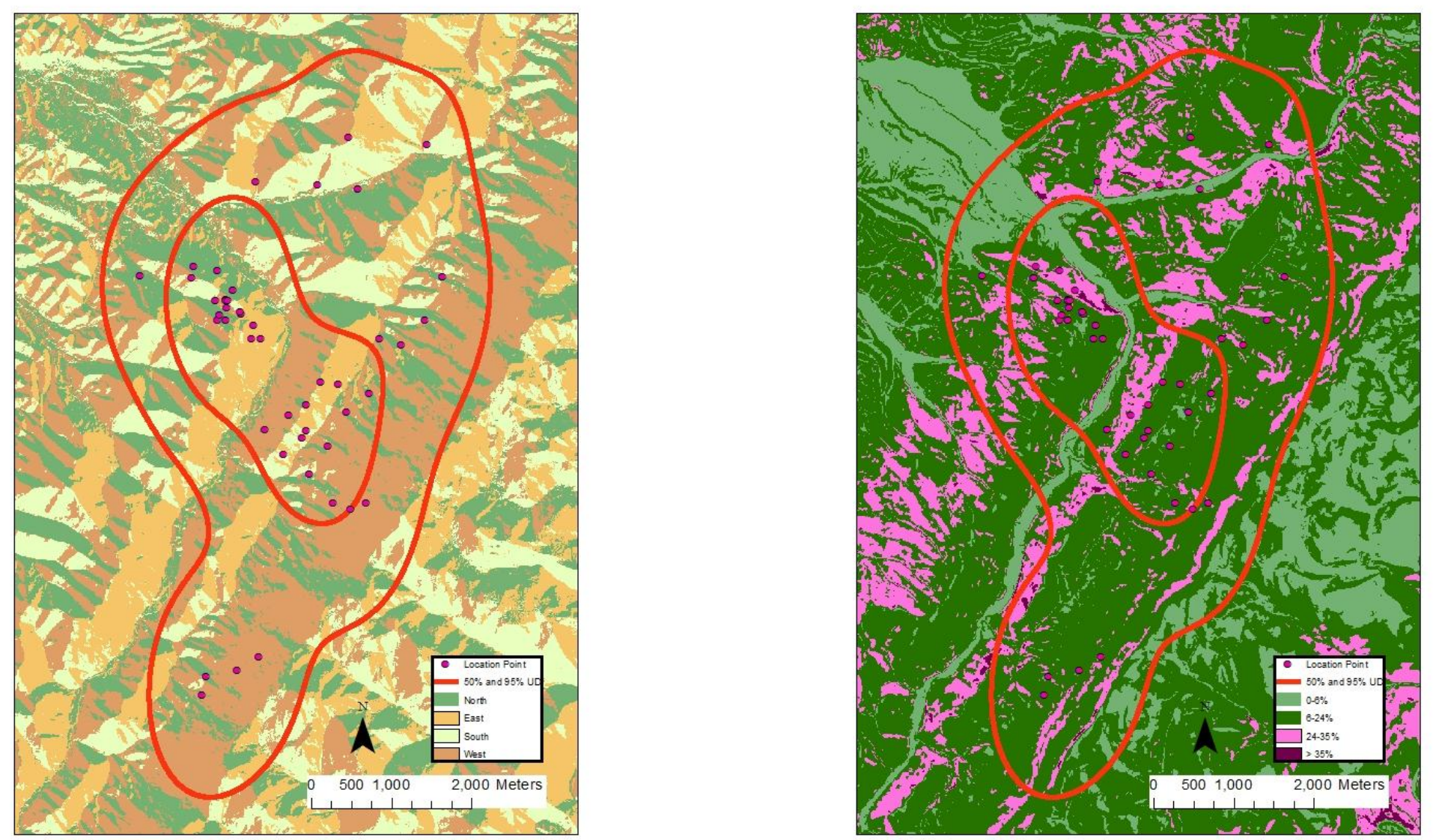
Appendix CCXLVa. 10142 (juvenile, annual) - 50\% core and 95\% periphery probability contours of the annual Gaussian fixed kernel home range utilization distributions. Smoothing parameter $(h)$ determined by least squares cross validation, Randolph County, West Virginia, 2004-2007 (land use and land cover, land fragmentation maps).
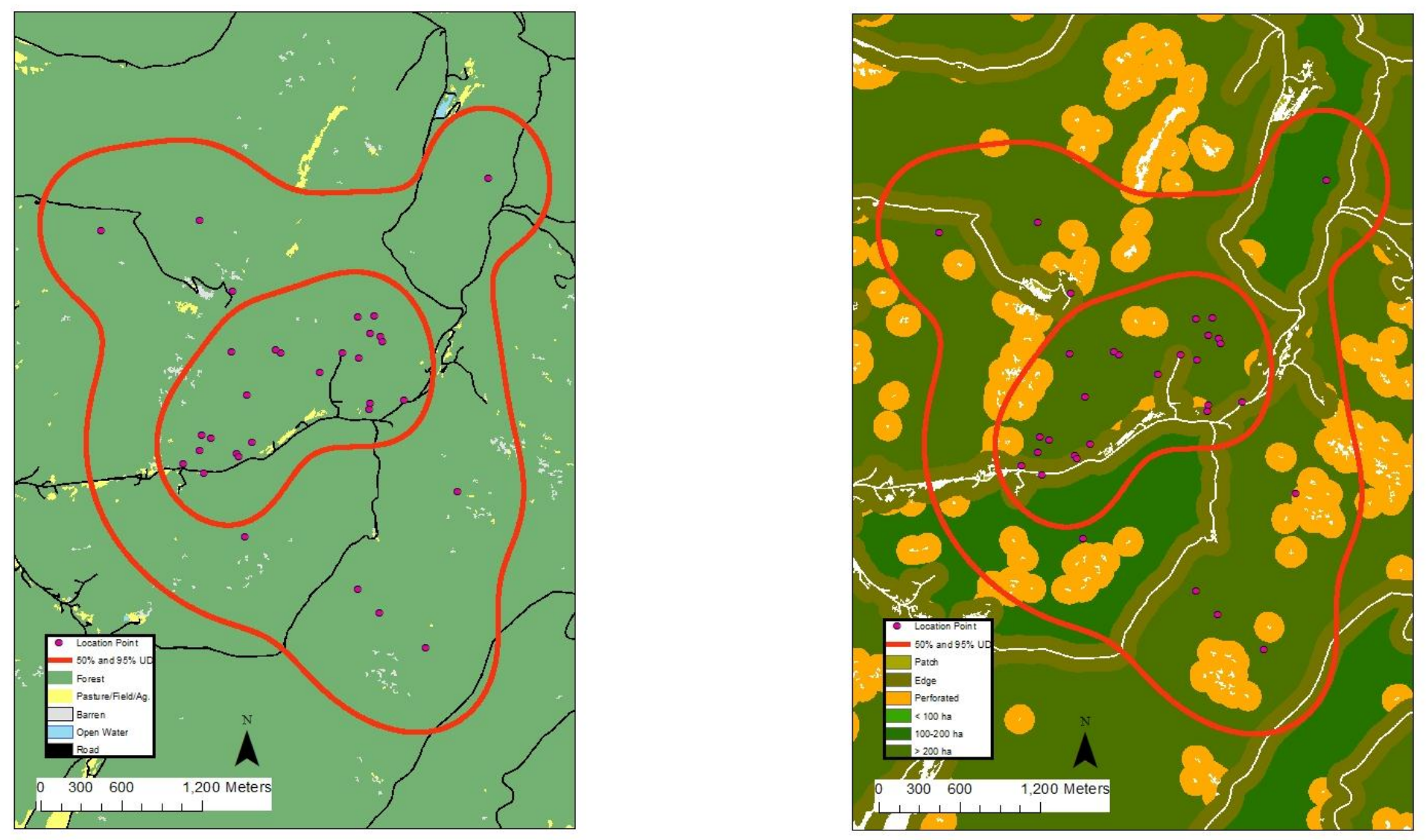
Appendix CCXLVIa. 10142 (juvenile, annual) - 50\% core and 95\% periphery probability contours of the annual Gaussian fixed kernel home range utilization distributions. Smoothing parameter $(h)$ determined by least squares cross validation, Randolph County, West Virginia, 2004-2007 (aspect and slope maps).
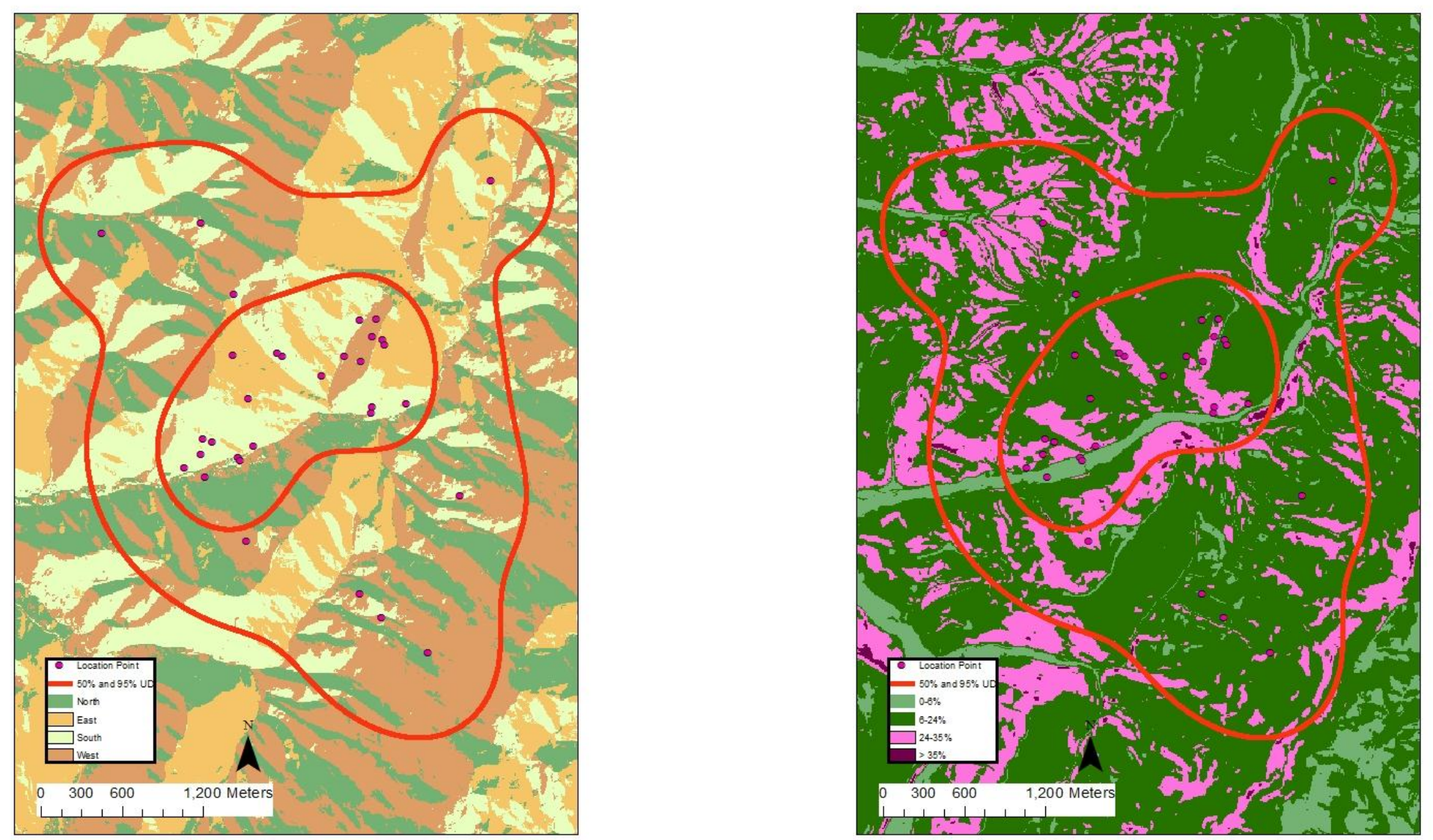
Appendix CCXLVII a. 10143 (juvenile, annual) - 50\% core and 95\% periphery probability contours of the annual Gaussian fixed kernel home range utilization distributions. Smoothing parameter $(h)$ determined by least squares cross validation, Randolph County, West Virginia, 2004-2007 (land use and land cover, land fragmentation maps).
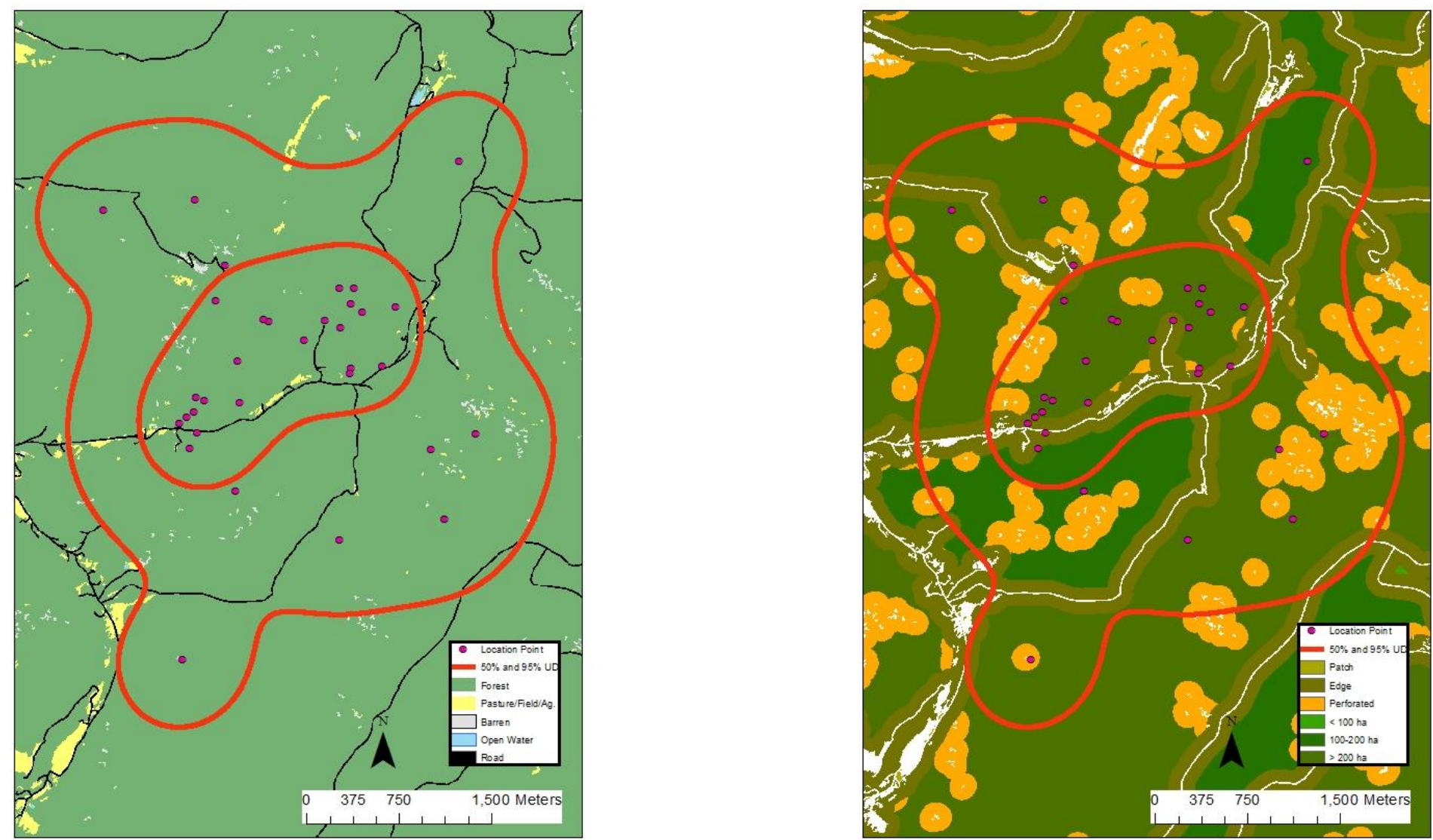
Appendix CCXLVIIIa. 10143 (juvenile, annual) - 50\% core and 95\% periphery probability contours of the annual Gaussian fixed kernel home range utilization distributions. Smoothing parameter $(h)$ determined by least squares cross validation, Randolph County, West Virginia, 2004-2007 (aspect and slope maps).
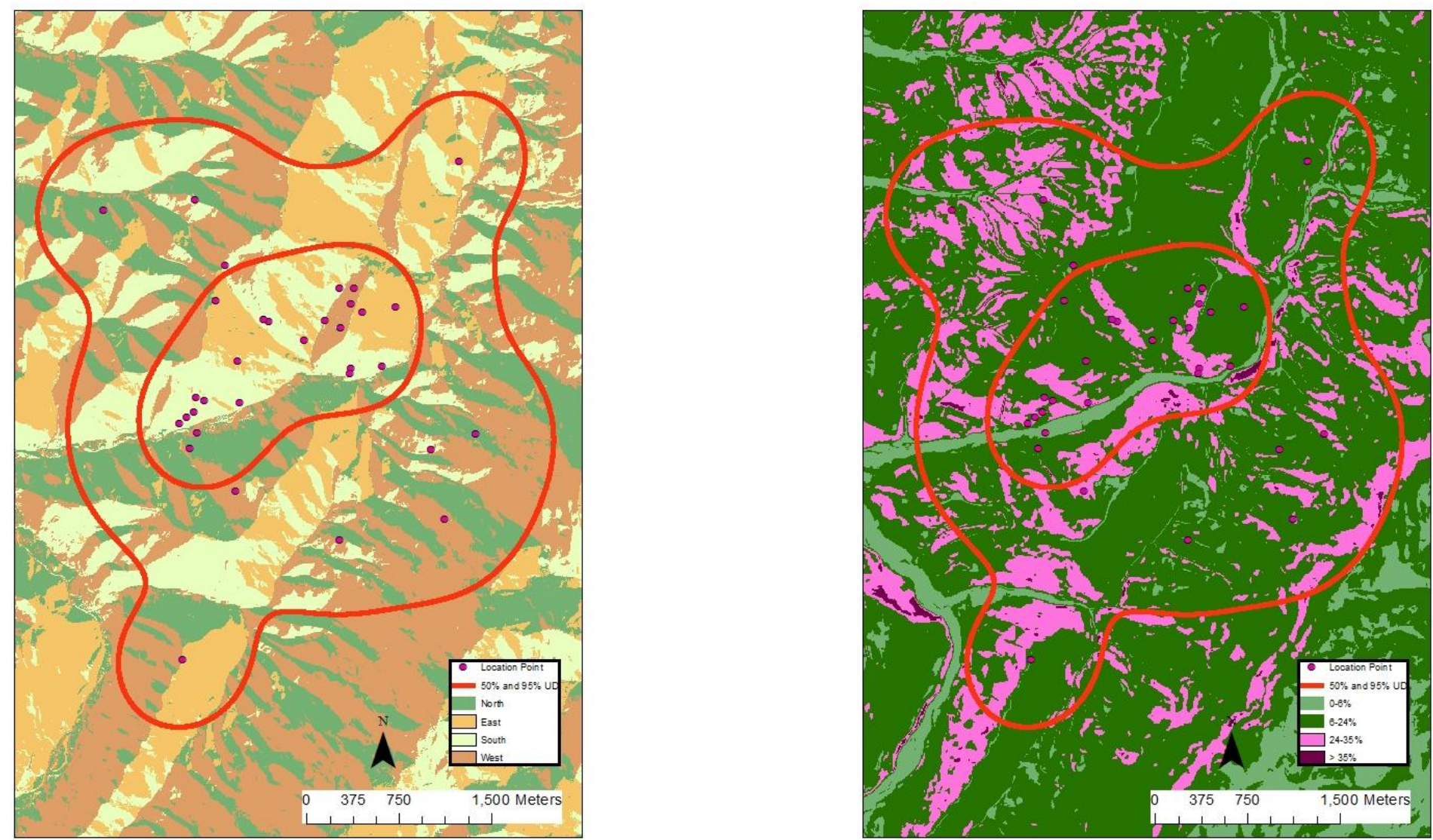
Appendix CCXLIXa. 10144 (adult, annual) - 50\% core and 95\% periphery probability contours of the annual Gaussian fixed kernel home range utilization distributions. Smoothing parameter $(h)$ determined by least squares cross validation, Greenbrier County, West Virginia, 2004-2007 (land use and land cover, land fragmentation maps).
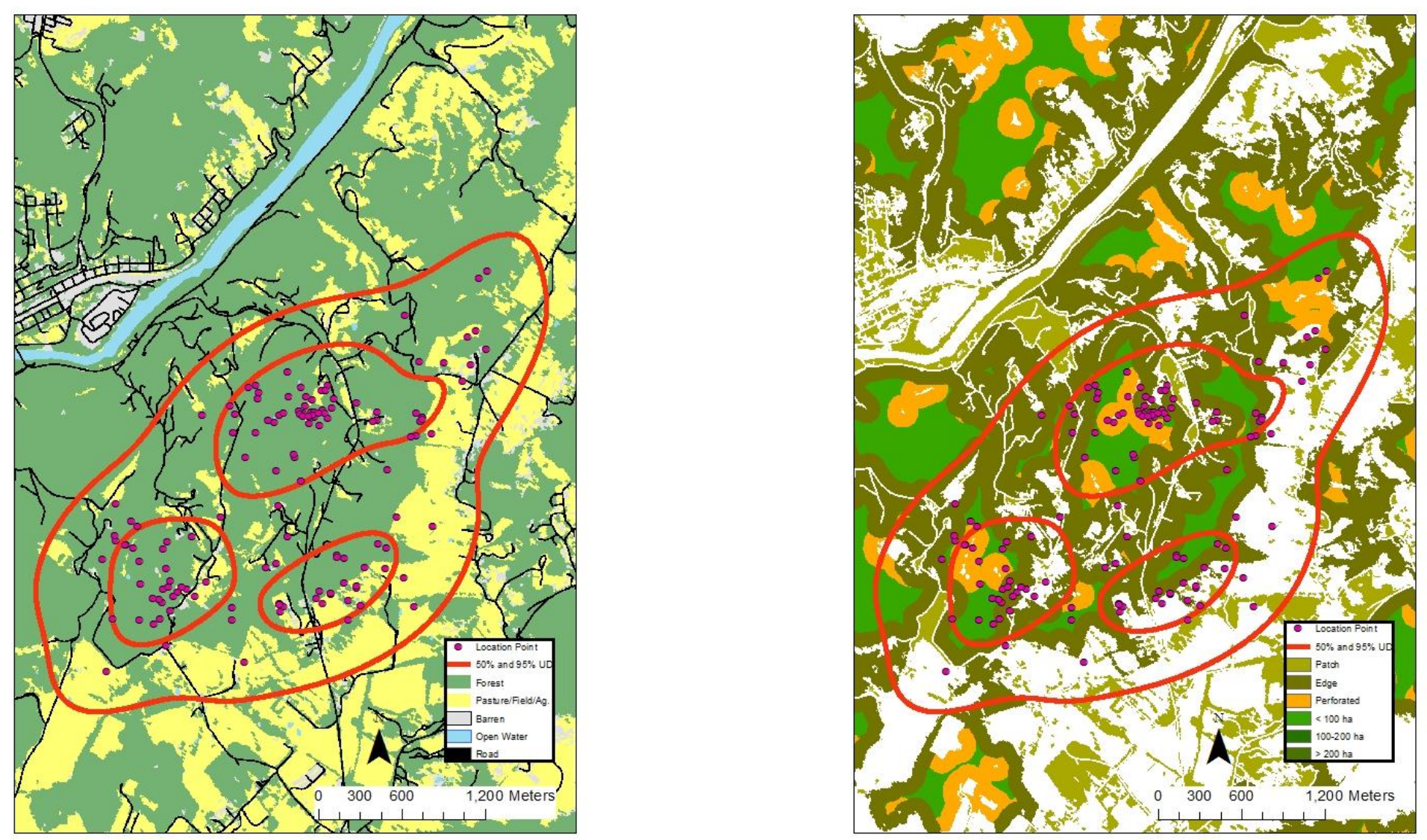
Appendix CCLa. 10144 (adult, annual) - 50\% core and 95\% periphery probability contours of the annual Gaussian fixed kernel home range utilization distributions. Smoothing parameter $(h)$ determined by least squares cross validation, Greenbrier County, West Virginia, 2004-2007 (aspect and slope maps).
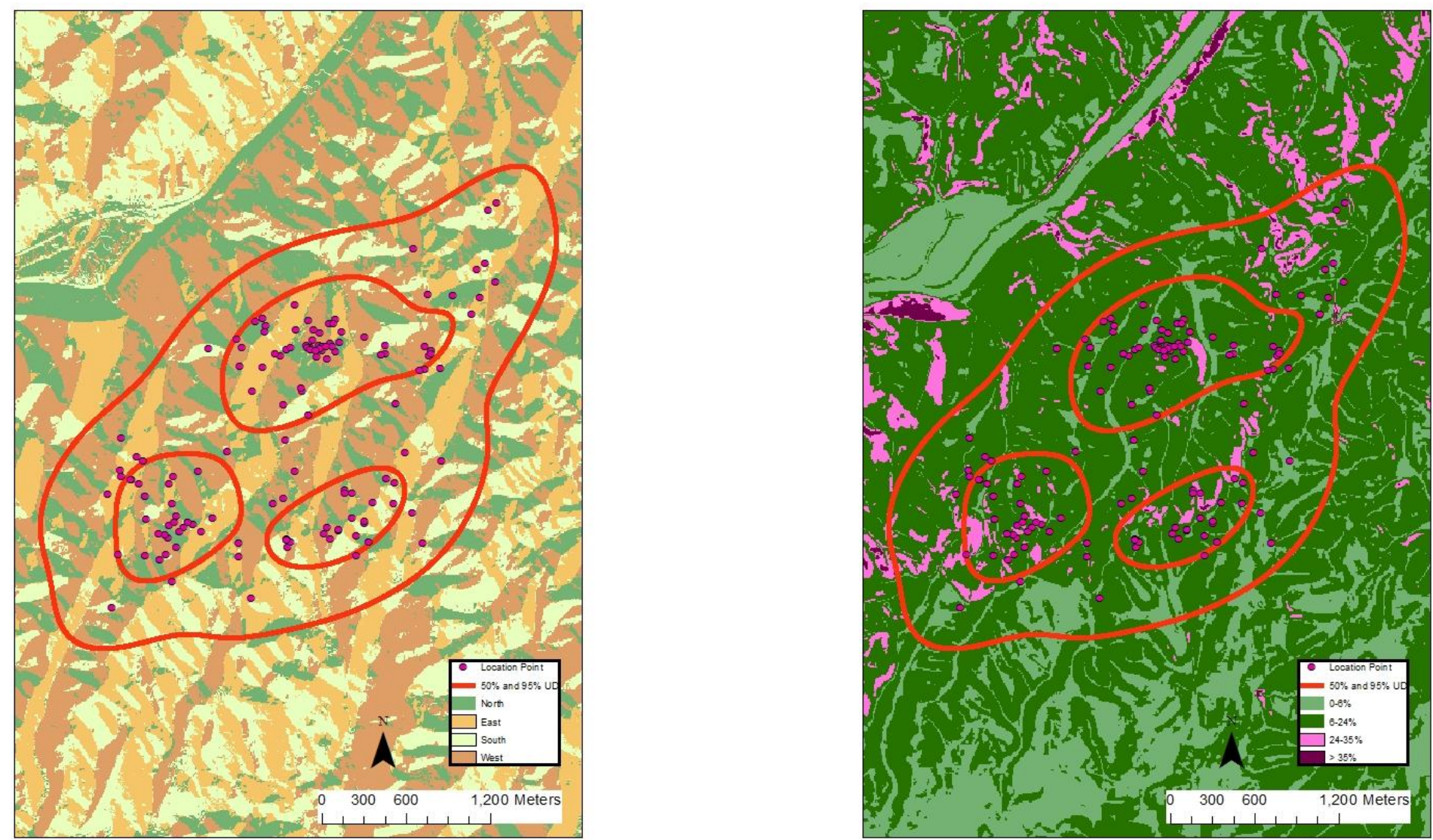
Appendix CCLIa. 10145 (adult, fall) - 50\% core and 95\% periphery probability contours of the annual Gaussian fixed kernel home range utilization distributions. Smoothing parameter $(h)$ determined by least squares cross validation, Greenbrier County, West Virginia, 2004-2007 (land use and land cover, land fragmentation maps).
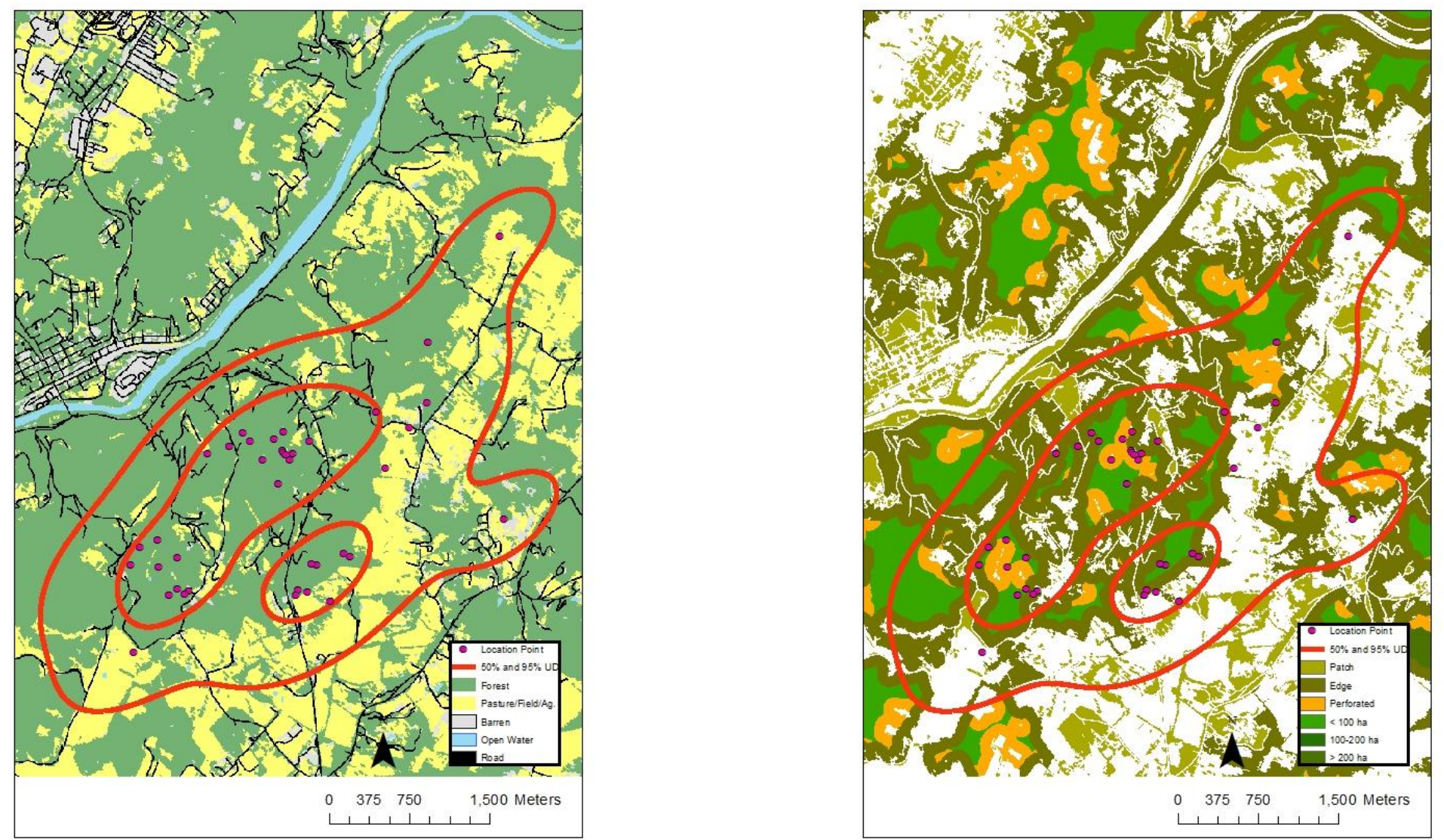
Appendix CCLII a. 10145 (adult, fall) - 50\% core and 95\% periphery probability contours of the annual Gaussian fixed kernel home range utilization distributions. Smoothing parameter $(h)$ determined by least squares cross validation, Greenbrier County, West Virginia, 2004-2007 (aspect and slope maps).
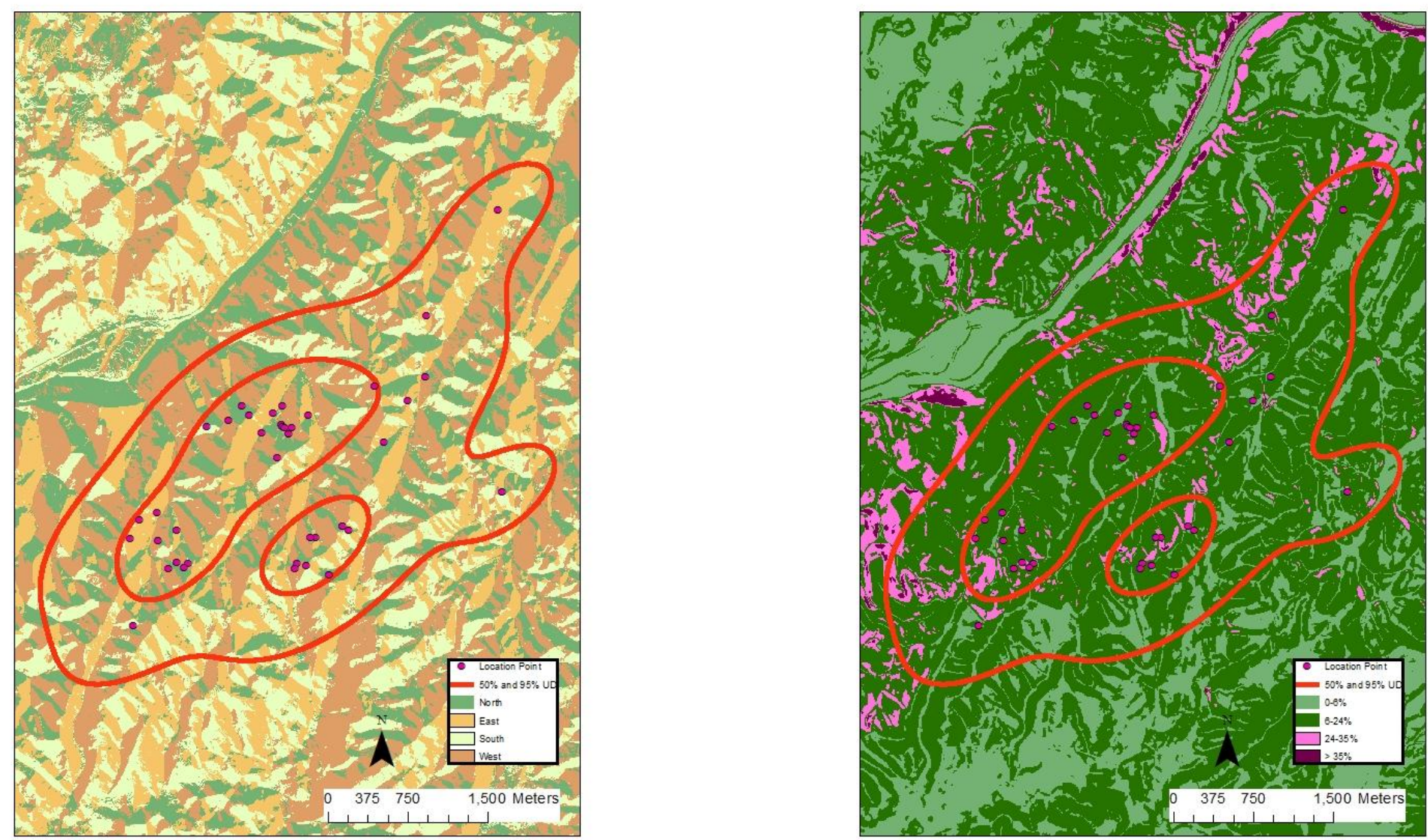
Appendix CCLIII $a$. 10146 (adult, fall-winter) - 50\% core and 95\% periphery probability contours of the annual Gaussian fixed kernel home range utilization distributions. Smoothing parameter $(h)$ determined by least squares cross validation, Greenbrier County, West Virginia, 2004-2007 (land use and land cover, land fragmentation maps).
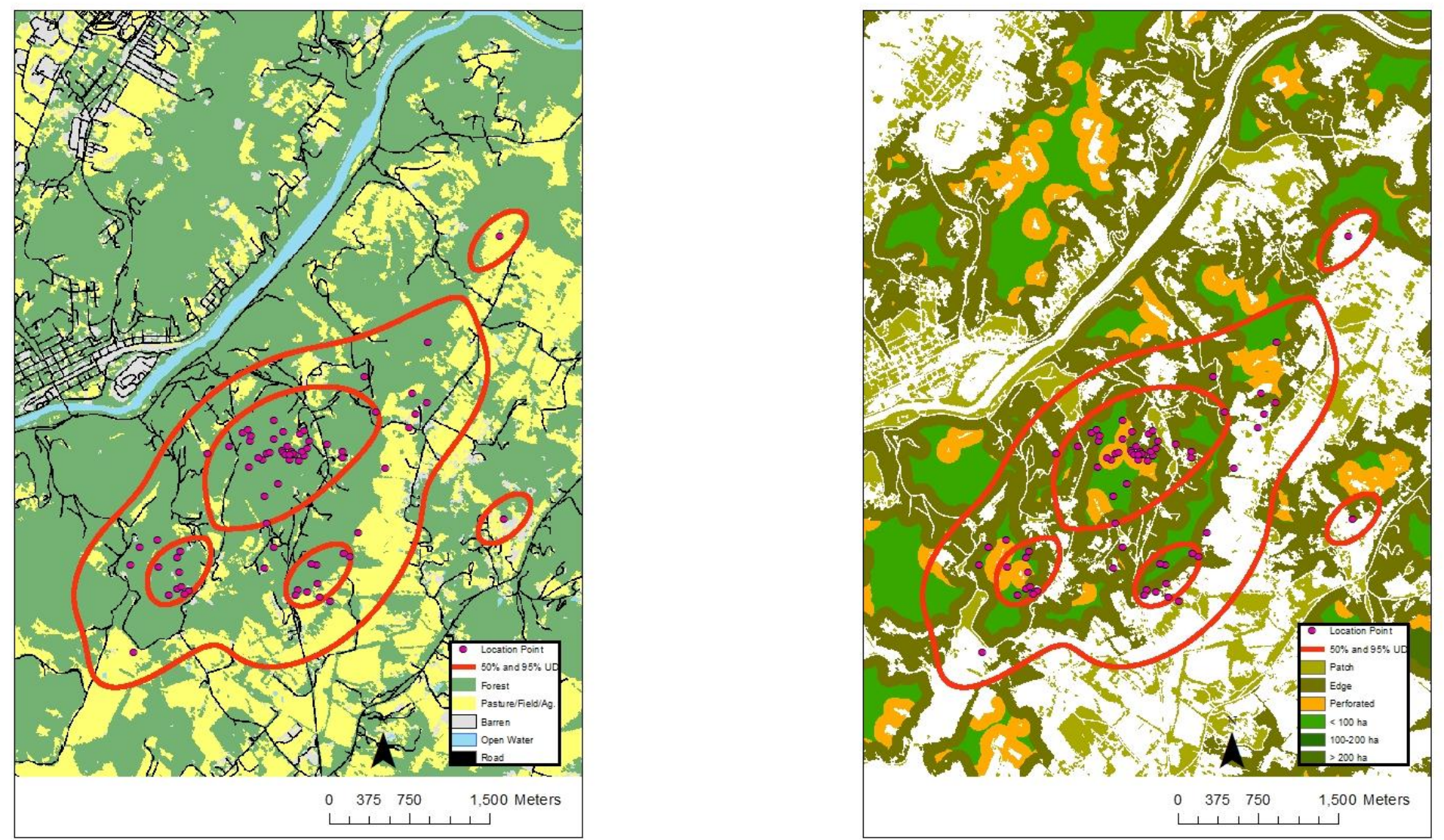
Appendix CCLIVa. 10146 (adult, fall-winter) - 50\% core and 95\% periphery probability contours of the annual Gaussian fixed kernel home range utilization distributions. Smoothing parameter $(h)$ determined by least squares cross validation, Greenbrier County, West Virginia, 2004-2007 (aspect and slope maps).
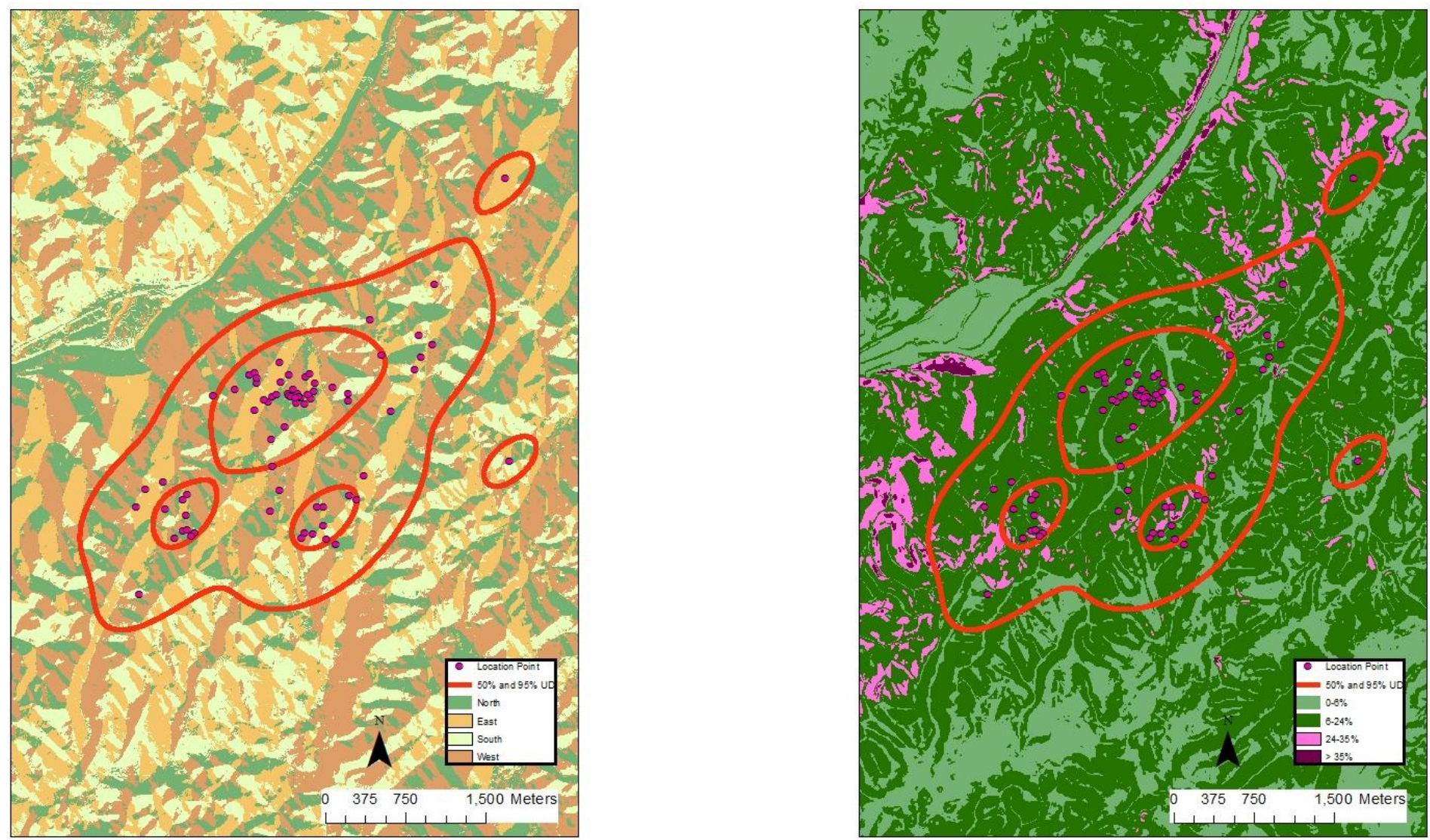
Appendix CCLVa. 10147 (adult, spring) - 50\% core and 95\% periphery probability contours of the annual Gaussian fixed kernel home range utilization distributions. Smoothing parameter $(h)$ determined by least squares cross validation, Greenbrier County, West Virginia, 2004-2007 (land use and land cover, land fragmentation maps).
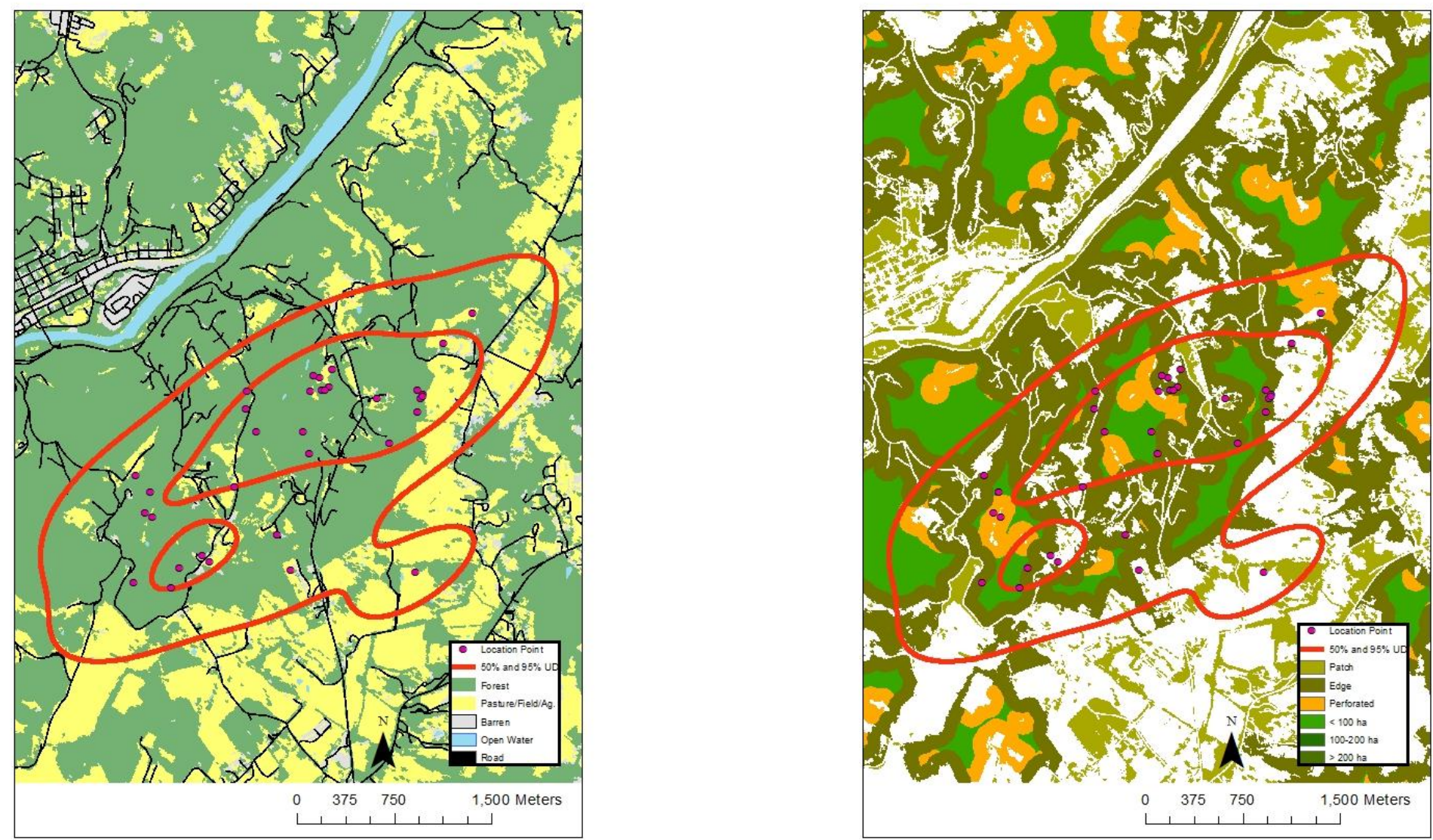
Appendix CCLVIa. 10147 (adult, spring) - 50\% core and 95\% periphery probability contours of the annual Gaussian fixed kernel home range utilization distributions. Smoothing parameter $(h)$ determined by least squares cross validation, Greenbrier County, West Virginia, 2004-2007 (aspect and slope maps).
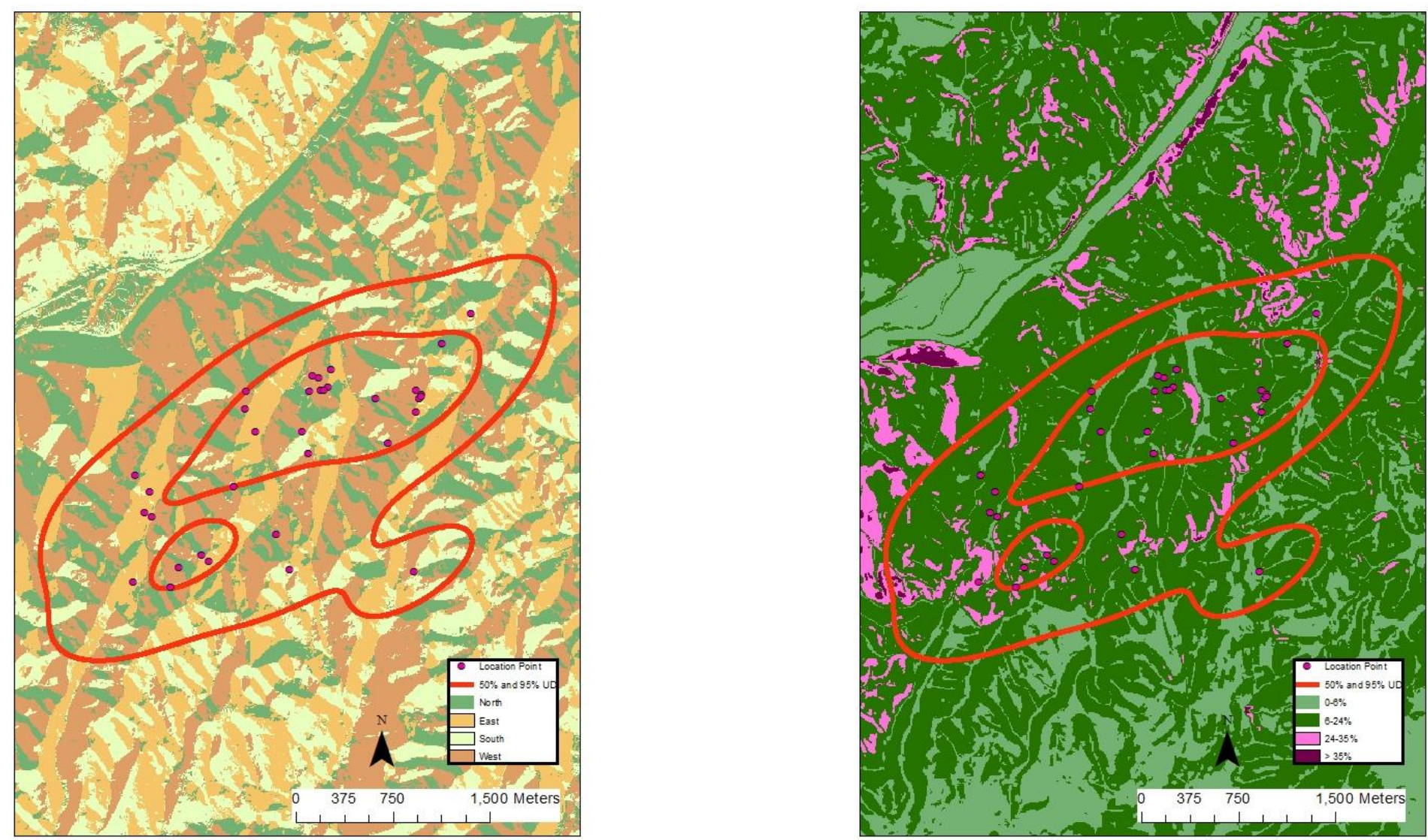
Appendix CCLVII a. 10148 (adult, spring-summer) - 50\% core and 95\% periphery probability contours of the annual Gaussian fixed kernel home range utilization distributions. Smoothing parameter $(h)$ determined by least squares cross validation, Greenbrier County, West Virginia, 2004-2007 (land use and land cover, land fragmentation maps).
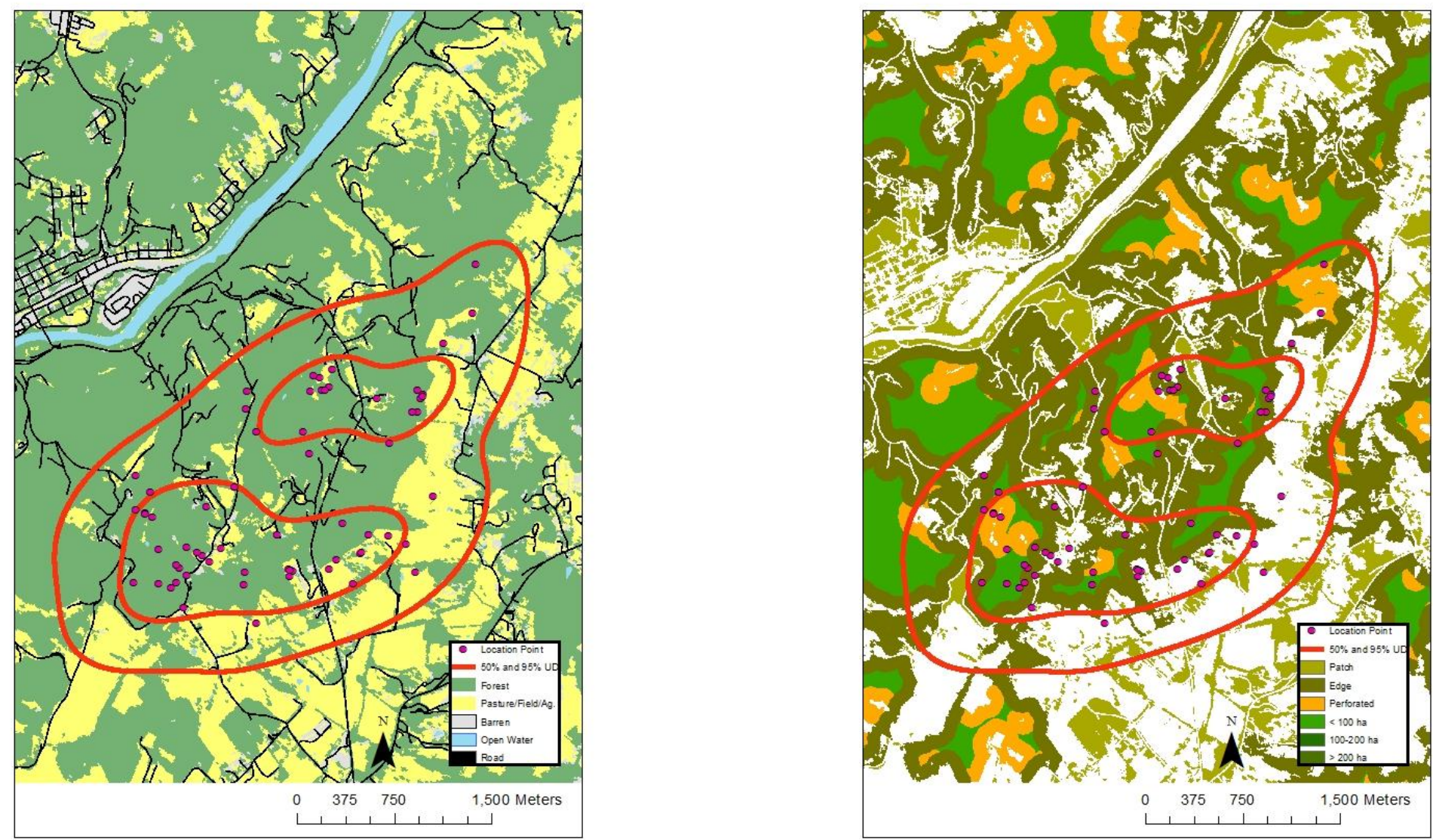
Appendix CCLVIIIa. 10148 (adult, spring-summer) - 50\% core and 95\% periphery probability contours of the annual Gaussian fixed kernel home range utilization distributions. Smoothing parameter $(h)$ determined by least squares cross validation, Greenbrier County, West Virginia, 2004-2007 (aspect and slope maps).
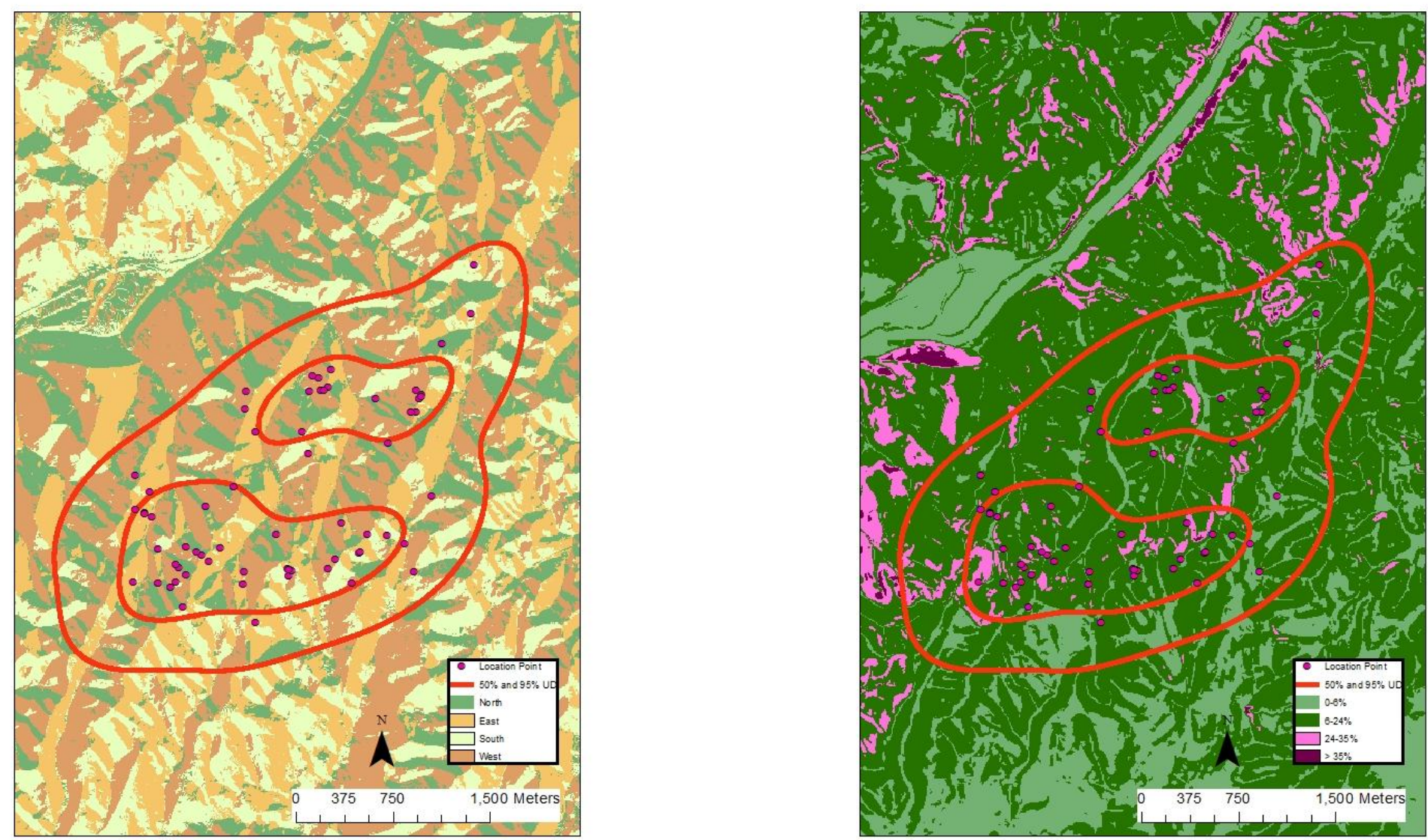
Appendix CCLIXa. 10149 (adult, winter) - 50\% core and 95\% periphery probability contours of the annual Gaussian fixed kernel home range utilization distributions. Smoothing parameter $(h)$ determined by least squares cross validation, Greenbrier County, West Virginia, 2004-2007 (land use and land cover, land fragmentation maps).
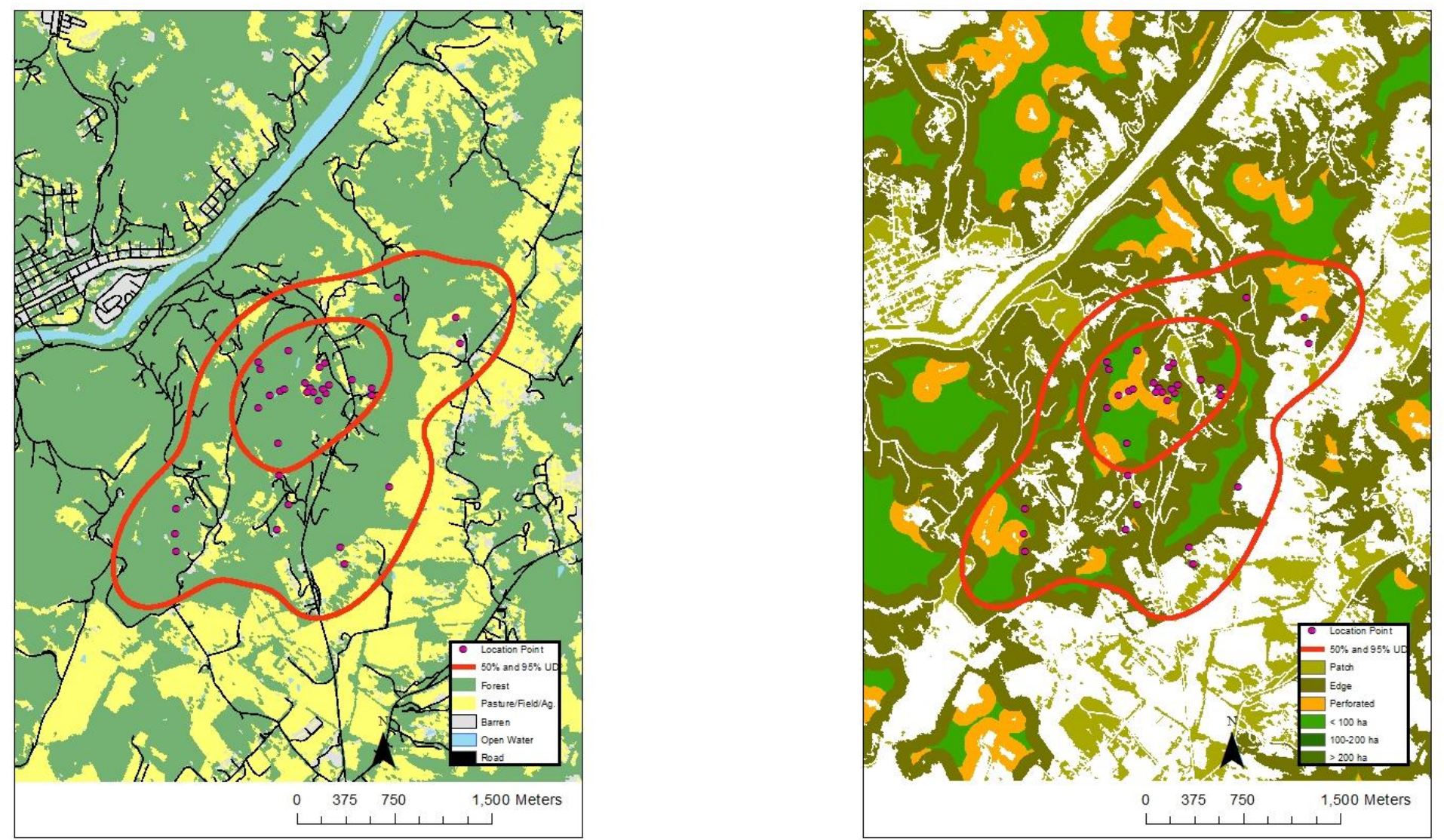
Appendix CCLXa. 10149 (adult, winter) - 50\% core and 95\% periphery probability contours of the annual Gaussian fixed kernel home range utilization distributions. Smoothing parameter $(h)$ determined by least squares cross validation, Greenbrier County, West Virginia, 2004-2007 (aspect and slope maps).
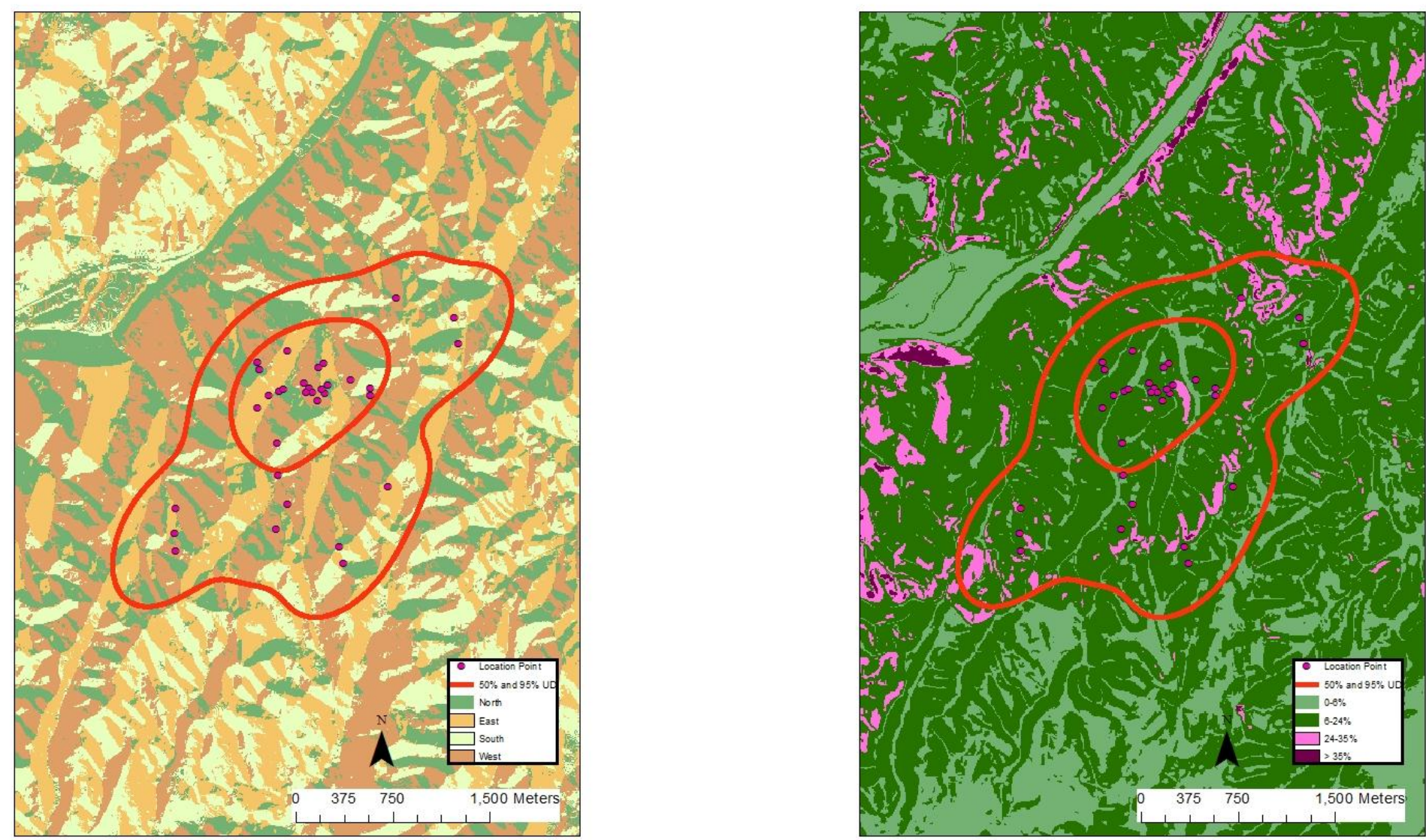
Appendix CCLXI $a$. 10150 (adult, annual) - 50\% core and 95\% periphery probability contours of the annual Gaussian fixed kernel home range utilization distributions. Smoothing parameter $(h)$ determined by least squares cross validation, Greenbrier County, West Virginia, 2004-2007 (land use and land cover, land fragmentation maps).
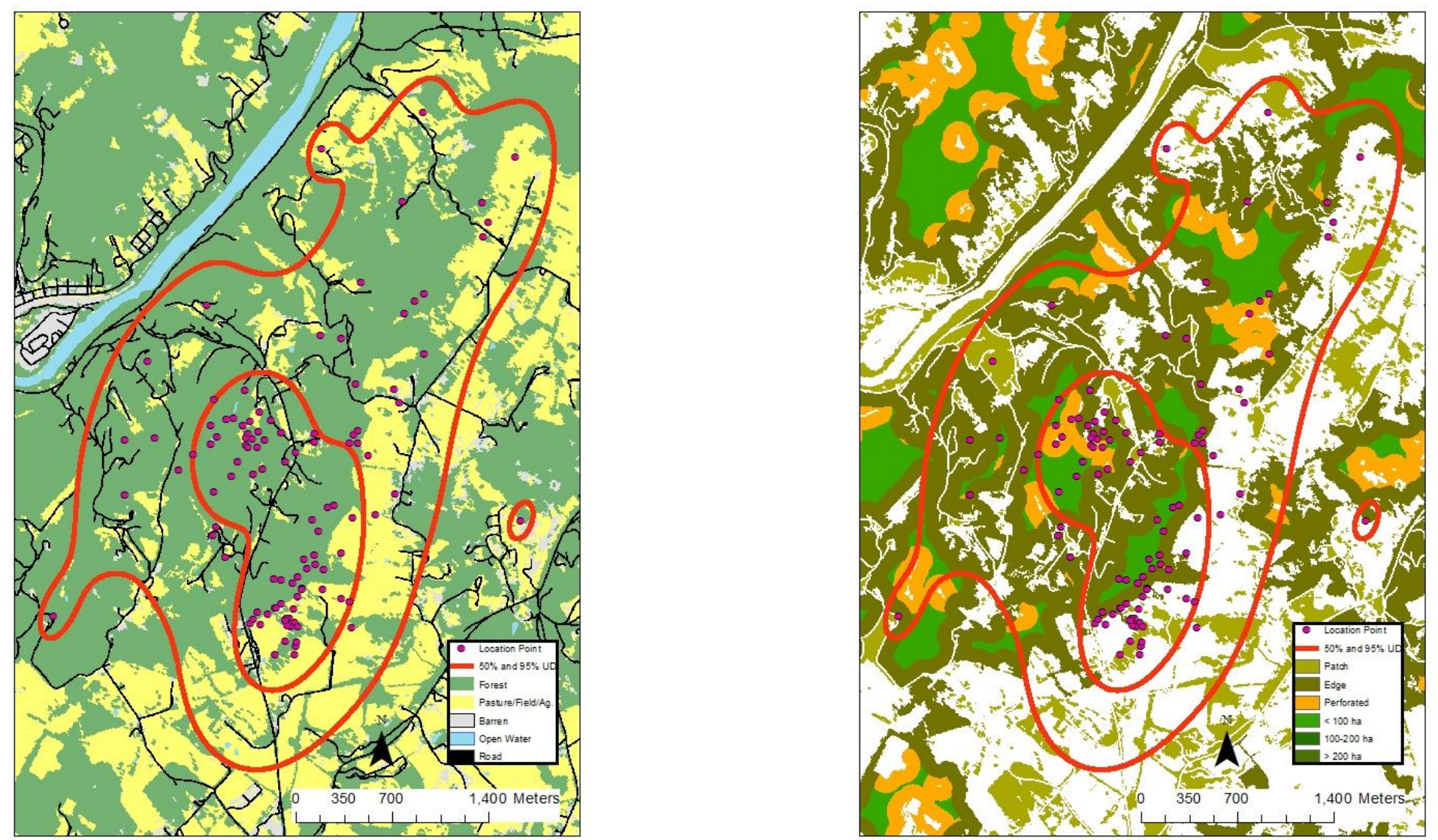
Appendix CCLXIIa. 10150 (adult, annual) - 50\% core and 95\% periphery probability contours of the annual Gaussian fixed kernel home range utilization distributions. Smoothing parameter $(h)$ determined by least squares cross validation, Greenbrier County, West Virginia, 2004-2007 (aspect and slope maps).
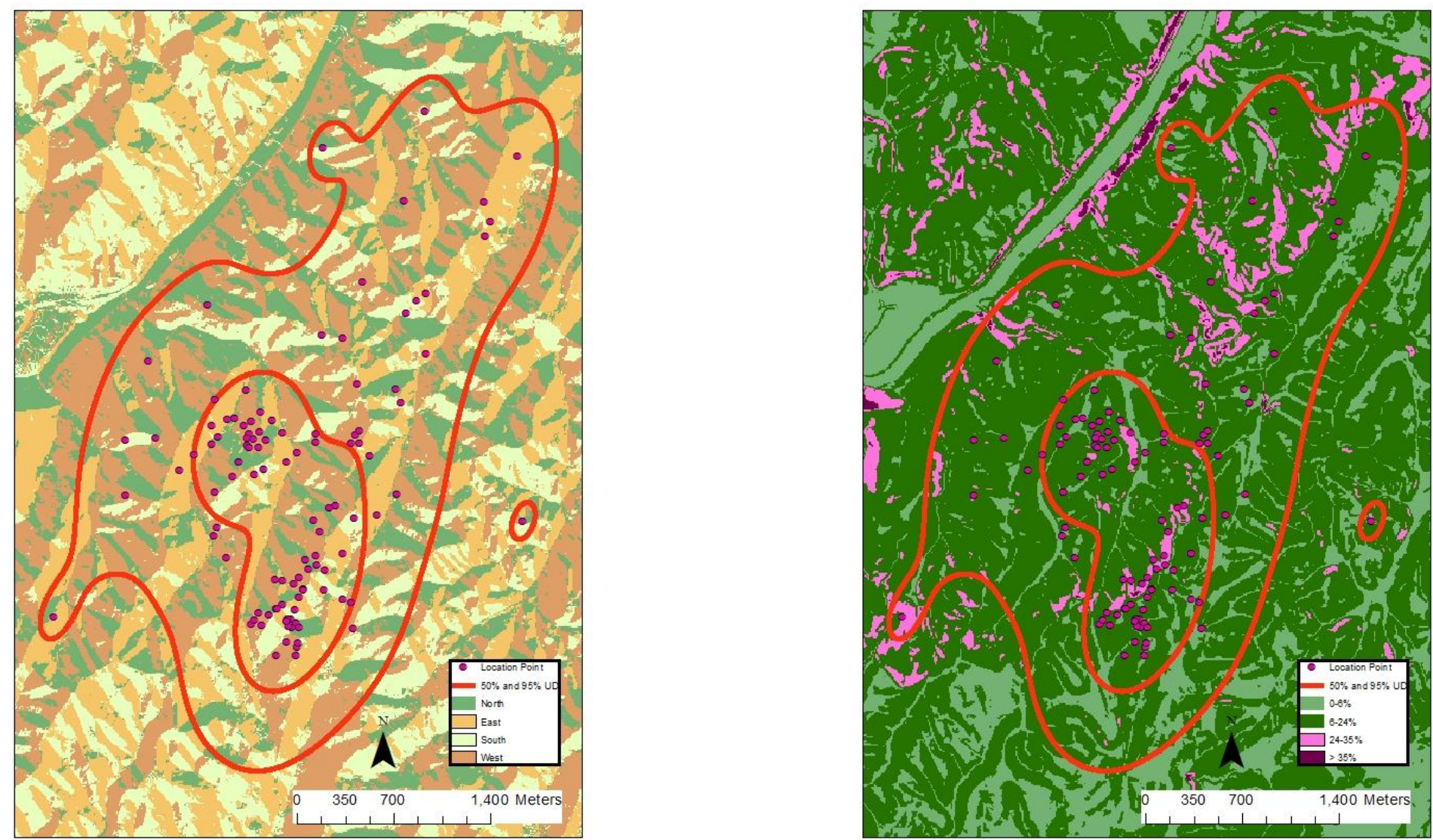
Appendix CCLXIII a. 10151 (adult, fall) - 50\% core and 95\% periphery probability contours of the annual Gaussian fixed kernel home range utilization distributions. Smoothing parameter $(h)$ determined by least squares cross validation, Greenbrier County, West Virginia, 2004-2007 (land use and land cover, land fragmentation maps).
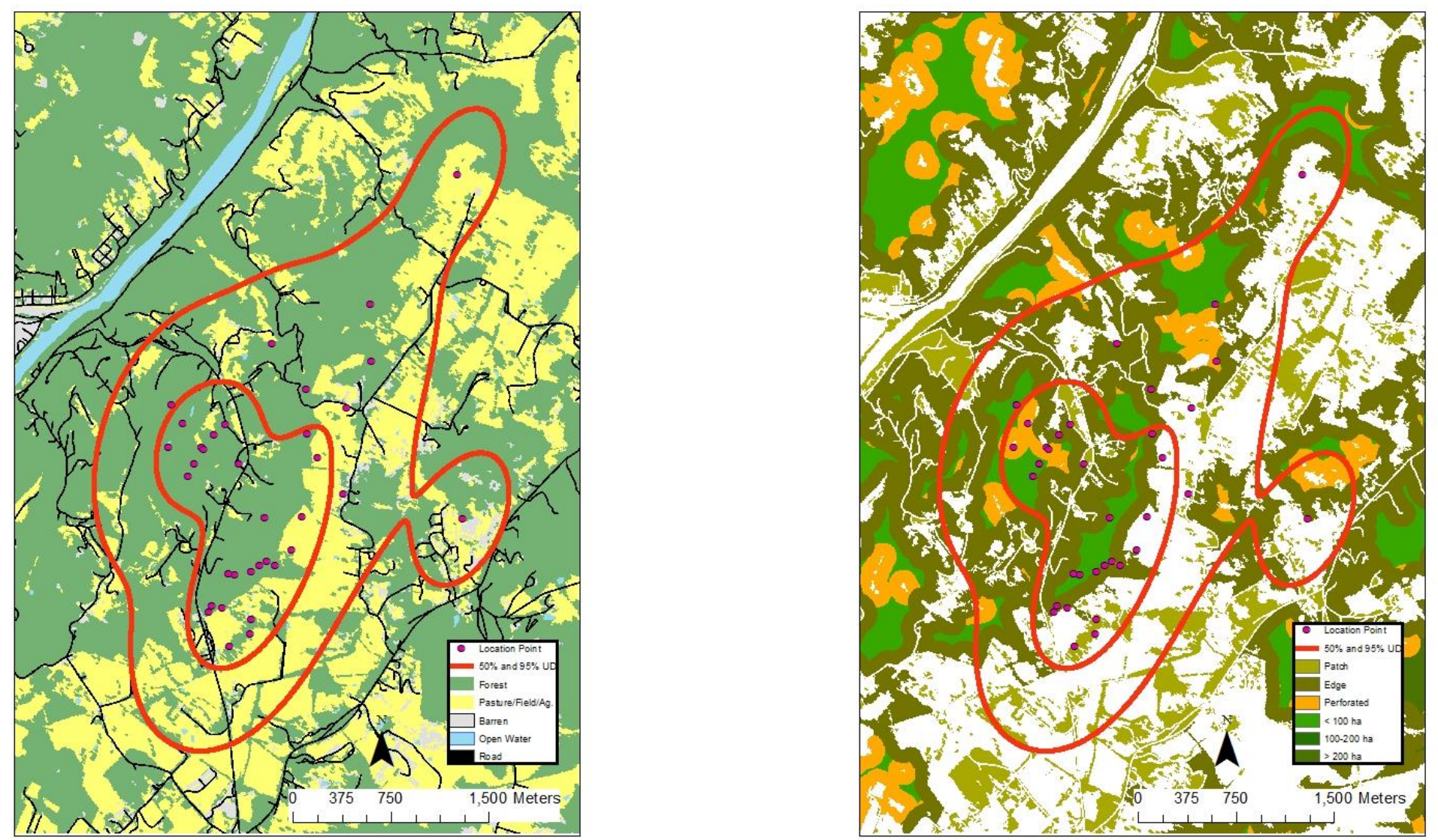
Appendix CCLXIVa. 10151 (adult, fall) - 50\% core and 95\% periphery probability contours of the annual Gaussian fixed kernel home range utilization distributions. Smoothing parameter $(h)$ determined by least squares cross validation, Greenbrier County, West Virginia, 2004-2007 (aspect and slope maps).
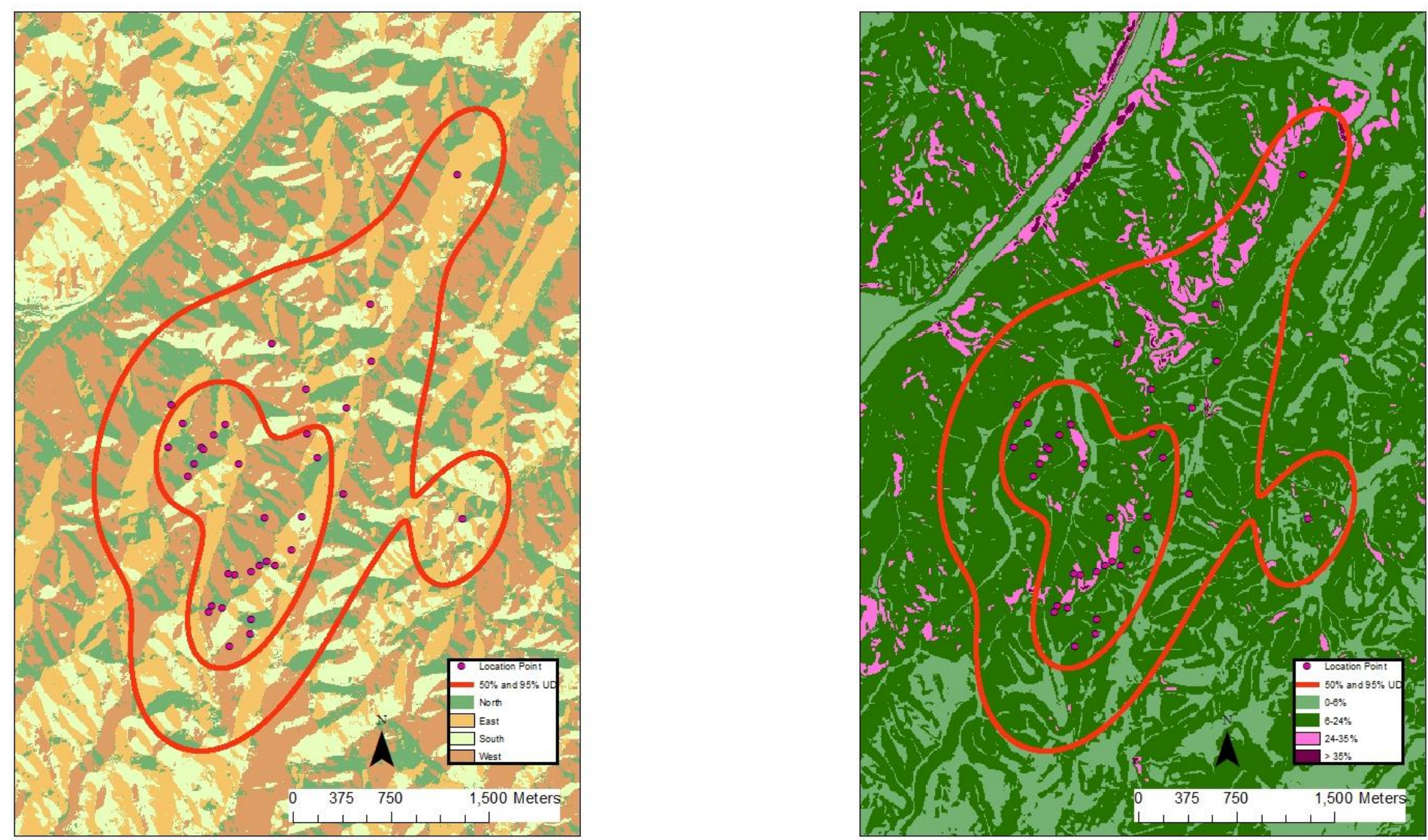
Appendix CCLXVa. 10152 (adult, fall-winter) - 50\% core and 95\% periphery probability contours of the annual Gaussian fixed kernel home range utilization distributions. Smoothing parameter $(h)$ determined by least squares cross validation, Greenbrier County, West Virginia, 2004-2007 (land use and land cover, land fragmentation maps).
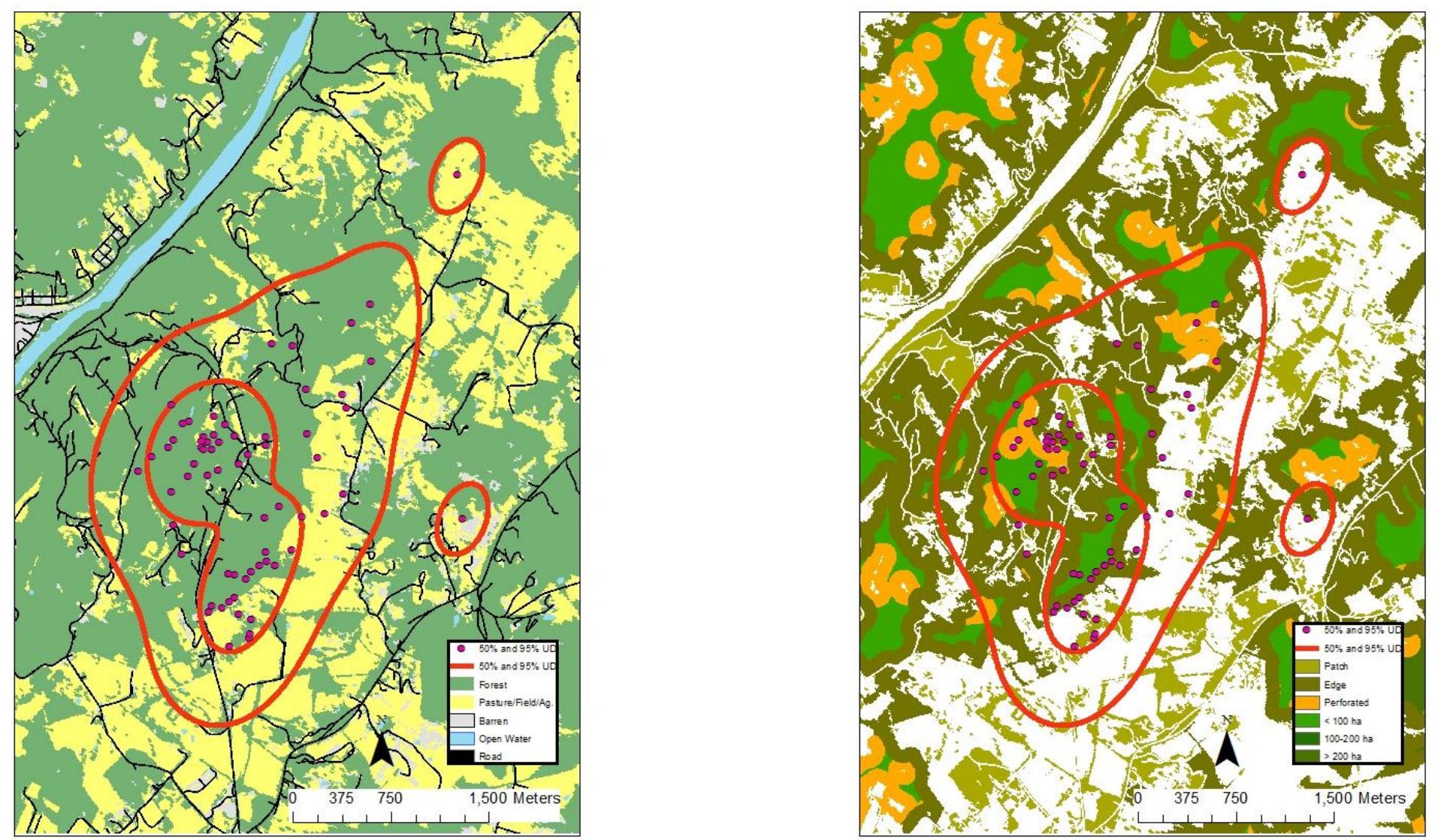
Appendix CCLXVIa. 10152 (adult, fall-winter) - 50\% core and 95\% periphery probability contours of the annual Gaussian fixed kernel home range utilization distributions. Smoothing parameter $(h)$ determined by least squares cross validation, Greenbrier County, West Virginia, 2004-2007 (aspect and slope maps).
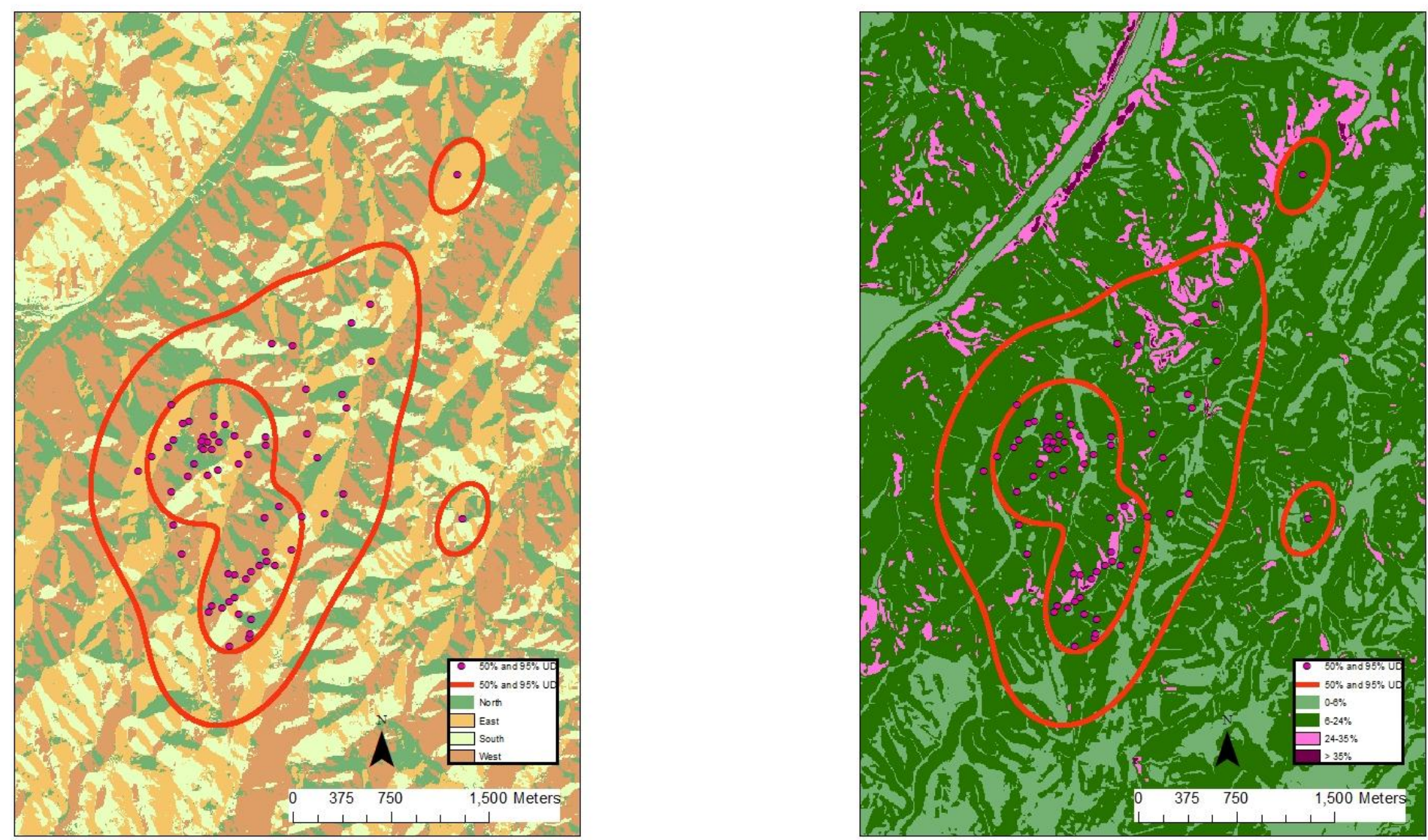
Appendix CCLXVII $a$. 10153 (adult, spring-summer) - 50\% core and 95\% periphery probability contours of the annual Gaussian fixed kernel home range utilization distributions. Smoothing parameter $(h)$ determined by least squares cross validation, Greenbrier County, West Virginia, 2004-2007 (land use and land cover, land fragmentation maps).
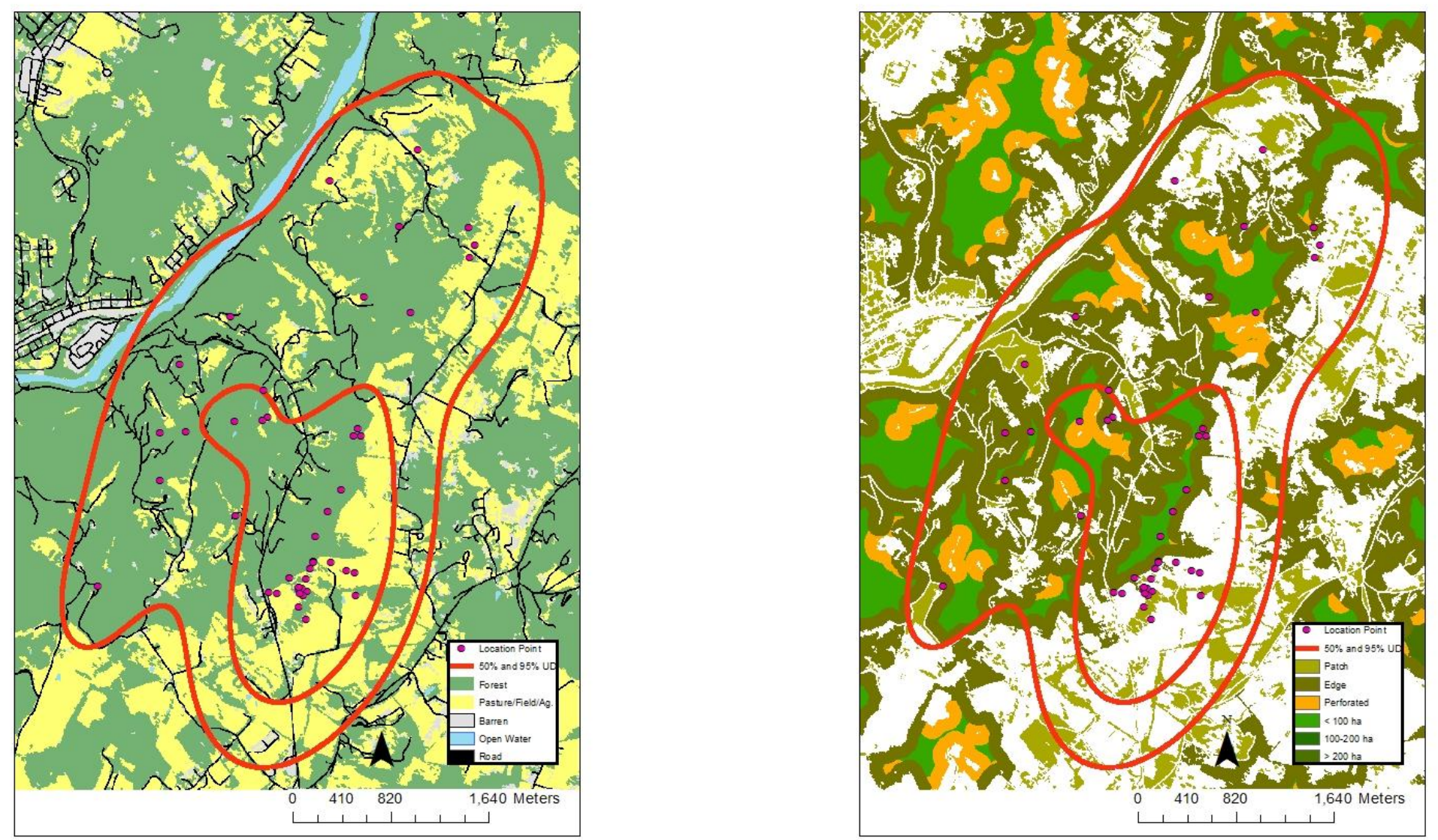
Appendix CCLXVIIIa. 10153 (adult, spring-summer) - 50\% core and 95\% periphery probability contours of the annual Gaussian fixed kernel home range utilization distributions. Smoothing parameter $(h)$ determined by least squares cross validation, Greenbrier County, West Virginia, 2004-2007 (aspect and slope maps).
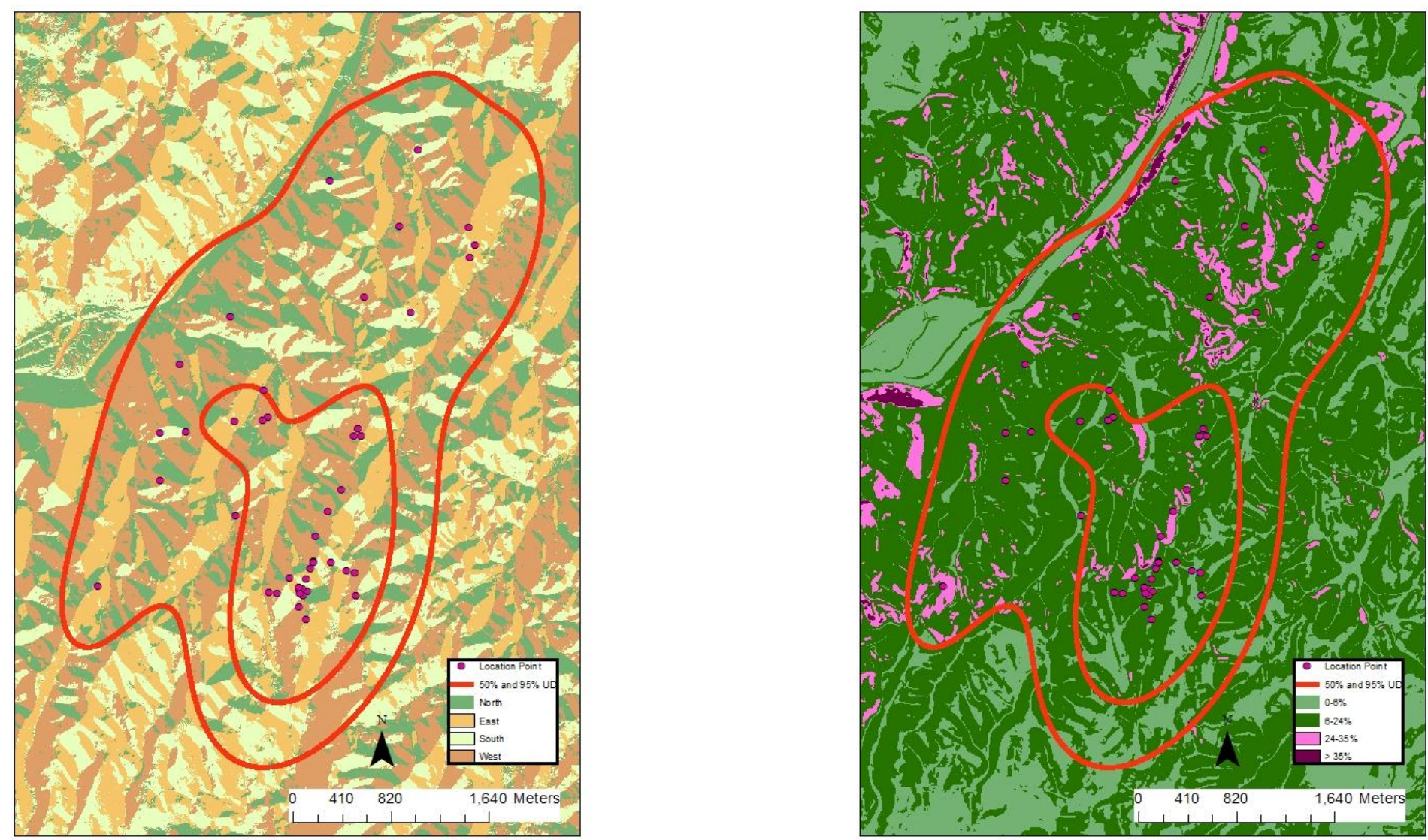
Appendix CCLXIXa. 10154 (adult, winter) - 50\% core and 95\% periphery probability contours of the annual Gaussian fixed kernel home range utilization distributions. Smoothing parameter $(h)$ determined by least squares cross validation, Greenbrier County, West Virginia, 2004-2007 (land use and land cover, land fragmentation maps).
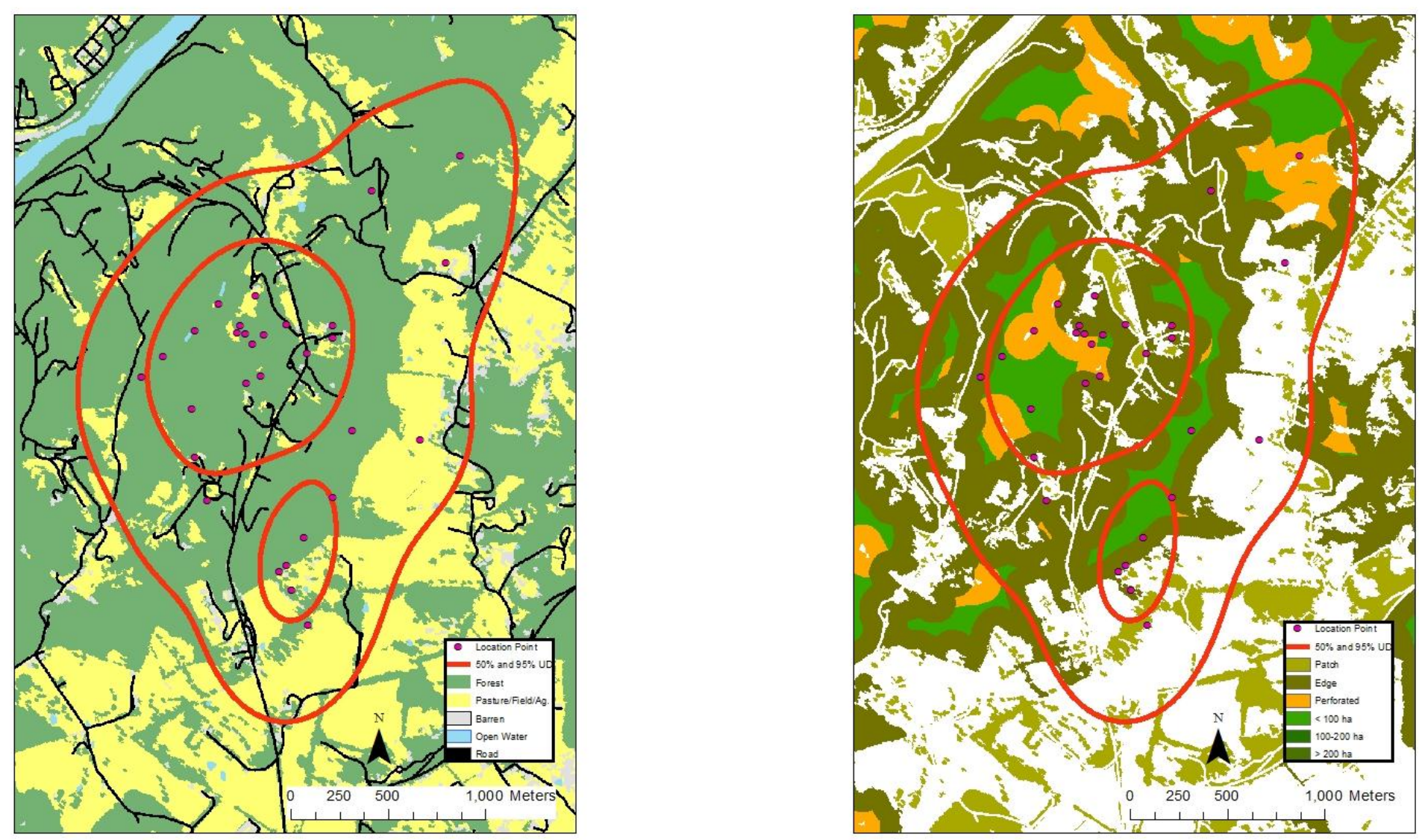
Appendix CCLXXa. 10154 (adult, winter) - 50\% core and 95\% periphery probability contours of the annual Gaussian fixed kernel home range utilization distributions. Smoothing parameter $(h)$ determined by least squares cross validation, Greenbrier County, West Virginia, 2004-2007 (aspect and slope maps).
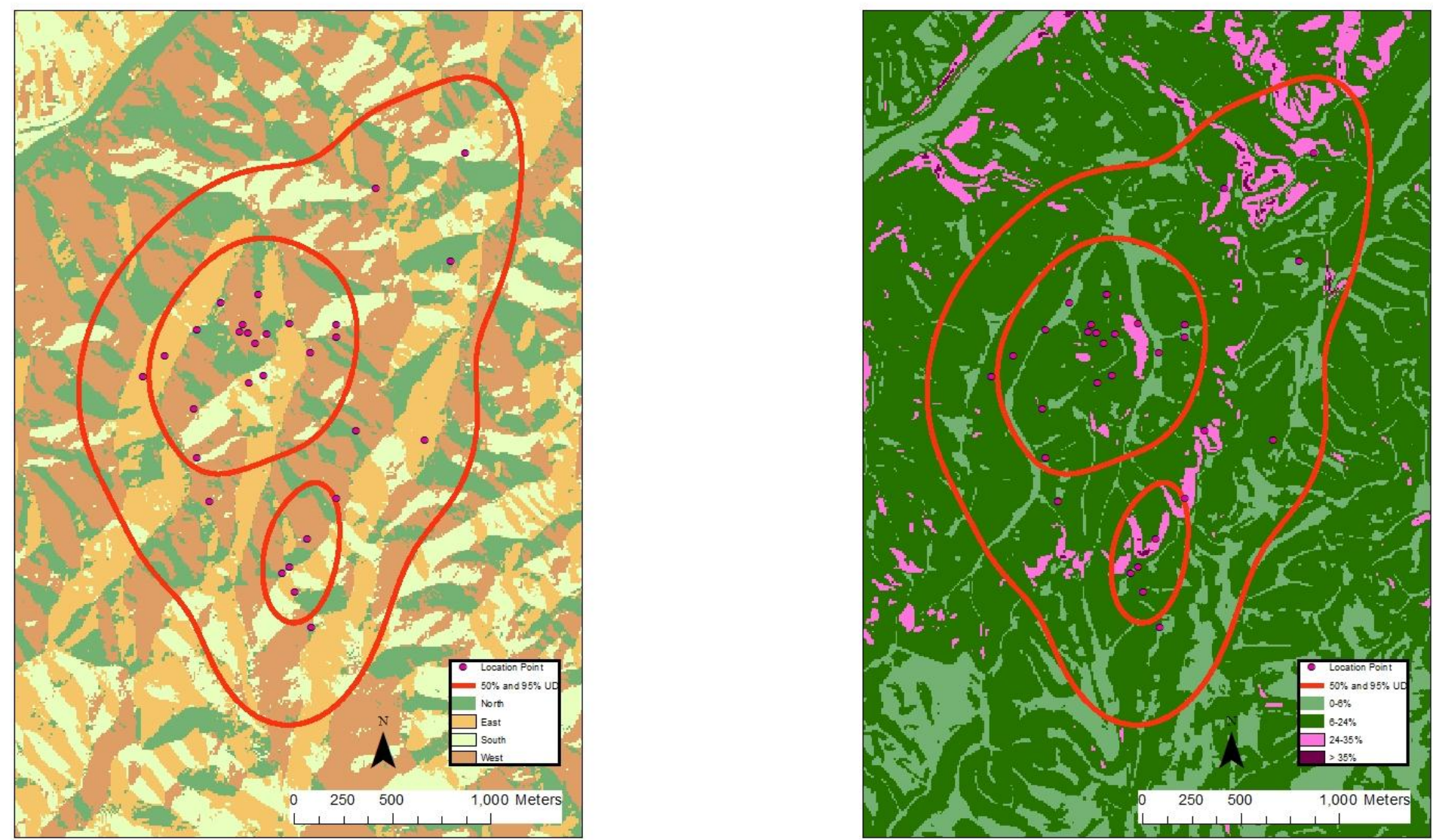
Appendix CCLXXI $a .10155$ (adult, annual) - 50\% core and 95\% periphery probability contours of the annual Gaussian fixed kernel home range utilization distributions. Smoothing parameter $(h)$ determined by least squares cross validation, Greenbrier County, West Virginia, 2004-2007 (land use and land cover, land fragmentation maps).
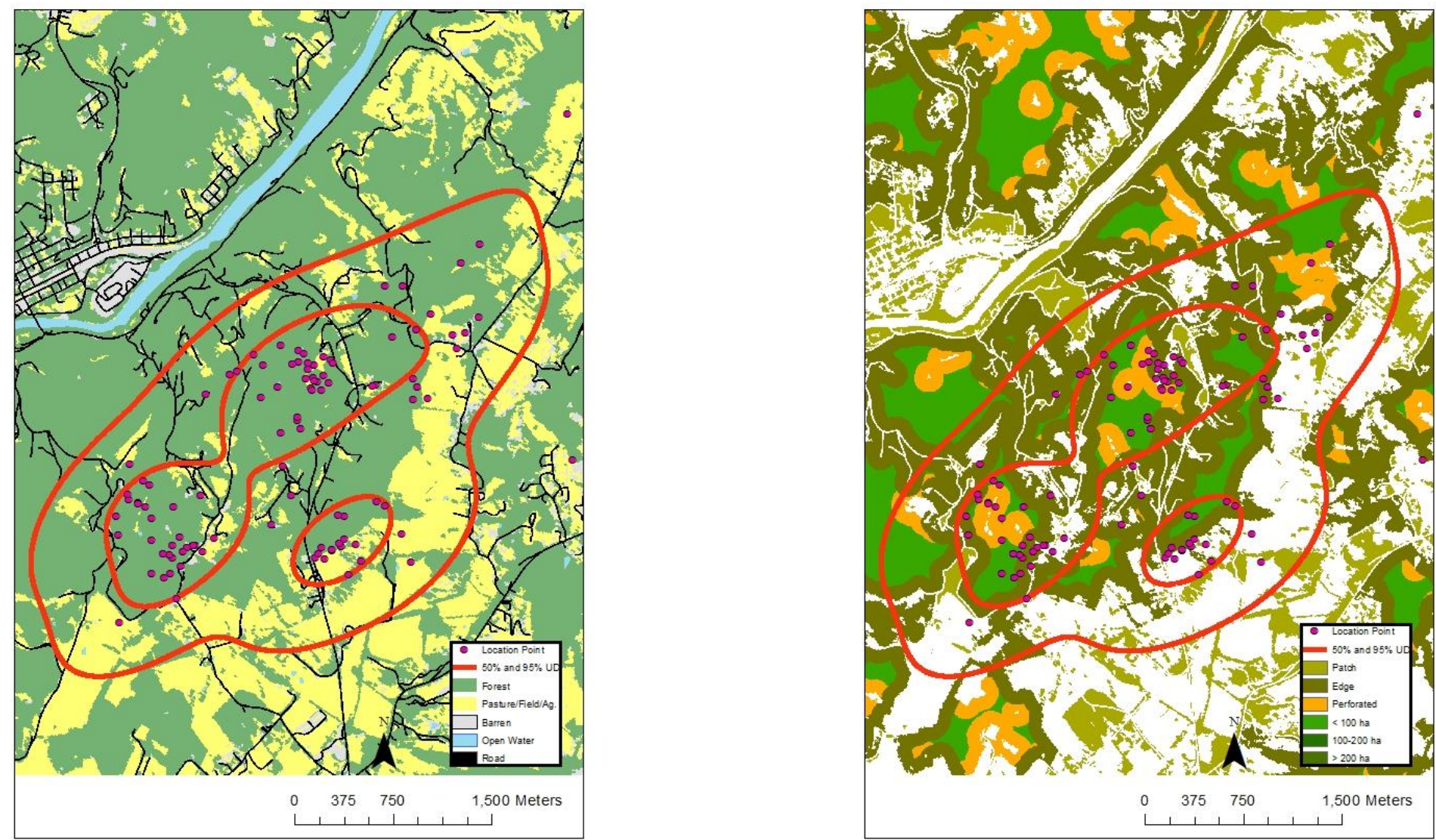
Appendix CCLXXII a. 10155 (adult, annual) - 50\% core and 95\% periphery probability contours of the annual Gaussian fixed kernel home range utilization distributions. Smoothing parameter $(h)$ determined by least squares cross validation, Greenbrier County, West Virginia, 2004-2007 (aspect and slope maps).
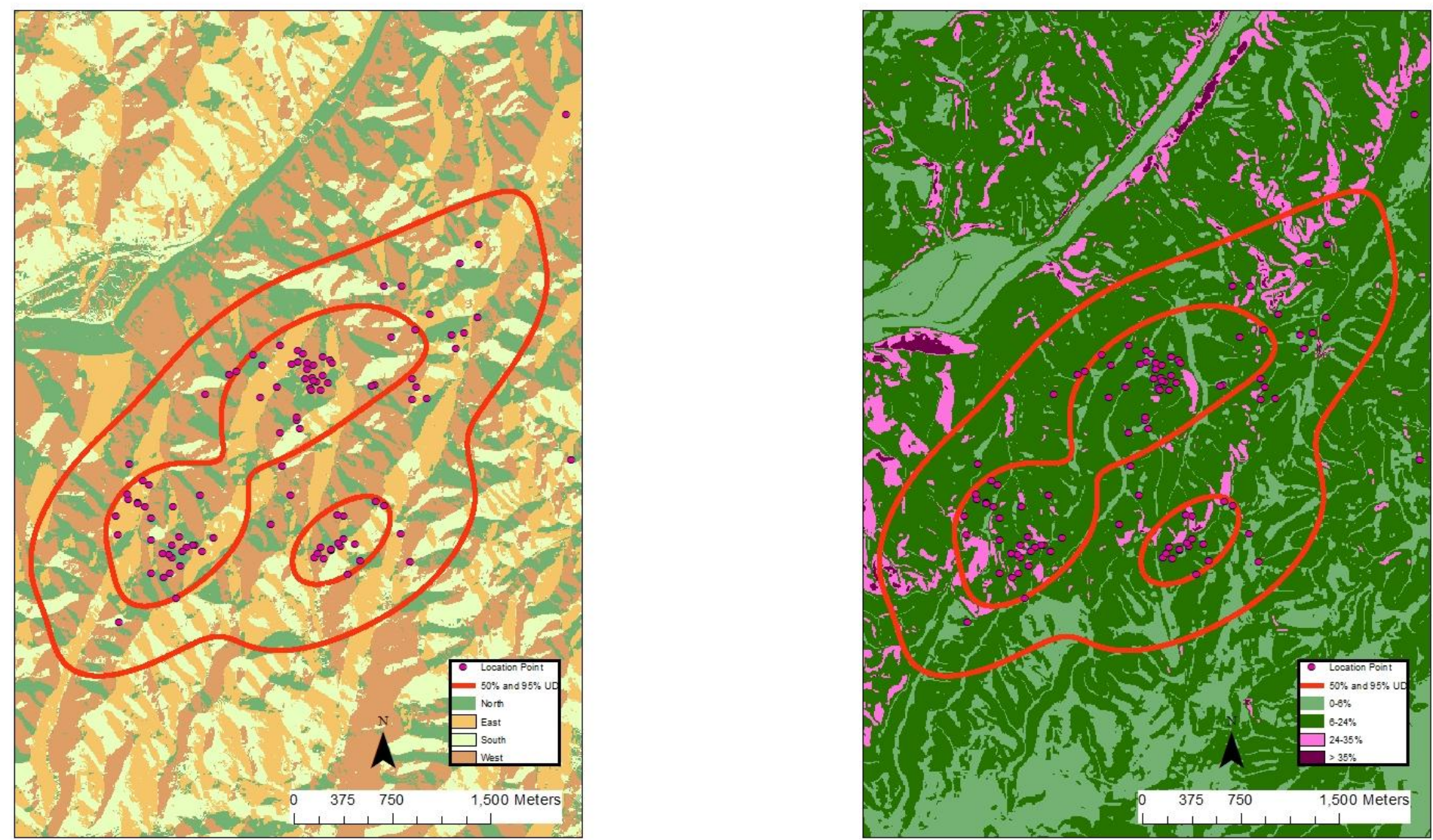
Appendix CCLXXIII a. 10156 (adult, fall-winter) - 50\% core and 95\% periphery probability contours of the annual Gaussian fixed kernel home range utilization distributions. Smoothing parameter $(h)$ determined by least squares cross validation, Greenbrier County, West Virginia, 2004-2007 (land use and land cover, land fragmentation maps).
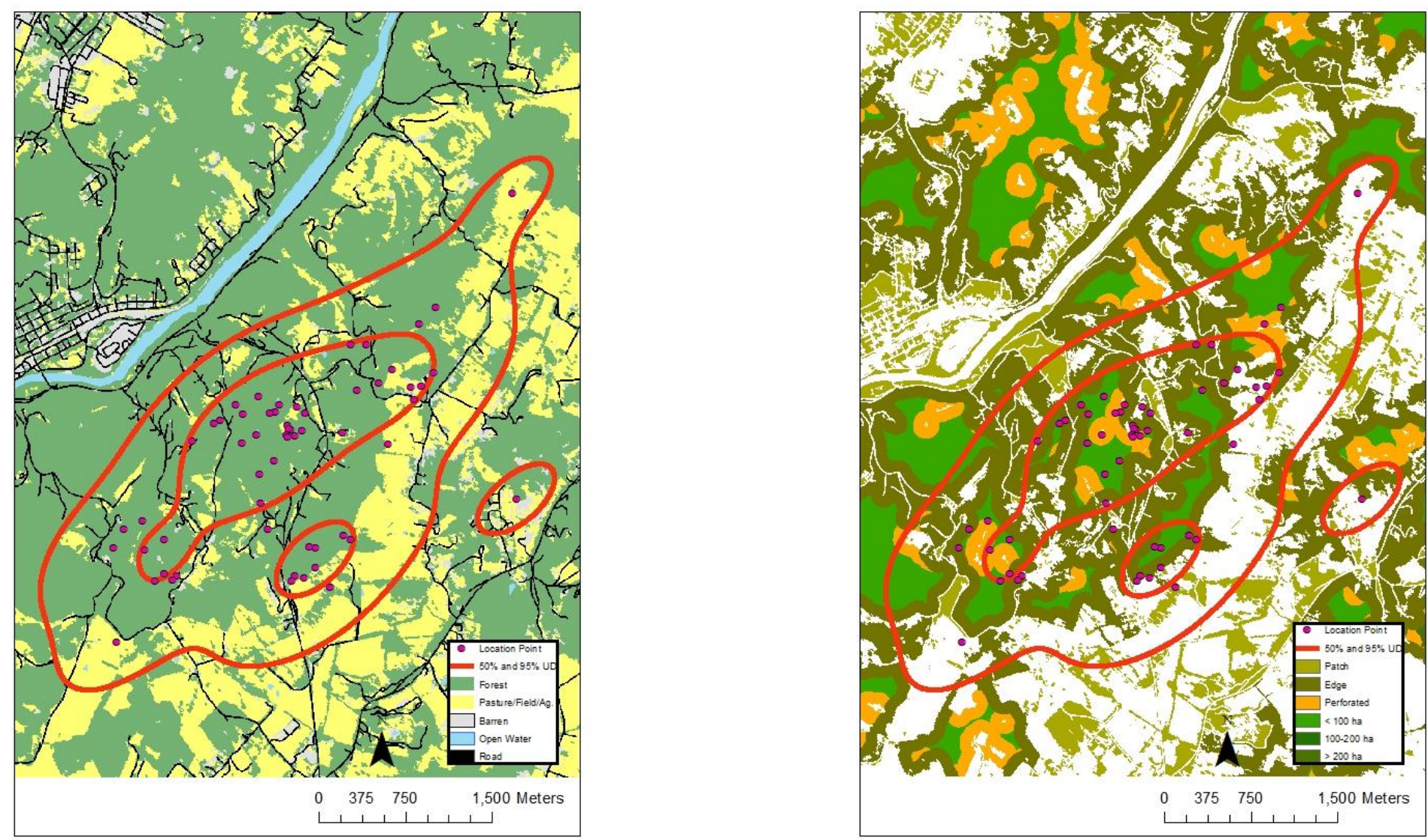
Appendix CCLXXIVa. 10156 (adult, fall-winter) - 50\% core and 95\% periphery probability contours of the annual Gaussian fixed kernel home range utilization distributions. Smoothing parameter $(h)$ determined by least squares cross validation, Greenbrier County, West Virginia, 2004-2007 (aspect and slope maps).
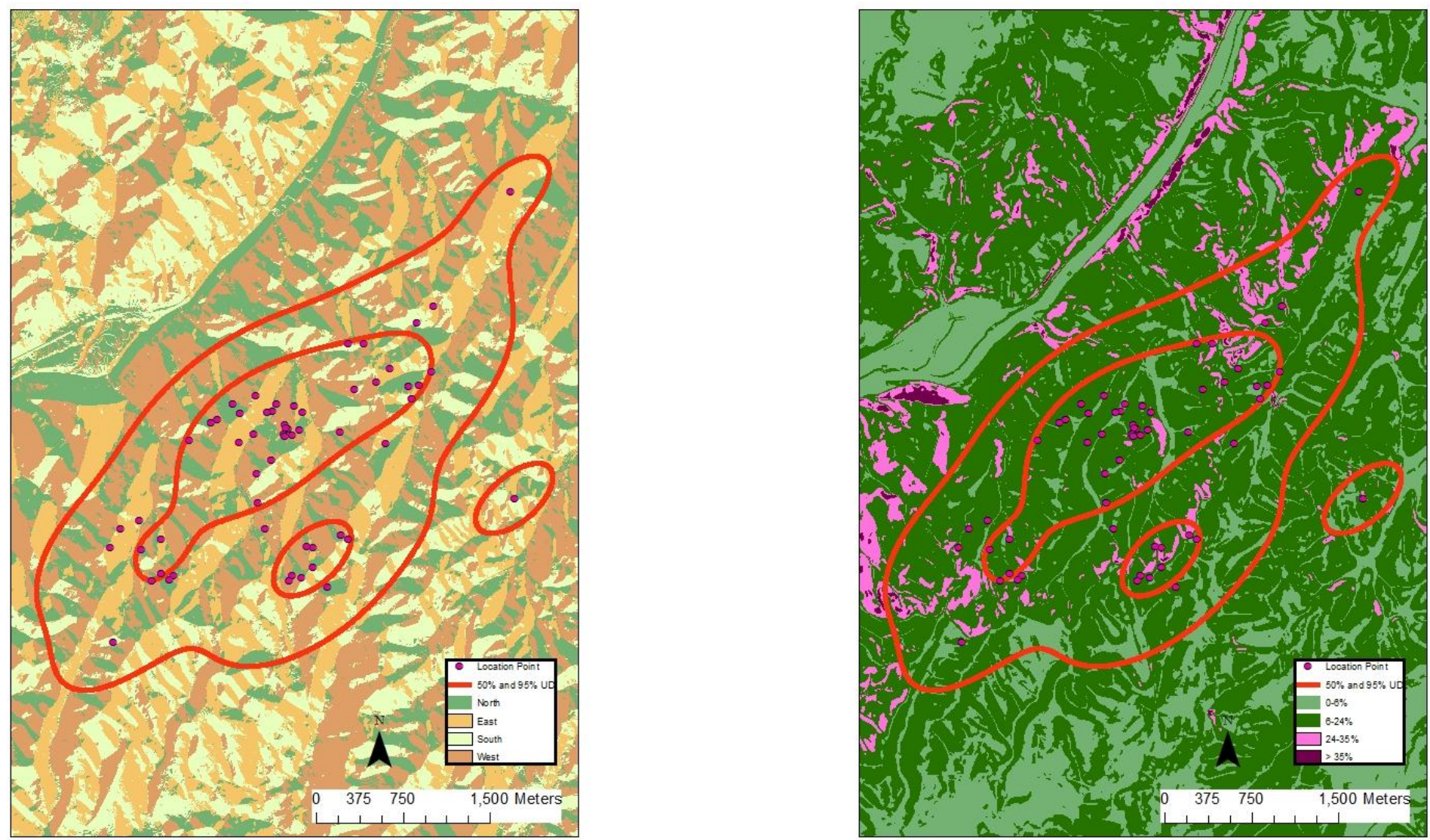
Appendix CCLXXVa. 10157 (adult, fall) - 50\% core and 95\% periphery probability contours of the annual Gaussian fixed kernel home range utilization distributions. Smoothing parameter $(h)$ determined by least squares cross validation, Greenbrier County, West Virginia, 2004-2007 (land use and land cover, land fragmentation maps).
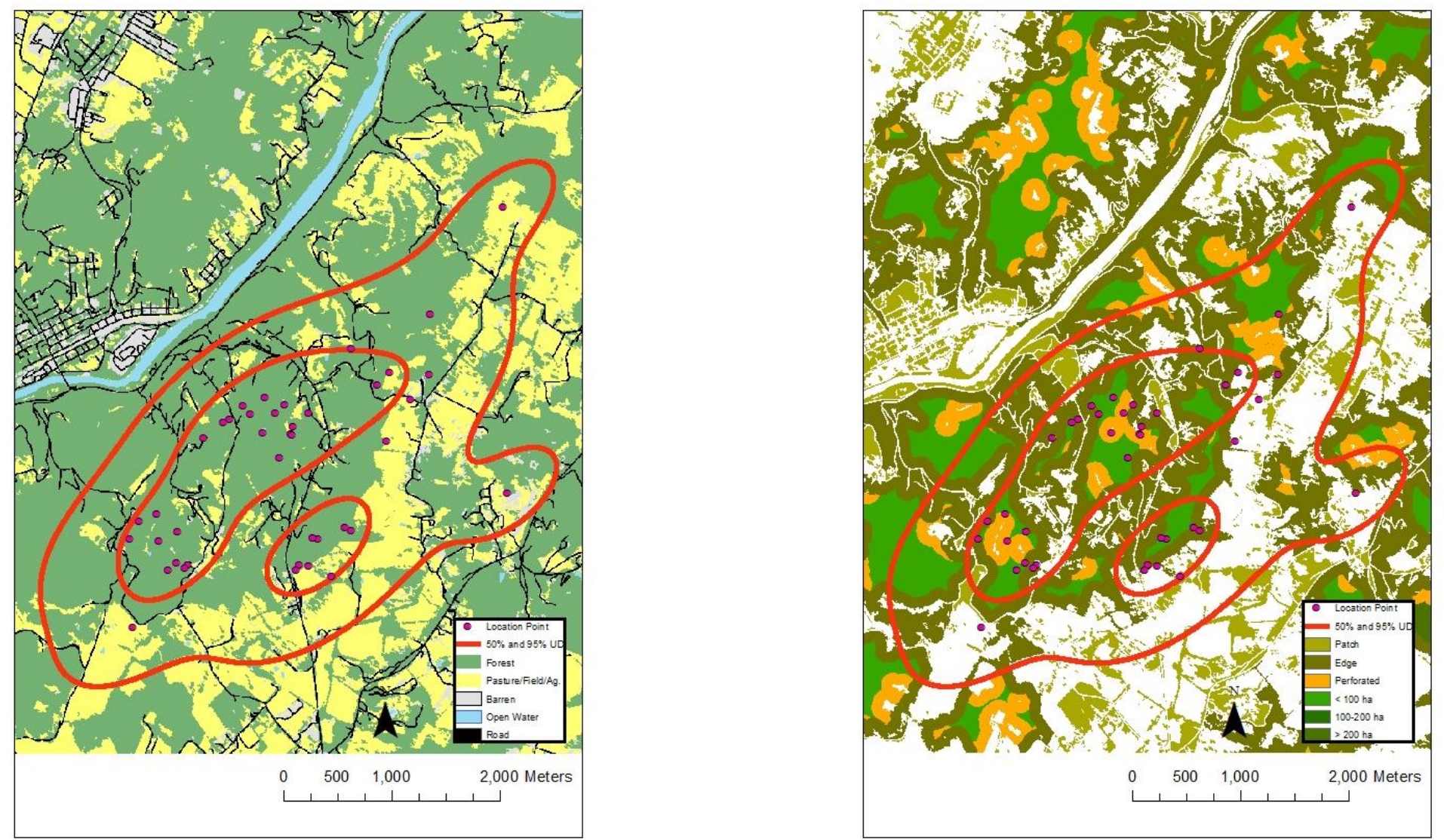
Appendix CCLXXVIa. 10157 (adult, fall) - 50\% core and 95\% periphery probability contours of the annual Gaussian fixed kernel home range utilization distributions. Smoothing parameter $(h)$ determined by least squares cross validation, Greenbrier County, West Virginia, 2004-2007 (aspect and slope maps).
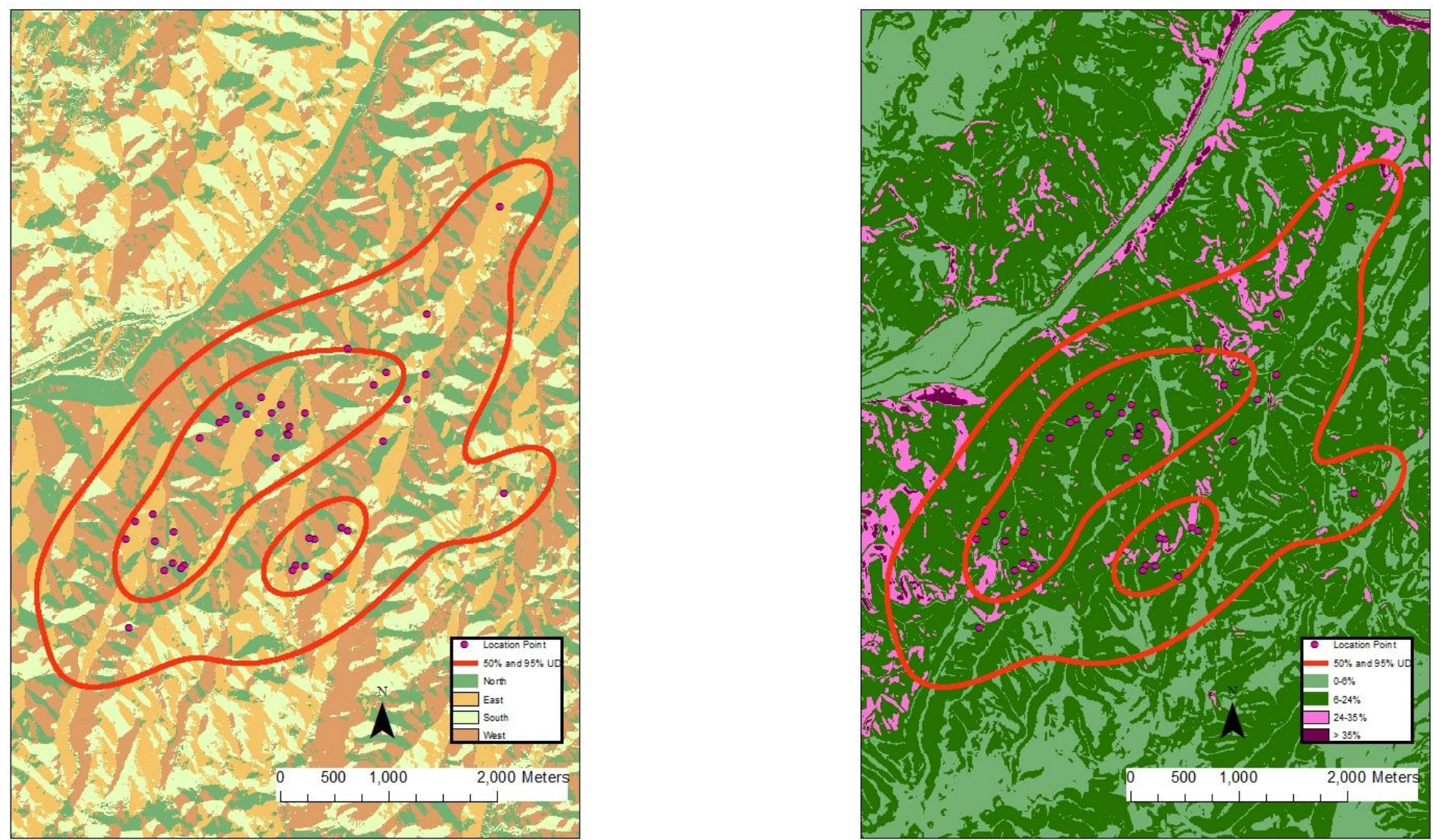
Appendix CCLXXVII a. 10158 (adult, spring-summer) - 50\% core and 95\% periphery probability contours of the annual Gaussian fixed kernel home range utilization distributions. Smoothing parameter $(h)$ determined by least squares cross validation, Greenbrier County, West Virginia, 2004-2007 (land use and land cover, land fragmentation maps).
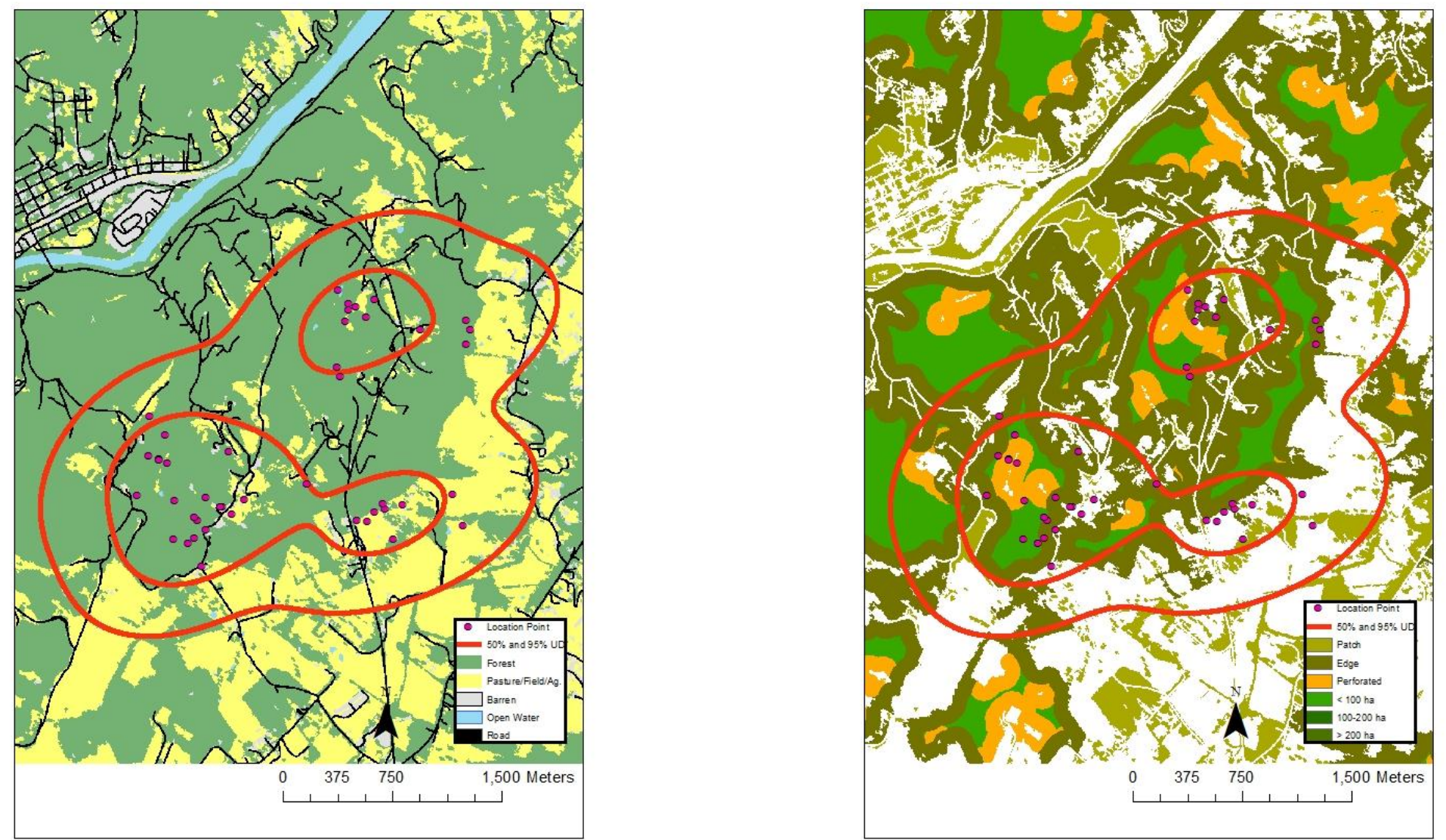
Appendix CCLXXVIII a. 10158 (adult, spring-summer) - 50\% core and 95\% periphery probability contours of the annual Gaussian fixed kernel home range utilization distributions. Smoothing parameter $(h)$ determined by least squares cross validation, Greenbrier County, West Virginia, 2004-2007 (aspect and slope maps).
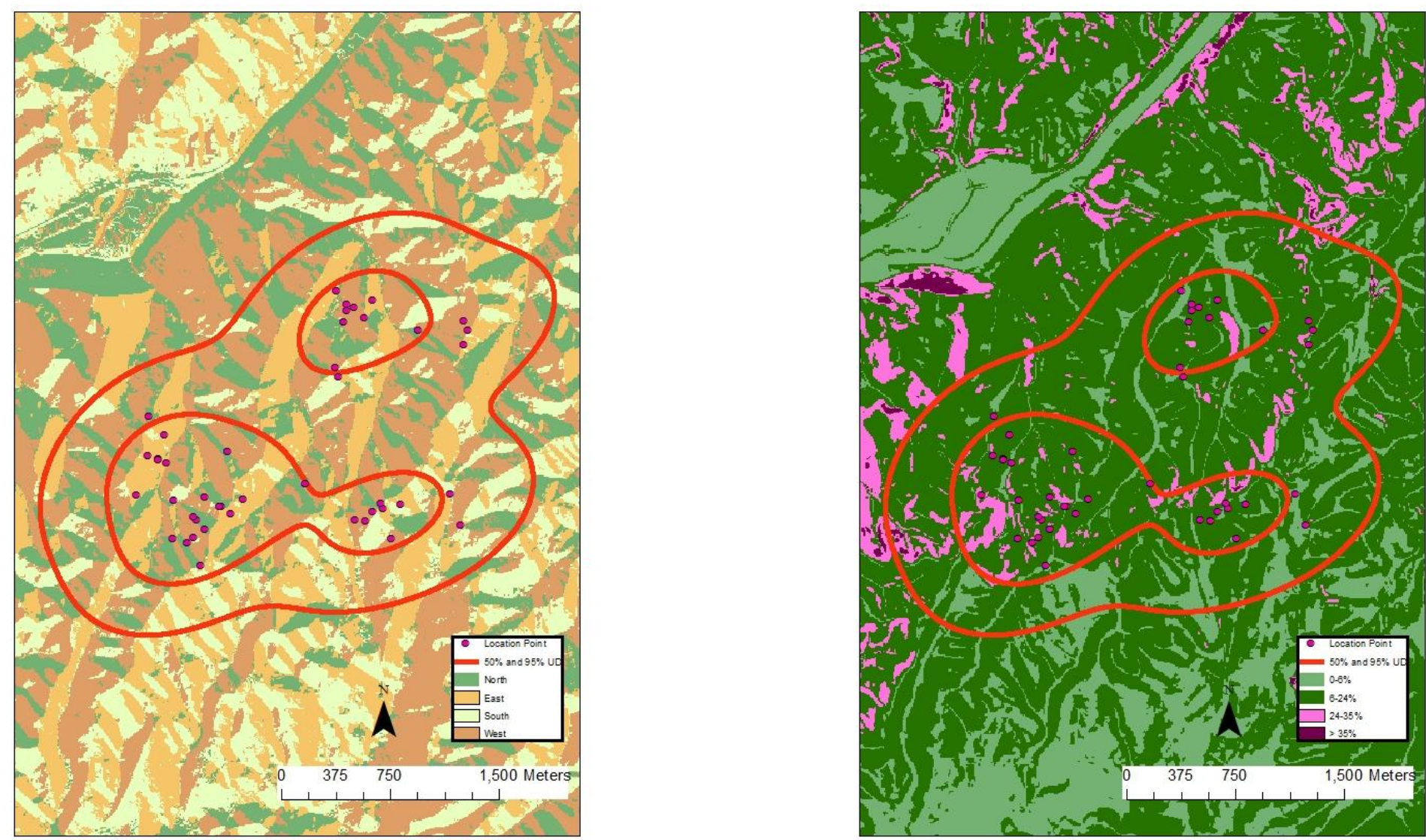
Appendix CCLXXIXa. 10159 (adult, annual) - 50\% core and 95\% periphery probability contours of the annual Gaussian fixed kernel home range utilization distributions. Smoothing parameter $(h)$ determined by least squares cross validation, Greenbrier County, West Virginia, 2004-2007 (land use and land cover, land fragmentation maps).
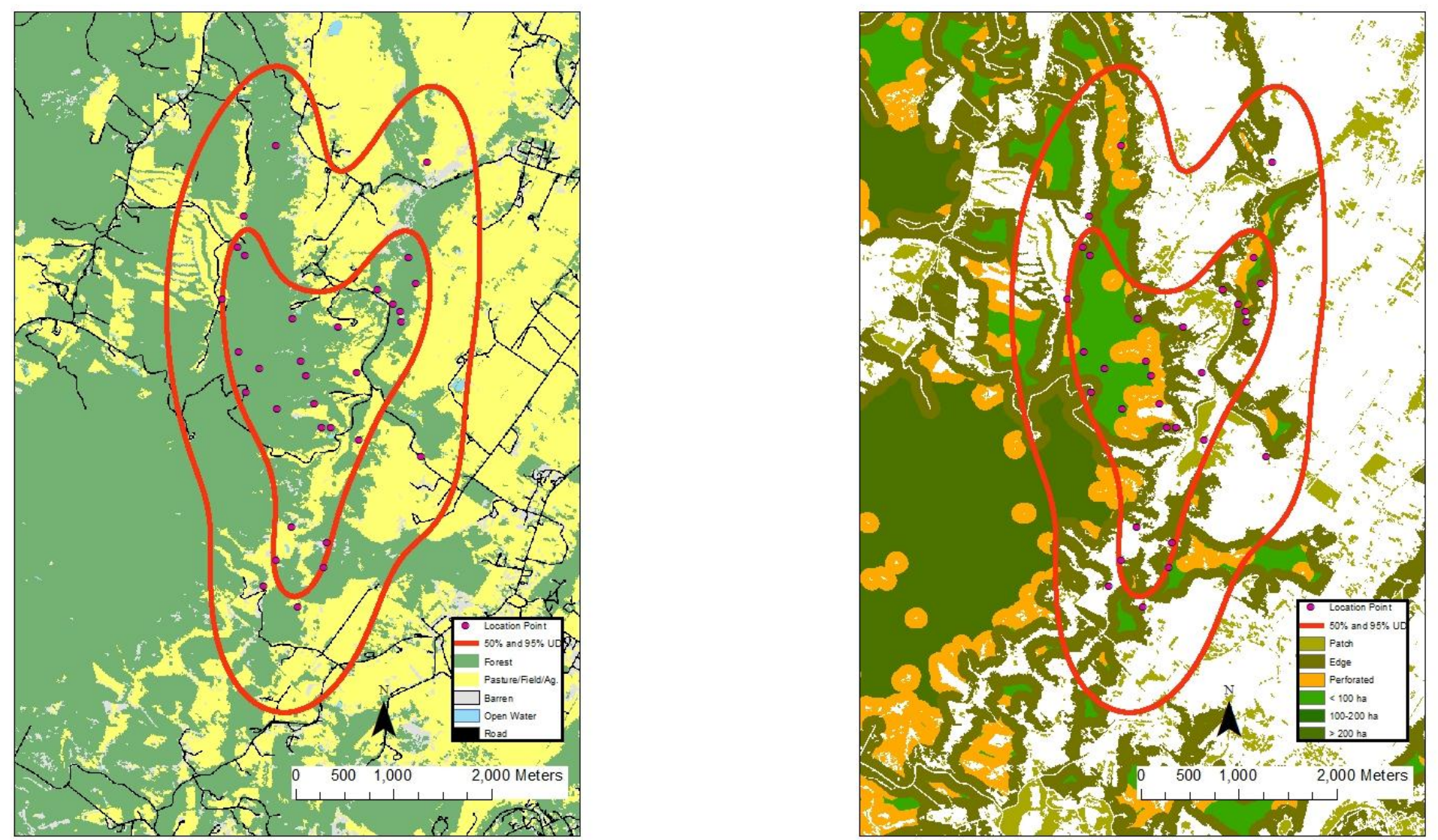
Appendix CCLXXXa. 10159 (adult, annual) - 50\% core and 95\% periphery probability contours of the annual Gaussian fixed kernel home range utilization distributions. Smoothing parameter $(h)$ determined by least squares cross validation, Greenbrier County, West Virginia, 2004-2007 (aspect and slope maps).
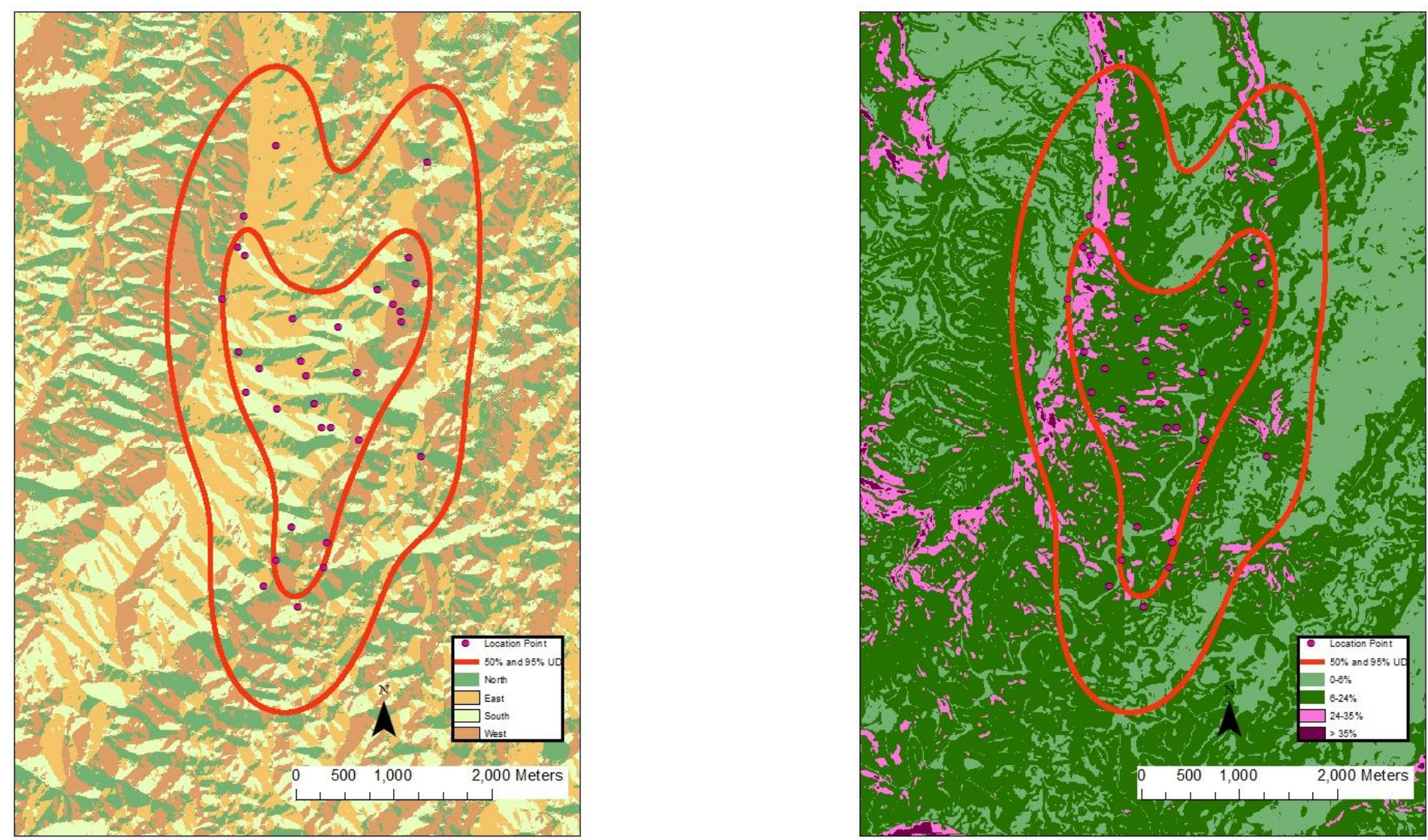
Appendix CCLXXXI a. 10160 (adult, annual) - 50\% core and 95\% periphery probability contours of the annual Gaussian fixed kernel home range utilization distributions. Smoothing parameter $(h)$ determined by least squares cross validation, Greenbrier County, West Virginia, 2004-2007 (land use and land cover, land fragmentation maps).
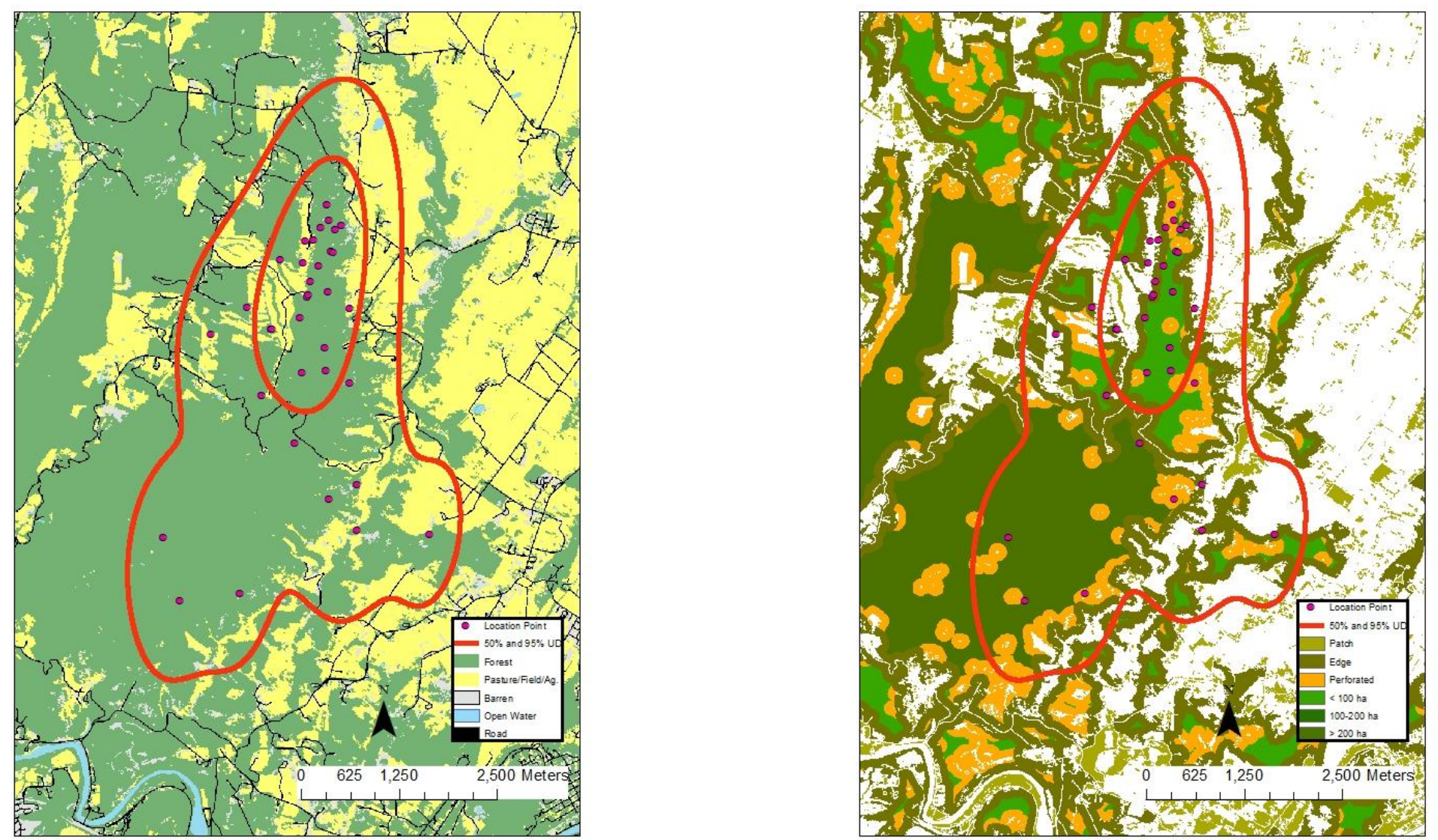
Appendix CCLXXXII $a$. 10160 (adult, annual) - 50\% core and 95\% periphery probability contours of the annual Gaussian fixed kernel home range utilization distributions. Smoothing parameter $(h)$ determined by least squares cross validation, Greenbrier County, West Virginia, 2004-2007 (aspect and slope maps).
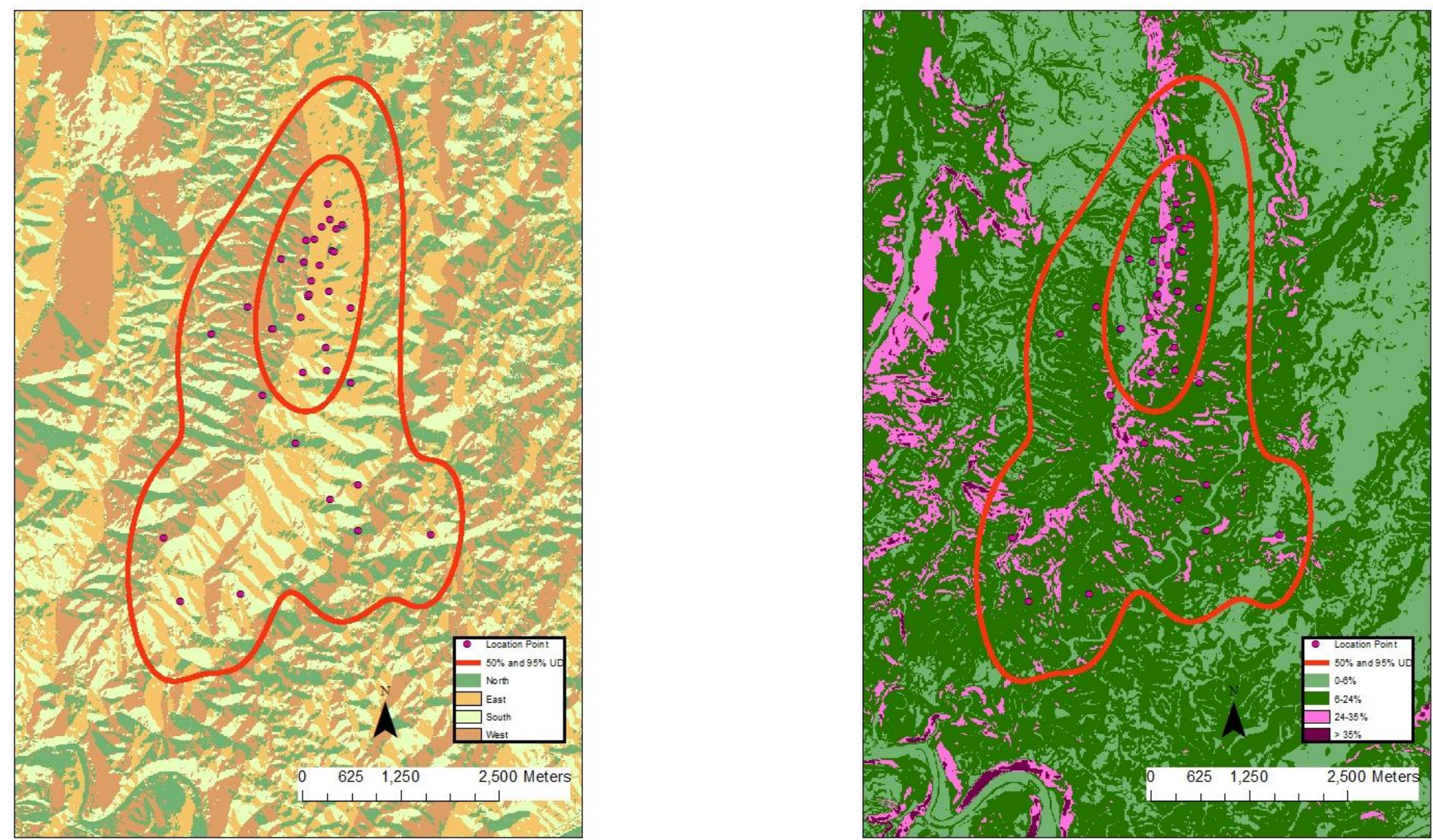
Appendix CCLXXXIII $a$. 10161 (juvenile, annual) - 50\% core and 95\% periphery probability contours of the annual Gaussian fixed kernel home range utilization distributions. Smoothing parameter $(h)$ determined by least squares cross validation, Greenbrier County, West Virginia, 2004-2007 (land use and land cover, land fragmentation maps).
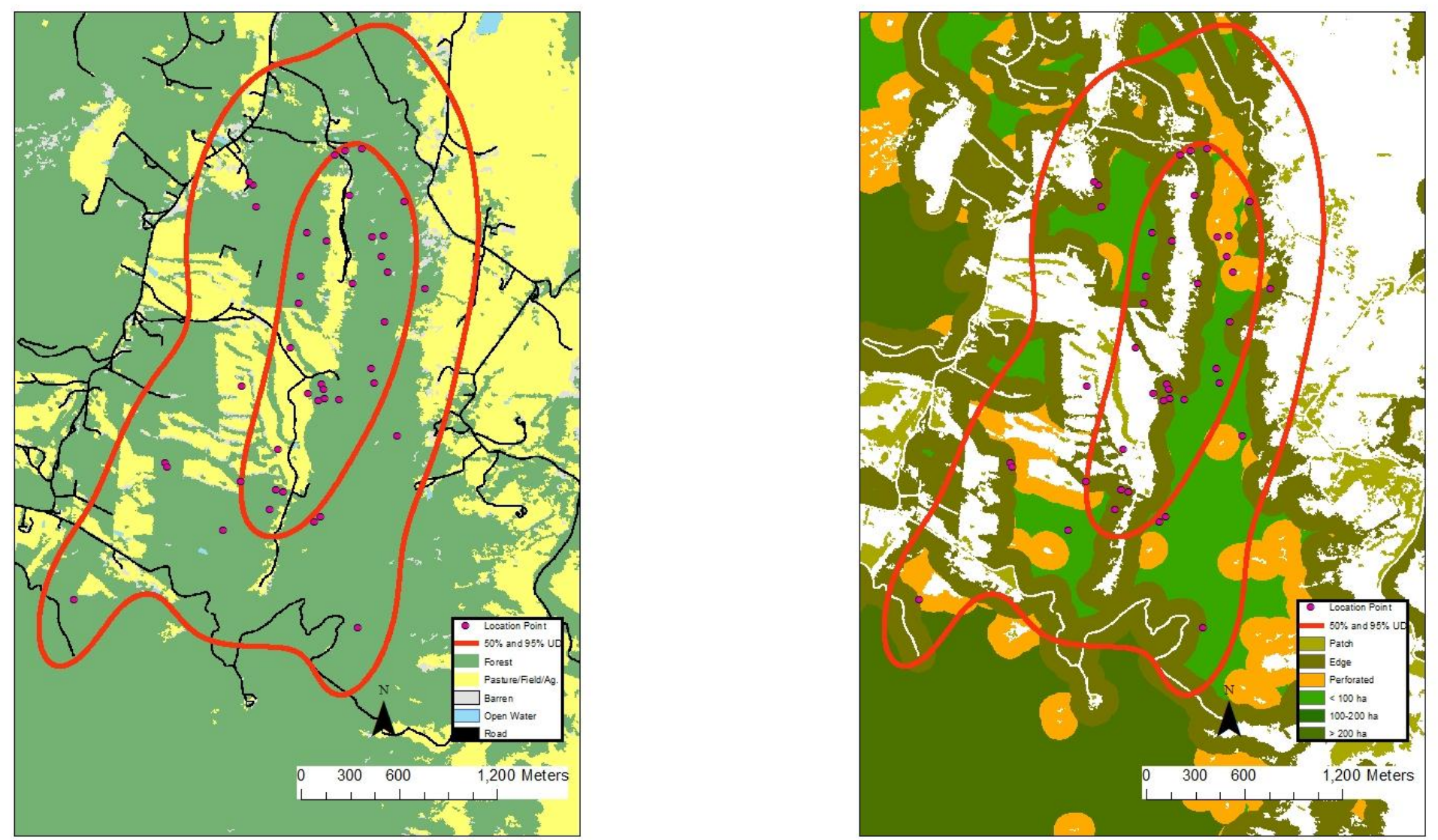
Appendix CCLXXXIVa. 10161 (juvenile, annual) - 50\% core and 95\% periphery probability contours of the annual Gaussian fixed kernel home range utilization distributions. Smoothing parameter $(h)$ determined by least squares cross validation, Greenbrier County, West Virginia, 2004-2007 (aspect and slope maps).
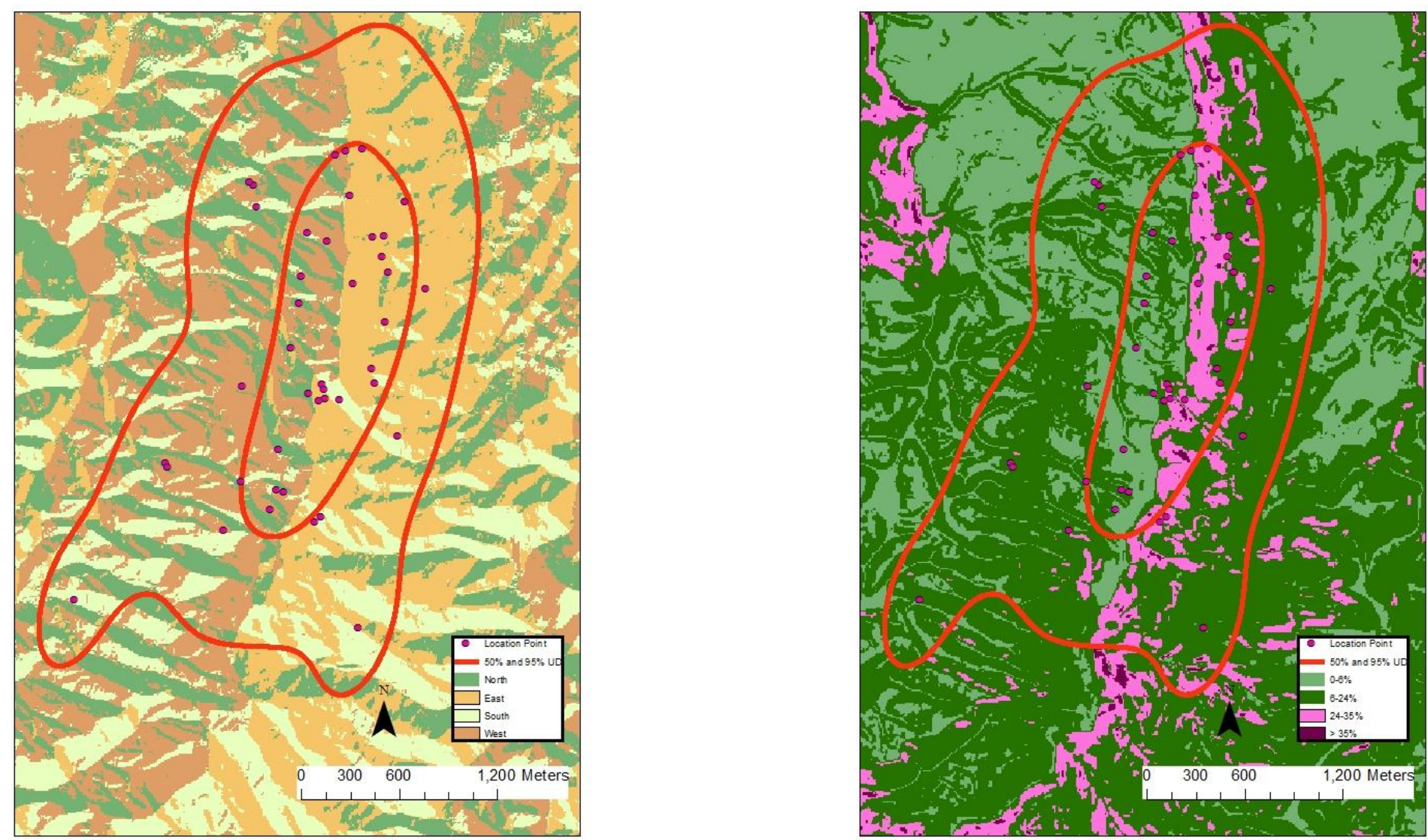
Appendix CCLXXXVa. 10162 (adult, annual) - 50\% core and 95\% periphery probability contours of the annual Gaussian fixed kernel home range utilization distributions. Smoothing parameter $(h)$ determined by least squares cross validation, Greenbrier County, West Virginia, 2004-2007 (land use and land cover, land fragmentation maps).
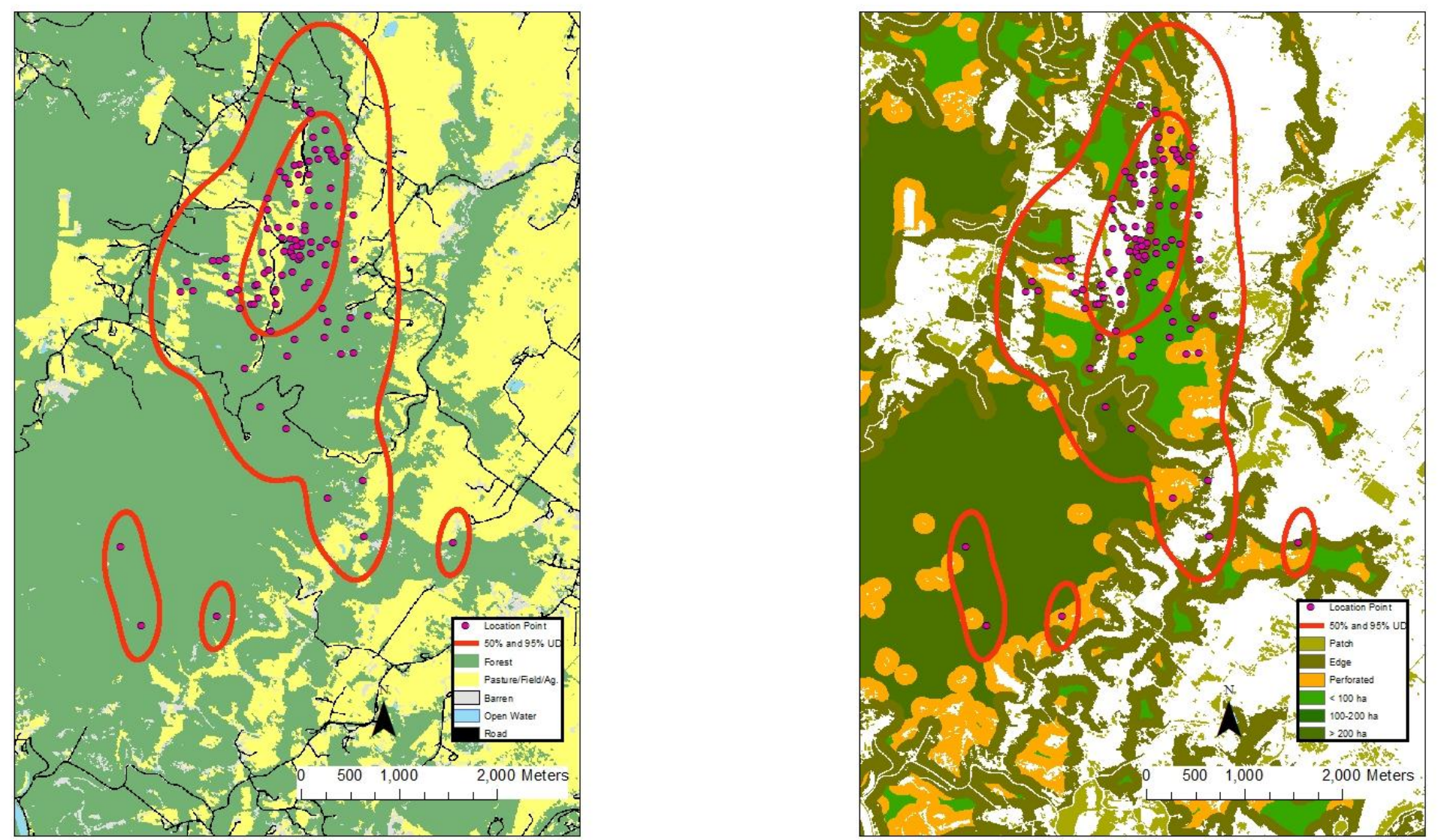
Appendix CCLXXXVIa. 10162 (adult, annual) - 50\% core and 95\% periphery probability contours of the annual Gaussian fixed kernel home range utilization distributions. Smoothing parameter $(h)$ determined by least squares cross validation, Greenbrier County, West Virginia, 2004-2007 (aspect and slope maps).
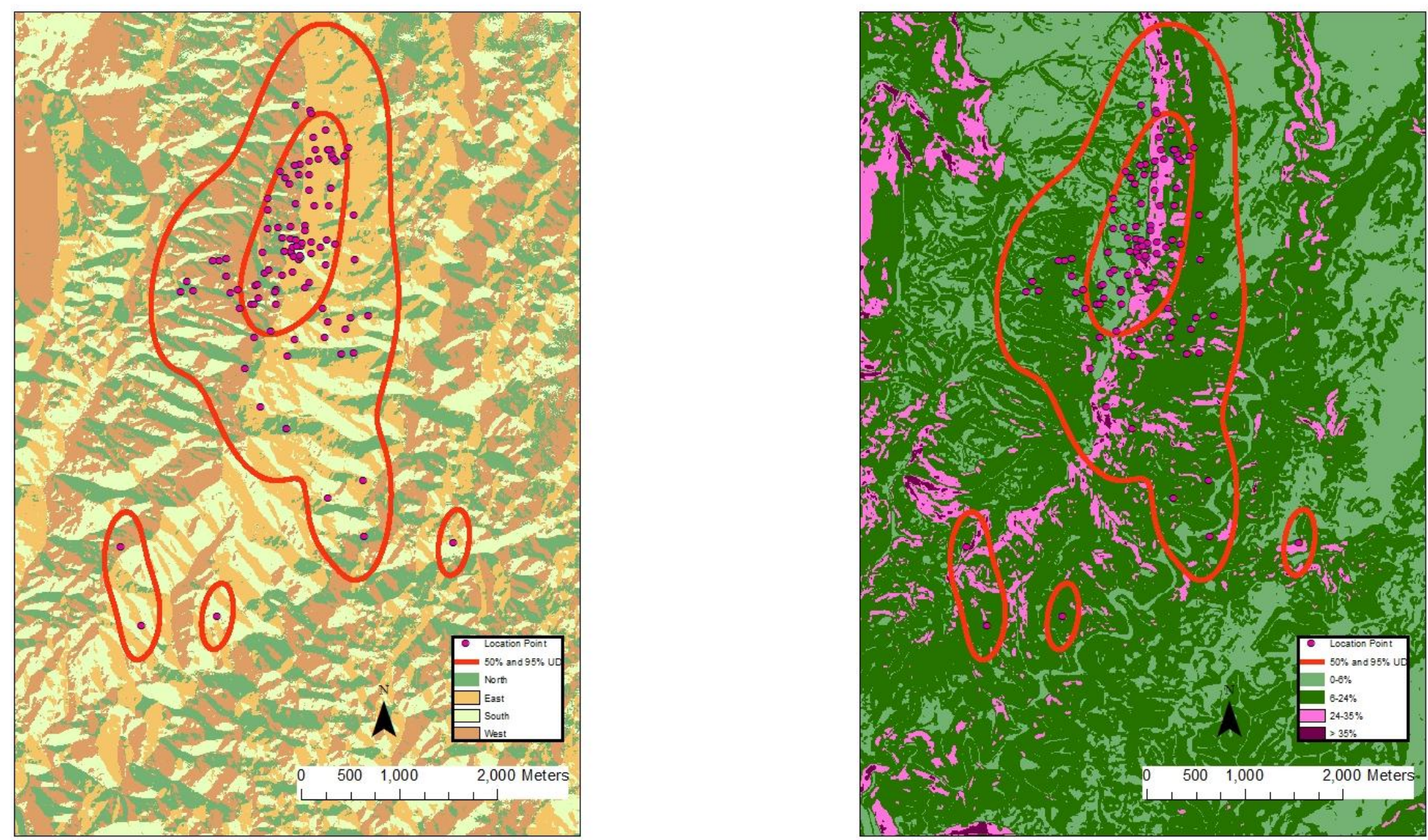
Appendix CCLXXXVIIa. 10163 (adult, fall-winter) - 50\% core and 95\% periphery probability contours of the annual Gaussian fixed kernel home range utilization distributions. Smoothing parameter $(h)$ determined by least squares cross validation, Greenbrier County, West Virginia, 2004-2007 (land use and land cover, land fragmentation maps).
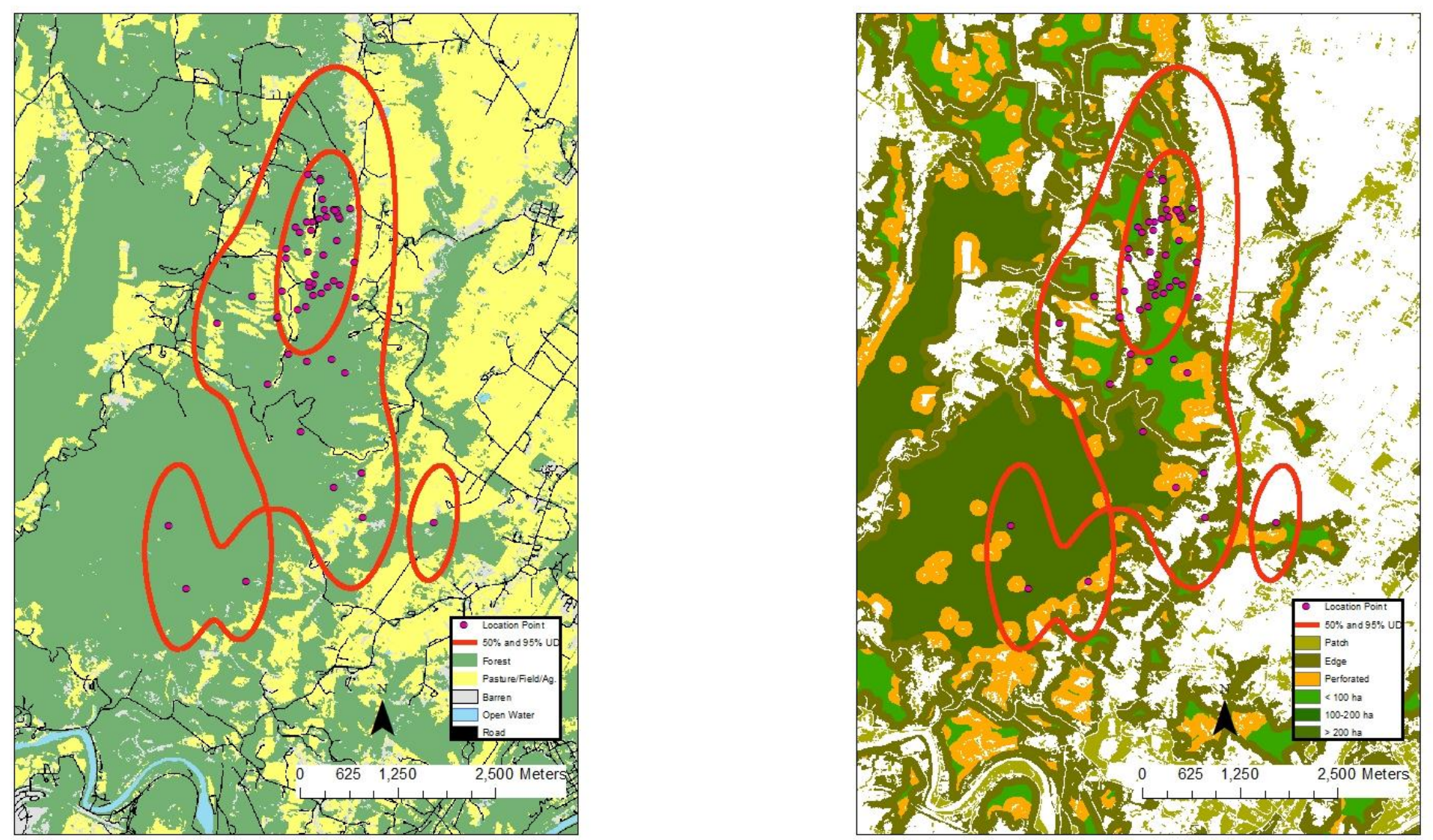
Appendix CCLXXXVIII $a .10163$ (adult, fall-winter) - 50\% core and 95\% periphery probability contours of the annual Gaussian fixed kernel home range utilization distributions. Smoothing parameter $(h)$ determined by least squares cross validation, Greenbrier County, West Virginia, 2004-2007 (aspect and slope maps).
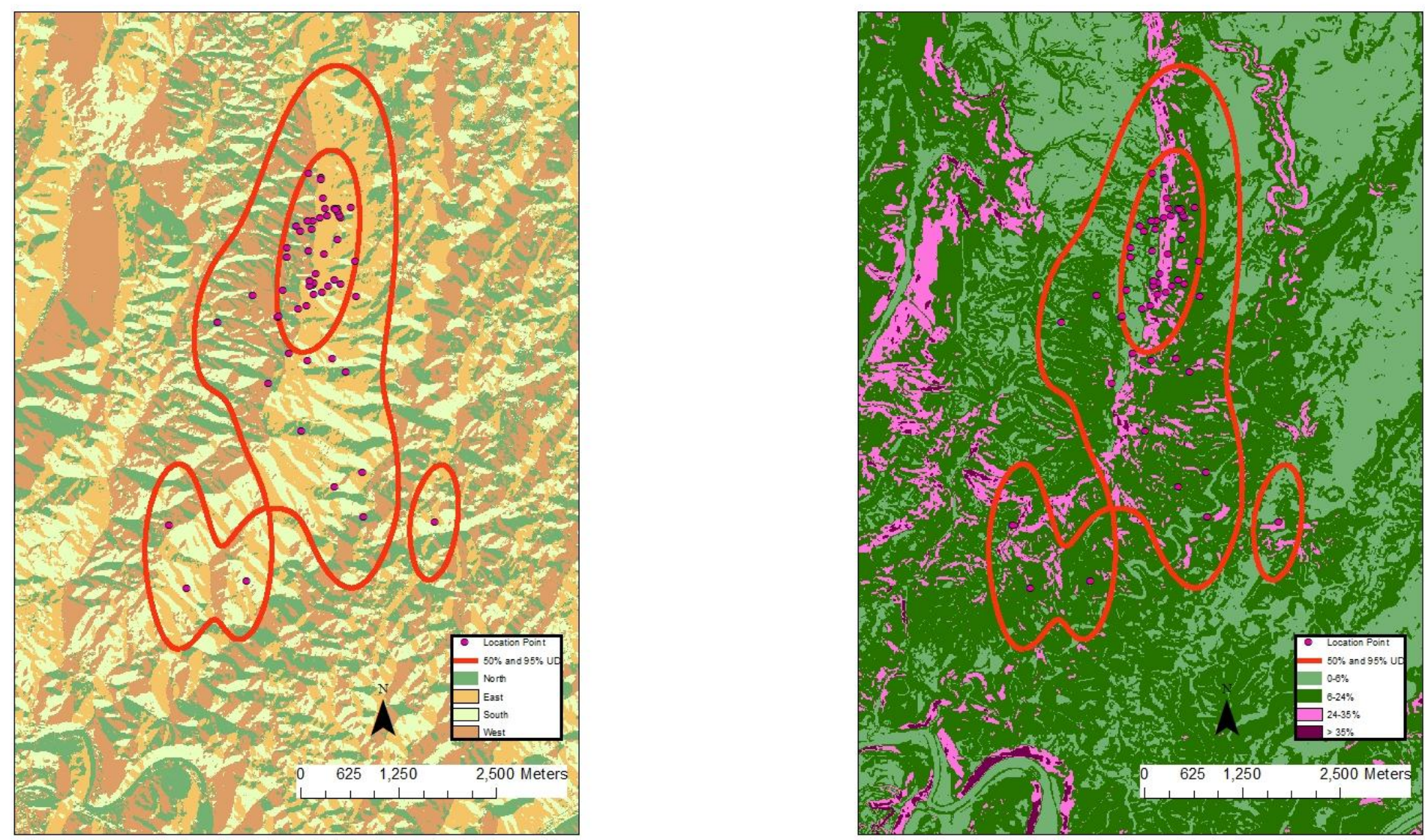
Appendix CCLXXXIXa. 10164 (juvenile, annual) - 50\% core and 95\% periphery probability contours of the annual Gaussian fixed kernel home range utilization distributions. Smoothing parameter $(h)$ determined by least squares cross validation, Greenbrier County, West Virginia, 2004-2007 (land use and land cover, land fragmentation maps).
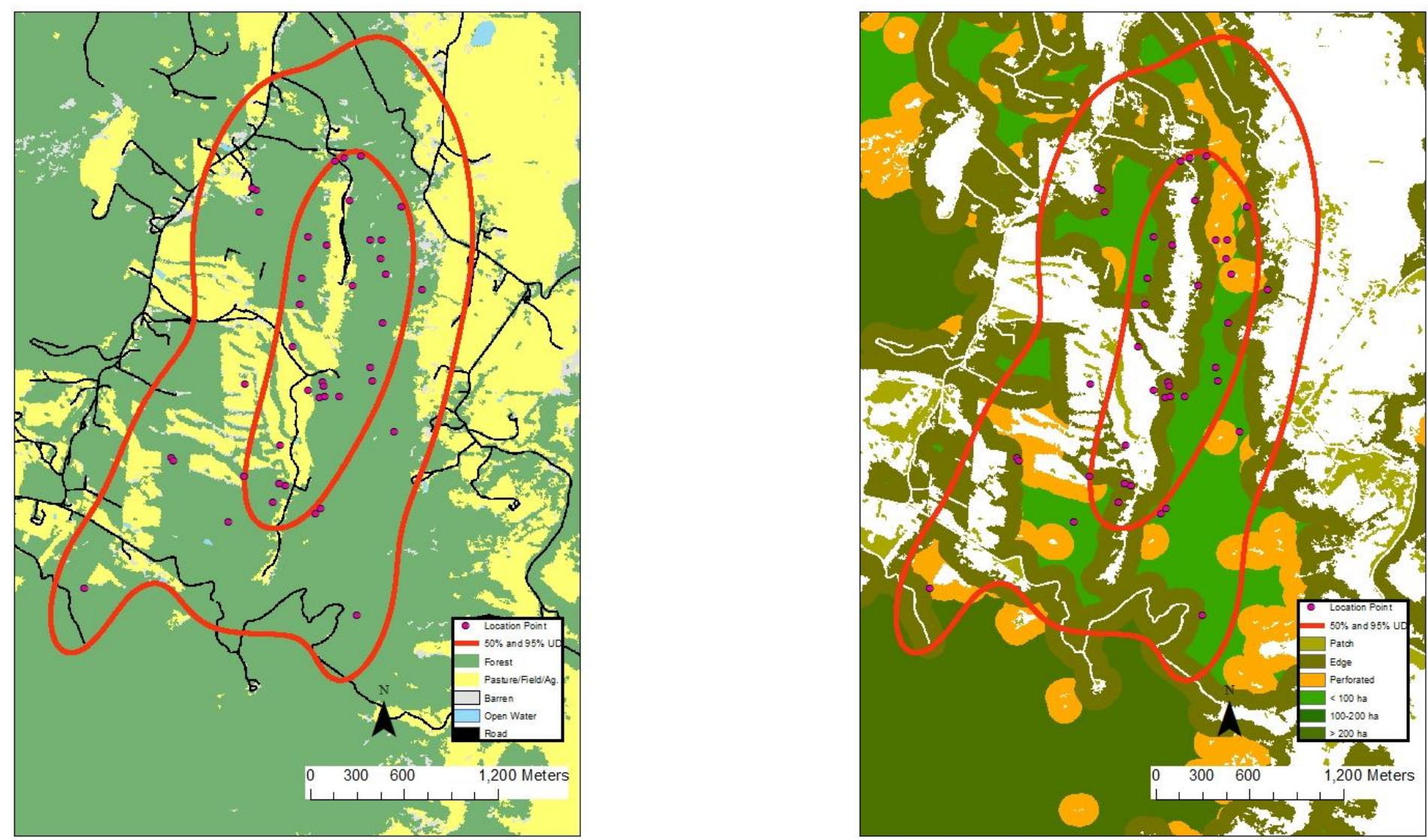
Appendix CCXCa. 10164 (juvenile, annual) - 50\% core and 95\% periphery probability contours of the annual Gaussian fixed kernel home range utilization distributions. Smoothing parameter $(h)$ determined by least squares cross validation, Greenbrier County, West Virginia, 2004-2007 (aspect and slope maps).
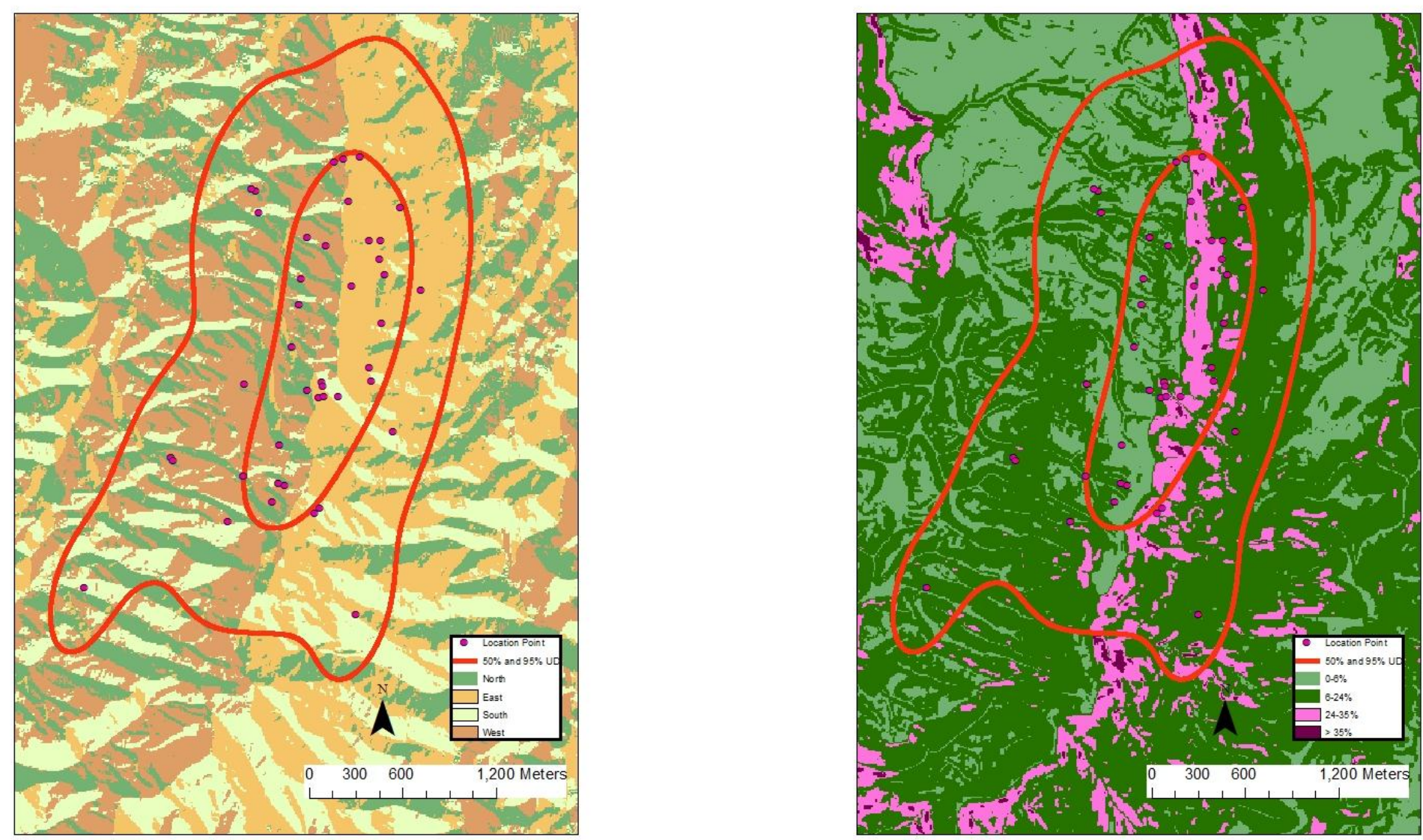
Appendix CCXCI $a .10165$ (adult, spring-summer) - 50\% core and 95\% periphery probability contours of the annual Gaussian fixed kernel home range utilization distributions. Smoothing parameter $(h)$ determined by least squares cross validation, Greenbrier County, West Virginia, 2004-2007 (land use and land cover, land fragmentation maps).
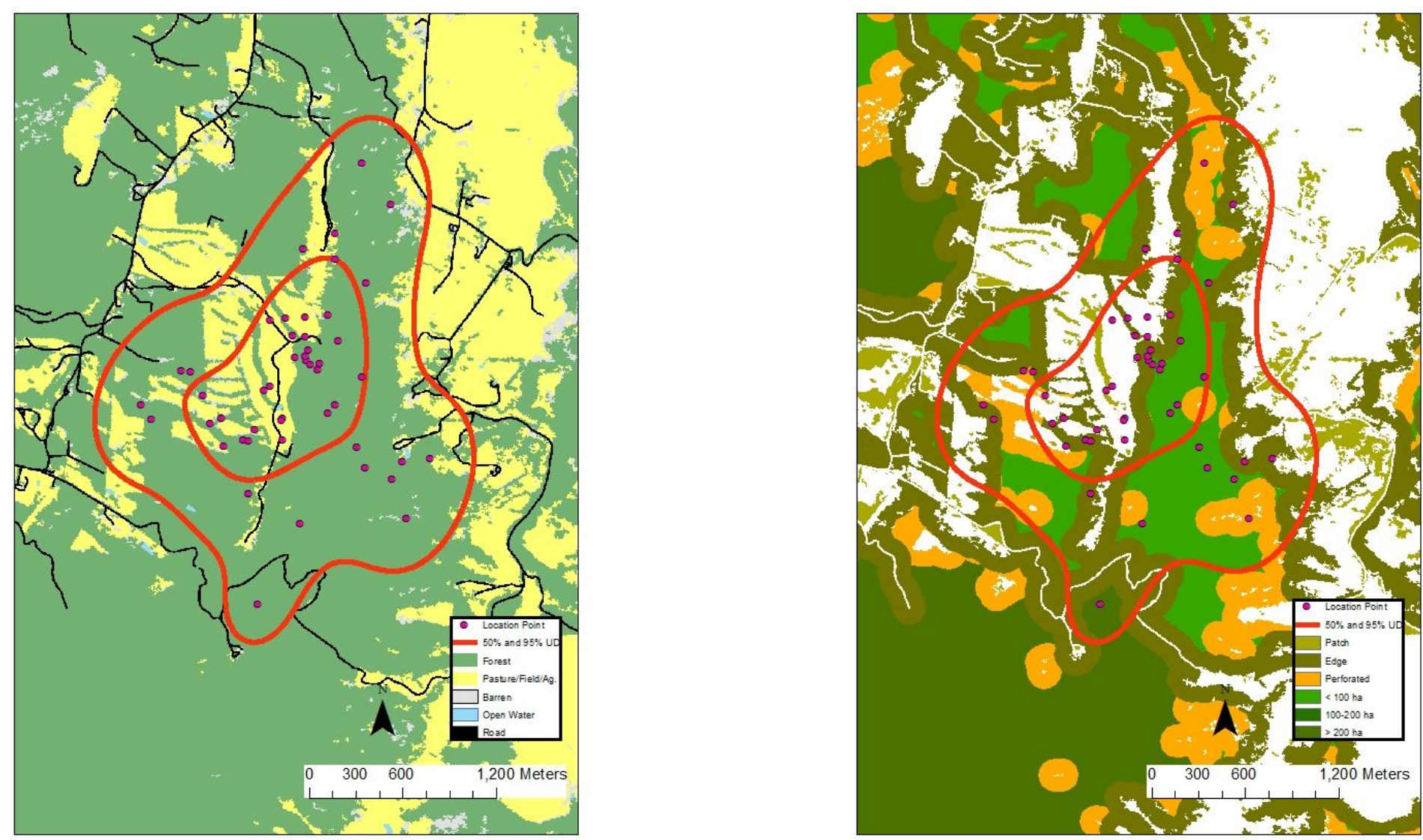
Appendix CCXCIIa. 10165 (adult, spring-summer) - 50\% core and 95\% periphery probability contours of the annual Gaussian fixed kernel home range utilization distributions. Smoothing parameter $(h)$ determined by least squares cross validation, Greenbrier County, West Virginia, 2004-2007 (aspect and slope maps).
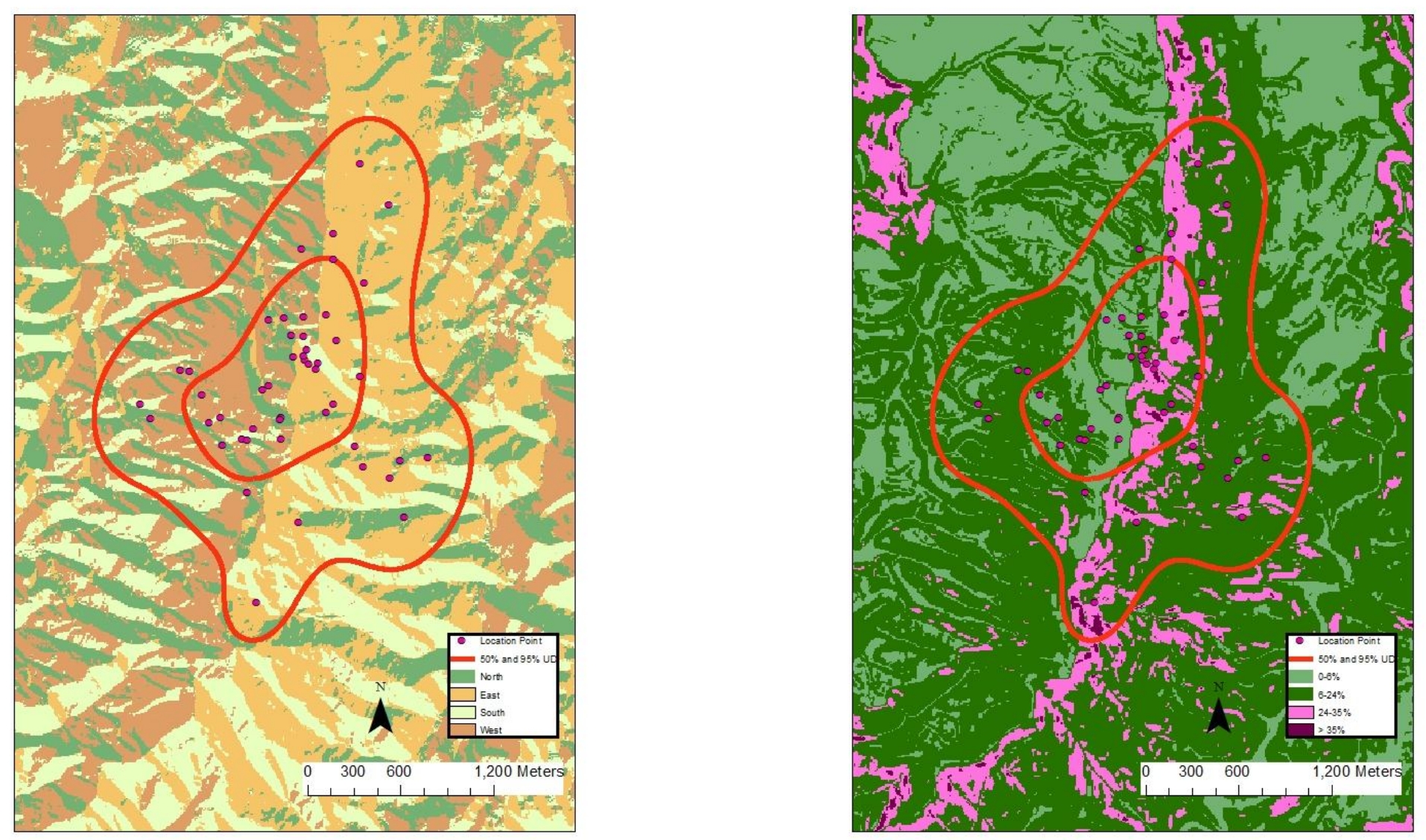
Appendix CCXCIII a. 10166 (adult, winter) - 50\% core and 95\% periphery probability contours of the annual Gaussian fixed kernel home range utilization distributions. Smoothing parameter $(h)$ determined by least squares cross validation, Greenbrier County, West Virginia, 2004-2007 (land use and land cover, land fragmentation maps).
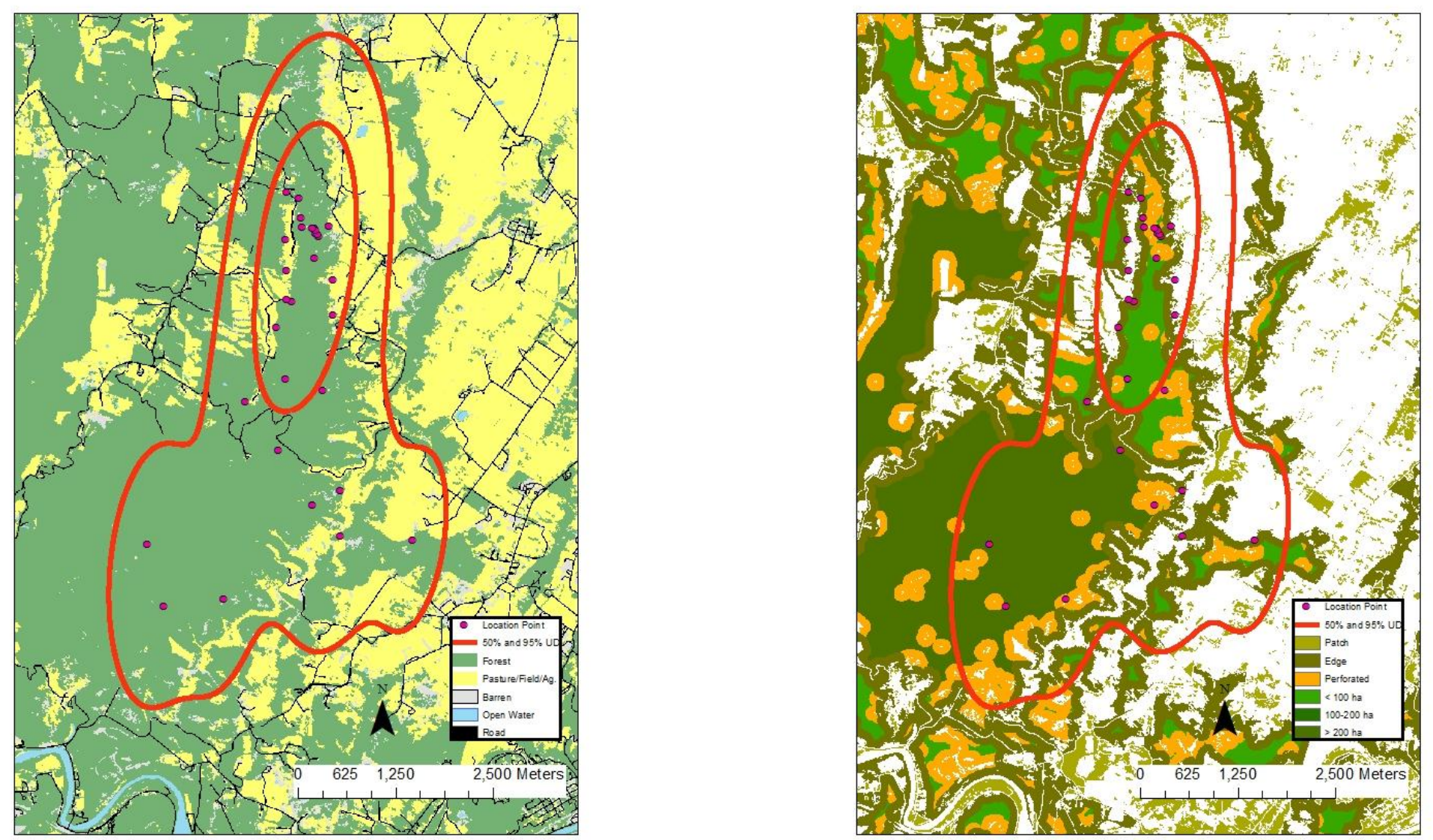
Appendix CCXCIVa. 10166 (adult, winter) - 50\% core and 95\% periphery probability contours of the annual Gaussian fixed kernel home range utilization distributions. Smoothing parameter $(h)$ determined by least squares cross validation, Greenbrier County, West Virginia, 2004-2007 (aspect and slope maps).
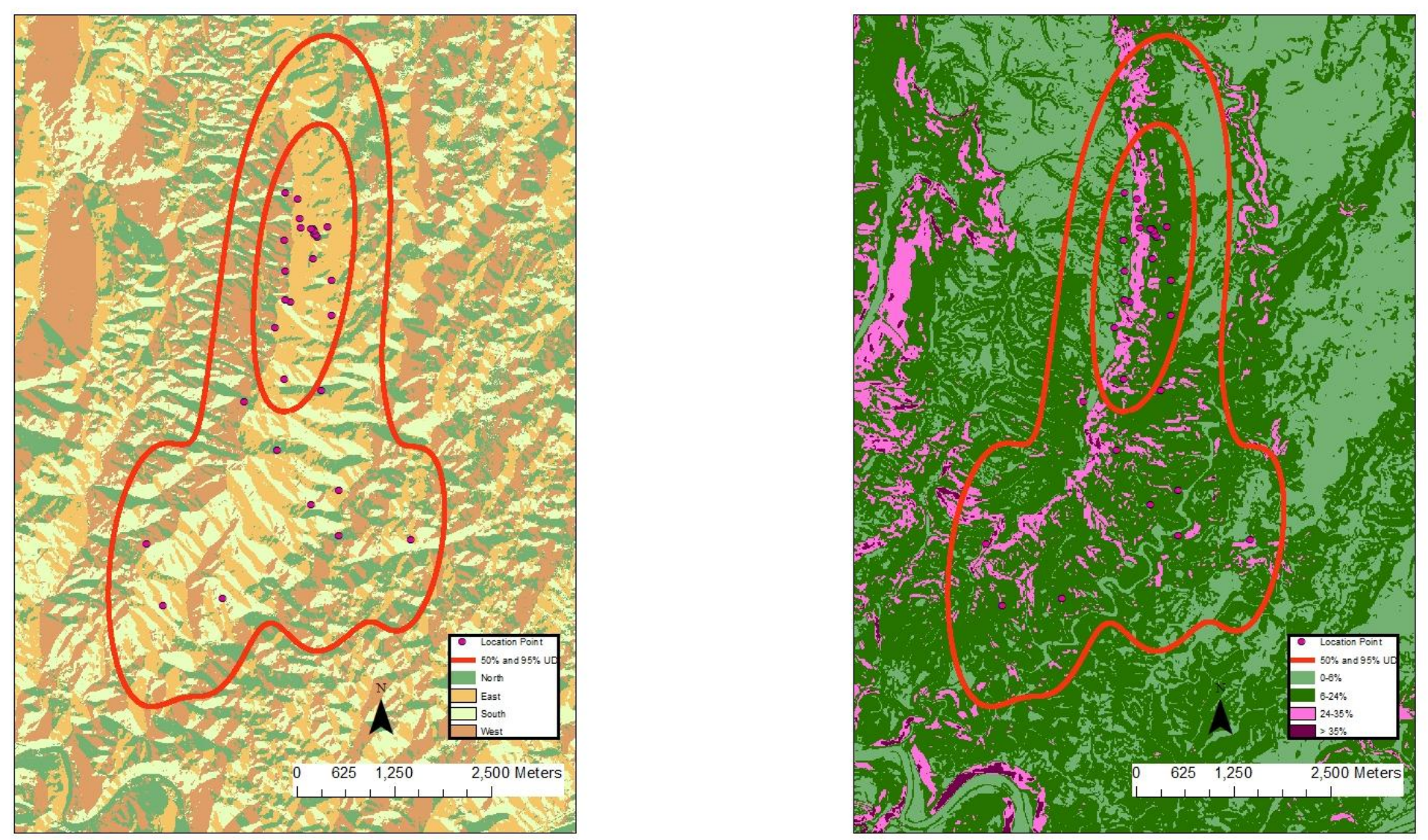
Appendix B. Regional male wild turkey land use and land cover, land fragmentation, slope, and aspect habitat resource selection in regions 2, 3, 4, and 6 in West Virginia, 2004-2007. Due to small sample size and lack of data regions 1 and 5 were not used in regional habitat selection analysis. 
Appendix B.

Regional Male Second-order Selection. - Statewide annual adult $(\bar{x}=1,409.9$ ha, SE $=$ 180.3) and juvenile $(\bar{x}=1,394.3$ ha, $\mathrm{SE}=790.8) 95 \%$ home ranges $(n=66)$ were similar in West Virginia $(W=515, P=0.780)$. Male wild turkey $95 \%$ UD home ranges were not significantly different between ecological regions $2,3,4$, and $6\left(\chi_{3,63}^{2}=2.78, \mathrm{P}=0.430\right)$. Turkeys $(n=16)$ selected forested areas at higher rates than other land use land cover habitat resources in region 2 (Wilks' $\lambda=0.02, P=0.001$ ). Turkeys also selected for perforated and edges at higher rates than other land fragmentation categories (Wilks' $\lambda=0.01, P=0.001$ ). Turkeys selected for $\geq 6-35 \%$ gradients at higher rates than other slope categories in region 2 (Wilks' $\lambda=0.22, P=0.001$ ). Turkeys also selected east and west at higher rates than north and south facing aspects (Wilks' $\lambda$ $=0.39, P=0.007)$.

Male wild turkeys $(n=6)$ selected for pasture and crop at marginally higher rates than other land use and land cover habitat resources in region 3 (Wilks' $\lambda=0.0001, P=0.050$ ). However, turkeys did not display a disproportionate selection of land fragmentation (Wilks' $\lambda=$ $0.0002, P=0.170$ ), slope (Wilks' $\lambda=0.08, P=0.090$ ), or aspect (Wilks' $\lambda=0.03, P=0.070$ ) resources in region 3. Turkeys $(n=35)$ selected for pastures and forests at higher rates than other land use and land cover habitat resources in region 4 (Wilks' $\lambda=0.12, P=0.001$ ). Turkeys selected for edge habitats at higher rates than other land fragmentation categories in region 4 (Wilks' $\lambda=0.13, P=0.001)$. Turkeys selected for slopes $\leq 24 \%$ (Wilks' $\lambda=0.69, P=0.006$ ). There was no significant selection of aspect in region 4 (Wilks' $\lambda=0.80, \mathrm{P}=0.060)$. Turkeys $(n$ =6) did not displayed a disproportionate selection of land use and land cover (Wilks' $\lambda=0.006$, $P=0.210$ ), land fragmentation (Wilks' $\lambda=0.005, P=0.380$ ), slope (Wilks' $\lambda=0.19, P=0.150$ ), or aspect $\left(\lambda\right.$ Wilks' $\left.^{\prime} 0.37, P=0.420\right)$ in region 6 . 
Appendix B cont.

Regional Male Third-order Selection. - Statewide annual adult and juvenile $(n=66) 95 \%$ $(\bar{x}=1,409.9$ ha, $\mathrm{SE}=180.3 ; \bar{x}=1,394.3$ ha, $\mathrm{SE}=790.8)(W=515, P=0.780)$ and $50 \%(\bar{x}=$ 310.3 ha, $\mathrm{SE}=38.7 ; \bar{x}=320.6$ ha, $\mathrm{SE}=190.3)(W=491, P=0.560)$ home ranges were similar in West Virginia. Both male wild turkey $95 \%\left(\chi_{3,63}^{2}=2.78, P=0.43\right)$ and $50 \%\left(\chi_{3,63}^{2}=5.49, P=\right.$ 0.140) UD home ranges were not significantly different between ecological regions 2, 3, 4, and 6 in West Virginia. Turkeys $(n=16)$ selected for forest and pasture at higher rate than other land use and land cover habitat resources in region 2 (Wilks' $\lambda=0.24, P=0.006$ ). Male wild turkeys also selected for $<100$ ha core, edge, patch, perforated, and 100-200 ha core at higher rates than $>200$ ha core areas (Wilks' $\lambda=0.09, P=0.002$ ). Although turkeys did not display a disproportionate selection of slope (Wilks' $\lambda=0.70, P=0.180$ ) birds did selected for east facing slopes at higher rates than other aspect categories in region 2 (Wilks' $\lambda=0.17, P=0.001$ ).

Male wild turkeys $(n=6)$ did not display a disproportionate selection of land use and land cover (Wilks' $\lambda=0.004, P=0.150$ ), land fragmentation (Wilks' $\lambda=0.007, P=0.330$ ), slope (Wilks' $\lambda=0.10, P=0.090$ ), or aspect (Wilks' $\lambda=0.76, P=0.890$ ) habitat resources in region 3. Turkeys $(n=35)$ selected forest at higher rates than other land use and land cover habitat resources in region 4 (Wilks' $\lambda=0.50, P=0.002$ ). Turkeys also selected for areas of $6-$ $24 \%$ gradients at higher rates than other slope categories (Wilks' $\lambda=0.43, P=0.001$ ). However, turkeys did not display a disproportionate selection of land fragmentation (Wilks' $\lambda=0.04, P=$ 0.760 ) or aspect (Wilks' $\lambda=0.95, P=0.720$ ) in region 4. Likewise, turkeys $(n=6)$ displayed no disproportionate selection of land use and land cover (Wilks' $\lambda=0.50, P=0.780$ ), land fragmentation (Wilks' $\lambda=0.28, P=0.790$ ), slope (Wilks' $\lambda=0.74, P=0.850$ ), or aspect (Wilks' $\lambda=0.91, P=0.970)$ within region 6. 
Appendix C. Regional 95\% and 50\% utilization distributions (UD) for Gaussian fixed kernel density estimations (KDE) home ranges, smoothing parameter $(h)$ determined by least squares cross validation, of male eastern wild turkeys in West Virginia, $2004-2007$.

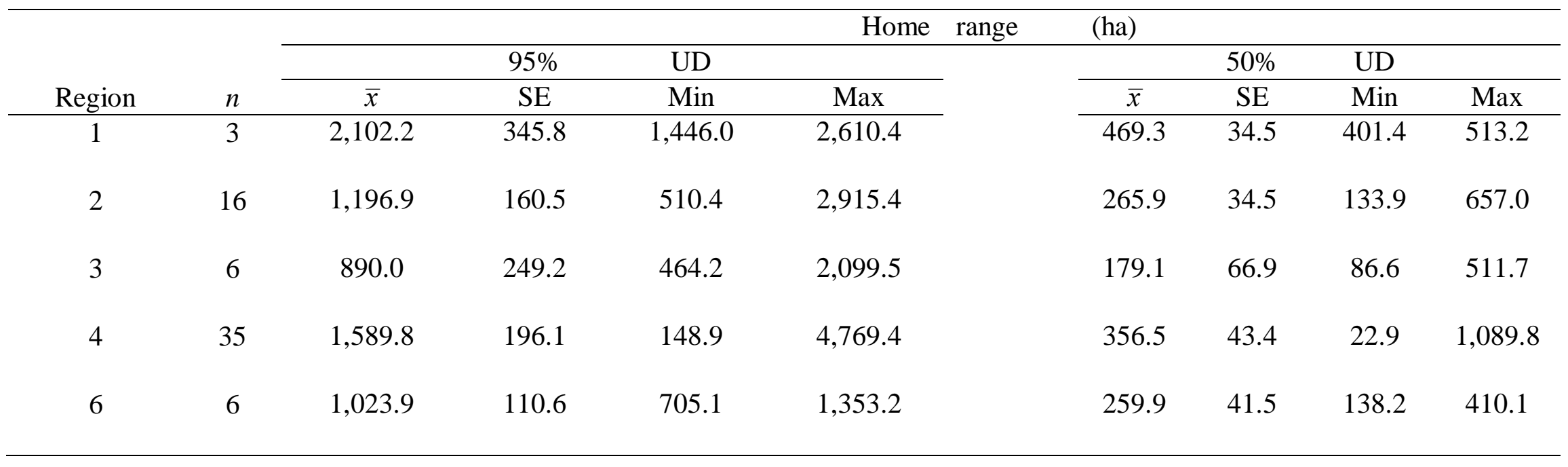


Appendix D. Id - VIII $d$ : Second- and third-order resource selection significance and rank of male eastern wild turkeys from 4 ecological regions in West Virginia, 2004-2007. Use proportions derived from $95 \%$ home range utilization distributions (UD) and availability derived from 100 ha block regional proportional summaries; proportions were analyzed using compositional analysis (CA) 
Appendix Id. Second-order land use and land cover resource selection significance and rank of male eastern wild turkeys from 4 ecological regions in West Virginia, 2004-2007. Use proportions derived from 95\% home range utilization distributions (UD) and availability derived from 100 ha block regional proportional summaries; proportions were analyzed using compositional analysis (CA).

\begin{tabular}{|c|c|c|c|c|c|c|c|c|c|}
\hline \multirow[b]{2}{*}{ Region } & \multirow[b]{2}{*}{$n$} & \multirow[b]{2}{*}{ Wilks' $^{\prime} \lambda$} & \multirow[b]{2}{*}{$P$} & \multicolumn{5}{|c|}{$\operatorname{Rank}^{\mathrm{a}}$} & \multirow[b]{2}{*}{ Water } \\
\hline & & & & Forest & Pasture & Crop & Road & Barren & \\
\hline 2 & 16 & 0.02 & 0.001 & $1 \mathrm{~A}$ & $4 \mathrm{AC}$ & $5 \mathrm{AC}$ & $2 \mathrm{BC}$ & $3 B C$ & $6 \mathrm{D}$ \\
\hline 3 & 6 & 0.0001 & 0.050 & $3 B$ & $1 \mathrm{~A}$ & $2 \mathrm{AB}$ & $4 \mathrm{BC}$ & $6 \mathrm{BD}$ & $5 \mathrm{ABC}$ \\
\hline 4 & 35 & 0.12 & 0.001 & $2 \mathrm{AB}$ & $1 \mathrm{~A}$ & $3 B$ & $4 \mathrm{BC}$ & $5 \mathrm{C}$ & $6 \mathrm{BD}$ \\
\hline 6 & 6 & 0.006 & 0.210 & $2 \mathrm{~A}$ & $3 \mathrm{~A}$ & $5 \mathrm{~A}$ & $1 \mathrm{~A}$ & $4 \mathrm{~A}$ & $6 \mathrm{~A}$ \\
\hline
\end{tabular}

\footnotetext{
${ }^{\mathrm{a}}$ The same letters following each rank within a row indicates no difference $(P>0.05)$ by compositional analysis $($ Aebischer et al. 1993$)$.
} 
Appendix II $d$. Second-order land fragmentation resource selection significance and rank of male eastern wild turkeys from 4 ecological regions in West Virginia, 2004-2007. Use proportions derived from 95\% home range utilization distributions (UD) and availability derived from 100 ha block regional proportional summaries; proportions were analyzed using compositional analysis (CA).

\begin{tabular}{|c|c|c|c|c|c|c|c|c|c|}
\hline \multirow[b]{2}{*}{ Region } & \multirow[b]{2}{*}{$n$} & \multirow[b]{2}{*}{ Wilks' $\lambda$} & \multirow[b]{2}{*}{$P$} & \multicolumn{5}{|c|}{$\operatorname{Rank}^{\mathrm{a}}$} & \multirow[b]{2}{*}{ >200ha } \\
\hline & & & & Edge & Perforations & Patch & $<100$ ha & 100-200ha & \\
\hline 2 & 16 & 0.02 & 0.001 & $2 \mathrm{AB}$ & $1 \mathrm{~A}$ & $4 \mathrm{BC}$ & $5 \mathrm{ABC}$ & $6 \mathrm{C}$ & $3 \mathrm{~B}$ \\
\hline 3 & 6 & 0.0002 & 0.170 & $2 \mathrm{~A}$ & $3 \mathrm{~A}$ & $4 \mathrm{~A}$ & $5 \mathrm{~A}$ & $6 \mathrm{~A}$ & $1 \mathrm{~A}$ \\
\hline 4 & 35 & 0.13 & 0.001 & $1 \mathrm{~A}$ & $3 B$ & $4 B$ & $2 \mathrm{~B}$ & $6 C$ & $5 \mathrm{C}$ \\
\hline 6 & 6 & 0.005 & 0.380 & $3 \mathrm{~A}$ & $1 \mathrm{~A}$ & $4 \mathrm{~A}$ & $2 \mathrm{~A}$ & $6 \mathrm{~A}$ & $5 \mathrm{~A}$ \\
\hline
\end{tabular}

\footnotetext{
${ }^{\mathrm{a}}$ The same letters following each rank within a row indicates no difference $(P>0.05)$ by compositional analysis $($ Aebischer et al. 1993).
} 
Appendix III $d$. Second-order slope resource selection significance and rank of male eastern wild turkeys from 4 ecological regions in West Virginia, 2004-2007. Use proportions derived from 95\% home range utilization distributions (UD) and availability derived from 100 ha block regional proportional summaries; proportions were analyzed using compositional analysis (CA).

\begin{tabular}{|c|c|c|c|c|c|c|c|}
\hline \multirow[b]{2}{*}{ Region } & \multirow[b]{2}{*}{$n$} & \multirow[b]{2}{*}{ Wilks' $\lambda$} & \multirow[b]{2}{*}{$P$} & \multirow[b]{2}{*}{$0-6 \%$} & \multicolumn{3}{|c|}{$\operatorname{Rank}^{\mathrm{a}}$} \\
\hline & & & & & $>6-24 \%$ & $>24-35 \%$ & $>35 \%$ \\
\hline 2 & 16 & 0.22 & 0.001 & $4 B$ & $2 \mathrm{~A}$ & $1 \mathrm{~A}$ & $3 B$ \\
\hline 3 & 6 & 0.08 & 0.090 & $2 \mathrm{~A}$ & $1 \mathrm{~A}$ & $3 \mathrm{~A}$ & $4 \mathrm{~A}$ \\
\hline 4 & 35 & 0.7 & 0.006 & $2 \mathrm{AB}$ & $1 \mathrm{~A}$ & $3 B$ & $4 \mathrm{C}$ \\
\hline 6 & 6 & 0.19 & 0.150 & $3 \mathrm{~A}$ & $2 \mathrm{~A}$ & $4 \mathrm{~A}$ & $1 \mathrm{~A}$ \\
\hline
\end{tabular}

\footnotetext{
${ }^{\mathrm{a}}$ The same letters following each rank within a row indicates no difference $(P>0.05)$ by compositional analysis (Aebischer et al. 1993).
} 
Appendix IVd. Second-order aspect resource selection significance and rank of male eastern wild turkeys from 4 ecological regions in West Virginia, 2004-2007. Use proportions derived from 95\% home range utilization distributions (UD) and availability derived from 100 ha block regional proportional summaries; proportions were analyzed using compositional analysis (CA).

\begin{tabular}{|c|c|c|c|c|c|c|c|}
\hline \multirow[b]{2}{*}{ Region } & \multirow[b]{2}{*}{$n$} & \multirow[b]{2}{*}{ Wilks' $\lambda$} & \multirow[b]{2}{*}{$P$} & \multirow[b]{2}{*}{ North } & \multicolumn{3}{|c|}{$\operatorname{Rank}^{\mathrm{a}}$} \\
\hline & & & & & East & South & West \\
\hline 2 & 16 & 0.22 & 0.007 & $4 \mathrm{C}$ & $1 \mathrm{~A}$ & $3 \mathrm{BC}$ & $2 \mathrm{AB}$ \\
\hline 3 & 6 & 0.03 & 0.070 & $3 \mathrm{~A}$ & $2 \mathrm{~A}$ & $1 \mathrm{~A}$ & $4 \mathrm{~A}$ \\
\hline 4 & 35 & 0.81 & 0.060 & $2 \mathrm{~A}$ & $3 \mathrm{~A}$ & $4 \mathrm{~A}$ & $1 \mathrm{~A}$ \\
\hline 6 & 6 & 0.37 & 0.420 & $4 \mathrm{~A}$ & $2 \mathrm{~A}$ & $3 \mathrm{~A}$ & $1 \mathrm{~A}$ \\
\hline
\end{tabular}

\footnotetext{
${ }^{\mathrm{a}}$ The same letters following each rank within a row indicates no difference $(P>0.05)$ by compositional analysis (Aebischer et al. 1993).
} 
Appendix $\mathrm{Vd}$. Third-order land use and land cover resource selection significance and rank of male eastern wild turkeys from 4 ecological regions in West Virginia, 2004-2007. Use proportions derived from 95\% home range utilization distributions (UD) and availability derived from 100 ha block regional proportional summaries; proportions were analyzed using compositional analysis (CA).

\begin{tabular}{|c|c|c|c|c|c|c|c|c|c|}
\hline \multirow[b]{2}{*}{ Region } & \multirow[b]{2}{*}{$n$} & \multirow[b]{2}{*}{ Wilks' $\lambda$} & \multirow[b]{2}{*}{$P$} & \multicolumn{5}{|c|}{$\operatorname{Rank}^{\mathrm{a}}$} & \multirow[b]{2}{*}{ Water } \\
\hline & & & & Forest & Pasture & Crop & Road & Barren & \\
\hline 2 & 16 & 0.24 & 0.006 & $1 \mathrm{~A}$ & $2 \mathrm{AB}$ & $4 \mathrm{AB}$ & $5 \mathrm{AB}$ & $3 B$ & $6 \mathrm{~B}$ \\
\hline 3 & 6 & 0.004 & 0.150 & $2 \mathrm{~A}$ & $1 \mathrm{~A}$ & $6 \mathrm{~A}$ & $3 \mathrm{~A}$ & $4 \mathrm{~A}$ & $5 \mathrm{~A}$ \\
\hline 4 & 35 & 0.49 & 0.002 & $1 \mathrm{~A}$ & $2 \mathrm{~B}$ & $3 \mathrm{BC}$ & $4 \mathrm{C}$ & $5 \mathrm{CD}$ & $6 \mathrm{D}$ \\
\hline 6 & 6 & 0.5 & 0.780 & $1 \mathrm{~A}$ & $2 \mathrm{~A}$ & $4 \mathrm{~A}$ & $5 \mathrm{~A}$ & $3 \mathrm{~A}$ & \\
\hline
\end{tabular}

${ }^{\mathrm{a}}$ The same letters following each rank within a row indicates no difference $(P>0.05)$ by compositional analysis (Aebischer et al. 1993).

Blank spaces in a row indicate that resources were not available for analysis. 
Appendix VId. Third-order land fragmentation resource selection significance and rank of male eastern wild turkeys from 4 ecological regions in West Virginia, 2004-2007. Use proportions derived from 95\% home range utilization distributions (UD) and availability derived from 100 ha block regional proportional summaries; proportions were analyzed using compositional analysis (CA).

\begin{tabular}{|c|c|c|c|c|c|c|c|c|c|}
\hline \multirow[b]{2}{*}{ Region } & \multirow[b]{2}{*}{$n$} & \multirow[b]{2}{*}{ Wilks' $\lambda$} & \multirow[b]{2}{*}{$P$} & \multicolumn{5}{|c|}{$\operatorname{Rank}^{\mathrm{a}}$} & \multirow[b]{2}{*}{$>200 \mathrm{ha}$} \\
\hline & & & & Edge & Perforations & Patch & $<100$ ha & 100-200ha & \\
\hline 2 & 16 & 0.09 & 0.002 & $2 \mathrm{~B}$ & $4 \mathrm{ABC}$ & $3 \mathrm{C}$ & $1 \mathrm{ABC}$ & $5 \mathrm{BD}$ & $6 \mathrm{D}$ \\
\hline 3 & 6 & 0.007 & 0.330 & $3 \mathrm{~A}$ & $2 \mathrm{~A}$ & $4 \mathrm{~A}$ & $6 \mathrm{~A}$ & $5 \mathrm{~A}$ & $1 \mathrm{~A}$ \\
\hline 4 & 35 & 0.04 & 0.760 & $4 \mathrm{~A}$ & $2 \mathrm{~A}$ & $5 \mathrm{~A}$ & $6 \mathrm{~A}$ & $1 \mathrm{~A}$ & $3 \mathrm{~A}$ \\
\hline 6 & 6 & 0.28 & 0.790 & $2 \mathrm{~A}$ & $3 \mathrm{~A}$ & $1 \mathrm{~A}$ & $5 \mathrm{~A}$ & & $4 \mathrm{~A}$ \\
\hline
\end{tabular}

${ }^{a}$ The same letters following each rank within a row indicates no difference $(P>0.05)$ by compositional analysis (Aebischer et al. 1993). Blank spaces in a row indicate that resources were not available for analysis. 
Appendix VII $d$. Third-order slope resource selection significance and rank of male eastern wild turkeys from 4 ecological regions in West Virginia, 2004-2007. Use proportions derived from 95\% home range utilization distributions (UD) and availability derived from 100 ha block regional proportional summaries; proportions were analyzed using compositional analysis (CA).

\begin{tabular}{|c|c|c|c|c|c|c|c|}
\hline \multirow[b]{2}{*}{ Region } & \multirow[b]{2}{*}{$n$} & \multirow[b]{2}{*}{ Wilks' $\lambda$} & \multirow[b]{2}{*}{$P$} & \multirow[b]{2}{*}{$0-6 \%$} & \multicolumn{3}{|c|}{$\operatorname{Rank}^{\mathrm{a}}$} \\
\hline & & & & & $>6-24 \%$ & $>24-35 \%$ & $>35 \%$ \\
\hline 2 & 16 & 0.69 & 0.180 & $3 \mathrm{~A}$ & $4 \mathrm{~A}$ & $1 \mathrm{~A}$ & $2 \mathrm{~A}$ \\
\hline 3 & 6 & 0.1 & 0.090 & $4 \mathrm{~A}$ & $3 \mathrm{~A}$ & $1 \mathrm{~A}$ & $2 \mathrm{~A}$ \\
\hline 4 & 35 & 0.43 & 0.001 & $3 B$ & $1 \mathrm{~A}$ & $2 \mathrm{~B}$ & $4 \mathrm{C}$ \\
\hline 6 & 6 & 0.74 & 0.850 & $3 \mathrm{~A}$ & $1 \mathrm{~A}$ & $2 \mathrm{~A}$ & $4 \mathrm{~A}$ \\
\hline
\end{tabular}

\footnotetext{
${ }^{\mathrm{a}}$ The same letters following each rank within a row indicates no difference $(P>0.05)$ by compositional analysis (Aebischer et al. 1993).
} 
Appendix VIIId. Third-order aspect resource selection significance and rank of male eastern wild turkeys from 4 ecological regions in West Virginia, 2004-2007. Use proportions derived from 95\% home range utilization distributions (UD) and availability derived from 100 ha block regional proportional summaries; proportions were analyzed using compositional analysis (CA).

\begin{tabular}{|c|c|c|c|c|c|c|c|}
\hline \multirow[b]{2}{*}{ Region } & \multirow[b]{2}{*}{$n$} & \multirow[b]{2}{*}{ Wilks' $\lambda$} & \multirow[b]{2}{*}{$P$} & \multirow[b]{2}{*}{ North } & \multicolumn{3}{|c|}{$\operatorname{Rank}^{\mathrm{a}}$} \\
\hline & & & & & East & South & West \\
\hline 2 & 16 & 0.16 & 0.001 & $3 B$ & $1 \mathrm{~A}$ & $2 \mathrm{~B}$ & $4 B$ \\
\hline 3 & 6 & 0.76 & 0.890 & $3 \mathrm{~A}$ & $4 \mathrm{~A}$ & $2 \mathrm{~A}$ & $1 \mathrm{~A}$ \\
\hline 4 & 35 & 0.95 & 0.720 & $2 \mathrm{~A}$ & $1 \mathrm{~A}$ & $4 \mathrm{~A}$ & $3 \mathrm{~A}$ \\
\hline 6 & 6 & 0.91 & 0.970 & $2 \mathrm{~A}$ & $3 \mathrm{~A}$ & $1 \mathrm{~A}$ & $4 \mathrm{~A}$ \\
\hline
\end{tabular}

\footnotetext{
${ }^{\mathrm{a}}$ The same letters following each rank within a row indicates no difference $(P>0.05)$ by compositional analysis (Aebischer et al. 1993).
} 